\title{
Administração
}
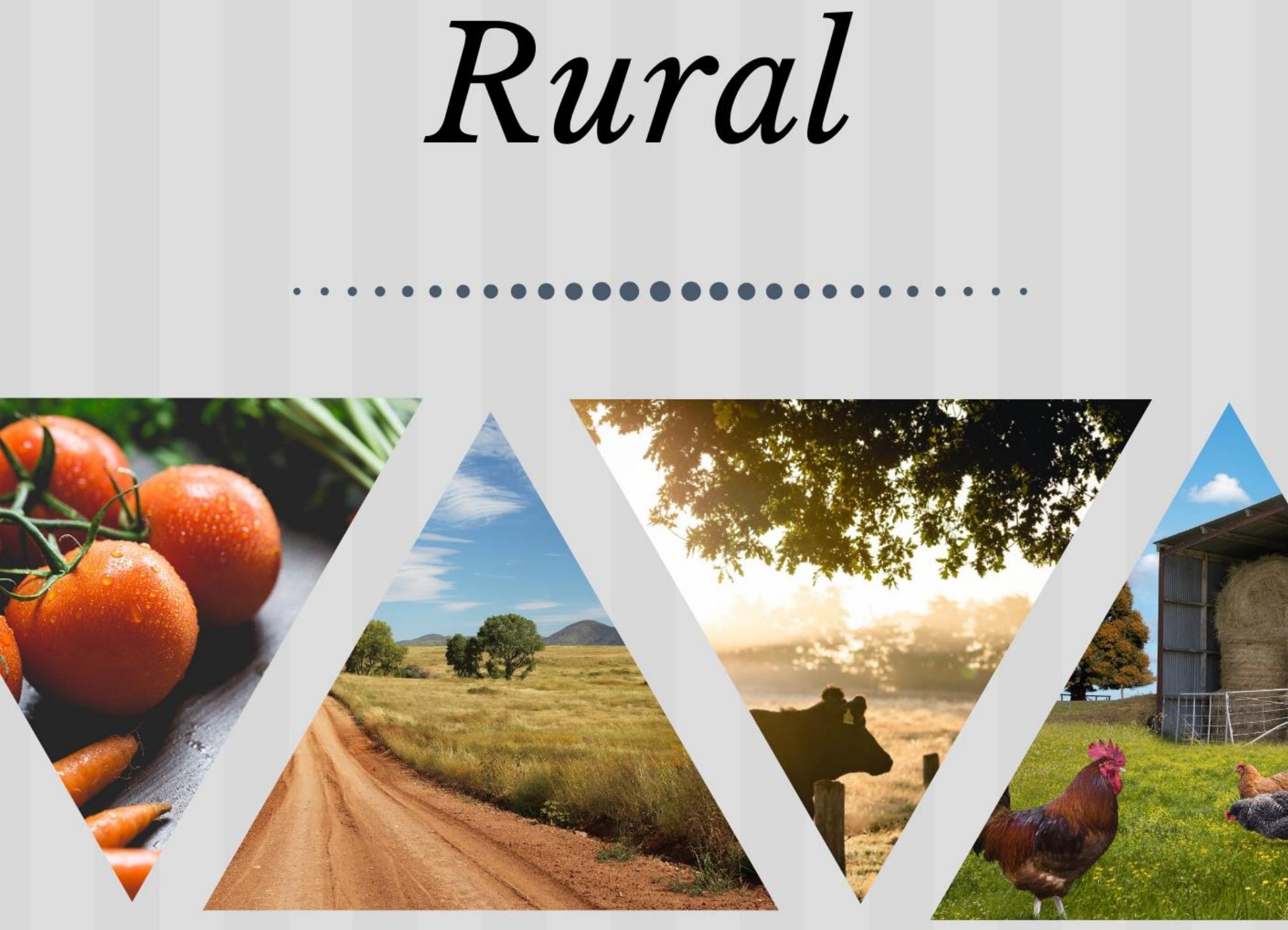

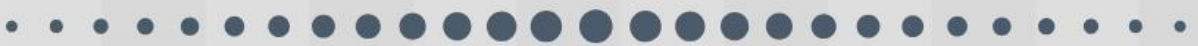

Organizador

Ezequiel Redin

Editora Poisson

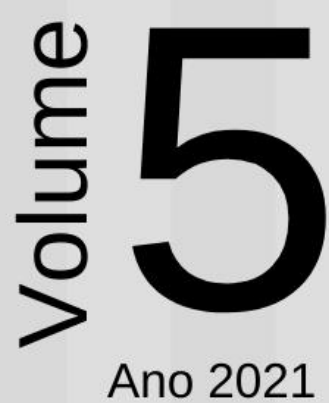


Organizador

Ezequiel Redin

\section{Administração Rural Volume 5}

1ạ Edição

Belo Horizonte

Poisson

2021 
Editor Chefe: Dr. Darly Fernando Andrade

\section{Conselho Editorial}

Dr. Antônio Artur de Souza - Universidade Federal de Minas Gerais

Ms. Davilson Eduardo Andrade

Dra. Elizângela de Jesus Oliveira - Universidade Federal do Amazonas

Msc. Fabiane dos Santos

Dr. José Eduardo Ferreira Lopes - Universidade Federal de Uberlândia

Dr. Otaviano Francisco Neves - Pontifícia Universidade Católica de Minas Gerais

Dr. Luiz Cláudio de Lima - Universidade FUMEC

Dr. Nelson Ferreira Filho - Faculdades Kennedy

Ms. Valdiney Alves de Oliveira - Universidade Federal de Uberlândia

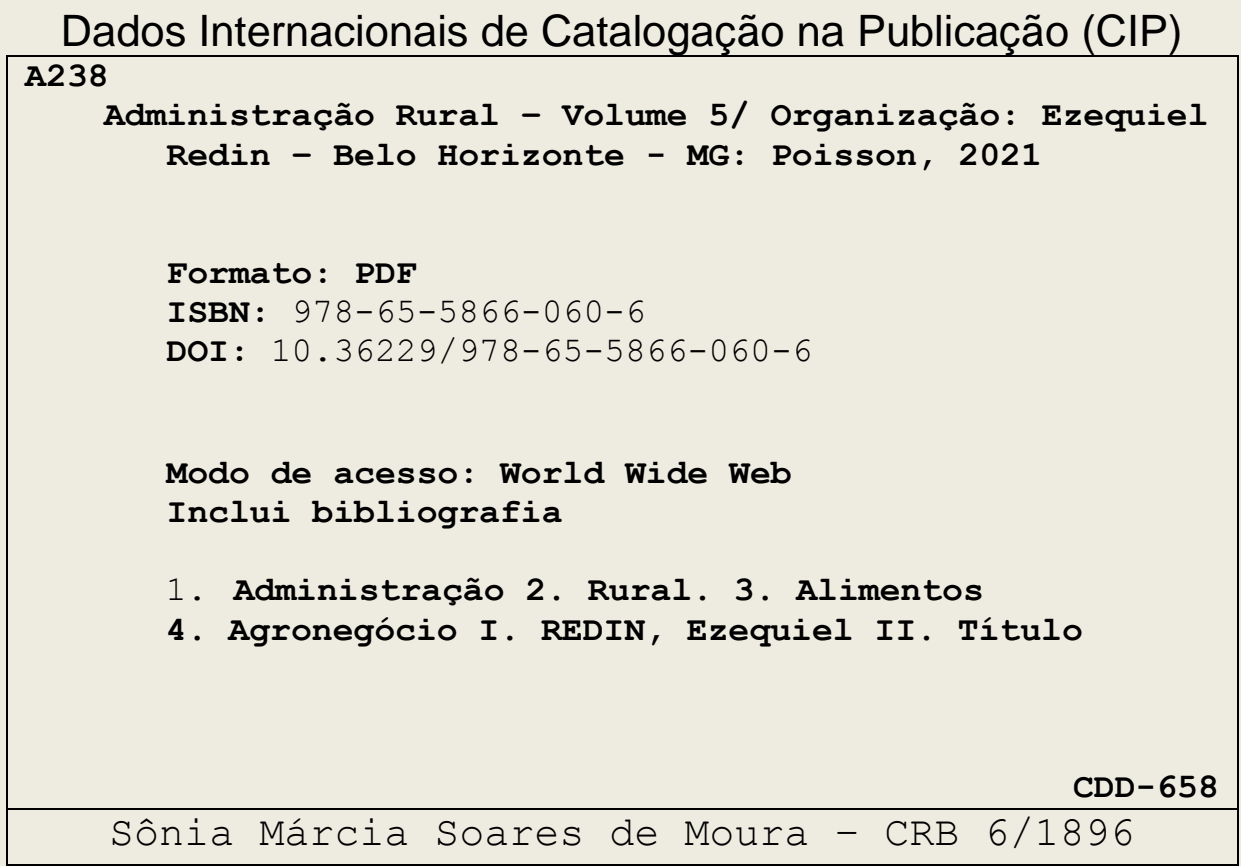

O conteúdo dos artigos e seus dados em sua forma, correção e confiabilidade são de responsabilidade exclusiva dos seus respectivos autores.

Baixe outros títulos gratuitamente em www.poisson.com.br 


\section{SUMÁRIO}

Capítulo 1: Transformações recentes e esperadas do Setor Agrícola: Mitos e perspectivas de mudanças. 07

Amilcar Baiardi, Maria Clotilde Meirelles Ribeiro, Gilton Alves Aragão (in memoriam)

DOI: 10.36229/978-65-5866-060-6.CAP.01

Capítulo 2: 0 setor produtivo do Cerrado Piauiense: Uma análise multivariada da estrutura produtiva 13

Gabriele Ferreira da Silva Monte, Edivane de Sousa Lima

DOI: $10.36229 / 978-65-5866-060-6 . C A P .02$

Capítulo 3: 0 crédito na agricultura brasileira no período 2013-2018: Um estudo do PRONAF, do PRONAMP e demais linhas de crédito rural, com ênfase no investimento 26

Irineu Brinker, Tiago Wickstrom Alves, Angélica Massuquetti

DOI: $10.36229 / 978-65-5866-060-6 . C A P .03$

Capítulo 4: Demanda por produtos lácteos no Brasil: Uma análise utilizando dados da POF 2008/2009. 43

Guilherme Fonseca Travassos, Glauco Rodrigues Carvalho, Lucas Campio Pinha, Juliana Mota Monteiro da Silva

DOI: $10.36229 / 978-65-5866-060-6 . C A P .04$

Capítulo 5: Comportamento de preços do pescado comercializado na Região Metropolitana de Belém, estado do Pará. 55

Nathália Carvalho de Matos, Caio Cezar Ferreira de Souza, Maria Lúcia Bahia Lopes, Marcos Antônio Souza dos Santos

DOI: $10.36229 / 978-65-5866-060-6 . C A P .05$

Capítulo 6: A cadeia produtiva da alface (Lactuca sativa) no Sudoeste do Paraná ..... 65

Cristina Venâncio Pereira, Sidemar Presotto Nunes, Celso Eduardo Pereira Ramos

DOI: 10.36229/978-65-5866-060-6.CAP.06

Capítulo 7: Tecnológica de plantio de produção agrícola: Como as tecnologias de plantio utilizadas vêm impactando a produtividade e a rentabilidade do milho nas cidades de Rio Verde - GO, Unaí - MG, Chapadão do Sul - MS, Primavera do Leste - MT e Passo Fundo - RS 77

Lucimari Andrade Paggiossi, Álvaro Alves de Moura Júnior

DOI: 10.36229/978-65-5866-060-6.CAP.07 


\section{SUMÁRIO}

Capítulo 8: Produção de soja e desmatamento na Amazônia Legal: Um estudo a partir da análise exploratória de dados espaciais 94

Anderson Pereira Rocha, Walberti Saith, Manuel Antonio Valdés Borrero

DOI: 10.36229/978-65-5866-060-6.CAP.08

Capítulo 9: Mapeamento e diagnóstico de agroindústrias orgânicas presentes na Rede de Agroecologia Povos da Mata no estado da Bahia. 103

Luciane Aliprandini, Josué de Souza Oliveira, Tatiane Botelho da Cruz, Guilherme Fontana Ramos, Viviane Maria Barazetti

DOI: 10.36229/978-65-5866-060-6.CAP.09

Capítulo 10: Avaliação sócioeconômica do setor produtivo do vestuário no estado de Mato Grosso entre os anos de 2010 a 2019 113

João Paulo de Almeida Ferreira Silva, Esdras Warley Nunes de Jesus, Anderson Nunes Vieira de Carvalho DOI: 10.36229/978-65-5866-060-6.CAP.10

Capítulo 11: Competitividade e orientação para o mercado em uma empresa do Setor Moveleiro de Coronel Freitas - SC. 130

Karen Ângela Flores, César Augustus Winck

DOI: 10.36229/978-65-5866-060-6.CAP.11

Capítulo 12: Gestão do saneamento rural no Povoado Mirolândia, Picos-PI. 153

Wesley Fernandes Araújo, Jaíra Maria Alcobaça Gomes, José Natanael Fontenele de Carvalho

DOI: $10.36229 / 978-65-5866-060-6 . C A P .12$

Capítulo 13: Análise do Programa Cisternas através do Modelo Sistêmico: 0 caso do Distrito de Livramento do Tiúma, Timbaúba-PE. 169

Vitória Roberta Martins de Melo Galindo de Lima, Mateus Gonçalves Lira, Tales Wanderley Vital

DOI: $10.36229 / 978-65-5866-060-6 . C A P .13$

Capítulo 14: Análise sobre doenças no aparelho respiratório nos municípios de Mato Grosso devido as queimadas no ano de 2015. 179

Nathalia de Pinho Markus, Kimberly Jéssica Montagner Prote, Arturo Alejandro Zavala Zavala DOI: 10.36229/978-65-5866-060-6.CAP.14 


\section{SUMÁRIO}

Capítulo 15: Sucessão geracional: Fatores decisórios na perspectiva de jovens sucessores rurais 190

Gabrieli dos Santos Amorim, Adriano Lago, Mariele Boscardin, Camila Weber

DOI: 10.36229/978-65-5866-060-6.CAP.15

Autores: 


\section{Capítulo 1}

\section{Transformações recentes e esperadas do Setor Agrícola: Mitos e perspectivas de mudanças}

\section{Amilcar Baiardi \\ Maria Clotilde Meirelles Ribeiro \\ Gilton Alves Aragão (in memoriam)}

Resumo: Os desafios e complexificação crescentes pelos quais vem passando o setor agrícola no mundo são claros e vêm sendo incessantemente exibidos na literatura. Tal realidade induz o setor a uma necessidade de transformação para tornar-se cada vez mais dinâmico e competitivo, pronto a produzir respostas prementes às demandas estratégicas no plano mundial, regional e local. 0 objetivo deste trabalho é debater a possibilidade de mudanças radicais na agropecuária, a partir da introdução de inovações tecnológicas baseadas nos avanços na Inteligência Artificial e na Manufatura Avançada e cotejar esta trajetória com as propostas neo obscurantistas da Agroecologia, adotando, como metodologia, uma revisão da literatura com base em autores atuais. 0 paper trata inicialmente das transformações em curso no setor agrícola, prosseguindo com a discussão das transformações esperadas neste setor e encerrando com elementos conclusivos na visão dos seus autores, apoiados na realidade deflagrada na literatura. 


\section{INTRODUÇÃO}

Não resta dúvida que o setor da agricultura vem enfrentando crescentes desafios nas últimas décadas, complexificando-se cada vez mais em decorrência de mudanças que vêm ocorrendo em escala mundial. Estas abrangem não apenas as transformações ambientais que vêm sendo exponencialmente visíveis no planeta, quanto estruturais que vêm ocorrendo no mercado global de alimentos e no agronegócio. Inserem-se, aqui, as mudanças no perfil dos consumidores, que nitidamente se transformam em atores ativos nos processos das mudanças tecnológicas (CHAVES, 2010, RIBEIRO, 2015).

Salles-Filho e Bin (2014) acrescentam, por sua vez, que a entrada das grandes corporações e o intenso esforço privado em pesquisa e inovação, nesse setor, vem sendo fatores contribuidores da grande mudança que o século XXI vem testemunhando em muitos países no cenário da pesquisa agrícola. De fato, os desafios crescentes que a realidade hoje acarreta, provoca uma necessidade de transformação da agricultura em um setor cada vez mais dinâmico e competitivo, que esteja apto a responder prontamente às amplas demandas estratégicas no plano mundial, regional e local.

No Brasil, o setor agropecuário vem exibindo um desempenho notável, constituindo-se um dos lastros para superação da recessão e para atenuação dos problemas das contas públicas, e tendo encontrado mecanismos de autofinanciamento e de apropriação de conhecimentos. Nas últimas décadas, tem garantido a segurança alimentar em termos de estoques, contribuído para a redução dos preços dos alimentos e participado dinamicamente da balança comercial, bem como tem dado contribuições significativas para a retomada do crescimento econômico. Tal performance do setor não seria possível sem transformações na organização produtiva, derivadas da adoção de novos paradigmas com base em conhecimento científico aplicado e na assunção de riscos por parte de empreendedores. 0 que pode se constatar hoje, diante dos recentes ecossistemas locais de inovação, é que esta trajetória de conquistas incrementais de produtividade e de eficiência, tendem a se consolidar e a se expandir, exponencialmente, face às transformações do setor agrícola, em decorrência da adoção de preceitos da inteligência artificial e da indústria 4.0.

Inobstante a inequívoca performance e contribuição do agro para a economia brasileira, alguns mitos relacionados à impactos negativos por ele proporcionados, permanecem em parte do senso comum e mesmo em alguns ambientes acadêmicos. 0 primeiro deles é de que o moderno agro brasileiro é concentrador de terra, destruidor da fertilidade das terras e que avança descontroladamente sobre a fronteira agrícola. 0 segundo mito é que que a agricultura brasileira não preserva a natureza e o terceiro é que a agroecologia poderia se transformar em modelo de sistema agrícola e reforçar o papel da agricultura familiar, que responderia por $70 \%$ da produção de alimentos do Brasil.

0 objetivo deste trabalho é debater a possibilidade de mudanças radicais na agropecuária, em decorrência da introdução de inovações tecnológicas baseadas nos avanços na Inteligência Artificial e na Manufatura Avançada e cotejar esta trajetória com as propostas neo obscurantistas da Agroecologia. Como metodologia adota a revisão de literatura (ou revisão narrativa), a qual é sempre recomendada para o levantamento da produção científica disponível e recente, que permite a (re)construção de conjuntos de pensamentos e conceitos, que articulam contribuições e possibilitam trilhar caminhos na direção daquilo que se deseja conhecer e explorar.

0 paper está organizado em quatro tópicos. 0 primeiro trata das transformações em curso no setor agrícola, prosseguindo, no segundo tópico, com a discussão das transformações esperadas neste setor. Por fim, diante das exposições trazidas, os autores encerram com elementos conclusivos na sua visão, apoiados na realidade deflagrada na literatura revisada.

\section{TRANSFORMAÇÕES EM CURSO}

A performance do setor agropecuário no Brasil tem, nas últimas décadas, garantido a segurança alimentar em termos de estoques, contribuído para redução dos preços do alimentos, participado dinamicamente da balança comercial e dado contribuições expressivas para retomada do crescimento econômico. Tendo encontrado mecanismos de autofinanciamento e de apropriação de conhecimentos, o setor mostra que se constitui hoje um dos lastros para superação da recessão e atenuação dos problemas das contas públicas. O sucesso da produção de alimentos e matérias primas de origem vegetal e animal do Brasil tem sido reconhecido em todo o mundo, a ponto da Organização das Nações Unidas para Alimentação e Agricultura (FAO, seu acrônimo usual em inglês), braço das Nações Unidas, ver no país a possibilidade de cumprir 
metas mundiais de oferta de produtos agropecuários ${ }^{1}$. Este desempenho não seria possível sem transformações na organização produtiva, derivadas da adoção de novos paradigmas com base em conhecimento científico aplicado e com base na assunção de riscos por parte de empreendedores.

A Tabela 1 a seguir, baseada nos resultados preliminares do Censo Agropecuário de 2017, evidencia o papel das ciências agrárias nas transformações e a magnitude do crescimento da produção e da produtividade no setor. Não obstante o avanço da produção e da produtividade, recente obra de Graziano e Navarro (2015) sugere que os últimos cenários relacionados ao agro brasileiro e ao desenvolvimento rural mostram que o rural brasileiro se encaminha celeremente para o desenvolvimento agrícola e não para o desenvolvimento rural, em decorrência de quatro características nele identificadas, quais sejam: despovoamento, concentração produtiva, concentração de renda e aumento da pobreza no meio rural.

Tabela 1-Dados comparativos dos Censos Agropecuários, 2006 / 2017 Fonte: IBGE

\begin{tabular}{|c|c|c|c|}
\hline \\
\hline Censos Agropecuários & 2006 & 2017 & Variação (\%) \\
\hline Número de estabelecimentos agropecuários & 5.175 .636 & 5.067 .656 & -3 \\
\hline Produtores agropecuários sem área de plantio & 255.019 & 76.782 & -30 \\
\hline Area Total de estabelecimentos em ha & 333.680 .937 & 345.144 .678 & 3 \\
\hline Área média de estabelecimentos em ha & 67,81 & 69,15 & 1 \\
\hline $\begin{array}{l}\text { Safra total de grãos, cereais, leguminosas e } \\
\text { oleaginosas, em milhões det }\end{array}$ & 131,4 & 224,3 & 71 \\
\hline
\end{tabular}

Os dados comparativos dos censos agropecuários do Brasil, coletados em um intervalo de onze anos (2006-2017), mostra um panorama claro. O número de produtores sem área de plantio em 2017 é alentador, visto que houve uma redução de $30 \%$ do número daqueles que não possuem acesso à terra. Em outra direção de análise, apesar do número de estabelecimentos agropecuários presentes no território brasileiro ter praticamente se mantido nesse período (com somente $3 \%$ de redução) e da área total de estabelecimentos em hectares também praticamente não ter se alterado (com 3\% de incremento), sendo também mantida a área média desses estabelecimentos em hectare (apenas 1\% de aumento), houve um vertiginoso crescimento de $71 \%$ na safra total brasileira de grãos, cereais, leguminosas e oleaginosas, em milhões de toneladas.

Estes elementos, põem por terra o primeiro mito que seria o de que o moderno agro brasileiro é concentrador de terra, destruidor da fertilidade das terras e que avança descontroladamente sobre a fronteira agrícola. A estabilidade da área dos estabelecimentos e o aumento da produção em praticamente a mesma área, demovem estas afirmações.

Utilizando informações geradas por satélites de observação da Terra e estudos sobre o uso e ocupação das terras no Brasil com base no Cadastro Ambiental Rural (CAR), a Embrapa Territorial estima área efetivamente cultivada do Brasil em 65,93 milhões hectares. Esta está muito próxima daquela de 63,99 milhões de hectares, área estimada pela National Aeronautics and Space Administration (NASA), agência do Governo Federal dos Estados Unidos responsável pela pesquisa e desenvolvimento de tecnologias e programas de exploração espacial, sendo de apenas 0,2\% a diferença entre ambas as medidas aqui consideradas.

Dados comparativos sobre o uso agrícola das terras em países mais industrializados mostram que o Brasil protege e preserva a vegetação nativa em mais de $66 \%$ de seu território e cultiva, apenas 7,6\% das terras. Dados sobre o centro e o norte da Europa mostram que a Dinamarca cultiva 76,8\%; a Irlanda, 74,7\%; os Países Baixos, 66,2\%; o Reino Unido 63,9\% e a Alemanha 56,9\%. A maior parte dos países desse continente utiliza $20 \%$ a $30 \%$ do território com agricultura. Os países membros da União Europeia usam entre 45\% e 65\%. Os Estados Unidos, 18,3\%; a China, 17,7\%; e a Índia, 60,5\%. Os agricultores brasileiros cultivam apenas $7,6 \%$, com muita tecnologia e profissionalismo.

${ }^{1}$ Fonte: < https://nacoesunidas.org/agencia/fao/>. Acesso em 30.08.2018 
Atualmente, 21\% do Brasil é dedicado à preservação da vegetação nativa e da biodiversidade dentro de seus estabelecimentos. São mais de 177 milhões de hectares registrados no Cadastro Ambiental Rural (CAR). Esta trajetória de conquistas incrementais de produtividade e de eficiência, tende a se consolidar e se expandir exponencialmente, face às transformações do setor agrícola, em decorrência da adoção de preceitos da inteligência artificial e da indústria 4.0.

O somatório de áreas preservadas dentro dos imóveis rurais, um conceito de unidade de propriedade que é diferente do de estabelecimentos agropecuários que é unidade de gestão, em decorrência da já aplicação do Novo Código Florestal, demove ou contesta outro mito, o de que a agricultura brasileira não preserva a natureza.

\section{TRANSFORMAÇÕES ESPERADAS}

Em poucos anos a mecanização agrícola no Brasil tenderá a adotar os fundamentos, preceitos e recursos da Indústria 4.0, enquanto a Inteligência Artificial, a AI, estará presente tanto na mecanização inspirada na manufatura avançada como em todos os suportes, inclusive hardwares e softwares, sinalizadores para as máquinas e equipamentos de irrigação automatizados, provedores de alimentos, água e demais insumos para as plantas e animais, além de monitoramento de doenças e de variáveis meteorológicas.

Estes sistemas automatizados e, em certos casos, robotizados de atendimento das necessidades biológicas, estarão integrados com bancos de dados que armazenarão, volumes significativos (big data) que, somados às técnicas de mineração de dados e a modelos de inteligência computacional, gerarão informações para apoiar o suporte à decisão no campo. Farão parte dele os sistemas de gerenciamento microeconômico dos estabelecimentos agrícolas e de relacionamento com os serviços de assistência técnica e pesquisa em ciências agrárias e com todos os tipos de mercado ou de logística para movimentação de fluxos de produtos, bem como de provimento de insumos para as unidades produtivas e também com a rede de unidades participantes, de consórcios e cooperativas.

Este novo campo de conhecimento avançado está sendo chamado de AgroTIC. Nele o avanço tecnológico dos sensores, das imagens de drones, da internet das coisas (IoT) e dos algoritmos de análise, possibilitará acessar uma gama de dados antes considerada impossível. Isso se dará porque a computação cognitiva e a inteligência artificial, auxiliarão a analisar o grande volume de dados, tornando possível gerar informação e conhecimento para a tomada de decisão com quantidade de dados considerada exponencial.

Malgrado o setor agrícola tenda a acompanhar a indústria e os serviços nesta quarta revolução industrial, ele tem características próprias, variáveis ambientais difíceis de controlar, como mudanças bruscas no clima ou interações ecológicas. Se na indústria existe um ambiente mais controlado, com menos fatores exógenos ao contexto da produção, o mesmo não se dá no setor agrícola, mas isso não é um impedimento para adoção da AI e da Indústria 4.0 no setor agrícola, segundo entendimento de Castro e Bonacelli (2018). As autoras defendem que, no caso do setor agrícola, estaria havendo a formação de um Ecossistema de Inovação, com novos negócios digitais, alcançando, em 2018, cerca de 250 startups do agro, com taxa de crescimento expressiva, levando à formação da AgTech Garage, um hub de inovação localizado em Piracicaba (SP). O hub engendra esforços para catalisar novas parcerias entre empresas de tecnologia aplicadas ao agronegócio, as chamadas Agtechs. (CASTRO; BONACELLI, 2018).

A dinâmica evolutiva das startups do agro em todo o mundo, e no Brasil em particular, está mudando a relação das grandes corporações com essas empresas emergentes. Na área de industrialização de alimentos e de comercialização agrícola isto se verifica mais intensamente. As grandes corporações, dependendo da avaliação que fazem, adquirem as startups ou estabelecem parcerias permanentes.

A configuração do ecossistema de inovação permite que se opere em uma atmosfera colaborativa e instrutiva, envolta por uma relação de vantagens mútuas na qual todos se apoiam para progredir. Trabalhando de forma cooperativa, não hierárquica, os resultados são maiores e melhores, à exemplo do protocolo de transferência de dados entre os instrumentos que coletam dados, transmitem e analisam seus resultados. Nesta interação quanto maior a interoperabilidade entre dados, maiores as chances de novos desenvolvimentos e novos negócios.

Ainda na visão de Castro e Bonacelli (2018), as Agtechs surgem com um papel muito importante no ecossistema de inovação agrícola, em virtude da facilidade em levar as inovações para dentro das empresas, sejam essas nas áreas de TI, biotecnologia, nanotecnologia, automação ou robótica. Um exemplo do dinamismo deste $h u b$ de inovação foi o crescimento da capacidade de financiamento, a qual evoluiu do 
autofinanciamento para mecanismos como Fundos de venture capital, fundos privados, crowdfunding, capital anjo etc.

Um exemplo bem-sucedido de startups do agronegócio digital é a Agrosmart que tem, como "carro chefe" da empresa, um produto que possibilita a irrigação inteligente das lavouras, por meio de sensores no solo que controlam temperatura, umidade e vento, entre outros parâmetros. A Agrosmart prosperou fortemente em função da existência de um ecossistema de inovação, que possibilitou a empresa engendrar boas ideias.

O avanço da Industria 4.0 na agricultura do Brasil ainda enfrenta dificuldades, sendo a principal a deficiência da cobertura da internet no campo. A infraestrutura é insuficiente e os programas de universalização da internet dependem de investimentos que tardam, o que tem limitado a difusão de uma infinidade de aplicativos já disponíveis. Não obstante seja possível desenvolver soluções que contornem a ausência da internet, maior benefício do conhecimento nesta área depende de uma rede com um maior tráfego de informação, a qual permitiria, aos agricultores, acessar, por celular, os diversos aplicativos que processam dados coletados no campo (CASTRO; BONACELLI, 2018).

Neste panorama, algumas soluções muito criativas estão aparecendo. Entre elas está a pareceria entre o CPqD, Centro de Pesquisa e Desenvolvimento em Telecomunicações, que tem estatuto de Oscip, organização da sociedade civil de interesse público, com o Grupo São Martinho, um dos maiores empreendimentos do setor sucroalcooleiro do Brasil, para desenvolver o projeto AgroTICs. O objetivo deste projeto é a implantação de uma rede móvel privada de banda larga, baseada no conceito de internet das coisas, no setor de agronegócios. A ideia é conectar áreas rurais e remotas da empresa. 0 projeto contou com apoio do BNDES, Banco Nacional de Desenvolvimento Econômico e Social, e da FINEP, Financiadora de Estudos e Projetos.

Outro desafio que se coloca, para que o setor agrícola adote conceitos e ferramentas da AI e da Indústria 4.0, é a qualificação da mão de obra. A mudança do trabalho no campo, caminhando cada vez mais para a automação das atividades rurais, além de necessária, inexorável e urgente, é também um desafio, dado que, contemporaneamente, existe um hiato entre a demanda de operadores qualificados e a oferta dos mesmos. À medida que a substituição do trabalho braçal avançar, haverá maior exigência por pessoas capacitadas para interpretar os dados coletados no campo, com conhecimento, discernimento e habilidades para a tomada de decisão, com rapidez e segurança. Hoje, por exemplo, a demanda por mão de obra capaz de manusear tratores inteligentes, sensores e internet é crescente.

A implantação do novo paradigma da agricultura digital enfrenta outra dificuldade, que é o ritmo mais lento da adoção de novas tecnologias no campo, malgrado o setor denominado de agronegócio manifeste propensão a assumir riscos e a adotar novas tecnologias. Uma forma de acelerar o ritmo da adoção de novas tecnologias no campo é praticar o efeito demonstração. Isso porque o produtor rural acompanha o sucesso dos demais agricultores que estão no seu entorno.

Dada a importância do Brasil no cenário agrícola internacional e dado o papel que as agências internacionais atribuem ao país em termos de produção de alimentos, é fundamental conceber iniciativas que visem a acelerar a interação entre centros de pesquisa e universidades, apoiar e apostar em startups, em novos perfis de investidores e em diferentes opções de financiamento e de valorização do capital da agricultura. 0 fortalecimento de ecossistemas de inovação voltados ao novo agro é, por sua vez, o caminho mais curto para alcançarmos a revolução advinda da "agricultura 4.0", que seria o estado da arte do agro após a absorção da indústria 4.0. Destarte, os países que dominarem tecnologias da indústria 4.0 sairão na frente, pois terão menos custos para produzir soluções, comparativamente aos países retardatários e menos tecnológicos (CASTRO; BONACELLI, 2018).

Face a estas tendências, cabe a pergunta: qual o papel da agroecologia no futuro da agricultura brasileira e poderá este suposto paradigma ser uma solução para que a agricultura familiar, que supostamente responde por $70 \%$ da produção de alimentos no Brasil venha se constituir alternativa ao agro moderno? A agroecologia pode ignorar o que está acontecendo com um "comportamento de avestruz"? Que dizer de uma suposta área de conhecimento que abstrai problemas como abastecimento da população e obtenção de saldos de alimento exportáveis? Que define entre seus objetivos interferir na correlação de forças de uma luta de classe imaginária entre o Leviatã mal-intencionado, que seria o agronegócio, e um "campesinato", que só adquire expressão numérica e social em hipóteses jamais testadas? Que defende uma paridade em parcerias de pesquisa entre homens de ciência e habitantes do meio rural, demonstrando incapacidade perceber os limites e a importância do senso comum para a pesquisa científica? Que se recusa a proceder qualquer avaliação econômica de seus sistemas à luz do mercado e 
considerando os custos de oportunidade? Que refuta a ideia de apresentar critérios de validação de suas "pesquisas", descrevendo o método e os limites de aproximação que permitam julgar o significado?

Estas condutas retiram da agroecologia qualquer valor universal e toda a possibilidade de se apresentar claramente como ciência, pelo menos pelos critérios globalmente aceitos do que seja ciência. Não obstante a agroecologia pretender se definir como um enfoque científico destinado a apoiar a transição dos atuais modelos de desenvolvimento rural e de agricultura convencionais para estilos de desenvolvimento rural e de agriculturas sustentáveis, que se proponha a proceder reflexões teóricas para conformar um corpus teórico e metodológico a subsidiar essa transição e até estabeleça etapas ou níveis de transição que poderiam parecer lógicos e sensatos, na prática se conduz de forma confusa, uma vez que dá uma peso desproporcional à atuação dos agentes sociais e econômicos nessa transição, visto que os mesmos deveriam internalizar crenças inabaláveis nas possibilidades da agroecologia, sem questionar os princípios da mesma. Inobstante as boas intenções em relação à biodiversidade, ao aquecimento global etc., a agroecologia está mais próxima de uma seita que de uma ciência. Neste sentido, em relação a ela, deve-se ser tolerante visto que jardins e hortas, como sistemas mais fechados, autossuficientes, tipo o "sistema mandala", podem ser aceitos como experiências estéticas, mas de impacto econômico extremamente limitado, e vistos como utopia, da mesma forma que Francis Bacon (1997, p. 246-251) descreveu e desenhou na "Nova Atlântida", provável fonte de inspiração da agroecologia. Contudo, o que não deve ser acolhido é o pleito da agroecologia ser aceita como ciência e nem tolerado o apoio do Estado a essas fantasiosas experiências de ajudar a agricultura brasileira, sobretudo os produtores rurais mais pobres. (BAIARDI, 2018).

No que tange a que a promessa agroecológica esteja associada ao fortalecimento da agricultura familiar e ao reforçamento de sua missão de responder por $70 \%$ da alimentação que chega nas mesas das famílias brasileiras, convém resgatar a pesquisa feita por Rodolfo Hofmann (2014) que afirma ser afirmação falsa, a de que a agricultura familiar responde por $70 \%$ da comida que chega à mesa de nossas casas. Para Hoffmann, que procedeu análise estatística rigorosa com base no Censo agropecuário de 2006, este aporte não alcançaria $25 \%$.

\section{CONCLUSÃO}

A inevitabilidade da inserção competitiva da agropecuária brasileira no mercado mundial de commodities e de espécimes com valor agregado elevado, vem se tornando óbvia. A este fato aduz-se as pressões e acordos internacionais que visam atribuir papel relevante ao Brasil na redução das carências de alimento ao nível mundial. Face esta realidade, o trabalho especula sobre o impacto na agricultura decorrente da adoção da Inteligência Artificial e da Indústria 4.0, sugerindo efeitos tanto na redução dos empregos diretos como na exclusão de estabelecimentos que não lograrem modernizar-se.

Conclui que, não obstante ser arriscado fazer projeções, a análise das transformações recentes e possíveis de virem a ocorrer nos processos produtivos na agricultura, decorrentes da adoção das referidas inovações sugere políticas agrícolas, em particular políticas de pesquisa agropecuária, que privilegiem demandas específicas e condutas de elevada racionalidade. Neste quadro de definições, o autor não identifica razões para apoio público às experiências no campo da Agroecologia.

\section{BIBLIOGRAFIA:}

[1] BACON, F. Novum Organum, ou verdadeiras indicações acerca da interpretação da natureza. Nova Atlântida. São Paulo: Abril Cultural, 1997.

[2] BAIARDI, A. Agronomia: vicissitudes de ser ciência. Ciência e Cultura. , v.69, p.29 - 33, 2017.

[3] CASTRO, P. D.; BONACELli M. B. M. Agtechs: Tecnologias para Agricultura Inspiram Novos Mercados. COMCIÊNCIA Laboratório de Estudos Avançados em Jornalismo (LABJOR) Dossiê Indústria 4.0 (FEV/2018).

[4] CHAVES, Roselene de Queiroz. Inovatividade no Sistema Brasileiro de Inovação na Agricultura: uma análise baseada na política de cooperacão internacional da Embrapa. Tese (Doutorado em Agronegócios) - Programa de Pósgraduação em Agronegócios da UFRGS, Porto Alegre, 2010.

[5] GRAZIANO, X; NAVARRO, Z. O novo mundo rural, a antiga questão agrária e os caminhos futuros da agropecuária no Brasil. São Paulo: Editora UNESP, 2015.

[6] HOFFMANN, R. A agricultura familiar produz 70\% dos alimentos consumidos no Brasil? Segurança Alimentar e Nutricional, Campinas, 21(1):417-421, 2014

[7] RIBEIRO, M. C. M. Cooperação Internacional em Ciência e Tecnologia: uma análise das experiências da Embrapa Semiárido. Tese (Doutorado em Administração) - Programa de Pós-graduação em Administração da EAUFBA, Salvador, 2015 


\section{Capítulo 2}

O setor produtivo do Cerrado Piauiense: Uma análise multivariada da estrutura produtiva

\section{Gabriele Ferreira da Silva Monte}

\section{Edivane de Sousa Lima}

Resumo: Esta pesquisa teve o objetivo de analisar o setor produtivo do cerrado piauiense entre 2002 e 2017. A metodologia adotada consistiu em estimar um Índice de Estrutura Produtiva Municipal através da técnica multivariada de análise fatorial por componentes principais e, dessa forma, classificar os municípios de acordo com seu grau de produtividade. Os resultados mostraram que no ano de 2002 os municípios de Floriano, São Raimundo Nonato e Uruçuí apresentaram alto grau de produtividade, enquanto os municípios de Antônio Almeida, Baixa Grande do Ribeiro, Bom Jesus, Canto do Buriti, Corrente, Guadalupe e Ribeiro Gonçalves apresentaram grau médio de produtividade. No ano de 2017, os municípios de Bom Jesus e Baixa Grande do Ribeiro passaram a apresentar índice de produtividade alto e os municípios de Floriano, São Raimundo Nonato e Uruçuí permaneceram com índice de produtividade alto. Concluiuse que o cerrado piauiense e a mesorregião na qual está inserido, demonstram potencial para transformações importantes em todos os setores econômicos, base da sua estrutura produtiva, nesse sentido, recomenda-se a elaboração e a aplicação de um plano de investimentos direcionados aos setores-chaves da economia regional com objetivo de elevar a produtividade e promover o desenvolvimento econômico regional.

Palavras-chave: Desenvolvimento Regional. Análise multivariada. Cerrado Piauiense. 


\section{INTRODUÇÃO}

O setor agrícola da Mesorregião do Sudoeste Piauiense passou por transformações a partir da década de 1990, com a introdução da produção de grãos, destacando-se a soja. A superação da baixa produtividade natural do solo, característica do bioma Cerrado, por meio dos avanços tecnológicos proporcionados pelas pesquisas da Empresa Brasileira de Pesquisa Agropecuária (EMBRAPA), voltadas para a elevação da produtividade agrícola, proporcionou o avanço desse setor. Somado a isso, a escassez de terras produtivas em outras regiões do país impulsionou a vinda de um grande volume de empreendedores que obtiveram incentivos do Estado e acesso à terra com preços inferiores aos praticados no mercado. 0 avanço do setor agrícola, com a introdução da soja como principal produto, teve impacto sobre os outros setores da estrutura produtiva $^{2}$ da Mesorregião do Sudoeste Piauiense (AGUIAR; MONTEIRO 2005; MONTEIRO 2002; ALVES 2005).

As transformações que ocorrem na dinâmica de cada setor produtivo têm o potencial de influenciar na dinâmica dos demais, isso se deve ao fato de estarem inter-relacionados. De acordo com Alves (2005), a vida econômica e social nas regiões que compõem a fronteira agrícola, como o Sudoeste Piauiense, se subordina ao ritmo e às necessidades da produção agrícola. Com o avanço do setor agrícola, surgem novas demandas que impulsionam os demais setores produtivos, como a indústria, o comércio e os serviços, provocando transformações na estrutura produtiva da região.

Dessa forma, torna-se evidente a importância do estudo da dinâmica produtiva da Mesorregião do Sudoeste Piauiense entre os anos 2002 e 2017, devido às transformações pelas quais tem passado. Essas transformações são essenciais para a compreensão da sua dinâmica evolutiva. Nesse sentido, o presente estudo teve como objetivo geral analisar o setor produtivo do cerrado piauiense entre 2002 e 2017 e observar a ocorrência de mudança na estrutura produtiva dos municípios que o compõem Especificamente, foi feita a caracterização da estrutura produtiva da Mesorregião do Sudoeste Piauiense; a identificação dos principais fatores determinantes da dinâmica produtiva dos municípios dessa região e a estimação de Índices de Estrutura Produtiva para esses municípios entre os anos 2002 e 2017. A análise dos setores produtivos teve como objeto os municípios que compõem a Mesorregião do Sudoeste Piauiense, obtendo-se um maior nível de desagregação, o que permitiu evidenciar as particularidades de cada município.

0 presente capítulo está estruturado em cinco tópicos. 0 primeiro corresponde à introdução, em que é apresentada uma visão geral do trabalho. No segundo tópico foi feita um breve referencial teórico das principais teorias de Economia Regional presentes na literatura. No terceiro tópico foram descritos a metodologia, a base de dados e o método empírico utilizados. No quarto tópico foram apresentadas a estimativa do Índice de Estrutura Produtiva Municipal e a análise dos resultados e, por último, tem-se a conclusão.

\section{BREVE REFERENCIAL TEÓRICO}

A Economia Regional trata da desigualdade na distribuição de recursos, sendo a má alocação de recursos um dos fatores que contribuem para que existam desigualdades regionais. De acordo com Souza (1981), a industrialização e a urbanização ocorreram de maneira disforme entre as regiões por conta de fatores como custos de transporte significativos, aprofundando ainda mais as distâncias entre regiões ricas e pobres dentro de um mesmo país (SOUZA, 1981).

Os estudos voltados para a análise regional se consolidaram a partir do século $\mathrm{XX}$, a partir de duas vertentes teóricas: as Teorias da Localização e as Teorias do Crescimento/Desenvolvimento Regional (LIBERATO, 2008).

\subsection{TEORIAS DA LOCALIZAÇ̃̃O E DE DESENVOLVIMENTO REGIONAL}

Segundo Waibel (1948), a ocupação de terras leva em consideração tanto as condições geográficas do local, como as condições relacionadas ao tipo de aproveitamento a ser dado à terra, que envolve fatores

\footnotetext{
${ }^{2}$ A estrutura produtiva de um país ou região pode ser entendida sendo a composição de setores ou subsetores da economia. Esses setores foram classificados por Clark (1940) como primário (atividades agropecuárias e extrativistas), secundário (atividades manufatureiras) e terciário (serviços) (BATISTI 2018; ALVES 2005).
} 
políticos, econômicos e sociais. Ademais, fatores como custos de transporte e distância entre as regiões ocupadas e os mercados também devem ser considerados.

Os precursores da Teoria da Localização ocuparam-se dessas questões, enfatizando o papel dos custos de transporte na escolha da localização ótima pela firma. Dentre as principais Teorias Clássicas da Localização está a desenvolvida por Johann Heinrich Von Thünen, que tratou principalmente da influência do fator distância em relação à economia agrária (WAIBEL, 1948; BASTOS, 2007).

Em sua Teoria da Localização, Von Thünen considera um Estado isolado do resto do mundo, com condições topográficas idênticas em toda a sua extensão. No cenário econômico, a população se dedicaria à agricultura e silvicultura e todas as propriedades agrícolas dependeriam do mercado. 0 mercado estaria localizado no centro desse Estado, onde todas as atividades desenvolvidas são não agrárias. A dinâmica entre a cidade e a zona rural nesse modelo se dá por meio da troca entre os produtos industriais, fornecidos pela primeira, e os mantimentos, fornecidos pela segunda. Os preços dos produtos agrícolas são influenciados pelo fator distância da zona agrícola ao mercado, pois são incluídas as tarifas de transporte. Dessa forma, as culturas agrárias se distribuiriam em torno do Estado em faixas concêntricas, no formato de anéis, considerando-se os custos de transporte (WAIBEL, 1948).

No caso de um aumento no custo de transporte, as culturas mais valorizadas estariam dispostas em faixas mais próximas das cidades, ou seja, dos mercados. Enquanto as faixas mais distantes seriam reservadas às culturas com menor rendimento, porém com custos de transporte inferiores (BASTOS, 2007).

A Teoria da Localização Industrial de Alfred Weber também considera os custos de transporte em sua análise. De acordo com essa teoria, a localização das indústrias seria influenciada por fatores locacionais, considerados como vantagens econômicas de determinado local, que seriam determinantes dessa localização. Weber (1929) identifica os fatores que influenciam a escolha da localização industrial e seriam comuns a todas das indústrias, são estes o custo de transporte, de matéria-prima e de mão de obra, que variam de região para região (LIBERATO, 2008).

As Teorias de Desenvolvimento Regional seguem as ideias keynesianas e possuem como ponto comum o fato de considerarem que existe uma atividade principal que provoca efeitos positivos sobre as outras atividades econômicas, gerando crescimento (BELLINGIERI, 2017).

Rosenstein-Rodan realizou estudos na área de Desenvolvimento Econômico e inspirou as Teorias de Desenvolvimento Regional. De acordo esse autor, a industrialização seria a via de desenvolvimento para as regiões consideradas atrasadas. 0 desenvolvimento econômico dessas regiões poderia ser alcançado de duas maneiras, a primeira seria a industrialização com seus próprios meios, sem utilizar capital externo, em que o próprio Estado seria responsável por prover o capital necessário e, portanto, seria mais lenta e o país estaria excluído da economia mundial. A segunda maneira seria a industrialização utilizando o capital externo que, ao contrário da primeira, ocorreria de forma mais rápida e o país estaria incluído na economia mundial. Ademais, o autor destaca a importância da participação do Estado na implantação de projetos de larga escala, essenciais para a industrialização (VASCONCELLOS, 2016).

A teoria de Perroux enfatiza o desenvolvimento através da industrialização. A Teoria dos Pólos de Crescimento de Perroux parte do pressuposto de que o crescimento econômico não se comporta de maneira uniforme em todos os espaços econômicos, sendo observado em pontos específicos. Três conceitos importantes são definidos por Perroux, o primeiro é o da indústria motriz, que seria aquela capaz de gerar efeitos sobre outras indústrias, aumentando as compras e vendas destas através do aumento de suas próprias compras e vendas produtivas. O segundo conceito é o da indústria movida, a que sofre os impactos da indústria motriz. 0 terceiro conceito é o da indústria-chave, aquela que provoca efeitos sobre a totalidade do grupo (JESUS; SPÍNOLA, 2015).

A teoria de Hirschman foi de grande contribuição para a Teoria do Desenvolvimento Regional, principalmente os conceitos de encadeamentos "para trás" e "para a frente". Com base nessa teoria, o desenvolvimento seria promovido por meio desses encadeamentos. 0 movimento indutor de encadeamentos surgiria em determinada atividade, o que estimularia movimentos dinâmicos "para a frente e para trás" daquela atividade, gerando efeitos sobre outras. As atividades industriais teriam maior capacidade de gerar esses encadeamentos quando comparadas com as atividades agrícolas (MALUF, 2015; OCAMPO, 2013). 


\subsubsection{EVIDÊNCIAS EMPÍRICAS A PARTIR DAS TEORIAS DE DESENVOLVIMENTO REGIONAL}

As Teorias da Localização foram utilizadas no estudo de Andrade et al. (2007) com o objetivo de determinar a localização economicamente ótima da agroindústria de abate e processamento de aves e suínos no Brasil. A minimização do custo de transporte e aquisição de insumos e dos custos de transporte do produto final foram consideradas no estudo para a determinação da localização ótima, assim como considerado nas Teorias da Localização. Os resultados mostraram que a localização ótima da agroindústria de abate e processamento de aves e suínos é a cidade de Cândido Mota, em São Paulo. Isso se deve ao fato de que a cidade está localizada próxima dos pólos de oferta de insumos, dos consumidores de carne e dos portos marítimos, reduzindo os custos de transporte.

Ferreira, Marques e Fernandes (2010) utilizaram as Teorias da Localização para identificar os fatores determinantes da localização de empresas de base tecnológica em Portugal. Para isso, utilizaram a amostra com 203 empresas portuguesas e fatores de natureza comportamental, institucional e neoclássica. Os autores concluíram que a maioria dos fatores que influenciaram as decisões de localização de empresas com base tecnológica eram de natureza comportamental e, em menor proporção, de natureza neoclássica. Além disso, percebeu-se que esse tipo de empresa está localizado em regiões menos rurais.

Por sua vez, Ribeiro e Rocha (2013) utilizaram as Teorias de Desenvolvimento Regional em um estudo empírico aplicado aos setores produtivos do estado da Bahia. Os autores analisaram a interdependência produtiva da economia do estado a partir da teoria de Hirschman. De acordo com os autores, para maximizar os efeitos do encadeamento é necessário avaliar o nível de interdependência entre os setores, por esse motivo, foi utilizado no estudo o modelo de Insumo-Produto. Os resultados mostraram que os setores-chaves da economia baiana são os setores de Metalurgia, de outros Químicos e Farmacêuticos e de Serviços Privados. Esses setores mostraram forte encadeamento a montante e a jusante da cadeia produtiva, sendo considerados setores estratégicos para o crescimento econômico do estado.

O papel da indústria como indutora do desenvolvimento econômico foi utilizado como base para a análise feita por Honório, Dutkievicz e Souza (2011), que teve como objeto de estudo a empresa Araupel, no município de Quedas do Iguaçu, e a microrregião onde está inserida. Os autores demonstraram que a empresa Araupel não se destaca como força motriz, ou seja, não provoca efeitos encadeadores sobre outros setores e não cria outras atividades para o abastecimento de insumos do seu processo de produção na própria região. Apesar disso, os autores destacam que essa empresa é considerada uma indústria-chave no município.

Segundo Carleial e Cruz (2009), a utilização de estratégias de adensamento das estruturas produtivas regionais, por meio da complementação das cadeias produtivas e aproveitamento de efeitos de encadeamento, é de suma importância para o desenvolvimento regional. Os autores propõem que sejam realizados investimentos pelo Poder Público em setores-chaves das economias regionais para a complementação de suas cadeias produtivas, o que incentivaria novos investimentos em outros setores essenciais por meio de encadeamentos, conceito definido por Hirschman.

Do ponto de vista da economia brasileira, Amorim, Coronel e Teixeira (2009) atribuíram grande importância ao setor agropecuário como responsável pelos encadeamentos produtivos. Esse setor mostrou-se relevante como comprador de bens e serviços e fornecedor de insumos dos demais setores da economia. Segundo os autores, o setor agropecuário ocupa papel central no desenvolvimento econômico do país, pois ao mesmo tempo que fornece insumos para o desenvolvimento dos outros setores, é consumidor de produtos industrializados.

Silva, Negri e Kubota (2006), por sua vez, enfatizam a importância do setor de serviços, mais especificamente os intensivos em conhecimento, como vetor de inovação da indústria. Entretanto, em termos de produtividade não há destaque a esse setor, o que pode ser atribuído ao seu grau de heterogeneidade, sendo algumas atividades mais produtivas que outras. Apesar disso, os autores consideram que esse setor ocupa um papel considerável no grau de produtividade dos outros setores, bem como na difusão de inovações.

Em contrapartida à ideia de que o setor de serviços tem efeitos consideráveis sobre os outros setores e para o crescimento econômico, Pereira, Bastos e Perobelli (2013) destacam que esse não é um setor-chave para a economia. Segundo os autores, os elos que o setor de serviços mantém com os demais são fracos quando comparados a outros setores, como a indústria. Além disso, a demanda final do setor de serviços não se mostrou significativamente impactante em relação ao resto da economia, assim como a demanda por insumos, porém mostrou-se como grande gerador de empregos. 
Nakabashi, Scatolin e Cruz (2010) destacaram o papel da indústria como importante fonte de encadeamentos para o resto da economia brasileira entre os anos 1948 e 2007. Segundo os autores, o setor industrial gerou encadeamentos sobre o próprio setor, sobre o setor agropecuário e sobre o comércio, demonstrando ter grande influência sobre o crescimento da economia brasileira no período.

A importância da indústria para compreensão do desenvolvimento econômico foi objeto de estudo da Comissão Econômica para a América Latina e o Caribe (CEPAL). 0 foco dos estudos da CEPAL era compreender os problemas ligados a industrialização periférica, tendo como seu líder intelectual Raúl Prebisch. Esse autor acreditava que a industrialização seria a indutora de efeitos positivos sobre os outros setores da economia, possibilitando a superação do subdesenvolvimento da América Latina (SILVA, 2017).

\section{O SETOR PRODUTIVO DO CERRADO PIAUIENSE}

A Mesorregião do Sudoeste Piauiense que abrange o cerrado piauiense foi responsável por 98,36\% da quantidade produzida de soja em lavouras temporárias e permanentes (IBGE, 2019; MDIC, 2019).

Alves (2005) destacou as transformações que ocorreram em cidades que se tornaram grandes sojicultores, como os municípios de Bom Jesus e Uruçuí. Segundo o autor, as mudanças experimentadas por esses municípios vão da infraestrutura do espaço urbano até os costumes. As novas empresas que se instalaram nessa região, impulsionadas pelo avanço da lavoura de soja, não se limitavam ao setor agrícola, mantendo ligações com o comércio e os serviços. Essas novas demandas por comércio e serviços surgiram a partir da chegada de migrantes, principalmente da região sul do país, incentivados pelas novas oportunidades que a lavoura de soja oferecia. Ademais, houve um aumento na oferta de emprego urbano. Dessa forma, o setor agrícola provocou efeitos positivos sobre outros setores, gerando novas demandas para estes. Como destaca Alves (2005), a partir dessas transformações esses municípios passaram a ter maior dinamismo econômico.

\subsection{PROCEDIMENTOS METODOLÓGICOS}

\subsubsection{MÉTODO ESTATÍSTICO}

O método estatístico utilizado para analisar os dados desta pesquisa foi a estatística multivariada de análise fatorial por componentes principais. A análise de componentes principais transforma um conjunto original de variáveis em um conjunto de componentes principais, o que ocorre com pouca perda de informações e, além disso, elimina variáveis originais que possuam pouca informação. É um método de extração de fatores e permite transformar um conjunto de variáveis correlacionadas em um conjunto de variáveis não-correlacionadas, tendo sido utilizado na presente pesquisa para a extração dos fatores na intenção de explicar as variáveis originais (VICINI, 2005).

A partir da análise fatorial, é possível identificar um número menor de novas variáveis, chamadas de fatores ou variáveis latentes, dentre um conjunto maior de variáveis originais correlacionadas. As variáveis originais correlacionadas são agrupadas formando fatores e cada fator corresponde a uma combinação linear das variáveis originais, sendo não observável e não correlacionados entre si. Após a identificação dos fatores, é possível obter os seus valores numéricos, ou escores, para cada elemento amostral (MINGOTI 2005; HAIR et al. 2009).

A especificação matemática da análise fatorial é representada através da combinação linear entre as variáveis (Xi) e $\mathrm{K}$ fatores comuns (F) da seguinte forma:

$$
X i=A_{i 1} F_{1}+A_{i 2} F_{2}+\cdots+A_{i k} F_{k}+U i+E i
$$

Em que: $X_{i}$ representa as variáveis utilizadas; $A_{i k}$ representa as cargas fatoriais; $F_{k}$ representa os fatores comuns; $U_{i}$ representa o fator único e $E_{i}$ o fator de erro (MELO E PARRÉ, 2007). Com a finalidade de verificar a adequada extração de fatores a partir das variáveis originais, foram utilizados dois critérios: a estatística Kaiser-Meyer-Olkin (KMO) e o teste de esfericidade de Bartlett. A estatística KMO fornece a proporção de variância comum a todas as variáveis na amostra utilizada, ou seja, que pode ser atribuída à existência de um fator comum. Essa estatística varia de 0 (zero) a 1 (um). Nesse sentido, valores mais próximos de 1(um) indicam que as variáveis compartilham um percentual de variância elevado ou correlações de Pearson altas e valores mais próximos de zero indicam correlações de Pearson baixas entre 
as variáveis, sendo um indicativo da inadequada utilização da análise fatorial. Segundo Mingoti (2005), um coeficiente de KMO igual a 0,9 seria excelente, enquanto um coeficiente igual a 0,5 seria inadequado, sendo, neste caso, necessário ajuste nos dados por meio da inclusão ou exclusão de variáveis.Essa estatística pode ser apresentada por meio da seguinte expressão, Kaiser (1970):

$$
\text { MSA }=\frac{\sum \sum_{j \neq k} r^{2}{ }_{j k}}{\sum \sum_{j \neq k} r^{2}{ }_{j k}+\sum \sum_{j \neq k} q^{2}{ }_{j k}}
$$

Em que: j e k representam, respectivamente, as linhas e colunas da matriz de correlações e o termo $r^{2}{ }_{j k}$ corresponde ao quadrado dos elementos da matriz de correlação original (fora da diagonal) e $q^{2}{ }_{j k}$ representa o quadrado dos elementos fora da diagonal da matriz anti-imagem da correlação (MARQUES, 2010).

Já o teste de esfericidade de Bartlett, consiste em comparar a matriz de correlações com uma matriz de identidade de mesma dimensão. Caso as diferenças entre os valores correspondentes fora da diagonal principal de cada matriz não forem estatisticamente diferentes de 0 (zero), a determinado nível de significância, considera-se que a extração dos fatores não será adequada. Nesta pesquisa, para demonstrar a adequação ao modelo, a estatística do teste Bartlett de esfericidade deve ser estatisticamente significante $(\mathrm{p}<0,05)$ (HAIR et al., 2009; FIGUEIREDO FILHO; SILVA JÚNIOR, 2010; MINGOTI, 2005; MARQUES, 2010).

A extração dos fatores a partir do conjunto de variáveis originais foi realizada com base em alguns critérios de escolha. 0 primeiro critério utilizado foi o da proporção da variância total relacionada com cada autovalor, segundo o qual a quantidade de fatores escolhidos corresponde à quantidade de autovalores que representam maiores proporções de variância total explicada. O segundo critério utilizado foi o de Kaiser, que baseia a escolha dos fatores em seus autovalores, sendo o critério de escolha o autovalor superior a 1 (um). Isso se deve ao fato de que fatores com baixos autovalores contribuem menos para explicar a variância das variáveis originais. Dessa forma, a quantidade de fatores será igual ao número de autovalores maiores ou iguais a um (FIGUEIREDO FILHO; SILVA JÚNIOR, 2010; MINGOTI 2005).

Para a interpretação dos dados, foi feita a transformação ortogonal dos fatores com o objetivo de simplificar a estrutura fatorial e facilitar a sua interpretação. 0 método escolhido para rotação dos fatores foi o método de rotação ortogonal Varimax. De acordo com Alves et al. (2018), a rotação dos fatores auxilia na sua interpretação, dado que reduz o número de variáveis fortemente relacionadas com cada fator (MINGOTI, 2005).

O método de rotação ortogonal Varimax tem por objetivo a simplificação das colunas da matriz fatorial, oferecendo uma separação mais clara entre os fatores. A interpretação dos fatores com a utilização desse método é simplificada, pois permite a interpretação a partir de valores mais próximos de +1 ou -1 , mostrando clara correlação negativa ou positiva, e a partir de valores iguais a 0 que demonstra falta de correlação (HAIR et al., 2009).

\subsubsection{BASE DE DADOS E VARIÁVEIS}

Na presente pesquisa foram utilizadas 15 variáveis para cada um dos 62 municípios que participaram da amostra nos anos de 2002 e 2017. O corte temporal foi feito com base no período da consolidação da produção de soja, pós-década de 1990, e no período mais recente que corresponde ao ano de 2017, devido à disponibilidade de dados. A divisão geográfica em municípios justifica-se pelo maior nível de desagregação, o que proporciona a análise do comportamento conjunto das variáveis na mesorregião. A pesquisa utilizou dados secundários do Instituto Brasileiro de Geografia e Estatística (IBGE) e do Ministério do Trabalho através da Relação Anual de Informações Sociais (RAIS).

As variáveis utilizadas neste estudo representaram, de forma geral, os setores primário, secundário e terciário expressas pelo valor adicionado da agropecuário, da indústria e do setor de serviços, bem como, a quantidade de estabelecimentos da indústria, da construção civil, do comércio, dos serviços e da agropecuária, além do número de trabalhadores nos setores supracitados e das áreas de lavouras temporárias e permanentes. 


\subsection{3. ÍNDICES DA ESTRUTURA PRODUTIVA}

Na elaboração desses índices, utilizou-se como referência o trabalho de Alves et al. (2018), em que os autores aplicaram a metodologia para a região nordeste brasileira. Seguindo ideia semelhante a desses autores na presente pesquisa, estimou-se, inicialmente, um Índice Bruto de Estrutura Produtiva (IBEP), expresso da seguinte forma:

$$
\operatorname{IBEP}=\frac{\sum_{i=0}^{n}(w i F i)}{\sum_{i=0}^{n}(w i)}
$$

Onde: wi corresponde à proporção da variância explicada por cada fator (raiz característica) e $F i$ são os escores fatoriais. Esse índice bruto é calculado a partir da média ponderada dos escores fatoriais para todas as observações, sendo o seu peso dado pela proporção da variância explicada por cada fator.

De posse desse índice, foi possível estimar o Índice de Estrutura Produtiva Municipal (IEPM) para os municípios do sudoeste piauiense. Esse índice foi constituído pela utilização do método mínimo e máximo, onde o maior valor (máximo) corresponde a $1(\mathrm{um}$ ) e o menor valor (mínimo) é igual a 0 (zero), em outras palavras, a variação do índice ocorre no intervalo entre 0 e 1. Dessa forma, o Índice de Estrutura Produtiva Municipal (IEPM) pode ser expresso da seguinte forma:

$$
\text { ?ํํ의 } \mathrm{M}=\frac{x q c-\min c(x q)}{\max c(x q)-\min c(x q)}
$$

Onde: $x q c$ é o valor da observação (q) do índice bruto para a mesorregião (c); minc é o menor valor do índice bruto entre os municípios e maxc é o maior valor do índice bruto entre os municípios. Com a estimação do Índice de Estrutura Produtiva Municipal (IEPM), foi possível classificar e ordenar os municípios da Mesorregião do Sudoeste Piauiense de acordo com seu grau de produtividade.

A classificação dos municípios em Alta (A), Média (M) e Baixa (B) produtividade foi feita com base no trabalho de Alves et al. (2018), em que os autores consideram a média $(\mu)$ e o desvio padrão $(\sigma)$ do Índice de Estrutura Produtiva Municipal para cada um dos municípios. Os municípios foram classificados com grau de produtividade da estrutura produtiva alto, quando apresentaram IEPM superior à soma da média com desvio padrão. Os classificados com grau de produtividade médio com valores de IEPM maiores ou iguais à média e menores que a soma da média com desvio padrão. Os classificados com baixo grau de produtividade da estrutura produtiva apresentou valor de IEPM menores que a média.

\section{RESULTADOS E DISCUSSÃO}

\subsection{RESULTADOS EMPÍRICOS PARA O ANO DE 2002}

A partir do método exploratório de análise multivariada por componentes principais para o ano de 2002, foi possível a extração de dois fatores: $\mathrm{O}$ fator $\mathrm{F}^{3}$ (indicador de estrutura econômica produtiva) e o fator F2 4 (indicador de estrutura agropecuária). Esses fatores apresentaram raiz característica superior à unidade, sendo este um dos critérios de escolha dos fatores. Após a realização do método de rotação varimax, foi possível obter a raiz característica dos fatores e concluiu-se que, juntos, eles explicam, aproximadamente, $85,72 \%$ da variância total das variáveis utilizadas, como é possível observar na Tabela 1. Os dois fatores extraídos pelo método análise de componentes principais sintetizam as informações presentes nas 15 variáveis utilizadas na presente pesquisa. 0 teste KMO para os dados referentes ao ano de 2002 apresentou o valor de 0,83, o que mostra adequação do modelo, e o teste Bartlett de esfericidade ${ }^{5}$ mostrou-se estatisticamente significativo, rejeitando a hipótese nula da matriz de correlação ser uma matriz identidade, o que permite viabilizar a extração de fatores a partir das variáveis originais.

30 fator F1 mostrou-se positivamente correlacionado às variáveis valor agregado dos serviços, quantidade de estabelecimentos da indústria, da construção civil, do comércio e dos serviços e quantidade de trabalhadores da indústria, do comércio, da construção civil e dos serviços.

4 O fator F2 apresenta correlação com as variáveis valor agregado do setor agropecuário, quantidade de estabelecimentos e trabalhadores desse setor, área plantada ou destinada à colheita das lavouras temporárias e permanentes e valor da produção das lavouras temporárias e permanentes.

50 teste Bartlett de esfericidade resultou em um $p$-valor significativo. 
Tabela 1 - Autovalor (raiz característica), variância explicada por cada fator (\%) e variância acumulada

(\%) para dados referentes ao ano de 2002

\begin{tabular}{|c|c|c|c|}
\hline Fator & Autovalor (raiz característica) & $\begin{array}{c}\text { Variância explicada pelo } \\
\text { fator (\%) }\end{array}$ & $\begin{array}{c}\text { Variância acumulada } \\
(\%)\end{array}$ \\
\hline F1 & 9,1414646817 & 60,943097878 & 60,94310 \\
F2 & 3,7172515686 & 24,781677124 & 85,72478 \\
\hline
\end{tabular}

Fonte: Elaboração própria com base nos resultados da pesquisa (2020).

Segundo Mingoti (2005), os coeficientes, ou cargas fatoriais, relacionados com cada fator para cada variável representam a correlação entre o fator e a variável. 0 fator F1, por exemplo, explicou 60,94\% da variação total das variáveis utilizadas neste estudo, compartilhando carga fatorial elevada e correlacionada positivamente com as variáveis que compõem esse fator, correspondentes aos setores de serviços, comércio, indústria e construção civil. Enquanto o segundo fator (F2) conseguiu explicar 24,78\% da variação total das variáveis, apresentando correlação positiva com as variáveis originais que o compõem, referentes ao setor agropecuário.

\subsubsection{0 ÍNDICE DE ESTRUTURA PRODUTIVA MUNICIPAL (IEPM) PARA O ANO DE 2002}

Para a obtenção da estimativa desse índice foram utilizados os escores fatoriais para cada um dos municípios da Mesorregião do Sudoeste Piauiense a partir dos resultados da análise fatorial. Utilizando-se os escores fatoriais para cada município e a raiz característica de cada fator, foi possível estimar o Índice Bruto de Estrutura Produtiva, que corresponde à média ponderada desses valores. A partir do índice bruto foi estimado o Índice de Estrutura Produtiva Municipal, que representa o grau de produtividade da estrutura produtiva dos municípios em um intervalo de 0 a 1.

Na Figura 1 estão destacados os municípios que apresentaram alto, médio e baixo grau de produtividade da estrutura produtiva da Mesorregião do Sudoeste Piauiense no ano de 2002, com base no Índice de Estrutura Produtiva Municipal. No ano supracitado, os municípios que apresentaram alto grau de produtividade da estrutura produtiva foram: Floriano, São Raimundo Nonato e Uruçuí. A quantidade de municípios que apresentaram alto grau de produtividade da estrutura produtiva corresponde a cerca de 4,84\%. 0 município de Floriano apresentou maior grau de produtividade da estrutura produtiva, com Índice de Estrutura Produtiva igual a 1. Os municípios que apresentaram produtividade média foram: Antônio Almeida, Baixa Grande do Ribeiro, Bom Jesus, Canto do Buriti, Corrente, Guadalupe e Ribeiro Gonçalves, o que corresponde a 11,29\% dos municípios. Enquanto os outros 52 municípios apresentaram baixo grau de produtividade da estrutura produtiva. Isso mostra que $83,87 \%$ dos municípios da Mesorregião do Sudoeste Piauiense apresentaram produtividade baixa no ano de 2002. A produtividade média da região, com base no Índice de Estrutura Produtiva Municipal, foi igual a 5,7\%, portanto, de forma geral a região apresentou baixa produtividade da estrutura produtiva.

Dentre os municípios que se destacaram pelo alto grau de produtividade da estrutura produtiva estão Floriano e São Raimundo Nonato, que se mostraram intensivos no fator F1 (indicador de estrutura econômica produtiva). Enquanto o município de Uruçuí mostrou-se intensivo do fator F2 (indicador de estrutura agropecuária). Esse município concentra boa parte da produção de soja no Piauí, sendo considerado um grande pólo da produção de grãos (soja, milho, algodão) (LEAL,2013).

Os municípios que apresentaram médio grau de produtividade da estrutura produtiva, com exceção do município de Antônio Almeida, Guadalupe e Corrente, mostraram-se intensivos no fator F2 (indicador de estrutura agropecuária). Os municípios de Bom Jesus e Ribeiro Gonçalves são considerados, também, grandes produtores de soja. Os municípios de Antônio Almeida, Guadalupe e Corrente, por sua vez, mostraram-se intensivos no fator F1 (indicador de estrutura econômica produtiva). Essas informações podem ser visualizadas na Figura 1. 
Figura 1: Distribuição espacial dos municípios da Mesorregião do Sudoeste Piauiense classificados de acordo com o grau de produtividade da estrutura produtiva (ano 2002)

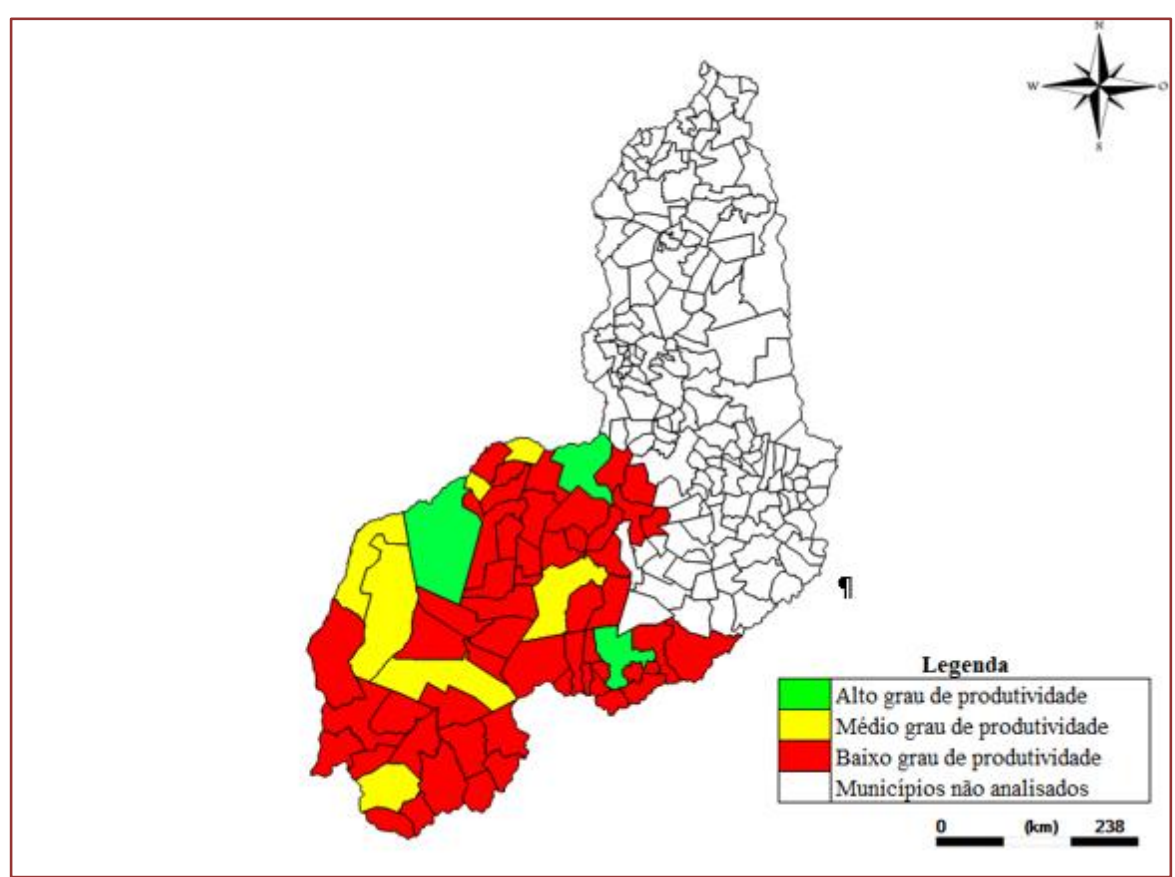

Fonte: Elaboração própria com base nos dados do IBGE (2020)

\subsection{RESULTADOS EMPÍRICOS PARA O ANO DE 2017}

Utilizando-se o método exploratório de análise dos componentes principais para dados referentes ao ano de 2017, foram extraídos dois fatores com base no critério da raiz característica superior a unidade: o fator F16 (indicador de estrutura econômica produtiva) e o fator F2 (indicador de estrutura agropecuária). A partir da rotação dos fatores pelo método varimax, foi possível concluir que, juntos, esses fatores explicam $91,26 \%$ da variância total das variáveis utilizadas. Os dois fatores extraídos pelo método ACP sintetizam as informações presentes nas 15 variáveis utilizadas na presente pesquisa. 0 teste KMO para os dados referentes ao ano de 2017 apresentou o valor de 0,83, o que mostra adequação do modelo, e o teste Bartlett de esfericidade ${ }^{8}$ mostrou-se estatisticamente significativo, rejeitando a hipótese nula da matriz de correlação ser uma matriz identidade, o que permite viabilizar a extração de fatores a partir das variáveis originais.

Tabela 2: Autovalor (raiz característica), variância explicada por cada fator (\%) e variância acumulada (\%) para dados referentes ao ano de 2017

\begin{tabular}{|c|c|c|c|}
\hline \multirow{2}{*}{ Fator } & Autovalor (raiz característica) & $\begin{array}{c}\text { Variância explicada pelo } \\
\text { fator (\%) }\end{array}$ & $\begin{array}{c}\text { Variância acumulada } \\
\text { (\%) }\end{array}$ \\
\hline F1 & 9,509217207 & 63,394781383 & 63,39478 \\
F2 & 4,180036109 & 27,866907394 & 91,26169 \\
\hline
\end{tabular}

Fonte: Elaboração própria com base nos resultados da pesquisa (2020)

0 critério utilizado para a interpretação dos fatores foi a escolha das cargas fatoriais superiores a 0,85. 0 primeiro fator (F1) explica 63,39\% da variância total das variáveis utilizadas na pesquisa e mostrou-se altamente correlacionado com as variáveis que o compõem, referentes ao setor de comércio, serviços,

60 fator F1 mostrou-se positivamente correlacionado às variáveis valor agregado dos serviços, quantidade de estabelecimentos da indústria, da construção civil, do comércio e dos serviços e quantidade de trabalhadores da indústria, do comércio, da construção civil e dos serviços.

$7 \mathrm{O}$ fator F2 apresenta correlação com as variáveis valor agregado do setor agropecuário, quantidade de trabalhadores do setor agropecuário, quantidade de estabelecimentos desse setor, área plantada ou destinada à colheita das lavouras temporárias e permanentes e valor da produção das lavouras temporárias e permanentes.

${ }^{8} 0$ teste Bartlett de esfericidade resultou em um p-valor significativo. 
indústria e construção civil. O fator F2, por sua vez, explica 27,87\% da variância total das variáveis utilizadas, apresentando correlação positiva com as variáveis do setor agropecuário.

\subsubsection{0 ÍNDICE DE ESTRUTURA PRODUTIVA MUNICIPAL (IEPM) PARA O ANO DE 2017}

Na Figura 2 estão destacados os municípios da Mesorregião do Sudoeste Piauiense de acordo com o grau de produtividade da estrutura produtiva, com base na estimativa do Índice de Estrutura Produtiva para o ano de 2017. Os municípios que se destacaram em termos de produtividade nesse ano foram: Baixa Grande do Ribeiro, Bom Jesus, Floriano, São Raimundo Nonato e Uruçuí. Esses municípios apresentaram grau de produtividade da estrutura produtiva alto, em especial o município de Floriano que apresentou Índice de Estrutura Produtiva igual a 1. Os municípios de Canto do Buriti, Corrente, Guadalupe, Ribeiro Gonçalves e Santa Filomena apresentaram grau de produtividade médio. Enquanto os outros 52 municípios apresentaram baixo grau de produtividade da estrutura produtiva, o que corresponde a $83,87 \%$ do total de municípios. De maneira geral, a produtividade média dos municípios estudados com base no Índice de Estrutura Produtiva Municipal foi de 7,29\%, demonstrando ser de baixa produtividade.

Dentre os municípios que apresentaram alto grau de produtividade da estrutura produtiva, Bom Jesus, Floriano e São Raimundo Nonato mostraram-se intensivos no fator F1 (indicador de estrutura econômica produtiva). Enquanto Baixa Grande do Ribeiro e Uruçuí mostraram-se intensivos no fator F2 (indicador de estrutura agropecuária). De fato, a atividade agrícola está presente de forma mais intensa nesses municípios, em destaque se encontra a produção de soja.

Os municípios de Canto do Buriti e Corrente mostraram-se intensivos no fator F1(indicador de estrutura econômica produtiva). Já os municípios de Guadalupe, Ribeiro Gonçalves e Santa Filomena mostraram-se intensivos no fator F2 (indicador de estrutura agropecuária). 0 município de Ribeiro Gonçalves, assim como o município de Uruçuí, passou por mudanças em sua estrutura produtiva desde a década de 1990 com a introdução da produção de grãos, em especial a soja. Desde então, esse município compõe o grupo de municípios produtores de soja no estado do Piauí (MONTEIRO,2002).

Figura 2: Mapa dos municípios da Mesorregião do Sudoeste Piauiense classificados de acordo com o grau de produtividade da estrutura produtiva (ano 2017)

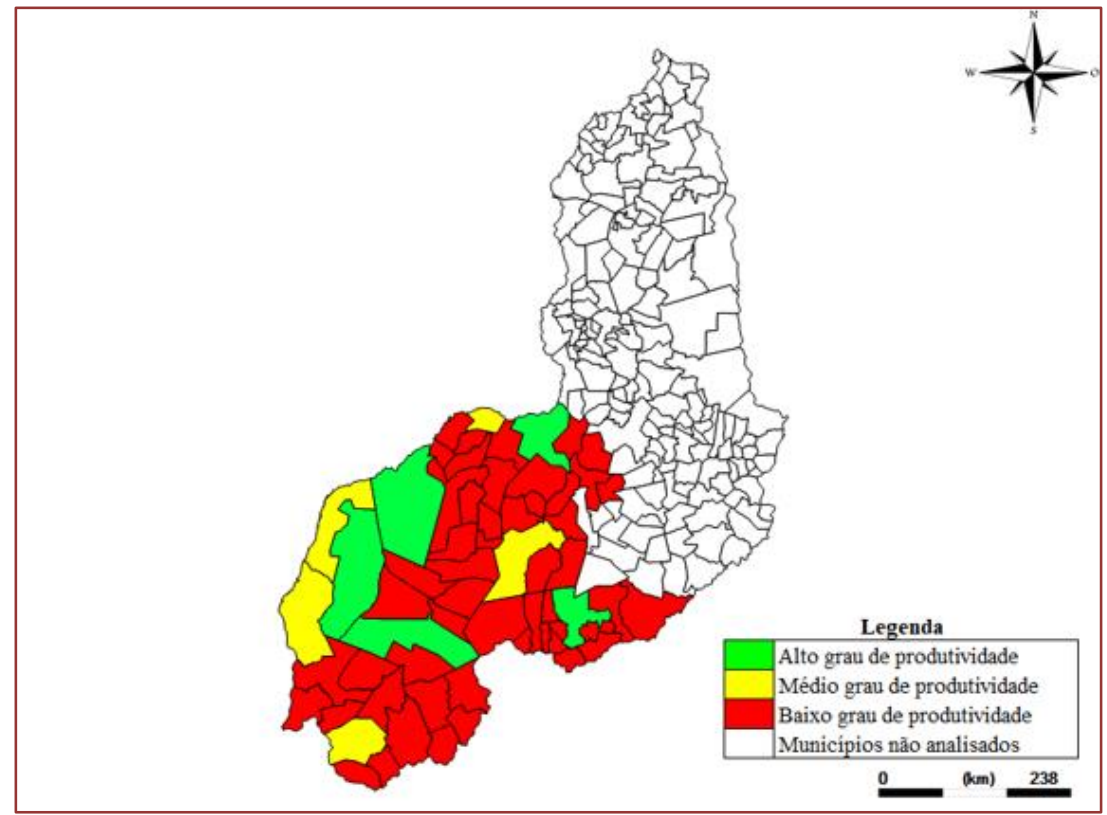

Fonte: Elaboração própria com base nos dados do IBGE (2020)

\section{CONCLUSÃO}

Esta pesquisa teve como propósito principal analisar o setor produtivo do cerrado piauiense entre 2002 e 2017, através da aplicação da técnica multivariada de análise fatorial por componentes principais, que demonstrou ser adequada aos dados e permitiu descrever o comportamento da estrutura produtiva da Mesorregião do Sudoeste Piauiense. 0 estudo se utilizou de variáveis consideradas relevantes para a 
construção de um índice de estrutura produtiva municipal que retratasse a dinâmica econômica dessa Mesorregião. Buscou-se considerar todos os aspectos dos setores produtivos da região, com o objetivo de obter resultados confiáveis que corroborassem com a realidade regional.

Constatou-se que o grau de produtividade dos municípios foi relativamente baixo nos anos de 2002 e 2017, ocorrendo apenas leve melhoria do Índice de Estrutura Produtiva Municipal no ano de 2017. A partir dos resultados, foi possível observar a ocorrência modesta no dinamismo da estrutura produtiva dos municípios dessa mesorregião, dado que não ocorreram grandes mudanças no período estudado. As evidências mostraram que os municípios com alto e médio grau de produtividade, em sua maioria, são intensivos no fator indicador de estrutura agropecuária.

De forma geral, a maioria dos municípios apresentou uma estrutura produtiva com participação dos dois fatores, porém, a estrutura agrária continua presente de forma expressiva. Como o fator F1 (indicador de estrutura econômica produtiva) abrange grande conjunto de setores, é razoável que apresente maior participação na estrutura produtiva em relação ao setor agropecuário. Dessa forma, apesar do fator F1 abranger um número maior de municípios, o fator 2 (indicador de estrutura agropecuária) permanece bastante expressivo.

É importante destacar que os municípios onde a produção de soja está mais concentrada, a exemplo de Bom Jesus, Uruçuí e Ribeiro Gonçalves, o fator F2 (indicador de estrutura agropecuária) está presente de maneira mais intensiva em 2002, o que corrobora estudos empíricos acerca do tema. Em 2017, apenas o município de Bom Jesus não apresenta maior expressividade do fator F2.

Dessa forma, os resultados da pesquisa corroboram com a realidade do cerrado, dado que se trata de uma região com inclinação acentuada para a atividade agropecuária, destacando-se como grande produtora de grãos. Os outros setores produtivos atuam de maneira menos expressiva, embora contribuam para a produtividade da região. Mesmo sendo menos expressivos, esses setores mostraram-se essenciais para muitos municípios que tiveram forte presença do fator indicador de estrutura econômica produtiva com base nos resultados do estudo. É possível observar, portanto, que a baixa produtividade desses municípios poderia ser superada por investimentos públicos e privados nesses setores, especialmente no setor industrial. De acordo com a literatura, o setor industrial possui o potencial de gerar efeitos positivos sobre outros setores produtivos, sendo um setor-chave para o desenvolvimento econômico regional. Nesse sentido, cabe ao poder público a elaboração de políticas de investimento público em setores-chaves, de encadeamento para frente e para trás, na intenção de proporcionar maior produtividade da região e desenvolvimento econômico.

\section{REFERÊNCIAS}

[1] AGUIAR, Teresinha de Jesus Alves de; MONTEIRO, Maria do Socorro Lira. Modelo Agrícola e Desenvolvimento Sustentável: a Ocupação do Cerrado Piauiense. Ambiente e Sociedade, Piauí, 2005.

[2] ALVES, Denis Fernandes et al. Estrutura Produtiva nas Mesorregiões do Nordeste Brasileiro: Uma Análise Fatorial. Informe GEPEC, [S. l.], 2018.

[3] ALVES, Vicente. A expansão da soja e o processo de urbanização nos cerrados piauienses. In: ENCONTRO DE GEÓGRAFOS DA AMÉRICA LATINA: DO LABIRINTO DA SOLIDÃO AO ESPAÇO DA SOLIDARIEDADE, 2005, São Paulo. Anais... São Paulo: Departamento de Geografia/FFLCH/USP, 2005.

[4] AMORIM, Airton Lopes; CORONEL, Daniel Arruda; TEIXEIRA, Ely Cardoso. A agropecuária na economia brasileira: uma análise de insumo-produto. Perspectiva Econômica, São Leopoldo, v.5, n.2, p. 01-19, jul/dez 2009.

[5] ANDRADE, Wendel Sandro de Paula. Localização economicamente ótima das novas agroindústrias de abate e processamento de aves e suínos no Brasil. Revista de Economia e Agronegócio, Viçosa, v. 5, n. 3, p. 379-400, 2007.

[6] BASTOS, Suzana Quinet de Andrade. Reflexões sobre o Desenvolvimento Local: a partir da análise do processo de industrialização de Juiz de Fora (MG). 2007. Dissertação (Mestrado em Economia Aplicada) - Faculdade de Economia e Administração, Universidade Federal de Juiz de Fora, Juiz de Fora, 2007.

[7] BATISTI, Vanessa de Souza. Transformação da Estrutura Produtiva Regional e Desenvolvimento Endógeno: o Caso do Vale do Rio dos Sinos. 2018. Tese (Doutorado) - Faculdade de Arquitetura, Universidade Federal do Rio Grande do Sul, Porto Alegre.

[8] BELLINGIERI, Julio Cesar. Teorias do Desenvolvimento Regional e Local: uma revisão bibliográfica. Revista de Desenvolvimento Econômico, Salvador, v. 2, n. 37, p. 6-34, Ago. 2017.

[9] BRASIL. Ministério do Trabalho e Emprego. Programa de Disseminação das Estatísticas do Trabalho. Relação Anual de Informações Sociais (RAIS). Brasília, 2002. 
[10] _. Ministério do Trabalho e Emprego. Programa de Disseminação das Estatísticas do Trabalho. Relação Anual de Informações Sociais (RAIS). Brasília, 2017.

[11] CARLEIAL, Liana; CRUZ, Bruno. Estratégia de Desenvolvimento Regional, Política Pública Negociada e novas Institucionalidades. Boletim Regional, Urbano e Ambiental - Artigos, [s.l], v. 3, p. 15-22, 2009.

[12] CEPRO- FUNDAÇÃO CENTRO DE PESQUISAS ECONÔMICAS E SOCIAIS. Produto Interno Bruto do Municipal do Piauí 2011. 2011.

[13] CLARK, Colin. The Conditions of Economic Progress. London: 1940

[14] FERREIRA, João José de Matos; MARQUES, Carla Susana; FERNANDES, Cristina. Teorias de Localização Aplicadas às Empresas de Base Tecnológica: um Estudo Empírico. Revista de Administração e Inovação, São Paulo, v.7, n.4, p.43-65, out./dez. 2010.

[15] FIGUEIREDO FILHO, Dalson Brito; SILVA JUNIOR, José Alexandre da. Visão além do alcance: uma introdução à análise fatorial. Opinião Pública, Campinas, v. 16, n. 1, p. 160-185, Jun. 2010.

[16] FOCHEZZATTO, Adelar. Desenvolvimento regional: recomendações para um novo paradigma produtivo. Três décadas de Economia Gaúcha, [S.l], v.1, p. 160-192, 2010.

[17] HAIR Jr, Joseph F et al. Análise Multivariada de Dados. 6.ed. Porto Alegre, Bookman, 2009. 688p.

[18] HONÓRIO, Marcelo; DUTKIEVICZ, Milton Lucas; SOUZA, Mariângela Pieruccini. O papel da indústria no crescimento regional: um estudo de caso da Empresa Araupel no município de Quedas do Iguaçu -PR. A Economia em Revista, Maringá, v.19, n.1, p.05-17, jul. 2011.

[19] IBGE - INSTITUTO BRASILEIRO DE GEOGRAFIA E ESTATÍSTICA. Censo Demográfico, 2010. Disponível em: < https://sidra.ibge.gov.br/tabela/1301>. Acesso em: 3 de abril de 2020.

[20] _. Panorama dos Municípios, 2020. Disponível em: < https://cidades.ibge.gov.br/panorama>. Acesso em: 2 de abril de 2020.

[21] _. População residente estimada, 2019. Disponível em:< https://sidra.ibge.gov.br/tabela/6579>. Acesso em: 3 de abril de 2020 .

[22] _. Produção Agrícola Municipal, 2002. Disponível em:<https://sidra.ibge.gov.br/tabela/1612>. Acesso em: 8 de outubro de 2019.

[23] _. Produção Agrícola Municipal, 2017. Disponível em:<https://sidra.ibge.gov.br/tabela/1612>. Acesso em: 8 de outubro de 2019.

[24] _. Produção Agrícola Municipal, 2018. Disponível em:<https://sidra.ibge.gov.br/tabela/1612>. Acesso em: 8 de outubro de 2019.

[25] __ Produto Interno Bruto dos Municípios, 2002. Disponível em: < https://sidra.ibge.gov.br/tabela/5938>. Acesso em: 2 de março de 2020.

[26] __ Produto Interno Bruto dos Municípios, 2017. Disponível em: < https://sidra.ibge.gov.br/tabela/5938>. Acesso em: 2 de março de 2020

[27] _ Território, 2020. Disponível em: < https://sidra.ibge.gov.br/territorio\#/N8/2203>. Acesso em: 2 de abril de 2020 .

[28] JESUS, Josias Alves de; SPÍNOLA, Noelio Dantaslé. Seis décadas da Teoria dos Pólos de Crescimento: revisitando Perroux. RDE - Revista de Desenvolvimento Econômico, Salvador, v. 17, n. 2, p. 935-952, 2015.

[29] LEAL, Manuela Nunes. Agronegócio da Soja no Piauí: região do fazer produtivo. 2013. Tese (Doutorado) Núcleo de Pós-Graduação em Geografia, Universidade Federal de Sergipe, São Cristóvão.

[30] LIBERATO, Rita de Cássia. Revisando os Modelos e as Teorias de Análise Regional. Caderno de Geografia, Belo Horizonte, v. 18, n. 29, p. 127-136, 2으. 2008.

[31] MACCALLUM, Robert C et al. Sample Size in Factor Analysis. Psychological Methods, [s.l] v. 4, n. 1, p. 84-99, 1999.

[32] MARQUES, Angela Fontana. Aplicação da análise multivariada na infraestrutura e no desempenho das escolas públicas do Ensino Fundamental e Médio pertencentes ao Núcleo Regional de Educação de Paranavaí. Acta Scientiarum. Technology, Maringá, v. 32, n. 1, p. 75-81, 2010.

[33] MALUF, R. S. Hirschman e a dessacralização da epopeia do desenvolvimento por um desenvolvimentista. Revista de Economia Política, São Paulo, v. 35, n. 1, p. 43-63, 2015.

[34] MELO, C. O.; PARRÉ, J. L. Índice de desenvolvimento rural dos municípios paranaenses: determinantes e hierarquização. Revista Economia e Sociologia Rural, v. 45 n. 2 Brasília, Abr./Jun 2007. 
[35] MDIC- MINISTÉRIO DA ÍNDUSTRIA, COMÉRCIO EXTERIOR E SERVIÇOS. Estatísticas de Comércio Exterior: Exportações, Importações e Balança Comercial - Estado: Piauí 2018. Disponível em: <http://www.mdic.gov.br/comercio-exterior/estatisticas-de-comercio-exterior/comex-vis/frame-uf-produto?uf=pi>. Acesso em: 8 de outubro de 2019.

[36] MINGOTI, S. A. Análise de dados através de métodos de estatística multivariada: uma abordagem aplicada. Minas Gerais, UFMG, 2005.

[37] MONTEIRO, M. do S. L. Ocupação do Cerrado Piauiense: estratégia empresarial e especulação fundiária. 2002. Tese (Doutorado) - Universidade Estadual de Campinas, Campinas 2002.

[38] NAKABASHI, L; SCATOLIN, F. D.; CRUZ, M. J. V. Impactos da Mudança Estrutural da Economia Brasileira sobre o seu Crescimento. Revista de Economia Contemporânea, Rio de Janeiro, v. 14, n. 2, maio/ago. 2010.

[39] OCAMPO, J. A. Hirschman, a industrialização e a teoria do desenvolvimento. Revista Economia Ensaios, Uberlândia v. 27, n. 2, p. 17-28, Jan./Jun. 2013.

[40] OLIMPIO, J. A.; MONTEIRO, M. do S. L. Impactos Modernos da Agricultura sobre o Solo e a Biodiversidade no Cerrado em Palmeira do Piauí e Currais. Carta Cepro, Piauí, 2005.

[41] PEREIRA, M. Z.; BASTOS, S. Q. de A.; PEROBELLI, F. S. Análise Sistêmica do Setor de Serviços no Brasil (2005). Pesquisa e Planejamento Econômico, [s.l], v.43, n.1, abr. 2013.

[42] RIBEIRO, L. C. de S.; ROCHA, G. de B. Interdependência Produtiva e Estratégias de Desenvolvimento para o Estado da Bahia. Revista Economia Ensaios, Uberlândia (MG), v. 27 n.2, p. 67-83, Jan./Jun. 2013.

[43] SILVA, A. M.; NEGRI, J. A.; KUBOTA, L. C.. Estrutura e Dinâmica do Setor de Serviços no Brasil. In: SILVA et. al. Estrutura e Dinâmica do Setor de Serviços no Brasil. Brasília: IPEA, 2006. 502p.

[44] SILVA, V. F. O papel da industrialização no pensamento de Raúl Prebisch. In: XII Congresso Brasileiro de História Econômica \& 13ํㅗㄹ Conferência Internacional de História de Empresas, 2017, Niterói. Anais... Niterói: Associação Brasileira de Pesquisadores em História Econômica, 2017. p. 01- 14.

[45] SOUZA, N. de J. Economia Regional: Conceito e Fundamentos Teóricos. Perspectiva Econômica, São Leopoldo, v. 11, n. 32 , p. 67-102, 1981.

[46] VASCONCELLOS, B. L. X. Desenvolvimento Regional e Estrutura Produtiva: Um Estudo Sobre a Região do Médio Paraíba (RJ). 2016. Dissertação - Instituto de Ciências Sociais Aplicadas, Universidade Federal Rural do Rio de Janeiro, Nova Iguaçu.

[47] VICINI, L. Análise Multivariada da Teoria à Prática. Santa Maria: 2005.

[48] WAIBEL, L. A Teoria de Von Thünen sobre a influência da distância do mercado relativamente a utilização da terra. Revista Brasileira de Geografia, [S.I], n. 1, p. 3-40, 1948.

[49] WEBER, A. Alfred Weber's theory of the location of industries. Illinois: The University of Chicago Press, 1929, p. 1-36. 


\section{Capítulo 3}

O crédito na agricultura brasileira no período 20132018: Um estudo do PRONAF, do PRONAMP e demais linhas de crédito rural, com ênfase no investimento

Irineu Brinker

Tiago Wickstrom Alves

Angélica Massuquetti

Resumo: 0 objetivo desta pesquisa foi analisar a evolução da distribuição dos recursos do PRONAF, do PRONAMP, na modalidade investimento, nos municípios brasileiros no período 2013-2018. A base de dados utilizada foi a de crédito rural do BCB e a base de dados socioeconômicos do IBGE. Utilizando-se o software Geoda, foi mensurado o Índice de Moran para a correlação entre as quantidades de operações e valores contratados das operações rurais, e índices socioeconômicos, como taxa de analfabetismo, índice de Gini, IDHM, PIB agrícola, participação do PIB agrícola no PIB municipal e renda per capita. Os resultados revelaram que no PRONAF, diferentemente do PRONAMP e das demais linhas de crédito rural, a quantidade de contratos teve correlação positiva com a taxa de analfabetismo, índice de Gini, com a razão entre a renda per capita média dos 10\% mais ricos e a renda per capita dos $40 \%$ mais pobres. Correlação negativa entre a quantidade de contratos e a taxa de empregados com 18 anos e mais com carteira assinada, IDHM, PIB agrícola, participação do PIB agrícola no PIB municipal e renda per capita municipal. O PRONAMP, devido a menor quantidade de operações e ao menor volume de recursos contratados, apresentou correlações bastante fracas. As demais linhas de crédito rural apresentaram correlações maiores nas variáveis PIB agrícola e participação do PIB agrícola no PIB municipal. As regiões mais ricas e com agropecuária mais produtiva, como Sul, Sudeste e Centro-Oeste, têm recebido os maiores volumes de recursos. Em contrapartida, as regiões mais pobres e menos desenvolvidas, tem recebido o maior número de operações, de menor valor médio e voltada a agropecuária de subsistência.

Palavras-chave: Crédito rural. PRONAF. PRONAMP. Moran. 


\section{INTRODUÇÃO}

Historicamente, o setor agropecuário brasileiro depende fortemente das políticas econômicas de Estado. Neste sentido, Araújo (2011, p. 40) argumentou que é "[...] difícil compreender a evolução do setor agropecuário sem examinar os objetivos e os resultado das intervenções de política econômica do governo central".

Nas décadas de 1960 e 1970, o setor agrícola foi fortemente impulsionado pela política de subsídios, tanto de juros de juros como de preços, além da prática de aquisição dos produtos agrícolas pelo setor público. (FAVERET FILHO, 2002). A partir da década de 1980, houve uma redução significativa das políticas de incentivos para os produtores rurais, que perdurou até meados da década de 1990, quando, em 1996, foi instituído o Programa Nacional de Fortalecimento da Agricultura Familiar (PRONAF), com a finalidade de promover o aumento da capacidade produtiva e da renda dos agricultores familiares, que até então quase não possuíam acesso às linhas de crédito para financiamento de suas atividades agropecuárias. (BENETTI, 2010). Em 2011, para atender os médios produtores rurais, o Governo Federal lançou o Programa Nacional de Apoio ao Médio Produtor Rural (PRONAMP).

O objetivo principal do PRONAF é apoiar a agricultura familiar através de financiamentos e apoio técnico a implantação, modernização ou ampliação de projetos que visem aumentar a produtividade e melhoria de práticas de produção sustentáveis. 0 objetivo principal do Programa Nacional de Apoio ao Médio Produtor Rural (PRONAMP) é o financiamento de projetos sustentáveis de aumento da produtividade, ampliação e modernização de projetos agropecuários dos médios produtores rurais. A demais linhas de crédito da agricultura empresarial é o conjunto de linhas de crédito de investimento agropecuário e fundos constitucionais que visam atender todos os agricultores e suas cooperativas que não se enquadrem no PRONAF e PRONAMP.

Diversos estudos foram realizados sobre o crédito agrícola no Brasil, sendo que o número de trabalhos tratando, especificamente, do PRONAF têm sido a maioria. A escassez de pesquisas tratando do PRONAMP torna menos conhecida a dinâmica de distribuição dos recursos no território brasileiro. Souza, Ney e Ponciano (2015) analisaram a distribuição dos financiamentos do PRONAF entre os estabelecimentos rurais e as suas medidas de concentração. Nesse estudo, os resultados sugeriram que a liberação dos financiamentos se deu de maneira concentrada em prol dos agricultores mais capitalizados. Já Silva et al. (2017) avaliaram a distribuição regional dos contratos de PRONAF e os seus impactos sobre o desenvolvimento rural da região Nordeste. Neste estudo, os resultados indicaram que há igualdade em números de contratos entre os estados brasileiros, mas há uma certa concentração na liberação do volume de recursos para as regiões Sul e Sudeste, desfavorecendo os estados da região Nordeste. Dado esses resultados, uma questão relevante que motiva essa pesquisa é como se deram a distribuição dos financiamentos do PRONAF, PRONAMP e as demais linhas do crédito rural entre 2013 e 2018 ? Buscando responder a essa questão é que se estabelece o objetivo desta pesquisa, que é analisar a distribuição dos créditos agrícolas do PRONAF, PRONAMP e demais linhas do crédito da agricultura empresarial no período de 2013 a 2018.

A distribuição dos recursos do PRONAF, do PRONAMP e demais linhas de crédito da agricultura empresarial para investimento nas regiões brasileiras permite a compreensão da dinâmica desses programas. Assim, a análise para o período 2013-2015-2018, por região e por tipo de financiamento, investimento, inclui o período de maior crise econômica até então vivenciada na economia brasileira, e assim, compreender como essas políticas foram empregadas permite avaliar se elas foram empregadas em regiões mais carentes, minimizando os efeitos da crise ou se elas se concentraram em regiões mais ricas, garantindo o pagamento dos créditos mas ampliando as desigualdades regionais e agravando os efeitos da crise nas regiões mais pobres.

Os estudos realizados até o momento tiveram abrangência restrita, ou seja, os estudos limitavam-se a estudar uma única linha de crédito numa única região ou conjunto de municípios, algumas vezes estudavam uma região mais abrangente, como um estado. Outras vezes estudavam um segmento inteiro, mas numa pequena região, ou seja, os objetivos dos estudos já publicados têm se concentrado em pontos específicos do crédito rural. Este estudo abrangeu como se deu a contratação do crédito rural, voltado ao investimento, em todos os segmentos e em todos os 5570 municípios brasileiros. Foi objeto de estudo a dinâmica da contratação do crédito rural desde o agricultor familiar, com o PRONAF, passando pelo médio produtor, com o PRONAMP, até o grande agricultor com as demais linhas da agricultura empresarial. Neste ponto esta pesquisa tornou-se ímpar, abrindo novos caminhos para novos questionamentos. 


\section{METODOLOGIA}

A análise dos programas de apoio ao agricultor, PRONAF, PRONAMP e demais linhas de crédito da agricultura empresarial foram feitas através de análise estatística descritiva, observando distribuição e apropriação dos recursos destes programas em todos os municípios brasileiros ao longo do período de 2013 a 2018 utilizando dados do crédito agrícola disponibilizados pelo Banco Central do Brasil, de forma a avaliar se esses três programas têm atingido os objetivos para o qual foram concebidos.

As análises das estatísticas descritivas ficaram centradas na avaliação da existência da formação de clusters espaciais na apropriação dos recursos públicos, nas taxas de crescimento e com isso avaliar o sombreamento entre ambas variáveis. Os clusters são calculados através do Índice de Moran, conforme descrito por Silva (2011), que se descreve a seguir.

O Índice de Moran (I-Moran) é uma ferramenta estatística amplamente utilizada para testar auto correlação espacial, indicando se a distribuição dos dados no espaço segue algum padrão não aleatório. Quando há algum padrão espacial para a variável analisada, esse padrão pode indicar a existência de auto correlação positiva ou negativa. Na autocorreção positiva os valores se aproximam no espaço, enquanto na negativa os valores se distanciam espacialmente. (SILVA; RESENDE, 2005).

A estatística I de Moran pode apresentar valores de -1 a +1 . Quando se aproxima de -1 há auto correlação negativa, ou seja, os valores baixos tendem a estar acompanhados por uma vizinhança valores baixos. Quando o I de Moran se aproxima de 0, evidencia-se que não há auto correlação espacial. Quando se aproxima de +1 há auto correlação positiva, ou seja, os valores altos tendem a estar localizados na vizinhança de valores altos. (MONASTERIO; AVILA, 2005).

Através da estatística de Moran Bivariada pode-se mensurar a auto correlação entre duas variáveis de interesse em regiões vizinhas.

O Índice de Moran é utilizado para avaliar o uso de um modelo de regressão espacial correto. Segundo Silva (2011, p. 74), o I-Moran Bivariado é dado pela seguinte equação: IZ1Z2 $=\mathrm{Z}_{1}^{\prime} \mathrm{WZ}_{2} / \mathrm{Z}_{1}^{\prime} \mathrm{Z}_{1}$, onde $\mathrm{Z}_{1}$ representa uma variável de interesse; $\mathrm{Z}_{2}$ é o valor de outra variável defasada; e $\mathrm{W}$ é a matriz de pesos espaciais.

Conforme Almeida e Haddad (2004),

0 modelo econométrico espacial que deve ser estimado depende dos aspectos que envolvem o processo espacial subjacente ao fenômeno em estudo. A auto correlação espacial pode manifestar-se na variável dependente, nas variáveis explicativas ou no termo de erro.

Portanto, para se efetuar a escolha entre o modelo econométrico padrão, de erro espacial ou de defasagem espacial deve-se fazer os testes dos multiplicadores de Lagrange (LM). Segundo Silva (2011, p. 75, grifo do autor), os multiplicadores de Lagrange são:

Multiplicador de Lagrange de Defasagem Espacial (LN-lag) e Multiplicador de Lagrange de Erro Espacial (LM-error). Cada um desses tipos se subdivide em mais duas estatísticas. Assim, o LM-lag e o LM-error podem ser simples ou robustos. Dessa forma, se um dos dois LM-lag for significante $(<10 \%)$, há um indicativo a favor do modelo de defasagem espacial - (pWVU). Por outro lado, se o LM-error (simples ou robusto) for significante, ou seja, inferior a 10\%, há um indicativo a favor do modelo de erro espacial.

Constroem-se uma matriz com pesos espaciais (W), definindo-se um critério de vizinhança, que comumente utiliza-se o critério de contiguidade, relacionando uma região com seus vizinhos. Dando mais peso ao vizinho mais próximo. (SILVA, 2011). Conforme Anselin (2005 apud SILVA, 2011, p. 75, grifo do autor), são três tipos de contiguidade espacial,

rook (lados em comum); bishop (vértices em comum); e queen (lados e/ou vértices em comum). Para este trabalho, a matriz de peso espacial foi gerada pelo método 'queen'. A matriz Wij apresenta valor 0 quando a região ' $i$ ' não possui vizinhança com ' $j$ '; caso sejam regiões vizinhas, apresenta valor igual a 1 . 
A análise de clusters poderá ser feita através dessa matriz, sendo que valores próximos a -1 indicam forte correlação negativa, quando um valor é alto, o dos vizinhos é baixo, tipo high-low. Ainda, na correlação negativa pode-se ter outra situação, tipo low-high, valores baixos cercado de valores altos. Na situação de correlação positiva as situações são tipo high-high e low-low, valores elevados e valores baixos. (SILVA, 2011).

Para realização do presente estudo trabalhou-se com os dados do crédito agrícola na modalidade investimento destinado a todos os segmentos de agricultores abrangidos dentro do SNCR nos anos de 2013, 2015 e 2018 disponibilizados pelo BACEN para todos os municípios brasileiros.

A ordenação dos dados foi feita utilizando-se as planilhas, com a relação de todos os municípios brasileiros, baixada diretamente do sistema SIDRA no site do IBGE. Foram utilizados 5565 dos 5570 municípios brasileiros, já de 5 municípios não possuíam dados completos para a análise.

Os empréstimos no âmbito do PRONAF atenderam os agricultores familiares. Os empréstimos no âmbito do PRONAMP atenderam os médios produtores rurais. Os empréstimos no âmbito das demais linhas de crédito agricultura empresarial, aqui também, chamado de demais ou empresarial, englobou todos os empréstimos de agricultores empresariais e outros que por qualquer motivo não se enquadraram no PRONAF ou PRONAMP.

Após a ordenação de todas as variáveis, os dados foram migrados para o software de estatística espacial Geoda, onde as análises foram feitas, como o cálculo do Índice de Moran Bivariado, a geração dos mapas de clusters e dos gráficos de dispersão. 0 Geoda é um software livre idealizado pelo professor Luc Anselin da Universidade de Chicago, Estados Unidos da América (EUA). Para realização das análises foram utilizadas diversas variáveis, conforme apresenta o quadro 1.

Variáveis Utilizadas

\begin{tabular}{|c|c|c|c|}
\hline \multicolumn{3}{|c|}{ Nome da Variável } & \multirow{2}{*}{$\begin{array}{l}\text { Definição } \\
\text { Quantidade de contratos de PRONAF nos anos de 2013, } 2015 \text { e 2018, por } \\
\text { município }\end{array}$} \\
\hline Q_T_Prf_13 & Q_T_Prf_15 & Q_T_Prf_18 & \\
\hline V_T_Prf_13 & V_T_Prf_15 & V_T_Prf_18 & $\begin{array}{l}\text { Valor total contratado de PRONAF nos anos de 2013, } 2015 \text { e 2018, por } \\
\text { município }\end{array}$ \\
\hline Q_T_Pnp_13 & Q_T_Pnp_15 & Q_T_Pnp_18 & $\begin{array}{l}\text { Quantidade de contratos de PRONAMP nos anos de 2013, } 2015 \text { e } 2018 \text {, } \\
\text { por município }\end{array}$ \\
\hline V_T_Pnp_13 & V_T_Pnp_15 & V_T_Pnp_18 & $\begin{array}{l}\text { Valor total contratado de PRONAMP nos anos de 2013, } 2015 \text { e 2018, por } \\
\text { município }\end{array}$ \\
\hline Q_T_Dm_13 & Q_T_Dm_15 & Q_T_Dm_18 & $\begin{array}{l}\text { Quantidade de contratos de demais linhas de crédito da agricultura } \\
\text { empresarial nos anos de } 2013,2015 \text { e } 2018 \text {, por município }\end{array}$ \\
\hline V_T_Dm_13 & V_T_Dm_15 & V_T_Dm_18 & $\begin{array}{l}\text { Valor total contratado de demais linhas de crédito da agricultura } \\
\text { empresarial nos anos de } 2013,2015 \text { e } 2018 \text {, por município }\end{array}$ \\
\hline \multicolumn{3}{|c|}{ QM } & $\begin{array}{l}\text { Média da quantidade de contratos para os anos de 2013, } 2015 \text { e 2018, } \\
\text { por município }\end{array}$ \\
\hline \multicolumn{3}{|c|}{ VM } & $\begin{array}{l}\text { Média do valor contratado para os anos de } 2013,2015 \text { e } 2018 \text {, por } \\
\text { município }\end{array}$ \\
\hline \multicolumn{3}{|c|}{ T_ANALF15M } & Taxa de analfabetismo para pessoas de 15 anos e mais, por município \\
\hline \multicolumn{3}{|c|}{ GINI } & Índice de Gini no município \\
\hline \multicolumn{3}{|c|}{ R1040 } & $\begin{array}{l}\text { Razão entre a renda per capta dos } 10 \% \text { mais ricos e os } 40 \% \text { mais pobres, } \\
\text { por município }\end{array}$ \\
\hline \multicolumn{3}{|c|}{ TRABCC } & $\begin{array}{l}\text { Taxa de trabalhadores com } 18 \text { anos e mais com carteira de trabalho } \\
\text { assinada, por município }\end{array}$ \\
\hline \multicolumn{3}{|c|}{ IDHM } & Índice de Desenvolvimento Humano Municipal \\
\hline \multicolumn{3}{|c|}{ PIB_AGR } & PIB agrícola do município \\
\hline \multicolumn{3}{|c|}{ PERCAGR } & Percentual do agronegócio no PIB municipal \\
\hline \multicolumn{3}{|c|}{ RDPC } & Renda per capita no município \\
\hline
\end{tabular}


Após efetuadas todas as análises por ano, utilizando-se as variáveis de quantidade de contratos e valor contratado paras o PRONAF, PRONAMP e demais linhas de crédito da agricultura empresarial para os anos de 2013, 2015 e 2018, o resultado foi uma quantidade acentuada dos gráficos de dispersão e de clusters. Dificultando a comparação entre as linhas de crédito. Com intuito de facilitar o trabalho de comparação entre as linhas de crédito, por parte do leitor, foram criadas as variáveis VM e QM. Os gráficos de dispersão e de clusters são os resultados das correlações entre a média das quantidades de contratos, valores contratados e a média das outras variáveis para os anos de 2013, 2015 e 2018.

Essa alteração não trouxe mudanças significativas nessas correlações, não provocou mudanças no sinal do Índice de Moran calculado para essas correlações, tão pouco provocou mudanças nas composições dos clusters, mas reduziu significativamente a quantidade de gráficos gerados.

\section{ANÁLISE E DISCUSSÃO DOS RESULTADOS}

\subsection{PRONAF, PRONAMP e demais linhas no contexto do crédito rural no Brasil}

No Gráfico 1 é possível observar a evolução na quantidade de contratos por segmento nos anos de 2013, 2015 e 2018 por região. Neste aspecto pode-se verificar que a região nordeste possui um número maior na quantidade de contratos de PRONAF.

Gráfico 1 - Evolução das linhas de crédito de investimento rural, PRONAF, PRONAMP e Demais linhas, em número de contratos - 2013-2015-2018

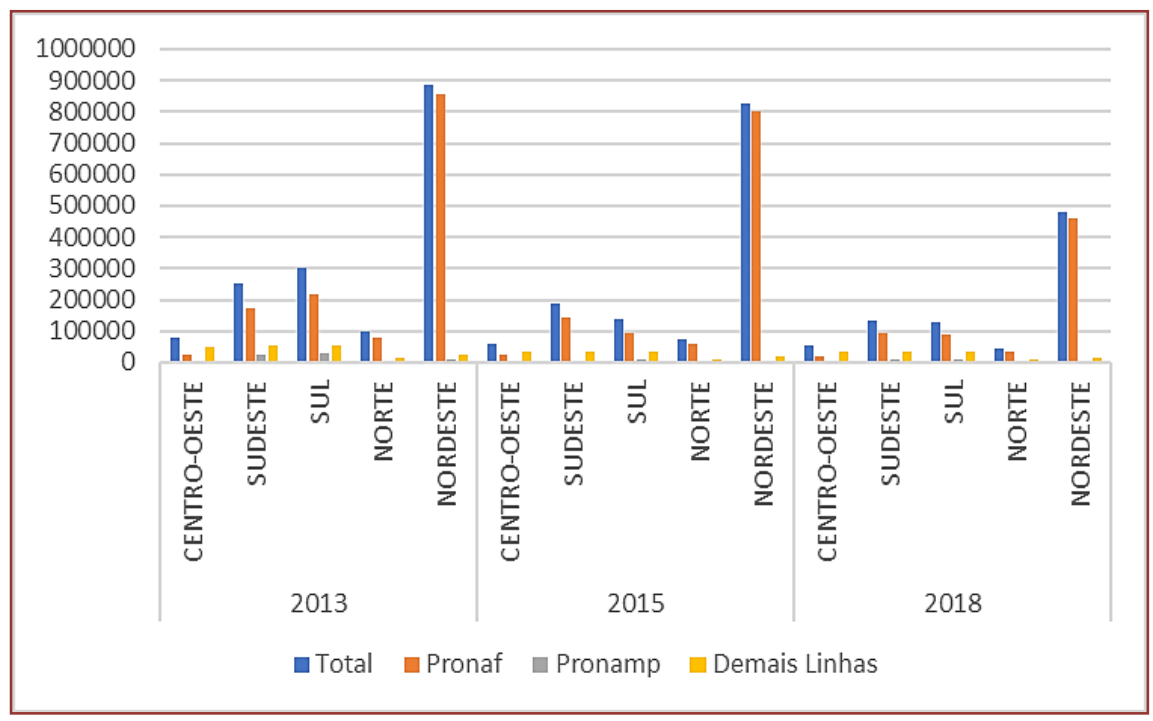

Fonte: Elaborado pelos autores a partir de BCB (2019).

O Gráfico 2 apresenta evolução do volume de recursos contratados por segmento e por região. Neste aspecto verifica-se que no ano de 2013 e 2015 a região sul obteve um volume contratado total maior do que o das outras regiões brasileiras. No ano de 2018 a região centro-oeste obteve o maior volume total de recursos contratados.

É possível notar no Gráfico 3 que há uma diferença acentuada entre os valores médios das operações por região e por segmento. As operações de PRONAF, por beneficiarem agricultores familiares e com menor receita bruta anual possuem, apresentaram os valores médios mais baixos em todas regiões, em especial na região nordeste, mantendo essa tendência para as outras linhas de crédito nesta região. De outro modo a região centro-oeste apresenta os maiores valores médios em todas as linhas de crédito. 
Gráfico 2 - Evolução das linhas de crédito de investimento rural, PRONAF, PRONAMP e Demais linhas, em R\$ milhão - 2013 - 2015 - 2018

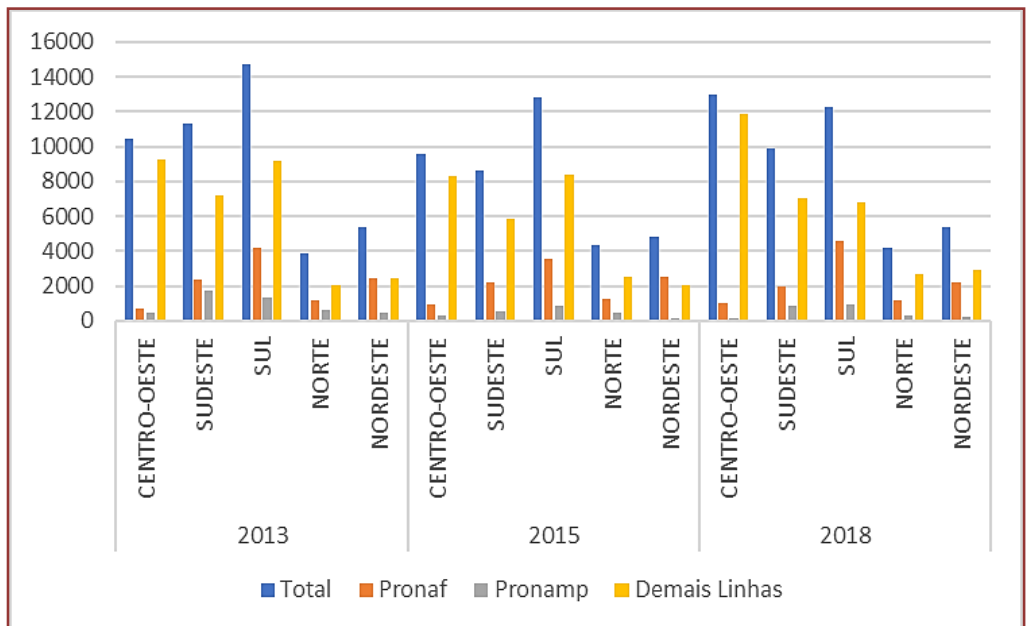

Fonte: Elaborado pelos autores a partir de BCB (2019).

Gráfico 3 - Evolução do valor médio das operações PRONAF Investimento, PRONAMP Investimento e Demais linhas de investimento rural - 2013-2018

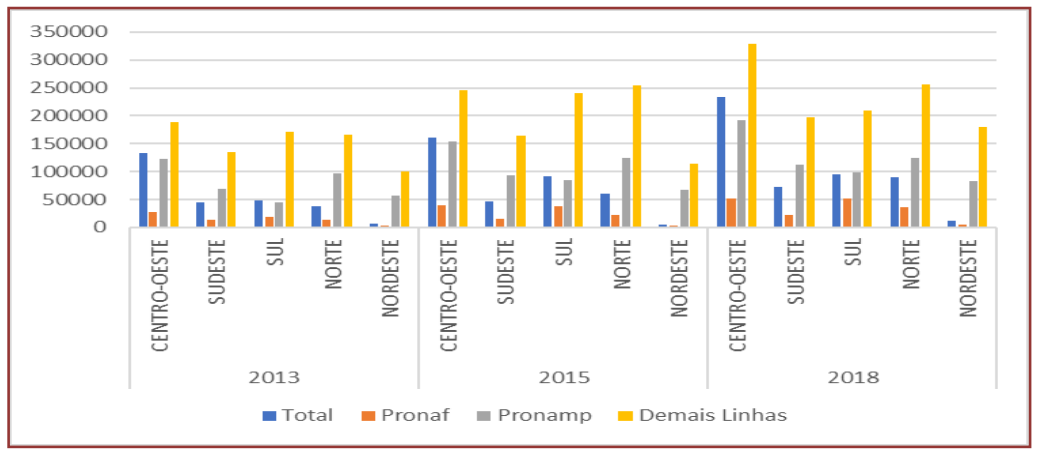

Fonte: Elaborado pelos autores a partir de BCB (2019).

Por fim, é possível notar no Gráfico 4, a distribuição percentual dos recursos por atividade beneficiada. Nota-se que nas operações de PRONAF e PRONAMP investimento os recursos têm um maior volume percentual para as operações que beneficiam a atividade agropecuária.

Gráfico 4 - Participação das atividades beneficiadas nas operações de PRONAF Investimento, PRONAMP Investimento e Demais linhas de investimento rural - 2013-2018

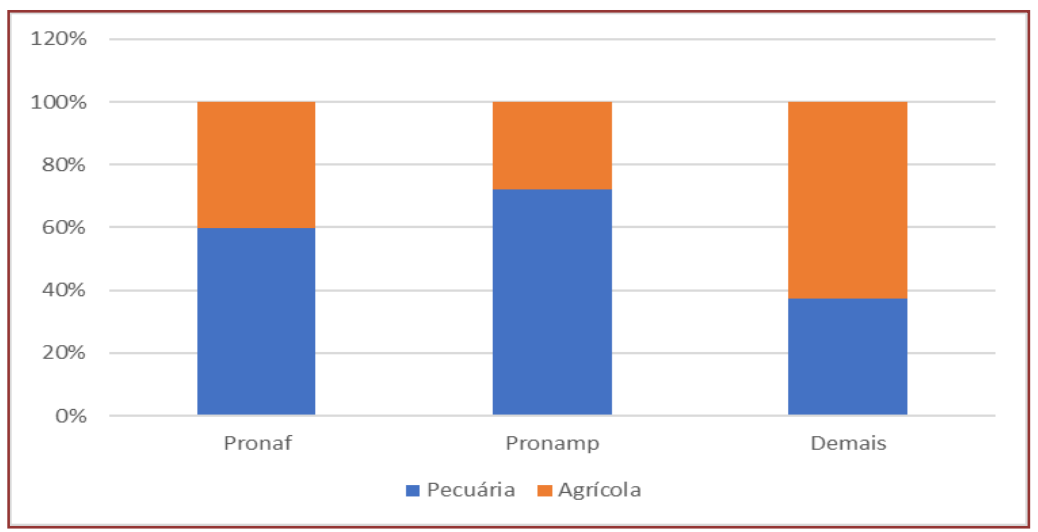

Fonte: Elaborado pelos autores a partir de BCB (2019). 


\section{1. ÍNDICE DE MORAN}

O Índice de Moran bivariado global para as linhas de crédito de investimento rural e os indicadores sócio econômicos apresentados nas Tabelas 1, 2 e 3. A Tabela 1 apresenta os dados calculados para o Índice de Moran bivariado global para o PRONAF nos anos de 2013, 2015 e 2018. Nota-se que a quantidade de operações possui uma maior correlação com os índices sócio econômicos. No caso do PRONAF, o indicador T_ANALF15M possui uma maior correlação com a quantidade de operações de PRONAF, seguido dos indicadores IDHM, TRABCC e RDPC.

Tabela 1 - Índice de Moran Global (PRONAF)

\begin{tabular}{|c|c|c|c|c|c|c|}
\hline & \multicolumn{7}{c|}{ PRONAF (ÍNDICE DE MORAN) } \\
\hline T_ANALF15M & Q_T_Prf_13 & Q_T_Prf_15 & Q_T_Prf_18 & V_T_Prf_13 & \multicolumn{1}{c|}{ V_T_Prf_15 } & \multicolumn{1}{c|}{ V_T_Prf_18 } \\
\hline GINI & 0.4132 & 0.4767 & 0.4384 & -0.1036 & -0.0657 & -0.1211 \\
\hline R1040 & 0.1964 & 0.2063 & 0.1929 & -0.0057 & 0.0166 & -0.0222 \\
\hline TRABCC & -0.3680 & -0.3608 & -0.3672 & -0.0107 & -0.1044 & -0.0728 \\
\hline IDHM & -0.3738 & -0.4211 & -0.3987 & 0.0543 & 0.0254 & 0.0769 \\
\hline PIB_AGR & -0.0937 & -0.1086 & -0.1288 & 0.0905 & 0.0939 & 0.0874 \\
\hline PERCAGR & -0.0622 & -0.1012 & -0.1089 & 0.1834 & 0.1740 & 0.1791 \\
\hline RDPC & -0.1805 & -0.2342 & -0.2349 & 0.0529 & 0.0310 & 0.0677 \\
\hline
\end{tabular}

Fonte: Elaborado pelos autores, com base em Geoda (2019).

A Tabela 2 apresenta os dados calculados para o índice de Moran bivariado global para o PRONAMP nos anos de 2013, 2015 e 2018. Nas operações de PRONAMP, a correlação espacial é maior entre os indicadores T_ANALF15M, IDHM, PIB_AGR, PERCAGR e quantidade de operações.

Tabela 2 - Índice de Moran Global (PRONAMP)

\begin{tabular}{|c|c|c|c|c|c|c|}
\hline \multicolumn{7}{|c|}{ PRONAMP (ÍNDICE DE MORAN) } \\
\hline & Q_T_Pnp_13 & Q_T_Pnp_15 & Q_T_Pnp_18 & V_T_Pnp_13 & V_T_Pnp_15 & V_T_Pnp_18 \\
\hline T_ANALF15M & -0.1822 & -0.1321 & -0.1817 & -0.1561 & -0.1491 & -0.1983 \\
\hline GINI & -0.0714 & -0.0129 & -0.0564 & -0.0520 & 0.0024 & -0.0557 \\
\hline R1040 & -0.0791 & -0.0311 & -0.0662 & -0.0617 & -0.0204 & -0.0613 \\
\hline TRABCC & 0.0726 & 0.0145 & 0.0509 & 0.1000 & 0.0295 & 0.0789 \\
\hline IDHM & 0.1372 & 0.0835 & 0.1334 & 0.1249 & 0.0963 & 0.1496 \\
\hline PIB_AGR & 0.1361 & 0.1305 & 0.1347 & 0.1432 & 0.1710 & 0.1612 \\
\hline PERCAGR & 0.1760 & 0.1674 & 0.1958 & 0.1666 & 0.2053 & 0.2058 \\
\hline RDPC & 0.0611 & 0.0576 & 0.0929 & 0.0639 & 0.0814 & 0.1112 \\
\hline
\end{tabular}

Fonte: Elaborado pelos autores, com base em Geoda (2019).

A Tabela 3, mostra os dados calculados para o Índice de Moran bivariado global para as Demais linhas de crédito de investimento rural nos anos de 2013, 2015 e 2018. Para as operações de demais linhas do crédito rural, as maiores correlações foram entre os indicadores T_ANALF15M, IDHM, PIB_AGR, PERCAGR, RDPC e a quantidade de operações. Quando o observado foi o valor total das operações, os indicadores com maior correlação foram T_ANALF15M, TRABCC, IDHM, PIB_AGR, PERCAGR E RDPC.

Tabela 3 - Índice de Moran Global (Demais Linhas)

\begin{tabular}{|c|c|c|c|c|c|c|}
\hline \multicolumn{7}{|c|}{ DEMAIS LINHAS (ÍNDICE DE MORAN) } \\
\hline & ${ }_{13}^{\text {Q_T_Dm }}$ & $\mathrm{Q}_{15}^{\text {T_Dm }}$ & $\underset{18}{\text { QT_Dm }_{-}}$ & $\mathrm{V}_{-} \mathrm{T}_{13} \mathrm{Dm}_{-}$ & $\mathrm{V}_{-} \mathrm{T}_{15} \mathrm{Dm}_{-}$ & $\begin{array}{c}\text { V_T_Dm }_{18} \\
\text { - }\end{array}$ \\
\hline T_ANALF15M & -0.1976 & -0.1697 & -0.1809 & -0.1656 & -0.1438 & -0.1443 \\
\hline GINI & -0.0230 & -0.0130 & -0.0125 & -0.0214 & -0.0143 & 0.0076 \\
\hline R1040 & -0.0524 & -0.0434 & -0.0379 & -0.0352 & -0.0277 & -0.0111 \\
\hline TRABCC & 0.0861 & 0.0632 & 0.0720 & 0.1084 & 0.0902 & 0.0957 \\
\hline IDHM & 0.1691 & 0.0140 & 0.1457 & 0.1469 & 0.1245 & 0.1239 \\
\hline PIB_AGR & 0.3144 & 0.2979 & 0.3460 & 0.3112 & 0.2728 & 0.3702 \\
\hline PERCAGR & 0.2698 & 0.2595 & 0.2739 & 0.2295 & 0.2031 & 0.2179 \\
\hline RDPC & 0.1213 & 0.1232 & 0.1573 & 0.1268 & 0.1348 & 0.1778 \\
\hline
\end{tabular}

Fonte: Elaborado pelos autores, com base em Geoda (2019). 
A Tabela 4 apresenta os dados calculados para o Índice de Moran bivariado médio e o desvio padrão para o período de 2013, 2015 e 2018, para o PRONAF, PRONAMP e para as linhas de crédito da agricultura empresarial.

Tabela 4 - Índice de Moran Médio e Desvio Padrão para 2013, 2015 e 2018

\begin{tabular}{|c|c|c|c|c|}
\hline \multicolumn{5}{|c|}{ PRONAF } \\
\hline & $\begin{array}{c}\text { I Moran Médio } \\
\text { Quantidade }\end{array}$ & Desvio Padrão & $\begin{array}{c}\text { I Moran Médio } \\
\text { Valor }\end{array}$ & Desvio Padrão \\
\hline T_ANALF15M & 0.4428 & 0.0320 & -0.0968 & 0.0283 \\
\hline GINI & 0.1985 & 0.0070 & -0.0038 & 0.0195 \\
\hline R1040 & 0.1325 & 0.0041 & -0.0159 & 0.0122 \\
\hline TRABCC & -0.3653 & 0.0039 & -0.0626 & 0.0477 \\
\hline IDHM & -0.3979 & 0.0237 & 0.0522 & 0.0258 \\
\hline PIB_AGR & -0.1104 & 0.0176 & 0.0906 & 0.0033 \\
\hline PERCAGR & -0.0908 & 0.0250 & 0.1788 & 0.0047 \\
\hline RDPC & -0.2165 & 0.0312 & 0.0505 & 0.0185 \\
\hline \multicolumn{5}{|c|}{ PRONAMP } \\
\hline T_ANALF15M & -0.1653 & 0.0288 & -0.1678 & 0.0266 \\
\hline GINI & -0.0469 & 0.0304 & -0.0351 & 0.0325 \\
\hline R1040 & -0.0588 & 0.0248 & -0.0478 & 0.0237 \\
\hline TRABCC & 0.0460 & 0.0294 & 0.0695 & 0.0362 \\
\hline IDHM & 0.1180 & 0.0300 & 0.1236 & 0.0267 \\
\hline PIB_AGR & 0.1338 & 0.0029 & 0.1585 & 0.0141 \\
\hline PERCAGR & 0.1797 & 0.0146 & 0.1926 & 0.0225 \\
\hline RDPC & 0.0705 & 0.0194 & 0.0855 & 0.0239 \\
\hline \multicolumn{5}{|c|}{ EMPRESARIAL } \\
\hline T_ANALF15M & -0.1827 & 0.0140 & -0.1512 & 0.0124 \\
\hline GINI & -0.0162 & 0.0059 & -0.0094 & 0.0151 \\
\hline R1040 & -0.0446 & 0.0073 & -0.0247 & 0.0123 \\
\hline TRABCC & 0.0738 & 0.0116 & 0.0981 & 0.0093 \\
\hline IDHM & 0.1096 & 0.0836 & 0.1318 & 0.0131 \\
\hline PIB_AGR & 0.3194 & 0.0244 & 0.3181 & 0.0491 \\
\hline PERCAGR & 0.2677 & 0.0074 & 0.2168 & 0.0132 \\
\hline RDPC & 0.1339 & 0.0203 & 0.1465 & 0.0274 \\
\hline
\end{tabular}

Para apresentação dos dados foram criadas as variáveis quantidade média (QM) e valor médio (VM). A Tabela 5 apresenta o índice de Moran Bivariado para a correlação entre a médias das variáveis.

Tabela 5 - Índice de Moran Bivariado para Média das Variáveis

\begin{tabular}{|c|c|c|c|c|c|c|}
\hline & \multicolumn{2}{|c|}{ PRONAF } & \multicolumn{2}{|c|}{ PRONAMP } & \multicolumn{2}{|c|}{ EMPRESARIAL } \\
\hline & $\mathrm{QM}$ & VM & $\mathrm{QM}$ & VM & $\mathrm{QM}$ & VM \\
\hline T_ANALF15M & 0.4693 & -0.1078 & -0.1867 & -0.1846 & -0.1922 & -0.1630 \\
\hline GINI & 0.2115 & -0.0054 & -0.0574 & -0.0414 & -0.0175 & -0.0095 \\
\hline R1040 & 0.1415 & -0.0183 & -0.0701 & -0.0555 & -0.0472 & -0.0261 \\
\hline TRABCC & -0.3844 & -0.1021 & 0.0578 & 0.0834 & 0.0784 & 0.1058 \\
\hline IDHM & -0.4211 & 0.0590 & 0.1344 & 0.1376 & 0.1602 & 0.1419 \\
\hline PIB_AGR & -0.1282 & 0.0991 & 0.1562 & 0.1858 & 0.3447 & 0.3559 \\
\hline PERCAGR & -0.0860 & 0.1979 & 0.1969 & 0.2090 & 0.2787 & 0.2357 \\
\hline RDPC & -0.2401 & 0.0553 & 0.0823 & 0.1000 & 0.1479 & 0.1658 \\
\hline
\end{tabular}

Em relação à análise de dispersão de Moran Bivariado e o mapa de clusters, neste artigo, optou-se por analisar apenas as variáveis PIB agrícola e participação percentual do PIB agrícola no PIB do município com o intuito de ilustrarem a compreensão do objeto de estudo. Na análise final, no entanto, todas as variáveis foram consideradas.

A Figura 1 apresenta o gráfico de dispersão de Moran bivariado para a correlação entre quantidade de contratos, valor total contratado de PRONAF, PRONAMP, linhas de crédito da agricultura empresarial e o PIB agrícola municipal, para a média dos anos de 2013, 2015 e 2018. 
Nota-se que a correlação entre a quantidade de contratos de PRONAF e o PIB agrícola municipal é negativa, ou seja, municípios com elevada a quantidade de contratos tendem a possuir um menor PIB agrícola. Para o PRONAMP e para as demais linhas de crédito da agricultura empresarial, a correlação entre a quantidade de contratos e o PIB agrícola é positiva, ou seja, municípios com alta quantidade de contratos tendem a possuir um PIB agrícola maior do que os municípios com baixa quantidade de contratos dessas modalidades.

Apresenta-se, também, o gráfico de dispersão de Moran bivariado para a correlação entre o valor contratado de PRONAF, PRONAMP, linhas de crédito da agricultura empresarial e o PIB agrícola municipal, para a média dos anos de 2013, 2015 e 2018. Nota-se que para o PRONAF, assim como para o PRONAMP e para as linhas de crédito da agricultura empresarial, a correlação entre as variáveis é positiva. Ou seja, municípios com elevado valor total contratado de crédito investimento rural nos três segmentos, tendem a possuir maior PIB agrícola.

Figura 1 - Gráfico de Dispersão de Moran Quantidade/Valor PRONAF/PRONAMP/demais X PIB Agrícola

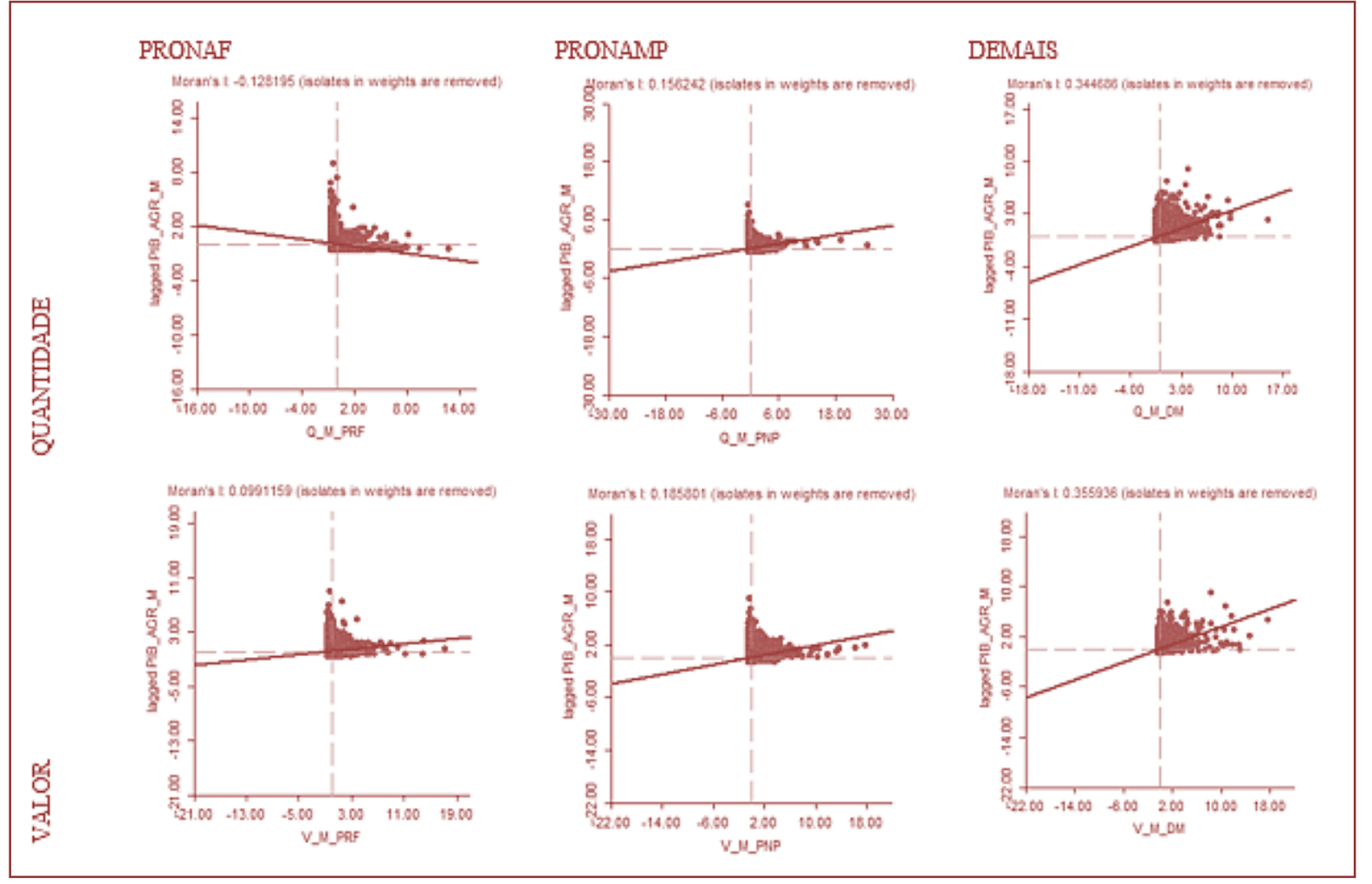

Fonte: Elaborado pelos autores, com base em Geoda (2019).

A Figura 2 apresenta os mapas de clusters local para a correlação bivariada entre a quantidade de contratos, valor contratado de PRONAF, PRONAMP, linhas de crédito da agricultura empresarial e o PIB agrícola municipal com significância estatística igual ou superior a 95\% para a média dos anos de 2013, 2015 e 2018. Nesta análise os municípios não significantes estatisticamente representam 69,33\% dos municípios.

No PRONAF o cluster High-High, composto por municípios com alta quantidade de contratos e alto PIB agrícola, apresentou em média $2,17 \%$ dos municípios, com poucos nichos espalhados por todas as regiões brasileiras, apresentando algumas oscilações durante os anos analisados. Já o cluster Low-Low, que apresenta os municípios com baixa quantidade de contratos de PRONAF e baixo PIB agrícola municipal, localiza-se principalmente na região Sudeste e com nichos espalhados nas outras regiões, com 9,06\% dos municípios. O cluster Low-High, apresentando os municípios com baixa quantidade de contratos de PRONAF e elevado PIB agrícola municipal, situa-se principalmente nas regiões Sudeste, Centro-Oeste e Norte com nichos nas regiões Sul, Nordeste, representando 9,60\% dos municípios brasileiros. 0 cluster High-Low, que apresenta os municípios com alta quantidade de contratos de PRONAF e baixo PIB agrícola municipal, está concentrado na região Nordeste, representando 9,79\% dos municípios. 
No PRONAMP, o cluster High-High, composto pelos municípios com alta quantidade de contratos de PRONAMP e elevado PIB agrícola, localiza-se distribuído em parte da região Sul, Sudeste, Centro-Oeste e Norte, com nichos na região Nordeste, representando cerca de 5,14\% dos municípios. 0 cluster Low-Low, composto por municípios com baixa quantidade de contratos de PRONAMP e menor PIB agrícola, localizou-se distribuído principalmente na região nordeste e em parte da Sudeste, com nichos nas regiões Sul e Norte, representando cerca de $17,16 \%$ dos municípios. 0 cluster Low-High, composto por municípios com baixa quantidade de contratos de PRONAMP e elevado PIB agrícola, distribui-se pelas regiões Centrooeste e Norte, com nichos nas regiões Sul e Sudeste. 0 cluster High-Low, composto por municípios com alta quantidade de contratos de PRONAMP e baixo PIB agrícola, distribuiu-se em nichos nas regiões Nordeste e Sudeste, representando cerca de $1,71 \%$ dos municípios.

Já para as linhas de crédito da agricultura empresarial, o cluster High-High, composto pelos municípios com alta quantidade de contratos elevado PIB agrícola, distribuiu-se pelas regiões Centro-Oeste, Sul, parte das regiões Sudeste, Norte e com nichos na região Nordeste, representando cerca de $7,67 \%$ dos municípios. O cluster Low-Low, composto dos municípios com baixa quantidade de contratos de demais linhas de crédito da agricultura empresarial e baixo PIB agrícola, localizou-se distribuído principalmente na região Nordeste e em parte da Sudeste, com nichos nas regiões Sul e Norte, representando cerca de $17,25 \%$ dos municípios. 0 cluster Low-High, composto por municípios com baixa quantidade de contratos de demais linhas de crédito da agricultura empresarial e elevado PIB agrícola, concentrou-se na região Norte, representando cerca de 4,10\% dos municípios. O cluster High-Low, composto por municípios com elevada quantidade de contratos e baixo PIB agrícola, distribuiu-se em nichos nas regiões Nordeste, Norte e Sudeste, representando cerca de 1,62\% dos municípios.

A Figura 2 apresenta também os mapas de clusters local para a correlação bivariada entre o valor contratado de PRONAF, PRONAMP, linhas de crédito da agricultura empresarial e o PIB agrícola municipal com significância estatística igual ou superior a 95\% para a média dos anos de 2013, 2015 e 2018. Nesta análise os municípios não significantes estatisticamente representam 69,33\% dos municípios.

No PRONAF, o cluster High-High, composto por municípios com alto valor contratado e elevado PIB agrícola, apresentou 5,00\% dos municípios, com uma distribuição pelas regiões Norte, Sul, Sudeste e Centro-Oeste e alguns nichos na região Nordeste. Já o cluster Low-Low, que apresenta os municípios com baixo valor contratado de PRONAF e baixo PIB agrícola municipal, localiza-se principalmente nas regiões Sudeste e Nordeste, com nichos espalhados nas regiões Norte e Sul, com 15,40\% dos municípios em média. 0 cluster Low-High, apresentando os municípios com baixo valor contratado de PRONAF e elevado PIB agrícola municipal, situa-se principalmente nas regiões Sudeste, Centro-Oeste e Norte, com nichos na região Sul, representando 6,77\% dos municípios brasileiros. 0 cluster High-Low, que apresenta os municípios com alto valor contratado de PRONAF e baixo PIB agrícola municipal, está concentrado em nichos na região Nordeste, representando 3,47\% dos municípios.

Para o PRONAMP, o cluster High-High, composto pelos municípios com alto valor contratado e elevado PIB agrícola, espalhou-se pelas regiões Sul, Sudeste, Centro-Oeste e Sudeste, representando cerca de 6,15\% dos municípios. O cluster Low-Low, composto pelos municípios com baixo valor contratado de PRONAMP e baixo PIB agrícola, distribuiu-se, principalmente, pela região Nordeste, parte da Sudeste e com nichos nas regiões Norte, Sul e Centro-Oeste, representando cerca de 17,38\% dos municípios. O cluster Low-High, com municípios com baixo valor contratado de PRONAMP e elevado PIB agrícola, localizou-se nas regiões Norte, Centro-Oeste e parte da Nordeste, com nichos nas regiões Sul e Sudeste, representando cerca de $5,62 \%$ dos municípios. 0 cluster High-Low, com municípios com alto valor contratado de PRONAMP e baixo PIB agrícola, localizou-se em parte da região Sudeste, representando cerca de 1,49\% dos municípios.

Nas linhas de crédito da agricultura empresarial, o cluster High-High, composto pelos municípios com alto valor contratado e elevado PIB agrícola municipal, espalhou-se pelas regiões Sul, Sudeste, Centro-Oeste, Sudeste e parte da Nordeste, representando cerca de 7,40\% dos municípios. 0 cluster Low-Low, composto pelos municípios com baixo valor contratado e baixo PIB agrícola, distribuiu-se, principalmente, pela região Nordeste, parte da Sudeste e com nichos nas regiões Norte e Sul, representando cerca de 18,40\% dos municípios. O cluster Low-High, com municípios com baixo valor contratado e elevado PIB agrícola, localizou-se na região Norte, com nichos nas regiões Centro-Oeste, Sul e Sudeste, representando cerca de $4,37 \%$ dos municípios. 0 cluster High-Low, com municípios com alto valor contratado de demais linhas de crédito da agricultura empresarial e baixo PIB agrícola, localizou-se em parte da região Sudeste, representando cerca de $0,47 \%$ dos municípios. 
Figura 2 - Mapa de Cluster Quantidade/Valor PRONAF/PRONAMP/demais X PIB Agrícola

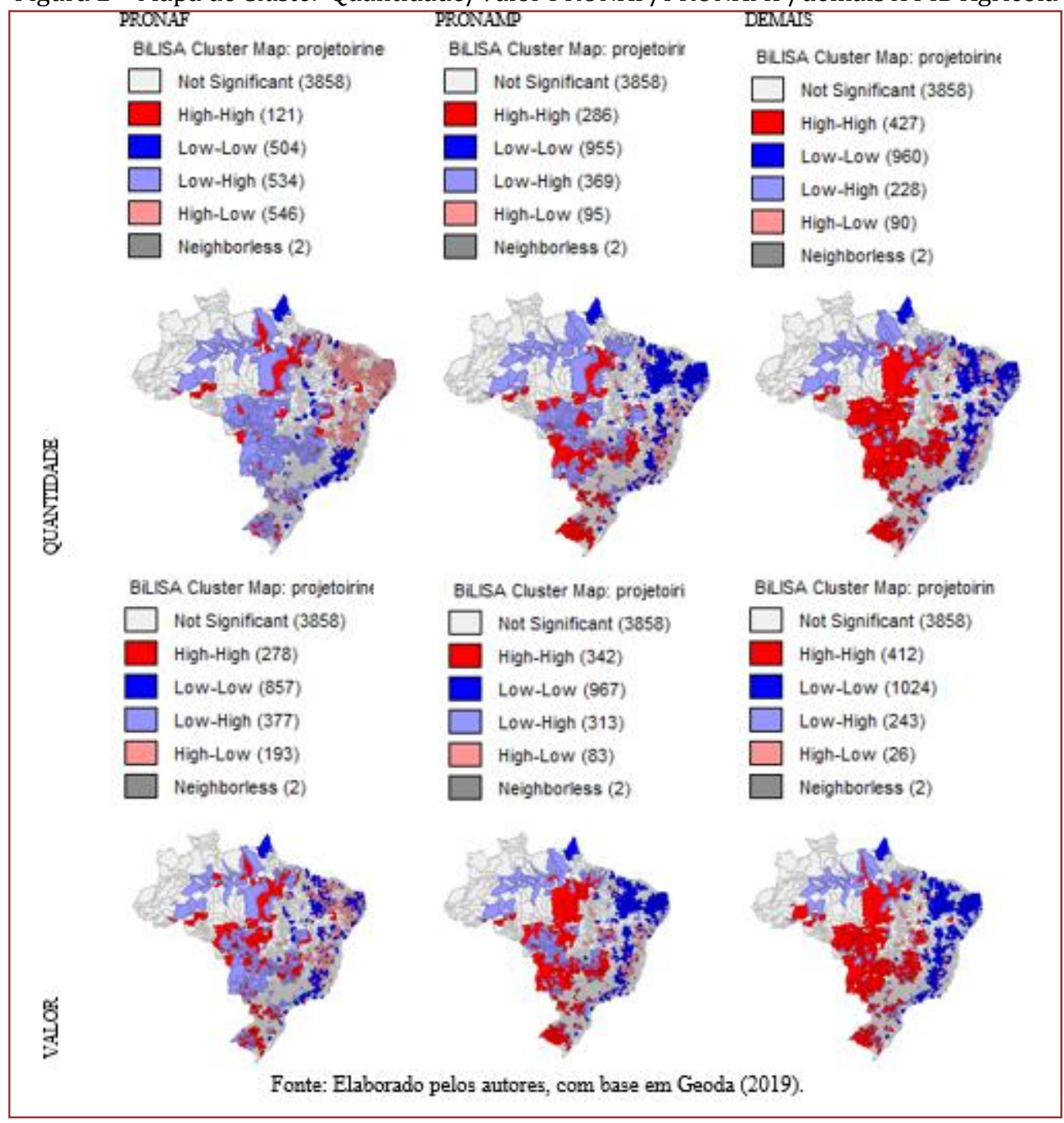

A Figura 3 apresenta o gráfico de dispersão de Moran bivariado para a correlação entre a quantidade de contratos, valor contratado de PRONAF, PRONAMP, linhas de crédito da agricultura empresarial e a participação percentual do PIB agrícola no PIB do município, para a média dos anos de 2013, 2015 e 2018.

Nota-se que, para o PRONAF, a correlação entre a quantidade de contratos e a participação percentual do PIB agrícola no PIB municipal é negativa, ou seja, municípios com alta quantidade de contratos de PRONAF tendem a possuir uma menor participação percentual do PIB agrícola no PIB municipal. Para o PRONAMP e para as linhas de crédito da agricultura empresarial, a correlação entre a quantidade de contratos e a participação do PIB agrícola no PIB municipal para a média os anos de 2013, 2015 e 2018 é positiva. Ou seja, municípios com alta quantidade de contratos de tendem a possuir uma maior participação do PIB agrícola no PIB municipal.

A Figura apresenta, também, o gráfico de dispersão de Moran bivariado para a correlação entre o valor contratado de PRONAF, PRONAMP, linhas de crédito da agricultura empresarial e a participação percentual do PIB agrícola no PIB do município, para a média dos anos de 2013, 2015 e 2018. Nota-se que, para o PRONAF, PRONAMP e para as linhas de crédito da agricultura empresarial, a correlação é positiva, ou seja, municípios com alto valor contratado de crédito rural investimento tendem a possuir uma maior participação percentual do PIB agrícola no PIB municipal. 
Gráfico de Dispersão de Moran Quantidade/Valor PRONAF/PRONAMP/demais X Percentual do PIB Agrícola

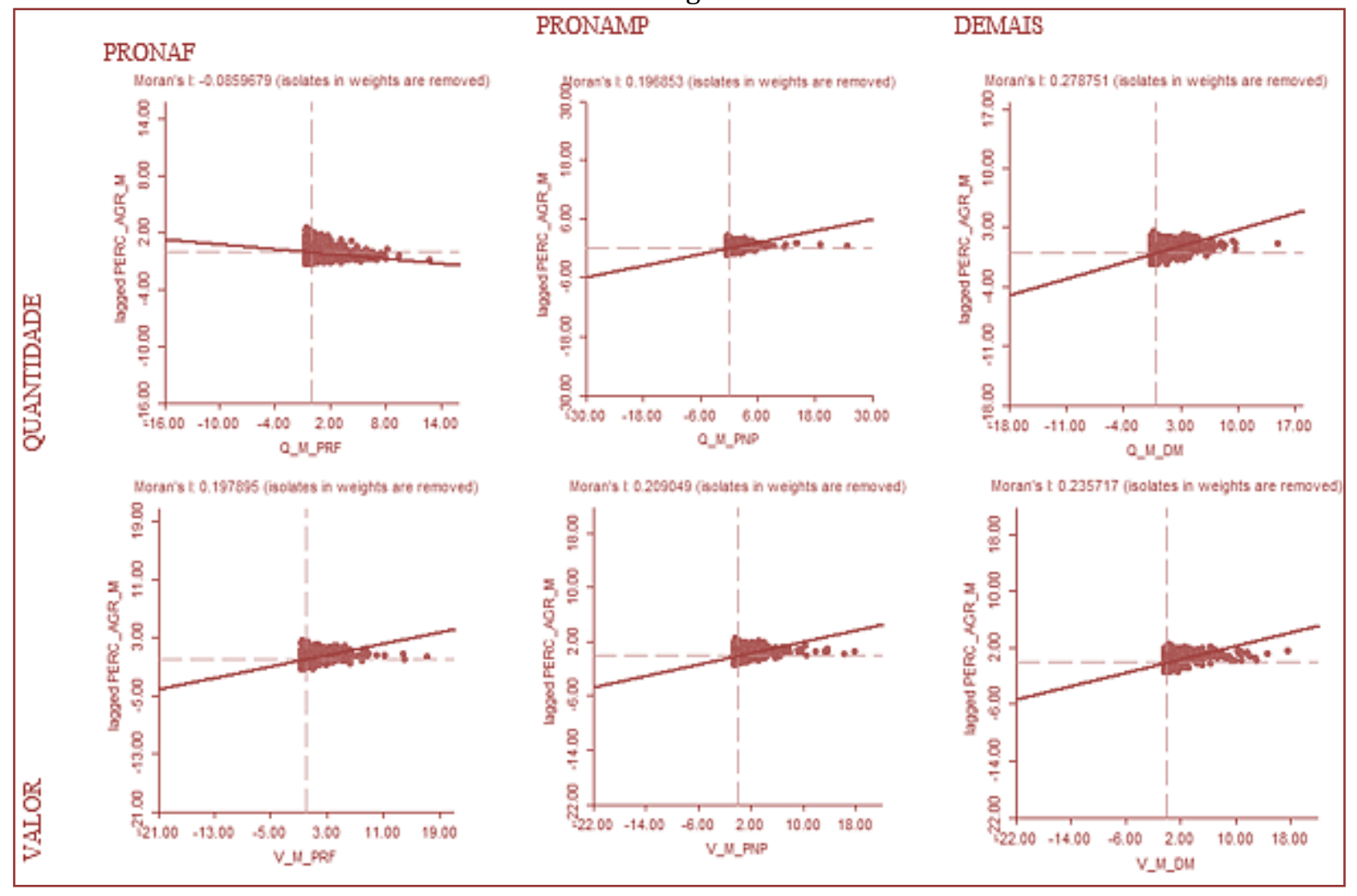

Fonte: Elaborado pelos autores, com base em Geoda (2019).

A Figura 4 apresenta os mapas de clusters local para a correlação bivariada entre a quantidade de contratos, valor contratado de PRONAF, PRONAMP, linhas de crédito da agricultura empresarial e a participação percentual do PIB agrícola no PIB municipal, com significância estatística igual ou superior a 95\% para a média dos anos de 2013, 2015 e 2018. Nesta análise os municípios não significantes estatisticamente representam 61,60\% dos municípios.

No PRONAF, o cluster High-High, composto por municípios com alta quantidade de contratos e elevada participação percentual do PIB agrícola no PIB municipal, apresentou em média 3,38\% dos municípios, espaçadamente distribuídos por todas as regiões. Já o cluster Low-Low, que apresenta os municípios com baixa quantidade de contratos e baixa participação percentual do PIB agrícola no PIB municipal, apresentou cerca de $13,66 \%$ dos municípios, localizando-se principalmente na região Sudeste, com nichos nas regiões Sul, Norte e Nordeste. O cluster Low-High, apresentando os municípios com baixa quantidade de contratos e elevada participação percentual do PIB agrícola no PIB municipal, apresentou cerca de $12,94 \%$ dos municípios, localizando-se principalmente nas regiões Sul, Sudeste, Centro-Oeste e parte da região Norte, com alguns nichos na região Nordeste. 0 cluster High-Low, que apresenta os municípios com alta quantidade e de contratos de PRONAF e baixa participação percentual do PIB agrícola no PIB municipal, está concentrado principalmente na região Nordeste, com nichos na região Sudeste, representando 8,39\% dos municípios.

No PRONAMP, o cluster High-High, composto pelos municípios com alta quantidade de contratos de PRONAMP e elevada participação do PIB agrícola no PIB municipal, localizou-se nas regiões Sul, CentroOeste e parte da Sudeste, Norte e Nordeste, representando cerca de 7,92\% dos municípios. 0 cluster LowLow, com os municípios com baixa quantidade de contratos de PRONAMP e baixa participação do PIB agrícola no PIB municipal, distribui-se pelas regiões Nordeste e Sudeste, com nichos nas regiões Norte e Sul, representando cerca de $20,20 \%$ dos municípios. O cluster Low-High, composto pelos municípios com baixa quantidade de contratos de PRONAMP e alta participação do PIB agrícola no PIB municipal, distribuiu-se pelas regiões Norte, Centro-Oeste, Sul e parte da Sudeste, representando cerca de 8,39\% dos municípios. O cluster High-Low, composto pelos municípios com alta quantidade de contratos de PRONAMP e baixa participação do PIB agrícola no PIB municipal, distribuiu-se através de nichos nas regiões Nordeste e Sudeste, representando cerca de 1,85\% dos municípios. 
Nas linhas de crédito da agricultura empresarial, o cluster High-High, composto pelos municípios com alta quantidade de contratos e elevada participação do PIB agrícola no PIB municipal, localizou-se nas regiões Sul, Centro-Oeste, Sudeste, parte das regiões Norte e Nordeste, representando cerca de $10,06 \%$ dos municípios. 0 cluster Low-Low, com os municípios com baixa quantidade de contratos e baixa participação do PIB agrícola no PIB municipal, distribui-se pelas regiões Nordeste e Sudeste, com nichos nas regiões Norte e Sul, representando cerca de $20,58 \%$ dos municípios. O cluster Low-High, composto pelos municípios com baixa quantidade de contratos de demais linhas de crédito da agricultura empresarial e elevada participação do PIB agrícola no PIB municipal, distribuiu-se pelas regiões Norte, Centro-Oeste, Sul e parte da Sudeste, representando cerca de 6,25\% dos municípios. O cluster High-Low, composto pelos municípios com alta quantidade de contratos de demais linhas de crédito da agricultura empresarial e baixa participação do PIB agrícola no PIB municipal, distribuiu-se através de nichos nas regiões Nordeste e Sudeste, representando cerca de $1,47 \%$ dos municípios.

A Figura 4 apresenta também os mapas de clusters local para a auto correlação bivariada entre o valor contratado de PRONAF, PRONAM, linhas de crédito da agricultura empresarial e a participação percentual do PIB agrícola no PIB municipal com significância estatística igual ou superior a 95\% para a média dos anos de 2013, 2015 e 2018.

No PRONAF, o cluster High-High, composto por municípios com alto valor contratado e elevada participação percentual do PIB agrícola no PIB municipal, apresentou em média 8,84\% dos municípios, distribuídos principalmente pela região Sul e com diversos nichos nas regiões Norte, Centro-Oeste e Sudeste. Já o cluster Low-Low, que apresenta os municípios com baixo valor contratado de PRONAF e baixa participação percentual do PIB agrícola no PIB municipal, apresentou cerca de 18,81\% dos municípios, localizando-se principalmente nas regiões Sudeste e Nordeste, com nichos nas regiões Sul e Norte. 0 cluster Low-High, apresentando os municípios com baixo valor contratado de PRONAF e elevada participação percentual do PIB agrícola no PIB municipal, apresentou cerca de 7,48\% dos municípios, localizando-se principalmente nas regiões Sudeste, Centro-Oeste e parte da região Norte, com alguns nichos na região Nordeste e Sul. O cluster High-Low, que apresenta os municípios com baixo valor contratado de PRONAF e baixa participação percentual do PIB agrícola no PIB municipal, está espalhado principalmente pela região Nordeste, com nichos na região Sudeste, apresentando 3,3,23\% dos municípios.

No PRONAMP, o cluster High-High, com municípios com alto valor contratado de PRONAMP e alta participação do PIB agrícola no PIB municipal, distribuiu-se pelas regiões Sul, Centro-Oeste, Sudeste, parte da Norte e Nordeste, representando cerca de 7,92\% dos municípios. 0 cluster Low-Low, composto pelos municípios com baixo valor contratado e baixa participação do PIB agrícola no PIB municipal, distribuiuse pelas regiões Nordeste, parte da Norte, parte da Sudeste e com nichos na região Sul, representando cerca de 20,41\% dos municípios. o cluster Low-High, composto pelos municípios com baixo valor contratado de PRONAMP e alta participação do PIB agrícola no PIB municipal, distribuiu-se em nichos nas regiões Norte, Nordeste Centro-Oeste, Sul e Sudeste, representando cerca de 7,53\% dos municípios. 0 cluster High-Low, composto pelos municípios com alto valor contratado de PRONAMP e baixa participação do PIB agrícola no PIB municipal, distribuiu-se através de nichos nas regiões Nordeste e Sudeste, representando cerca de $1,64 \%$ dos municípios.

Nas linhas de crédito da agricultura empresarial, o cluster High-High, com municípios com alto valor contratado e elevada participação do PIB agrícola no PIB municipal, distribuiu-se pelas regiões Sul, Centro-Oeste, Sudeste, parte da Norte e Nordeste, representando cerca de 9,20\% dos municípios. 0 cluster Low-Low, composto pelos municípios com baixo valor contratado de demais linhas de crédito d agricultura empresarial e baixa participação do PIB agrícola no PIB municipal, distribuiu-se pelas regiões Nordeste, parte da Norte, da Sudeste e com nichos na região Sul, representando cerca de $21,31 \%$ dos municípios. 0 cluster Low-High, composto pelos municípios com baixo valor contratado e elevada participação do PIB agrícola no PIB municipal, distribuiu-se em nichos nas regiões Norte, Nordeste Centro-Oeste, Sul e Sudeste, representando cerca de 7,12\% dos municípios. 0 cluster High-Low, composto pelos municípios com alto valor contratado de demais linhas de crédito da agricultura empresarial e baixa participação do PIB agrícola no PIB municipal, distribuiu-se através de nichos nas regiões Nordeste e Sudeste, representando cerca de $0,74 \%$ dos municípios. 
Figura 4 - Mapa de Cluster Quantidade/Valor PRONAF/PRONAMP/demais X Percentual do PIB Agrícola

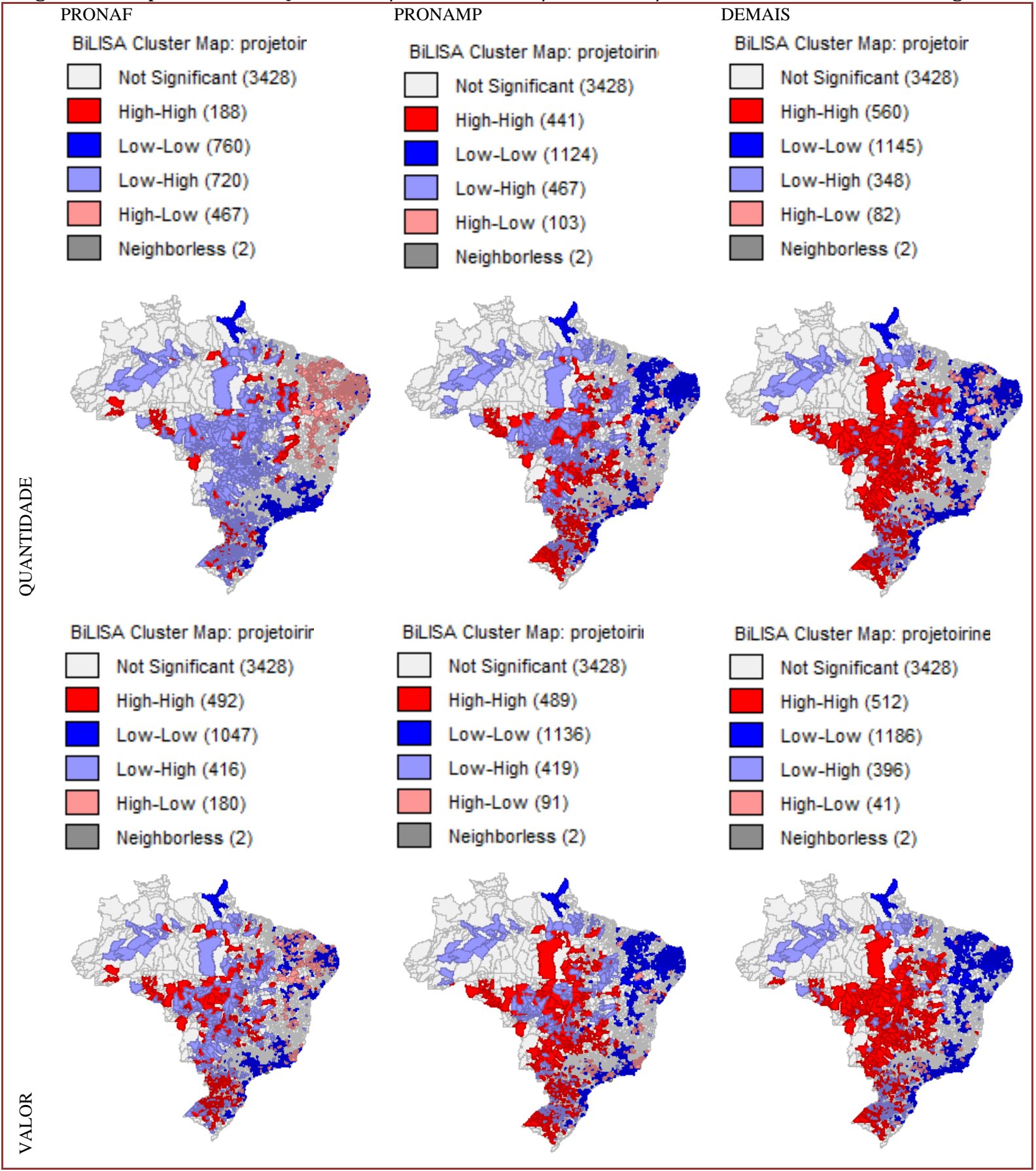

Fonte: Elaborado pelos autores, com base em Geoda (2019).

\subsection{ANÁLISE DOS RESULTADOS}

A região Nordeste obteve a maior quantidade de contratos do PRONAF, mas isso não se refletiu no valor contratado total, resultando em valores médios menores do que as outras regiões. Neste quesito, a região Centro-Oeste obteve o maior valor médio. A mensuração do índice de Moran Bivariado e a divisão em clusters revelou como se deu a alocação dos recursos das linhas de crédito rural para investimento. No PRONAF, a variável quantidade de contratos teve um comportamento diverso da variável valor total contratado, demonstrando uma dinâmica diferente das outras linhas de crédito. Através da divisão de clusters verificou-se que as regiões com maior taxa de analfabetismo receberam as maiores quantidades de operações. Já quando a variável analisada foi o valor contratado, as regiões com menores taxas de analfabetismo é que receberam o maior volume de recursos. No índice de Gini essa tendência é menor, pois a região Norte apresenta uma maior quantidade de municípios com índice de Gini mais elevado, mas a região Norte teve uma menor quantidade de contratos de PRONAF. Em relação ao valor total contratado o 
índice de Moran é bastante baixo, apresentando uma correlação bastante fraca. A correlação entre a quantidade de contratos de PRONAF e a razão entre a renda per capita média dos 10\% mais ricos e a renda per capita dos $40 \%$ mais pobres foi positiva, indicando que municípios com alta quantidade de contratos de PRONAF tenderam a ter uma maior desigualdade de renda per capita média entre os $10 \%$ mais ricos e os $40 \%$ mais pobres. Já quando a variável foi o total contratado, a correlação foi quase nula. Verificou-se que a correlação entre a quantidade de contratos de PRONAF e a taxa de trabalhadores com 18 anos e mais com carteira de trabalho assina é negativa, ou seja, indicando que municípios com alta quantidade de contratos de PRONAF tiveram menor taxa de trabalhadores com 18 anos e mais com carteira assinada. Neste quesito a região Nordeste apareceu com alta quantidade de contratos e baixa taxa de trabalhadores com 18 anos e mais com carteira assinada. Sendo o PRONAF um programa para agricultura familiar a maior quantidade de contratos acaba ocupando um maior número de pessoas sem carteira assinada. Quando a questão foi o valor total contratado, essa dinâmica continuou, mas foi menos acentuada. A correlação entre a quantidade de contratos de PRONAF e o IDHM foi negativa, ou seja, municípios com alta quantidade de contratos de PRONAF possuíam um menor IDHM. Novamente a região Nordeste apresentou uma alta quantidade de contratos de PRONAF e baixo IDHM. Já quando a correlação foi entre o valor total contratado e o IDHM, a correlação foi positiva. Apesar de ser menos pronunciada, ela indica que a maior quantidade de recursos foi liberada para regiões com maior IDHM, neste caso, a região Sul e parte da região Sudeste. Notadamente regiões de maior produtividade. A correlação entre a quantidade de contratos e o PIB agrícola foi negativa, mas com valor próximo a zero, assim como a correlação entre o valor total contratado e o PIB agrícola foi positiva, mas próxima a zero. A correlação entre a quantidade de contratos de PRONAF e a participação do PIB agrícola no PIB municipal apresentouse negativa, demonstrando que a maior quantidade de contratos não aumentou a participação da agricultura no PIB municipal, com exceção de nichos espalhados pelo país. Já quando a correlação foi entre o valor total contratado e a participação do PIB agrícola no PIB municipal, essa correlação foi positiva. 0 volume de recursos contratados impactou na participação do PIB agrícola no PIB municipal. Aqui a região Sul se destacou. A correlação entre a quantidade de contratos e a renda per capita foi negativa, indicando que municípios com alta quantidade de contratos de PRONAF tiveram menor renda per capita, ficando a região Nordeste em destaque. Já quando a correlação foi entre o valor total contratado de PRONAF e a renda per capita municipal a correlação foi bastante fraca, mas positiva. No PRONAF a correlação entre a quantidade de contratos e as outras variáveis foi mais forte do que a correlação do valor contratado com as outras variáveis, devido ao fato de que as quantidades de contratos foram bastante superiores as quantidades de contratos das outras linhas de crédito rural.

O PRONAMP diferentemente do PRONAF, a correlação negativa entre a quantidade de contratos, valor total contratado e a taxa de analfabetismo para pessoas de 15 anos e mais. Ou seja, municípios que tiveram alta quantidade de contratos e alto valor contratado de PRONAMP, apresentaram menor taxa de analfabetismo. Nesta variável os municípios com alta quantidade e valor de PRONAMP localizaram-se, em sua maioria, nas regiões Sul, Sudeste e parta da Centro-Oeste. Já os municípios com alta quantidade e valor contratado de PRONAMP, num menor número, localizaram-se na região Nordeste. Para o índice de Gini a correlação foi bastante fraca, onde a quantidade de municípios que contrataram baixas quantidades e valores de PRONAMP foi bastante superior aos municípios com alta quantidade e valor contratado de PRONAMP. A correlação entre a quantidade de contratos, valor contratado de PRONAMP e a razão entre a renda per capita média dos 10\% mais ricos e a renda per capita média dos $40 \%$ mais pobres foi baixa, onde os municípios com baixa quantidade de contratos e valor contratado foram a maioria. Os municípios com alta quantidade de contratos e valor contratado de PRONAMP situaram-se nas regiões Sudeste e parte da Sul. A correlação entre a quantidade de contratos e valor contratado de PRONAMP e a taxa de empregados com 18 anos e mais com carteira assinada é positiva, mas fraca, onde os municípios com baixa quantidade de contratos e valor contratado de PRONAMP foram a maioria dos municípios. Os municípios com alta quantidade de contratos e valor contratado de PRONAMP ficaram concentrados na região CentroOeste. A correlação entre a quantidade de contratos, valor contratado de PRONAMP e o índice de desenvolvimento humano municipal foi fraca, mas positiva, onde os municípios que tiveram alta quantidade de contratos, valor contratado e IDHM distribuíram-se pelas regiões Sul, Centro-Oeste e Sudeste e os municípios com alta quantidade de contratos e valor contratado de PRONAMP, localizaram-se nas regiões Norte e Nordeste. A correlação entre a quantidade de contratos, o valor contratado de PRONAMP e o PIB agrícola foi positiva, ou seja, os municípios que tiveram alta quantidade de contratos e alto valor contratado de PRONAMP tiveram maior PIB agrícola. Estes municípios ficaram espalhados nas regiões Sul, Sudeste e Centro-Oeste, com nichos nas regiões Nordeste e Norte. A correlação entre a quantidade de contratos, valor contratado de PRONAMP e a participação do PIB agrícola no PIB municipal teve esse mesmo comportamento. Já a correlação entre a quantidade de contratos, valor contratado de PRONAMP e a renda per capita mostrou a mesma tendência desses itens. Esse comportamento da 
correlação da quantidade de contratos, valores contratados de PRONAMP e as outras variáveis deve-se a quantidade de contratos e ao volume de recursos contratado de PRONAMP ser bastante inferior aso volumes do PRONAF e as demais linhas de crédito rural, não estabelecendo correlações robustas e consequentemente dificultando a padronização dos clusters.

Nas demais linhas de crédito rural a correlação entre a quantidade de contratos, valor contratado e a taxa de analfabetismo para pessoas de 15 anos e mais foi negativa, isto é, municípios com alta quantidade de contratos e alto valor contratado de crédito rural tinham menores taxas de analfabetismo. Apesar de a quantidade de municípios com baixa quantidade de contratos e baixo valor contratado ser maior, os municípios nas regiões Sul, Sudeste e Centro-Oeste destacam-se pela alta quantidade de contratos e alto valor contratado de demais linhas de crédito rural e menor taxa de analfabetismo. A correlação entre a quantidade de contratos, valor contratado e o índice de Gini, apesar de negativa, foi bastante fraca, onde os municípios com baixa quantidade de contratos e baixo valor contratado foram a grande maioria. A correlação entre a quantidade de contratos, valor contratado e a razão entre a renda per capita média entre os $10 \%$ mais ricos e os $40 \%$ mais pobres foi negativa, mas fraca, onde os municípios com alta quantidade de contratos, alto valor contratado e menor desigualdade entre a renda per capita dos $10 \%$ mais ricos em relação aos $40 \%$ mais pobres ficou localizado em parte das regiões Sul, Sudeste e CentroOeste. A correlação entre a quantidade de contratos, valor contratado e a taxa de empregados com 18 anos e mais com carteira assinada foi positiva, isto é, indica que municípios com maior quantidade de contratos e de valor contratado tiveram maiores taxas de emprego, esses municípios concentraram-se principalmente na região Centro-Oeste, já os municípios com baixa quantidade de contratos e baixo valor contratado foram a grande maioria, revelando o baixo impacto do crédito agrícola no emprego formal. A correlação entre a quantidade de contratos, valor contratado e o índice de desenvolvimento humano municipal foi positiva, isto é, municípios com alta quantidade de contratos e alto valor contratado de demais linhas de crédito rural possuíam maiores IDHM. Os municípios com alta quantidade de contratos, alto valor contratado de demais linhas de crédito rural e maior IDHM estavam mais concentrados nas regiões Centro-Oeste, Sudeste e Sul. Os municípios com alta quantidade de contratos, alto valor contratado e menor IDHM, estavam espalhados pelas regiões Norte e Nordeste. A correlação entre a quantidade de contratos, valor contratado e o PIB agrícola e entre a participação do PIB agrícola no PIB municipal apresentaram forte correlação, nesses casos os municípios com alta quantidade de contratos, alto valor contratado de demais linhas de crédito rural, alto PIB agrícola e alta participação do PIB agrícola no PIB municipal estavam distribuídos pelas regiões Sul, Centro-Oeste, parte da Sudeste e parte da Norte. A correlação entre a quantidade de contratos, valor contratado e a renda per capita municipal é positiva, isto é, municípios com alta quantidade de contratos, alto valor contratado de demais linhas de crédito rural apresentaram maior renda per capita, apesar da maioria dos municípios terem tido baixa quantidade de contratos e baixo valor contratado de demais linhas de crédito rural. As correlações entre a quantidade de contratos e o montante de recursos contratado de demais linhas de crédito rural e as diversas variáveis aqui estudadas foram fracas, com exceção do PIB agrícola e o percentual agrícola do PIB municipal. Demonstrando que os impactos do crédito agrícola para investimento nos indicadores sócio econômicos municipais sejam limitados.

\section{CONSIDERAÇÕES FINAIS}

Nesta pesquisa, analisou-se a dinâmica da distribuição dos recursos do PRONAF, do PRONAMP e das demais linhas de crédito da agricultura empresarial de investimento no Brasil e em suas regiões no período 2013-2018. Os programas foram considerados na modalidade investimento e apresentados em número de contratos e valor. A análise dos dados permitiu observar que no PRONAF, os municípios mais pobres, em especial a região Nordeste, com os piores indicadores contrataram as maiores quantidades de operações, cujos valores médios são mais baixos. Mostrado claramente pelos gráficos de dispersão de Moran. Já quando o critério foi o volume de recursos contratados, nota-se que as regiões mais ricas, com os melhores indicadores receberam um volume maior de recursos. Nota-se neste caso que agricultura familiar nas regiões Norte e Nordeste são mais voltadas a subsistência. Já as regiões Sul, Centro-Oeste e parte da Sudeste possuem um perfil mais profissional, com maior produtividade.

Quando o objeto de estudo passa a ser o PRONAMP e as demais linhas da agricultura empresarial essa dinâmica se altera, pois as regiões com maior quantidade de contratos, tendem a ser as regiões que receberam os maiores volumes de recursos. Notadamente as regiões Centro-Oeste e Sul. Em resumo, esta pesquisa procurou identificar a relevância das linhas de crédito voltadas ao investimento rural e os seus impactos nos diversos indicadores sócio econômicos. Verificou-se que na maior parte dos casos a 
relevância se mostrou limitada. Para uma pesquisa futura, a inclusão das linhas de crédito de custeio e comercialização possa auxiliar na identificação da completa relevância do crédito rural nos municípios.

\section{REFERÊNCIAS}

[1] ARAÚJO, Paulo Fernando Cidade de. Política de crédito rural: reflexões sobre a experiência brasileira. CEPAL - Textos para discussão Cepal - Ipea, Brasília, n. 37, 2011. Disponível em: < http://www.ipea.gov.br/portal/images/stories/PDFs/TDs/td _ 1555.pdf>. Acesso em: 20 mai. 2018.

[2] BANCO CENTRAL DO BRASIL. https://www3.bcb.gov.br/mcr 19/02/2019

[3] BANCO DO BRASIL. https://www.bb.com.br/pbb/pagina-inicial/agronegocios/agronegocio---produtos-e-servicos/credito/investirem-sua-atividade/PRONAMP-investimento\#/_19/02/2019

[4] BENETTI, Maria D. 0 agronegócio gaúcho entre os anos 1980 e 2008. In: CONCEIÇÃO, Octávio A. C. et al. (Org.). 0 movimento da produção. Porto Alegre: FEE, 2010. (Três décadas de economia gaúcha, 2). Disponível em: <https://www. fee.rs.gov.br/3-decadas/downloads/volume2/3/maria-benetti.pdf>. Acesso em 12 maio 2018.

[5] BRASIL. Ministério de Agricultura Pecuária e Abastecimento. Secretaria de Política Agrícola Departamento de Crédito e Estudos Econômicos. Estatísticas e dados básicos de economia agrícola. Brasília, DF, 2017. Disponível em: <http://www. agricultura.gov.br/assuntos/politica-agricola/todas-publicacoes-de-politica-agricola/ estatisticas-e-dados-basicos-de-economiaagricola/PASTA DEDEZEMBR017.pdf>. Acesso em 15 maio 2018.

[6] BRASIL. Ministério do Planejamento, Orçamento e Gestão. Instituto Brasileiro de Geografia e Estatística - IBGE. Censo Agropecuário 2006: Brasil, grandes regiões e unidades da federação. Brasília, DF, 2006. Disponível em: <https://biblioteca. ibge.gov.br/visualizacao/periodicos/51/agro_2006.pdf>. Acesso em 10 maio 2018.

[7] BRASIL: 70\% dos alimentos que vão à mesa dos brasileiros são da agricultura familiar. Brasília, 02 out. 2017. Disponível em: <http://www.mda.gov.br/sitemda /noticias/brasil-70-dos-alimentos-que-v\%C3\%A3o-\%C3\%A0-mesa-dos-brasileiros-s\%C3\%A3o-daagricultura-familiar>. Acesso em 10 mai. 2018.

[8] CONTAS nacionais trimestrais: indicadores de volume e valores correntes. Indicadores IBGE, Brasília, outubro 2017. Disponível

<https://agenciadenoticias .ibge.gov.br/media/com_mediaibge/arquivos/5452d8356484c9bf115862b4f64d9079.pdf>. Acesso em 03 maio 2018

[9] FAVERET FILHO, Paulo. Evolução do crédito rural e tributação sobre alimentos na década de 1990: implicações sobre as cadeias de aves, suínos e leite. BNDES Setorial, Rio de Janeiro, n. 16, p.31-56, set. 2002. Disponível em: <https://web. bndes.gov.br/bib/jspui/bitstream/1408/2597/1/BS\%2016\%20Evolu\%C3\%A7\%C3\%A3o\%20do\%20Cr\%C3\%A9dito\%20Rural_P.p df> Acesso em: 13 mai. 2018.

[10] MONASTERIO, Leonardo M.; ÁVILA, Rodrigo Peres de. Uma Análise Espacial do Crescimento Econômico do Rio Grande do Sul (1939-2001). Anais do XXXII Encontro Nacional de Economia, 113, ANPEC - Associação Nacional dos Centros de Pós-Graduação em Economia, 2004.

[11] PRONAF mais alimentos. Portal BNDES: formas de concessão de crédito. [S.l.], 24 jun. 2018. Disponível em: <https://www.bndes.gov.br/wps/portal/site/ home/ financiamento/produto/PRONAF-mais-alimentos>. Acesso em: 24 jun. 2018.

[12] SILVA, Alexandre Manoel Angelo da; RESENDE, Guilherme Mendes. A Importância do Acesso aos Serviços Públicos na Renda por Habitante dos Municípios Nordestinos. IPEA - Texto para Discussão, n. 1132. Rio de Janeiro, 2005.

[13] SILVA, Cátia Fernanda da. Dinâmica dos financiamentos habitacionais nos municípios do rio grande do sul de 2006 a 2010. 2011. 114 f. Dissertação (Mestrado em Economia) - Programa de Pós-Graduaçao em Economia da Universidade do Vale do Rio dos Sinos, São Leopoldo, 2011. Disponível em: <http://biblioteca.asav.org.br/vinculos/tede/CatiaFernandadaSilva.pdf>. Acesso em: 29 jun. 2018>

[14] SILVA, Diago Marenilson Oliveira Batista da et al. PRONAF: uma avaliação da distribuição regional dos contratos de crédito e seus impactos sobre o desenvolvimento rural do nordeste brasileiro. Revista Okara: Geografia em Debate, João Pessoa, v. 2, n. 2, p. 376-396. 2017. Disponível em: <http://eds.b.ebscohost.com/eds/pdfviewer/pdfviewer?vid=4\&sid=4ef95a25-6370-41a0-96e81d25ef8c1b18\%40sessionmgr120>. Acesso em: 28 mai. 2018.

[15] SILVA, Roniel Antonio. Impactos do PRONAF em municípios selecionados de Santa Catarina. 2016. 267f. Dissertação (Mestrado em Administração) - Programa de Pós-Graduação em Administração, Universidade Federal de Santa Catarina. Florianópolis. $\quad 2016 . \quad$ Disponível em: $\quad<$ file:///H:/Disserta\%C3\%A7\%C3\%A3o/Material\% 20para\%20a\%20disserta\%C3\%A7\%C3\%A3o/342178.pdf>.Acesso em: 15 jun. 2018.

[16] SOBRE o programa. Secretaria Especial de Agricultura Familiar e do Desenvolvimento Agrário. [s.l]. Disponível $\mathrm{em}:<\mathrm{http}: / /$ www.mda.gov.br/sitemda/ secretaria/saf-creditorural/sobre-o-programa>. Acesso em 17 maio 2018.

[17] SOUZA, Paulo M.; NEY, Marlon G.; PONCIANO, Niraldo J. A análise da distribuição dos financiamentos rurais entre os estabelecimentos agropecuários brasileiros. Revista de Economia e Sociologia Rural, Brasília, v. 53, n. 2, abr. /jun. 2015. Disponível em: <http://www.scielo.br/scielo.php?script=sci_arttext\&pid=S0103-20032015000200251>. Acesso em: 24 jun. 2018.

[18] VERGARA, Sylvia Constant. Projetos e relatórios de pesquisa em administração. 15. ed. São Paulo: Atlas, 2014. 


\section{Capítulo 4}

Demanda por produtos lácteos no Brasil: Uma análise utilizando dados da POF 2008/2009,

Guilherme Fonseca Travassos

Glauco Rodrigues Carvalho

Lucas Campio Pinha

\section{Juliana Mota Monteiro da Silva}

Resumo: Apesar da importância do setor lácteo brasileiro, não tem sido comum nos últimos anos a realização de estudos sobre a demanda por produtos lácteos no País. Desse modo, o objetivo deste trabalho foi analisar as elasticidades-renda, preço próprias e preço cruzadas da demanda por 14 produtos lácteos utilizando os microdados da POF 2008/09. Para a estimação das equações foi utilizado o modelo QUAIDS - Quadratic Almost Ideal Demand System, com os devidos tratamentos para endogeneidade e consumo zero, comuns em sistemas de demanda e pesquisas familiares. Os resultados obtidos indicaram que características de localização domiciliar e composição familiar afetam a propensão a consumir produtos lácteos. No caso das elasticidades-renda e preço próprias, os produtos lácteos em sua maioria mostraram-se mais sensíveis à variações da renda e menos sensíveis à variações nos preços. No caso das elasticidadescruzadas diversos produtos se mostraram como substitutos, destacando-se o Leite fluido com Leite em pó e Iogurte, e o Queijo minas com a Mozarela, Parmesão e Requeijão. Portanto, estes resultados contribuem para o desenho de políticas públicas que visem, por exemplo, a adequação do consumo de lácteos às recomendações do Ministério da Saúde pela Pirâmide Alimentar adaptada para a população brasileira. Além disso, pecuaristas e empresários responsáveis pelo processamento, distribuição e varejo no mercado de lácteos, podem se beneficiar do padrão de substituição entre os produtos lácteos, como as fornecidas neste estudo.

Palavras-chave: elasticidade, políticas públicas, modelo QUAIDS, sistemas de demanda. 


\section{INTRODUÇÃO}

O setor lácteo é um dos mais importantes do agronegócio brasileiro. De acordo com dados do Instituto Brasileiro de Geografia e Estatística - IBGE (2017), o Brasil é o quarto maior produtor mundial de leite de vaca com cerca de 35 milhões de toneladas em 2015, o que permite uma ampla produção de derivados e torna a cadeia produtiva de lácteos no Brasil dinâmica e diversificada. Ainda segundo IBGE (2017), o valor bruto da produção de leite foi de $\mathrm{R} \$ 34,7$ bilhões em 2015 , o que representou cerca de $75 \%$ de toda a produção de origem animal no país e $13 \%$ de todo o valor gerado pelo agronegócio brasileiro naquele ano. Em relação à importância dos produtos lácteos no Índice de Preços ao Consumidor Amplo - IPCA, este tem o peso geral de 2,06\% e 8,05\% respectivamente em relação ao Índice Geral e à categoria de Alimentos e bebidas, demonstrando a importância do setor para a economia nacional. A indústria de laticínios, por sua vez, é a segunda em faturamento no setor de alimentos brasileiro, atrás apenas do setor de carnes. 0 faturamento dessa indústria foi cerca de $\mathrm{R} \$ 60$ bilhões em 2015 (ABIA, 2016).

Os produtos lácteos também merecem destaque por constituírem um grupo de alimentos de grande valor nutricional, dado que são fontes consideráveis de proteínas de alto valor biológico, além de conterem vitaminas e minerais, com destaque para o cálcio, nutriente que, além de outras funções, é fundamental para a formação e a manutenção da estrutura óssea do organismo (MUNIZ et al., 2013). A ingestão de produtos lácteos tem sido associada a efeitos benéficos no que diz respeito à saúde óssea e muscular, além de efeitos sobre determinantes da síndrome metabólica ${ }^{10}$ e sobre o gerenciamento de peso e hidratação. Além disso, a diversidade de produtos lácteos permite que estes alimentos sejam inseridos em diferentes momentos ao longo do dia, a fim de que sejam alcançadas as três porções diárias de leites e derivados recomendada pela Pirâmide Alimentar ${ }^{11}$ adaptada para a população brasileira (MINISTÉRIO DA SAÚDE, 2014).

Desse modo, de acordo com a Pesquisa de Orçamentos Familiares - POF 2008/09, os Laticínios representaram o segundo maior subgrupo de aquisição média domiciliar per capita pelos brasileiros em relação ao grupo de Alimentos e Bebidas em 2009, com cerca de 43,707 kg/ano, atrás apenas das Bebidas e infusões $(50,713 \mathrm{~kg})$ e seguido por Cereais e leguminosas $(38,969 \mathrm{~kg})$, Frutas $(28,863 \mathrm{~kg})$ e Hortaliças $(27,075 \mathrm{~kg})$. Apesar disso, o consumo domiciliar per capital por produtos lácteos no Brasil ainda é considerado baixo. Segundo as recomendações do Ministério da Saúde (2014), o consumo de leite, na forma fluida ou de derivados lácteos, varia de acordo com a idade das pessoas. A recomendação para crianças de até dez anos é de $400 \mathrm{ml} /$ dia, isto é, 146 litros/ano de leite fluido ou equivalente na forma de derivados. Para os jovens de 11 a 19 anos, o consumo é maior, de $700 \mathrm{ml} /$ dia ou 256 litros/ano e para os adultos acima de 20 anos a recomendação é de $600 \mathrm{ml} /$ dia ou 219 litros/ano, inclusive para os idosos.

Em comparação à POF 2002/03, a aquisição domiciliar per capita por Laticínios diminuiu cerca 12,5\% em 2009, muito em função da queda no consumo do Leite fluído ${ }^{12}$, que passou de 42,6 kg em 2003 para 35,4 kg per capita em 2009. Destaca-se também a queda no consumo do Leite em pó $(18,1 \%)$ e da Manteiga $(15,7 \%)$, e um aumento na aquisição domiciliar per capita do Leite fermentado (158\%), Queijo mozarela (39,3\%), Creme de Leite (32\%), Leite condensado (25,7\%) e Queijo Minas (20,9\%). Portanto, percebe-se que houve uma queda no consumo domiciliar dos laticínios considerados tradicionais e um aumento no consumo dos queijos e demais produtos lácteos de maior processamento (IBGE, 2010a). Vale a pena ressaltar que os dados divulgados pela POF não consideram a variação de consumo em equivalência litros de leite.

\footnotetext{
10 De acordo com a Sociedade Brasileira de Cardiologia (2010), o termo Síndrome Metabólica descreve um conjunto de fatores de risco metabólico que se manifestam num indivíduo e aumentam as chances de desenvolver doenças cardíacas, derrames e diabetes.

11 De acordo com Achterberg et al. (1994), Pirâmide Alimentar é uma representação gráfica facilitadora para a visualização de alimentos assim como a sua escolha nas refeições do dia. Portanto, representa um instrumento de orientação nutricional utilizado por profissionais com o objetivo de promover mudanças nos hábitos alimentares visando à saúde global do indivíduo e a prevenção de doenças.

12 Seguindo a nomenclatura da POF, este produto representa a soma do consumo domiciliar per capita dos produtos Leite de vaca fresco e Leite de vaca pasteurizado. Optou-se por tratar estes bens conjuntamente para o melhor ajuste do modelo e análise dos resultados.
} 
Assim, as informações até aqui apresentadas evidenciam a importância do consumo de lácteos no Brasil e que este vem se alterando nos últimos anos, principalmente por mudanças estruturais, tais como urbanização, mudanças nas características demográficas, elevação da demanda por praticidade, com a maior inserção da mulher no mercado de trabalho, aumento na qualidade dos produtos lácteos tornandoos menos perecíveis, queda nos preços dos produtos lácteos e aumento da renda real das famílias, principalmente daquelas consideradas de baixa renda. Além disso, as informações acima demonstram a relevância do mercado de lácteos para o Brasil, sendo responsável diretamente pelo rendimento de diversos produtores e atendendo a demanda de milhares de consumidores. Portanto, tais informações evidenciam a necessidade de um melhor entendimento sobre a demanda por produtos lácteos no Brasil.

Apesar da relevância do mercado lácteo brasileiro, a maioria dos estudos ${ }^{13}$ sobre a demanda por alimentos no Brasil concentram-se na análise de grupos agregados ou itens básicos sem considerar a importância e implicação de laticínios específicos na dieta dos brasileiros. Entretanto, destaca-se Oliveira e Carvalho (2006) que realizaram uma análise das elasticidades-renda para lácteos no Brasil em diferentes estratos de rendimento utilizando dados da POF 2002/03. Os autores afirmaram as elasticidades-renda do Brasil revelaram que a demanda pelo agregado de leite e derivados é inelástica. Além deste estudo, têm-se Carvalho et al. (2015) que buscaram identificar possíveis efeitos da participação no programa Bolsa Família sobre a demanda de produtos lácteos. Os autores utilizaram dados da POF 2008/09 e o método de dois estágios de Heckman para a elaboração da análise quantitativa com nove produtos lácteos. Os autores encontraram elasticidades-renda e preço abaixo da unidade. Eles ainda concluem que o programa Bolsa Família aumenta a probabilidade das famílias em comprar leite em pó e leite não pasteurizado e, no âmbito de políticas públicas, uma melhor orientação sobre os riscos de leite não pasteurizado e educação nutricional para as famílias beneficiadas com o programa deveria ser considerada.

Desta forma, foram realizados poucos estudos sobre a demanda desagregada por produtos lácteos no País nos últimos anos, apesar de sua importância para o mercado interno. Portanto, a contribuição desse estudo em relação aos demais é realizar uma análise desagregada utilizando 14 produtos lácteos com dados mais recentes da POF, utilizando um sistema de demanda (QUAIDS) que está de acordo com a Teoria Econômica e com estimação que leva em consideração a relação entre os erros das equações de demanda (Seemingly unrelated regressions - SUR) e abordando questões metodológicas pouco exploradas em outros estudos (endogeneidade de preços e dispêndio, curvas de Engel não lineares no log do dispêndio). Desse modo, o objetivo do presente trabalho é analisar as elasticidades-renda, preço próprio e preço cruzado da demanda por produtos lácteos utilizando os microdados da POF 2008/09.

Considera-se que este tema é importante devido à escassez de trabalhos que estimam as elasticidades de demanda por produtos lácteos no Brasil, ressalta-se ainda que, com base nas elasticidades, é possível verificar em quais produtos uma política pública de elevação e/ou redistribuição de renda teria maior efeito na demanda domiciliar, bem como uma política de redução de preços (isenção tributária, por exemplo) teria maior eficácia sobre os consumidores. Além disso, o conhecimento das elasticidades pode ser relevante também para a iniciativa privada, pois as informações poderiam auxiliar nos planejamentos estratégicos das empresas, visto que entender quais bens são substitutos e quais produtos reagem em maior magnitude a alterações nos preços e na renda da população poderia contribuir para as estratégias de mercado do ofertante.

Este estudo está dividido em quatro seções, incluindo esta introdução. Na segunda seção, apresenta-se o referencial analítico e os procedimentos adotados para estimar um sistema de demanda por produtos lácteos no Brasil. Na terceira seção, são apresentados os resultados sobre a decisão de aquisição dos produtos lácteos pelos consumidores e elasticidades-preço, preço-cruzado e dispêndio. Na quarta seção serão realizadas as considerações finais.

\section{METODOLOGIA}

\subsection{FORMA FUNCIONAL}

Devido ao alto nível de desagregação de bens, como permitem geralmente as pesquisas de orçamento familiares como a POF/IBGE, a não-linearidade das curvas de Engel14 é bastante provável. Dessa forma, o modelo denominado como Quadratic Almost Ideal Demand System - QUAIDS é o mais adequado para a estimação do sistema de demanda por produtos lácteos:

\footnotetext{
13 Como Pintos-Payeras (2009), Hoffmann (2007), Hoffmann (2010) e Coelho et al. (2010), por exemplo.

14 Descreve como a despesa dos domicílios com determinado bem ou serviço varia de acordo com o rendimento familiar (DEATON; MUELLBAUER, 1980a).
} 


$$
w_{i}=\alpha_{i}+\sum_{j} \gamma_{i j} \ln p_{j}+\beta_{i} \ln \left(\frac{x}{a(p)}\right)+\frac{\lambda_{i}}{b(p)}\left\{\ln \left(\frac{x}{a(p)}\right)\right\}^{2}
$$

em que $\mathrm{w}_{\mathrm{i}}=\frac{p_{i} q_{i}}{\sum_{i=1}^{n} p_{i} q_{i}}$ é a parcela de gastos com o i-ésimo bem; $m$ é o dispêndio total com o bem; $\mathrm{p}_{\mathrm{j}}$ é o preço do $j$-ésimo bem; e $\alpha_{i}, \gamma_{i j}, \beta_{i}$ e $\lambda_{i}$ são os parâmetros a serem estimados, sendo o último, o parâmetro requerido para o termo quadrático do dispêndio.

\subsection{PROCEDIMENTOS ECONOMÉTRICOS}

\subsubsection{PROCEDIMENTO DE SHONKWILLER E YEN}

Um dos problemas que podem surgir na estimação de sistemas de demanda com bens desagregados é o gasto com o i-ésimo bem ser igual à zero em determinado domicílio (Problema do consumo zero) ${ }^{15}$. No presente trabalho, para lidar com esse problema, pretende-se utilizar o procedimento de Shonkwiller e Yen (1999), os quais propõem um método de estimação em dois estágios, que permite englobar todas as observações. No primeiro estágio, estima-se um modelo de escolha binária para determinar a probabilidade de determinado domicílio consumir o item, em função das características sóciodemográficas. Já o segundo estágio considera a estimação do sistema de demanda. 0 procedimento é descrito da seguinte forma:

\section{1ํo estágio}

$d_{i k}^{*}=z_{i k}^{\prime} \alpha_{i}+\vartheta_{i k}$

$d_{i k}=\left\{\begin{array}{l}1 \text { se } d_{i k}^{*}>0 \\ 0 \text { se } d_{i k}^{*} \leq 0\end{array}\right.$

\section{2o estágio}

$y_{i k}^{*}=f\left(s_{i k}, \beta_{i}\right)+\epsilon_{i k}$,

$y_{i k}=d_{i k} y_{i k}^{*},(i=1, \ldots, m ; k=1, \ldots, K)$

em que: $d_{i k}^{*}=$ variável latente representando a diferença em utilidade entre comprar ou não o i-ésimo bem; $d_{i k}=$ variável binária observada para representar a escolha do k-ésimo domicílio em consumir i-ésimo bem $\left(d_{i k}=1\right)$ ou não $\left(d_{i k}=0\right)$; $y_{i k}^{*}=$ variável latente representando a quantidade consumida do i-ésimo produto; $y_{i k}=$ variável dependente observada representando a quantidade consumida com o i-ésimo produto; $f\left(s_{i k}, \beta_{i}\right)$ é a função de demanda; $z_{i k}$ e $s_{i k}$ são vetores de variáveis exógenas; $\beta_{i}$ e $\alpha_{i}$ são vetores de parâmetros; e $\epsilon_{i k}$ e $\vartheta_{i k}$ são os erros aleatórios.

0 vetor $z_{i k}$ considera as características sócio-demográficas do k-ésimo domicílio que podem influenciar a propensão de se consumir o i-ésimo bem. No primeiro estágio, obtêm-se as estimativas de $\alpha_{i}$, por meio do modelo probit. Calculam-se a função de densidade de probabilidade $\phi\left(z^{\prime}{ }_{i k} \widehat{\alpha}_{l}\right)$ e a função de distribuição acumulada $\Phi\left(z_{i k}^{\prime} \widehat{\alpha}_{l}\right)$. Em seguida, estima-se $y_{i k}$ por SUR (regressões aparentemente não correlacionadas). Desse modo, os vetores $z_{i k}$ e $s_{i k}$ utilizados no $1^{\mathrm{o}}$ e $2^{\mathrm{o}}$ estágio, respectivamente, são formados por variáveis que permitem captar as diferenças no padrão de consumo entre os domicílios, em relação à localização e composição domiciliar ${ }^{16}$.

15 O Problema do Consumo Zero pode surgir de duas maneiras distintas: primeiro, como em pesquisas de orçamentos familiares os dados são coletados em determinado período, o não consumo desses alimentos pode surgir devido à baixa frequência de aquisições pelos domicílios. Em segundo lugar, ao considerar grupos alimentares específicos, que exigem um maior nível de desagregação, é pouco provável que os consumidores adquiram todos os produtos considerados. Portanto, a desconsideração do Problema do Consumo Zero gera estimativas enviesadas e inconsistentes dos sistemas de demanda.

${ }^{16}$ As variáveis que compõem esses vetores são: dummy se o domicílio pertence à região Sul, Sudeste, Nordeste ou Centro-oeste; renda domiciliar per capita; dummy para o sexo do chefe do domicílio; anos de estudo do chefe do 


\subsubsection{ENDOGENEIDADE DOS PREÇOS}

Nas Pesquisas de Orçamentos Familiares, o preço pago pelo bem $p_{i}$ não é disponibilizado, e sim a despesa total com a compra do bem e a quantidade adquirida com o mesmo. Assim, o preço com o i-ésimo bem pode ser representado pelo valor unitário de cada bem $\left(U V_{i}\right)$, calculado pela divisão do dispêndio com o iésimo bem pelo k-ésimo domicílio $\left(x_{i k}\right)$ pela quantidade adquirida com o i-ésimo bem pelo k-ésimo domicílio $\left(q_{i k}\right)$, expresso da seguinte forma (DEATON, 1997):

$$
U V_{i k}=\frac{x_{i k}}{q_{i k}},
$$

Analisando tal procedimento, Cox e Wohlgenant (1986) e Deaton (1988) concluíram que a utilização de valores unitários pode comprometer a estimação de equações de demanda, devido ao fato de eles não serem exógenos, incorporando atributos externos como qualidade do bem. De forma geral, como consumidores com maior renda tendem a comprar bens de maior qualidade, os valores unitários tendem a ser positivamente correlacionados com o dispêndio total. Para solucionar este problema, aplica-se o método de Cox e Wohlgenant (1986), que consiste em estimar os preços corrigidos pelos "efeitos qualidade", regredindo a diferença entre $\mathrm{UV}_{\mathrm{ik}}$ e seus valores médios por estado (UV), pelas características domiciliares $\mathrm{A}_{\mathrm{ik}}$, utilizadas como proxy das preferências dos domicílios por qualidade ${ }^{17}$. Assim:

$$
U V_{i k}-\overline{U V}=\sum_{t} \eta_{i k} A_{i k}+v_{i}
$$

em que $v_{i}$ segue uma distribuição normal $\left(v_{i} \sim N\left(0, \sigma^{2}\right)\right)$. Assume-se que os desvios em relação aos valores unitários médios refletem "efeitos qualidade" induzidos por características domiciliares, como também fatores não sistemáticos ligados à oferta. Os preços ajustados $\left(p_{i k}\right)$ são obtidos da seguinte forma:

$$
p_{i k}=U V_{i k}-\sum_{t} \hat{\eta}_{i k} A_{i k}
$$

ou $p_{i k}=\overline{U V}+\hat{v}_{i k}$, em que $p_{i k}$ é o preço ajustado pela qualidade a ser utilizado na estimação da demanda, $\hat{v}_{i k}$ é o resíduo estimado da equação (5). Para os domicílios que não consumiram o i-ésimo bem, ou seja, $m_{i}=0$, foram utilizados os preços médios $\bar{p}_{i}$ calculados para o Brasil.

\subsubsection{ENDOGENEIDADE DO DISPÊNDIO}

Ao considerar o consumo de lácteos como fracamente separável do dispêndio total, assume-se que a quantidade demandada do i-ésimo bem considerado $\left(q_{i}\right)$ é uma função do dispêndio com lácteos $\left(x_{r}\right)$. Entretanto, é possível que exista um viés de simultaneidade, devido à determinação conjunta da quantidade demandada de lácteo $\left(q_{r}\right)$ e seu dispêndio $\left(x_{r}\right)$. Dessa forma, não se pode considerar o dispêndio com produtos lácteos estritamente exógeno (LAFRANCE, 1991). Assim, para corrigir esse possível problema de endogeneidade, utiliza-se a abordagem de estimação por regressão aumentada de Blundell e Robin (1999), que consiste de duas etapas: primeiro, o dispêndio com lácteos $\left(x_{r}\right)$ é regredido num conjunto de variáveis exógenas (um vetor de características domiciliares $\left(A_{i k}\right)$ e um índice de preços como instrumento adicional):

$$
\ln \left(x_{r k}\right)=\alpha_{0}+\sum_{k} a_{k} A_{i k}+b_{j} \log P+v_{k},
$$

domicílio; dummy se tem criança no domicílio; dummy se tem adolescente no domićlio; e dummy se tem idoso no domicílio.

${ }^{17}$ As variáveis que compõem o vetor $A_{i k}$ são: dummy se o domicílio pertence à região Sul, Sudeste, Nordeste ou Centrooeste; renda domiciliar per capita; dummy para o sexo do chefe do domicílio; anos de estudo do chefe do domicílio; e total de pessoas no domicílio. 
Em seguida, utiliza-se os resíduos dessa estimação $\left(\hat{v}_{k}\right)$ como variável explicativa na equação de demanda, juntamente com o dispêndio com lácteos $\left(m_{r}\right)$, permitindo assim corrigir e testar ${ }^{18}$ a endogeneidade do dispêndio (BLUNDELL; ROBIN, 1999).

\subsection{MODELO ECONOMÉTRICO}

O sistema de demanda a ser estimado pelo segundo estágio do procedimento de Shonkwiller e Yen para se analisar as mudanças no perfil do consumidor brasileiro de lácteos é o seguinte:

$$
\begin{aligned}
w_{i k}=\left[\sum_{k} \theta_{i k} D_{i k}\right. & \left.+\alpha_{i}+\sum_{j} \gamma_{i j} \log p_{j}+\beta_{i} \log \left(\frac{x_{r}}{a(p)}\right)+\frac{\lambda_{i}}{b(p)}\left\{\log \left(\frac{x_{r}}{a(p)}\right)\right\}^{2}+u_{i} \hat{v}_{k}\right] \Phi\left(z^{\prime}{ }_{i k} \hat{\alpha}_{i}\right)+\delta_{i} \phi\left(z^{\prime}{ }_{i k} \widehat{\alpha}_{l}\right) \\
& +\vartheta_{i k}
\end{aligned}
$$

em que $\phi\left(z_{i k}^{\prime} \widehat{\alpha}_{l}\right)$ é a função de densidade de probabilidade calculada no primeiro estágio do procedimento de Shonkwiller e Yen; $D_{i k}$ é um vetor de variáveis que caracterizam o $k$-ésimo domicílio; $\theta_{i k}$ são os parâmetros estimados para cada variável; $b(p)=\prod_{n} p_{k}^{\beta_{\lambda}}$ é um agregador de preços Cobb-Douglas; $\Phi\left(z^{\prime}{ }_{i k} \widehat{\alpha}_{l}\right)$ é a função de distribuição acumulada também calculada no primeiro estágio do procedimento de Shonkwiller e Yen; e $\vartheta_{i k}$ é o erro aleatório com média zero. Para a estimação dos sistemas de demanda no presente trabalho, adota-se o índice de preços de Laspeyers, descrito como ${ }^{19}$ :

$$
\log a(p)=\log P=\sum_{j} w_{j}^{0} \ln p_{j}
$$

em que $w_{j}^{0}$ é a parcela de gastos no período base, também podendo ser considerada como a média da parcela de gastos com o j-ésimo bem.

Para encontrar as elasticidades-dispêndio, elasticidades-preço da demanda e elasticidades-preço cruzadas, primeiramente, diferencia-se a equação (8) em relação ao logaritmo do dispêndio e dos preços, respectivamente gerando os seguintes termos (BANKS et al., 1997):

$$
\begin{aligned}
& \mu_{i} \equiv \frac{\partial w_{i}}{\partial \ln m}=\Phi\left(z^{\prime}{ }_{i k} \hat{\alpha}_{i}\right)\left\{\beta_{i}+\frac{2 \lambda_{i}}{b(p)}\left(\log x_{r}-\log P\right)\right\} \\
& \mu_{i j} \equiv \frac{\partial w_{i}}{\partial \ln p_{j}}=\Phi\left({z^{\prime}}^{\prime} \hat{\alpha}_{i}\right)\left\{\gamma_{i j}-\left[\beta_{i}+\frac{2 \lambda_{i}}{b(p)}\left(\log x_{r}-\log P\right)\right]\left(w_{j}^{0}\right)-\frac{\lambda_{i} \gamma_{i}}{b(p)}\left[\log x_{r}-\log P\right]^{2}\right\}
\end{aligned}
$$

A elasticidade-dispêndio $\left(e_{i}\right)$ e elasticidades-preço marshallianas $\left(e_{i j}^{u}\right)$ podem ser definidas como:

$$
\begin{aligned}
& e_{i}=\frac{\mu_{i}}{w_{i}}+1, \\
& e_{i j}^{u}=\frac{\mu_{i j}}{w_{i}}-\delta_{i j},
\end{aligned}
$$

${ }^{18}$ Para testar a endogeneidade do dispêndio, basta examinar a significância do coeficiente de $\hat{v}_{k}$, ou seja, $u_{i}$ na equação (8).

${ }^{19} 0$ índice de preços padrão do modelo AIDS não é linear nos parâmetros, portanto, Deaton e Muellbauer (1980b) sugerem o índice de Stone, com o objetivo de linearizar o modelo. Isso facilita a estimação e a convergência dos resultados. No entanto, Moschini (1995) prova que tal índice não é invariante em relação a mudanças de preços e quantidades, sugerindo, nesse caso, como substitutos o índice de Stone corrigido ou índice de Laspeyres. 
As elasticidades-preço compensadas (hickisianas) $\left(e_{i j}^{c}\right)$ podem ser calculadas pela equação de Slutsky $\left(e_{i j}^{c}=e_{i j}^{u}+e_{i} w_{j}\right)$, e são usadas para classificar os bens como substitutos ou complementares.

Para estimar os parâmetros do modelo QUAIDS, utiliza-se a rotina de programação para o STATA descrita em Poi (2008) e acrescenta-se o procedimento de Shonkwiller e Yen, as variáveis de controle e correção da endogeneidade do dispêndio, de acordo com Tafere et al. (2010). Para garantir a imposição de aditividade das parcelas de gasto, trata-se um dos bens como "residual" e estima-se o sistema de demanda para $n-1$ bens (YEN et al., 2003). 0 bem residual escolhido foi "Outros lácteos", pois, apesar de sua representatividade, é o bem de menor interesse na estimação ${ }^{20}$. Por meio da restrição de aditividade, é possível recuperar os parâmetros e calcular as elasticidades para esse bem.

Apesar de se aplicar um índice de preços linear, o modelo QUAIDS ainda é não linear devido ao termo $b(p)$. Por consequência dessa característica, estimam-se as equações de demanda por um sistema não linear de regressão aparentemente não relacionada (SUR), de acordo com o comando NLSUR do STATA. 0 método utilizado será o IFGNLS (iterated feasible generalized non-linear least squares), semelhante às estimações de Máxima Verossimilhança.

\subsection{BASE DE DADOS}

As informações utilizadas nesse estudo são provenientes dos microdados da Pesquisa de Orçamentos Familiares - POF, sendo esta de caráter amostral, realizada pelo Instituto Brasileiro de Geografia e Estatística (IBGE), para o ano de 2008/09. Essa pesquisa foi realizada para uma amostra de 55.970 domicílios, situados nas áreas urbanas e rurais de todo território brasileiro, disponibilizando informações sobre a composição orçamentária doméstica e sobre as condições de vida da população (IBGE, 2010b).

Devido aos microdados da POF apresentarem dados muito desagregados, foi necessário agregar os vários subtipos de produtos lácteos de forma a se obter as categorias desejadas ${ }^{21}$. Essa agregação foi obtida pela ponderação de cada subtipo pela parcela da despesa total do subtipo no produto correspondente para cada consumidor ${ }^{22}$. Para este estudo de demanda por lácteos, foram utilizados todos os subprodutos oriundos desse grupo selecionados pela POF, sendo eles: creme de leite, leite condensado, leite fluído, leite em pó, leite com sabor, queijo minas, queijo mozzarella, queijo parmesão, queijo prato, requeijão, iogurte, leite fermentado, manteiga e outros lácteos ${ }^{23}$, totalizando 14 produtos lácteos. A amostra final totalizou 31.586 domicílios que consumiram algum dos produtos lácteos.

\section{RESULTADOS E DISCUSSÕES}

\subsection{DECISÃO DE COMPRA}

O primeiro estágio do procedimento de Shonkwiller e Yen (1999) é importante não somente pela resolução do problema do consumo zero, mas também por apresentar estimativas da propensão marginal de aquisição dos bens em análise. Portanto, na Tabela 1 são apresentados os efeitos marginais das variáveis de localização domiciliar e composição domiciliar sobre a decisão dos domicílios de consumir produtos lácteos. A maioria dos coeficientes (124 dos 154 coeficientes ou aproximadamente 80\%) mostrou-se significativo para os produtos lácteos.

\footnotetext{
${ }^{20}$ De acordo com Coelho et al. (2010), a escolha do bem residual deve ser cuidadosa, geralmente recaindo no bem em que o pesquisador tem menor interesse.

21 Por exemplo, há varias denominações na POF para leite condensado (Ex: leite beijinho, leite moça, moça festa, ...), que foram agregadas inicialmente em "Leite Condensado".

$22 \mathrm{O}$ valor gasto e a quantidade adquirida de forma agregada foram encontrados por meio da soma dos valores gastos e quantidades com cada bem que compôs o grupo de interesse, respectivamente. 0 preço agregado foi encontrado por meio do somatório do valor gasto com cada bem em relação ao valor total gasto com o agregado multiplicado pelo preço de cada bem.

${ }^{23}$ De forma geral, este bem é composto pelos seguintes produtos: demais queijos, coalhada, nata, chantilly e cream cheese, além de suas variações light/diet.
} 
Tabela 1 - Efeitos marginais das variáveis demográficas sobre a propensão marginal a consumir produtos lácteos, 2009

\begin{tabular}{|l|r|r|r|r|r|r|r|r|r|}
\hline & Norte \\
\hline
\end{tabular}

Nível de significância: ${ }^{*} 10 \%,{ }^{* *} 5 \%,{ }^{* * *} 1 \%$.

Fonte: Resultados da pesquisa.

Dentre as variáveis de composição domiciliar, as que apresentaram maior frequência de significância foram Anos de estudo e a Renda domiciliar per capita. Os sinais obtidos, em sua maioria, foram os esperados para ambas as variáveis: quanto há um aumento da escolaridade do chefe e/ou da renda no domicílio, a propensão a consumir lácteos aumenta. A exceção foi o Leite fluído que obteve sinal negativo para ambas as variáveis. No caso da Renda domiciliar per capita, as magnitudes foram muito baixas: por exemplo, para Creme de leite, a cada $\mathrm{R} \$ 100$ de aumento na renda per capita, tudo o mais constante, a propensão a consumir aumenta em apenas 0,004 pontos percentuais. 0 maior efeito foi encontrado para Iogurte $(0,17$ pontos percentuais para $\mathrm{R} \$ 100$ de aumento). Apesar de ser utilizado o indivíduo com renda média na análise, a baixa influência da renda na decisão de compra também foi encontrada por Silva e Coelho (2014). Em relação à variável Escolaridade, destaque para Queijo mozarela e o Iogurte, com efeito marginal de 1,9 e 1,1 pontos percentuais respectivamente. As magnitudes neste caso são bem mais elevadas do que no caso da renda.

Já me relação às variáveis de composição domiciliar que refletem a presença de indivíduos específicos no domicilio, quando significativos, a maioria apresentou sinal positivo. Em relação à presença de crianças nos domicílios merece destaque o aumento da propensão a consumir os esperados Iogurte $(9,9$ pontos percentuais) e Leite fermentado (2,4 pontos percentuais), e uma queda na propensão a consumir queijos como um todo. Na presença de adolescentes nos domicílios destaca-se a maior propensão a consumir Leite condensado (2,2 pontos percentuais) e Queijo mozarela (2,1 pontos percentuais). Por fim, a presença de idosos no domicílio sugere uma maior propensão a consumir queijos no geral, com destaque para o Queijo Minas (4,7 pontos percentuais).

Em relação a variável relacionada ao fato de a mulher ser a pessoa de referência do domicílio, os sinais dos coeficientes foram pouco significativos e em sua maioria negativos, com destaque para Leite fluido $(2,1$ pontos percentuais) e Queijo minas (1,9 pontos percentuais). Ou seja, a uma maior propensão a consumir produtos lácteos em domicílios que o homem é a pessoa de referência do domicilio. Portanto, a hipótese inicial de que haveria um aumento da propensão a consumir produtos lácteos mais processados quando a mulher fosse a pessoa de referência do domicílio, refletindo uma maior demanda por praticidade, não se confirmou neste estágio.

Por fim, as variáveis de localização domiciliar também se mostraram significativas em sua maioria, aproximadamente $82 \%$ dos coeficientes. Este resultado é bastante relevante, pois mostra que há diferenças regionais em relação à região Sudeste e ao fato de o domicílio encontrar-se na zona rural na aquisição de produtos lácteos, que devem refletir diferenças em hábitos, gostos e disponibilidade local. Assim como em Coelho et al (2010), a propensão marginal a consumir Leite fluído é menor nas regiões Norte e Nordeste e a propensão a consumir Leite em pó é maior nas regiões Norte e Nordeste, em comparação a região Sudeste. A maior propensão a consumir Leite em pó nas regiões Norte e Nordeste também foi encontraram em Carvalho et al (2015). Os autores chamaram a atenção para a questão de ser 
regiões mais remotas, com maior restrição de refrigeração e mais pobres. A possibilidade de adicionar mais água do que a indicada no Leite em pó cria uma falsa ideia de rendimento em população mais carente. Parece haver uma menor propensão a consumir produtos lácteos nas demais regiões brasileiras: cerca de $70 \%$ dos coeficientes significativos foram negativos. Além dos já mencionados, destaca-se a baixa propensão a consumir queijos como um todo e os lácteos com maior nível de processamento nas regiões Norte, Nordeste e Centro-Oeste em comparação a região Sudeste. Além disso, o fato de o domicílio situarse na zona urbana tende a aumentar a propensão marginal ao consumo de produtos lácteos, com destaque para Queijo mozarela (9 pontos percentuais), Iogurte (4,5 pontos percentuais) e o Leite fluído (3,2 pontos percentuais). Dentre os coeficientes significantes, apenas para o Leite em pó a propensão a consumir cai na zona urbana em relação à zona rural, provavelmente em função da maior restrição de energia elétrica e refrigeração.

\subsection{ELASTICIDADES-RENDA, ELASTICIDADES-PREÇO PRÓPRIAS E ELASTICIDADES-PREÇO CRUZADAS}

No que se refere à elasticidade-renda e elasticidade-preço da demanda, a maioria dos resultados encontrados fizeram sentido econômico, seja no sinal esperado ou na magnitude dos coeficientes. As elasticidades-renda foram positivas e as elasticidades-preço da demanda negativas, conforme a teoria econômica. Além disso, as elasticidades-preço foram em sua maioria menores do que a unidade, indicando que a maioria dos produtos lácteos possuem demanda inelástica em relação a preço em linha com os resultados de Carvalho et al (2015). Merece destacar ainda que, praticamente todas as elasticidades foram estatisticamente significativas, a maioria ao nível de significância de 1\% (Tabela 2).

Tabela 2 - Elasticidade-renda e elasticidade-preço próprio para produtos lácteos, 2009

\begin{tabular}{|c|c|c|}
\hline & $\begin{array}{l}\text { Elasticidade- } \\
\text { renda }\end{array}$ & Elasticidade-preço \\
\hline \multirow{2}{*}{ Creme de leite } & $0,986^{* * *}$ & $-0,389 * *$ \\
\hline & $(0,075)$ & $(0,198)$ \\
\hline \multirow{2}{*}{ Leite condensado } & $1,024^{* * *}$ & $-0,844^{* * *}$ \\
\hline & $(0,080)$ & $(0,178)$ \\
\hline \multirow{2}{*}{ Leite fluído } & $1,023^{* * *}$ & $-0,052^{* * *}$ \\
\hline & $(0,008)$ & $(0,005)$ \\
\hline \multirow{2}{*}{ Leite em pó } & $0,948^{* * *}$ & $-0,132^{* * *}$ \\
\hline & $(0,018)$ & $(0,012)$ \\
\hline \multirow{2}{*}{ Leite com sabor } & $1,313^{* * *}$ & $-2,602^{* * *}$ \\
\hline & $(0,102)$ & $(0,153)$ \\
\hline \multirow{2}{*}{ Queijo minas } & $0,921^{* * *}$ & $-0,889 * * *$ \\
\hline & $(0,056)$ & $(0,056)$ \\
\hline \multirow{2}{*}{ Queijo mozarela } & $0,776^{* * *}$ & $-0,469 * * *$ \\
\hline & $(0,043)$ & $(0,058)$ \\
\hline \multirow{2}{*}{ Queijo parmesão } & $1,301^{* * *}$ & $-2,784^{* * *}$ \\
\hline & $(0,126)$ & $(0,191)$ \\
\hline \multirow{2}{*}{ Queijo prato } & $1,146^{* * *}$ & $-0,575^{* * *}$ \\
\hline & $(0,040)$ & $(0,077)$ \\
\hline \multirow{2}{*}{ Requeijão } & $1,053^{* * *}$ & $-0,941^{* * *}$ \\
\hline & $(0,085)$ & $(0,158)$ \\
\hline \multirow{2}{*}{ Iogurte } & $0,902^{* * *}$ & $-0,622^{* * *}$ \\
\hline & $(0,040)$ & $(0,038)$ \\
\hline \multirow{2}{*}{ Leite fermentado } & $1,423^{* * *}$ & $-2,241^{* * *}$ \\
\hline & $(0,068)$ & $(0,127)$ \\
\hline \multirow{2}{*}{ Manteiga } & $0,586^{* * *}$ & $-1,148^{* * *}$ \\
\hline & $(0,110)$ & $(0,113)$ \\
\hline \multirow{2}{*}{ Outros lácteos } & $0,812^{* * *}$ & $-0,550^{* * *}$ \\
\hline & $(0,163)$ & $(0,137)$ \\
\hline
\end{tabular}

Nível de significância: * $10 \%,{ }^{* *} 5 \%,{ }^{* * *} 1 \%$. Erros padrão em parênteses.

Fonte: Resultados da pesquisa.

No caso das elasticidades-renda da demanda, vale destacar alguns pontos. Dos 14 produtos analisados, 7 deles apresentaram elasticidade-renda superiores a unidade, mostrando-se como um bem de luxo. 
Produtos como Leite fermentado, Leite com sabor e Queijo parmesão tiveram destaque em termos de elasticidade-renda. Ou seja, para um aumento de 1\% na renda ocorre um aumento de 1,3\% na demanda de Leite com sabor e Queijo parmesão e 1,42\% na demanda de Leite fermentado. Estes produtos não são de consumo em massa e, portanto, são incorporados na cesta de consumo em função de aumentos na renda familiar.

Para o Leite fluido e Queijo prato chama a atenção o fato de apresentarem elasticidades-renda superiores a unidade, sobretudo o primeiro. Como Leite fluido é um produto mais essencial, esperavam-se valores inferiores para esta elasticidade. Isso pode estar relacionado ao fato de a estimação não ter sido feita por classe de renda. Sabe-se que as classes de renda mais baixas possuem elasticidades-renda superiores para estes produtos, conforme analisado em Hoffmann (2000) e Oliveira e Carvalho (2006). Por outro lado, produtos lácteos como Creme de leite, Leite em pó, Queijo minas, Queijo mozarela, Iogurte e Manteiga, mostraram-se inelásticos em relação à renda.

No caso das elasticidades-preços, os produtos com demanda mais sensível ao aumento de preços foram Leite com sabor, Queijo parmesão e Leite fermentado, justamente os mesmo que registraram elevada elasticidade-renda. Por outro lado, Creme de leite, Leite fluido, Leite em pó e Queijo mozarela foram os produtos com menor resposta a preço, mostrando que incrementos em preço tendem a reduzir a demanda por esses produtos em menor magnitude.

Para as elasticidades preço-cruzadas, os resultados foram menos intuitivos em alguns produtos e devem ser interpretados com mais cuidado. Para outros, no entanto, os resultados fizeram sentido econômico, como esperado (Tabela 3). O Leite fluido, o principal produto consumido pelos brasileiros, mostrou-se como substituto do Leite em pó e Iogurte, apesar dos coeficientes serem muito próximos de zero. Esse resultado indica que um aumento no preço do Leite em pó causa incremento na demanda por Leite fluido. A mesma analogia serve para o Iogurte.

Os queijos, que também representam uma categoria de consumo mais elevado, também apresentaram algum grau de substituição entre si. O Queijo minas apresentou-se como substituto do Leite em pó, Mozarela, Parmesão, Requeijão e Manteiga. Vale destacar a elasticidade-cruzada relativamente mais elevada, mas ainda inelástica, do Queijo minas com o Queijo Mozarela, de 0,56, ou seja, um aumento de 1\% no preço do Queijo Mozarela provoca uma elevação de 0,56\% na demanda por Queijo minas, o que deve ser considerado pela cadeia produtiva em suas estratégias de precificação.

Outra associação com elasticidade-preço cruzada relativamente mais alta foi do Leite com sabor e Iogurte, de 0,92 . Portanto, um aumento de $1 \%$ no preço do Iogurte leva a um incremento de quase a unidade na demanda de Leite com sabor, pois são produtos com características similares em termos de paladar e forma de consumo. Finalmente, no caso do Iogurte, verificou resultados significativos para a substituição com Leite Fluido, Leite com sabor e Leite fermentado, o que intuitivamente faz sentido pela forma líquida de consumo.

Tabela 3 - Elasticidade-preço cruzadas para produtos lácteos, 2009

\begin{tabular}{|c|c|c|c|c|c|c|c|c|c|c|c|c|c|c|}
\hline & $\begin{array}{l}\text { Creme de } \\
\text { leite }\end{array}$ & $\begin{array}{l}\text { Leite } \\
\text { condensado }\end{array}$ & Leite fluido & Leite em pó & $\begin{array}{l}\text { Leite com } \\
\text { sabor }\end{array}$ & $\begin{array}{l}\text { Queijo } \\
\text { minas }\end{array}$ & $\begin{array}{c}\text { Queijo } \\
\text { mozarela }\end{array}$ & $\begin{array}{l}\text { Queijo } \\
\text { parmesäo }\end{array}$ & $\begin{array}{l}\text { Queijo } \\
\text { prato }\end{array}$ & Requeijäo & Iogurte & $\begin{array}{c}\text { Leite } \\
\text { fermentado }\end{array}$ & Manteiga & $\begin{array}{l}\text { Outros } \\
\text { lácteos }\end{array}$ \\
\hline Creme de leite & $-0,390^{* \#}$ & 0,135 & 0,236 & 0,107 & $0,144^{\# \#}$ & $-0,305^{* 1 *}$ & $-0,134$ & $-0,113^{* 11}$ & 0,025 & $0,159^{*}$ & $-0,008$ & $-0,003$ & $0,281^{*}$ & $-0,004$ \\
\hline Leite condensado & 0,082 & $-0,844$ & 0,099 & $-0,490^{\prime \prime \prime}$ & 0,349 & 0,11 & 0,194 & $-0,124$ & $-0,034$ & $0,158^{* *}$ & $-0,12$ & 0,042 & 0,106 & $-0,042^{* *}$ \\
\hline Leite fluído & 0,001 & 0,001 & $-0,052^{\# *}$ & $0,012^{* 1 *}$ & $-0,003^{\prime \prime \#}$ & $-0,001$ & 0 & 0 & $-0,002^{\# \#}$ & $-0,001$ & 0,019 & $-0,001$ & $-0,002$ & $0,002^{* 14}$ \\
\hline Leite em pó & 0,006 & $-0,045^{* 44}$ & 0,237 & $-0,132^{\ldots+1}$ & $0,026^{* 14}$ & 0,050 & $-0,068^{\prime \cdots}$ & $-0,021$ & 0,019 & 0,001 & $0,065^{\prime \#}$ & 0 & $0,018^{*}$ & 0 \\
\hline Leite com sabor & 0,494 & 1,926 & $-4,784$ & $1,278^{* 1 *}$ & $-2,602$ & 0,137 & $-0,730^{+14}$ & $0,542^{* 1 *}$ & $-0,17$ & $0,320 *$ & 0,916 \#\# & $0,452^{\text {\#\# }}$ & $-0,447$ & $0,115^{* *}$ \\
\hline Queijo minas & $-0,138^{\prime \prime}$ & 0,086 & 0,215 & 0,390 & 0,024 & $-0,899 \neq *$ & $0,558^{* 1 \neq}$ & 0,166 & 0 & 0,167 & $-0,411$ & $-0,015$ & 0,112 & $-0,071^{\prime \prime \prime}$ \\
\hline Queijo mozarela & $-0,028$ & $0,074^{*}$ & $0,552^{\ldots 14}$ & $-0,200$ & $-0,042^{* \ldots+}$ & 0,269 & $-0,469$ & $-0,009$ & $0,127^{* 1+4}$ & $-0,012$ & $0,335^{* 14}$ & $-0,01$ & $-0,049 *$ & 0,003 \\
\hline Queijo parmesão & $-0,918^{\prime \prime}$ & $-1,677^{* 4+14}$ & $-3,211^{* *}$ & $-3,168$ & 1,260 & $2,924^{* \ldots *}$ & $-0,363$ & $-2,784^{\prime \# \#}$ & $0,608^{* 1 * 1}$ & $-0,580^{\prime \prime \prime}$ & \begin{tabular}{|c|c|}
$-0,099$ \\
\end{tabular} & $0,625^{* 1+1}$ & $2,319+1$ & $0,510^{* 14}$ \\
\hline Queijo prato & 0,033 & $-0,083$ & $-1,376^{\# \#}$ & 0,339 & $-0,06$ & $-0,022$ & $0,758^{\prime+14}$ & 0,104 & $-0,575^{* 1 *}$ & $-0,057$ & $-0,22$ & $-0,028$ & $-0,219$ & 0,179 \\
\hline Requeijão & $0,324^{*}$ & $0,519^{* *}$ & $-0,897$ & $-0,02$ & $0,196 *$ & 0,741 & $-0,145$ & $-0,141 *$ & $-0,083$ & $-0,941$ & $0,501^{\#}$ & $0,129^{*}$ & 0,009 & $-0,068^{* *}$ \\
\hline Iogurte & $-0,001$ & $-0,017$ & 0,544 & 0,116 & 0,030 & $-0,091$ & $0,147^{\prime 14}$ & 0,001 & $-0,012$ & $0,026 *$ & $-0,622^{\# 11}$ & $0,045^{* 1 *}$ & $0,040^{\prime \prime 4}$ & $-0,012$ \\
\hline Leite fermentado & $-0,019$ & 0,284 & $-4,835^{\prime \prime \prime}$ & \begin{tabular}{|c|}
$-0,362$ \\
\end{tabular} & $0,644^{* 1+1}$ & $-0,237$ & $-0,345$ & $0,386^{* 1+1}$ & $-0,104$ & $0,290^{*}$ & 1,964 & $-2,241$ & $0,469 *$ & $0,205^{* *}$ \\
\hline Manteiga & 0,374 & 0,256 & 1,728 & 0,568 & $-0,160$ & 0,335 & $-0,309 *$ & $0,384 \ldots$ & $-0,198^{\prime \#}$ & 0,018 & 0,610 & 0,153 & $-1,148^{+14}$ & $-0,102^{\prime \prime 1}$ \\
\hline Outros lácteos & $-0,043$ & $-0,688^{* 1 *}$ & $5,893^{* 1 *}$ & 0,242 & $0,330^{* *}$ & $-1,598^{\prime \prime 4}$ & 0,288 & $0,646^{* * *}$ & $1,424^{* * * *}$ & $-0,346^{\# *}$ & $-1,139=$ & $0,443^{* 1 *}$ & $-0,729$ & $-0,550^{\# \#}$ \\
\hline
\end{tabular}

Nível de significância: * $10 \%,{ }^{* *} 5 \%,{ }^{* * *} 1 \%$. Erros padrão em parênteses.

Fonte: Resultados da pesquisa.

\section{CONCLUSÕES}

O setor lácteo é extremamente importante para agronegócio brasileiro, sendo responsável diretamente pelo rendimento de diversos produtores e atendendo a demanda de milhares de consumidores. 0 consumo de lácteos no Brasil vem se alterando nos últimos anos, principalmente por mudanças 
estruturais, tais como urbanização, mudanças nas características demográficas, elevação da demanda por praticidade, com a maior inserção da mulher no mercado de trabalho, aumento na qualidade dos produtos lácteos tornando-os menos perecíveis, queda nos preços dos produtos lácteos e aumento da renda real das famílias, principalmente daquelas consideradas de baixa renda. Portanto, devido à falta de estudos sobre a demanda desagregada por produtos lácteos no País, a principal contribuição deste artigo foi analisar as elasticidades-renda, preço próprias e preço cruzadas de 14 produtos lácteos com dados mais recentes da POF.

Os resultados encontrados confirmaram que a decisão de compra por produtos lácteos é afetada por características de localização domiciliar e composição familiar. Entretanto, a hipótese inicial de que haveria um aumento da propensão a consumir produtos lácteos mais processados quando a mulher fosse à pessoa de referência do domicílio, refletindo uma maior demanda por praticidade, não se confirmou neste estágio. Além disso, os resultados apresentados possibilitam uma melhor compreensão de como os domicílios demandam produtos lácteos no Brasil. 0 entendimento das elasticidades de demanda por produtos lácteos pode contribuir para o desenho de políticas públicas que visem, por exemplo, a adequação do consumo de lácteos às recomendações do Ministério da Saúde pela Pirâmide Alimentar adaptada para a população brasileira. Portanto, crescimento econômico e melhor distribuição de renda poderiam melhorar substancialmente o consumo de produtos lácteos e melhorar a nutrição das famílias mais carentes, dado que a maioria dos produtos lácteos se mostraram mais sensíveis a variações da renda. Além disso, pecuaristas e empresários, responsáveis pelo processamento, distribuição e varejo no mercado de lácteos, podem se beneficiar do padrão de substituição entre os produtos lácteos, como as fornecidas neste estudo.

Porém, devem-se levar em consideração algumas limitações. Muitas destas limitações são em função da estrutura dos dados utilizados e como eles foram coletados, como por exemplo, os efeitos da sazonalidade sobre a demanda, não considerados devido a não divulgação do período exato da coleta das informações. Além disso, uma análise da demanda por lácteos em estratos de renda poderia oferecer estimativas de elasticidades mais condizentes com a realidade brasileira, bem como uma análise do impacto de variáveis sociodemográficas sobre a demanda por produtos lácteos, dado as diferenças nacionais.

\section{REFERENCIAL}

[1] ABIA. Números do setor - faturamento. São Paulo. Associação Brasileira das Indústrias da Alimentação (ABIA). Disponível em: < http://www.abia.org.br/vsn/anexos/faturamento 2015.pdf>. Acesso em: 20 novembro 2016.

[2] ACHTERBERG, G.; McDONNELL, E.; BAGBY, R. How to put the food guide into pratice. Journal of American Dietetic Association, Chicago, v.94, n.9, p.1030-1035, 1994.

[3] BANKS, J., BLUNDELL, R., LEWBEL, A. Quadratic Engel curves and consumer demand. The Review of Economics and Statistics, Vol. LXXIX, n. 4, 527-539, November 1997.

[4] BLUNDELL, R.; ROBIN, J. M. Estimation in large and disaggregated demand systems: An estimator for conditionally linear systems. Journal of Applied Econometrics, 14, p.209-32, 1999.

[5] CARVALHO, G. R.; MAISASHVILI, A.; RICHARDSON, J. W.; CARVALHO, C. O. Demand analysis on food: effects of Bolsa Família on dairy consumption as a source of calcium. Revista de Planejamento e Políticas Públicas, n. 45, jul./dez. 2015.

[6] COELHO, A. B.; AGUIAR, D. R. D. de; EALES, J. S.. Food demand in Brazil: an application of Shonkwiler and Yen Two-Step estimation method. Estudos Econômicos. São Paulo: USP, v.40, n.1, p. 186-211, 2010.

[7] COX, T. L; WOHLGENANT, M. K. Prices and Quality Effects in Cross-Sectional Demand Analysis. Amer. J. Agr. Econ., 68, n.4, p. 908-19, 1986.

[8] DEATON, A.; MUELLBAUER, J. Economics and consumer behavior. New York: Cambridge, 1980a, 450p.

[9] _ _ An Almost Ideal Demand System. The American Economic Review, 70. p. 312-26, 1980b.

[10] DEATON, A. Quality, quantity and spatial variation of prices. The American Economic Review, v. 78, n. 3, p. 418-430, jun., 1988. (Baltimore: Johns Hopkins University Press), 1997.

[12] HOFFMANN, R. Elasticidades-renda das despesas e do consumo físico de alimentos no Brasil metropolitano em 1995-96. Agricultura em São Paulo. 2000;47(1):111-22. 
[13] HOFFMANN, R. Elasticidade-renda das despesas e do consumo de alimentos no Brasil em 2002-2003. In: SILVEIRA, F.G. et al. (Org.). Gasto e consumo das famílias brasileiras contemporâneas. Brasília: IPEA, 2007. v. 2, p. 463483.

[14] _. Estimativas das elasticidades-renda de várias categorias de despesa e de consumo, especialmente alimentos, no Brasil, com base na POF de 2008-2009. Revista de Economia Agrícola (Impresso), v. 57, p. 49-62, 2010.

[15] INSTITUTO BRASILEIRO DE GEOGRAFIA E ESTATíSTICA - IBGE. Pesquisa de Orçamentos Familiares: Aquisição domiciliar per capita. Rio de Janeiro: 2010a.

[16] _ Microdados da POF 2008-2009 (Pesquisa de Orçamentos Familiares). CD-Rom. Rio de Janeiro: 2010b.

[17] . Produção Agrícola Municipal. Disponível em:< https://sidra.ibge.gov.br/pesquisa/ppm/quadros/brasil/2015>. Acesso em: 10 mar. 2017.

[18] LAFRANCE, J. T. When is expenditure "exogenous" in separable demand models? Western Journal of Agricultural Economics, v. 16, n.1, p. 49-62, 1991.

[19] MINISTÉRIO DA SAÚDE (BR), SECRETARIA DE ATENÇÃO À SAÚDE, DEPARTAMENTO DE ATENÇÃO BÁSICA. Guia Alimentar para a População Brasileira. 2. ed. Brasília (DF): Ministério da Saúde (BR); 2014.

[20] MOSCHINI, G. Units of measurement and the Stone Index in demand system estimation. American Journal of Agricultural Economics, v. 77, p. 63-68, feb., 1995.

[21] MUNIZ, L. C.; MADRUGA, S. W.; ARAÚJO, C. L. Consumo de leite e derivados entre adultos e idosos no Sul do Brasil: um estudo de base populacional. Ciência \& Saúde Coletiva. 18(12): 3515-3522.

[22] OLIVEIRA, A. F.; CARVALHO, G. R. Evolução das elasticidades-renda dos dispêndios de leite e derivados no Brasil. In: CONGRESSO DA SOCIEDADE BRASILEIRA DE ECONOMIA E SOCIOLOGIA RURAL: Fortaleza - CE, 2006.

[23] PINTOS-PAYERAS, J. A. Estimação do sistema de demanda quase ideal para uma cesta ampliada de produtos empregando dados da POF de 2002-2003. Economia Aplicada, v. 13, n. 2, p. 231-255, 2009.

[24] POI, B. P. Demand-system estimation: Update. The Stata Journal, v. 8, n. 4, p. 554-556, 2008.

[25] SHONKWILER, J.; YEN, S. Two-step estimation of a censored system of equations. American Journal of Agricultural Economics, v. 81, n. 4, p. 972-982, Nov. 1999.

[26] TAFERE, K.; TAFFESSE, A. S.; TAMRU, S.; TEFERA, N.; P. Z. Food demand elasticities in Ethiopia: estimates using Household Income Consumption Expenditure (HICE) Survey Data. ESSP II, Addis Ababa: IFPRI/EDRI, 2010 (Working Paper n. 11).

[27] SOCIEDADE BRASILEIRA DE CARDIOLOGIA - SBC. VI Diretrizes Brasileiras de Hipertensão. Arquivos Brasileiros de Cardiologia, V. 95, 2010.

[28] YEN, S. T.; LIN, B.; SMALLWOOD, D. M. Quasi- and simulated-likelihood approaches to censored demand systems: food consumption by food stamp recipients in the United States, American Journal of Agricultural Economics, 85, pp. 458-478, 2003. 


\section{Capítulo 5}

Comportamento de preços do pescado comercializado na Região Metropolitana de Belém, estado do Pará

\section{Nathália Carvalho de Matos}

\section{Caio Cezar Ferreira de Souza}

Maria Lúcia Bahia Lopes

Marcos Antônio Souza dos Santos

Resumo: Nos últimos anos a população mundial vem aumentando, devido a isso, a demanda alimentícia se torna um problema que deve ser solucionado em escala global, por isso é importante que as cadeias produtivas sejam aprimoradas de modo a contribuir com a segurança alimentar e a cadeia produtiva do pescado brasileiro se destaca entre as atividades econômicas mais importantes para atender esta crescente demanda. Assim, propõe-se analisar o comportamento dos preços de pescado na Região Metropolitana de Belém (RMB) determinando a existência de sazonalidade. A pesquisa é de caráter quantitativo, sendo analisadas sete espécies de pescado a partir do modelo de séries temporais para um período temporal de seis anos (2010 a 2016). Os resultados mostraram que o preço médio do pescado oscilou bastante, nunca sendo menor que $\mathrm{R} \$ 13,85 / \mathrm{kg}$ ou maior que $\mathrm{R} \$ 17,32 / \mathrm{kg}$, neste período, variando de preço entre as espécies mais consumidas na cidade de Belém. As espécies que apresentaram maior variação foram o Filhote e a Dourada com amplitude de variação de $24,54 \%$ e $24,74 \%$, respectivamente.

Palavras-chave: Sazonalidade; Índice Estacional de Preço; Amazônia; Mercado Pesqueiro. 


\section{INTRODUÇÃO}

A atividade da pesca apresenta grande abrangência econômica, social e cultural na Amazônia, destacando os peixes como principal fonte de proteína na dieta da população. A região Norte do Brasil é uma das regiões com maior participação quanto no volume produzido, sua capacidade produtiva é influenciada principalmente por possuir um ecossistema bem característico quanto ao clima, que favorece a formação de cardumes e insere no processo produtivo ciclos sazonais, que tende a favorecer o fornecimento regular de pescado (ISAAC e BARTHEM, 1995).

Apesar das viabilidades advindas de condições ambientais e naturais, ainda é necessária a estruturação de programas e políticas de governo voltadas a promover o desenvolvimento do setor pesqueiro, não somente na região Norte, mas nas diversas regiões brasileiras. Promovendo assim, o avanço do setor, seja na incorporação de novas tecnologias, ou no fomento da atividade.

Segundo a FAO (2014) o consumo per capita mundial de pescado quase duplicou, pois em 1960, era de 10 $\mathrm{kg}$ e em 2012, aumentou para $19 \mathrm{~kg}$. Mostrando a importância do pescado destinada à alimentação humana e animal, pois $25 \%$ da produção mundial de pescado é destinada a formulação de farinha e óleo, e também à formulação de rações.

No Brasil, o consumo de pescados vem crescendo a cada ano. Aliado à crescente produção em cativeiro e ao aumento considerável na importação de pescados, a média nacional per capita confirma o aumento do consumo dessa proteína pelos brasileiros. De 1999 a 2011 o consumo per capita passou de 6,15 $\mathrm{kg} / \mathrm{hab} /$ ano para 11,17 kg/hab/ano, um aumento bastante significativo de 81\% (SEBRAE, 2015).

Ao analisar o aumento do consumo do pescado, é importante levar em consideração o que ocorreu para que houvesse este aumento. Em 1994 ocorreu a estabilização da economia que levou ao controle da inflação, o limite de crédito foi ampliado, ocorreu um aumento da renda dos brasileiros e também a expansão dos programas sociais de transferência de renda, foram fatores que criaram no Brasil um mercado consumidor mais atuante, complexo e maior (VENTURA, 2010), capaz de influenciar a maneira de se comportar dos consumidores de diferentes vertentes, inclusive os de pescado.

Porém, na região Norte a média alcança cerca de $30 \mathrm{~kg} / \mathrm{hab}$./ano, já em outros estados, como o Rio Grande do Sul, a média per capita encontra-se bem abaixo do valor nacional. Esse fato deve-se à disponibilidade regional, patamar de preços, tradição e cultura local (SEBRAE, 2015).

O estado do Pará, isoladamente, foi responsável por 63\% da produção da Região Norte e 15,5\% da produção nacional, em 2013, constituindo-se como maior produtor de pescado do país (SEBRAE, 2015). Apesar de todo o potencial produtivo e da grande gama de espécies que a região oferece, podendo ser capturadas pelos mais diversos métodos, existem algumas barreiras à compra de pescado pelos consumidores na RMB, pois de acordo com Rocha Neto (2010), 35\% dos consumidores escolhem o pescado pelo preço e $35 \%$ pela qualidade e $30 \%$ outros motivos.

Na RMB os preços do pescado chegam a ser proibitivos nas épocas de maior consumo, como por exemplo, a semana santa. Assim, com o intuito de promover maior entendimento das variações nos preços, realizado pelos comerciantes sobre o preço pago pelos consumidores, o estudo sobre o índice de preços pago pelos consumidores do pescado na RMB, torna-se um importante instrumento para analisar as variações dos preços e subsidiar políticas públicas que garantam a segurança alimentar dos consumidores de pescado.

Pelo exposto e em função da importância socioeconômica da atividade para a segurança alimentar da população nortista justifica-se o desenvolvimento de trabalhos que permitam a compreensão à cerca de seus aspectos socioeconômicos. Assim, o objetivo da pesquisa é determinar a existência de sazonalidade nos preços do pescado e verificar se houve mudança no padrão sazonal, com vistas a subsidiar políticas de preços que contribuam com a segurança alimentar dos consumidores da RMB.

\section{MATERIAL E MÉTODOS}

\subsection{FONTE DE DADOS}

A pesquisa foi realizada na região metropolitana de Belém (RMB), incluindo os municípios de Ananindeua, Belém, Benevides, Castanhal, Marituba, Santa Bárbara do Pará e Santa Isabel do Pará. Para análise da sazonalidade e de preços do pescado na RMB, os dados secundários foram obtidos a partir da Fundação Amazônia de Amparo a Estudos e Pesquisas do Governo do Pará (FAPESPA) que coleta as informações 
sistematicamente no município de Belém, com os dados do índice de preço ao consumidor na região metropolitana de Belém, com preços médios mensais de 2010 a 2016.

As espécies de pescado cujos preços médios foram avaliados (por serem as espécies mais consumidas na RMB) são: Tainha (Mugil sp.), Serra (Scomberomerus brasiliensis), Pescada Amarela (Cynoscion acoupa), Piramutaba (Brachyplatystoma vaillantii), Filhote (Brachyplatystoma filamentosum), Dourada (Brachyplatystoma flavicans) e Corvina (Micropogonias furnieri).

\subsection{ANÁLISE DE SAZONALIDADE}

Para fazer a análise da sazonalidade de preços do pescado comercializado por espécie, foi calculado o Índice Estacional de Preço (IEP) e o percentual do Coeficiente de Variação (CV) para cada uma das espécies estudadas.

Para observar a sazonalidade das séries utilizou-se o método da Média Móvel Centralizada (MMC) em 12 meses para os 6 anos pesquisados (2010-2016), como o que foi utilizado em trabalhos, como o de Mendes e Padilha Júnior (2007), Barroso Neto et al. (2015) e Sousa et al. (2016).

Em seguida estimou-se os Índices Sazonais (IS), que se trata do resultado percentual entre o preço médio de cada mês, para cada ano estudado, pela Média Móvel (MM). 0 Desvio Padrão e o Coeficiente de Variação (VC), também foram calculados.

O Índice Estacional de Preço (IEP), foi obtido para cada espécie de acordo com cada mês no período de 6 anos, e o Limite Superior de cada uma delas foi calculado através da soma entre o IEP e o Desvio Padrão. Já a Amplitude de Variação foi calculada com base no valor da subtração entre o valor máximo pelo valor mínimo do IEP.

Para análise dos dados e construção dos gráficos utilizou-se o Microsoft Excel@e, versão 2013.

\section{RESULTADOS E DISCUSSÃO}

As linhas de costa dos estados do Pará, Amapá e Maranhão estão incluídas no litoral amazônico e apresentam uma tendência natural para a exploração de recursos pesqueiros. Neste local, a matéria orgânica da decomposição das florestas de mangue e das planícies inundadas do Rio Amazonas e os sedimentos carregados pelos rios para a plataforma continental formam condições propícias de produtividade biológica (ISAAC, 2006).

A descarga do Rio Amazonas influencia bastante a dinâmica do estuário amazônico porque é variável ao longo do ano, nos meses de março a maio, a descarga é máxima e esse fenômeno coincide com o período de maior pluviosidade na região, já nos meses de setembro a novembro, a descarga é mínima e o período é de menor pluviosidade, e os demais meses (dezembro a fevereiro e junho a agosto), são os períodos de intermediários de transição climática (NITTROUER, 1995). De acordo com Barthem (1985), toda essa variação pluviométrica é um dos fatores que mais influenciam a diversidade de espécies do estuário amazônico, que, de maneira geral no período de descarga máxima predominam espécies de água doce e nos períodos de descarga mínima, predominam espécies de água salgada.

O litoral Norte é bastante diversificado na diversidade pesqueira, podendo ocorrer tanto nos estuários quanto na região costeira e também nos limites da plataforma continental, e a produção pesqueira desembarcada no estado do Pará é proveniente desta área (ALMEIDA et al., 2006).

Porém, o período chuvoso, de dezembro a maio, quando a forte descarga do Amazonas desloca a água salobra para leste do estado do Pará, é mais produtivo do que o período seco. Com barcos preferencialmente de madeira e operação manual das artes de pesca, fato que teoricamente causaria pouco impacto aos ecossistemas, a pesca do litoral norte é predominantemente de caráter artesanal, sendo poucas modalidades consideradas industriais (ISAAC, 2006).

Baseado em dados históricos de preço dos pescados, através da FAPESPA, criou-se os gráficos de evolução de preços no período de janeiro de 2010 a dezembro de 2016 (Figura 1). 
Figura 1. Variação do preço das espécies de pescado mais consumidas na RMB (2010-2016) em reais (R\$).

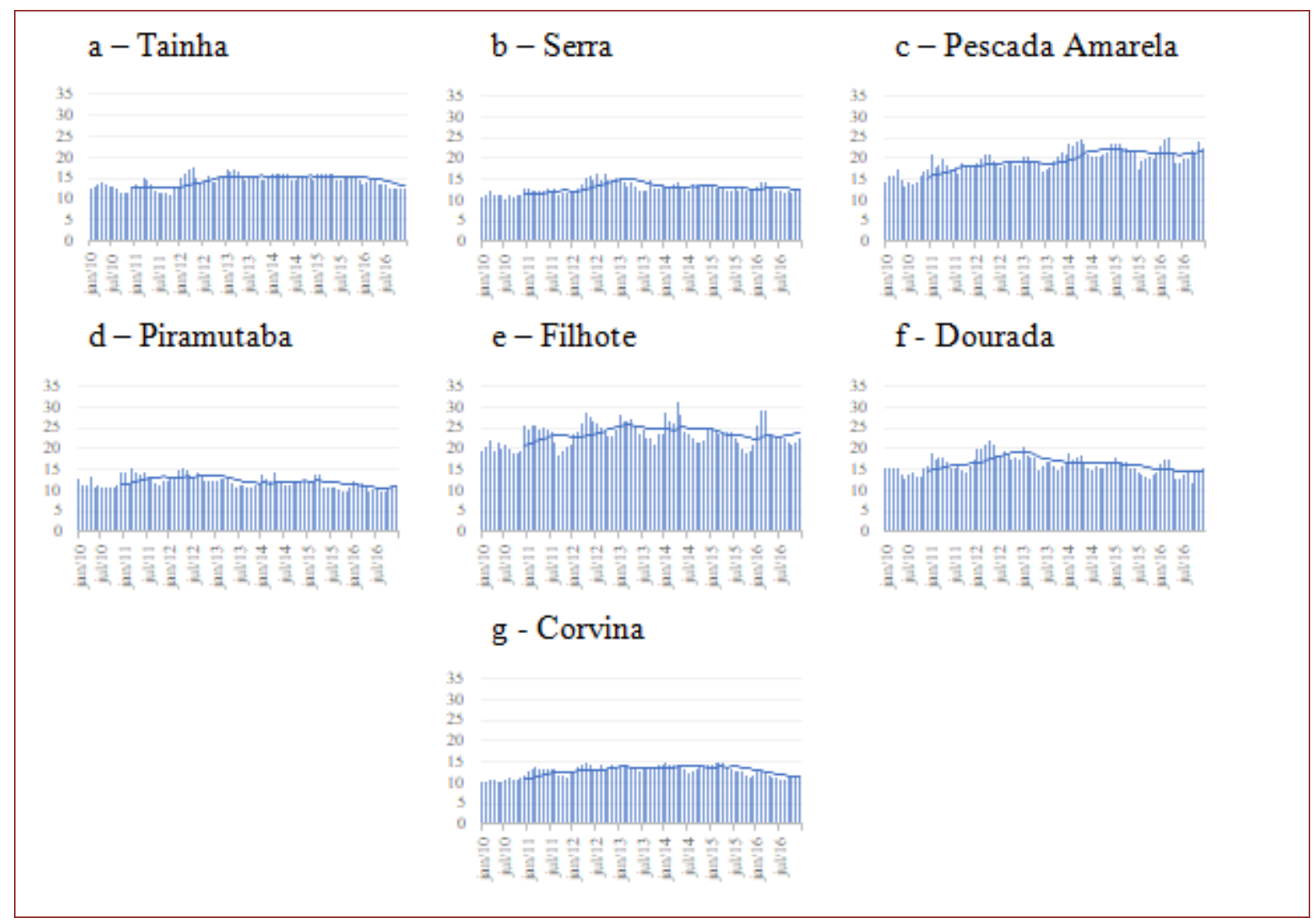

Para o consumidor da RMB, o quilo da Tainha foi vendido em média a $R \$ 14,43$ durante os anos de 2010 a 2016, com média de preço/kg menor nos meses de agosto, quando chegou a custar em média R $\$ 12,50$ e nunca em um valor maior que a média de $\mathrm{R} \$ 14,67$.

Dessa forma, analisando a evolução dos preços no período estudado, é possível notar, de acordo com a média móvel de razão 12, representada na Figura 1a, que no período de dezembro de 2010 até dezembro de 2011, os preços pouco variaram, fazendo com que a linha de tendência se mantivesse praticamente estável. Já, no período de janeiro de 2012 até janeiro de 2013, houve uma tendência de aumento de preço, passando de $\mathrm{R} \$ 15,28 / \mathrm{kg}$ para $\mathrm{R} \$ 17,02 / \mathrm{kg}$ e depois apresentando uma estabilização de fevereiro de 2013 a outubro de 2015, e novamente, apresentando uma tendência de diminuição de preço no final do período estudado (outubro de 2015 até dezembro de 2016).

O preço médio do quilo da Serra na Região Metropolitana de Belém foi de $\mathrm{R} \$ 12,98$ durante o período estudado (2010 a 2016), com destaque para o meses de agosto, onde quilo custava em média $\mathrm{R} \$ 11,16$, ou seja, o mais barato que a Serra custou e média de $\mathrm{R} \$ 13,24 / \mathrm{kg}$ no mês de junho, para o valor mais caro cobrado pelo quilo da Serra.

Dessa forma, analisando a evolução dos preços no período estudado, é possível notar, de acordo com a média móvel de razão 12, representada na Figura 1b, que no período de dezembro de 2010 até janeiro de 2013, os preços apresentaram tendência de crescimento constante, passando de $\mathrm{R} \$ 12,87 / \mathrm{kg}$ para $\mathrm{R} \$ 15,44$. Já, no período de fevereiro de 2013 até fevereiro de 2014, houve uma tendência de queda de preço, passando de $\mathrm{R} \$ 14,31 / \mathrm{kg}$ para $\mathrm{R} \$ 13,42 / \mathrm{kg}$ e depois apresentou uma estabilização de março de 2014 a dezembro de 2016.

0 preço médio do quilo da Pescada Amarela na Região Metropolitana de Belém foi de $\mathrm{R} \$ 19,62$ durante o período de 2010 ao ano de 2016, com destaque para o meses de agosto, onde quilo custava em média $\mathrm{R} \$ 16,65$, ou seja, o menor preço que a Pescada Amarela apresentou, e em média $\mathrm{R} \$ 20,30 / \mathrm{kg}$ no meses de junho, sendo este o valor mais caro cobrado pelo quilo da Pescada Amarela. 
Sendo assim, ao analisar a evolução dos preços no período estudado, é possível notar, de acordo com a média móvel de razão 12, representada na Figura 1c, que no período de dezembro de 2010 até fevereiro de 2013, os preços apresentaram tendência de crescimento, passando de $\mathrm{R} \$ 17,22 / \mathrm{kg}$ da Pescada Amarela para $\mathrm{R} \$ 20,32$. Percebe-se também, um pequeno período de estabilidade entre março e setembro de 2013. Porém, logo seguido de outro crescimento acentuado entre outubro de $2013(\mathrm{R} \$ 20,66 / \mathrm{kg})$ e janeiro de $2015(\mathrm{R} \$ 23,67)$, seguido de pouca variação de fevereiro de 2015 a dezembro de 2016.

0 preço médio do quilo da Piramutaba na Região Metropolitana de Belém, para o consumidor foi de $\mathrm{R} \$ 12,09$ durante o período de 2010 ao ano de 2016, porém nos meses de agosto, o quilo custou em média R \$ 10,53 ou seja, o menor preço apresentado pela espécie, e o maior preço ocorreu nos meses de outubro, que custou em média $\mathrm{R} \$ 12,31 / \mathrm{kg}$.

Contudo, ao analisar a evolução dos preços no período estudado, é possível notar, de acordo com a média móvel de razão 12, representada na Figura 1d, que no período de dezembro de 2010 até agosto de 2011, os preços apresentaram tendência de crescimento, seguido de um período de estabilidade que foi de janeiro a agosto de 2012. Porém, apresentou-se uma queda entre setembro de 2012 (R $\$ 13,66 / \mathrm{kg})$ e outubro de 2013 (R $\$ 10,71 / \mathrm{kg}$ ), seguida de outro período de estabilidade entre dezembro de 2013 e abril de 2015, e outra tendência de diminuição nos preços a partir de maio de 2015 até dezembro de 2016.

O preço médio do Filhote na RMB para o consumidor no período dos anos de 2010 - 2016 foi de $\mathrm{R} \$ 23,53 / \mathrm{kg}$, sendo que nos meses de agosto foi encontrado o seu menor preço médio ( $\mathrm{R} \$ 20,18 / \mathrm{kg}$ ), e nos meses de junho o seu maior preço $(\mathrm{R} \$ 24,02 / \mathrm{kg})$.

Dessa forma, ao analisar a evolução dos preços no período estudado, é possível notar, de acordo com a média móvel de razão 12, representada na Figura 1e, que no período de dezembro de 2010 até março de 2013 , os preços apresentaram tendência de crescimento, partindo de $R \$ 25,58 / \mathrm{kg}$ para $\mathrm{R} \$ 26,80$. O Filhote, mostrou uma oscilação de preço de forma constante de abril de 2013 até janeiro de 2015, seguida de uma leve queda de julho a dezembro de 2015, e seguiu estável até o final do período estudado (dezembro de 2016).

Para o consumidor da RMB, o preço médio do quilo da Dourada, no período analisado (2010 - 2016), foi de $\mathrm{R} \$ 16,32$, sendo o valor mais acessível de $\mathrm{R} \$ 14,15 / \mathrm{kg}$ nos meses de agosto e o valor médio do quilo mais caro, sendo vendido a $\mathrm{R} \$ 16,56$ nos meses de dezembro.

Sendo assim, ao analisar a evolução dos preços no período estudado, é possível notar, de acordo com a média móvel de razão 12, representada na Figura 1f, que de uma maneira geral, o preço dessa espécie, não apresentou uma oscilação muito grande, apenas uma leve tendência de crescimento entre dezembro de $2010(\mathrm{R} \$ 16,08 / \mathrm{kg})$ e janeiro de $2013(\mathrm{R} \$ 20,50 / \mathrm{kg})$, seguido por tendência de queda até o final do período estudado, chegando a dezembro de 2016 a custar $\mathrm{R} \$ 15,30 / \mathrm{kg}$.

0 preço médio da Corvina disponível na RMB no período estudado foi de $\mathrm{R} \$ 13,12$, e nos meses de agosto apresentou o menor preço ( $\mathrm{R} \$ 12,25)$, e o preço do quilo mais alto praticado foi de $\mathrm{R} \$ 13,90$ nos meses de julho.

Dessa forma, ao analisar a evolução dos preços no período estudado, é possível notar, de acordo com a média móvel de razão 12, representada na Figura 1g, que de uma maneira geral, o preço dessa espécie, não apresentou uma oscilação muito grande, mantendo sempre a mesma tendência estável, pois os preços não variam de forma drástica, no período estudado.

Compreender essas variações no preço das espécies de pescado mais consumidas na RMB é de fundamental importância, visto que, segundo a FAO e OPAS (2017), o preço dos alimentos é um dos principais agentes limitantes ao acesso à alimentação saudável pelas populações de renda inferior. Sendo assim, políticas publicas que garantam o abastecimento do pescado durante todo o ano sem grandes alterações em seu preço são essenciais para garantir a segurança alimentar dos paraenses.

Também baseado nos dados históricos de preço dos pescados, obtidos no sistema da FAPESPA, criou-se os gráficos do índice estacional de preço e desvio padrão no período de janeiro de 2010 a dezembro de 2016 (Figura 2). 
Figura 2. Índice estacional de preço e desvio padrão das espécies de pescado mais consumidas na RMB entre os anos de 2010 - 2016.

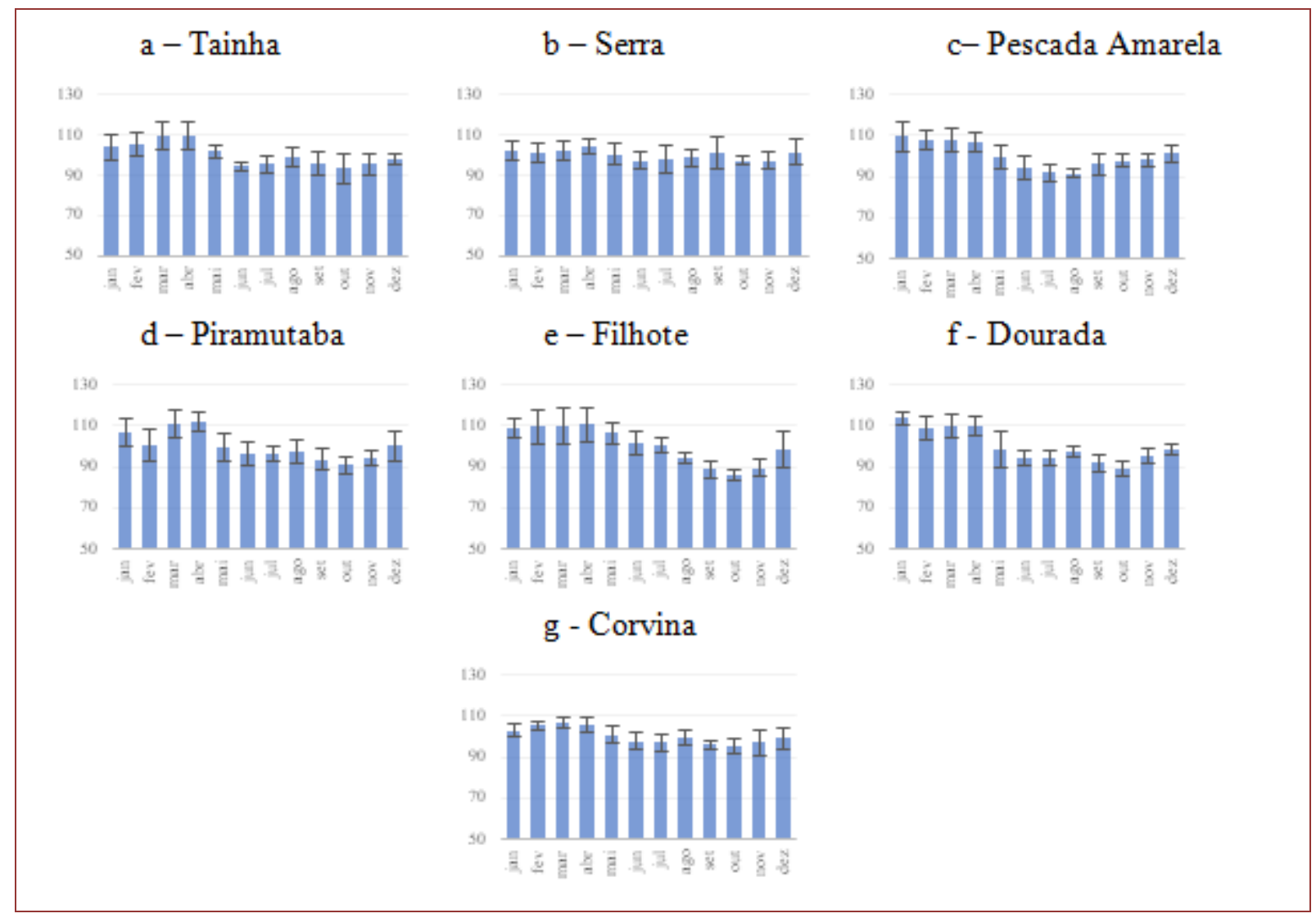

O índice estacional mínimo da Tainha é verificado no mês de outubro $(93,26)$ e o índice estacional máximo ocorre no mês de março $(109,49)$, o que determina uma amplitude entre o maior e o menor índice de 16,23\% (Figura 2a). A variação estacional dos preços em torno da média apresenta-se relativamente estável ao longo do ano, como se observa na Figura 2a. Embora tenha uma certa estabilidade, as maiores amplitudes de variação ocorrem nos meses de janeiro a maio, enquanto as menores variações se encontram nos meses de junho, julho e outubro.

Os meses que apresentaram maior desvio padrão, representado pela barra de erros, em ambas as direções, na Figura 2a, foram os meses de janeiro, fevereiro, março, abril e outubro, apresentando assim, uma maior variação nos preços da Tainha, e os meses que apresentaram menor desvio padrão foram maio, junho e dezembro, portanto, com menor variação nos preços durante os anos de 2010 a 2016.

A média de preço não varia muito pelo fato da Tainha ser uma espécie pescada ao longo do ano todo, já que é possível verificar indivíduos maduros da espécie em todos os meses do ano (ARAÚJO \& SILVA, 2013). A espécie também não possui período de defeso na região norte, podendo, portanto, ser explorada durante o ano inteiro, garantindo assim o abastecimento para a população.

O índice estacional mínimo da Serra é verificado no mês de novembro $(96,91)$ e o índice estacional máximo ocorre no mês de abril $(104,50)$, o que determina uma amplitude entre o maior e o menor índice de 7,59\% (Figura 2b). A variação estacional dos preços em torno da média apresenta-se relativamente estável ao longo do ano, como se observa na Figura 2b. Porém, apesar de ser estável, as maiores amplitudes de variação ocorrem nos meses de março e abril, enquanto as menores variações se encontram nos meses de outubro e novembro.

Os meses que apresentaram maior desvio padrão, representado pela barra de erros, em ambas as direções na Figura 2b, foram os meses de setembro e dezembro, apresentando assim, uma maior variação nos preços do quilo da Serra, e os meses de outubro apresentaram menor desvio padrão, ou seja, menor variação nos preços durante os anos de 2010 a 2016.

Nos meses de janeiro a março a Serra tende a migrar para o hemisfério sul, apresentando IEP acima da média 100 (Figura 2b), devido ao aumento dos estoques de Serra na costa norte do Brasil. Os IEPs nos 
meses de junho e julho, outubro e novembro são menores e podem ser explicadas pelo fato de que nestes meses os estoques da espécie migram de volta ao hemisfério norte, o que acaba diminuindo a disponibilidade da mesma na região da costa norte brasileira. (BENTES et al., 2012).

O índice estacional mínimo da Pescada Amarela é verificado no mês de agosto $(91,56)$ e o índice estacional máximo ocorre no mês de janeiro $(109,61)$, o que determina uma amplitude entre o maior e o menor índice de 18,05\% (Figura 2c). A variação estacional dos preços em torno da média apresenta-se relativamente estável ao longo do ano, como se observa na Figura 2c. Porém, apesar de apresentar certa estabilidade, as maiores amplitudes de variação ocorrem nos meses de janeiro a abril, enquanto as menores variações se encontram nos meses de junho a agosto.

Os meses que apresentaram maior desvio padrão, representado pela barra de erros, em ambas as direções na Figura 2c, foram os meses de janeiro e maio, apresentando assim, uma maior variação nos preços do quilo da Pescada Amarela, e os meses de agosto apresentaram menor desvio padrão, ou seja, menor variação nos preços durante os anos de 2010 a 2016.

De acordo com Mourão (2007), no ponto ecológico, a pescada amarela pode ser capturada durante o ano inteiro, porém nos meses de maio a dezembro podem ser mais intensas, que coincide com o período de transição chuvoso-seco (maio a junho) e seco (julho a dezembro). De acordo com o Figura 2c os meses com maior IEP, são os meses de janeiro, onde a pesca da c. acoupa, não ocorre de forma intensa, porém, nos meses de junho a agosto, apresentam menor oscilação, ou seja, no meio do período considerado seco, onde há captura intensa da espécie.

O índice estacional mínimo da Piramutaba é verificado no mês de outubro $(90,64)$ e o índice estacional máximo ocorre no mês de abril $(112,11)$, o que determina uma amplitude entre o maior e o menor índice de 21,47\% (Figura 2d). A variação estacional dos preços em torno da média apresenta-se relativamente estável ao longo do ano, como se observa na Figura 2d. Porém, as maiores amplitudes de variação ocorrem nos meses de março e abril, enquanto as menores variações se encontram nos meses de setembro e outubro.

Os meses que apresentaram maior desvio padrão, representado pela barra de erros, em ambas as direções na Figura 2d, foram os meses de dezembro, janeiro e fevereiro, apresentando assim, uma maior variação nos preços do quilo da Piramutaba, e os meses de julho, outubro e novembro, apresentaram menor desvio padrão, ou seja, menor variação nos preços durante os anos de 2010 a 2016.

Segundo Sanyo Tecno Marine (1998), a Piramutaba é um peixe de água doce, que ocorre apenas em rios e estuários e é mais abundante durante o período chuvoso, e de acordo com a Figura $2 \mathrm{~d}$, os meses de dezembro, janeiro e fevereiro foram os que demonstraram maior desvio padrão de forma contínua, ou seja, a oscilação dos preços médios foi grande nessa época, onde a piramutaba é mais abundante por serem os meses com maior volume de chuva na região em que é capturada. É possível perceber também, que no período de defeso que vai do dia 15 de setembro até 30 de novembro, as oscilações de IEP são menores, pois não há grande abundância da espécie para ser comercializada.

O índice estacional mínimo do Filhote é verificado no mês de outubro $(85,82)$ e o índice estacional máximo ocorre no mês de abril $(110,36)$, o que determina uma amplitude entre o maior e o menor índice de $24,54 \%$ (Figura 2e). A variação estacional dos preços em torno da média apresenta-se relativamente estável ao longo do ano, como se observa na Figura 2e. Porém, as maiores amplitudes de variação ocorrem nos meses de março e abril, enquanto as menores variações se encontram nos meses de janeiro a abril.

Os meses que apresentaram maior desvio padrão, representado pela barra de erros, em ambas as direções na Figura 2e, foram os meses de fevereiro a abril, apresentando assim, uma maior variação nos preços do quilo do Filhote, e os meses de agosto, apresentaram menor desvio padrão, ou seja, menor variação nos preços durante os anos de 2010 a 2016.

O Filhote capturado na pesca artesanal é caracterizado pela sazonalidade. É uma espécie de água doce e é capturado no primeiro semestre do ano, nos meses de janeiro a junho (período chuvoso). Dessa forma, explica-se o porquê de nesses meses, os IEP estarem acima da média (100), como demonstrado na Figura 2e, já que há uma maior quantidade da espécie para comercialização, e nos meses de agosto a novembro, as oscilações de IEP do quilo do filhote serem menores, pois trata-se do período "seco", com menor incidência de chuvas e menor captura da espécie.

0 índice estacional mínimo da Dourada é verificado no mês de outubro $(88,79)$ e o índice estacional máximo ocorre no mês de janeiro $(113,53)$, o que determina uma amplitude entre o maior e o menor índice de 24,74\% (Figura 2f). A variação estacional dos preços em torno da média apresenta-se 
relativamente estável ao longo do ano, como se observa na Figura 2f. Porém, as maiores amplitudes de variação ocorrem nos meses de janeiro a maio, enquanto as menores variações se encontram nos meses de setembro e outubro.

Os meses que apresentaram maior desvio padrão, representado pela barra de erros, em ambas as direções na Figura 2f, foram os meses de maio, apresentando assim, uma maior variação nos preços do quilo da Dourada, e os meses de agosto, apresentaram menor desvio padrão, ou seja, menor variação nos preços durante os anos de 2010 a 2016.

Nos meses de janeiro a abril, grandes oscilações nos IEPs da Dourada são perceptíveis, o que pode ser explicado pelo fato de que nos meses mais chuvosos há uma abundância na captura da espécie devido a seu ciclo reprodutivo, fazendo com que a maior quantidade disponível de Dourada, cause uma maior variedade no preço. Já nos meses mais "secos" como outubro, as oscilações de IEP são as menores, devido a diminuição das capturas durante a pesca da espécie.

O índice estacional mínimo da Corvina é verificado no mês de outubro $(94,97)$ e o índice estacional máximo ocorre no mês de março $(106,65)$, o que determina uma amplitude entre o maior e o menor índice de 11,68\% (Figura 2g). A variação estacional dos preços em torno da média apresenta-se relativamente estável ao longo do ano, como se observa na Figura $2 \mathrm{~g}$. Porém, as maiores amplitudes de variação ocorrem nos meses de janeiro a maio, enquanto as menores variações se encontram nos meses de setembro e outubro.

Os meses que apresentaram maior desvio padrão, representado pela barra de erros, em ambas as direções na Figura $2 \mathrm{~g}$, foram os meses de novembro e dezembro, apresentando assim, uma maior variação nos preços do quilo da Corvina, e os meses de setembro, apresentaram menor desvio padrão, ou seja, menor variação nos preços durante os anos de 2010 a 2016.

Com o intuito de sintetizar o comportamento dos preços médios do quilo de cada espécie pesquisada foi calculada a amplitude de variação dos preços (Figura 3).

Figura 3. Amplitude de variação com base no índice estacional de preço para espécies de pescado entre os anos de 2010 a 2016 em reais $(\mathrm{R} \$)$.

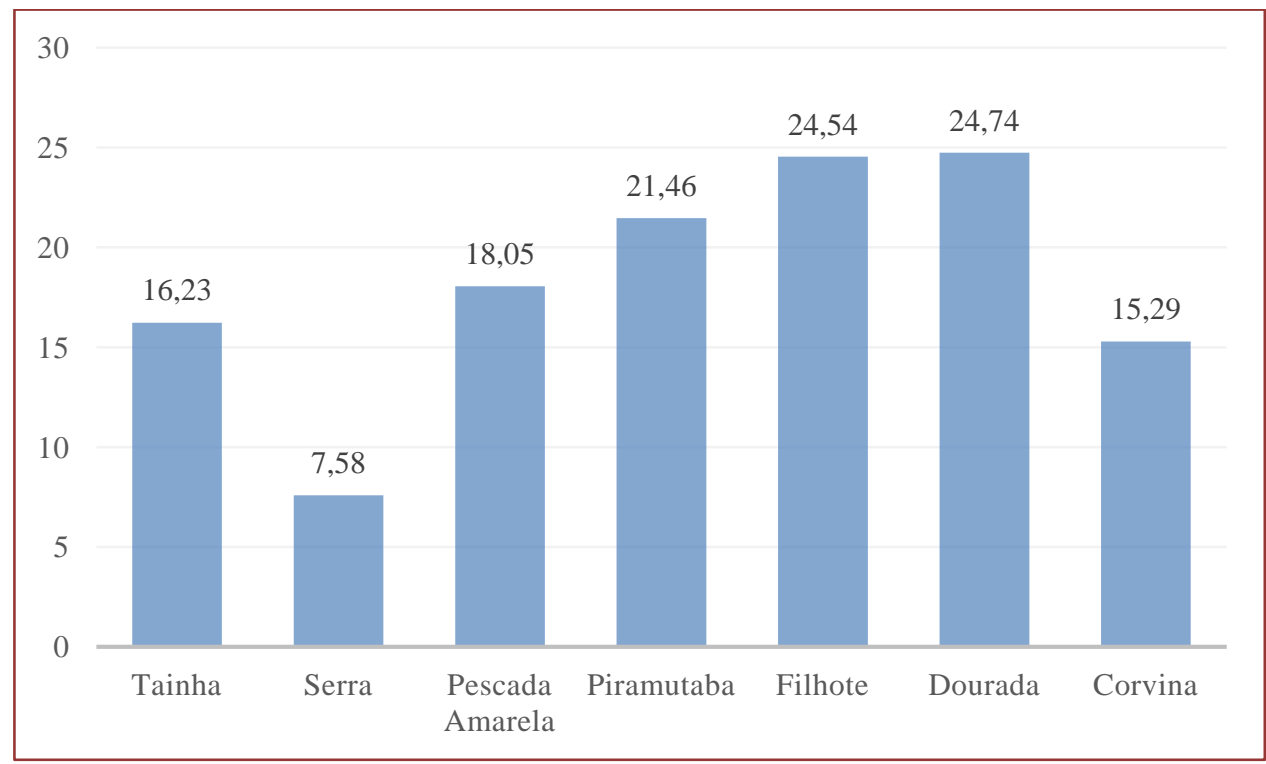

Foi possível observar que as espécies que apresentaram maior variação foram o Filhote e a Dourada com IEP de 24,54\% e 24,74\%, respectivamente, ou seja, os preços dessas espécies foram os que mais variaram nos anos de 2010 a 2016 para o consumidor da RMB, o que pode ser explicado pelo fato de serem espécies de grande procura e preferência de mercado.

Já, a espécie que apresentou menor variação de amplitude foi a Serra, com IEP de 7,58\%, pelo fato de ser uma espécie que apresentou preços bastante uniformes e com baixa variação durante todo período estudado. 


\section{CONCLUSÃO}

Em uma série temporal de seis anos, o preço médio do pescado oscilou bastante nunca sendo menor que $\mathrm{R} \$ 13,85 / \mathrm{kg}$ ou maior que $\mathrm{R} \$ 17,32 / \mathrm{kg}$, neste período, variando de preço entre as espécies mais consumidas na cidade de Belém (Tainha, Serra, Pescada Amarela, Piramutaba, Filhote, Dourada e Corvina).

Com relação a sazonalidade dos preços de pescado na RMB, com a metodologia adotada foi possível determinar a existência de sazonalidade nos preços do pescado na RMB no período do ano de 2000 a 2016, e verificar se houve mudança no padrão sazonal.

Foi possível perceber um padrão sazonal de preços do pescado, onde fica mais alto no mês de janeiro e abril, tanto pelo aumento das chuvas, quanto pelo feriado da Semana Santa. E a diminuição do preço médio do pescado nos meses entre junho a novembro, especialmente em outubro por conta da diminuição da incidência de chuvas na região.

Portanto, apesar de a prática da pesca ocorrer ao longo do ano todo, em decorrência do caráter sazonal de disponibilidade das espécies capturadas que foram usadas nesta pesquisa dependendo do mês do ano, algumas espécies estarão mais caras ou com preços mais acessíveis. Dessa forma, políticas públicas que garantam um maior equilíbrio no preço do pescado durante o ano todo são importantes para garantir o acesso à alimentação saudável a todas as camadas da população.

Com o intuito de sintetizar o comportamento dos preços médios do quilo de cada espécie pesquisada foi calculada a amplitude de variação dos preços. Desse modo, foi possível observar que as espécies que apresentaram variação foram o Filhote e a Dourada com índice estacional de preço (IEP) de $24,54 \%$ e $24,74 \%$, respectivamente, ou seja, os preços dessas espécies foram os que mais variaram nos anos de 2010 a 2016 para o consumidor da RMB, o que pode ser explicado pelo fato de serem espécies de grande procura e preferência de mercado.

Já, a espécie que apresentou menor variação de amplitude foi a Serra, com IEP de 7,58\%, pelo fato de ser uma espécie que apresentou preços bastante uniformes e com baixa variação durante todo período estudado.

\section{REFERÊNCIAS}

[1] ALMEIDA, Z. S., CASTRO, A. C. L., PAZ, A. C., RIBEIRO, D., BARBOSA, N. \& RAMOS, T. Diagnóstico da pesca artesanal no litoral do estado do Maranhão. In: ISAAC, V. J., MARTINS, A. S., HAIMOVICI, M. \& ANDRIGUETTO FILHO, J. M. (Orgs.). 2006. A pesca marinha e estuarina do Brasil no início do século XXI: recursos, tecnologias, aspectos socioeconômicos e institucionais. Belém: UFPA, p. 41 - 65.

[2] ARAÚJO, A. R.; SILVA, F. D. Aspectos da pesca e biologia da tainha, Mugil curema (osteichthyes: mugilidae), no estuário do rio Vaza Barris, Sergipe, Brasil. Arquivos de Ciências do Mar, v. 46, n. 1, 2013.

[3] BARRoso NETO, A. M. ARAÚJO, L. B. R. SOUSA, A. M. VASCONCELOS, M. R. A. BLEICHER, E. Fenologia de produção e comportamento de preços da Berinjela no estado do Ceará. Enciclopédia Biosfera, v. 11 n. 22, 2015.

[4] BARTHEM, R. B. Ocorrência, distribuição e biologia dos peixes da Baía do Marajó, Estuário Amazônico. Boletim do Museu Paraense Emílio Goeldi, v. 6, n. 1, p. 15-28, 1985.

[5] BENTES, B., ISAAC, V. J., ESPÍRITO-SANTO, R. V. D., FRÉDOU, T., ALMEIDA, M. C. D., MOURÃO, K. R. M., FRÉDOU, F. L. Multidisciplinary approach to identification of fishery production systems on the northern coast of Brazil. Biota Neotropica, v. 12, n. 1, p. 81-92, 2012.

[6] COSTA, T. V.; SILVA, R. R. S.; SOUZA, J. L.; BATALHA, O. S.; HOSHIBA, M. A. Aspectos do consumo e comércio de pescado Parintins. Boletim do Instituto de Pesca, v. 39, n. 1, p. 63-75, 2013.

[7] FAO - Organização das Nações Unidas para a Alimentação e a Agricultura. The State of World Fisheries and Aquaculture. Roma: FAO, 2014.

[8] FAO - Organização das Nações Unidas para a Alimentação e a Agricultura; OPAS - Organização Pan-Americana da Saúde. América Latina e o Caribe: panorama da segurança alimentar e nutricional. Santiago: FAO; OPAS, 2017.

[9] FREIRE, J.; OLIVEIRA, A.; AZEVEDO, M.; SOUZA, I.; PINHEIRO, M.; MATANGRANO, R.; NASCIMENTO, D.; CASTRO, M.; CUNHA, M.; MARÇAL, L.; SOUZA, A.; PEREIRA, M. Perfil socioeconômico do consumidor de pescado no município de Belém - PA. In: 19² Encontro Nacional de Grupos PET, 19. Anais. Santa Maria: UFSM, 2014.

[10] ISAAC-NAHUM, V. J.; RUFFINO, M. L. A estatística pesqueira no Baixo Amazonas: Experiência do Projeto IARA. IBAMA, Coleção Meio Ambiente Série Estudos de Pesca, v. 22, p. 201-224, 2000. 
[11] ISAAC, V. J.; BARTHEM, R. B. Os recursos pesqueiros da Amazônia brasileira. Bol. Mus. Par. Emílio Goeldi, série antropologia. 11(2): 295-339. 1995.

[12] ISAAC-NAHUM, V. J. Explotação e manejo dos recursos pesqueiros no litoral amazônico: um desafio para o futuro. Ciência e Cultura, v. 58, n. 3, p. 33-36, 2006.

[13] MENDES, J. T. G; PADILHA JR, J. B. Agronegócio: uma abordagem econômica. São Paulo: Pearson Prentice Hall, 2007.

[14] MOURÃO, K. R. M. Descrição das pescarias de serra e pescada amarela da costa do Pará: uma contribuição à elaboração de manejo. Dissertação (Mestrado em Ciência Animal) - Universidade Federal do Pará, Belém, 2007.

[15] NITTROUER, C. A. An introdution to the geological significance of the sediment transport and accumulation on the Amazon continental shelf. Marine Geology, v. 125, p. 177-92, 1995.

[16] SANYO TECNO MARINE. Draft Final Report for the Fishery Resources study of the Amazon and Tocantins Rivers Mouth Áreas in the Federative Republic of Brazil. Tokyo: JICA,1998.

[17] SEBRAE. 1 Anuário Brasileiro de Pesca e Aquicultura. Brasil: SEBRAE, 2015.

[18] SOUSA, A. M. TABOSA, F. J. S. NETO, A. M. B. FILHO, F. C. REIS, J. N. P. Análise do comportamento dos preços das principais frutas e hortaliças-fruto comercializados na Ceasa-Ce. Enciclopédia Biosfera, v.13, n.23, 2016.

[19] VENTURA, R. Mudanças no perfil do consumo no Brasil: principais tendências nos próximos 20 Anos. Rio de Janeiro: Macroplan - Prospectiva, Estratégia \& Gestão, 2010. 


\section{Capítulo 6}

\section{A cadeia produtiva da alface (Lactuca sativa) no Sudoeste do Paraná}

\section{Cristina Venâncio Pereira \\ Sidemar Presotto Nunes \\ Celso Eduardo Pereira Ramos}

Resumo: A alface é uma hortaliça folhosa da família das asteraceas, originária do leste do Mediterrâneo e trazida ao Brasil pelos portugueses, com grande aceitação de mercado no mundo todo. Este trabalho teve como objetivo principal conhecer a estrutura da cadeia produtiva da alface na região Sudoeste do Paraná. 0 estudo foi desenvolvido através do levantamento de dados secundários constantes nos sites do IBGE, FAO e Comexstat, e de dados primários, obtidos à campo, por meio de entrevistas. Segundo a FAO, a China é a maior produtora, a Espanha é a maior exportadora e o Canadá é o maior importador de alface do mundo. De acordo com o Censo Agropecuário do IBGE, a alface é a segunda hortaliça mais produzida no Brasil e a primeira hortaliça mais produzida na região Sul, no estado do Paraná e na região sudoeste do Paraná. Por ser um produto perecível ao transporte, os municípios com maior produção no Brasil estão localizados próximo das grandes cidades, como Teresópolis (RJ) e Ibiúna (SP). Na região sudoeste do Paraná, Francisco Beltrão é o município que se destaca, assim como em outras hortaliças. Para a obtenção dos dados secundários foram entrevistados olericultores, feirantes, estabelecimentos comerciais e secretaria de agricultura de Dois vizinhos, a partir do que se verificou que a produção de alface e outras hortaliças são produzidas por pequenos produtores, que utilizam principalmente a força de trabalho familiar, comercializam em redes de supermercados regionais, feiras de agricultores e para mercados institucionais, sobretudo ao PNAE.

Palavras-chave: Hortaliças folhosas, Comercialização, Brasil, Produção 


\section{INTRODUÇÃO}

Originária do leste do Mediterrâneo, a alface (Lactuca sativa L.) é uma planta anual, originária de clima temperado, uma das hortaliças mais consumidas no Brasil e no mundo (HENZ; SUINAGA, 2009). Pertence à família Asteraceae, a mesma da alcachofra, almeirão, chicória e escarola. Para Henz e Suinaga (2009), a alface se desenvolve melhor em climas amenos, principalmente no período de crescimento vegetativo. Afirma também que em temperaturas mais elevadas as plantas o ciclo da cultura é acelerado e pode resultar em plantas menores e pendoamento precoce.

A área cultivada com alface e chicória no mundo, segundo a FAO (2020), foi de 1,27 milhões de hectares em 2018, onde foram produzidas 27,2 milhões e toneladas, uma produtividade média de 21,4 toneladas por hectare cultivado. Tanto a produção quanto a área cultivada estão constantemente sendo ampliadas. Entre 1994 e 2018 a área cultivada e a produção cresceram aproximadamente $80 \%$.

Por se tratar de um produto perecível, consumido in natura, os circuitos de comercialização tendem a ser curtos, o que limita o comércio exterior de alface e chicória, mesmo assim as quantidades exportadas são significativas. A Espanha é, segundo a FAO (2020) a maior exportadora de alface, com 828 mil toneladas exportadas em 2017 (exporta a quase totalidade do que produz), seguida pelos Estados Unidos (335 mil ton.), México (218 mil ton.), Holanda (135 mil ton.) e Itália (127 mil ton.). Já no que se refere aos maiores importadores, destaca-se o Canadá (282 mil ton.), Estados Unidos (276 mil ton.), Alemanha (269 mil ton.), Reino Unido (183 mil ton.) e a França (126 mil ton.).

Embora haja comércio exterior, no Brasil a alface é basicamente um produto de mercado interno. As exportações de alface e chicórias, frescas ou refrigeradas, que em 2019 foram de pouco mais de US\$ 400 mil, foram destinadas principalmente à Argentina, mas também houve exportação para outros países (COMEXSTAT, 2020). A importação também é realizada, mas em pequenos valores.

A alface é a segunda hortaliça mais produzida no Brasil, logo após o tomate, segundo o Censo Agropecuário (2017), do IBGE. A cultura da alface se destaca na produção de hortaliças, 908 mil toneladas ano, ficando atrás apenas da produção de tomate, que em 2017 foi de 1.974 .000 toneladas. A cenoura está na terceira posição, com 715 mil toneladas. A batata doce está na quarta posição, com 352 mil toneladas.

Quanto ao número de produtores de cada tipo de hortaliça, observamos que a alface é a que possui o maior número em relação a todas as outras hortaliças: 109 mil. Em seguida vem a cebolinha com 87 mil produtores, seguido de batata doce, berinjela e couve, todas com 67 mil produtores.

Dentre as folhosas, a alface é mais cultivada no Brasil. 0 mesmo ocorre na região Sul, Paraná e nos municípios pesquisados. 0 número de produtores de alface é de 25 em Dois Vizinhos, 74 em Francisco Beltrão e 84 em Pato Branco. Considerando as quatro folhosas juntas, Dois Vizinhos possui 35 produtores; Francisco Beltrão, 169 e Pato Branco, 109 (obviamente, uma parte dos produtores pode produzir mais do que uma destas folhosas, de forma que aparecem duplicados).

O objetivo do trabalho foi conhecer a cadeia produtiva da alface no sudoeste do Paraná. Os objetivos específicos foram: identificar a estrutura de produção, comercialização e industrialização; conhecer a evolução da produção e do consumo brasileiro, mundial, no Paraná e no sudoeste do Paraná de alface e identificar as políticas de apoio à produção e ao consumo.

Foi desenvolvido com base na metodologia definida no Acordo de cooperação técnica 06/2019 DEPET DV, firmado entre a UTFPR e SEAB-PR/ DERAL, e se baseou no estudo de Nunes e Heindrickson (2019). Para tanto, parte de: a) dados secundários: Pesquisa Agrícola Municipal (PAM) e Censo Agropecuário, do Instituto Brasileiro de Geografia Estatística (IBGE); Comércio Exterior Brasileiro (COMEX); Organização das nações Unidas para Alimentação e Agricultura (FAO); b) Pesquisa de campo: realizada em três municípios da região Sudoeste do Paraná, que também apresentam as maiores produções e mercados consumidores (Francisco Beltrão, Pato Branco e Dois Vizinhos - esta etapa foi concluída apenas no último município).

Para a realização da pesquisa de campo foram desenvolvidos roteiros de entrevistas para os seguintes tipos de entrevistados: a) informantes-chave e formuladores de políticas para o setor (Secretarias de Agricultura e Emater); b) Organizações de agricultores (associações e cooperativas); c) comerciantes (atacado e varejo, existentes nos referidos municípios ou fora deles quando se avaliar a necessidade); d) Pequenas indústrias; e) Produtores de alface, escolhidos segundo as características do grupo que representam, conforme a escala de produção e o grau de especialização na atividade.

Dos municípios pesquisados no sudoeste do Paraná, segundo o Censo Agropecuário 2017, do IBGE (Instituto Brasileiro de Geografia e Estatística), o município de Francisco Beltrão é o maior produtor de 
hortaliças no geral (alface, almeirão, chicória e couve folha) e também de alface. Na região também coincide a localização da produção com o consumo, ou seja, as cidades com maior produção também possuem potencialmente os maiores mercados consumidores.

No município de Dois Vizinhos, onde a primeira parte do levantamento de campo foi realizada, a atividade é desenvolvida por pequenos produtores, que possuem pequena área de cultivo, entre 0,6 e 1,2 hectares, desenvolvem a atividade com força de trabalho familiar, o cultivo predominante é o convencional, embora a produção no sistema hidropônico venha crescendo muito. Os principais canais de comercialização deste produto são a feira do produtor eo mercado institucional, como o PNAE (programa nacional de alimentação escolar) e, em menor escala, a comercialização direta ao consumidor.

\section{PRODUÇÃO E COMÉRCIO MUNDIAL}

\subsection{PRODUÇÃO MUNDIAL}

A área cultivada com alface e chicória no mundo, segundo a FAO, foi de 1,27 milhões de hectares em 2018, onde foram produzidas 27,2 milhões e toneladas, uma produtividade média de 21,4 toneladas por hectare cultivado. Tanto a produção quanto a área cultivada estão constantemente sendo ampliadas. Entre 1994 e 2018 a área cultivada e a produção cresceram aproximadamente $80 \%$.

Figura 1 - Produção e área cultivada com alface e chicória entre 1994 e 2018

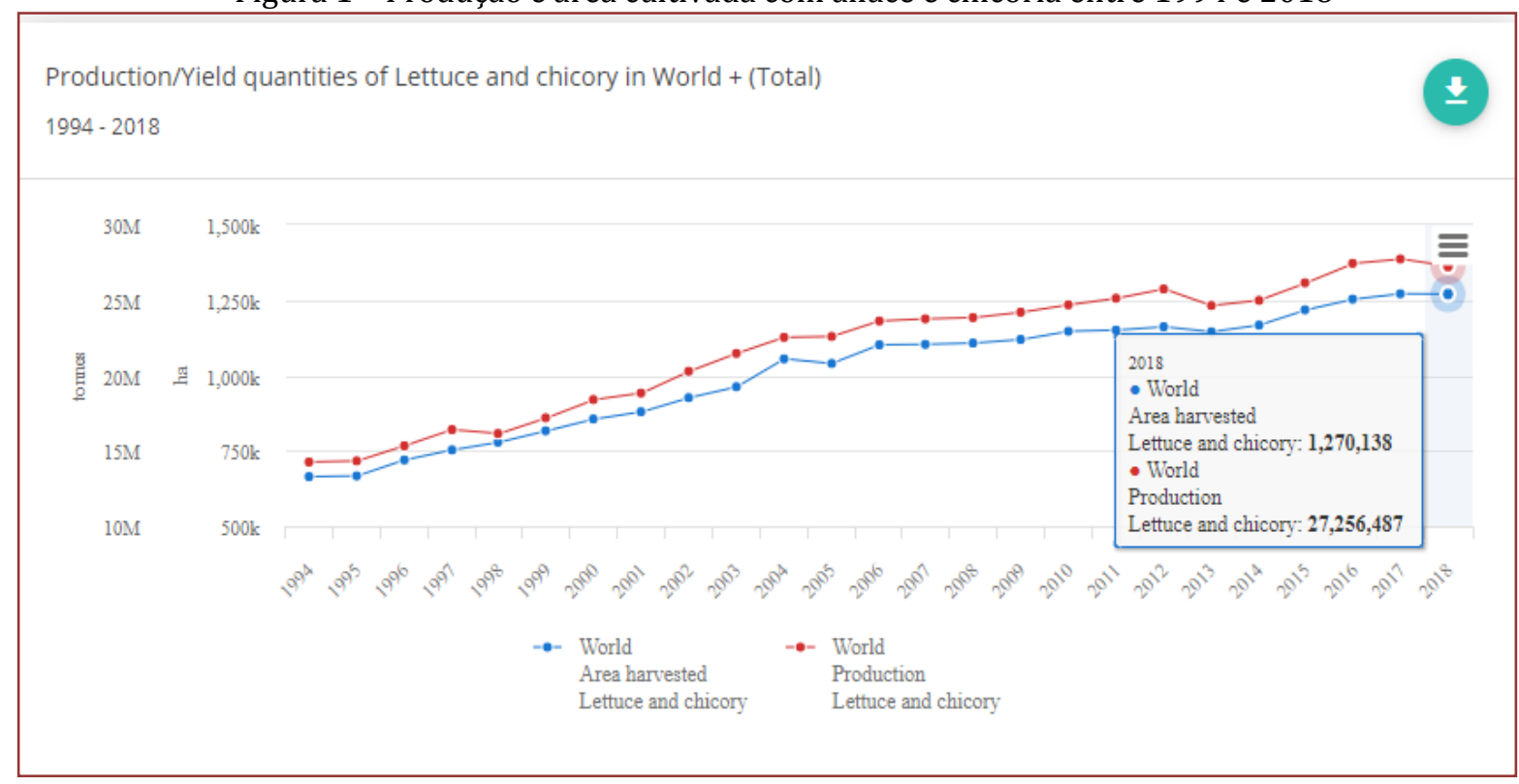

A Ásia é de longe o continente/região com a maior participação na produção mundial de alface e chicória, respondendo por 60,6\% do total na média do período compreendido entre 1994 e 2018, seguido das Américas $(22,2 \%)$ e Europa $(14,8 \%)$. África e Oceania possuem um peso muito menor na participação mundial, 1,6\% e 0,8\%. Quando se leva em conta apenas o último ano (2018), o peso do continente asiático na produção de alface e chicória é ainda maior: 69,3\%, puxado principalmente pelo aumento da produção da China, onde o cultivo cresceu muito nos últimos anos, passando de pouco mais de 4,2 milhões para 15,5 milhões de toneladas. 
Figura 2 - Produção de alface e chicória por região/continente - média do período 1994-2018 (FAO).

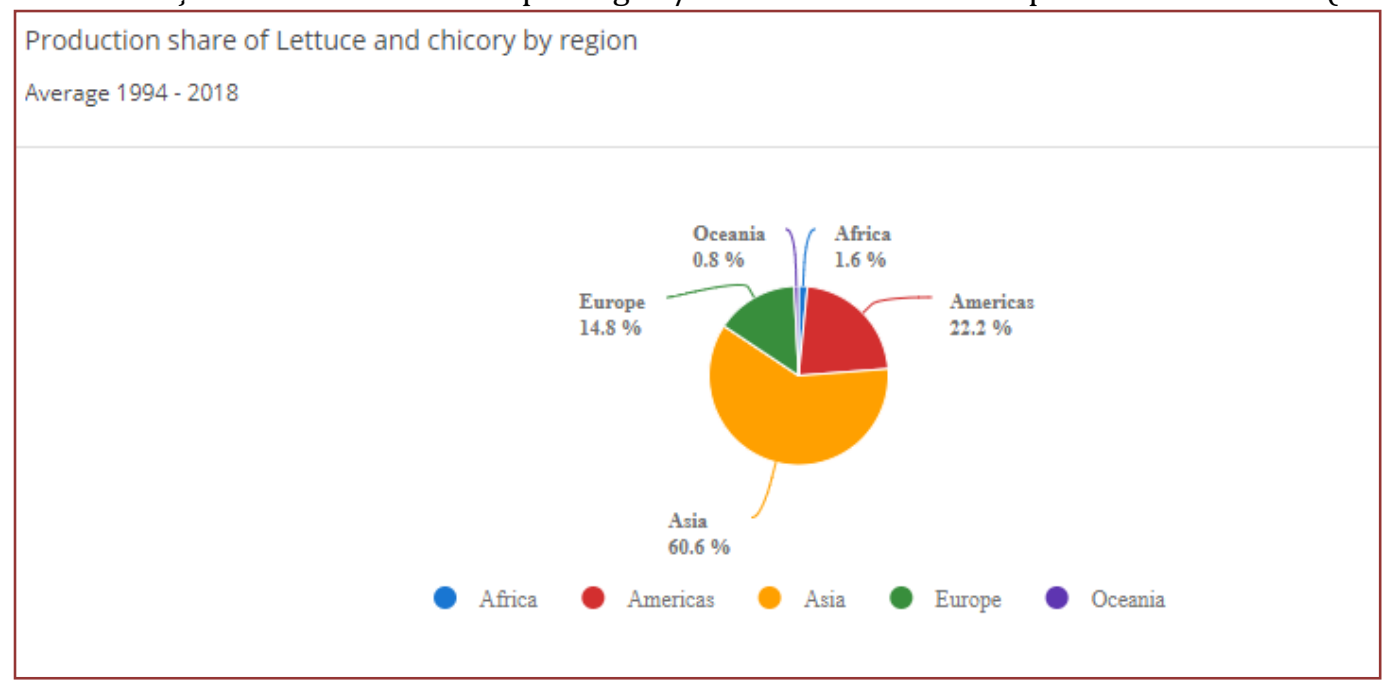

Entre os principais países produtores de alface, segundo a FAO, destaca-se a China, com uma produção acima de 15 milhões de toneladas, muito à frente dos Estados Unidos, que é segundo maior produtor, e que possui uma produção equivalente a 3milhões de toneladas. 0 terceiro colocado é a Índia, com 1,09 milhões de toneladas, 15vezes menor que a produção chinesa. Espanha, Itália, Japão, Irã, Peru, México e Alemanha completam a lista dos dez maiores produtores mundiais. Estes dados podem ser verificados por meio da tabela a seguir.

Tabela 1- Maiores produtores mundiais de alface em 2018

\begin{tabular}{|l|c|}
\hline \multicolumn{1}{|c|}{ País } & Produção (toneladas) \\
\hline Estados Unidos & 3.836 .820 \\
\hline Índia & 1.090 .770 \\
\hline Espanha & 976.112 \\
\hline Itália & 735.873 \\
\hline Japão & 547.646 \\
\hline Irã & 513.041 \\
\hline Peru & 490.423 \\
\hline México & 480.808 \\
\hline Alemanha & 353.883 \\
\hline
\end{tabular}

Fonte: FAO.

A figura a seguir apresenta os locais de produção de alface no mundo, utilizando diferentes matizes e cores para apresentar as quantidades produzidas. As cores mais escuras, como vermelho e laranja mostram as áreas com maiores produções, como, por exemplo, China e Estados Unidos, e as cores mais claras como bege e branco representam as áreas com menores produção como é o caso do Brasil. 
Figura 3 - Quantidade de alface e chicória produzida por país em 2018.

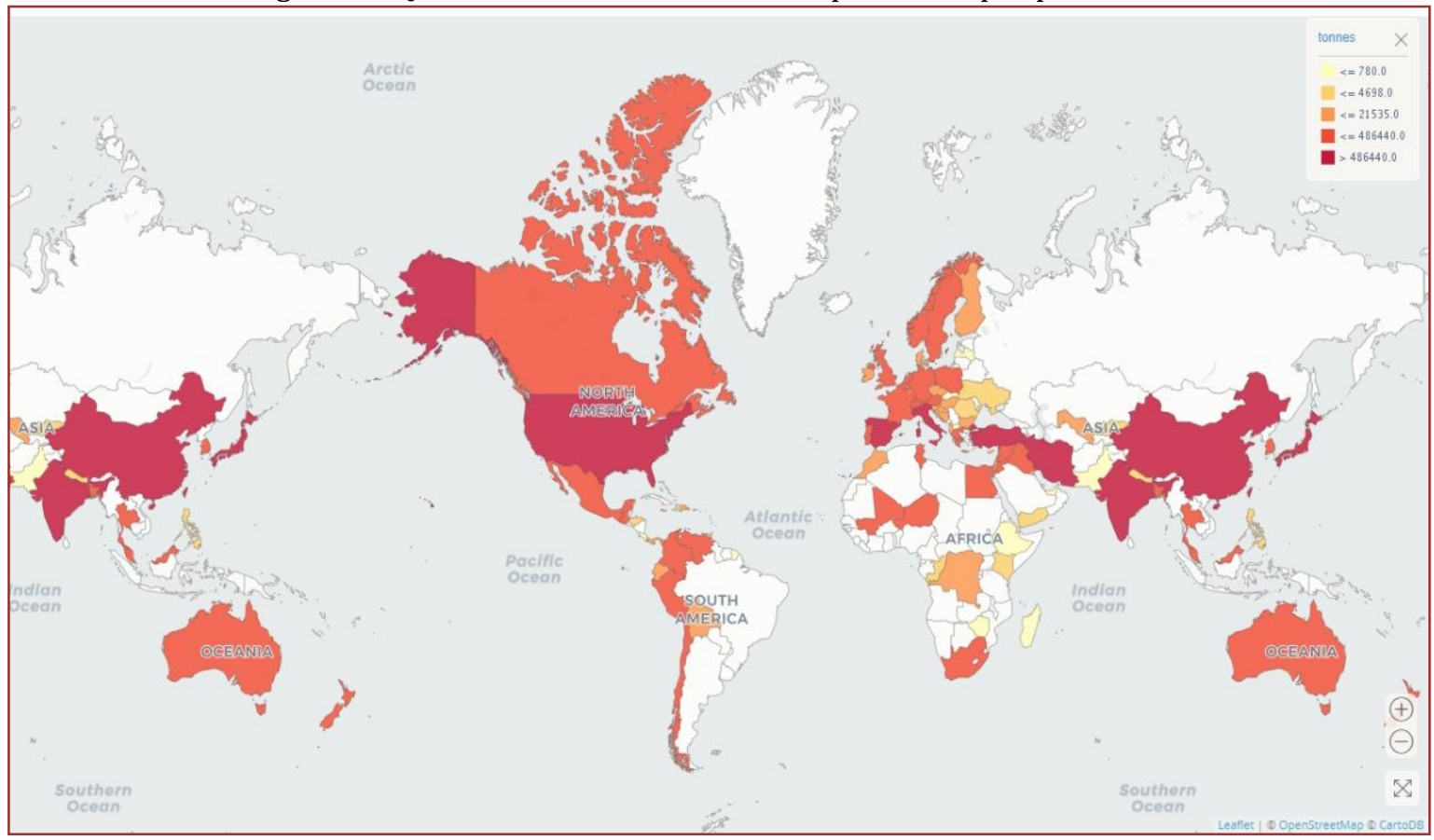

Fonte: FAO.

\subsection{COMÉRCIO EXTERIOR - IMPORTAÇÕES E EXPORTAÇÕES}

Por se tratar de um produto perecível, consumido in natura, os circuitos de comercialização tendem a ser curtos, o que limita o comércio exterior de alface e chicória, mesmo assim as quantidades exportadas são significativas. A Espanha é a maior exportadora de alface, com 828 mil toneladas exportadas em 2017 (exporta a quase totalidade do que produz), seguida pelos Estados Unidos (335 mil ton.), México (218 mil ton.), Holanda (135 mil ton.) e Itália (127 mil ton.). Já no que se refere aos maiores importadores, destacase o Canadá (282 mil ton.), Estados Unidos (276 mil ton.), Alemanha (269 mil ton.), Reino Unido (183 mil ton.) e a França (126 mil ton.).

Figura 4 - Os cinco maiores exportadores e os cinco maiores importadores de alface em 2017 (FA0).

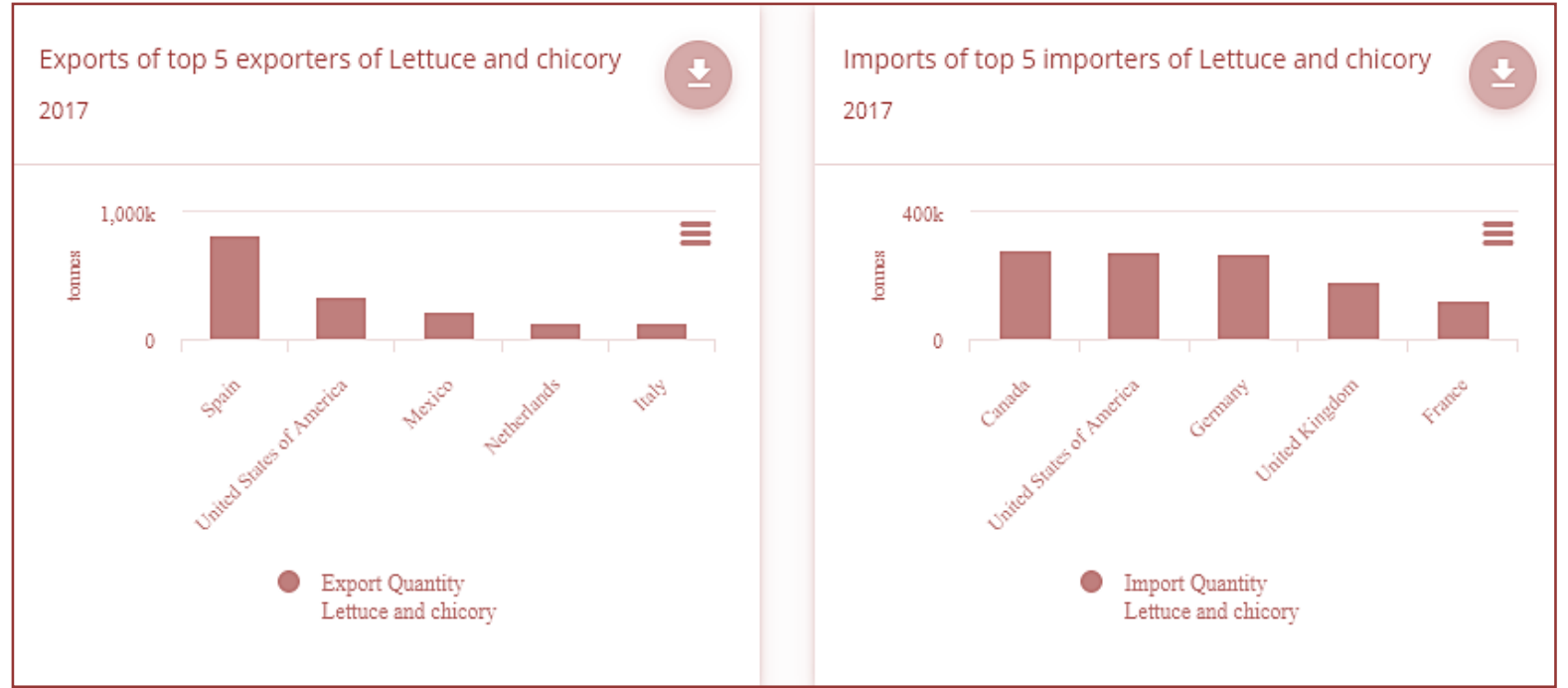


A Espanha, maior exportador mundial de alface e chicória, vem elevando constantemente as quantidades exportadas. Em 1990 o país exportou 119 mil toneladas e em 2017 foram 828 mil, um crescimento de mais de $600 \%$ no período. Embora a FAO não disponibilize a informação, muito provavelmente a produção no país vem crescendo para abastecer a Europa, já que sua localização no continente permite que o produto atravesse as fronteiras entre os países da União Europeia em um tempo relativamente curto, uma condição necessária para o comércio de hortaliças perecíveis, como é o caso da alface.

Figura 5 - Evolução das exportações espanholas de alface e Chicória entre 1990 e 2017.

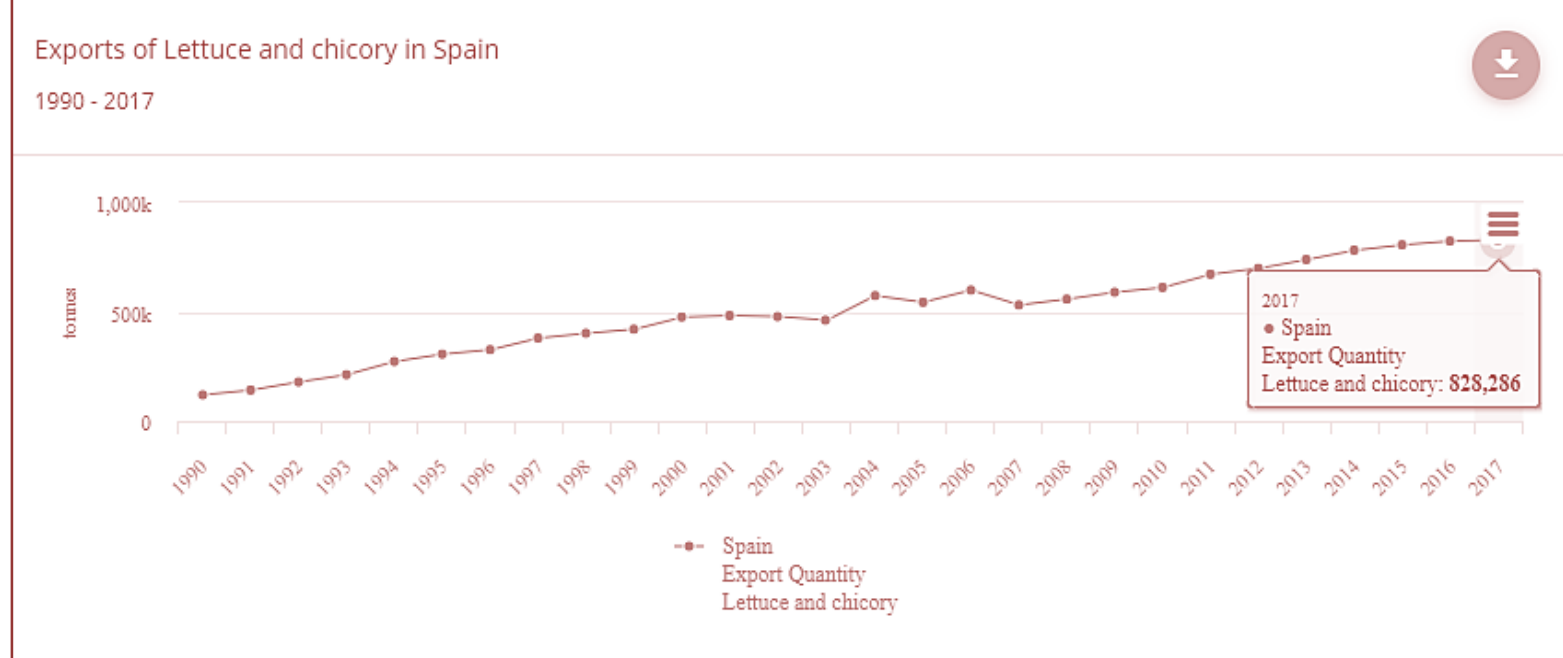

\subsection{COMÉRCIO EXTERIOR BRASILEIRO}

De acordo com o Comexstat, do Ministério do Desenvolvimento, Indústria e Comércio Exterior, as exportações brasileiras de alface e chicórias, frescas e congeladas, em 2019, atingiram o valor de US\$ 442.277,00 para um total exportado de $268 \mathrm{mil} \mathrm{kg}$, ou seja, cerca de US\$1,80/kg. Este valor oscilou bastante ao longo dos últimos 4 anos. Em 2017 o valor exportado foi de apenas US\$ 4 mil.

Tabela 2 - Exportações brasileiras de alface e chicórias, frescas ou refrigeradas

\begin{tabular}{|c|c|c|}
\hline \multicolumn{1}{|c|}{ Ano } & Valor FOB (US\$) & Quantidade $(\mathrm{kg})$ \\
\hline $2020^{*}$ & 90.102 & 50.996 \\
\hline 2019 & 442.277 & 268.602 \\
\hline 2018 & 97.226 & 86.508 \\
\hline 2017 & 4.346 & 12.095 \\
\hline 2016 & 23.435 & 81.733 \\
\hline
\end{tabular}

Fonte: Comexstat. *Referente aos três primeiros meses do ano.

Como era de se esperar, a maior parte das exportações brasileiras de alface e chicórias, frescas e refrigeradas, tiveram como destino a Argentina, em 2019. 0 país importou naquele ano $34 \mathrm{mil} \mathrm{kg}$ do produto, equivalente a US\$ 84 mil, cerca de 18\% das exportações brasileiras. No entanto, também houve exportação do produto para locais mais distantes, como as Ilhas Marshall, Hong Kong e Libéria. 
Tabela 3 - Exportações brasileiras de alface e chicórias frescas e refrigeradas segundo o país de destino, em 2019.

\begin{tabular}{|l|c|c|}
\hline \multicolumn{1}{|c|}{ País } & Valor FOB (US\$) & Kg Líquido \\
\hline Argentina & 84.907 & 34.752 \\
\hline Ilhas Marshall & 45.920 & 26.024 \\
\hline Hong Kong & 44.459 & 30.308 \\
\hline Libéria & 42.022 & 22.747 \\
\hline Panamá & 41.812 & 26.573 \\
\hline Cingapura & 24.420 & 13.194 \\
\hline Malta & 24.187 & 12.741 \\
\hline Grécia & 15.078 & 8.303 \\
\hline Bahamas & 14.200 & 6.335 \\
\hline China & 13.296 & 8.694 \\
\hline \multicolumn{3}{|c|}{ Fonte: Comexstat. } \\
\hline
\end{tabular}

\section{PRODUÇÃO E COMÉRCIO NACIONAL E REGIONAL DE ALFACE}

A alface é a segunda hortaliça mais produzida no Brasil, logo após o tomate, segundo o Censo Agropecuário 2017, do IBGE. A cultura da alface se destaca na produção de hortaliças, 908 mil toneladas ano, ficando atrás apenas da produção de tomate, que em 2017 foi de 1.974 .000 toneladas. A cenoura está na terceira posição, com 715 mil toneladas. A batata doce está na quarta posição, com 352 mil toneladas.

Quanto ao número de produtores de cada tipo de hortaliça, observamos que a alface é a que possui o maior número em relação a todas as outras hortaliças: 109 mil. Em seguida vem a cebolinha com $87 \mathrm{mil}$ produtores, seguido de batata doce, berinjela e couve, todas com 67 mil produtores.

Verifica-se, portanto, que a alface é cultivada por um grande número de produtores no Brasil. Trata-se de um produto de cultivo relativamente simples, que não exige muito conhecimento técnico, possui ciclo de produção curto e retorno financeiro rápido. No entanto, quando o cultivo se dá por meio da hidroponia estas características se alteram consideravelmente: a necessidade de investimentos é alta, o conhecimento técnico necessário ao cultivo é elevado, mesmo assim o número de produtores com sistema hidropônico de produção tem se elevado, pois garante redução no custo unitário de produção e maior regularidade de oferta.

Figura 6 - Produção de hortaliças no Brasil

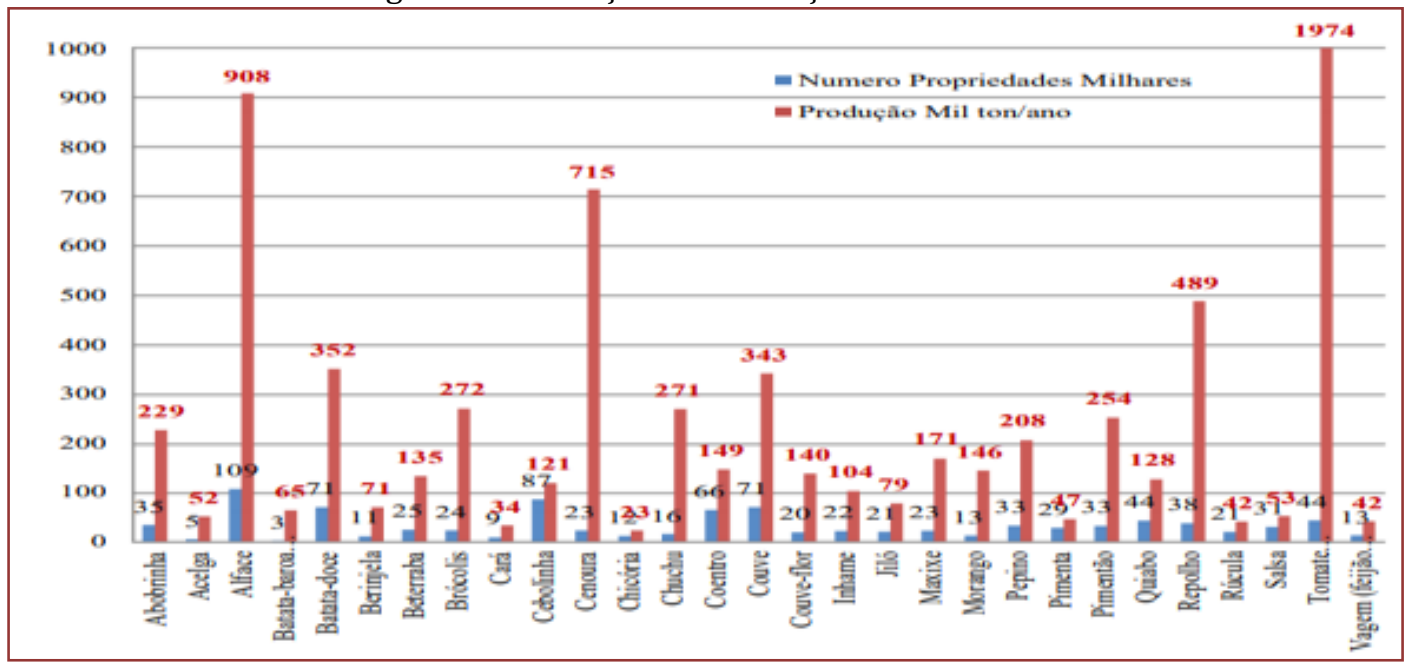

Fonte: Censo Agropecuário 2017 - IBGE, elaborado por YOKORO e Pereira (2018).

A exploração econômica das hortaliças folhosas se dá em mais de 162 mil estabelecimentos no Brasil, sendo que deste total $41 \%$ produzem alface ( $66 \mathrm{mil}$ ), $21 \%$ couve (34 mil) e 16,6\% repolho (27 mil) estabelecimentos (VILELA; LUENGO, 2017). Os maiores volumes comercializados de folhosas e os maiores valores foram realizados pelo mercado de São Paulo, (63\% e 58\%), respectivamente, seguidos por Paraná (13\% e 11\%), Rio de Janeiro e Minas Gerais. 
De acordo com a FAO, a produção de vegetais primários, onde se encontram as hortaliças, ocupam área de aproximadamente 367 mil hectares no Brasil e a produção é de cerca de nove milhões de toneladas. Entre 2009 e 2017, último ano para que a informação se encontra disponível, tanto a área quanto a produção tiveram pequena variação. Como se trata de produção destinada principalmente ao comércio interno, o não aumento da produção está bastante ligado ao baixo crescimento econômico no período, já que a falta de renda limita o acesso ao consumo de hortaliças.

Tabela 4 - Produção de vegetais primários no Brasil

\begin{tabular}{|l|c|c|c|c|c|}
\hline \multicolumn{1}{|c|}{ Vegetais primários } & 2009 & 2011 & 2013 & 2015 & 2017 \\
\hline Área colhida (há) & 373.681 & 380.209 & 354.656 & 370.134 & 367.702 \\
\hline Produção (Toneladas) & 8.559 .082 & 8.956 .395 & 8.728 .807 & 8.728 .034 & 9.050 .659 \\
\hline \multicolumn{7}{c}{ Fonte: FAO. }
\end{tabular}

Segundo o IBGE, os municípios com maior produção de alface no Brasil são Teresópolis (RJ), com uma produção de 51.388 tonelada; em seguida vem Ibiúna (SP) com uma produção de 50.015 toneladas; e Piedade (SP) com uma produção de 41.357 toneladas. Trata-se de cidades próximas dos grandes centros, entre $75 \mathrm{~km}$ e $100 \mathrm{~km}$, e que abastecem aquele mercado consumidor, neste caso São Paulo e Rio de Janeiro. No Paraná, a região metropolitana de Curitiba é abastecida pela produção realizada principalmente nos municípios de Colombo e São José dos Pinhais. Os agricultores destes municípios comercializam a produção, principalmente, por meio do Ceasa de Curitiba e também diretamente aos supermercados, alguns dos quais possuem contratos de exclusividade.

Os municípios do sudoeste do Paraná, especificamente os estudados, possuem uma baixa produção de alface quando comparados com os maiores produtores do país, possivelmente por sua característica de grandes produtores de grãos e também pelo menor mercado consumidor, quando comparado com as cidades próximas dos grandes centros. Francisco Beltrão ocupa a posição 210 no ranking, com uma produção de 392 toneladas; Pato Branco ocupa a posição 396, com uma produção de 188 toneladas; Dois Vizinhos ocupa a posição 527, com uma produção de 132 toneladas.

Tabela 5 - Ranking da produção de alface nos municípios do Brasil

\begin{tabular}{|c|c|c|}
\hline Ranking & Município (estado) & $\begin{array}{l}\text { Produção } \\
\text { (toneladas) }\end{array}$ \\
\hline 1 & Teresópolis (RJ) & 51.388 \\
\hline 2 & Ibiúna (SP) & 50.015 \\
\hline 3 & Piedade (SP) & 41.357 \\
\hline 4 & Sumidouro (RJ) & 31.641 \\
\hline 5 & Mogi das Cruzes (SP) & 23.120 \\
\hline 6 & Biritiba Mirim (SP) & 20.393 \\
\hline 7 & Brasília (DF) & 16.134 \\
\hline 8 & Tianguá (CE) & 15.778 \\
\hline 9 & Suzano (SP) & 13.571 \\
\hline 10 & São José dos Pinhais (PR) & 10.810 \\
\hline 11 & Nova Friburgo (RJ) & 10.572 \\
\hline 12 & Colombo (PR) & 9.898 \\
\hline 13 & Santa Maria de Jetibá (ES) & 6.804 \\
\hline 14 & Cotia (SP) & 5.001 \\
\hline 15 & Campinas (SP) & 4.496 \\
\hline 16 & Selesópolis (SP) & 4.368 \\
\hline 17 & Tuiuti (SP) & 4.353 \\
\hline 18 & São Francisco de Paula (RS) & 4.147 \\
\hline 19 & Vitória do Santo Antão (PE) & 3.938 \\
\hline 20 & Louveira (SP) & 3.325 \\
\hline 210 & Francisco Beltrão (PR) & 392 \\
\hline 396 & Pato Branco (PR) & 188 \\
\hline 527 & Dois Vizinhos (PR) & 132 \\
\hline
\end{tabular}

Fonte: IBGE. 
Pato Branco e Francisco Beltrão são os municípios da região que, além de alface, apresentam as maiores produções de hortaliças da região. Trata-se dos municípios com o maior mercado consumidor da região e que também possuem histórico com a comercialização direta de hortaliças por meio das feiras, estruturadas há vários anos em ambas as cidades. A comercialização por meio das feiras se constitui em uma alternativa aos agricultores que produzem em pequena escala, já que os supermercados são abastecidos por atacadistas que adquirem seus produtos diretamente do Ceasa, mais baratos que os produtos locais e, em alguns casos, por meio de contratos com agricultores da região. Esse não é exatamente o caso da alface, já que se trata de uma folhosa com alta perecibilidade, mas de grande parte das hortaliças que não se encontram nesta condição.

O Brasil possui uma produção de aproximadamente 908 mil toneladas de alface, segundo o Censo Agropecuário 2017. A região Sul responde por 12,8\% desta produção e o estado do Paraná por 5,79\% da produção nacional e $45 \%$ da produção da região Sul. Os municípios de Dois Vizinhos, Pato Branco e Francisco Beltrão respondem, respectivamente, por 0,01; 0,02 e 0,04\% da produção nacional e 0,25; 0,35 e $0,74 \%$ da produção estadual, num total de 1,34\%.

Tabela 6 - Produção de alface em 2017

\begin{tabular}{|l|c|c|}
\hline Brasil & Produção (toneladas) & Participação \% \\
\hline Sul & 908.186 & 100 \\
\hline Paraná & 116.937 & 12,88 \\
\hline Dois Vizinhos (PR) & 52.621 & 5,79 \\
\hline Pato Branco (PR) & 132 & 0,01 \\
\hline Francisco Beltrão (PR) & 188 & 0,02 \\
\hline
\end{tabular}

Fonte: Censo Agropecuário 2017 - IBGE

No que se refere ao número de estabelecimentos agropecuários com horticultura no Brasil, de acordo com o Censo Agropecuário 2017, nota-se que o número de produtores de alface é o maior, seguido de couve, almeirão e chicória. 0 mesmo ocorre na região Sul, Paraná e nos municípios pesquisados. 0 número de produtores de alface é de 25 em Dois Vizinhos, 74 em Francisco Beltrão e 84 em Pato Branco. Considerando as quatro folhosas juntas, Dois Vizinhos possui 35 produtores; Francisco Beltrão, 169 e Pato Branco, 109 (obviamente, uma parte dos produtores pode produzir mais do que uma destas folhosas, de forma que aparecem duplicados).

Tabela 7- Números de estabelecimento agropecuários com horticultura (unidades) em 2017

\begin{tabular}{|l|c|c|c|c|}
\hline \multicolumn{1}{|c|}{ Localidade } & Alface & Almeirão & \multicolumn{1}{c|}{ Chicória } & Couve \\
\hline Brasil & 108.382 & 15.256 & 12.354 & 71.279 \\
\hline Sul & 28.247 & 3.220 & 1.654 & 11.110 \\
\hline Paraná & 9.742 & 2.321 & 778 & 5.696 \\
\hline Dois Vizinhos & 25 & 3 & 1 & 6 \\
\hline Francisco Beltrão & 74 & 30 & 21 & 44 \\
\hline Pato Branco & 84 & 7 & 8 & 10 \\
\hline
\end{tabular}

Fonte: Censo Agropecuário 2017 - IBGE

Quando nos referimos às vendas das hortaliças no Brasil notamos que a quantidade comercializada de alface é extremamente maior do ue as outras hortaliças folhosas. Enquanto a alface ocupa a primeira posição com 611.584 toneladas, a couve, a segunda colocada, teve 152.941 toneladas comercializadas, um quarto do volume de alface comercializada. 
Em nível de grande região, a quantidade de alface comercializada foi de 99.824 toneladas, equivalente a $16,3 \%$ da produção do país. Comparando com as outras hortaliças folhosas, a alface continua ocupando a primeira posição e, em seguida, novamente a couve folha, com 16.566 toneladas comercializadas.

Dentre os estados do sul, o Paraná é responsável por praticamente metade do comércio de alface da região, 46.702 toneladas. Esta quantidade é $750 \%$ maior do que a comercialização de couve, que foi de 6.563 toneladas.

Regionalmente verifica-se que a alface continua à frente das outras hortaliças folhosas, e o que chama a atenção é que nos municípios de Francisco Beltrão e Pato Branco a couve não ocupa mais o segundo lugar após a alface, mas o almeirão. Em Dois Vizinhos chama muito a atenção a diferença na proporção da comercialização de cada hortaliça folhosa, onde a comercialização de couve equivale a apenas $8 \%$ da comercialização de alface, o almeirão equivale a 1\% e a chicória nem é comercializada no município.

Tabela 8- Quantidade vendida de produtos da horticultura (toneladas)

\begin{tabular}{|l|c|c|c|c|} 
& \multicolumn{1}{c}{ Alface } & \multicolumn{1}{c|}{ Almeirão } & Chicória & Couve \\
\hline Brasil & 611.584 & 21.830 & 20.996 & 152.941 \\
\hline Sul & 99.824 & 4.679 & 2.960 & 16.566 \\
\hline Paraná & 46.702 & 3.147 & 1.520 & 6.563 \\
\hline Dois Vizinhos & 100 & 1 & $\mathrm{X}$ & 8 \\
\hline Francisco Beltrão & 361 & 71 & 12 & 43 \\
\hline Pato Branco & 180 & 13 & 9 & 4 \\
\hline
\end{tabular}

Fonte: Censo Agropecuário 2017 - IBGE

\section{A CADEIA PRODUTIVA DA ALFACE NA REGIÃo SUDOESTE DO PARANÁ}

De acordo com Roessing (2002), o estudo de cadeia produtiva busca retratar a realidade econômica, em âmbito mundial, de um setor da economia. Na agricultura, o conceito serve para retratar o conjunto das atividades básicas, desde a produção primária, industrialização, transporte, comercialização, distribuição e consumo. Além dessas etapas podem se incluir outros atores e atividades que contribuem para o seu funcionamento, como é o caso de fornecedores de insumos e serviços, os quais desenvolvem atividades de apoio.

Batalha e Silva (2000) afirma que a cadeia produtiva pode ser considerada um conjunto de operações, desde produção até comercialização, ou seja, desde a base de um produto na mão de um usuário, seja ele particular ou organização, até a sua comercialização, que se finaliza com o consumo. 0 trabalho utiliza desses conceitos de cadeia produtiva para compreender o objeto da pesquisa.

Em função de que se trata de um trabalho em desenvolvimento, nesta parte se apresenta alguns resultados preliminares, obtidos a partir de levantamento realizado no município de Dois Vizinhos. Embora os dados secundários e algumas considerações apresentadas anteriormente deem um pouco a ideia da estrutura da cadeia produtiva, o trabalho de campo é fundamental para qualificar estas informações e também para levantar outras, especificamente aquelas que as estatísticas oficiais não captam, já que retratam basicamente a produção e o comércio, não as relações de produção sobre as quais elas se estruturam.

\subsection{OS PRODUTORES}

Para a obtenção dos dados secundários se entrevistou alguns produtores de alface que comercializam seus produtos na feira do município de Dois Vizinhos e a Secretaria Municipal de Agricultura.

Aos produtores se perguntou sobre a área utilizada para o cultivo da alface; sobre os motivos que os incentivaram a entrar nesta atividade e quanto tempo a exercem; sobre a produção e quais variedades utilizam; sobre os pontos de comercialização; sobre as principais dificuldades, tempo necessário para o retorno do valor investido nesta atividade; sobre os valores pagos; se os valores variam com a época do ano ou até mesmo conforme a fonte de comercialização; e para finalizar perguntamos sobre receber incentivos de forma direta ou indireta do governo.

Os produtores de alface no geral são pequenos agricultores cuja sua fonte de mão de obra é familiar, e normalmente não são especializados na produção de hortaliças. Os entrevistados possuem uma área para cultivo de alface entre 0,6 a 1,2 hectares e o trabalho é desenvolvido por duas ou três pessoas. Os produtores não são especializados na produção de alface, pois produzem diversos produtos da 
horticultura. Alguns possuem a horticultura como atividade principal e outros como atividade complementar.

Os motivos que os levaram a iniciar na horticultura foi o fato de um bom aproveitamento de suas pequenas propriedades, já que esta é uma atividade que ocupa uma pequena área, o investimento normalmente é baixo e o retorno é rápido pelo fato de o ciclo das hortaliças serem curtos, principalmente da alface, que possui um ciclo de aproximadamente 45 dias. Outro motivo destacado foi produzir algo cujas técnicas de produção conhecem.

O tempo em que os entrevistados exercem esta atividade varia de 3 anos e meio a aproximadamente 9 anos, e ambos comentaram sobre ter planos para continuar ainda por muito tempo nesta atividade, pois estão satisfeitos.

A quantidade de pés de alfaces produzidas por cada produtor varia de 2.400 pés de alfaces por mês a 6.000 pés. As variedades utilizadas são a americana, a crespa verde e também a crespa roxa. Os entrevistados desenvolvem o cultivo no sistema convencional (não hidropônico e não orgânico). Apesar disso, a produção por meio da hidroponia vêm crescendo bastante, pois segundo alguns produtores os patógenos atacam em menor quantidade, a colheita é feita com maior rapidez.

Os produtores de alface adquirem as mudas de viveiristas, que se especializaram na atividade e para isto possuem toda a infraestrutura necessária como cultivo protegido e sistema de irrigação.

\subsection{A COMERCIALIZAÇÃO E OS PREÇOS}

Os principais canais de comercialização dos entrevistados são as feiras do produtor e mercados institucionais como o PNAE (programa nacional de alimentação escolar), e algumas festas comunitárias.

0 preço médio recebido pelos produtores por pé de alface é de aproximadamente $\mathrm{R} \$ 1,75$. Na feira o preço médio é de R\$2,00 por e no Programa Nacional de Alimentação Escolar - PNAE, o preço é R\$1,55. Como em qualquer atividade econômica os preços variam ao longo do ano conforme a variação do valor, materializado no custo de produção, e também em função da relação entre oferta e procura.

\subsection{POLÍTICAS DE APOIO}

Com relação aos incentivos do governo, alguns produtores comentaram sobre não receber nenhum tipo de incentivo, e outros comentaram que recebem assistência técnica do órgão estadual, o Instituto Emater. Ambos os produtores relataram sobre a falta de incentivo e que gostariam de receber mais incentivos do governo para este tipo de produção, além de subsídios, para realizar mais investimentos.

Apesar da manifestação de que não há apoio, a prefeitura municipal construiu, recentemente, uma sede para a feira do produtor, onde alguns produtores comercializam a produção duas vezes por semana. Além da sede da feira, também apoia a Cooperativa da Agricultura Familiar - Coafar, que possui cerca de 300 associados, onde se encontram a quase totalidade dos horticultores do município.

Outra iniciativa pública de apoio à atividade é o Programa Nacional de Alimentação Escolar - PNAE, por meio do qual as escolas são abastecidas, com apoio da prefeitura municipal. 0 município de Dois Vizinhos ultrapassou a meta de compra local da agricultura familiar definido em lei, que é de 30\%. Estes agricultores podem planejar sua produção com garantia de mercado e de preço, embora esteja um pouco abaixo do preço de mercado, atualmente.

\section{CONSIDERAÇÕES FINAIS}

A alface é uma hortaliça muito produzida no mundo, sendo a China a maior produtora, seguida pelos Estados Unidos e a Índia. Os maiores exportadores são a Espanha, Estados Unidos e o México. Já os maiores importadores são o Canadá, Estados Unidos e Alemanha.

Embora haja comércio exterior, no Brasil a alface é basicamente um produto de mercado interno. As exportações de alface e chicórias, frescas ou refrigeradas, que em 2019 foram de pouco mais de US\$ 400 mil, foram destinadas principalmente à Argentina, mas também houve exportação para outros países.

A alface é a segunda hortaliça mais produzida no Brasil e no Paraná é a hortaliça mais produzida. Os estados do Brasil que mais produzem são São Paulo e Rio de Janeiro e os municípios que mais produzem 
estão localizados nas proximidades das grandes cidades, que também são grandes centros consumidores, em sua maioria as capitais.

Dos municípios pesquisados no sudoeste do Paraná, segundo o Censo Agropecuário do IBGE (Instituto Brasileiro de Geografia e Estatística), o município de Francisco Beltrão é o maior produtor de hortaliças no geral (alface, almeirão, chicória e couve folha) e também de alface. Na região também coincide a localização da produção com o consumo, ou seja, as cidades com maior produção também possuem potencialmente os maiores mercados consumidores.

No município de Dois Vizinhos a atividade é desenvolvida pelos pequenos produtores, que possuem pequena área de cultivo, desenvolvem a atividade com força de trabalho familiar, o cultivo predominante é o convencional, embora a produção no sistema hidropônico venha crescendo muito. Os principais canais de comercialização deste produto são a feira do produtor e o mercado institucional, como o PNAE (programa nacional de alimentação escolar) e, em menor escala, a comercialização direta ao consumidor.

\section{REFERÊNCIAS}

[1] BATALHA, M. O.; SILVA, A. L. Gerenciamento de sistemas agroindustriais: definições e correntes metodológicas. In: BATALHA, M. O. (Coord.). Gestão Agroindustrial. São Paulo: Atlas, 2000. p. 23-61.

[2] COMEXSTAT. Exportações e importações. Disponível em: <http://comexstat.mdic.gov.br/pt/home>. Acesso em: 02. Abr. 2020.

[3] FOOD AND AGRICULTURE ORGANIZATION - FAO. Faostat. Disponível em: <http://www.fao.org/faostat/en/\#data>. Acesso em: 02 abr. 2020.

[4] HENZ, G. P.; SUINAGA, F. Tipos de alface cultivados no Brasil. Brasília, DF: EMBRAPA, 2009. (Comunicado Técnico, n. 75).

[5] INSTITUTO BRASILEIRO DE GEOGRAFIA E ESTATÍSTICA - IBGE. Censo Agropecuário 2017. Disponível em: $<$ www.sidra.ibge.gov.br>. Acesso em: 27 mar. 2020.

[6] NUNES, S. P.; HEINDRICKON, M. A cadeia produtiva do mel no Brasil: análise a partir do sudoeste Paranaense. Brazilian Journal of Development. V.5, n.9, 2019. Disponível em: <http://www.brjd.com.br/index.php/BRJD/article/view/3494>. Acesso em: 03 abr. 2020.

[7] ROESSING, A. C., Cadeias produtivas: roteiro para estudo de sistemas agroalimentares. EMBRAPA Soja, p. 60.Londrina - $\quad$ PR, 2002. Acessado em: 26 nov. $2019 . \quad$ Disponível: <https://ainfo.cnptia.embrapa.br/digital/bitstream/item/80229/1/Cadeias-produtivas-roteiro-para-estudo-desistemas-agroalimentares.pdf.>

[8] VILELA, N. J.; LUENGO, R. F. A. Produção de Hortaliças Folhosas no Brasil. Campo \& Negócios, Hortifruti, Uberlândia, ano XII, n. 146, ago 2017.

[9] YOKORO, G. K.; PEREIRA, J. A. Produção e comercialização da alface: um estudo a partir da perspectiva dos produtores do município de Naviraí-MS. II EIGEDIN. p.5, 2018. Disponível em: <https://periodicos.ufms.br/index.php/EIGEDIN/article/view/7214> . Acesso em: 03 abr.2020. 


\section{Capítulo 7}

Tecnológica de plantio de produção agrícola: Como as tecnologias de plantio utilizadas vêm impactando a produtividade e a rentabilidade do milho nas cidades de Rio Verde - GO, Unaí - MG, Chapadão do Sul - MS, Primavera do Leste - MT e Passo Fundo - RS

\section{Lucimari Andrade Paggiossi \\ Álvaro Alves de Moura Júnior}

Resumo: 0 presente artigo tem como objetivo demonstrar como a inovação na agropecuária vem tornando o Brasil um exemplo de excelência em produtividade e competitividade na produção agrícola do milho. Para tanto, o trabalho faz uma revisão das principais teorias econômicas evolucionárias de inovação tecnológica, bem como apresenta as principais inovações ocorridas nos últimos anos no cultivo do milho no País. Como forma de apresentar os resultados gerados pelas referidas inovações, são realizados cálculos de produtividade e rendimento médio por tipo de plantio tecnológico para cultivo agrícola do milho nos municípios de Rio Verde em Goiás Unaí em Minas gerais, Chapadão do sul em Mato Grosso do Sul, Primavera do Leste em Mato grosso e Passo Fundo em Rio Grande do Sul, resultando um crescimento. No resultado desse estudo verificou-se que, todas as cidades, exceto Unaí em Minas Gerais, essa tecnologia de plantio surtiu efeito, demonstrando que, a produtividade e o rendimento ficaram expressivos em algumas cidades.

Palavras-chave: Tecnologia, Inovação, Produtividade, Rendimento, Agronegócio. 


\section{INTRODUÇÃO}

A agricultura no Brasil desde a década de 1960, vem se tornando um importante influenciador de ambiente favorável à inovação e à adaptação de tecnologia. A Empresa Brasileira de Pesquisa Agropecuária (Embrapa) foi criada nesse processo de inovação na década de 1970. Pesquisas de melhoramento genético foram realizadas para adaptar a produção ao clima tropical, bem como para ampliar a produtividade das pastagens. Outro fator importante é a expansão da fronteira agrícola, a partir de 1970. (Gasques, José; Vieira, José, 2016, p. 15).

Confirmando esse processo de inovação, houve duas ondas de crescimento expressivos nessa época, uma delas foi na década de 1980 com a tropicalização de diversos cultivos ao bioma do Cerrado; e a outra, mas recente com o desenvolvimento de sementes melhoradas nos ciclos produtivos mais curtos, possibilitando o aumento produtivo da safrinha em várias regiões. A biotecnologia é, desta forma, primordial nesse processo, que busca maior produção com utilização mais eficiente dos recursos naturais. (Gasques, José; Vieira, José, 2016, p.15).

Outro ponto importante, além da inovação, a demanda por alimentos e fibras nas economias emergentes e as condições internas, como a disponibilidade de terras e o desenvolvimento de tecnologias que favoreceram a produtividade e a maior oferta de recursos financeiros para as políticas agrícolas, confirma explosão de commodities do período recente e a consequente expansão do agronegócio brasileiro. (Gasques, José; Vieira, José, 2016, p. 19). Complementado todo esse processo, agrega-se oferta e demanda dos mercados de commodities dentro do contexto dos ciclos de Kondratieff (ondas longas de movimentos cíclicos) e a importância da atividade financeira sobre o processo de formação dos preços. (Gasques, José; Vieira, José, 2016, p. 19).

Dito isso, afloram indícios que essa ocasião não vai se repetir na próxima década, pois a economia mundial estará em desaceleração do seu ciclo - retorno à trajetória de equilíbrio de longo prazo dos mercados de commodities, implicando que, agronegócio brasileiro terá que lidar com um cenário externo não tão favorável. (Gasques, José; Vieira, José, 2016, p. 19).

Uma das mais robustas provas da emergência de um modo de acumulação centrado na determinação financeira, desde os anos 1990, tem sido uma inflexão verificada nas formas de financiamento da produção agropecuária, as quais vêm sendo privatizadas, em detrimento do papel do crédito estatal. ${ }^{124}$ São evidências emblemáticas, porque indicam ser uma atividade que, em sua essência, vem se tornando "mais capitalista" com o passar dos anos, igualmente atraindo firmas privadas e, assim, simultaneamente, uma "lógica capitalista geral" vai se impondo como o eixo principal norteador que comanda a agropecuária no país. Sobre a crescente financeirização da economia brasileira, Balestro e Lourenço realçam que, em 2001, dos contratos de futuros e opções relacionadas a commodities (principalmente agrícolas) negociados na Bolsa de Valores de São Paulo, 80\% eram contratos com entrega física e o restante, contratos financeiros, mas "essas cifras foram invertidas em 2011: 71\% de contratos financeiros e $29 \%$ de contratos com entrega física", salientando que na Bolsa, "as empresas brasileiras de capital aberto são principalmente do setor de agronegócio" (Balestro e Lourenço, 2014, p. 256).

24 Repetindo situações internacionais similares: "nos anos recentes, diversas instituições financeiras - incluindo Consórcios de ativos privados, fundos hedge, fundos de investimento, fundos de pensão, bancos comerciais, fundos soberanos e outros - começaram a investir fortemente no sistema alimentar e na produção agrícola, em todo o mundo (...). Além de um crescente envolvimento na produção agrícola, muitas instituições financeiras e companhias do setor e alimentação estão também crescentemente envolvidas no mercado de mercadorias agrícolas como ativos 'virtuais', em particular através de hedging, estratégias de administração de ativos e especulação em mercados futuros de commodities" (Lawrence et al., 2015, p. 309). 
Conforme mencionado acima, nesse trabalho será feito uma revisão das principais teorias econômicas evolucionistas, demonstrando que as atividades científicas e tecnológicas são fortes atributos no papel de fatores econômicos e será apresentado a magnitude de relevância da produção do milho nos municípios de Rio Verde em Goiás Unaí em Minas gerais, Chapadão do sul em Mato Grosso do Sul, Primavera do Leste em Mato grosso e Passo Fundo em Rio Grande do Sul, por meio de pesquisa com diferentes tecnologias de plantio aplicadas no campo e técnicas de análises descritivas, sumarizando e descrevendo as produções e rendimentos mais eficientes ao longo do tempo. Os resultados da análise descritiva partirão da avaliação das quantidades produzidas, das áreas plantadas e da média de rendimento de produção por diferentes tipos de plantios e safras.

Em razão disso, o documento tem por objetivo demonstrar como a inovação na agropecuária vem tornando o Brasil um exemplo de excelência em produtividade e competitividade na produção agrícola do milho. Como resultado, será apresentado as referidas inovações, por meio de cálculos de produtividade e rendimento nos municípios de Rio Verde em Goiás Unaí em Minas gerais, Chapadão do sul em Mato Grosso do Sul, Primavera do Leste em Mato grosso e Passo Fundo em Rio Grande do Sul, a partir da base de dados da Conab e PAM (Produção Agrícola Municipal).

\section{INOVAÇÃO TECNOLÓGICA E DESENVOLVIMENTO TECNOLÓGICO NA CULTURA DEMILHO}

\subsection{TEORIAS EVOLUCIONÁRIAS: INOVAÇÃO TECNOLÓGICA SEGUNDO OS NEO-SCHUMEPETERIANOS}

Schumpeter (1982) conceitua o sistema econômico em estado de equilíbrio estático, em que não existe estímulo ou motivação para mudar de posição, exceto por uma suave adaptação às alterações existentes, porém visando a condição por um estado dinâmico. 0 autor considera as inovações como o equilíbrio lentamente mutável com desejo de expansão econômica, desenvolvimento, progresso e evolução, deslocando a função de produção por meio de novas combinações, como: a) novos produtos; b) novos métodos de produção; c) abertura de novos mercados; d) novas fontes de matérias-primas e; e) novas formas de organização industrial. Na sua interpretação, as atividades de inovação ocorrem em períodos de expansão e de depressão, pois não são um processo contínuo e sofrem descontinuidade temporal.

Nos períodos de depressão, quando ocorrem irregularidades, perdas e incertezas, as firmas tendem, para sobreviver, a adotar outros métodos, passar por testes, corrigir erros; já no período de expansão, quando as firmas estão enriquecidas, a indústria é reorganizada e os custos de produção são reduzidos.

Já os neo-schumpeterianos consideram que a inovação é uma descoberta, desenvolvimento, imitação e adoção de novos produtos, novos processos e nova organização (DOSI, 1988). Desta forma, a inovação não é estática, mas, ao contrário, é um processo inventivo e um fator chave para explicar os ciclos econômicos e a dinâmica do crescimento econômico. A visão teórica enfatiza as necessidades do mercado e tenta satisfazer essas necessidades por meio de avanços tecnológicos ou trata a tecnologia como um fator autônomo, ou quase autônomo. Ambas as visões são incapazes de explicar o tempo das inovações e a descontinuidade de seus padrões e desconsideram a complexidade e o papel da incerteza no processo inovativo.

Tentando resolver essas limitações, os neo-schumpeterianos propõem similaridades entre a natureza e os procedimentos da ciência e da tecnologia. Assim como existe o paradigma científico de Thomas Kunh (os "paradigmas são as realizações cientificas universalmente reconhecidas que, durante algum tempo, fornecem problemas e soluções modelares para uma comunidade de praticantes de uma ciência" (KUHN, 1991, p.13) existe o paradigma tecnológico para os neo-schumpeterianos. A corrente neo-schumpeteriana contrapõe o enfoque estático tradicional, segundo Kupfer; Hasenclever (2002) e vê na concorrência um processo evolutivo e dinâmico, o qual é gerado por fatores internos (endógenos) ao processo de desenvolvimento econômico. As necessidades de inovações surgem nas empresas quando buscam novas oportunidades lucrativas em sua interação competitiva.

As teorias Evolucionárias são destacadas por três princípios: Primeiro princípio: as teorias Evolucionárias são fundamentadas em inovações de produtos e processos e nas formas de organização da produção: "paradigmas técnico-econômicos" de Dosi (1982); Segundo princípio: baseado no processo de aprendizado ao longo das interações com o mercado e novas tecnologias (Winter, 1993; Dosi, 1991; Coriat e Weinstein, 1995); Terceiro princípio: refere-se à propriedade de auto-organização/adaptação da firma, como resultado das flutuações do mercado. 
Para Dosi (2006), a tecnologia é como um conjunto de parcelas de conhecimento "prático" (relacionados a problemas e dispositivos concretos) e teórico - know how, métodos, procedimentos, experiências, dispositivos físicos e equipamentos. Ao mesmo tempo, há uma parte "desincorporada" da tecnologia que se constitui de expertise específica, da experiência de tecnologias do passado, juntamente com conhecimento e as realizações do estado-da-arte. Dosi (2006) vai além fazendo uma analogia dos paradigmas científicos com os "paradigmas tecnológicos". Em linhas gerais, define o paradigma científico como uma "perspectiva" de problemas relevantes, um "modelo" e um "padrão" de investigação. Na ciência normal, constitui-se a efetivação dessa promessa atingida pelo conhecimento dos fatos por meio do paradigma como especialmente significadores, pela harmonização dos fatos com a teoria e pela articulação da teoria (resolução de ambiguidades e problemas) (Kuhn, 1963).

Em ampla analogia ao "paradigma científico de Kuhn, Dosi (2006) define o "paradigma tecnológico" como um "modelo" e um "padrão" de solução de problemas tecnológicos selecionados. Estas similaridades se relacionam, especialmente, com os mecanismos e os procedimentos. Da mesma forma que o paradigma científico determina o campo de investigação, os problemas, os procedimentos e as tarefas ("quebracabeças", conforme Kuhn), também a tecnologia o faz, definindo o campo de investigação, os problemas, os procedimentos e as tarefas. A sugestão de Dosi (2006) é de que seria melhor falar de "agrupamento de tecnologias", como por exemplo: tecnologias nucleares, tecnologias químicas, tecnologia agrícola; que são os principais fatores para a produção eficiente e rentável. Em síntese, assim como a "ciência normal" constitui a efetivação de uma promessa composta num paradigma cientifico, também o progresso tecnológico é definido por intermédio de um determinado "paradigma tecnológico".

Entretanto, o autor também diz que essa analogia não deve ser considerada como uma identidade, pois há uma clara diferença entre a natureza das resoluções dos problemas e o conhecimento tecnológico que é menos articulado do que o conhecimento científico. De qualquer forma, de seu ponto de vista, ambas as atividades (científica e tecnológica) representam fortemente atributos poderosos.

\subsection{TRAJETÓRIA TECNOLÓGICA NO CULTIVO DO MILHO}

A cultura do milho tem passado por uma série de transformações no Brasil, inclusive tornando o grão uma cultura mais nobre, para os consumidores, e rentável, para os produtores brasileiros. A visão agrícola trata de uma série de aspectos e ações que participaram para a alavancagem dos negócios vinculados a cultura do grão e do resgate histórico do milho no Brasil e no mundo, passando temas relacionadas as inovações tecnológicas referentes a cadeia de produção, incluindo: seu melhoramento genético, sua fisiologia, o manejo do solo, os processos de proteção, a aquisição de insumos e a própria cultura; a utilização de técnicas mais eficientes voltadas a atividades de colheita, armazenagem e beneficiamento; industrialização e comercialização dessa commodity agrícola. Segundo, a Visão Agrícola da Escola Superior de Agricultura "Luiz de Queiroz"(ESALQ) nos próximos 10 anos, o preço do cereal deve aumentar 5,5\% ao ano e a produtividade deve crescer cerca de 5,2 t/ha, com a ampliação das exportações.(USP ESALQ ANO 9 JUL | DEZ 2015; United States Department of Agriculture (USDA) - base abril/2015; elaboração, Clarivi Consultoria)

O milho é uma das culturas mais relevantes, mundialmente, seja do ponto de vista econômico, seja do ponto de vista social. Salienta-se por ser o grão mais produzido no mundo: segundo informações do Departamento de Agricultura dos Estados Unidos (USDA), a produção mundial deste cereal deverá o primeiro grão produzido com 991,9 milhões de toneladas, sendo seguido pelos grãos de trigo, arroz, soja e cevada, com 726,5; 474,6; 315,5 e 140,8 milhões de toneladas respectivamente. É importante enfatizar que, entre as safras 2004/05 e 2014/15, a produção mundial de milho registrou um crescimento de $38,4 \%$. Este expressivo incremento ocorreu para atender a necessidade de abastecer a demanda, que registrou uma expansão de 41\%, no mesmo período. 0 milho também se destaca como o grão mais consumido do mundo: estima-se que, na safra 2014/15, seu consumo alcance 971,2 milhões de toneladas, seguido pelos grãos de trigo, arroz, soja e cevada, com 812,8; 480,8; 288,9 e 141,5 milhões de toneladas respectivamente. (USP ESALQ ANO 9 JUL | DEZ 2015; United States Department of Agriculture (USDA) base abril/2015; elaboração, Clarivi Consultoria).

Há uma tendência natural de crescimento do destaque do milho no cenário global e no doméstico. Países como a China, por exemplo, tendem a elevar seu consumo do grão, devido seu crescimento econômico e populacional. Para exemplificar, o consumo per capita de carne na China e de cerca de 55 $\mathrm{kg} /$ habitante/ano, enquanto, no Brasil, o consumo já ultrapassa os $90 \mathrm{~kg} /$ habitante/ano. 
O crescimento econômico global tem diminuído pessoas da linha de pobreza, de forma que elas passam a ter acesso a maior consumo de proteína animal. Por isto, a trading global do milho tem crescido, de forma expressiva. Entre as safras 2004/05 e 2014/15, o comercio mundial do produto passou de 77,7 milhões de toneladas para 117,7 milhões de toneladas. (USP ESALQ ANO 9 JUL | DEZ 2015; United States Department of Agriculture (USDA) - base abril/2015; elaboração, Clarivi Consultoria).

Segundo o USDA, as Projeções apontam que a trading global de milho deverá atingir, na safra 2024/25, cerca de 140 milhões de toneladas. O Japão se sobressai como maior importador mundial do milho, comerciando um volume superior a 15 milhões de toneladas; o México e União Europeia se destacam globalmente, importando anualmente volumes de 10,9 milhões de toneladas e 8,0 milhões de toneladas, respectivamente. Este cenário de aumento mundial da demanda representa uma excelente oportunidade para nosso país, um dos poucos que possuem estoques de áreas disponíveis, globalmente. Importante destacar que possuímos grandes recursos naturais e tecnologia agrícola de ponta, para aumentar nossa participação no mercado global. Porém, infelizmente, só não somos mais competitivos em função de deficiência logísticas e do baixo apoio governamental ao setor. (USP ESALQ ANO 9 JUL | DEZ 2015; United States Department of Agriculture (USDA) - base abril/2015; elaboração, Clarivi Consultoria).

Corroborando com a necessidade mundial, é necessário explicar que, a tecnologia é um fator importante nesse processo de aumento de produção e consumo do grão, para isso, temos que mencionar a engenharia genética. Dito isso, desde o início da agricultura, as plantas vêm sendo modificadas geneticamente pelo homem. Até há pouco tempo, a única forma para introdução de características de interesse em um indivíduo ou espécie era por meio de cruzamentos. Contudo, estes métodos convencionais retêm limitações, como as barreiras de isolamento filogenético entre e dentro de grupos genéticos e a ligação genica, além do tempo para a transferência dos caracteres de interesse. Com os desenvolvimentos da biotecnologia, o melhoramento de plantas conta com importante ferramentas para a introdução de novas atributos, como a engenharia genética e a transformação. Com surgimento destas técnicas, os cientistas passaram a incorporar genes de diferentes espécies vegetais, animais ou microrganismos (Perani et al., 1986), de modo controlada, no genoma vegetal, independente de cruzamentos, suprimindo as barreiras filogenéticas entre os organismos dos três grandes domínios (Eubacterias, Archaea e Eukarya). A transformação genética de plantas pode ser definida como a introdução de uma sequência de DNA no genoma receptor, excluindo-se a inserção por fecundação. (USP ESALQ ANO 9 JUL | DEZ 2015 e Santarém, 2000).

Outro fator importante para sustentar o crescimento mundial é o manejo do solo. A cultura do milho ocupa cerca de $30 \%$ da área agricultada do país, com produção de 80 milhões de toneladas de grãos, entre safra e safrinha (Conab, 2013). Com a aumento dos últimos 10 anos, o país atingiu a terceira posição maior produtor mundial. Entre os fatores que sustentam a compor este cenário, se sobressai o sistema de produção em plantio direto (SPD): sua adoção se expandiu como em nenhum outro país e, praticamente é unanimidade entre os produtores de milho comercial. As vantagens desse sistema de produção para o produtor rural é redução da erosão e uma significativas conservação de solo. A agricultura no Brasil abrange regiões de climas tropical e subtropical, nas quais os solos, de forma geral, são predominantemente cauliníticos, isto é, suscetíveis a erosão provocada pelas chuvas tropicais. As chuvas tropicais são de grande intensidade e em curto espaço de tempo, facilitando maior ação dos processos erosivos. A erosão é um processo que ocorre, majoritariamente, na superfície do solo. Desse modo, as condições da superfície definem se ocorrerá ou não erosão e seu grau de intensidade. Com a adoção do SPD é gerada uma superfície de resíduos vegetais sobre o solo que age como barreira física contra os impactos das gotas da chuva e, também, mantém a estabilidade de agregados, principalmente na camada superficial, onde começa-se o processo erosivo. No SPD a quantidade de agregados do solo aumenta (Arai et al., 2013), o que implica maior resistência do solo ao deflúvio superficial. (Oliveira, Silas et al, USP ESALQ ANO 9 JUL | DEZ 2015)

A cultura de milho é muito dependente em relação a fertilidade do solo. A preservação da camada superficial detém os nutrientes - como nitrogênio, potássio e fosforo - sejam levados junto as águas das enxurradas. Desse modo, evita-se o empobrecimento do solo e o cultivo em camadas de menor fertilidade, cuja correção demanda investimentos. Em declividade de 0,03 m m-1 e pluviosidade anual de $1350 \mathrm{~mm}, \mathrm{o}$ SPD reduziu a perda de solo em $650 \mathrm{~kg} \mathrm{ha}^{-1} \mathrm{ano}^{-1}$, se comparado ao sistema convencional (SC) (Hernani et al, 1999). Desse modo, preveniu-se perda anual de 21 bilhões de quilos de solo, quantidade suficiente para preencher 8.250 vezes o estádio do Maracanã. Em solos com fertilidade média, esta perda corresponderia a 336 mil quilos de fosforo movidos para cursos d'agua. Ademias do prejuízo ambiental, há o prejuízo econômico. 
E como se $40 \%$ de todo superfosfato simples produzido pelo Brasil, em 2012, fosse perdido, equivalendo a 1,8 bilhão de quilos do fertilizante.(Oliveira, Silas et al, USP ESALQ ANO 9 JUL | DEZ 2015)

Baseado nos estudos e desenvolvimentos tecnológicas mencionados acima, para tal crescimento, a tecnologia vem mudando os sistemas de produção de milho no Brasil, tornando o cultivo mais profissional pelos produtores por meio de papel cada vez mais importante de técnicos, consultores e extensionistas das redes públicas e privadas, além do maior fluxo de informações via mídias especializadas. Dentre elas, destacam-se:

1) Utilização de cultivares de alto potencial genético (híbridos simples e triplos) e de cultivares não transgênicas e transgênicas com resistência a lagartas e ao uso do herbicida glifosato.

2) Espaçamento reduzido associado à maior densidade de plantio, permitindo melhor controle de plantas daninhas, controle de erosão, melhor aproveitamento de água, luz e nutrientes, além de permitir uma otimização das máquinas plantadoras.

3) Melhoria na qualidade das sementes associada ao tratamento dos grãos, especialmente o tratamento industrial, máquinas e equipamentos de melhor qualidade, que garante boa plantabilidade, boa distribuição das plantas emergidas, garantindo assim maior índice de sobrevivência do plantio à colheita.

Uso intensivo do Manejo Integrado de Pragas, Doenças e Plantas Daninhas (MIP).

5) Correção do solo baseando-se em dados de análise e levando em consideração o sistema, e não a cultura individualmente.

Além dessas tecnologias, enfatiza-se a utilização de tecnologias de agricultura de precisão e melhores técnicas de irrigação, que têm permitido uma melhoria do potencial produtivo das lavouras. (Embrapa, 2015). Com o objetivo de demonstrar claramente que a trajetória tecnológica vem fazendo diferencial na produção do milho, seguem dois exemplos dessas tecnologias utilizadas no cultivo do milho.

Destacam-se a densidade de plantio, a distribuição de sementes e os coeficientes técnicos. A densidade de plantio e a distribuição de sementes são afetadas pela velocidade de plantio. As velocidades acima do recomendado aumentam o número de falhas duplas e prejudicam a uniformidade da profundidade das sementes. Esses dois fatores reduzem a população de plantas e aumentam o número de plantas dominadas, prejudicando dois dos principais componentes do rendimento: o número de espigas por área e o número de grãos por espiga. Com destino aos coeficientes técnicos, para os sistemas de produção identificados, o que mais prontamente assimila as tecnologias disponíveis na busca de competitividade diz respeito ao "produtor comercial de grãos". Para esse sistema, tem-se observado grande homogeneização do padrão tecnológico empregado pelos produtores na condução das lavouras de milho, variando pouco entre as principais regiões produtoras. (Embrapa, 2015).

\section{PROCEDIMENTOS METODOLÓGICOS}

\subsection{CONCEITOS, MEDIDAS E METODOLOGIA}

A produtividade e o rendimento de produção envolvem a quantidade produzida e a área plantada, como demonstra-se nas equações a seguir:

Equação 1- Produtividade $=\frac{\text { Quantidade Produzida }}{\text { Área Planta }}=$ Produt. $=\frac{\mathrm{Q}}{\mathrm{AP}}$
Equação $2-$ Rendimento Médio de produção $=\frac{\text { Quilograma }}{\text { Hectare }}=\mathrm{RM}=\frac{\mathrm{Kg}}{\mathrm{ha}}$
Equação $3-$ Produtividade Média $=\bar{P}=\frac{\mathrm{P} 1+\mathrm{p} 2+\mathrm{p} 3+\cdots}{n}$
Equação $4-$ Rendimento Médio $=\bar{R}=\frac{\mathrm{R} 1+\mathrm{R} 2+\mathrm{R} 3+\cdots}{n}$


Em que,

\section{n: período das safras por tipo de plantio}

O sistema plantio direto é composto por um conjunto de ações, cujo resultado objetivado é a sustentabilidade do negócio agrícola, maximizando os fatores do sistema e, ao mesmo tempo, reduzindo a degradação dos recursos naturais. Além de uma técnica de preparo de solo, envolve-se todo um conjunto de operações que permeiam o ciclo da cultura, assim como suas rotações e sucessões.

Com base nesse conceito, compreende-se que o sucesso do plantio direto dependerá de ações fundamentais, que são requisitos para sua implantação e manutenção, ressaltando-se, entre elas, as coberturas do solo, as semeadoras, o manejo do solo, a rotação das culturas, o controle de plantas daninhas, o controle de pragas e doenças, a colheita e a pós-colheita. 0 plantio direto tem cooperado para a melhoria do solo e dos lençóis freáticos e a fixação biológica de nitrogênio tem possibilitado a redução da aplicação de fertilizantes químicos. (ESALQ, 2018)

A Conab (Brasil, 1996) considera pacote tecnológico e coeficientes técnicos da produção o plantio de alta tecnologia. No cálculo do custo de produção de uma determinada cultura, consta a informação básica sobre combinação de insumos, de serviços, de máquinas e de implementos utilizados ao longo do processo produtivo, que indica a quantidade de cada item em particular, por unidade de área, e que resulta num determinado nível de produtividade.

Essas quantidades relacionadas à unidade de área (hectare) são denominadas de coeficientes técnicos de produção, podendo ser expressas em tonelada, quilograma ou litro (corretivos, fertilizantes, sementes e defensivos), em horas (máquinas e equipamentos) e em dia de trabalho (humano ou animal) e, dada as peculiaridades da atividade agrícola, os referidos coeficientes são influenciados diretamente pela diversidade de condições ambientais (clima, solo, topografia, sistema de cultivo etc.) que acomodam, na prática, uma grande variedade de padrões tecnológicos de produção (Brasil, 1996; Conab, 2018).

Os organismos geneticamente modificados (OGMs) são organismos vivos, sejam eles plantas, animais ou micro-organismos, cujo material genético foi alterado por meio de engenharia genética, seja pela introdução de sequências de DNA exógenas, que podem ser originárias de qualquer organismo vivo, inclusive de organismos filogeneticamente distantes à espécie a ser modificada, conforme Tozzini (2004 Apud Conceição, Moreira, Binsfeld, 2006), seja pela inativação de genes endógenos de acordo com Terada et al. (2002 Apud Conceição, Moreira, Binsfeld, 2006).

De acordo com a Embrapa, a transgenia é uma evolução do melhoramento genético convencional, uma vez que transfere características de interesse agronômico entre espécies diferentes. Dessa forma, essa tecnologia permite aos cientistas isolarem genes de microrganismos, por exemplo, e transferi-los para plantas com o objetivo de torná-las resistentes a doenças ou mais nutritivas, entre outras inúmeras aplicações. Transgênico é sinônimo para a expressão "Organismo Geneticamente Modificado" (OGM). É um organismo que recebeu um gene de outro organismo doador. Essa mudança no seu DNA permite que se manifeste uma característica que não havia antes.

É importante ressaltar que, na natureza, sempre ocorreram alterações ou mutações naturais. A Embrapa descreve que a técnica de cultivo mínimo consiste em um preparo mínimo do solo. Este tipo de preparo do solo é indicado para locais onde não se verifica forte compactação ou problemas com barreiras químicas, que demandariam calagem e gessagem, ou ainda a existência de pragas de solo. Essa técnica é indicada também para áreas mais declivosas, onde os problemas de erosão são mais críticos.

A metodologia de cálculo da Conab busca compor todos os dispêndios de custos consumidos na produção, sendo eles explícitos ou não, que começam pela preparação e correção do solo até a fase inicial de comercialização do produto. Para o cálculo dos custos relacionados a uma determinada cultura, por exemplo, para o milho, a metodologia considera o município produtivo, a diversidade das tecnologias de plantios e os custos dos fatores utilizados (Conab, 2010).

As quantidades produzidas e áreas plantadas foram coletados dos dados públicos do Sistema SIDRA do IBGE - Instituto Brasileiro de Geografia e Estatística e da Produção Agrícola Municipal (PAM). Já as tecnologias de plantios foram reunidas pelo site da CONAB - Companhia Nacional de Abastecimento por médio das informações dos dispêndios de custos em cada safra. Os índices de crescimento do PIB do Brasil e Participação do Agronegócio no PIB Brasil, foram utilizados a partir da coleta do site do IBGE, do 
IPEADATA - Instituto de Pesquisa Econômica Aplicada (Base de Dados Macroeconômicos) e do CEPEA Centro de Estudos Avançados em Economia Aplicada da Esalq - Escola Superior de Agricultura Luiz de Queiroz.

\section{ANÁLISE E DISCUSSÃO DOS RESULTADOS}

O estudo iniciou-se por meios dos dados de custeio da CONAB para cada cidade, safra e tipo de plantio, estruturando esses dados, coleta-se do site IBGE-PAM, os dados de produção, área plantada e rendimento médio da produção. Em uma segunda etapa organiza-se os tipos de plantios para cada cidade com suas devidas produções, áreas plantadas e rendimentos de produção. Em seguida, analisa-se o estudo mais relevante dessa pesquisa, onde verifica-se o comportamento de desempenho e o crescimento produtivo das amostras dos cultivos demilho, nos municípios de Rio Verde em Goiás Unaí em Minas gerais, Chapadão do sul em Mato Grosso do Sul, Primavera do Leste em Mato grosso e Passo Fundo em Rio Grande do Sul, resultando um crescimento. No resultado desse estudo, verificou-se o comportamento do desempenho da produção das safras de todas as cidades e as tecnologias de plantio empregadas. Os resultados são demonstrados por meio de gráficos, a produtividade média e rendimento médio à luz das tecnologias de plantio ao longo das safras.

A Tabela 1 apresenta-se os dados de quantidade produzida, área plantada, rendimento de produção por tecnologia de plantio, cidade e safra.

Tabela 1 de Dados da Amostra de Cultivo de Milho nos Municípios de e Rio Verde em Goiás Unaí em Minas gerais, Chapadão do sul em Mato Grosso do Sul, Primavera do Leste em Mato grosso e Passo Fundo em Rio Grande do Sul

\begin{tabular}{|c|c|c|c|c|c|}
\hline SAFRA & MUNICIPIO & TPO DE PLANTIO & $\begin{array}{l}\text { Produção } \\
\text { (ton.) }\end{array}$ & $\begin{array}{c}\text { Área } \\
\text { plantada } \\
\text { (ha) }\end{array}$ & $\begin{array}{l}\text { Rendimento da } \\
\text { produção } \\
(\mathrm{Kg} / \mathrm{ha})\end{array}$ \\
\hline $1998 / 99$ & RIO VERDE - GO & PLANTIO DIRETO (80\%) & 154.500 & 35.000 & 4.414 \\
\hline $1999 / 20$ & RIO VERDE - GO & PLANTIO DIRETO (80\%) & 230.700 & 57.000 & 4.806 \\
\hline $2000 / 01$ & RIO VERDE - GO & PLANTIO DIRETO (80\%) & 237.500 & 60.000 & 3.958 \\
\hline $2001 / 02$ & RIO VERDE - GO & PLANTIO DIRETO (80\%) & 285.400 & 56.000 & 5.285 \\
\hline $2002 / 03$ & RIO VERDE - GO & PLANTIO DIRETO (80\%) & 222.400 & 56.000 & 4.276 \\
\hline $2003 / 04$ & RIO VERDE - GO & PLANTIO DIRETO (80\%) & 225.900 & 43.000 & 5.253 \\
\hline $2004 / 05$ & RIO VERDE - GO & PLANTIO DIRETO (80\%) & 161.600 & 31.000 & 5.212 \\
\hline $2005 / 06$ & RIO VERDE - GO & PLANTIO DIRETO (80\%) & 132.000 & 31.000 & 4.258 \\
\hline $2006 / 07$ & RIO VERDE - GO & PLANTIO DIRETO (80\%) & 308.500 & 59.000 & 5.228 \\
\hline $2007 / 08$ & RIO VERDE - GO & PD & 320.500 & 77.000 & 4.162 \\
\hline $2008 / 09$ & RIO VERDE - GO & PD & 480.000 & 85.000 & 5.647 \\
\hline $2009 / 10$ & RIO VERDE - GO & PD & 508.000 & 95.330 & 5.328 \\
\hline $2010 / 11$ & RIO VERDE - GO & PD & 501.600 & 104.000 & 4.823 \\
\hline $2011 / 12$ & RIO VERDE - GO & $\begin{array}{l}\text { PLANTIO DIRETO-ALTA } \\
\text { TECNOLOGIA } \\
\end{array}$ & 667.250 & 128.500 & 5.193 \\
\hline $2012 / 13$ & RIO VERDE - GO & $\begin{array}{l}\text { PLANTIO DIRETO-ALTA } \\
\text { TECNOLOGIA } \\
\end{array}$ & 1.070 .000 & 190.000 & 5.632 \\
\hline $2013 / 14$ & RIO VERDE - GO & $\begin{array}{l}\text { PLANTIO DIRETO-ALTA } \\
\text { TECNOLOGIA } \\
\end{array}$ & 1.036 .800 & 213.000 & 4.868 \\
\hline $2014 / 15$ & RIO VERDE - GO & $\begin{array}{c}\text { PLANTIO DIRETO-ALTA } \\
\text { TECNOLOGIA } \\
\end{array}$ & 1.234 .500 & 216.000 & 5.715 \\
\hline $2005 / 06$ & UNAÍ - MG & PLANTIO DIRETO (100\%) & 253.200 & 44.000 & 5.754 \\
\hline $2006 / 07$ & UNAÍ - MG & PLANTIO DIRETO (100\%) & 163.200 & 34.000 & 4.800 \\
\hline $2007 / 08$ & UNAÍ - MG & PLANTIO DIRETO (100\%) & 247.200 & 46.000 & 5.373 \\
\hline $2008 / 09$ & UNAÍ - MG & PLANTIO DIRETO (100\%) & 255.900 & 37.000 & 6.916 \\
\hline $2009 / 10$ & UNAÍ - MG & PLANTIO DIRETO (100\%) & 296.500 & 36.500 & 8.123 \\
\hline $2010 / 11$ & UNAÍ - MG & PLANTIO DIRETO (100\%) & 236.500 & 29.000 & 8.155 \\
\hline $2011 / 12$ & UNAÍ - MG & $\begin{array}{c}\text { PLANTIO DIRETO-ALTA } \\
\text { TECNOLOGIA }\end{array}$ & 254.500 & 32.000 & 7.953 \\
\hline $2012 / 13$ & UNAÍ - MG & $\begin{array}{c}\text { PLANTIO DIRETO-ALTA } \\
\text { TECNOLOGIA }\end{array}$ & 351.000 & 45.000 & 7.800 \\
\hline
\end{tabular}


(Continuação)

Tabela 1 de Dados da Amostra de Cultivo de Milho nos Municípios de e Rio Verde em Goiás Unaí em Minas gerais, Chapadão do sul em Mato Grosso do Sul, Primavera do Leste em Mato grosso e Passo Fundo em Rio Grande do Sul

\begin{tabular}{|c|c|c|c|c|c|}
\hline SAFRA & MUNICIPIO & TPO DE PLANTIO & Produção (ton.) & $\begin{array}{c}\text { Área } \\
\text { plantada } \\
\text { (ha) }\end{array}$ & $\begin{array}{c}\text { Rendimento da } \\
\text { produção } \\
\text { (Kg/ha) }\end{array}$ \\
\hline $2013 / 14$ & UNAÍ - MG & $\begin{array}{c}\text { PLANTIO DIRETO-ALTA } \\
\text { TECNOLOGIA }\end{array}$ & 325.200 & 43.000 & 7.563 \\
\hline $2014 / 15$ & UNAÍ - MG & $\begin{array}{l}\text { PLANTIO DIRETO-ALTA } \\
\text { TECNOLOGIA }\end{array}$ & 316.800 & 53.000 & 5.977 \\
\hline $2015 / 16$ & UNAÍ - MG & $\begin{array}{l}\text { PLANTIO DIRETO-ALTA } \\
\text { TECNOLOGIA }\end{array}$ & 297.000 & 48.000 & 6.188 \\
\hline $2016 / 17$ & UNAÍ - MG & $\begin{array}{l}\text { PLANTIO DIRETO-ALTA } \\
\text { TECNOLOGIA }\end{array}$ & 213.000 & 61.000 & 3.492 \\
\hline $2017 / 18$ & UNAÍ - MG & $\begin{array}{l}\text { PLANTIO DIRETO-ALTA } \\
\text { TECNOLOGIA-OGM }\end{array}$ & 348.000 & 58.000 & 6.000 \\
\hline $2018 / 19$ & UNAÍ - MG & $\begin{array}{l}\text { PLANTIO DIRETO-ALTA } \\
\text { TECNOLOGIA-OGM }\end{array}$ & 380.400 & 56.000 & 6.793 \\
\hline $2007 / 08$ & CHAPADÃO DO SUL - MS & PLANTIO DIRETO (100\%) & 156.595 & 23.624 & 6.628 \\
\hline $2008 / 09$ & CHAPADÃO DO SUL - MS & PLANTIO DIRETO (100\%) & 204.000 & 30.000 & 6.800 \\
\hline $2009 / 10$ & CHAPADÃO DO SUL - MS & PLANTIO DIRETO (100\%) & 210.600 & 36.000 & 5.850 \\
\hline $2010 / 11$ & CHAPADÃO DO SUL - MS & PLANTIO DIRETO (100\%) & 179.600 & 31.000 & 5.793 \\
\hline $2011 / 12$ & CHAPADÃO DO SUL - MS & $\begin{array}{l}\text { PLANTIO DIRETO-ALTA } \\
\text { TECNOLOGIA }\end{array}$ & 141.408 & 25.000 & 5.656 \\
\hline $2012 / 13$ & CHAPADÃO DO SUL - MS & $\begin{array}{l}\text { PLANTIO DIRETO-ALTA } \\
\text { TECNOLOGIA }\end{array}$ & 222.000 & 31.000 & 7.161 \\
\hline $2013 / 14$ & CHAPADÃO DO SUL - MS & $\begin{array}{l}\text { PLANTIO DIRETO-ALTA } \\
\text { TECNOLOGIA }\end{array}$ & 333.900 & 48.800 & 6.842 \\
\hline $2014 / 15$ & CHAPADÃO DO SUL - MS & $\begin{array}{l}\text { PLANTIO DIRETO-ALTA } \\
\text { TECNOLOGIA-OGM }\end{array}$ & 278.400 & 38.000 & 7.326 \\
\hline $2015 / 16$ & CHAPADÃO DO SUL - MS & $\begin{array}{l}\text { PLANTIO DIRETO-ALTA } \\
\text { TECNOLOGIA-OGM }\end{array}$ & 310.400 & 40.000 & 7.760 \\
\hline $2016 / 17$ & CHAPADÃO DO SUL - MS & $\begin{array}{l}\text { PLANTIO DIRETO-ALTA } \\
\text { TECNOLOGIA-OGM }\end{array}$ & 221.250 & 38.150 & 5.799 \\
\hline $2017 / 18$ & CHAPADÃO DO SUL - MS & $\begin{array}{l}\text { PLANTIO DIRETO-ALTA } \\
\text { TECNOLOGIA-OGM }\end{array}$ & 288.000 & 40.000 & 7.200 \\
\hline $2018 / 19$ & CHAPADÃO DO SUL - MS & $\begin{array}{l}\text { PLANTIO DIRETO-ALTA } \\
\text { TECNOLOGIA-OGM }\end{array}$ & 216.000 & 34.000 & 6.353 \\
\hline $1997 / 98$ & $\begin{array}{l}\text { PRIMAVERA DO LESTE - } \\
\text { MT }\end{array}$ & PLANTIO DIRETO (50\%) & 139.838 & 39.708 & 3.521 \\
\hline $1998 / 99$ & $\begin{array}{l}\text { PRIMAVERA DO LESTE - } \\
\text { MT }\end{array}$ & PLANTIO DIRETO (50\%) & 64.740 & 32.000 & 2.232 \\
\hline $1999 / 20$ & $\begin{array}{l}\text { PRIMAVERA DO LESTE - } \\
\text { MT }\end{array}$ & PLANTIO DIRETO (50\%) & 64.679 & 25.309 & 3.035 \\
\hline
\end{tabular}


(Continuação)

Tabela 1 de Dados da Amostra de Cultivo de Milho nos Municípios de e Rio Verde em Goiás Unaí em Minas gerais, Chapadão do sul em Mato Grosso do Sul, Primavera do Leste em Mato grosso e Passo Fundo em Rio Grande do Sul

\begin{tabular}{|c|c|c|c|c|c|}
\hline SAFRA & MUNICIPIO & TPO DE PLANTIO & Produção (ton.) & $\begin{array}{c}\text { Área } \\
\text { plantada } \\
\text { (ha) }\end{array}$ & $\begin{array}{l}\text { Rendimento da } \\
\text { produção } \\
\text { (Kg/ha) }\end{array}$ \\
\hline $2000 / 01$ & $\begin{array}{c}\text { PRIMAVERA DO LESTE - } \\
\text { MT }\end{array}$ & PLANTIO DIRETO (50\%) & 71.832 & 37.393 & 1.921 \\
\hline $2001 / 02$ & $\begin{array}{l}\text { PRIMAVERA DO LESTE - } \\
\text { MT }\end{array}$ & PLANTIO DIRETO (50\%) & 134.369 & 32.000 & 4.199 \\
\hline $2002 / 03$ & $\begin{array}{c}\text { PRIMAVERA DO LESTE - } \\
\text { MT }\end{array}$ & PLANTIO DIRETO (50\%) & 141.570 & 35.000 & 4.044 \\
\hline $2003 / 04$ & $\begin{array}{l}\text { PRIMAVERA DO LESTE - } \\
\text { MT }\end{array}$ & PLANTIO DIRETO (50\%) & 151.649 & 32.234 & 4.704 \\
\hline $2004 / 05$ & $\begin{array}{c}\text { PRIMAVERA DO LESTE - } \\
\text { MT }\end{array}$ & PLANTIO DIRETO (50\%) & 112.770 & 24.234 & 4.653 \\
\hline $2005 / 06$ & $\begin{array}{l}\text { PRIMAVERA DO LESTE - } \\
\text { MT }\end{array}$ & PLANTIO DIRETO (50\%) & 109.546 & 26.363 & 4.219 \\
\hline $2006 / 07$ & $\begin{array}{c}\text { PRIMAVERA DO LESTE - } \\
\text { MT }\end{array}$ & PLANTIO DIRETO (50\%) & 157.573 & 32.966 & 4.779 \\
\hline $2007 / 08$ & $\begin{array}{l}\text { PRIMAVERA DO LESTE - } \\
\text { MT }\end{array}$ & PLANTIO DIRETO (50\%) & 310.993 & 69.994 & 4.443 \\
\hline $2008 / 09$ & $\begin{array}{c}\text { PRIMAVERA DO LESTE - } \\
\text { MT }\end{array}$ & PLANTIO DIRETO (50\%) & 366.945 & 73.050 & 5.023 \\
\hline $2009 / 10$ & $\begin{array}{l}\text { PRIMAVERA DO LESTE - } \\
\text { MT }\end{array}$ & PLANTIO DIRETO (50\%) & 385.220 & 71.200 & 5.410 \\
\hline $2010 / 11$ & $\begin{array}{l}\text { PRIMAVERA DO LESTE - } \\
\text { MT }\end{array}$ & PLANTIO DIRETO (50\%) & 407.360 & 84.700 & 4.809 \\
\hline $2011 / 12$ & $\begin{array}{l}\text { PRIMAVERA DO LESTE - } \\
\text { MT }\end{array}$ & $\begin{array}{c}\text { PLANTIO DIRETO-ALTA } \\
\text { TECNOLOGIA } \\
\end{array}$ & 382.630 & 88.641 & 4.317 \\
\hline $2012 / 13$ & $\begin{array}{c}\text { PRIMAVERA DO LESTE - } \\
\text { MT }\end{array}$ & $\begin{array}{c}\text { PLANTIO DIRETO-ALTA } \\
\text { TECNOLOGIA } \\
\end{array}$ & 588.748 & 97.325 & 6.049 \\
\hline $2013 / 14$ & $\begin{array}{l}\text { PRIMAVERA DO LESTE - } \\
\text { MT }\end{array}$ & $\begin{array}{c}\text { PLANTIO DIRETO-ALTA } \\
\text { TECNOLOGIA }\end{array}$ & 683.962 & 112.020 & 6.106 \\
\hline $2008 / 09$ & Passo Fundo - RS & PLANTIO DIRETO (60\%) & 13.860 & 2.200 & 6.300 \\
\hline $2009 / 10$ & Passo Fundo - RS & PLANTIO DIRETO (60\%) & 11.040 & 2.300 & 4.800 \\
\hline $2010 / 11$ & Passo Fundo - RS & PLANTIO DIRETO (60\%) & 16.200 & 2.000 & 8.100 \\
\hline $2011 / 12$ & Passo Fundo - RS & $\begin{array}{c}\text { PLANTIO DIRETO-ALTA } \\
\text { TECNOLOGIA }\end{array}$ & 22.500 & 2.500 & 9.000 \\
\hline $2012 / 13$ & Passo Fundo - RS & $\begin{array}{c}\text { PLANTIO DIRETO-ALTA } \\
\text { TECNOLOGIA } \\
\end{array}$ & 12.240 & 3.500 & 3.600 \\
\hline $2013 / 14$ & Passo Fundo - RS & $\begin{array}{c}\text { PLANTIO DIRETO-ALTA } \\
\text { TECNOLOGIA } \\
\end{array}$ & 13.650 & 2.100 & 6.500 \\
\hline $2014 / 15$ & Passo Fundo - RS & $\begin{array}{l}\text { PLANTIO DIRETO-ALTA } \\
\text { TECNOLOGIA-OGM }\end{array}$ & 10.400 & 1.600 & 6.500 \\
\hline $2015 / 16$ & Passo Fundo - RS & $\begin{array}{l}\text { PLANTIO DIRETO-ALTA } \\
\text { TECNOLOGIA-OGM }\end{array}$ & 10.800 & 1.200 & 9.000 \\
\hline $2016 / 17$ & Passo Fundo - RS & $\begin{array}{l}\text { PLANTIO DIRETO-ALTA } \\
\text { TECNOLOGIA-OGM }\end{array}$ & 9.000 & 1.000 & 9.000 \\
\hline $2017 / 18$ & Passo Fundo - RS & $\begin{array}{l}\text { PLANTIO DIRETO-ALTA } \\
\text { TECNOLOGIA-OGM }\end{array}$ & 9.000 & 1.000 & 9.000 \\
\hline $2018 / 19$ & Passo Fundo - RS & $\begin{array}{l}\text { PLANTIO DIRETO-ALTA } \\
\text { TECNOLOGIA-OGM }\end{array}$ & 10.920 & 1.400 & 7.800 \\
\hline
\end{tabular}

Fonte: CONAB e IBGE-PAM

Dados as amostras da tabela 1, explora-se a produtividade que é medida pela relação da quantidade de produção e área plantada, logo após, observa-se os resultados obtidos das produtividades médias dos 
Municípios, a evolução produtiva com seus devidos tipos de plantios.

No Gráfico 1 - 0 município de Rio Verde- GO observa-se que sua produtividade entre o plantio direto 80\% e o plantio direto $100 \%$ houve um aumento de $8 \%$, enquanto ocorre o mesmo entre os plantio direto $100 \%$ e plantio de direto com alta tecnologia, um aumento de 7\%, resultando em todas safras entre $1998 / 99$ e 2014/15, e os tipos de plantio da amostra um aumento produtivo total de $16 \%$.

Gráfico 1 - Produtividade média por Tecnologia de Plantio ao longo das safras 1998/99 e 2014/15 -

Cultivo de Milho nos Municípios de RIO VERDE - GO

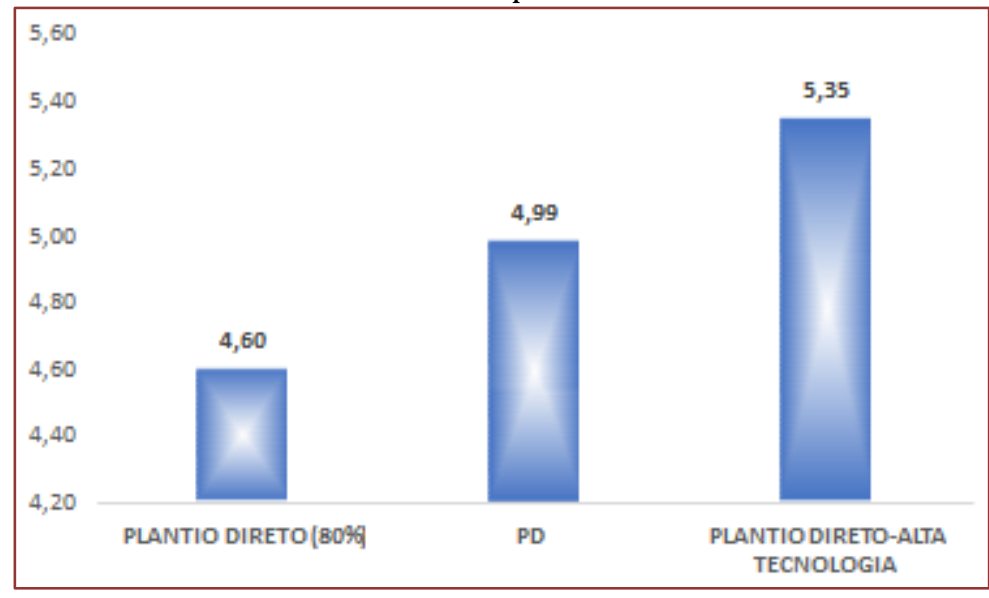

Fonte: CONAB e IBGE-PAM

No Gráfico 2 - 0 município de Unaí-MG observa-se que sua produtividade entre o plantio direto $100 \%$ e o plantio de direto com alta tecnologia houve uma diminuição de $-0,4 \%$, enquanto ocorre o mesmo entre o plantio de direto com alta tecnologia e plantio direto com alta tecnologia e OGM, uma diminuição de -1,5\%, resultando em todas safras entre 2005/06 e 2018/19, e os tipos de plantio da amostra um total de diminuição produtiva de $-1,9 \%$.

Gráfico2 - Produtividade média por Tecnologia de Plantio ao longo das safras 2005/06 e 2018/19- Cultivo de Milho nos Municípios de UNAÍ - MG

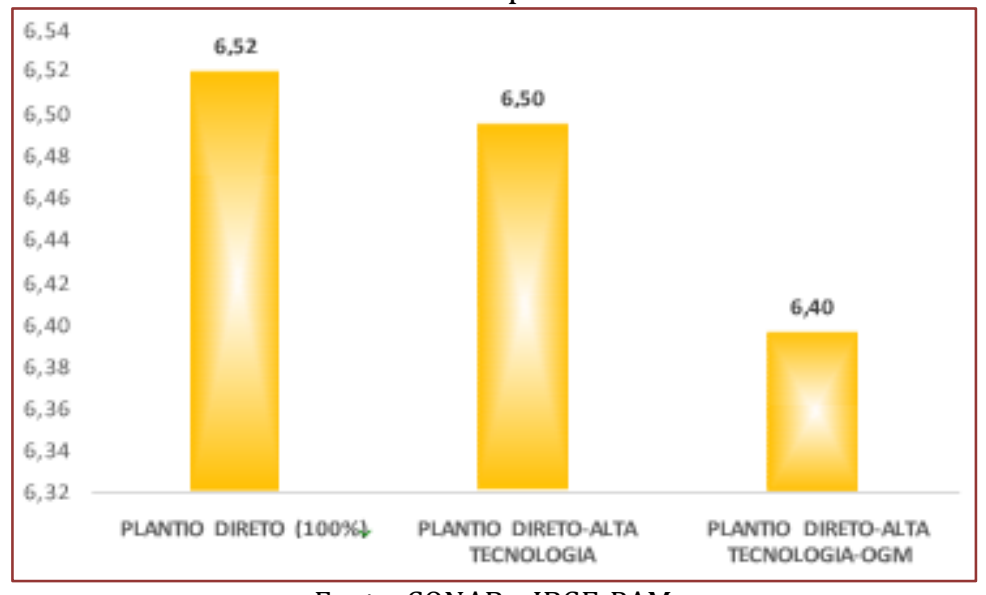

Fonte: CONAB e IBGE-PAM

O Gráfico 3 - 0 município de Chapadão do Sul - MS observa-se que sua produtividade entre o plantio direto $100 \%$ e o plantio de direto com alta tecnologia houve um aumento de $5 \%$, enquanto ocorre o mesmo entre o plantio de direto com alta tecnologia e plantio direto com alta tecnologia e OGM, um aumento de 5\%, resultando em todas safras entre 2007/08 e 2018/19, e os tipos de plantio da amostra um total de aumento produtivo de $10 \%$. 
Gráfico 1 - Produtividade média por Tecnologia de Plantio ao longo das safras 2007/08 e 2018/19- Cultivo de Milho nos Municípios de CHAPADÃO DO SUL - MS

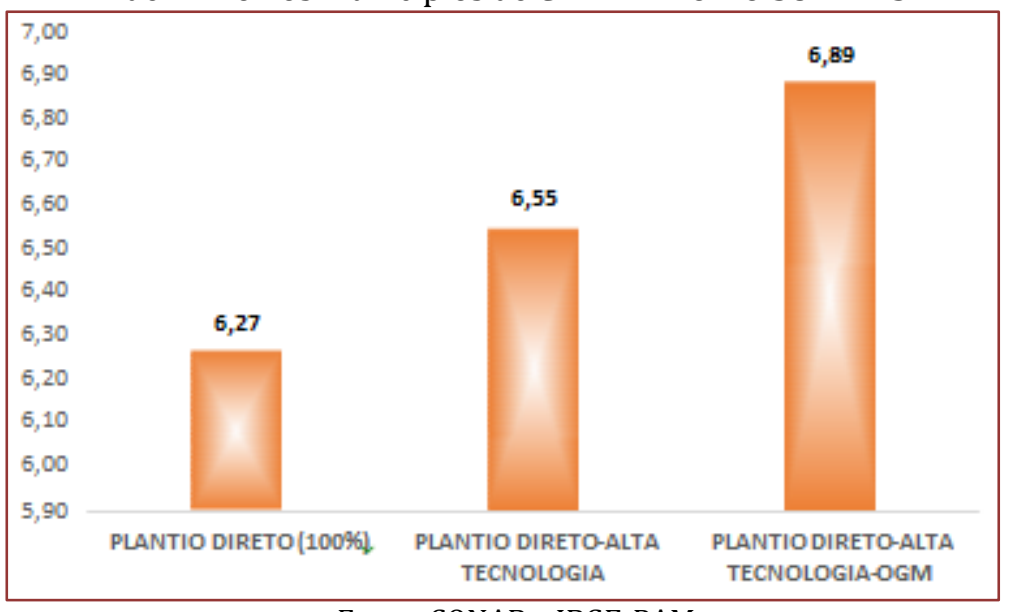

Fonte: CONAB e IBGE-PAM

No Gráfico 4 - 0 município de Primavera do Leste - MT observa-se que sua produtividade entre o plantio direto $50 \%$ e o plantio de direto com alta tecnologia houve um aumento de $37 \%$, resultando em todas safras entre 1997/98 e 2013/14, e os tipos de plantio da amostra um total de aumento produtivo de $37 \%$.

Gráfico 4 - Produtividade média por Tecnologia de Plantio ao longo das safras 1997/98 e 2013/14, Cultivo de Milho nos Municípios de PRIMAVERA DO LESTE - MT

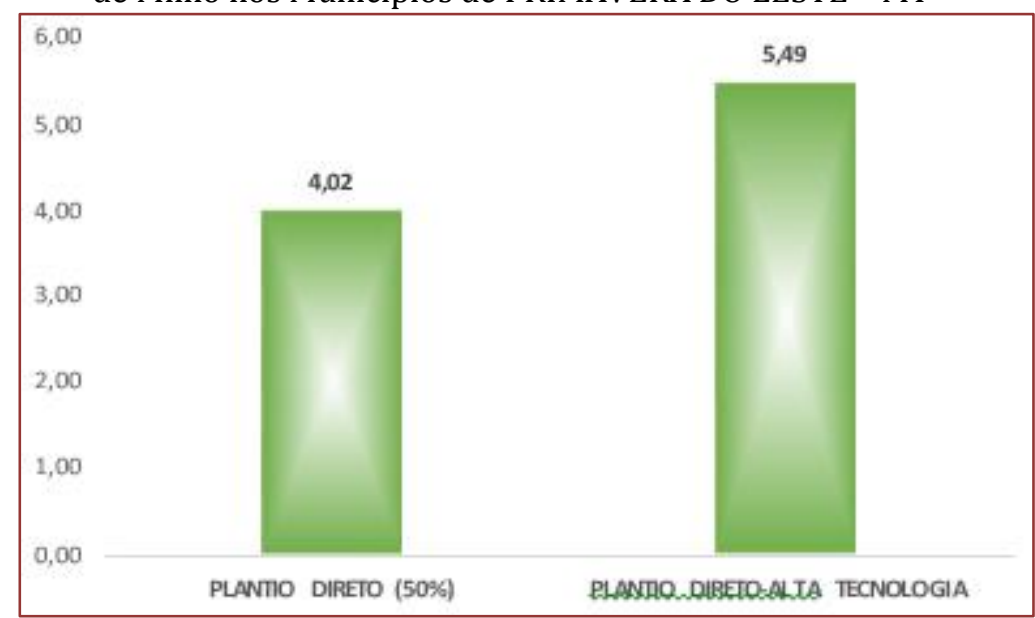

Fonte: CONAB e IBGE-PAM

No Gráfico 5 - 0 município de Passo Fundo - RS observa-se que sua produtividade entre o plantio direto $60 \%$ e o plantio de direto com alta tecnologia houve uma diminuição de - $1 \%$, enquanto que, entre o plantio de direto com alta tecnologia e plantio direto com alta tecnologia e OGM, um aumento de $30 \%$, resultando em todas safras entre 2008/09 e 2018/19, e os tipos de plantio da amostra um total de aumento produtivo de $29 \%$. 
Gráfico 5 - Produtividade média por Tecnologia de Plantio ao longo das safras 2008/09 e 2018/19- Cultivo de Milho nos Municípios de Passo Fundo - RS

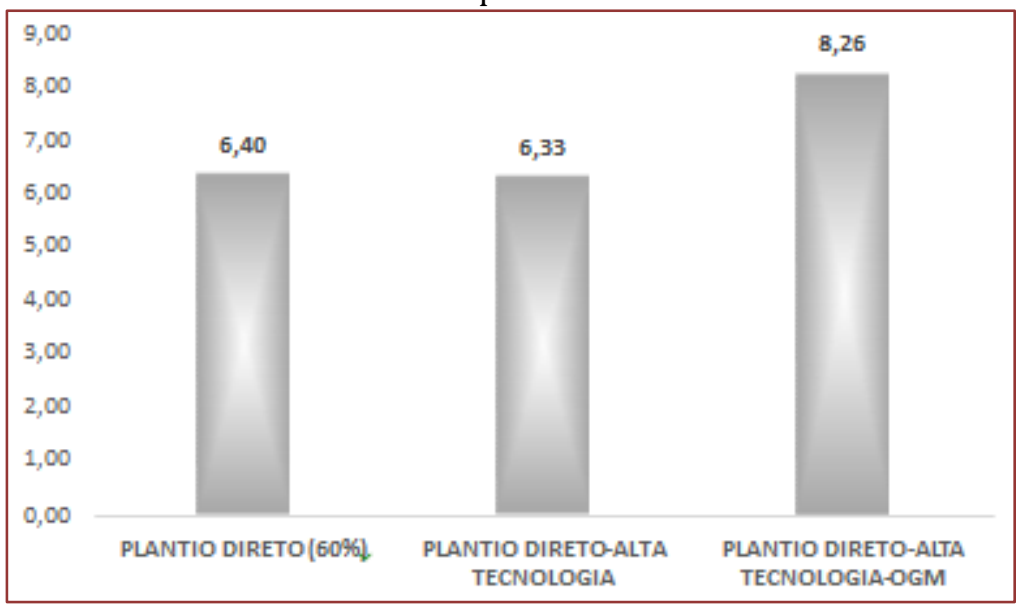

Fonte: CONAB e IBGE-PAM

Dados as amostras da tabela 1, explora-se a Rentabilidade de Produção, não apenas dentro safra, mas entre as safras e o tipo de plantio tecnológico, que é a medida da somatória média da rentabilidade médias das safras para cada tipo de plantio tecnológico, demonstrado dessa forma, o comparativo entre as médias de rentabilidades os tipos de plantios tecnológicos.

O objetivo dessa demonstração é calcular a somatória da média de rentabilidade de produção, que é a relação entre a produção e área plantada em quilos e o hectare, demonstrando mais uma vez que, a cultura de milho é muito dependente em relação a fertilidade do solo e sua preservação da camada superficial, esclarecendo que o sistema de plantio direto reduze a perda de solo em $650 \mathrm{~kg} \mathrm{ha}^{-1} \mathrm{ano}^{-1}$, se comparado ao sistema convencional (SC), conforme explicação de Hernani et al, 1999

No Gráfico 6 - 0 município de Rio Verde- GO observa-se que sua rentabilidade de produção entre o plantio direto $80 \%$ e o plantio direto $100 \%$ houve um aumento de $5 \%$, enquanto ocorre o mesmo entre os plantio direto $100 \%$ e plantio de direto com alta tecnologia, um aumento de 7\%, resultando em todas safras entre 1998/99 e 2014/15, e os tipos de plantio da amostra um aumento rentabilidade total de produção de $13 \%$.

Gráfico 6 - Rendimento Médio por Tecnologia de Plantio ao longo das safras 1998/99 e 2014/15- Cultivo de Milho nos Municípios de RIO VERDE - GO

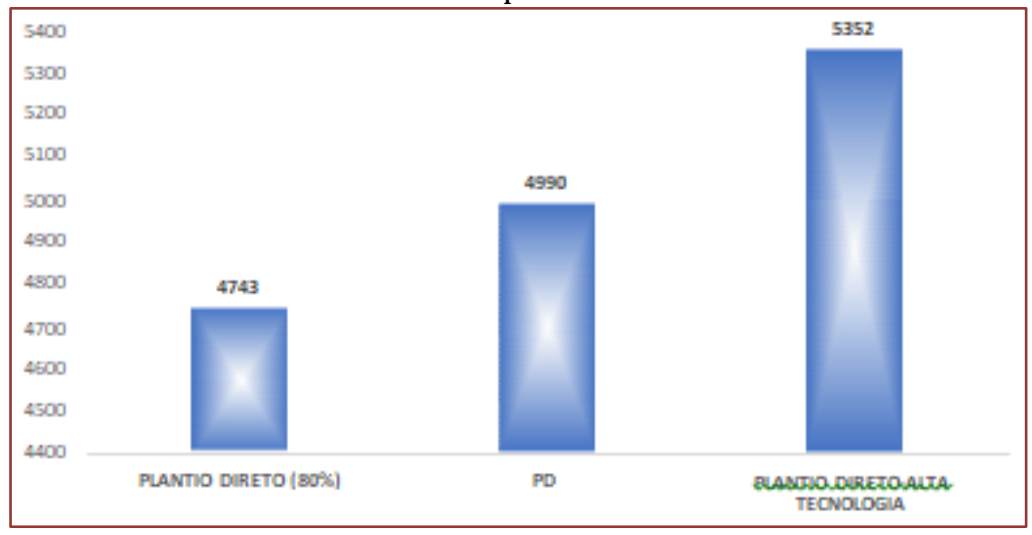

Fonte: CONAB e IBGE-PAM

No Gráfico 7 - 0 município de Unaí-MG observa-se que sua rentabilidade de produção entre o plantio direto $100 \%$ e o plantio de direto com alta tecnologia houve uma diminuição de - $0,4 \%$, enquanto ocorre o mesmo entre o plantio de direto com alta tecnologia e plantio direto com alta tecnologia e OGM, uma diminuição de $-1,5 \%$, resultando em todas safras entre 2005/06 e 2018/19, e os tipos de plantio da amostra uma diminuição de rentabilidade total de produção de $-1,9 \%$. 
Gráfico 7 - Rendimento Médio por Tecnologia de Plantio ao longo das safras 2005/06 e 2018/19- Cultivo de Milho nos Municípios de UNAÍ - MG

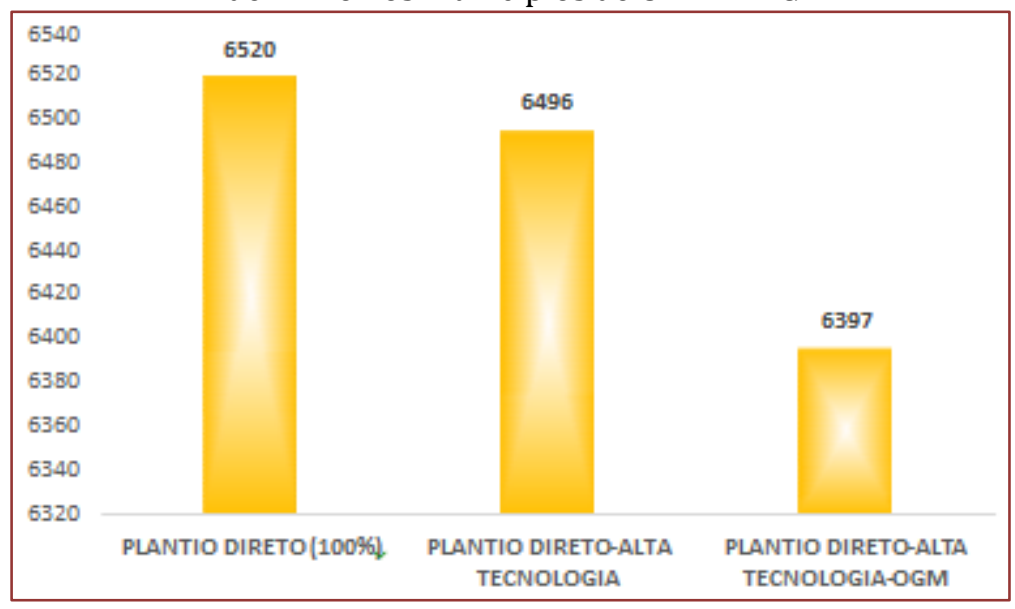

Fonte: CONAB e IBGE-PAM

No Gráfico 8 - 0 município de Chapadão do Sul - MS observa-se que sua rentabilidade de produção entre o plantio direto $100 \%$ e o plantio de direto com alta tecnologia houve um aumento de $5 \%$, enquanto ocorre o mesmo entre o plantio de direto com alta tecnologia e plantio direto com alta tecnologia e OGM, um aumento de 5\%, resultando em todas safras entre 2007/08 e 2018/19, e tipos de plantio da amostra um aumento de rentabilidade total de produção de $10 \%$.

Gráfico 8 - Rendimento Médio por Tecnologia de Plantio ao longo das safras 2007/08 e 2018/19- Cultivo de Milho nos Municípios de CHAPADÃO DO SUL - MS

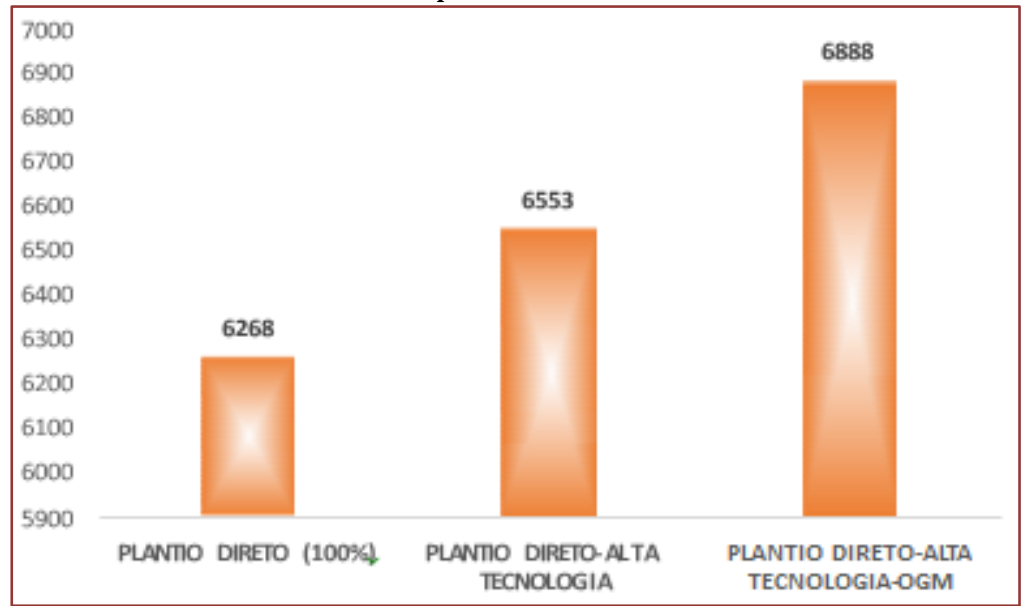

Fonte: CONAB e IBGE-PAM

No Gráfico 9 - 0 município de Primavera do Leste - MT observa-se que sua rentabilidade de produção entre o plantio direto $50 \%$ e o plantio de direto com alta tecnologia houve um aumento de $37 \%$, resultando em todas safras entre 1997/98 e 2013/14, e os tipos de plantio da amostra um total de aumento de rentabilidade total de produção de $37 \%$. 
Gráfico 9 - Rendimento Médio por Tecnologia de Plantio ao longo das safras 1997/98 e 2013/14- Cultivo de Milho nos Municípios de PRIMAVERA DO LESTE - MT

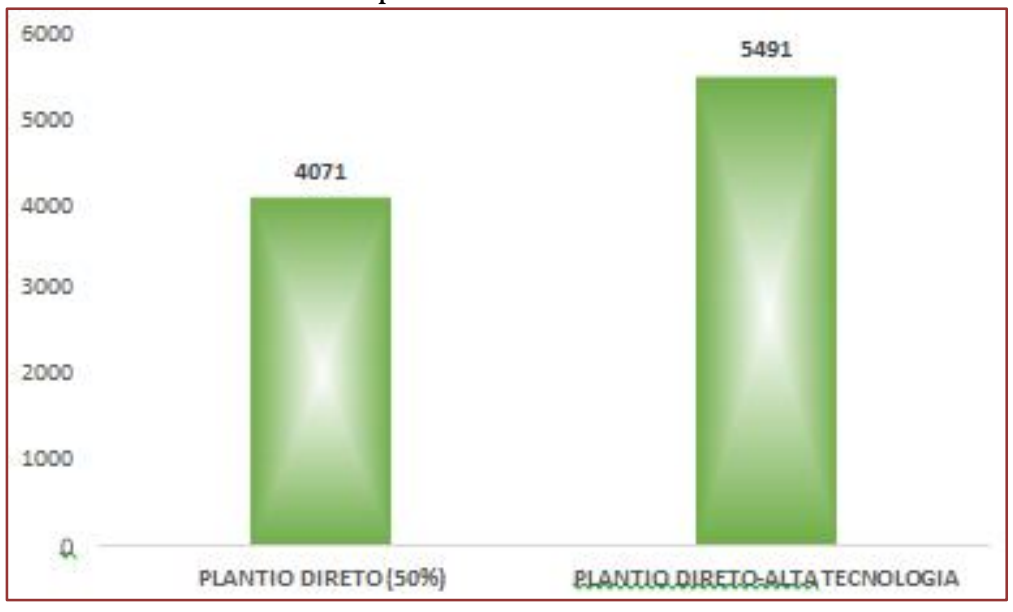

Fonte: CONAB e IBGE-PAM

No Gráfico 10 - 0 município de Passo Fundo - RS observa-se que sua rentabilidade de produção entre o plantio direto $60 \%$ e o plantio de direto com alta tecnologia houve uma diminuição de -1\%, enquanto que, entre o plantio de direto com alta tecnologia e plantio direto com alta tecnologia e OGM, um aumento de $29 \%$, resultando em todas safras entre 2008/09 e 2018/19, e os tipos de plantio da amostra um total de aumento rentabilidade de produção de $29 \%$.

Gráfico 10 - Produtividade média por Tecnologia de Plantio ao longo das safras 2008/09 e 2018/19-

Cultivo de Milho nos Municípios de Passo Fundo - RS

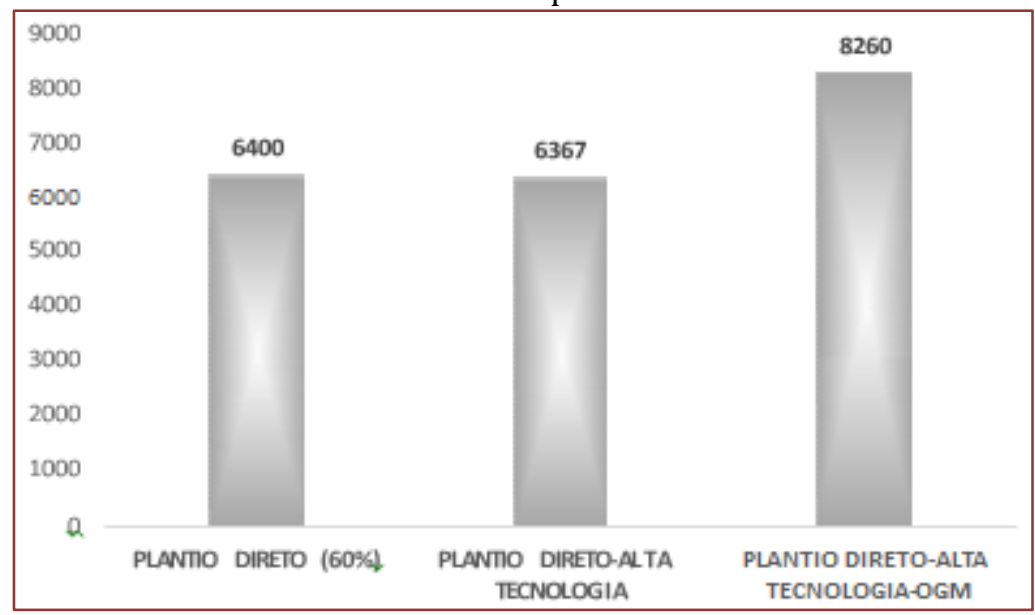

Fonte: CONAB e IBGE-PAM

\section{CONSIDERAÇÕES FINAIS}

Baseado na prioridade da sociedade por aumento da demanda por alimentos, nos impactos da inovação tecnológica na produção agrícola e na relevância da produção no setor de agronegócio como estratégica e política para o Brasil e para o mundo, evidencia-se que, nos últimos 20 anos, conforme a CNA e o CEPEA (2017), toda cadeia do setor de agronegócio (PIB do Agronegócio é avaliado de forma discriminada em quatro segmentos: insumos, primários-agropecuária, agroindústria-bases agrícola e pecuária e agroserviços) vem contribuindo em média com 24,3\% do PIB brasileiro. Mesmo em anos de crise histórica no Brasil, como 2014, 2015 e 2016, a participação do PIB do agronegócio no PIB brasileiro foi na ordem de $19,1 \%, 20,5 \%$ e $22,8 \%$ respectivamente.

Para tanto, o presente trabalho avalia a produtividade e a rentabilidade do cultivo do milho nos municípios de Rio Verde em Goiás Unaí em Minas gerais, Chapadão do sul em Mato Grosso do Sul, Primavera do Leste em Mato grosso e Passo Fundo em Rio Grande do Sul, com o objetivo de analisar a importância da inovação tecnológica no setor, tendo como referência as principais teorias econômicas evolucionárias, que 
asseveram que as atividades científicas e tecnológicas são fortes atributos no papel de fatores econômicos, por meio de pesquisa com diferentes tecnologias de plantio aplicadas no campo.

Para avaliar os impactos tecnológicos sobre a atividade do cultivo de milho, são coletadas os dados de quantidades produzidas, as áreas plantadas, a rentabilidade de produção de cada safra e o seu tipo de plantio que serão sintetizadas no cálculo da produtividade e rendimento da produção de acordo com decorrer das tecnologias de plantios empregadas no cultivo do milho.

No decorrer dos anos, o crescimento vertiginoso na produção de milho graças à incorporação de novas tecnologias no processo de produção desse sistema de cultivo, destacando-se a participação do Milho Safrinha no abastecimento de milho nos municípios empregados. Para tal crescimento, a tecnologia vem mudando os sistemas de produção de milho no Brasil, por meio de utilização de cultivares de alto potencial genético (híbridos simples e triplos) e de cultivares não transgênicas e transgênicas com resistência a lagartas e ao uso do herbicida glifosato, espaçamento reduzido associado à maior densidade de plantio, permitindo melhor controle de plantas daninhas, controle de erosão, melhor aproveitamento de água, luz e nutrientes, além de permitir uma otimização das máquinas plantadoras, melhoria na qualidade das sementes associada ao tratamento dos grãos, especialmente o tratamento industrial, máquinas e equipamentos de melhor qualidade, que garante boa plantabilidade, boa distribuição das plantas emergidas, garantindo assim maior índice de sobrevivência do plantio à colheita, uso intensivo do Manejo Integrado de Pragas, Doenças e Plantas Daninhas (MIP), correção do solo baseando-se em dados de análise e levando em consideração o sistema, e não a cultura individualmente, tornando o cultivo mais profissional pelos produtores por meio de papelcada vez mais importante de técnicos, consultores e extensionistas das redes públicas e privadas, além do maior fluxo de informações via mídias especializadas.

Essa inovação é um desenvolvimento que resultou em extensão do produto com novos processos e nova organização, um fator chave para explicar os ciclos econômicos e a dinâmica do crescimento econômico da produção do milho e colaboração com crescimento do setor de agronegócio.

Na ótica da tecnologia mencionada em todo o trabalho e baseado nos cálculos, os resultados advindos dos números representam esses cenários e demonstram que, ao longo das safras o município de Rio Verde GO, a produtividade cresceu em $16 \%$ e a rentabilidade de produção $13 \%$, o município de Unaí - MG, a produtividade teve um decréscimo de 1,9 e a rentabilidade de produção 1,9\% negativa, o município de Chapadão do Sul - MS, a produtividade cresceu em $10 \%$ e a rentabilidade de produção $10 \%$, o município de Primavera do Leste - MT, a produtividade cresceu em 37\% e a rentabilidade de produção $35 \%$, e município de Passo Fundo - RS, a produtividade cresceu em 29\% e a rentabilidade de produção 29\%.

Os resultados reproduziram que as tecnologias de plantios empregadas ao longo das safras foram expressivamente crescentes nas produtividades, bem como nas rentabilidades de produções dos municípios, exceto no município de Unaí - MG.

Em Unaí - MG as tecnologias de plantios não resultaram maior produtividade e rentabilidade nesse município no cultivo do milho. Conforme Oliveira, Marcelo; et al., Efeitos da Introdução do Sistema de Plantio Direto de Milho por Agricultores Familiares do Município de Unaí, MG (Cerrado Brasileiro), colocalizado no site www.agro.ufg.br/pat, em 2020, o uso de herbicidas, para desenvolver condições de plantio no Sistema de Plantio Direto, resultou em custo médio por hectare de R\$ 64,89. No plantio convencional dos anos 2002/2003 e 2003/2004, os custos por hectare, para o preparo de solo, foram de $\mathrm{R} \$ 63,32$ e $\mathrm{R} \$ 125,24$, respectivamente. Os agricultores também aumentaram o número de passagens de grade de arado e acrescentaram uma gradagem niveladora, ou aumentaram o tempo trabalhado. Ainda que, desse esforço, não obteve melhoria significativa na qualidade do preparo de solo, pois não se resolveu o problema da disponibilidade de máquinas e equipamentos, da época de realização da operação e das condições do solo. Outro dado importante no emprego de Sistema de Plantio Direto é a capacitação dos agricultores, reconhecimento das plantas daninhas, escolha dos herbicidas e calibração dos equipamentos de aplicação, para garantir a eficiência do controle. 


\section{REFERÊNCIAS}

[1] ANP - Agência Nacional do Petróleo, Gás Natural e Biocombustíveis. Disponível em: http://www.anp.gov.br/. Acesso; dezembro 2018

[2] CEPEA Cent Pesquis Econômicas Esco Superior. Disponível em: https://www.cepea.esalq.usp.br/br. Acesso; novembro 2018

[3] Centro de Estudos Avançados em Economia Aplicada (CEPEA). Metodologia PIB do agronegócio brasileiro: base e evolução. $\quad$ Piracicaba, $2017 . \quad$ Disponível em: https://www.cepea.esalq.usp.br/upload/kceditor/files/Metodologia\%20PIB_divulga\%C3\%A7\%C3\%A 3o.pdf. Acesso em março de 2019.

[4] CNA Confederação da Agricultura e Pecuária do Brasil. Disponível em: https://www.cnabrasil.org.br/. Acesso: novembro 2018

[5] CONAB. Companhia Nacional de Abastecimento. Disponível em https://www.conab.gov.br/. Acesso Novembro 2018

[6] CONCEIÇÃO, Fabricio R.; Moreira, Angela N.; BINSFELD, Pedro C. Detecção e quantificação de organismos geneticamemte modificados em alimentos e ingredientes alimentares, Ciência Rural, Santa Maria, v.36, n.1, p.315-324, jan-fev, 2006 I

[7] CONCEIÇÃO, Octavio A. C. A centralidade do Conceito de inovação tecnológica no processo de mudança estrutural. Ensaios FEEE. Porto Alegre, v. 21, n. 2, p. 58-76,2000.

[8] DOSI, G. Sources, procedures, and microeconomic effects of innovation. Journal of Economic Literature, v. 26, p. 1120-1171, September 1988.

[9] Technical change and industrial transformation. New York: St. Martin's Press, 1984. 338 p.

[10] DOSI, G. Mudança Técnicas e Transformação Industrial. Editora Unicamp, 2006. Capitulos 2.1, 2.2 e 5.1

[11] Escola Superior de Agricultura "Luiz de Queiroz", Visão Agrícola, USP ESALQ ANO 9 JUL | DEZ 2015

[12] GASQUES, J.G. \& VERDE, J.E.R. Crescimento da agricultura brasileira e política agrícola nos anos oitenta. Agricultura em São Paulo, 37(1): 183-204, 1990.

[13] GASQUES, J.G. \& VIEIRA, C.M.V. Agricultura, transformação produtiva e sustentabilidade. Instituto de Pesquisa Econômica Aplicada Brasília: Ipea, 2016.

[14] INSTITUTO BRASILEIRO DE GEOGRAFIA E ESTATÍSTICA (IBGE).IPEADATA Instituto de Pesquisas Economicas. Disponível em: http://www.ipeadata.gov.br/Default.aspx. Acesso: nombro 2018

[15] KUPFER, D. (1991) Padrões de concorrência e competitividade. Rio de Janeiro: IEI/UFRJ. Texto para Discussão $\mathrm{n}$

[16] NELSON, R. R.; WINTER, S. G. Uma Teoria Evolucionária da Mudança Econômica. Editora Unicamp, 2012. Capítulos 10 e 11

[17] Oliveira, Marcelo; Xavier, José; Silva, Fernando; Scopel, Eric; Zoby, José. Efeitos da Introdução do Sistema de Plantio Direto de Milho por Agricultores Familiares do Município de Unaí, MG (Cerrado Brasileiro). Goiânia, GO, Brasil, 2009

[18] PAGGIOSSI, LUCIMARI. Inovação tecnológica e eficiência econômica de produção agrícola. São Paulo, 2019, 93p.

[19] PAM Produção Agrícola Municipal. Disponível: em https://sidra.ibge.gov.br/pesquisa/pam/tabelas. Acesso: novembro 2018

[20] SCHUMPETER, Joseph A. Capitalismo, socialismo, democracia. Rio de Janeiro: Fundo de Cultura, 1961.

[21] Fundamentos do pensamento econômico. Rio de Janeiro: Zahar Editores, 1968.

[22] Teoria do desenvolvimento econômico: uma investigação sobre lucros, capital, crédito, juro e o ciclo econômico. São Paulo: Abril Cultural, 1982.

[23] O fenômeno fundamental do desenvolvimento econômico. In A Teoria do Desenvolvimento Econômico. Rio de Janeiro: Nova Cultural, 1985.

[24] TERADA, R. et al. Efficient gene targeting by homologous recombination in rice. Nature Biotechnology, v.20, p.1030-1034, 2002

[25] TOZZINI A.C. Detección de OGMs en la Cadena Agroalimentaria. In: ECHENIQUE, V. et al. Biotecnología y mejoramiento vegetal. Buenos Aires: INTA, 2004. p.409-424. 


\section{Capítulo 8}

Produção de soja e desmatamento na Amazônia Legal: Um estudo a partir da análise exploratória de dados espaciais

Anderson Pereira Rocha

Walberti Saith

Manuel Antonio Valdés Borrero

Resumo: A Amazônia Legal é palco de discussões científicas e políticas em torno de sua preservação, por tratar-se de uma das maiores florestas tropicais do mundo, consonante à sua importância para mitigação dos efeitos das mudanças climáticas. 0 presente estudo teve como objetivo verificar os impactos da produção de soja em face do desmatamento na Amazônia Legal. Utilizamos estatísticas espaciais para verificar a distribuição da área plantada de soja e desmatamento na Amazônia Legal e suas relações. Os resultados indicam a presença de autocorrelação positiva para todos os anos analisados e a formação de clusters significativos alto-alto e alto-baixo em ambos os anos. Verificamos assim, que existem evidências que o crescimento da soja está levando ao aumento do desmatamento na Amazônia Legal.

Palavras-chave: AEDE, Clusters, Convergência, Econometria Espacial, Fronteira Agrícola. 


\section{INTRODUÇÃO}

A divisão geográfica da Amazônia brasileira foi delimitada a partir da lei no 1.806, (criação da Superintendência do Plano de Valorização Econômica da Amazônia - SPVEA) de 06 de janeiro de 1953, para fins de planejamento e inserção de políticas públicas na região. Em seu artigo $2^{o}$ é definido que a Amazônia brasileira era compreendida pela área dos "Estados do Pará e do Amazonas, pelos territórios federais do Acre, Amapá, Guaporé e Rio Branco e ainda, a parte do Estado de Mato Grosso a norte do paralelo de 16으, a do Estado de Goiás a norte do paralelo de 13ำ e a do Maranhão a oeste do meridiano de 440" (BRASIL, 1953).

A lei no 5.173 (que extinguiu a SPVEA e criou a Superintendência do Desenvolvimento da Amazônia SUDAM), de 27 de outubro de 1966, no seu artigo segundo, define a região Amazônica brasileira a área "compreendida pelos Estados do Acre, Pará e Amazonas, pelos Territórios Federais do Amapá, Roraima e Rondônia, e ainda pelas áreas do Estado de Mato Grosso a norte do paralelo 16ํㅡㄹ do Estado de Goiás a norte do paralelo 13o e do Estado do Maranhão a oeste do meridiano de 440" (BRASIL, 1966).

Os decretos lei no 291, de 28 de fevereiro de 1967 e no 365, de 15 de agosto de 1968, caracterizam como Amazônia Ocidental, a faixa territorial composta pelos Estados do Amazonas, Acre e territórios de Rondônia e Roraima (BRASIL, 1967). Por exclusão, a Amazônia Ocidental é formada pelos Estados do Pará, de Mato Grosso a norte do paralelo 16으, do Estado de Goiás a norte do paralelo $13^{\circ}$ e do Estado do Maranhão a oeste do meridiano de 44, pelo Território Federal do Amapá.

Através do artigo 45 da Lei complementar no 31 (cria o Estado do Mato Grosso do Sul), de 11 de outubro 1977, a região amazônica "compreenderá também toda a área do Estado de Mato Grosso" (BRASIL, 1977). E por fim, com as disposições transitórias da Constituição Federal da República Federativa do Brasil, de 05 de outubro de 1988, em seu artigo 13 é criado o Estado do Tocantins (com área desmembrada do Estado de Goiás) e no artigo 14 "os Territórios Federais de Roraima e do Amapá são transformados em Estados federados" (BRASIL, 1988).

No arcabouço jurídico, o termo Amazônia Legal foi utilizado pela primeira vez na Lei no 11.952 , de 25 de junho de 2009, onde é citado em alguns dos seus artigos, mas não é definido formalmente como referência alusiva à Amazônia brasileira (BRASIL, 2009). A lei no 12.651 (Código Florestal), de 25 de maio de 2012, em seu inciso primeiro do art. $3^{\circ}$, define para seus efeitos que o espaço geográfico chamado Amazônia Brasileira passa a ser chamado de Amazônia Legal, sendo formada pela área pertencente dos "Estados do Acre, Pará, Amazonas, Roraima, Rondônia, Amapá e Mato Grosso e as regiões situadas ao norte do paralelo $13^{\circ} \mathrm{S}$, dos Estados de Tocantins e Goiás, e ao oeste do meridiano de 44ㅇ W, do Estado do Maranhão" (BRASIL, 2012).

A Amazônia Legal possui uma área aproximada de $5.217 .423 \mathrm{~km}^{2}$, o que corresponde a cerca de $60 \%$ da área do território brasileiro. Além do bioma Amazônia (que é predominante na região), parte do território geográfico da Amazônia Legal é coberto por outros biomas, como o Cerrado e o Pantanal, tendo também outras matas de transição.

Embora o Estado brasileiro tenha investido diversos esforços, seja por meio de atividades de planejamento e ações de políticas públicas voltadas à região, o desenvolvimento econômico da Amazônia Legal foi pouco organizado, acarretando em diversos impactos socioambientais e econômicos (MONTESANTI, 2014).

Diante desse contexto, é importante conhecermos a dinâmica da distribuição espacial do cultivo de Soja e o desmatamento na Amazônia Legal, no intuito de melhor entendermos a trajetória e tendências desse processo. Assim, poderemos entender como essa dinâmica permeia-se na região, em suas dimensões espacial e temporal.

Este trabalho tem por objetivo principal, analisar o avanço da produção de soja e sua relação com o desmatamento na Amazônia Legal. Verificando também a sua distribuição, por meio da presença de clusters e outliers espaciais.

Além da introdução, o artigo está dividido em mais quatro seções. A próxima seção analisa a discussão teórica acerca do impacto do plantio de Soja no desmatamento da região. A terceira seção apresenta a metodologia empregada e as fontes dos dados utilizados no artigo. A quarta seção apresenta os resultados e a contribuição analítica para o tema desenvolvido. A quinta seção apresenta as principais conclusões do artigo. 


\section{REFERENCIAL TEÓRICO}

\subsection{SOJA NA AMAZÔNIA LEGAL}

Segundo Barbosa (2015), a produção de soja na Amazônia Legal se deu através da expansão da fronteira agrícola, na direção do Norte do Brasil a partir de Mato Grosso, proporcionada principalmente pelo incentivo governamental e a disponibilidade de infraestrutura logística voltada ao deslocamento dessa produção.

O avanço da produção de soja na região não está ligada diretamente ao desmatamento, esta expansão darse essencialmente pela atividade pecuária, à exemplo do Estado de Mato Grosso, percebe-se que:

“A expansão da soja deverá continuar gerando, indiretamente, novos desmatamentos, pois, além da área de cerrado, que há muito tem ocupado, passa agora a utilizar áreas de pastagem que também estão em expansão. Atualmente, $33 \%$ da soja produzida no Estado são provenientes de municípios cujo ecossistema principal é representado pelas florestas de transição. Com capital disponível e infra-estrutura regional adequada, a expansão da soja em áreas de floresta pode ser muito rápida no norte do Mato Grosso nos próximos anos." (ALENCAR et al, 2004, p. 38-40).

De acordo com Domingues e Bermann (2012), a produção de soja na região é um agente financiador do desflorestamento indireto, através de uma dinâmica compreendida a partir da derrubada da floresta, onde se implanta a atividade pecuária que posteriormente transforma-se esta em área voltada à agricultura mecanizada. 0 investimento direto em estruturas logísticas (estradas, hidrovias, portos e armazéns) também tem fomentado o desmatamento na região (DOMINGUES e BERMANN, 2012).

Os estudos propiciados pelos autores Oliveira (2006) e Martins et al (2012), reforçam a tese de que a atividade de produção de soja não tem impacto direto sobre o desmatamento na Amazônia Legal.

A área plantada de soja na Amazônia Legal saltou de 3,21 milhões de hectares cultivados na safra 2000/2001, com produção de 9,86 milhões de toneladas e produtividade média de $2.587 \mathrm{Kg} / \mathrm{Ha}$ saltando para cerca de 11,45 milhões de hectares plantados na safra 2017/2018, tendo uma produção de 38,38 milhões de toneladas e uma produtividade de $2.968 \mathrm{Kg} / \mathrm{Ha}$, um salto expressivo, conduzido principalmente pelo Estado de Mato Grosso. O valor da produção saiu da cifra de R\$ 4,56 Bi no ano de 2000, para a marca de R\$39,63 Bi em 2017 (CONAB, 2019).

Em 2017, o ramo de exportação da produção de soja na Amazônia Legal, representou 32,56\% do faturamento total do país, com a cifra de US\$ 8,37 Bi e 32,57\% do volume total exportado, com 22,20 Bi de toneladas comercializadas (SECEX, 2019).

\subsection{DESMATAMENTO NA AMAZÔNIA LEGAL}

O desmatamento ou desflorestamento pode ser definido como a supressão total ou parcial da cobertura florestal de uma determinada região, onde a floresta original que estava intacta passa por um processo ou distúrbio que altera a homogeneidade da paisagem deste ambiente (INPE, 2019a). Segundo o dicionário virtual Dicio, desmatamento pode ser compreendido como a "Ação ou efeito de desmatar; ato que consiste na retirada do mato; desflorestamento".

Conforme a nota metodológica do Instituto Nacional de Pesquisas Espaciais (INPE, 2019a), o processo de desmate pode ser classificado como Desmatamento De Corte Raso ou Desmatamento por Degradação Florestal. Sendo que no primeiro caso é feito a remoção completa da vegetação e em um curto espaço de tempo, este processo é mais detectável pelas imagens de satélite. Já na degradação florestal, o desmate é feito por etapas, retirando-se primeiramente as madeiras nobres, posteriormente as que tenham uso na construção civil e por último é retirado as madeiras mais leves utilizadas principalmente na produção de placas e compensados. 0 que chama a atenção, é que todo este processo pode perdurar-se por anos, contando com equipes especializadas para cada etapa no processo de desmate, sendo mais difícil a visualização deste desmate por imagem de satélites (INPE, 2019a).

De acordo com Sousa (2007), o desmatamento é considerado um dos grandes problemas ambientais de nosso tempo, pois tem impacto direto não somente nos ecossistemas, mas à vida humana também, com reflexos diretos na economia e na sociedade. 
Devido às ações do Estado brasileiro para reprimir o desmatamento na Amazônia Legal, principalmente por meio do Plano de Ação Para a Prevenção e Controle do Desmatamento na Amazônia - PPCDAm, "associada à influência de fatores econômicos, tais como a redução dos preços internacionais da soja e da carne e a valorização do real, que desestimularam as exportações", o que de certa forma, provocaram uma expressiva redução na área desmatada da região entre os anos de 2004 e 2012 (CARVALHO e DOMINGUES, 2016). A partir do ano de 2013, voltamos a ter tendências de crescimento do desmatamento na região, ver Figura 1. Nos últimos 16 anos, a Amazônia Legal apresentou uma taxa média anual de desmate de $7,22 \%$.

Figura 1. Evolução da área desmatada $\left(\mathrm{Km}^{2}\right)$ na Amazônia Legal de 2004 a 2019.

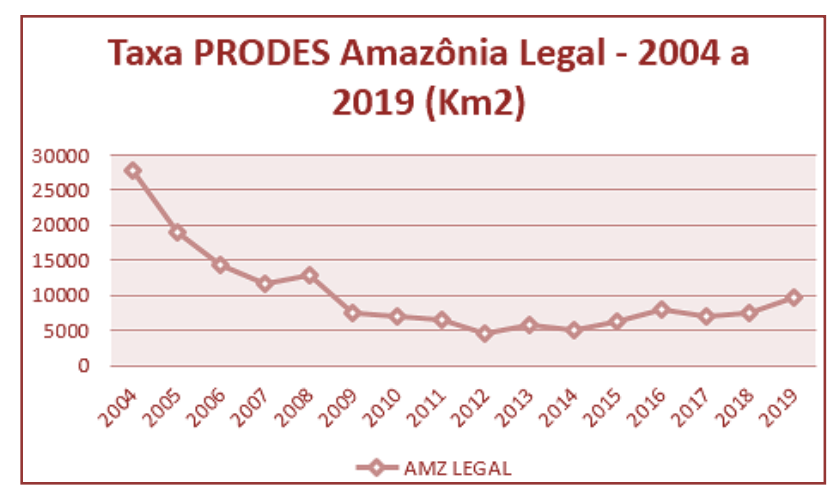

Fonte: INPE, 2019b. Elaborado pelos autores.

No ano de 2019, a região chamou atenção da imprensa e da comunidade internacional por causa da retomada do crescimento do desmatamento e dos focos de queimadas na região (GOMES, 2019). Neste mesmo ano, a região registrou um aumento de $29,54 \%$ na área desmatada, quando comparado com o ano de 2018 (INPE, 2019b).

Destaca-se o aumento das taxas de desmatamento dos Estados de Roraima, Acre e Pará, com crescimento de 216,41\%, 54,95\% e 40,74\%, respectivamente, quando comparado os dados dos anos de 2018 e 2019. Os Estados do Amapá, Tocantins e Maranhão, apresentaram redução de 66,67\%, 16\% e 15,02\%, respectivamente, nos níveis de desmatamento no mesmo período (INPE, 2019b).

O Estado do Pará foi o que apresentou a maior área desmatada na Amazônia Legal no ano de 2019, com $3.862 \mathrm{Km}^{2}$. Em uma lista com 13 municípios que apresentaram os maiores incrementos de desmatamento, constam oito municípios do Estado do Pará, ver Tabela 1. Ressalta-se a capital do Estado de Rondônia, Porto Velho, ocupando a terceira posição de município com maior incremento de desmatamento, com uma área de desmate incrementada de 3.214,07 $\mathrm{Km}^{2}$ (INPE, 2019c).

Tabela 1. Lista dos municípios com maiores níveis de desmatamento.

\begin{tabular}{|l|c|c|}
\multicolumn{2}{|c|}{$\begin{array}{c}\text { Incrementos de Desmatamento Acumulado dos Municípios da Amazônia Legal - } 2019 \\
\text { Aunicípio }\end{array}$} & $\begin{array}{c}\text { Aercentual (\%) } \\
\left(\mathrm{Km}^{2}\right)\end{array}$ \\
\hline Altamira (PA) & 3941,01 & 4,67 \\
\hline São Félix do Xingu (PA) & 3805,38 & 4,51 \\
\hline Porto Velho (RO) & 3214,07 & 3,81 \\
\hline Novo Repartimento (PA) & 2249,32 & 2,67 \\
\hline Lábrea (AM) & 2079,47 & 2,47 \\
\hline Pacajá (PA) & 1899,92 & 2,25 \\
\hline Colniza (MT) & 1825,83 & 2,16 \\
\hline Novo Progressso (PA) & 1774,11 & 2,10 \\
\hline Itaituba (PA) & 1442,95 & 1,71 \\
\hline Apuí (AM) & 1353,74 & 1,60 \\
\hline Nova Mamoré (RO) & 1335,21 & 1,58 \\
\hline Portel (PA) & 1126,64 & 1,34 \\
\hline Marabá (PA) & 1079,29 & 1,28 \\
\hline
\end{tabular}

Fonte: INPE, 2019c. Elaborado pelos autores. 


\section{METODOLOGIA}

Esta parte tem por finalidade demonstrar o método empregado para o desenvolvimento deste estudo. Inicialmente, apresenta-se a Análise Exploratória de Dados Espaciais - AEDE. A análise aqui feita é de natureza quantitativa (GIL, 2002).

\subsection{ANÁLISE EXPLORATÓRIA DE DADOS ESPACIAIS - AEDE}

A AEDE pode ser definida como um conjunto ferramental voltado à analisar estatisticamente informações geográficas, objetivando a descoberta de dinâmicas espaciais nos dados utilizados e também formulando hipóteses (ALMEIDA, 2004). As ferramentas da AEDE são os indicadores, que avaliam as posições absolutas e relativas dos dados num âmbito global, possibilitando diversas formas de análise dos dados a partir de sua distribuição espacial (ALMEIDA, 2004).

\subsubsection{DE MORAN}

O coeficiente de correlação espacial I de Moran foi proposto pioneiramente em 1948. Essa estatística é dada pela equação:

$$
\mathrm{I}=(\mathrm{n} / \Sigma \mathrm{ijwij}) \Sigma \mathrm{ij} \mathrm{wij}(\mathrm{xi}-\mu) / \Sigma \mathrm{i}(\mathrm{xi}-\mu)
$$

Segundo Almeida (2004, p. 36) a "A estatística I de Moran tem um valor esperado de -[1/(n-1)], isto é, o valor que seria obtido se não houvesse padrão espacial nos dados".

\subsubsection{INDICADORES LOCAIS DE ASSOCIAÇÃO ESPACIAL (LISA)}

Os Indicadores Locais de Associação Espacial verificam a presença de padrões locais de associação espacial linear na amostra, sendo também utilizada para medir a hipótese nula de ausência de associação espacial local (ALMEIDA, 2004).

\subsection{FONTES DE DADOS}

Os dados aqui utilizados para análise do presente estudo são considerados secundários (GIL, 2002). Os dados referentes ao desmatamento foram obtidos juntos ao programa PRODES do Instituto Nacional de Pesquisa Espacial - INPE (INPE, 2018). Para soja utilizou-se a área cultivada de soja em hectares, coletados pela Produção Agrícola Municipal do Instituto Brasileiro de Geografia e Estatística - IBGE (IBGE, 2019).

A realização da análise espacial se dá por meio de mapas no formato shapefile da região em estudo, que foi obtido junto ao IBGE (IBGE, 2019). Sendo a unidade de análise os 760 municípios que compõe a Amazônia legal.

Os anos escolhidos para análise foram 2000, ano que se inicia a amostra da área desmatada e 2018 último ano disponível da área plantada da soja. Para realização deste estudo foi utilizado a linguagem de programação livre $R$.

\section{RESULTADOS E DISCUSSÕES}

Foram elaborados mapas quantílicos microrregionais de distribuição de dados para as variáveis áreas produzidas de soja e desmatamento de floresta. Os mapas dividem os dados em um número específico de categorias. Desta maneira, são separados em quartis os menores valores, depois valores pouco baixos, depois pouco maiores e por fim, o último quarto fica contendo os maiores valores apresentados para cada variável. 
Figura 2. Produção de Soja na Amazônia Legal nos anos 2000 e 2018.

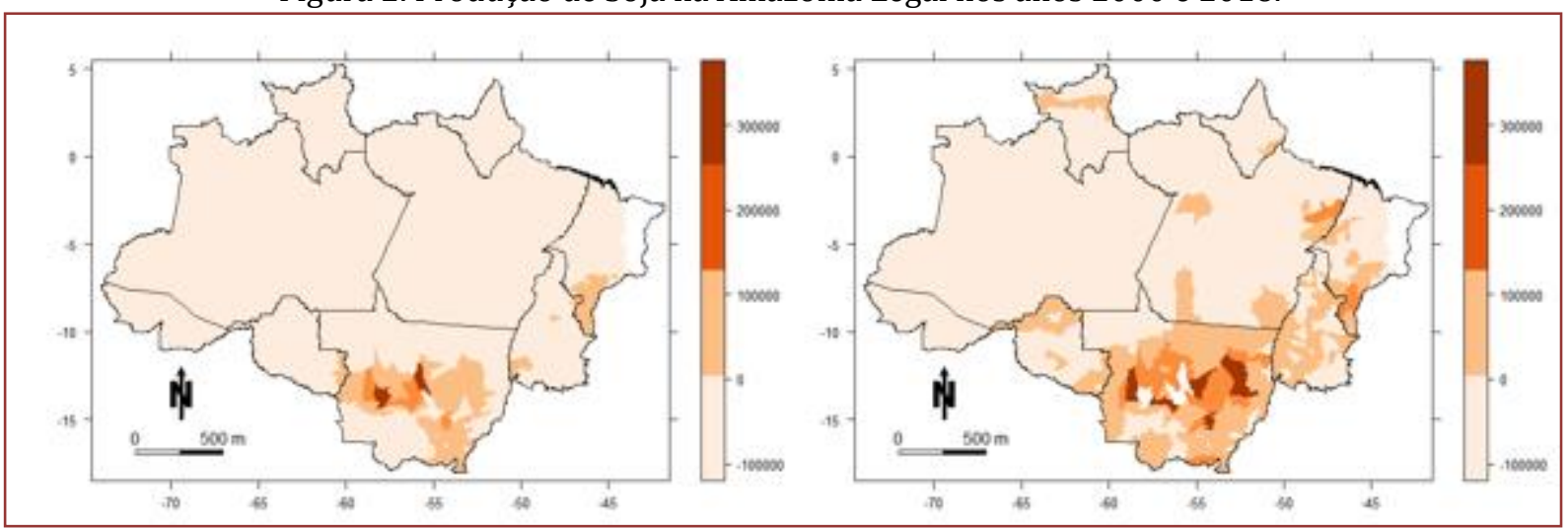

Fonte: IBGE, 2019. Elaborado pelos autores.

Ao observarmos a Figura 2, comparando os anos de 2000 e 2018, fica evidente o crescimento da área plantada de Soja na Amazônia Legal. Enquanto que no ano de 2000 a soja ocupava grande parte do Estado de Mato Grosso, com pequenas áreas produzidas no Estado do Tocantins, na fronteira com o Mato Grosso, e no sul do Estado do Maranhão. Nos Estados restantes, quase não existiam áreas plantadas de Soja.

Já no ano de 2018, esse cenário muda bastante, com um aumento considerável da área plantada, principalmente nos Estados de Mato Grosso (que incrementou ainda mais áreas plantadas), de Rondônia (especificamente na região do cone sul do estado e na região da capital Porto Velho) e Tocantins que teve um aumento considerável da área plantada, com maior intensidade na fronteira com Mato Grosso. Passouse a registrar áreas de produção entre 100.000 ha e 200.000 ha no Estado do Pará. Registram-se também as áreas plantadas de Soja nos Estados de Roraima e Amapá, que no ano de 2000 quase não possuíam áreas de cultivo de Soja.

Figura 3. Desmatamento na Amazônia Legal nos anos 2000 e 2018.

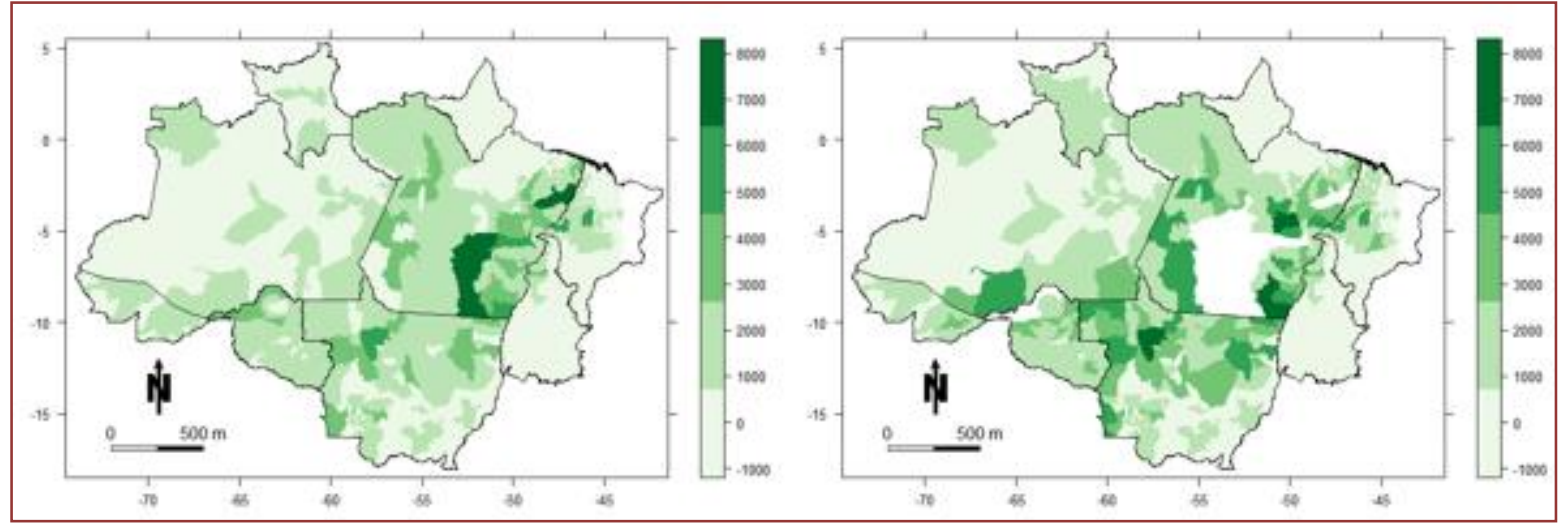

Fonte: INPE, 2019a. Elaborado pelos autores.

Como podemos observar, ao verificarmos a Figura 3, percebemos que a dinâmica do desmate na região é muito parecida com a da produção de soja, mas somente os mapas quantílicos não são suficientes para diagnosticar essa possível correlação.

\subsection{ANÁLISE GLOBAL}

No intuito de verificarmos a distribuição espacial da área plantada de soja e sua possível correlação com o desmatamento na Amazônia Legal, estimamos o I de Moran para os anos de 2000 e 2018. 0 I de Moran pode ser representado por um diagrama de dispersão, esses resultados são apresentados na Figura 4. 
Figura 4. Índice Global de correlação de Moran em 2000 e 2018.

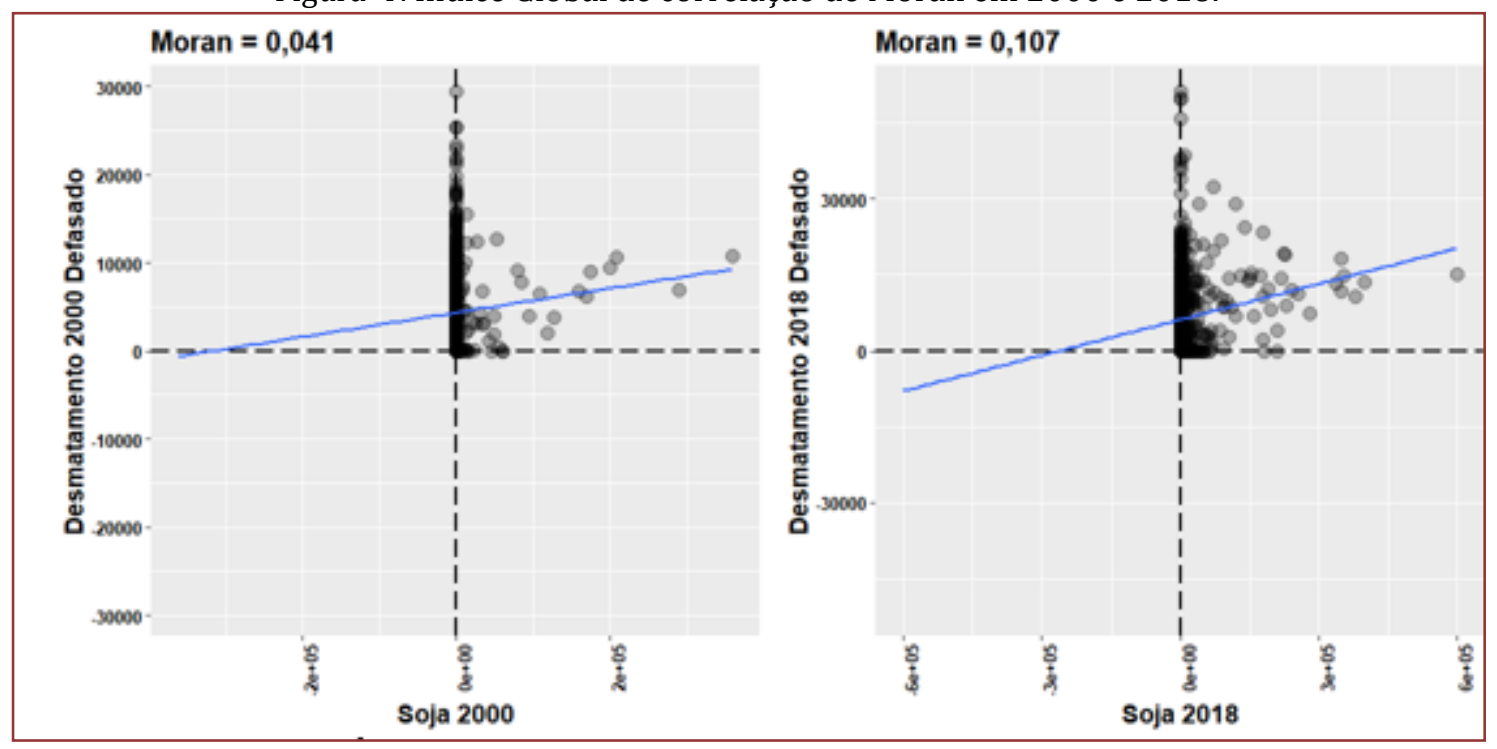

Fonte: Os autores.

Em ambos os anos analisados, a área plantada e o desmatamento, apresentaram correlação espacial positiva e estatisticamente significantes, onde este resultado nos indica que existe uma tendência para que municípios com uma grande área plantada e desmatada, estejam cercados também por municípios com grandes áreas plantadas e desmatadas. No ano de 2000, o nível de correlação espacial era de 4,10\%, enquanto que em 2018, essa correlação foi de $10,70 \%$, isto é, um incremento de 6,60 p.p. no intervalo de 18 anos.

Esse resultado é um indicativo que de fato o surgimento da soja na Amazônia Legal é acompanhado de um crescimento do desmatamento. Embora não seja um percentual de correlação extremamente grande, esse resultado indica que a um forte crescimento da relação em toda região.

\subsection{ANÁLISE LOCAL}

Uma das desvantagens da análise anterior é que não mostra as associações locais, uma vez que assume que a correlação é geral, ou seja, vale para toda a região. Para analisar padrões mais locais, foram utilizados os mapas de clusters.

A visualização de clusters de dados espaciais é possível através de mapas criados a partir das estatísticas I de Moran. Têm-se abaixo, na Figura 5, os mapas de clusters para os anos de 2000 e 2018.

No ano de 2000, podemos observar que existia um grande cluster do tipo Alto-Alto no Estado do Mato Grosso que se estende até a região sul do Estado de Rondônia. Destaca-se a existência de clusters no formato Baixo-Baixo nos Estados do Amazonas, Roraima, Pará, Amapá, Maranhão e Tocantins. Percebe-se também a presença de um grande cluster Alto-Baixo que ocupa a maior parte do Estado do Pará e parte dos Estados de Mato Grosso, Tocantins e Rondônia. 
Figura 5. Mapas de clusters para os anos de 2000 e 2018.

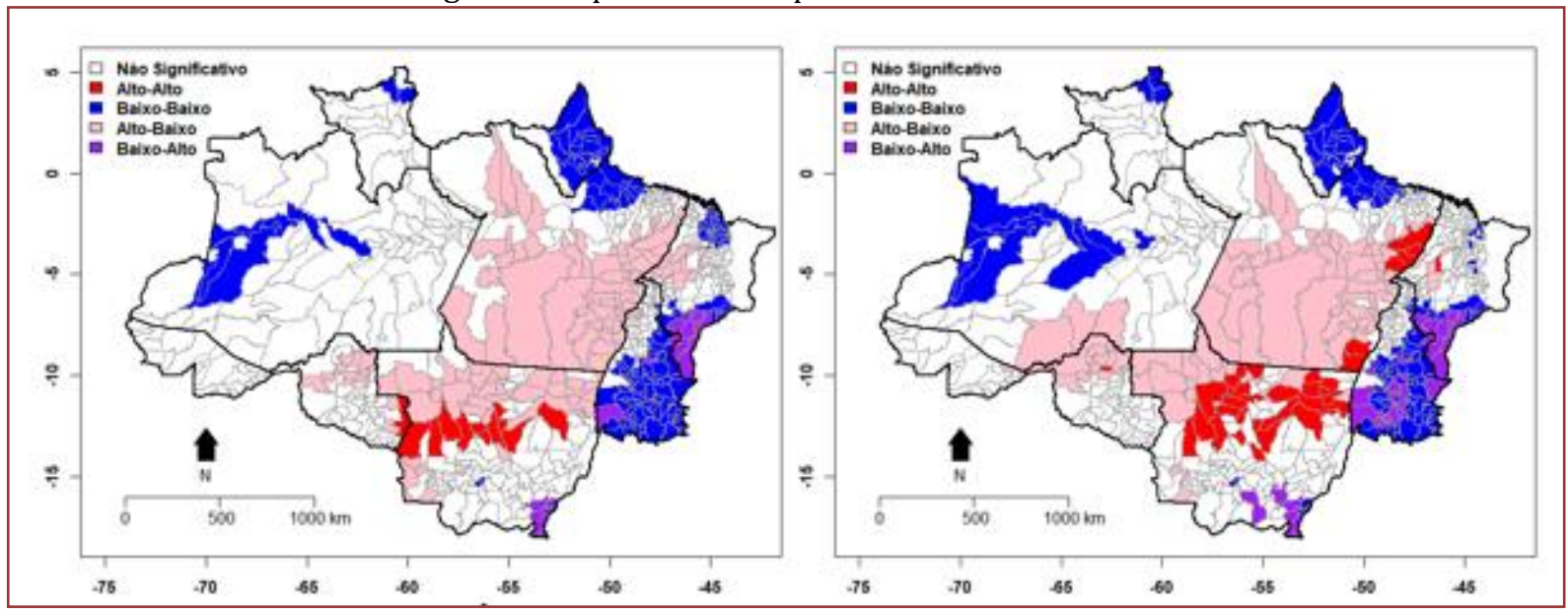

Fonte: Os autores.

Já no ano de 2018, vemos uma expansão ainda maior do cluster Alto-Baixo, avançando de forma expressiva no Estado do Pará, passando a incrementar uma maior parte da região norte do Estado de Rondônia e do sul do Estado do Amazonas. Os Estados do Pará e Maranhão passaram a ter clusters do tipo Alto-Alto, sendo que no Estado de Mato Grosso teve um aumento expressivo neste mesmo tipo de cluster.

Esse resultado mostra um aspecto extremamente importante da dinâmica da soja na Amazônia Legal, o seu avanço sobre a região. Como mostrado, após a expansão da soja em Mato Grosso, a mesma segue avançando na região no sentido norte, e gerando pressão para o desmatamento nos outros estados. Em especial, Rondônia e Pará que fazem fronteira com Mato Grosso.

\section{CONCLUSÃO}

De acordo com estudo ora elaborado, percebe-se uma dinâmica da produção de soja na Amazônia Legal, e principalmente sua autocorrelação com o desmatamento da região. 0 objetivo desta pesquisa foi de analisar a dinâmica do cultivo de soja e o desmatamento na Amazônia Legal brasileira, utilizando de métodos estatísticos espaciais. Onde se percebe que a dinâmica da produção de soja tem avançado no sentido norte da Amazônia Legal, com isso impulsionando o desmatamento nestes locais.

Pode-se observar que existe uma relação direta entre crescimento da soja e crescimento do desmatamento. Embora essa relação não seja extremamente alta, vem crescendo nos últimos anos.

O governo brasileiro deve prover cada vez mais de políticas públicas voltadas ao controle e a prevenção do desmatamento na região, propiciando o equilíbrio entre produção do agronegócio e meio ambiente. A Amazônia tem uma significativa relevância para os sistemas naturais não só do país, como do planeta, deve ser preservada e cuidada com intuito de resguardar as gerações futuras.

\section{REFERÊNCIAS}

[1] ALENCAR, Ane; NEPSTAD, Daniel; MCGRATH, Davi; MoUTinHo, Paulo; PACHECO, Pablo; DIAZ, M. C. V.; \& FILHO, B. S. Desmatamento na Amazônia: Indo Além da "Emergência Crônica". Belém/PA. Março, 2004. Disponível em: < https://ipam.org.br/bibliotecas/desmatamento-na-amazonia-indo-alem-da-emergencia-cronica/>. Acesso em: 22 nov. 2019.

[2] ALMEIDA, Eduardo Simões. Curso de econometria espacial aplicada -Piracicaba: Esalq-USP, 2004.

[3] BARBOSA, Maria Zeferino. Fronteira Agrícola: a soja na Amazônia Legal. Análise e Indicadores do Agronegócio, 2015. Disponível em: < http://www.iea.sp.gov.br/out/LerTexto.php?codTexto=13575>. Acesso em: 22 nov. 2019.

[4] BRASIL. Constituição da República Federativa do Brasil, de 05 de outubro de 1988. Diário Oficial [da] República Federativa do Brasil, Brasília, DF, 05 out. 1988. Disponível em: <http://www.planalto.gov.br/ccivil_03/constituicao/constituicao.htm\#adct>. Acesso em: 21 nov. 2019. 
[5] BRASIL. Lei complementar no 31, de 11 de outubro de 1977. Cria o Estado de Mato Grosso do Sul. Diário Oficial [da] República Federativa do Brasil, Brasília, DF, 11 out. 1977. Disponível em: <http://www.planalto.gov.br/ccivil_03/leis/lcp/Lcp31.htm>. Acesso em: 21 nov. 2019.

[6] BRASIL. Lei no 1.806, de 6 de janeiro de 1953. Dispõe sobre o plano de valorização econômica da Amazônia. Diário Oficial [da] República dos Estados Unidos do Brasil, Rio de Janeiro, RJ, 6 jan. 1953. Disponível em: <https://www.planalto.gov.br/ccivil_03/leis/1950-1969/11806.htm>. Acesso em: 21 nov. 2019.

[7] BRASIL. Lei no 11.952, de 25 de junho de 2009. Dispõe sobre a regularização fundiária das ocupações. Diário Oficial [da] República Federativa do Brasil, Brasília, DF, 25 jun. 2009 . Disponível em: <http://www.planalto.gov.br/ccivil_03/_Ato2007-2010/2009/Lei/L11952.htm>. Acesso em: 21 nov. 2019.

[8] BRASIL. Lei no 12.651, de 25 de maio de 2012. Dispõe sobre a proteção de vegetação nativa. Diário Oficial [da] República Federativa do Brasil, Brasília, DF, 25 mai. 2012. Disponível em: <http://www.planalto.gov.br/ccivil_03/_Ato2007-2010/2009/Lei/L11952.htm>. Acesso em: 21 nov. 2019.

[9] BRASIL. Lei no 291, de 28 de fevereiro de 1967. Estabelece incentivos para o desenvolvimento da Amazônia Ocidental. Diário Oficial [da] República Federativa do Brasil, Brasília, DF, 27 fev. 1967. Disponível em: <http://www.planalto.gov.br/ccivil_03/Decreto-Lei/1965-1988/Del0291.htm>. Acesso em: 21 nov. 2019.

[10] BRASIL. Lei no 5.173, de 27 de outubro de 1966. Extingue a superintendência do plano de valorização econômica da Amazônia. Diário Oficial [da] República Federativa do Brasil, Brasília, DF, 27 out. 1966. Disponível em: <http://www.planalto.gov.br/ccivil_03/leis/L5173.htm\#art63>. Acesso em: 21 nov. 2019.

[11] CARVAlHo, Terciane Sabadini; DOMINGUES, Edson Paulo. Projeção de um cenário econômico e de desmatamento para a Amazônia Legal brasileira entre 2006 e 2030. Nova econ., Belo Horizonte , v. 26, n. 2, p. 585621, 2016.

[12] CONAB, Companhia Nacional de Abastecimento. Séries histórica das safras, 2019. Disponível em: <https://www.conab.gov.br/info-agro/safras/serie-historica-das-safras?start=30>. Acesso em: 22 nov. 2019.

[13] DICIO, Dicionário Online de Português. Desmatamento. Disponível em: < https://www.dicio.com.br/desmatamento/>.Acesso em: 30 nov. 2019.

[14] DOMINGUES, Mariana Soates \& BERMANN, Célio. 0 arco do desflorestamento da Amazônia: da pecuária à soja. Ambient. soc. vol.15 no.2 São Paulo May/Aug. 2012.

[15] GIL, Antônio Carlos, 1946. Como elaborar projetos de pesquisa/Antônio Carlos Gil. - 4. ed. - São Paulo: Atlas, 2002.

[16] GOMES, Lindauro. 'Brasil arde', diz El País; veja a repercussão das queimadas na mídia internacional; Jornal de Brasília, 2019. Disponível em: < https://jornaldebrasilia.com.br/brasil/brasil-arde-diz-el-pais-veja-a-repercussaodas-queimadas-na-midia-internacional/>. Acesso em 30 jan. 2020.

[17] IBGE, Instituto Brasileiro de Geografia e Estatística. Pesquisa Agrícola Municipal, 2019. Disponível em: <https://sidra.ibge.gov.br/tabela/1612>. Acesso em: 22 nov. 2019.

[18] INPE, Instituto Nacional de Pesquisas Espaciais. Metodologia Utilizada nos Projetos PRODES e DETER, 2019a. Disponível em: <http://www.obt.inpe.br/OBT/assuntos/programas/amazonia/prodes>. Acesso em: 20 jan. 2020.

[19] INPE, Instituto Nacional de Pesquisas Espaciais. Observação da Terra, 2019b. Disponível em: <http://www.obt.inpe.br/OBT/assuntos/programas/amazonia/prodes>. Acesso em: 20 jan. 2020.

[20] INPE, Instituto Nacional de Pesquisas Espaciais. TerraBrasilis, 2019c. Disponível em: <http://terrabrasilis.dpi.inpe.br/app/dashboard/deforestation/biomes/legal_amazon/increments>. Acesso em: 20 jan. 2020.

[21] MARTINS, C. E. R; BARROS, R. P; JUNIOR, J. N. O; SILVA, A. L. F \& DINIZ, M. B. Causas dos Determinantes da Intensidade do Desmatamento na Amazônia Legal: Uma Abordagem Multinomial. Disponível em: < https://www.bnb.gov.br/documents/160445/220414/causas.pdf/e4713375-498b-47c1-a4a9-2a983bd6dce7>.

Acesso em: 22 nov. 2019.

[22] MONTESANTI, Júlia de Almeida Costa. Amazônia Legal, 2014. Infoescola. Disponível em: < https://www.infoescola.com/ecologia/amazonia-legal/>. Acesso em: 25 nov. 2019.

[23] OLIVEIRA, Ariovaldo Umbelino de. A Amazônia e a nova geografia da produção da soja. Revista Terra Live, v. 1, n. 26, p.13-43, 2006.

[24] SECEX, Secretaria de Comércio Exterior. Comex Stat, 2019. Disponível em: < http://comexstat.mdic.gov.br/pt/geral>. Acesso em: 22 nov. 2019.

[25] SOUSA, Rafaela. "Desmatamento"; Brasil Escola, $2007 . \quad$ Disponível em: <https://brasilescola.uol.com.br/geografia/o-desmatamento.htm>. Acesso em 30 jan. 2020. 


\section{Capítulo 9}

Mapeamento e diagnóstico de agroindústrias orgânicas presentes na Rede de Agroecologia Povos da Mata no estado da Bahia

\section{Luciane Aliprandini}

Josué de Souza Oliveira

Tatiane Botelho da Cruz

Guilherme Fontana Ramos

Viviane Maria Barazetti

Resumo: 0 presente trabalho apresenta o panorama das agroindústrias, atualmente informais que almejam receber o certificado orgânico e fazer uso do selo em seus produtos, através da Associação Povos da Mata, primeiro Organismo Participativo de Avaliação da Conformidade do estado da Bahia. Para isso, foi realizada uma pesquisa no banco de dados da Plataforma Circuitos Agroecológicos, que é uma articulação, entre as organizações Rede de Agroecologia Povos da Mata, Instituto Ibiá e Taboa Fortalecimento Comunitário e tem como objetivo, fortalecer a agroecologia e enriquecer a oferta de produtos no circuito de comercialização, além de organizar a produção local, o beneficiamento de seus produtos e ofertar crédito para os membros das redes parceiras. Algumas das informações tabuladas correspondem ao posicionamento geográfico, produtos beneficiados, origem de matérias primas, aspectos operacionais, procedimentos higiênicos, mecanismos de controle de recebimento e estoque, além da identificação de rotulagem. A área estudada neste trabalho corresponde aos 04 núcleos regionais desta Rede, abrangendo os biomas da Mata Atlântica e Caatinga. A sistematização dos dados analisados neste artigo, contribuirá na implementação da Plataforma Circuito Agroecológicos, o qual visa proporcionar o apoio técnico para a formalização das agroindústrias estudadas que almejam posteriormente conquistar a certificação orgânica de seus produtos.

Palavras-chave: Legalização Sanitária. Agricultura familiar. Certificação. 


\section{INTRODUÇÃO}

Os processos estabelecidos mediante a implantação de agroindústrias rurais, propiciam novas configurações para a produção da agricultura familiar. Nesta perspectiva, o processamento de alimentos, prática usual que visa conservação dos produtos para consumo na entressafra, passa a se configurar como relevante estratégia da agricultura familiar, constituindo uma nova alternativa de rentabilidade para as unidades de produção (MIOR,2007).

No Brasil, os estabelecimentos relacionados à manipulação, beneficiamento, embalagem e distribuição de alimentos devem estar devidamente formalizados junto aos órgãos técnicos competentes, conforme as atividades exercidas (Brasil, 1969).

Atualmente, os órgãos técnicos reguladores de tais atividades, são representados pelo MS (Ministério da Saúde), ANVISA (Agência Nacional de Vigilância Sanitária), serviços da VISA (Vigilância Sanitária) dos estados e municípios (BRASIL, 1999). Também estas atividades devem se apresentar em conformidade com exigências do MAPA (Ministério da Agricultura, Pecuária e Abastecimento) e pelos órgãos, Secretarias / Superintendências de Agricultura dos estados e municípios (BRASIL, 2018).

Neste contexto, é encargo da ANVISA a normatização e regulamentação das diretrizes sanitárias. A VISA tem como responsabilidade controlar e monitorar os processos produtivos realizados nas agroindustriais de alimentos de origem vegetal, águas envasadas e embalagens para os alimentos (BRASIL, 1999).

A regulamentação e controle dos processos produtivos dos alimentos de origem animal, como carnes de bovinos, suínos, aves e pescados, ovos e mel, é de responsabilidade do MAPA (BRASIL, 2017). Este órgão também é responsável pela regulamentação e controle das atividades relacionadas a produção de bebidas alcoólicas e não alcoólicas (polpas de frutas, sucos, néctar, refrigerantes água de coco, vinagres e outros), fermentadas e vegetais in natura (BRASIL, 2009).

Segundo Wurlitzer e Araújo (2008) as legislações sanitárias visam a preservação da saúde. Uma vez que, o objetivo é garantir as condições higiênico sanitárias desde a matéria prima, passando por todas as etapas de agroindustrialização até chegar aos consumidores.

Agroindustrializar é manipular matérias primas de origem vegetal ou animal mudando suas características físicas para obtenção de novos produtos (MOSCHEN, 2011 apud DA ROCHA E LEISMANN, 2017). Esta abordagem também é realizada pelo IBGE (Instituto Brasileiro de Geografia e Estatística) que entende o conceito da seguinte maneira:

Uma agroindústria é onde se realiza as atividades de transformação e beneficiamento de produtos agropecuários de origem animal ou vegetal, que foram realizadas em instalações próprias, comunitárias ou de terceiros, a partir de matéria-prima produzida no próprio estabelecimento agropecuário ou adquirida de outros produtores, desde que a destinação final do produto tivesse sido dada pelo produtor (IBGE, 2006, p.31).

No que se refere à formalização das agroindústrias, (FREITAS, et, al., 2013, apud HAHN et. al, 2017), esse processo, além de ampliar os canais de comercialização, valoriza a qualidade dos produtos e proporciona segurança ao consumidor. Fatores essências para esses empreendimentos, cujo o principal objetivo está relacionado à comercialização. No entanto, existem agroindústrias, que operam na informalidade, por encontrarem dificuldades em se adaptar às normas legais (HAHN et. al, 2017). Tais dificuldades podem estar relacionadas com forma de atuação dos órgãos regulamentadores, os quais não operam no sentido de orientar, mas sim de punir (PREZOTTO, 2002, apud WAQUIL, et, al.,2013).

Mior (2005) considera que estes empreendimentos, as agroindústrias, influenciam positivamente nos territórios onde estão inseridos, pois segundo o autor, promovem aspectos como a dinamização da economia regional e o fortalecimento de sistemas de produção com matriz agroecológica.

Neste sentido destacam-se as agroindústrias de produtos orgânicos, onde o surgimento e ampliação deste segmento está relacionado à crescente preocupação com a qualidade e segurança dos alimentos (GOODMAN, 2003 apud PASCHOAL, 2015).

Os alimentos orgânicos, são alimentos cultivados sem o emprego de substâncias como agrotóxicos, antibióticos, fertilizantes químicos (BRASIL,1999) fatores que contribuem para a promoção e a preservação da saúde. Além desses benefícios, tendem a serem mais saborosos, conter mais vitamina C e compostos fenólicos e a ter menor proporção de água quando comparados aos convencionais (LIMA, 2006). 
No Brasil a certificação da produção orgânica é responsabilidade dos organismos de avaliação da conformidade, entidades credenciados junto ao MAPA, as quais correspondem à três mecanismos de controle: Certificação por Auditoria, SPG (Sistema Participativo de Garantia) e OCS (Organismo de Controle Social na Venda Direta) (BRASIL, 2007).

Os Sistemas Participativos de Garantia, correspondem à mecanismos de certificação, formados por grupos de agricultores familiares, consumidores, comerciantes, colaboradores técnicos, organizações da sociedade civil, que constituem uma rede de produção, a qual igualmente atua na articulação da comercialização. Este grupo de atores deve estar associado a um OPAC (Organismo Participativo de Avaliação da Conformidade) entidade credenciada junto ao MAPA (BRASIl, 2007).

Nesta perspectiva, destaca-se o OPAC Povos da Mata da Bahia, instituição que se configura como primeiro OPAC do estado da Bahia, juridicamente representado pela Associação Povos da Mata de Certificação Participativa, organização criada por agricultores familiares, assentados da reforma agrária, comunidades indígenas, quilombolas, consumidores e colaboradores. A Rede de Agroecologia Povos da Mata é credenciada junto ao MAPA e está autorizada a emitir certificado orgânico, desde o mês de agosto do ano de 2016 (HIRATA E ROCHA,2020).

Um dos princípios, desta organização é fortalecer a Agroecologia em seus mais amplos aspectos, disponibilizar informações entre os atores e criar mecanismos legítimos de geração de credibilidade e de garantia dos processos desenvolvidos por seus membros (ARAÚJ0, et. al, 2020).

Tendo em vista o fortalecimento da Agroecologia, a Rede Povos da Mata, elaborou junto às organizações Instituto Ibiá e Taboa Fortalecimento Comunitário, no ano de 2018, o projeto Circuitos Agroecológicos, o qual tornou-se uma Plataforma de Fortalecimento da Agroecologia.

A Plataforma Circuitos Agroecológicos é uma articulação que tem como objetivo enriquecer a oferta de produtos dentro do circuito de comercialização da Rede Povos da Mata, promovendo a diversificação dos sistemas de produção, estimulando as famílias a ampliarem suas capacidades produtivas e organizativas, fomentando ações associativas e cooperativas e agregar valor na produção através de beneficiamento e processamento de alimentos (CIRCUITOS AGROECOLÓGICOS, 2019).

O objetivo geral deste trabalho é conhecer o panorama atual das agroindústrias da Rede Povos da Mata, no que se refere aos aspectos de posicionamento geográfico, tipos de produtos beneficiados e infraestrutura operacional. Para atender este objetivo, foi realizada uma abordagem teórica referente aos temas relevantes que servirão de suporte a este estudo. Serão abordadas informações relacionadas a localização dos estabelecimentos, diversificação de produtos, origem das matérias primas e aspectos de controles operacionais. Tais informações são advindas de pesquisa documental realizada no banco de dados Circuitos Agroecológicos. Em seguida essas informações serão analisadas e discutidas.

A sistematização desses dados contribuirá para a implementação dos Circuito Agroecológicos, visando o apoio técnico para a formalização das agroindústrias estudadas.

\section{METODOLOGIA}

A elaboração da pesquisa tem como finalidade a obtenção de respostas para os problemas que estão propostos (GIL, 2002).

A pesquisa realizada neste estudo, pode ser considerada uma pesquisa aplicada, pois tenciona "gerar conhecimentos para aplicação prática dirigidos à solução de problemas específicos. Envolve verdades e interesses locais" (PRODANOV E FREITAS, 2013 p. 51). Neste sentido, busca-se a identificação de elementos que contribuam nos processos de regularização e certificação de agroindústrias de alimentos orgânicos, localizadas na área de estudo.

No que se refere aos objetivos gerais, esta pesquisa é classificada como qualitativa, descritiva e exploratória, visto que, a mesma descreve as características das agroindústrias vinculadas a Rede Povos da Mata. Ao realizar um diagnóstico sobre os empreendimentos estudados, o trabalho irá conceber uma nova ótica sobre o problema, o que servirá de base para aprimorar a implementação da plataforma Circuitos Agroecológicos (GIL, 2002; PRODANOV E FREITAS, 2013). 
O presente estudo foi realizado através de consulta ao arquivo do banco de dados da Plataforma Circuitos Agroecológicos. $\mathrm{O}$ acervo conta com documentos escritos, como questionários, relatórios e planilhas contidos no arquivo particular desta articulação, sendo a metodologia também uma pesquisa documental (MARCONI E LAKATOS, 2003)

Entre os materiais consultados, encontram-se informações advindas de questionários, aplicados entre os meses de novembro do ano 2018 e abril do ano de 2019 pela equipe de Beneficiamento do Circuito Agroecológico. A aplicação destes questionários possibilitou identificar fatores relacionados ao histórico, localização, categoria de produtos, volume processado, origem da matéria prima, segregação de produtos orgânicos e convencionais, entre outros aspectos de controle de processo operacional.

\subsection{CARACTERIZAÇÃO DA ÁREA DE ESTUDO}

A área de estudo corresponde à 04 núcleos regionais da Rede Povos da Mata, localizados em distintas regiões do estado da Bahia, como os núcleos de Serra Grande, Pratigi, Monte Pascoal e Raízes do Sertão.

O núcleo denominado Serra Grande é formado pelos municípios de Uruçuca, Arataca, Santa Luzia, Itacaré e Ilhéus, localizados no Bioma Mata Atlântica, região que apresenta índice pluviométrico em média de $1700 \mathrm{~mm}$ anuais (BAHIA/SEMARH, 2005) o que possibilita o cultivo de sistemas produtivos como o sistema cabruca (SAMBUICHI, 2003) e agroflorestal, com grande diversidade de frutas, hortaliças, produção animal e seus derivados.

A cultura predominante neste núcleo é a produção do cacau, única cultura no mundo que para seu desenvolvimento é necessário preservar a mata, por conta do melhor desenvolvimento da planta em meio a sombra. Suas amêndoas, depois de colhidas, são fermentadas em campo e transformadas em produtos como nibs (amêndoas torradas, descascadas e trituradas), chocolate e cacauada.

No núcleo Pratigi, atendido pelo município de Ibirapitanga, localizado no Bioma Mata Atlântica, apresenta sistemas produtivos similares aos encontrados no núcleo Serra Grande. Este município, destaca-se pela produção e organização do Pré-Assentamento Dois Riachões, que é bastante diversificado e ainda, processam polpas de frutas, nibs, cocada de cacau e chocolate, como afirma Tavares (2018).

O núcleo Monte Pascoal está localizado no município de Porto Seguro. Este núcleo é formado por agricultores familiares, indígenas e assentado de projetos da reforma agrária, de municípios da região do Extremo Sul do estado da Bahia, denominada Costa do Descobrimento.

A região Costa do Descobrimento, conhecida pela sua importância histórica, apresenta grande diversidade sociocultural. Suas atividades econômicas envolvem setores de turismo, pesca, produção de artesanato (ARAÚJO, 2005; MUNIZ, 2005). Esta região também se destaca pelos indicadores relacionados ao desmatamentos, que ocorreram sucessivamente desde o período de 1945 até os anos 1990, (CARVALHO, 2008). Essas práticas são atribuídas em grande parte aos latifundiários que visavam a comercialização da madeira. Além desses fatores, iniciou-se na década 1980 a implantação da monocultura de eucalipto em grandes áreas (ROCHA, 2000 apud ARAÚJO, 2004). Tais fatores influenciaram nas dinâmicas sócio produtivas de agricultores familiares, assentados da reforma agrária e indígenas os quais vislumbram nas práticas agroecológicas e a certificação da produção, um novo contexto para geração de renda.

O núcleo Raízes do Sertão está situado na microrregião de Irecê, no centro norte baiano (CBHASF, 2013). Esta região, cujo bioma é a Caatinga, foi conhecida no passado por se destacar na produção da cultura de feijão. Atualmente o cultivo de hortaliças como alho, cebola, cenoura, beterraba, destaca-se na economia regional (MOURA, 1997). Segundo a autora o desenvolvimento da cidade de Irecê, considerada como polo regional, está ligado ao desenvolvimento da agricultura. 
Figura 1: Localização geográfica dos núcleos da Rede Povos da Mata

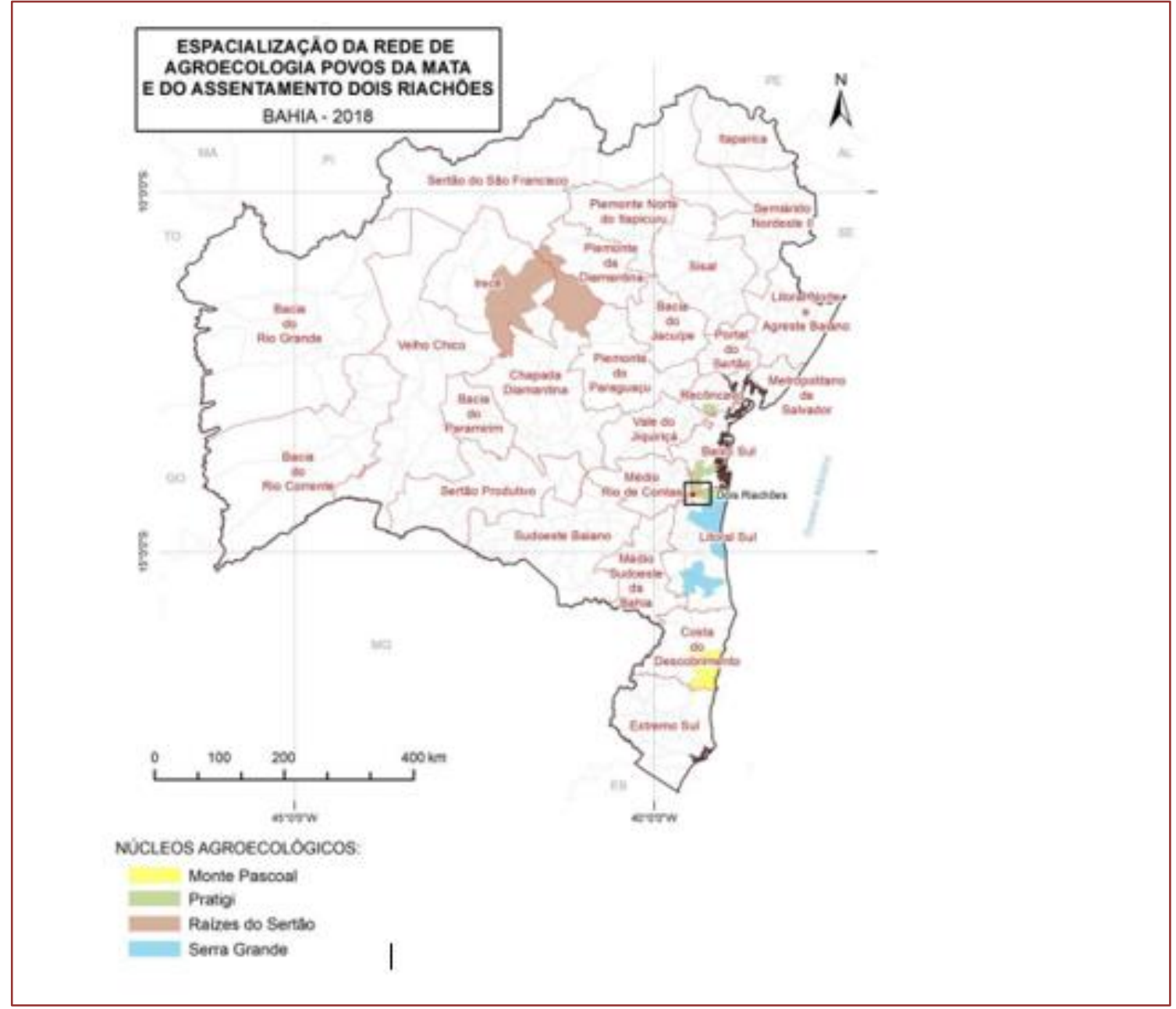

Fonte: Adaptado de Farran (2019, p.25)

\section{ANÁLISE E DISCUSSÃO DOS DADOS}

Ao observar o banco de dados foi possível identificar 22 agroindústrias informais que foram mapeadas pela Plataforma Circuitos Agroecológicos. Este mapeamento visou conhecer a localização geográfica das agroindústrias, bem como fatores referentes às instalações operacionais, infraestrutura existente, ramo de atividade, linhas de produtos, capacidade produtiva, gestão de recursos e práticas de higiene.

No entanto, para a discussão proposta por esse trabalho, foram consideradas somente 21 iniciativas informais, devido ao fato que, durante o período de levantamento dos dados para a construção da Plataforma, uma das agroindústrias alcançou a formalização junto ao órgão local de Vigilância Sanitária e avançou para receber o certificado orgânico da Rede Povos da Mata, deixando assim de ser público alvo do levantamento. Fato que consideramos como resultado positivo e inspirador para as demais agroindústrias informais mapeadas pela Plataforma Circuitos Agroecológicos.

Geograficamente, identificou-se o maior número de agroindústrias de beneficiamento individual, no Núcleo Serra Grande, com 11 empreendimentos. 0 menor número foi encontrado no Núcleo Pratigi, com apenas 02 estabelecimentos. 
Figura 2: Quantificação das agroindústrias dentro dos núcleos da Rede Povos da Mata

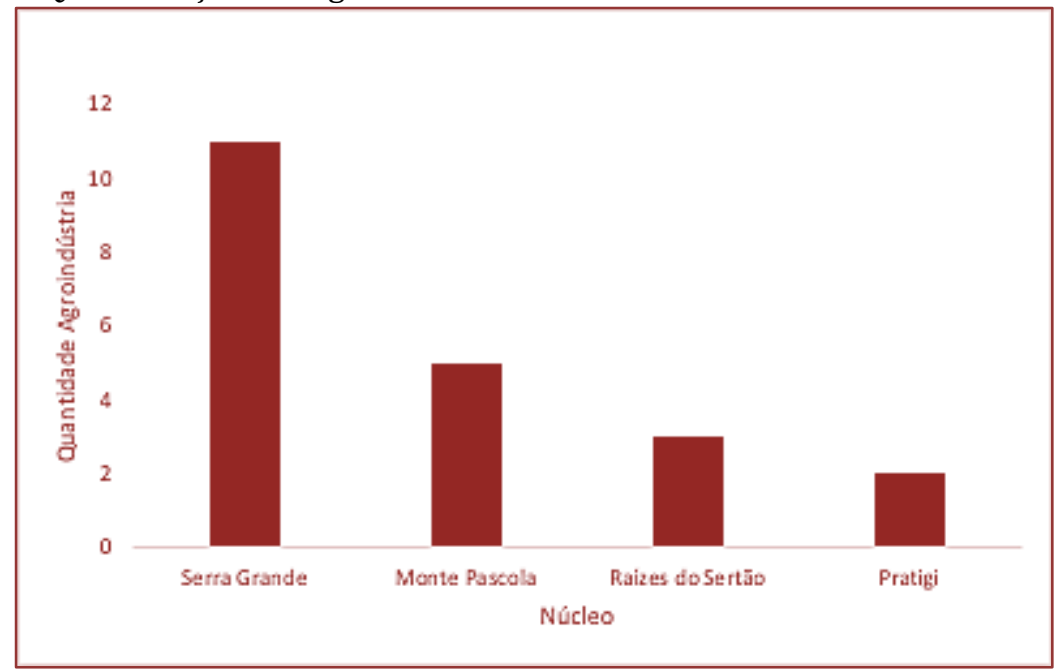

Fonte: CIRCUITOS AGROECOLÓGICOS, 2019

Além do posicionamento geográfico, foi possível observar uma significativa diversidade produtiva, decorrente da agrobiodiversidade presente na área de estudo, como chocolates, nibs, geleias, polpa de frutas, frutas desidratadas, mel, derivados de mandioca, derivados de coco, pães, bolos, hambúrgueres e sucos. Tais elementos podem estar relacionados com o fato da Rede Povos da Mata abranger áreas de dois biomas, Caatinga e Mata Atlântica que apresentam características edafoclimáticas distintas.

No que se refere a processamento desta ampla gama de alimentos, identificou-se que o mesmo ocorre, majoritariamente, em cozinhas domiciliares. Nesse processos estão envolvidos atributos relacionados aos saberes da culinária tradicional, ancestralidade e cultura regional/local. Tais fatores remetem às características da agricultura camponesa, que, conforme Gorgen (2017), muitas vezes se manifesta em hábitos alimentares, místicas, danças e culturas religiosas.

A produção resultante dos processos de beneficiamento é posteriormente comercializada de maneira informal em mercados locais. 0 processamento dos produtos in natura reduz o desperdício de frutas e hortaliças nos períodos de sazonalidade e aumenta a disponibilidade desses produtos em outros épocas do ano.

A legalização e certificação dos empreendimentos permitirá a inserção dessa diversificação produtiva em diferentes canais e circuitos de comercialização da Rede Povos da Mata.

Outro fato importante na análise desse dado, corresponde identificação desses produtos por unidade individual, uma vez que a regulamentação se dá em órgãos diferentes, o que confundo o beneficiador. No que trata a Lei n. 8.080/90, está definido que não é permitido a duplicidade de órgãos fiscalizadores (SIF, SIE, SIM) com um mesmo intuito (BRASIL, 1990). Portanto, é necessário que as agroindústrias conheçam quais são os alimentos de responsabilidade de cada órgão para a tomada de decisão da linha de beneficiamento e/ou processamento de suas unidades produtivas.

Ainda é observado o beneficiamento e/ou processamento dos alimentos com uso de matérias primas e ingredientes externos, ou seja, adquiridos de terceiros. Neste sentido $52 \%$ das agroindústrias investigadas, apresentaram esta prática, afirmando adquirir $24 \%$ da matéria prima e/ou ingredientes em fontes externas, a qual é utilizada como forma para compor o produto final.

A aquisição de produtos em fontes externas se dá através de mercados convencionais ou de outros produtores orgânicos, como por exemplo, o açúcar, a farinha de trigo e o vinagre de maçã. Este fato, foi apontado como um dos desafios para o processamento. Os beneficiários responsáveis pelas agroindústrias ao serem questionados justificam que a aquisição destes produtos, em mercados de produtos convencionais, é motivada pela falta de acesso a produtos orgânicos. Os quais, quando encontrados, apresentam valores elevados, quando comparados a produtos não orgânicos, fatores que influenciam no valor final para comercialização.

Neste sentido, é apresentada como alternativa, pela Rede Povos da Mata a aquisição de produtos oriundos de outras SPGs. Esta dinâmica, já ocorre através da parceria firmada pela Rede Povos da Mata com a Rede Ecovida, que mediante uma articulação conjunta, visa a redução dos preços de custo. 
Mediante esta análise, constatou que $76 \%$ da matéria prima utilizada nos processos de beneficiamento e/ou processamento de alimentos nos estabelecimentos estudados é de produção própria, correspondendo a alimentos orgânicos certificados pela Rede Povos da Mata. Fator importante para a sobrevivência desses empreendimentos a nível de mercado, uma vez que produção própria da matéria prima proporciona redução no preço final dos produtos comercializados (GOMES,2006).

No que se refere às formas de controle dos fluxos de matérias primas, verificou-se a ocorrência de diferentes maneiras de realizar este monitoramento, a fim de manter a informação documentada. Algumas dessas medidas correspondem ao arquivamento de documentos como nota fiscal, recibo, Declaração de Transação Comercial - DTC (ARAÚJO et. al, 2020), cópia do certificado do agricultor, que visam assegurar a transparência dos processos e facilitar a rastreabilidade dos volumes comercializados. Segundo Moe (1998) cada unidade processadora deve implantar seus métodos de controle de forma a viabilizar e garantir o sistema de rastreabilidade.

O controle do estoque dos produtos utilizados nas agroindústrias ocorre mediante a utilização de ferramentas e mecanismos particulares de cada empreendimento, como registros em cadernos, arquivamentos de recibos, notas fiscais e caderno de campo, este último corresponde a uma das ferramentas dos processos de certificação.

Ainda sobre a gestão das as agroindústrias, o estudo encontrou 14 empreendimentos que declararam efetuar registros para controle próprio e 10 empreendimentos que afirmaram realizar as anotações no caderno de campo. Essas dinâmicas oferecem um controle mais efetivo no que se refere ao controle dos insumos, matéria prima e comercialização dos produtos. Essas medidas garantem maior efetividade nos processos de gestão, precificação e rastreabilidade dos produtos.

Dentre as agroindústrias orgânicas que também beneficiam e/ou processam matérias primas e ingredientes não orgânicos, apenas 30\% fazem a separação e controle durante o armazenamento. 50\% dos estabelecimentos declararam que não realizam a separação, indicativo que se apresenta como um fator negativo, uma vez a separação dos produtos durante o armazenamento é obrigatório, sendo estabelecido pelo Regulamento Técnico para o Processamento, Armazenamento e Transporte de Produtos Orgânicos (BRASIL, 2009). Tendo em vista que estabelecimentos estudados vislumbram a certificação orgânica, esta prática deverá ser revista por parte dos mesmos.

Quanto ao processo de limpeza e higienização dos espaços e áreas de produção, identificou-se o emprego de produtos como sabão, detergente neutro, água sanitária, álcool, desengordurantes, dando preferência ao uso de produtos permitidos no processo de certificação, medidas que visam a não contaminação do solo e das águas (BRASIL, 2009). Não foram encontrados depoimentos sobre o uso de produtos não biodegradáveis, sendo um resultado extremamente positivo que demonstra a conscientização em proteger o meio ambiente, uma vez que não geram resíduos poluentes. Outro ponto positivo para essas unidades que buscam além da formalização a certificação orgânica de seus produtos, é estarem enquadradas dentro dos requisitos necessários para tal certificação.

Outra ação importante observada nos questionários e que vai ao encontro das normas de conformidade para a certificação orgânica, é a utilização de telas em portas e janelas, além da limpeza continua no entorno das estruturas utilizadas como forma de garantir o controle de insetos. Nenhum dos estabelecimentos estudados declarou o uso de produtos químicos para controle de insetos e roedores. De acordo com a Instrução normativa conjunta no 18, em seu art. 21 "É proibida a aplicação de produtos químicos sintéticos nas instalações de processamento, armazenamento e transporte de produtos orgânicos" (BRASIL, 2009).

Para condicionar os produtos ainda são utilizados pela maioria dos estabelecimentos, embalagens de material plástico, $90 \%$ dos estabelecimentos utilizam esse tipo de embalagem, além de outros materiais como vidro, papelão e isopor. Importante ressaltar que essas informações são referentes às diversas funções: embalagens primárias, secundárias e terciárias.

O estudo também investigou questões relevantes quanto a apresentação dos produtos, neste sentido verificou-se informações como a logomarca dos produtos, a existência de rótulos e o acompanhamento técnico para elaboração de rotulagem de acordo com as normas vigentes. Mediante a análise dos dados, constatou-se que $74 \%$ dos estabelecimentos declaram possuir uma marca para seus produtos. No entanto, no que concerne a existência de rótulos, esse número foi reduzido para $63 \%$. Dentre os estabelecimentos que possuem rótulos em seus produtos, $89 \%$ dos estabelecimento declaram que não tiveram apoio técnico nesta elaboração e que provavelmente seus rótulos não estão de acordo com as normas vigentes para 
rotulagem. Entendemos ser um número expressivo e preocupante, uma vez que a rotulagem é a comunicação direta do produtor com o consumidor.

Foi identificado como desafio para esses empreendimentos familiares, a melhoraria da apresentação dos produtos, deixando-os mais apresentáveis para os consumidores. Essa medida requer conhecimento da legislação e/ou suporte técnico qualificado. Por serem complexos, requerem o conhecimento de inúmeros dispositivos legais que regulamentam a rotulagem de alimentos, com RDCs, leis, portarias, decretos específicos para cada informação contida na rotulagem.

\section{CONSIDERAÇÕES FINAIS}

Com o mapeamento e diagnóstico da Plataforma Circuitos agroecológicos foi possível ter uma visão panorâmica da real situação das agroindústrias e seus principais desafios. Com base na análise dos dados, pode-se afirmar que existem necessidades de adequações estruturais, de controles documentais e de gestão, porém observa-se que a formalização destas unidades são tangíveis.

É importante ressaltar a necessidade de melhorar a compreensão por parte da agricultura familiar no que tange à legislação e regularização dos empreendimentos familiares. Foi possível constatar, que esses processos se apresentam de forma complexa, assim como também observou-se falta de conhecimentos técnicos. Em virtude disso, é possível ainda concluir que a orientação técnica se faz necessária para transferir conhecimento aos beneficiadores, empoderamento de seus processos e estreitar as relações com os órgãos fiscalizadores. E com isso, formalizar as agroindústrias de acordo com a legislação e posteriormente receberem o almejado selo de certificação orgânica em seus produtos.

\section{REFERÊNCIAS}

[1] ARAÚJO, N. G. et. al,. Construção e desenvolvimento de Rede Povos da Mata. In: HIRATA, A.R; ROCHA, L. C. D.(ORG). Sistemas participativos de garantia do Brasil: Histórias e Experiências. Pouso Alegre: Instituto Federal de Educação, Ciência e Tecnologia do Sul de Minas Gerais, 2020.

[2] ARAÚJO, C. P. PORTO (in) Seguro: a perda do paraíso. Os reflexos do turismo na paisagem. 2004.160 p. Dissertação ( Arquitetura e Urbanismo) Universidade de São Paulo, São Paulo, 2004

[3] ARAÚJO, C. P. Um Porto Seguro para os próximos 500 anos. BAHIA Análise \& Dados, Salvador, v. 15, nº 2-3, p. 323-332, 2005.

[4] BAHIA/SEMARH-Secretaria Estadual de Meio Ambiente e Recursos Hídricos. 2005. Plano de Manejo da Parque Estadual da Serra do Conduru. 320p.

[5] BRASIL.Decreto no 6.323, de 27 de dezembro de 2007. Regulamenta a Lei no 10.831, de 23 de dezembro de 2003, que dispõe sobre a agricultura orgânica, e dá outras providências. 2007. Disponível em:<http://www.planalto. Gov. br/cciv il_0 3/_ato20072010/2007/Decreto/D6323.htm>. Acesso em: 07 mai. 2020

[6] Instrução normativa Conjunta de $\mathrm{n}^{\circ} 18$ de 29 de maio de 2009. Aprova regulamento técnico para o processamento, armazenamento e transporte de produtos orgânicos. Diário Oficial da União, Brasília, 29 de maio de 2009, seção 1, p. 5. Disponívelem:<https://www.gov.br/agricultura/ptbr/assuntos/sustentabilida de/organicos/legislacao/portugues/instrucao-normativa-no-18-de-28-de-maio-de-2009-alterada-pela-in-no-24-11processamento.pdf/view> Acesso em: 29 mai. 2020.

[7] Decreto-Lei $n^{\circ}$ 986, de 21 de outubro de 1969. Institui normas básicas sobre alimentos. Brasília, DF: Presidência da República, [1969]. Disponível em:< http://www.planalto.gov.br/ccivil_03/Decreto-Lei/Del0986.htm>. Acesso em: 29 mai. 2020

[8] Decreto $n^{\circ}$ 6.871, de 04 de junho de 2009. Regulamenta a Lei no 8.918, de 14 de julho de 1994, que dispõe sobre a padronização, a classificação, o registro, a inspeção, a produção e a fiscalização de bebidas. Brasília, DF: Presidência da República, [2009]. Disponível em:< http://www.planalto.gov.br/ccivil_03/_Ato20072010/2009/Decreto/D6871.htm> Acesso em: 29 mai. 2020.

[9] Lei n 8.080 de 19 de setembro de 1990. Dispõe sobre as condições para a promoção, proteção e recuperação da saúde, a organização e o funcionamento dos serviços correspondentes e dá outras providências.Brasilia, DF:residência da República, [1990].Disponivel em:<http://www.planalto.gov.br/ccivil_03/leis/l8080.htm>Acesso em: 30 mai. 2020

[10] Lei n 9.782 de 26 de janeiro de 1999. Define o Sistema Nacional de Vigilância Sanitária, cria a Agência Nacional de Vigilância Sanitária, e dá outras providências. Brasília, DF: Presidência da República, [1999]. Disponível em:< http://www.planalto.gov.br/ccivil_03/leis/19782.htm> Acesso em: 25 mai. 2020. 
[11] Decreto n $^{\circ}$ 9.013, de 29 de março de 2017. Regulamenta a Lei no 1.283, de 18 de dezembro de 1950, e a Lei no 7.889, de 23 de novembro de 1989, que dispõem sobre a inspeção industrial e sanitária de produtos de origem animal. Brasília, DF: Presidência da República, [2017]. Disponível em:< http://www.planalto. gov.br/cc ivil_03/_ato2015-2018/2017/decreto/d9013.htm> Acesso em: 26 mai. 2020.

[12] Lei $\mathrm{n}^{\circ} 13.680$, de 14 de junho de 2018. Altera a Lei no 1.283, de 18 de dezembro de 1950, para dispor sobre o processo de fiscalização de produtos alimentícios de origem animal produzidos de forma artesanal. DF: Presidência da República, [2018]. Disponível em:< http://www.planalto.gov.br/ccivil_03/_ato2015-2018/2018/Lei/L1 3680.htm> Acesso em: 29 mai. 2020.

[13] CARVALHO, C.R. Uma abordagem geográfica do turismo em Porto Seguro. 2008, 104 p. Dissertação (Geografia Física) Universidade de São Paulo, São Paulo, SP, 2008.

[14] CBHSF. Comitê da Bacia Hidrográfica do Rio São Francisco, 2013. Você já conhece a microrregião de Irecê?. Disponível em:<https://cbhsaofranc isco.org.br/notic ias/cbh sf_blog/voce-ja-conhece-a-microrregiao-de-irece/>. Acesso em:29. Mai. 2020

[15] CIRCUITOS AGROECOLÓGiCOS. Boletins e Resultados, Ponto de Partida, 2019, disponivel em: <https://www.circuitosagroecologicos.org.br/quemsomos/relatorios/>, acesso em: 29. Mai. 2020

[16] DA ROCHA, P. M. R.; LEISMANN, E. L. Mapeamento de riscos na agroindústria familiar e possibilidades de sua mitigação. Revista de Extensão e Estudos Rurais, Viçosa v. 6, nº. 1, p. 63-81, jan./jun. 2017

[17] FARRAN, K. S. Territorialização da Agroecologia na Bahia: Uma análise a partir do Assentamento Dois Riachões ( Movimento CETA) e da Rede de Agroecologia Povos da Mata(2015-2018). 2019, 183 p. Dissertação (programa de Pós-Graduação em Geografia) Universidade Federal da Bahia, Salvador, BA, 2019.

[18] GIL, A. C. Como elaborar projetos de pesquisa. 4. ed. São Paulo: Atlas, 2002

[19] GOMES, Ezio José. Agroindústria Familiar: uma alternativa de renda aos agricultores. Boletim do Deser, $\mathrm{n}$. 150, mar., p. 18- 20, 2006.

[20] GÖRGEN, S. A. F. A revolução verde e os impactos na agricultura camponesa. In: Trincheiras da resistência camponesa: sob o pacto do poder agroecológico. Candiota - RS: Instituto Cultural Padre Josimo, 2017. p. 616.

[21] HAHN, C. L. et al. Análise de mercado dos produtos da agroindústria familiar: estudo de caso do perfil do consumidor e do produtor Santo-Angelense, Rio Grande do Sul, Brasil. Revista Espacios, Caracas, v. 38, $\mathrm{n}^{\circ} 21$, p.5 , 2017.

[22] HIRATA, A. R.; ROCHA, L. C. D. Sistemas participativos de garantia do Brasil: Histórias e Experiências. Pouso Alegre: Instituto Federal de Educação, Ciência e Tecnologia do Sul de Minas Gerais, 2020.

[23] IBGE, Instituto Brasileiro de Geografia e Estatística. Censo agropecuário de 2006. Sistema IBGE de Recuperação Automática (SIDRA). 2007. Disponível em:<https://sidra.ibge.gov.br/pesquisa/censoagropecuario/censo-agropecuario-2006/segunda-apuracao> . Acesso em: 20. Mai. 2020

[24] LAKATOS, E. M.; MARCONI, M. A. Fundamentos de metodologia científica. 5. ed. São Paulo: Atlas, 2003.

[25] LIMA, E. E. Alimentos Orgânicos na alimentação escolar pública catarinense: um estudo de caso . 2006. 128 p. Dissertação (Nutrição) universidade Federal de Santa Catarina, Florianópolis, 2006

[26] MIOR, L. C. Agricultura familiar, agroindústria e desenvolvimento territorial. In: Colóquio Internacional de Desenvolvimento Rural Sustentável. Florianópolis, v. 22, 2007

[27] MOURA, A. M. O impacto da agricultura no crescimento do comércio na cidade de Irecê: análise da década de oitenta aos dias atuais.1997. 39 p. Monografia( Ciências Econômicas) Universidade Federal da Bahia, Salvador, 1997.

[28] MUNIZ, Vera Lúcia Travençolo; ARRUDA, José Jobson de A. História econômica e meio ambiente: Porto Seguro em perspectiva histórica. 2005.Universidade de São Paulo, São Paulo, 2005.

[29] PASCHOAL, R. A. A agroindústria de produtos orgânicos: negócios alternativos da pequena propriedade rural com vistas à agregação de valor. 2015, 33 p. Trabalho de Conclusão de Curso(Especialista em Agronegócio) Universidade Federal do Paraná, Curitiba, 2015

[30] PRODANOV, C.C.; FREITAS, E. C. Metodologia do trabalho científico: Métodos e Técnicas da Pesquisa e do Trabalho Acadêmico. 2 ${ }^{\mathrm{a}}$ ed. Universidade FEEVALE - Novo Hamburgo, Rio Grande do Sul, 2013.

[31] SAMBUICHI, R. H. R. Ecologia da vegetação arbórea de Cabruca-Mata Atlântica raleada utilizada para cultivo de cacau-na região Sul da Bahia. 2003. 140 p. Tese (Doutorado em Ecologia) Universidade de Brasília, Brasília, 2003

[32] TAVARES, L. Produtores de Olerícolas do Pré-Assentamento Dois Riachões - Bahia. 2018. Disponível em:<https://www.slowfoodbrasil.com/comunidades-do-alimento/comunidades-brasileiras/23-nordeste/1441produtores-de-olericolas-do-pre-assentamento-dois-riachoes-bahia>Acesso em: 18.Mai.2020 
[33] WAQUIL, P. D. et al. O perfil da agroindústria rural no Brasil: uma análise com base nos dados do Censo Agropecuário 2006. Brasília, DF, p. 86, 2013.

[34] WURLITZER, N. J.; ARAÚJO, I. O. Treinamento e preparação de mão de obra para a segurança de alimentos. In: BASTOS, M. do S. R. (Org). Ferramentas da Ciência e Tecnologia para a segurança dos alimentos. Fortaleza: Embrapa Agroindustrial Tropical; Banco do Nordeste do Brasil, 2008. p. 193-201. 


\section{Capítulo 10}

\section{Avaliação sócioeconômica do setor produtivo do}

vestuário no estado de Mato Grosso entre os anos de 2010 a 2019

\section{João Paulo de Almeida Ferreira Silva \\ Esdras Warley Nunes de Jesus \\ Anderson Nunes Vieira de Carvalho}

Resumo: Este trabalho avalia as inter-relações da montante com a jusante do setor produtivo do vestuário de Mato Grosso, com base em indicadores socioeconômicos. 0 problema, versar no questionar: qual a avaliação os indicadores socioeconômicos para o setor produtivo do vestuário de Mato Grosso entre os anos de 2010 a 2019? A análise sugere mudanças para com os pontos de estrangulamentos, redução de custos de transação e efetividade de mercado. A pesquisa tem por finalidade pesquisa para solução do problema, analisar os indicadores socioeconômicos na construção dos fluxos produtivos, empregabilidade, comportamento do consumo e, por fim, comparar o desempenho institucional com a teoria da dependência. Há pouca efetividade por meio de governança para os mercados interno e externos, justificando pela forte impacto transacional dos insumos locais e a transformação tecnológica de matéria-prima que acompanha o setor de mercado externo. Constatou-se hipoteticamente que o setor produtivo do vestuário se desenvolve com experiências adquiridas de outros Estados através da participação em exposições, congressos e que a produção e estrutura de governança sofre forte impacto alinhado à Teoria da Dependência.

Palavras-chave: 1. Setor Produtivo. 2. Vestuário. 3. Avaliação e Desempenho. 


\section{INTRODUÇÃO}

Mato Grosso possui uma localização geopolítica estratégica para desenvolvimento econômico brasileiro, pois insere-se no centro geodésico da América do Sul que fica justamente em sua capital, Cuiabá. Com dinamismo, sua economia é liderada pela produção de açúcar, álcool, grãos e forte arranjo de cadeias produtivas com ênfase à indústria de transformação. A produção média in natura está inserida em altitudes que variam de 500 a 980 metros e são influenciadores diretos nas economias dos municípios as quais pertencem, sendo possível a ligação com os países andinos por meio da hidrovia Rio Paraguai, da Rodovia Cuiabá-Santarém, da Ferrovia da Ferronorte, do complexo hidráulico do Rio Manso, do Porto Seco (Cuiabá) e as rodovias federais BR-364, BR-163 e BR-07025.

Atualmente o setor produtivo do vestuário instituído pelo Decreto № 518, de 07 de abril de 2016, vem somando esforços junto ao Governo de Mato Grosso na busca do desenvolvimento econômico e social, praticando ações integradas de políticas públicas direcionadas ao aumento do emprego e renda e a diminuição das desigualdades regionais e sociais. Portanto, o estudo busca avaliar o setor produtivo de Mato Grosso, especificamente na produção de vestuário, no tanger de levantamento de dados que promovam às inter-relações da montante (fornecedores de insumos, tecnologias e prestação de serviços) com a jusante (industrialização e a distribuição) com o olhar econômico-produtivo entre os anos de 2010 a 2019.

As temáticas que se pretende levantar versam desenvolver um panorama do setor produtivo, empregabilidade, consumo das famílias, avaliar o desempenho institucional e estrutura de governança e contratos. Justifica-se a analisar indicadores alinhados às características da mão de obra junto a Pesquisa Nacional por Amostra de Domić́lios (PNAD); a produtividade e dificuldades para o consumo de acordo com a Pesquisa de Orçamentos Familiares (POF) e; a análise da disponibilidade ou escassez de recursos que influenciam no crescimento do setor produtivo, para melhor entendimento do dinamismo industrial, fomento e eficiências dos fatores de produção dentro do sistema.

Durante a realização da pesquisa, foi observado que a problemática a ser respondida é: Qual a avaliação dos indicadores socioeconômicos para o setor produtivo do vestuário de Mato Grosso entre os anos de 2010 a 2019? Constatou-se hipoteticamente que o setor produtivo do vestuário se desenvolve com experiências adquiridas de outros Estados através da participação em exposições, congressos e que a produção e estrutura de governança sofre forte impacto alinhado à Teoria da Dependência. Levantou-se os requisitos que regem toda essa situação a respeito da transformação em escala, para entender os problemas encontrados no setor.

\section{PANORAMA DO SETOR PRODUTIVO DO VESTUÁRIO}

\subsection{O FLUXO PRODUTIVO DO SETOR}

O setor produtivo têxtil (englobado com a confecção) inclui a distribuição e a comercialização. Bezerra (2014, p.3) contextualiza afirmando que a industrial têxtil “(...) é uma etapa dessa cadeia, compreendendo a fiação, a tecelagem, a malharia e o beneficiamento (tinturaria, estamparia, lavanderia etc.)". Portanto, a setorização de produção demanda matérias-primas compostas por fibras naturais (de origem do algodão), filamentos sintéticos e artificiais, sendo que a transformação destes são ofertados à vestuários e artigos para o lar.

Figura 1: Fluxo produtivo da Cadeia Têxtil e de Confecção

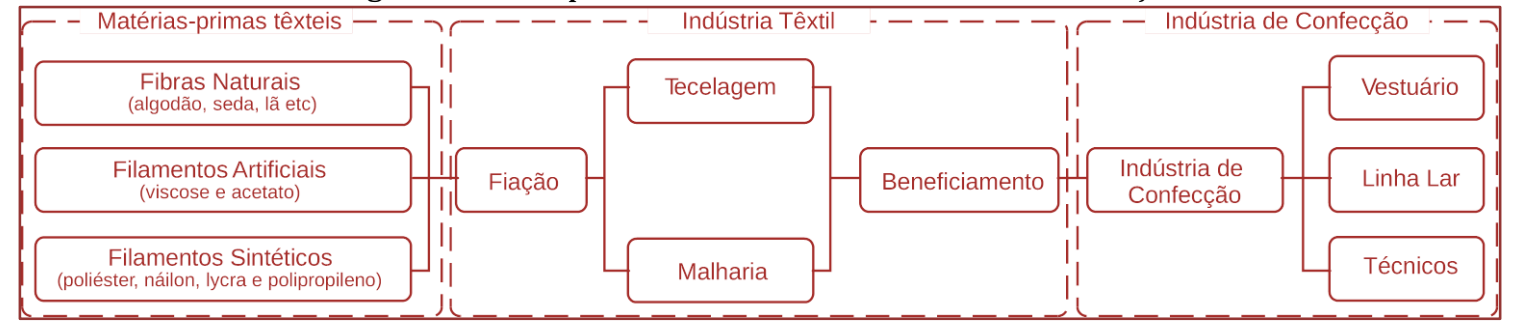

25 Fonte: SEDEC-MT, Secretaria de Estado de Desenvolvimento Econômico. Documento acessado em 23/02/2020. 
O fluxo produtivo de uma operação produtiva denota-se com as aplicações de recursos de transformação. Na Figura 1, de forma simples o arranjo (ou fluxo produtivo) propõe em ambiente macroeconômico a decisão de instalar máquinas, equipamento e pessoal de produção.

Necessário se faz destacar que os segmentos estão identificados em insumo - indústria têxtil - indústria de confecção, e a real possibilidade de "(...) descontinuidade das operações possibilita flexibilidade na organização da produção e a existência de empresas com escalas de produção e níveis de atualização tecnológica diferentes", conforme Bezerra (2014, p.4).

A primazia empresarial do setor produtivo do vestuário, concerne na característica de volume-variedade de insumos. Percebe-se que há superposição de insumos entre os tipos de processos produtivos. No caso, a superposição de matéria-prima denota-se por diferentes tipos de centro de custos oriundos da diversificação existentes de matérias-primas, ou seja, o reforçando o delineamento dos centros de responsabilidade:

O delineamento dos centros de responsabilidade é, na prática, uma tarefa difícil

$e$, a instalação de um sistema de controle, muitas vezes descobre casos de superposição de responsabilidade, que precisa ser corrigida. (MARQUES, 2013, p.62)

Quando há variações de preço ou quantidade, o "fluxo" não torna-se uma questão central, pois em operações de manufaturas a maior probabilidade é que um arranjo físico local seja utilizado à condicionar a armazenagem, ou seja, "(...) cada produto é diferente dos outros e porque produtos "fluem" através de outras operações" macroeconômicas, não valendo a pena arranjar recursos que minimizem o custeio do fluxo produtivo. (SLACK, 2007, p.172).

O setor do vestuário, independente do seu porte, não pode mais ser feita de maneira amadora. Assim sendo, é fundamental que os gestores possam dispor de ferramentas adequadas às especificidades dos seus sistemas produtivos e de suas culturas empresariais. Entre as ferramentas gerenciais destacam-se os indicadores de desempenho.

Algumas peculiaridades não são abordadas pelos indicadores de desempenho, nem mesmo os mais modernos, além destes pontos, não seriam possíveis contratar profissional somente para atuar nesta função dentro de sua empresa. Portanto, é necessária a urgente elaboração de ferramentas de fácil aplicação e manuseio que atendam necessidades de toda a cadeia produtiva, conforme relata Batalha (2003).

Os setores produtivos de Mato Grosso trabalham com suas primícias baseadas no agronegócio e com indicadores que norteiam os proprietários de latifúndios a enxergarem as tendências demanda das commodities. Assim, a economia do setor de transformação pode viver dias difíceis em cada unidade de produção, porém os contratos garantem muitas vezes que o ciclo de plantio e colheita de algodão esteja garantido junto as safras.

Segundo Hoffmann et. al. (1987):

(...) o objetivo mais importante dos registros agrícolas deve ser a avaliação financeira da empresa agrícola e a determinação de seus lucros e prejuízos durante um período determinado, fornecendo, assim, a base exigida para fazer o diagnóstico da empresa e seu planejamento eficaz.

Neste caso pode-se compreender que a indústria do vestuário tem a necessidade de visualizar que os produtores de algodão estão demandando empreendedores que façam a conversão insumo-produto dentro do Estado. Batalha et al (2004) aponta que há "necessidade de maiores esforços por parte dos produtores rurais, dos profissionais da assistência técnica e dos pesquisadores" no sentido de desenvolver a cadeia de um setor produtivo. A administração do setor produtivo deve ser considerada como o estudo que considera a organização e operacionalização de uma empresa visando o uso mais eficiente dos recursos que tragam resultados compensadores e constantes.

0 trabalho de Lima (2005), vem confirmar a carência na área da administração no setor produtivo no Brasil, afirmando haver "(...) falta de referência teórica e metodológica que instrumentalize os profissionais que trabalham com assistência técnica". Mas gestão do setor produtivo, que compreende a coleta de dados, geração de informações, tomada de decisões e ações que derivam destas decisões, não é tratada de forma satisfatória na literatura nacional e internacional. 
Os trabalhos existentes nesta área estão quase sempre restritos aos aspectos financeiros e econômicos (custos, finanças e contabilidade). Tradicionalmente a questão da gestão no setor produtivo do vestuário é abordada de forma muito compartimentada e específica. São incipientes os esforços dedicados à ferramentas de gestão, principalmente nos critérios de definição do produto e do processo de produção que ultrapassem a visão de curto prazo das margens de contribuição, sistemas de gestão da qualidade, sistemas de planejamento e controle da produção e sistema de logística (BATALHA et al, 2005). Formalizar, isto é, colocar no papel, o que se pretende que aconteça em determinado momento no futuro, torna-se difícil no planejamento da produção.

"(...) é diferenciada e particularmente mais difícil que nos demais setores da economia. $O$ equilíbrio entre a oferta e a demanda da produção, numa situação de queda de preços não é retomado simplesmente por uma decisão gerencial" (BATALHA, 1997).

Não há dúvidas de que muitos empresários utilizem ferramentas adequadas de gestão, mas também é verdadeiro que muitos terão que realizar importantes esforços para estar de acordo com os tempos atuais, de modo que possam manter o crescimento ou mesmo a manutenção de seus negócios.

De acordo com Hoffmann et al. (1987), alguns riscos para as propriedades que não têm controle de custos, orçamentos e fluxo de caixa estão no (1) desconhecimento do resultado econômico, (2) o aumento ou diminuição das atividades exploradas com base somente na intuição do gestor, (3) muitas vezes investimentos desnecessários, mal dimensionados ou realizados em momentos impróprios e a (4) facilidade de endividar-se.

De acordo com a Organização Mundial do Comércio (OMC), os três principais exportadores do ramo têxtil em 2015 foram a China, União Europeia e Índia, nos quais mantiveram aproximadamente dois terços das exportações mundiais, porém houve queda nos valores das exportações na União Europeia $(-14 \%)$, Turquia (-13\%). A menor queda ocorreu na China (-2\%).

Tabela1: Produção têxtil e vestuário mundial

\begin{tabular}{|c|c|c|c|c|}
\hline \multicolumn{3}{|c|}{ Produção têxtil } & \multicolumn{2}{|c|}{ Produção vestuário } \\
\hline & País & $\%$ & País & $\%$ \\
\hline 1 & China & 50,20 & China & 47,20 \\
\hline 2 & Índia & 6,90 & Índia & 7,10 \\
\hline 3 & Estados Unidos & 5,30 & Paquistão & 3,10 \\
\hline 4 & Paquistão & 3,60 & Brasil & 2,60 \\
\hline 5 & Brasil & 2,40 & Turquia & 2,50 \\
\hline 6 & Indonésia & 2,40 & Coréia do Sul & 2,10 \\
\hline 7 & Taiwan & 2,30 & México & 2,10 \\
\hline
\end{tabular}

Fonte: ABIT / gotexshow.com.br (2020)

Dados gerais do setor apontam que em quantidade de produção somos o quarto maior parque de confecções e quinto no ramo têxtil mundial. Porém ao analisarmos os valores (US\$) obtidos para exportação, o Gráfico 1 revela outro comportamento do mercado. 
Gráfico 1: Países exportadores do ramo têxtil - Bilhões US\$ - (2015)

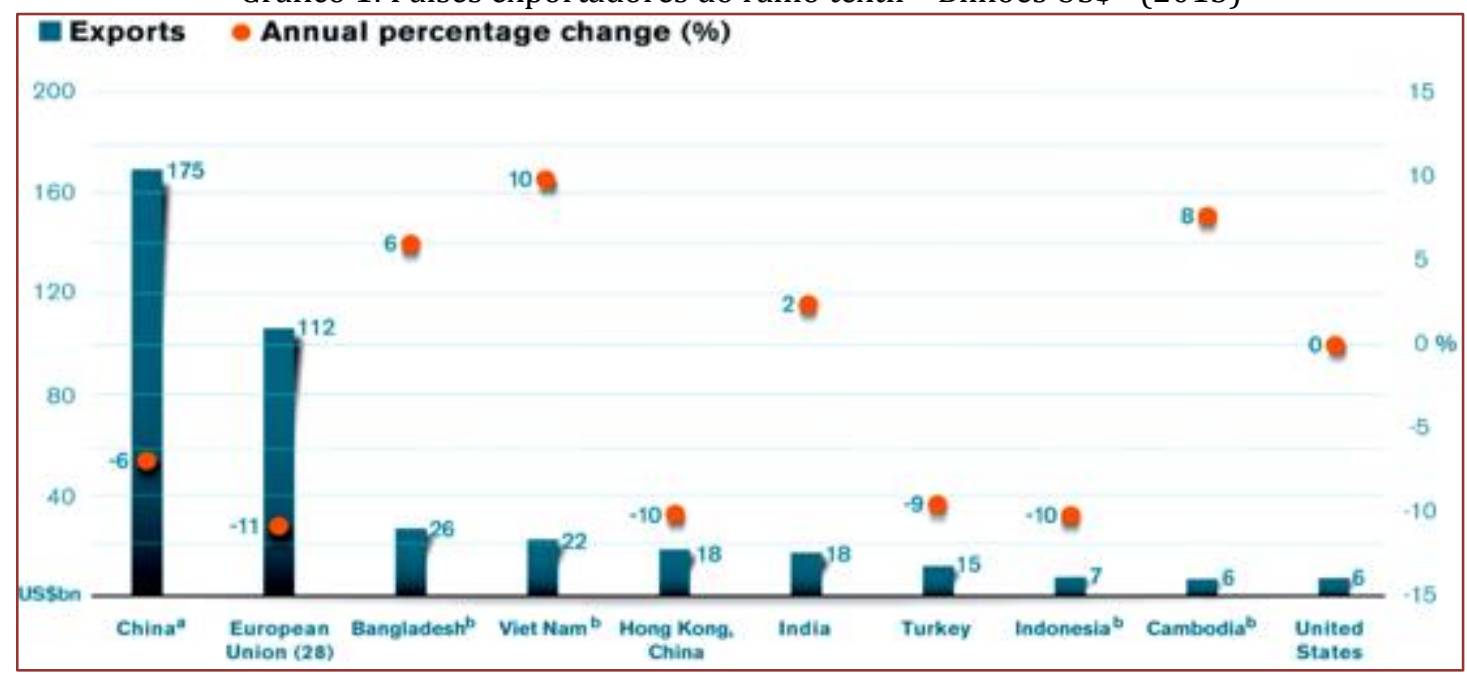

Fonte: WTO Statistic Review (2016)

Nos valores de exportação (bilhões/2015) no ramo do vestuário, a China esteve em primeiro lugar com US\$ 175, seguidos da União Europeia com US\$ 112 e Bangladesh com US\$ 26. Em percentuais Vietnã (+10\%), Camboja (8\%), Bangladesh (+6\%) e Índia (2\%) obtiveram melhores êxitos. Demais exportadores viram os valores exportados dos Estados Unidos registrar uma estagnação. Em 2015, os dez primeiros responsáveis por $87 \%$ do mundo exportações de vestuário.

Isto prova que a influência de terceiros, ou atravessadores na comercialização das commodities é outro problema grave no Brasil, pois a transformação do algodão em filamento ocorre no exterior, pois não há um equilíbrio das (1) perdas e ganhos obtidos por produtividade e ou aumento dos preços dos produtos e o (2) crescimento sem sustentação. Quanto ao mercado nacional, a Balança Comercial apontou que entre os anos 2010 a 2015 os valores (US\$ FOB) no ramo do vestuário e outras confecções têxteis tiveram sucessíveis déficits.

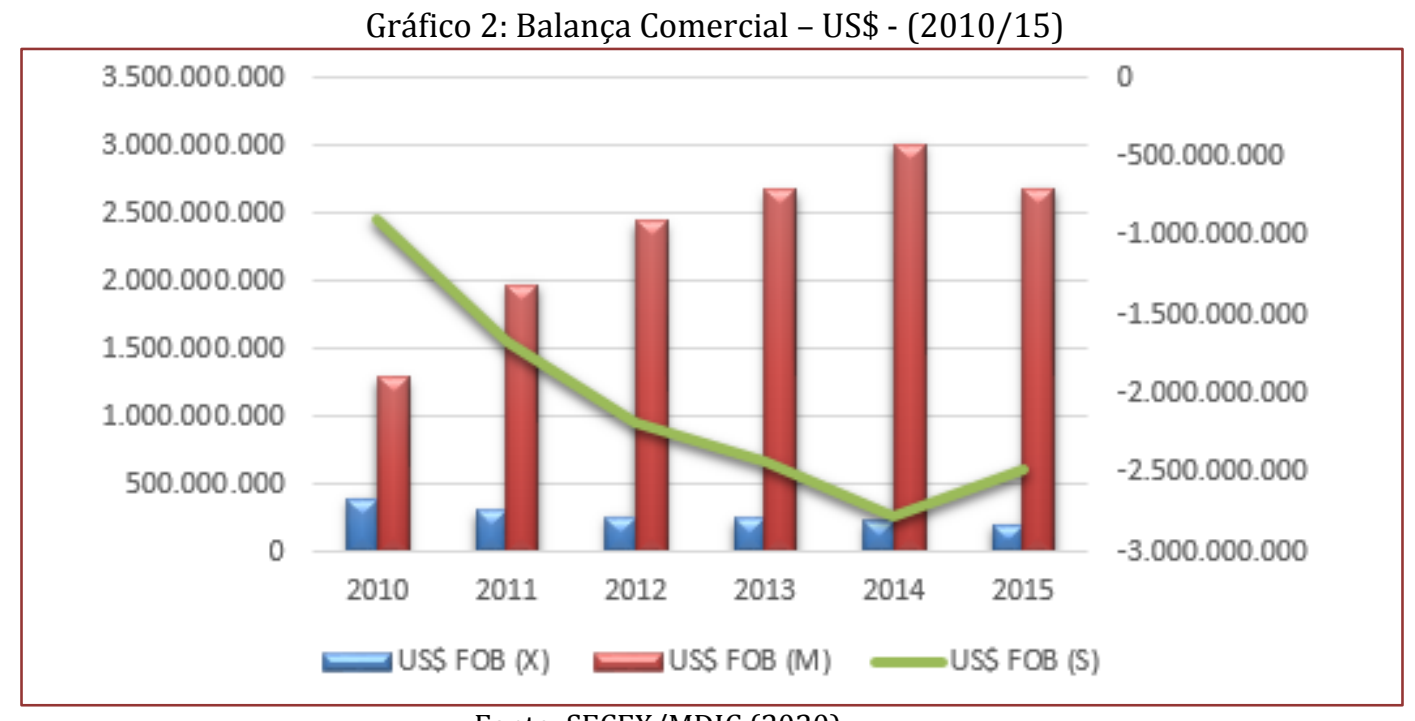

Fonte: SECEX/MDIC (2020) 
Quanto os valores de exportação - US\$ FOB (X), pode-se afirmar:

- $\quad$ Em 2010 houve a maior arrecadação com US\$ 389.855.364;

- $\quad$ Em 2015 houve a menor arrecadação em US\$202.924.408;

- $\quad$ A média dos valores pagos à exportação foram US\$271.627.291;

- $\quad$ O desvio-padrão26: US\$ 61.616.303,86

Os valores pagos à importação - US\$ FOB (M):

- $\quad$ Em 2014 foi registrado o maior valor: US\$3.010.152.025;

- $\quad$ Em 2015 foi registrado o menor valor: US\$ 1.283.827.880;

- $\quad$ A média dos valores pagos: US\$2.343.911.588;

- $\quad$ O desvio-padrão: US\$568.100.897,83.

Em comparação às médias dos valores pagos, a importação $(M)$ obteve índice de 8,63 vezes maior que a exportação $(\mathrm{X})$ de vestuário e outras confecções têxteis. O desvio-padrão da importação $(\mathrm{M})$ obteve índices de 9,22 vezes maior que a exportação (X).

Os saldos anuais da Balança Comercial - US\$ FOB (M) - operaram em déficit comercial no setor:

- $\quad$ Em 2010 o maior valor com (-) US\$ 893.972.516;

- $\quad$ Em 2014 houve o maior recuo do déficit comercial para (-) US\$2.782.977.862;

- $\quad$ A média comercial operou em déficit anual de (-) US\$ 2.072.284.297;

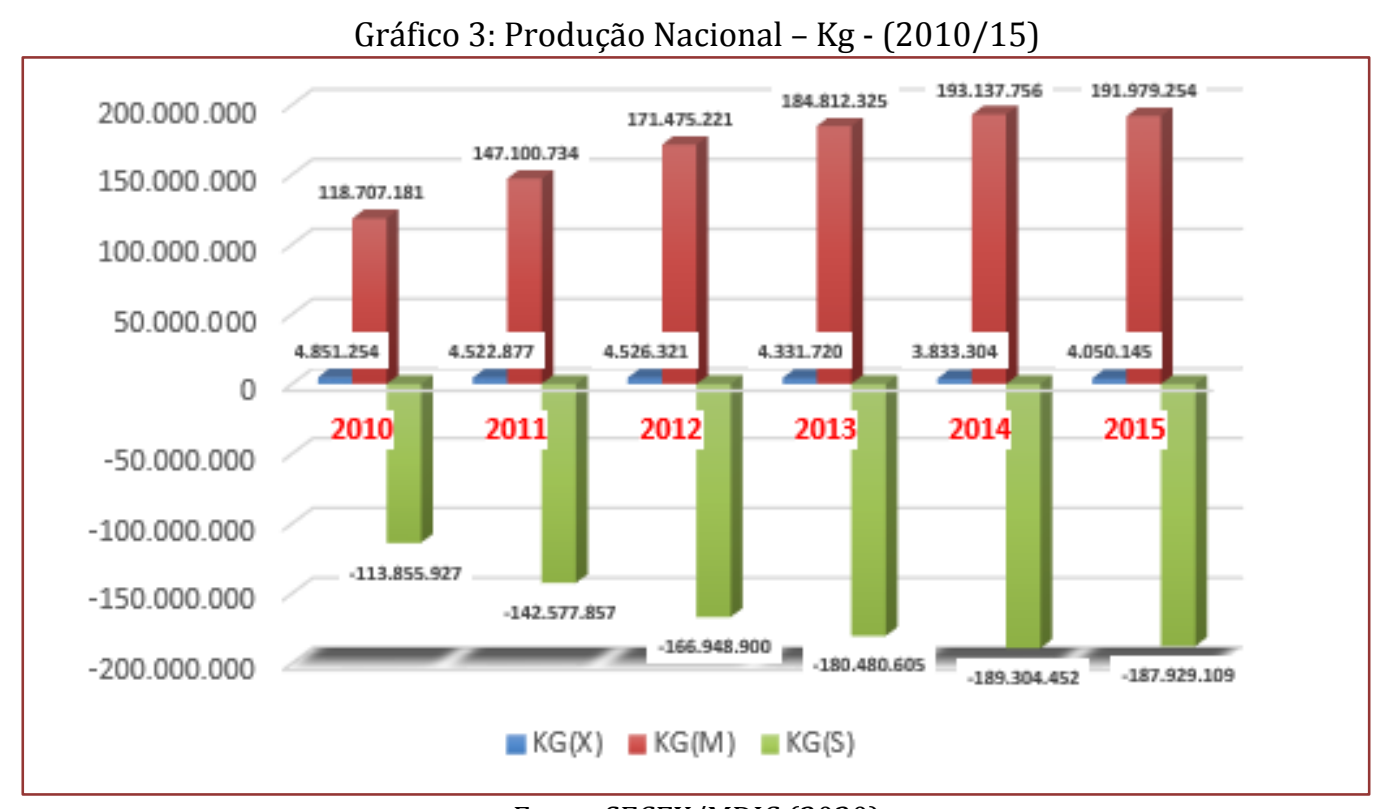

Fonte: SECEX/MDIC (2020)

A produção exportada - $\mathrm{KG}(\mathrm{X})$, operou com maior alta em $2010(4.851 .254 / \mathrm{Kg})$, a menor em 2014 $(3.833 .304 / \mathrm{kg})$, com média anual de $4.352 .604 / \mathrm{kg}$ e desvio-padrão entre os anos 2010 a 2015 de $334.019 / \mathrm{kg}$.

\footnotetext{
${ }^{26}$ Desvio-padrão, na prática aponta o grau de oscilação dos valores em comparação com a média.
} 
A maior quantidade importada - KG(M), ocorreu em 2014 com $193.137 .756 / \mathrm{Kg}$, a menor em $118.707 .181 / \mathrm{kg}$, com média entre os anos de $167.868 .745 / \mathrm{kg}$ e desvio-padrão entre $26.981 .786 / \mathrm{kg}$. 0s saldos das balanças comerciais - KG(S) apresentaram fortes déficits anuais. 0 maior ocorreu em 2010 com (-) 113.855.927/Kg, menor em 2014 com (-) 189.304.452/Kg, sendo média entre os anos de 2010 a 2015 de (-) 163.516.142/kg. O desvio-padrão no mesmo período registrou $27.279 .893 / \mathrm{Kg}$.

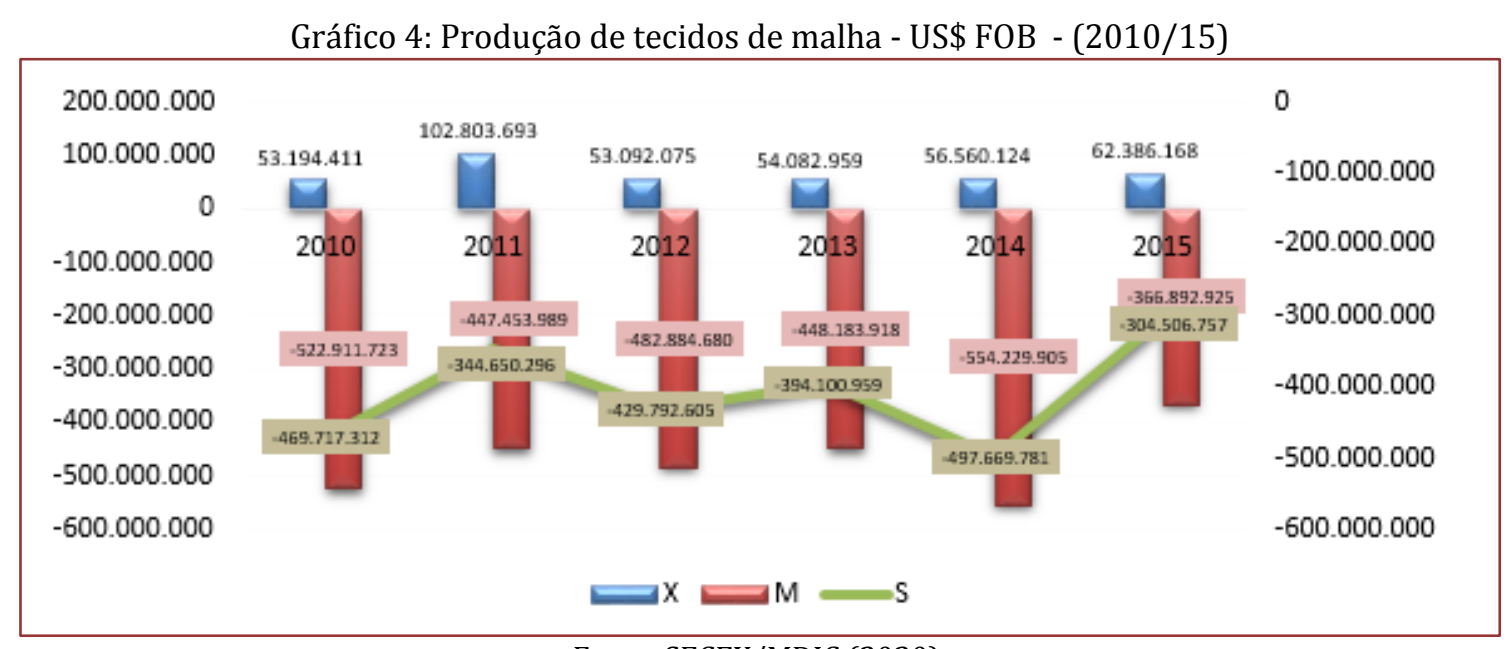

Fonte: SECEX/MDIC (2020).

Na produção de tecidos de malha (2010 a 2015), os dados demonstraram que a importação (M) cresceu em média 30\% a.a., sendo que na exportação (X) a média anual declinou (-) 17\% a.a. 0 saldo médio da balança comercial operou com déficit (-) $35 \%$ a.a.

Gráfico 5: Vestuário e seus acessórios de malha - US\$ FOB - (2010/15)

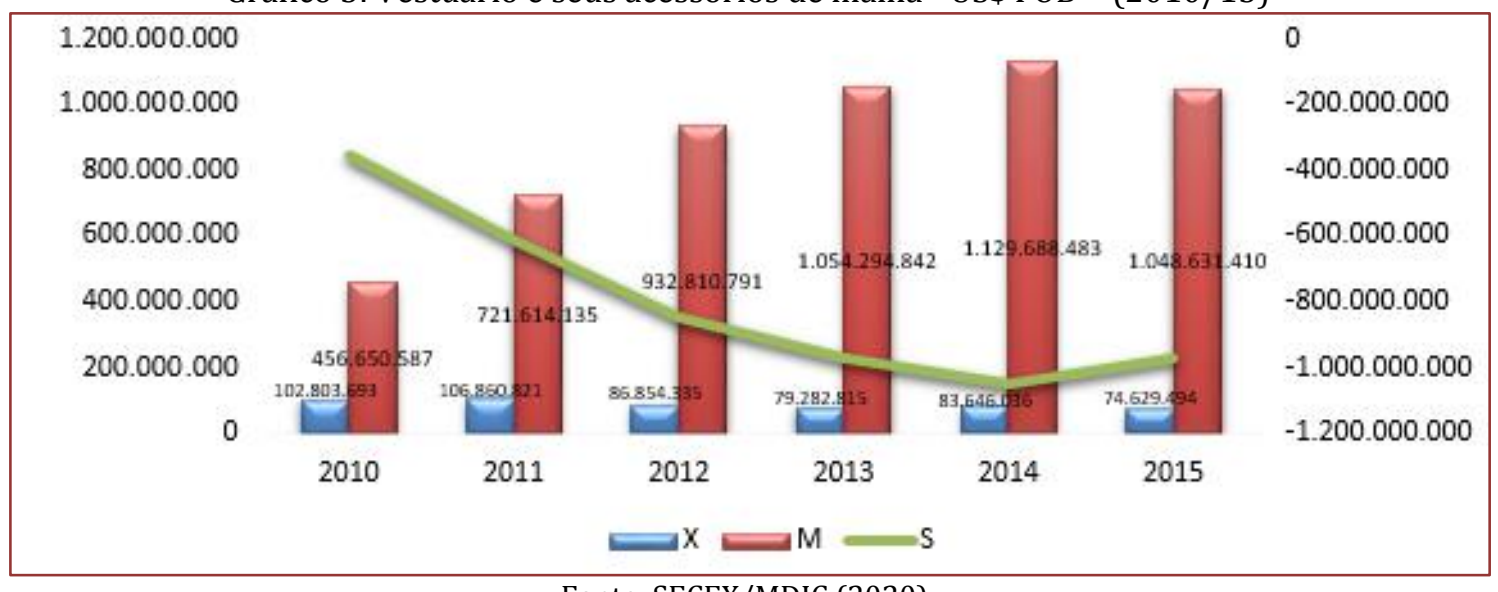

Fonte: SECEX/MDIC (2020)

A produção no vestuário e seus acessórios de malha (2010 a 2015), apontaram que a importação (M) cresceu em média 130\% a.a., com exportação (X) média em (-) 27\% a.a. 0 saldo comercial operou com déficit de (-) 135\% a.a. 
Gráfico 6: Vestuário e seus acessórios, exceto de malha - US\$ FOB (2010/15)

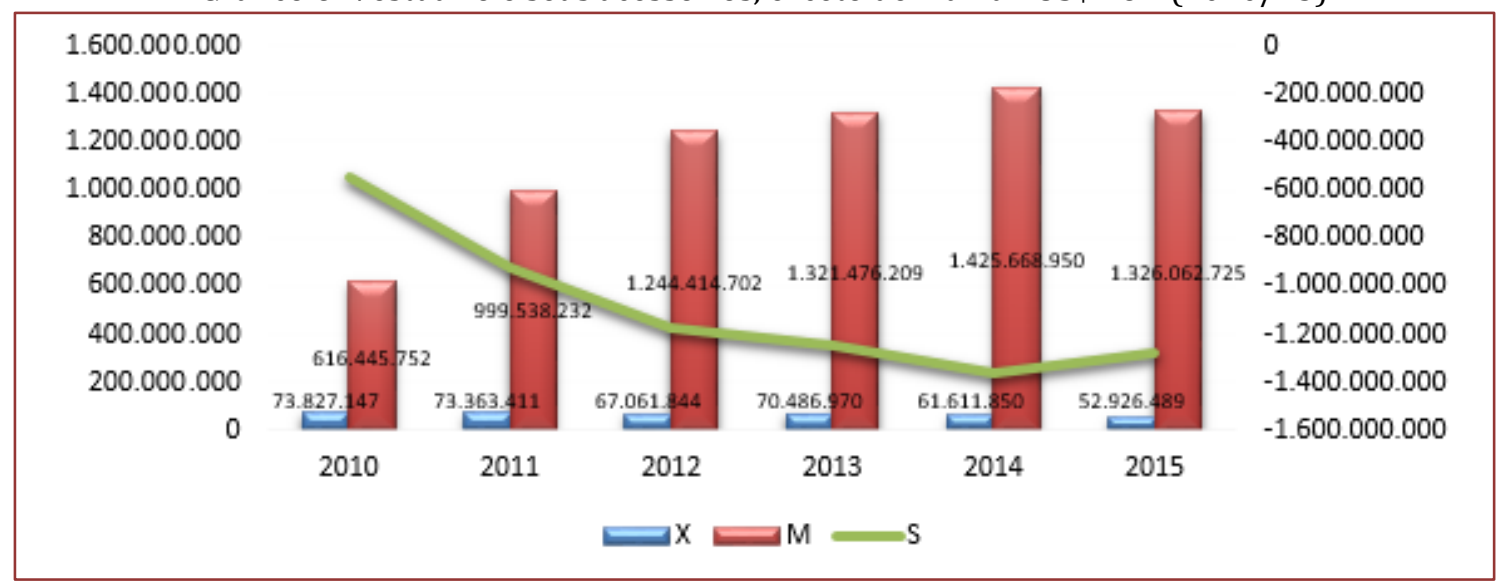

Fonte: SECEX/MDIC (2020).

O vestuário e seus acessórios, exceto de malha (2010 a 2015), obtiveram na importação (M) o crescimento médio de $115 \%$ a.a., com declínio na exportação (X) média em (-) 28\% a.a. 0 saldo comercial operou com déficit de (-) 135\% a.a.

Gráfico 7: Outros artefatos têxteis confeccionados, etc. - US\$ FOB (2010/15)

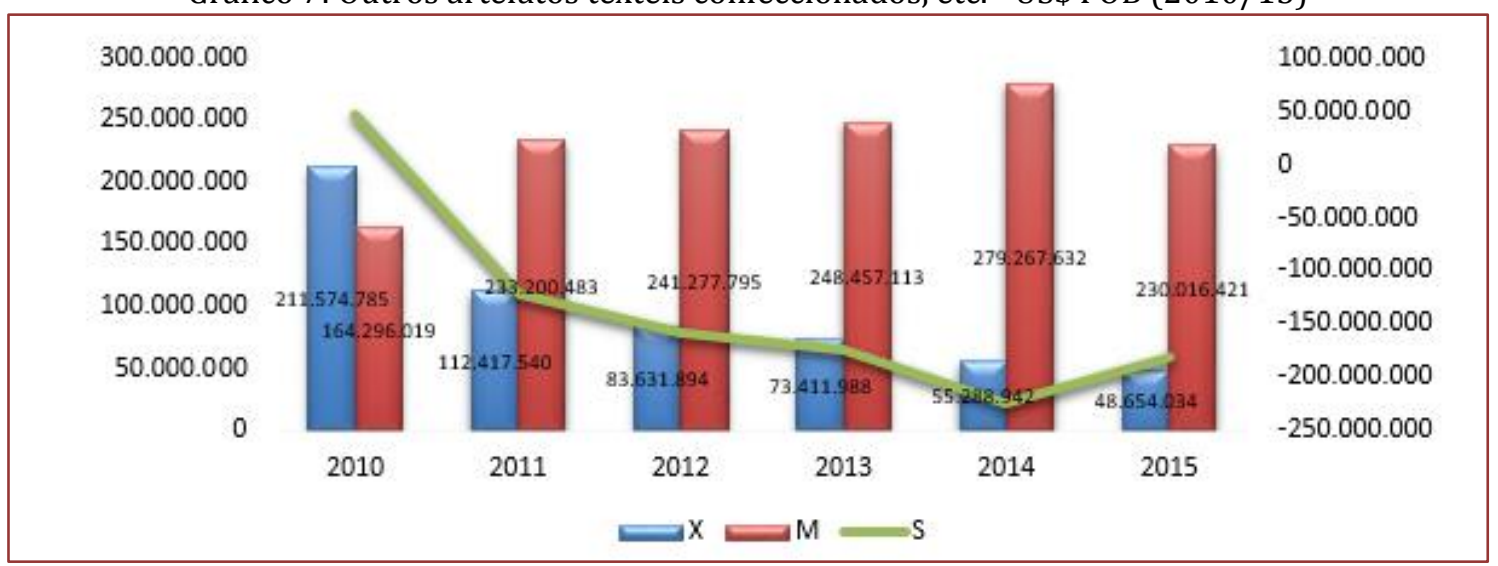

Fonte: SECEX/MDIC (2020).

7Para outros artefatos têxteis confeccionados etc. (2010 a 2015), os dados apontaram que a importação (M) média cresceu $40 \%$ a.a., com exportação (X) média declinando em (-) 77\% a., porém o saldo comercial operou com déficit médio (-) 484\% a.a. 


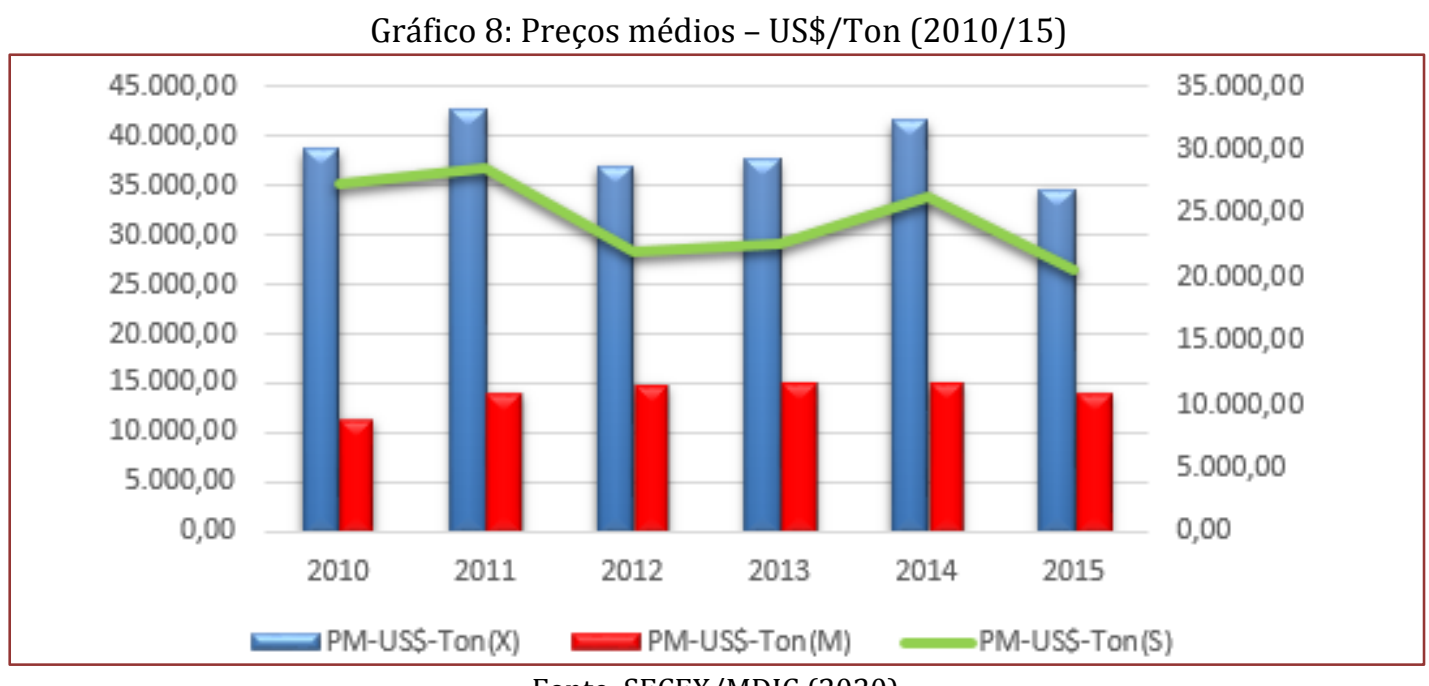

Fonte: SECEX/MDIC (2020).

0 preço recebido por tonelada exportada - PM-US\$-Ton(X), teve maior concentração de renda em 2011 com US\$ 42.643/ton, sendo a menor em 2015 com US\$34.602/ton com média anual de US\$38.675/ton. O desvio-padrão (2010 a 2015) registrado foi de US\$2.746,30/ton. Referente aos preços médios pagos por tonelada importada - PM-US\$-Ton(X), os dados descreveram em 2014 ocorreu o maior pagamento (US\$ 15.221/ton), o menor em 2010 (US\$ 11.419/ton), com médio entre 2010 a 2015 de US\$ 14.119/ton. 0 desvio-padrão foi registrado em US\$1.286,64/ton.

A balança comercial registrou - PM-US\$-Ton(S), oscilação dos preços entre US\$28.596/ton (maior), US\$ 20.499/ton (menor), US\$24.556 /ton (médio). 0 desvio-padrão foi de US\$2.998,55/ton. Assim, os produtores de algodão correm sérios riscos de altos endividamentos, descapitalização de suas terras, dependência de atravessadores, aumentos constantes dos custos financeiros, queda na margem de lucratividade, escassez ou aumento dos custos dos insumos e serviços. Ainda há fatores exógenos que influenciam na produção do agricultor como eventos climáticos, falta de crédito e a dependência de políticas governamentais.

\subsection{EMPREGABILIDADE DO SETOR TÊXTIL/VESTUÁRIO}

Retratar o dinamismo econômico brasileiro é uma tarefa que exige enorme envergadura de discussão e intelectualidade, por isso a realidade das descrições dos fatos à primeira leitura demanda sempre uma apreensão crítica por parte do analista econômico. A conjuntura busca traçar um mapa da correção das forças econômicas, políticas, sociais, geográficas, históricas e demais que constituem os processos decisórios e as transformações no ambiente econômico que influenciam a sociedade e seus vínculos nas relações de poder.

Para inserção de um país continental à competitividade mundial atualmente é preciso explorar com afinco os potenciais endógenos sociais e automaticamente reestruturar o fundamentalismo de produção nacional instalado por métodos sofisticados e diversificados.

Para Sicsú (2007), o crescimento econômico sustentável e a redução do desemprego precedem da estabilidade de preços e de equilíbrio do setor econômico no exterior, ou seja, a neutralidade da moeda promove em curto prazo êxito e estímulo. 0 uso eficiente da política monetária força de forma eficaz o controle inflacionário, mal este reconhecido pelos Keynesianos e Pós-Keinesianos a necessidade premente de combate. 
Gráfico 9: Brasil: evolução do emprego (têxtil/vestuário)

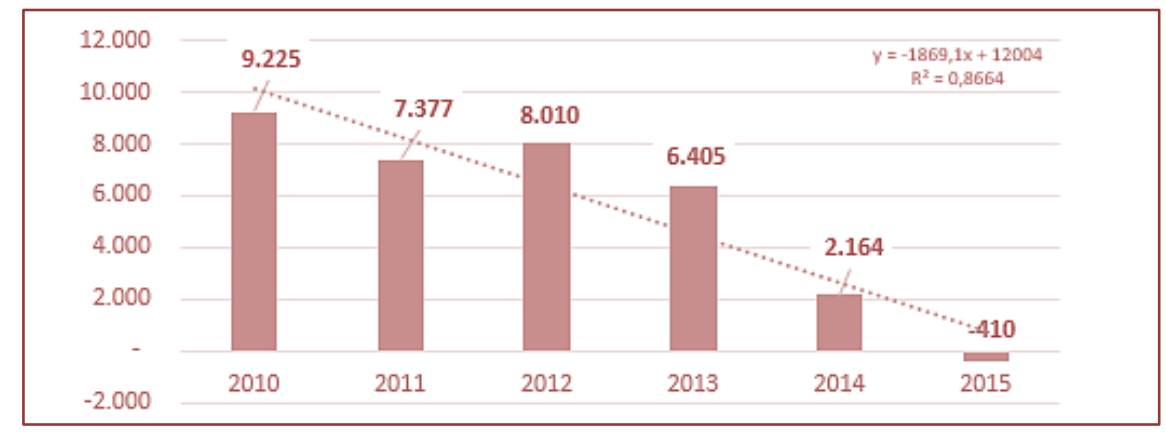

Fonte: MTE/CAGED (2019)

Analisando o Gráfico 9, a evolução do emprego na atividade econômica têxtil/vestuário, entre os anos de 2010 a 2015, que é expressa em "Saldo = Admissões - Desligamentos", onde obteve-se as variações:

- 2010 a 2011 em (-) 20,03\%;

- 2011 a 2012 em (+) 8,58\%;

- 2012 a 2013 em (-) 20,04\%;

- 2013 a 2014 em (-) 66,21\%;

- 2014 a 2015 em (-) 118,95\%.

Analisando de forma isolada, os saldos médios da empregabilidade no setor variaram em 4.042 trabalhadores de 2012 a 2015, logo após 2.720 de 2013 a 2015, e encerrando o biênio de 2014 a 2015 em 877 trabalhadores. Os dados apontam que a crescente importação de peças de vestuário fabricadas com mão de obra barata é um dos principais desafios encontrado pelo setor produtivo ${ }^{27}$.

Aos olhos de Keynes, os resultados que poderiam ser obtidos por uma redução da taxa de juros seriam duradouros. Mais fábricas, por exemplo, seriam abertas e parte daqueles que estavam involuntariamente desempregados encontraria trabalho. (SICSÚ, 2007)

As taxas de juros é um debate que demanda conceitos teóricos empíricos, pois as estruturas de capitais monetário, humano, tecnológico são importantes para resguardar a economia de choques externos proporcionando autonomia ao setor produtivo do vestuário brasileiro.

Gráfico 10: Pesquisa Industrial Mensal de Emprego e Salário (2015)

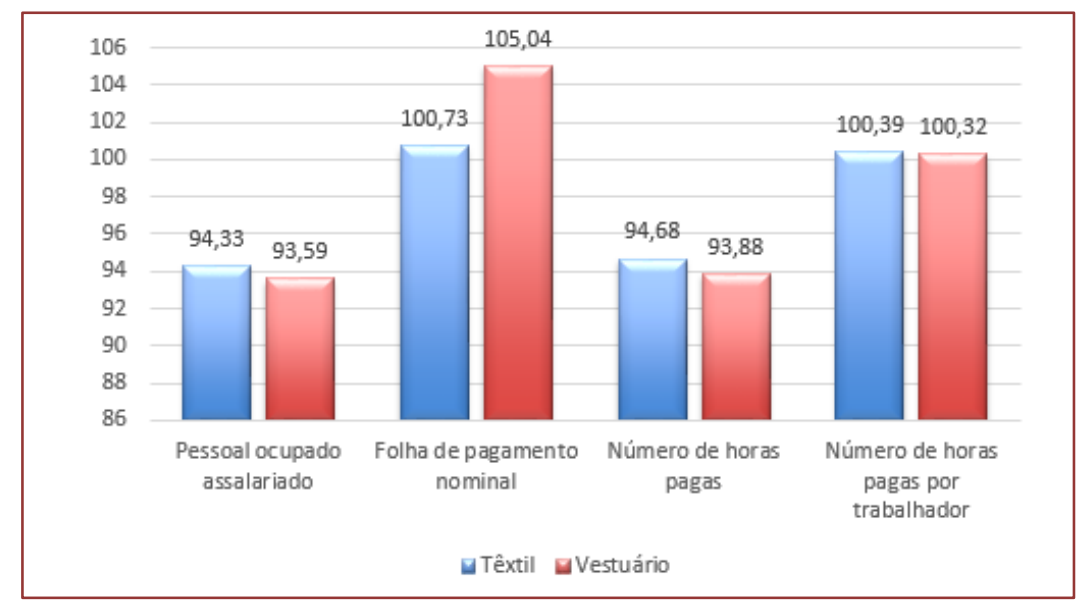

Fonte: IBGE - Pesquisa Industrial Mensal de Emprego e Salário28.

27 Fonte: http://www2.camara.leg.br/camaranoticias/noticias/INDUSTRIA-E-COMERCIO/466531-INDUSTRIATEXTIL-APONTA-IMPORTACOES-E-MAO-DE-OBRA-BARATA-NO-EXTERIOR-COMO-CAUSA-DE-DIFICULDADES.html 28 Tipo de Índice acumulado de 12 meses (Base: últimos 12 meses anteriores = 100). 
Os desempenhos das variáveis ${ }^{29}$, referente ao ano de 2015, apontaram que o pessoal ocupado assalariado, (remunerados diretamente por empresas) e plenamente ocupados nas atividades de produção e manutenção de bens e serviços industriais, que no ramo têxtil registro (-) 5,67\% e no vestuário (-) 6,41\%.

A folha de pagamento nominal - seria valor pago ao pessoal ocupado assalariado (com ou sem vínculo) não inclusos os encargos trabalhistas - demonstraram que houver aumentos no ramo têxtil de 0,73\% e vestuário 5,04\%.

Referente ao número de horas pagas (NHP) ${ }^{30}$, foram apontadas quedas no ramo têxtil em (-) 5,32\% e no vestuário (-) 6,12, porém o número de horas pagas ao trabalhador (NHPT) aumentaram 0,9\% (têxtil) e 0,32\% (vestuário). Analisando de forma isolada, percebe-se que o ano de 2015 que a redução de emprego aumenta a carga horaria dos atuais trabalhadores com ou sem vínculos empregatícios.

\subsection{COMPORTAMENTO DO CONSUMO}

Num contexto geral, Mato Grosso vem sofrendo quedas constantes para exportar no segmento do vestuário. Os dados apontaram que a redução de US\$ (FOB) tem sido de $\Delta=-19,76 \% /$ a.a., porém nos países selecionados (Tabela 3) a China ( $\Delta=-28,00 \% /$ a.a.), Turquia $(\Delta=-55,88 \% /$ a.a.) e Malásia $(\Delta=-$ $55,88 \%$ /a.a.) foram os principais agentes que reduziram suas importações.

Analisando de forma isolada, a variação média anual $(\Delta)$ foi de $(-) 23,62 \%$ de divisas pagas pelos produtos têxteis mato-grossenses entre os anos de 2011 a 2013. Mesmo com esse quadro de evasões, é importante ressaltar que a Coréia $(\Delta=4,00 \% /$ a.a.) e Japão $(\Delta=2,52 \% /$ a.a.) foram os países que obtivemos variações positivas na aquisição têxtil de MT, conforme dados da Tabela 3.

Tabela 3: Setor Têxtil de MT (Comex - US\$1000 - FOB) - Exportações

\begin{tabular}{|c|c|c|c|c|c|c|}
\hline & \multicolumn{2}{|c|}{2011} & \multicolumn{2}{c|}{2012} & \multicolumn{2}{c|}{2013} \\
\hline & Mundo Agregado & 732.338 & Mundo Agregado & 1.089 .866 & Mundo Agregado & 665.071 \\
\hline 1 & China & 263.526 & China & 368.580 & Coréia & 147.429 \\
\hline 2 & Indonésia & 95.746 & Indonésia & 148.542 & Indonésia & 140.177 \\
\hline 3 & Coréia & 82.600 & Coréia & 139.086 & China & 109.727 \\
\hline 4 & Turquia & 55.141 & Paquistão & 81.274 & Paquistão & 40.138 \\
\hline 5 & Paquistão & 38.626 & Turquia & 73.643 & Tailândia & 38.460 \\
\hline 6 & Malásia & 38.372 & Tailândia & 51.456 & Turquia & 30.116 \\
\hline 7 & Tailândia & 18.983 & Malásia & 51.184 & Malásia & 29.560 \\
\hline 8 & Japão & 17.411 & Japão & 12.384 & Japão & 11.303 \\
\hline 9 & África do Sul & 7.492 & Equador & 3.800 & Equador & 2.759 \\
\hline 10 & Alemanha & 2.474 & Índia & 3.575 & Alemanha & 2.071 \\
\hline
\end{tabular}

Fonte: MDIC / Sistema Radar Comercial.

Para fins de análise, o ranking das reduções monetárias superiores à média anual esperada de cada país em US\$ (FOB), ficou assim estabelecido na Tabela 4:

Tabela 4: Desvio-padrão têxtil/MT entre 2011 a 2013 (US\$ 1000 - FOB)

\begin{tabular}{|c|c|c|c|}
\hline & Países & Média de redução/a.a. & Desvio-padrão/a.a. \\
\hline 1 & Mundo Agregado & $\$ 829.091,67$ & $\$ 228.327,95$ \\
\hline 2 & China & $\$ 247.277,67$ & $\$ 130.189,19$ \\
\hline 3 & Coreia & $\$ 123.038,33$ & $\$ 35.268,19$ \\
\hline 4 & Indonésia & $\$ 128.155,00$ & $\$ 28.376,94$ \\
\hline 5 & Paquistão & $\$ 53.346,00$ & $\$ 24.198,17$ \\
\hline 6 & Turquia & $\$ 52.966,67$ & $\$ 21.844,81$ \\
\hline 7 & Tailândia & $\$ 36.299,67$ & \$16.343,94 \\
\hline 8 & Malásia & $\$ 39.705,33$ & $\$ 10.873,49$ \\
\hline 9 & Japão & \$ $13.699,33$ & $\$ 3.259,52$ \\
\hline
\end{tabular}

Fonte: MDIC / Sistema Radar Comercial.

\footnotetext{
${ }^{29}$ Fonte: IBGE, Indicadores Conjunturais da Indústria (2014, p. 14-45).

$30 \mathrm{NHP}=$ Jornada mensal de trabalho + horas suplementares + descanso remunerado e férias
} 
O desvio-padrão possibilita identificar e analisar os valores em US\$/FOB (e os países) que estiveram superiores à média esperada de redução de divisas estrangeiras. É importante ressaltar que a elaboração do desvio-padrão tem objetivo enxergar o comportamento das variáveis além da média geral.

Quanto aos valores pagos para importação do setor têxtil mato-grossense, os dados apresentaram que a variação média anual foi de $\Delta=(-) 0,60 \%$. As menores variações entre as relações comerciais com o EUA e Japão não ultrapassaram a variação anual de $\Delta=(-) 0,02 \%$.

Tabela 5: Setor Têxtil de MT (Comex - US\$ 1000 - FOB) - Importações

\begin{tabular}{|c|c|c|c|c|c|c|}
\multicolumn{3}{c}{2011} & \multicolumn{3}{c|}{2012} & \multicolumn{2}{c|}{2013} \\
\hline 1 & Mundo Agregado & 682.831 .944 & Mundo Agregado & 634.701 .977 & Mundo Agregado 535.722 .479 \\
\hline 2 & Alemanha & 54.259 .597 & Alemanha & 46.598 .605 & Alemanha & 49.699 .949 \\
\hline 3 & Japão & 41.631 .779 & Japão & 42.357 .790 & Japão & 41.812 .378 \\
\hline 4 & China & 36.895 .350 & China & 39.978 .219 & China & 39.349 .565 \\
\hline 5 & França & 31.918 .886 & França & 28.651 .269 & França & 29.956 .177 \\
\hline 6 & Espanha & 20.674 .861 & Espanha & 17.586 .065 & Espanha & 19.085 .473 \\
\hline 7 & Bélgica & 14.453 .499 & Bélgica & 12.339 .666 & Bélgica & 13.995 .663 \\
\hline 8 & Turquia & 13.586 .840 & Coréia & 11.736 .322 & Coréia & 13.141 .795 \\
\hline 9 & Coréia & 12.443 .625 & Turquia & 11.254 .657 & Turquia & 12.366 .492 \\
\hline 10 & Indonésia & 8.525 .038 & Austrália & 8.451 .234 & Austrália & 8.682 .261 \\
\hline
\end{tabular}

Fonte: MDIC / Sistema Radar Comercial.

As maiores variações comerciais de importação, ocorreram na Bélgica com cerca de $\Delta=(-) 1,96 \%$, Turquia $\operatorname{com} \Delta=(-) 1,96 \%$ e Espanha com $\Delta=(-) 1,27 \%$. A justificativa de queda desses pequenos percentuais, seria a desvalorização da moeda nacional frente ao US\$.

Tabela 2: Despesa monetária e não monetária média mensal familiar em vestuário

\begin{tabular}{|c|c|c|c|c|c|c|c|c|c|c|c|c|}
\hline \multirow{3}{*}{$\begin{array}{l}\text { Grupos de idade da } \\
\text { pessoa de } \\
\text { referência da } \\
\text { família }\end{array}$} & \multicolumn{6}{|c|}{$\begin{array}{l}\text { Despesa monetária e não monetária média mensal } \\
\text { familiar }(\mathrm{R} \$)\end{array}$} & \multicolumn{6}{|c|}{$\begin{array}{l}\text { Distribuição da despesa monetária e não } \\
\text { monetária média mensal familiar (\%) }\end{array}$} \\
\hline & \multicolumn{2}{|c|}{ Total } & \multicolumn{2}{|c|}{ Urbana } & \multicolumn{2}{|c|}{ Rural } & \multicolumn{2}{|c|}{ Total } & \multicolumn{2}{|c|}{ Urbana } & \multicolumn{2}{|c|}{ Rural } \\
\hline & 2002 & 2008 & 2002 & 2008 & 2002 & 2008 & 2002 & 2008 & 2002 & 2008 & 2002 & 2008 \\
\hline De 10 a 19 anos & 57,3 & 86,6 & 61,4 & 94,2 & 26,1 & 40,2 & 5,9 & 7,0 & 5,8 & 7,2 & 6,8 & 5,0 \\
\hline De 20 a 29 anos & 78,4 & 108,3 & 84,8 & 116,8 & 40,9 & 58,9 & 6,4 & 6,0 & 6,4 & 6,0 & 5,9 & 6,0 \\
\hline De 30 a 39 anos & 81,8 & 120,0 & 87,7 & 128,4 & 45,3 & 75,7 & 4,8 & 4,9 & 4,8 & 4,9 & 5,2 & 5,5 \\
\hline De 40 a 49 anos & 101,7 & 148,3 & 109,5 & 159,6 & 53,3 & 84,1 & 4,7 & 5,0 & 4,7 & 5,0 & 5,6 & 5,3 \\
\hline De 50 a 59 anos & 92,9 & 127,5 & 101,8 & 136,8 & 47,4 & 74,2 & 4,3 & 4,1 & 4,2 & 4,0 & 5,1 & 4,7 \\
\hline De 60 a 69 anos & 71,9 & 99,2 & 79,1 & 107,8 & 40,8 & 57,8 & 4,1 & 3,5 & 4,1 & 3,5 & 4,4 & 4,0 \\
\hline 70 anos ou mais & 45,2 & 67,6 & 48,0 & 72,1 & 31,9 & 44,4 & 3,2 & 3,2 & 3,1 & 3,1 & 4,0 & 3,8 \\
\hline
\end{tabular}

Fonte: IBGE - Pesquisa de Orçamentos Familiares $(2002,2008)^{31}$

As famílias brasileiras com idade entre 40 a 49 anos foram os que mais consumiram com cerca de $\mathrm{R} \$ 159,60$, porém a população rural apresentou $50 \%$ menor ( $\mathrm{R} \$ 84,10)$ que a população urbana. Em valores percentuais de consumo (\%), os agentes que mais consumiram vestuário são pertencentes à faixa etária de 10 a 19 anos com média de 6,0\% a 7,2\% das rendas. Os agentes com 70 anos ou mais, foram os que menos consumiram vestuários e seus percentuais ficaram entre $3,1 \%$ a $4,0 \%$ de rendas.

\subsection{DESEMPENHO INSTITUCIONAL E A TEORIA DA DEPENDÊNCIA}

Para retratar-se inicialmente os aspectos que influenciam as transações entre os fatores de produção, é preciso analisar a atividade industrial do vestuário como parte institucional, no qual reportemos aos conhecimentos do professor americano Robert D. Putnam que em seus estudos sobre a Itália, coletou evidências significativas da confiança social e normas democráticas foram vitais para formação do estoque de capital social.

\footnotetext{
31 Nota: 0 termo família está sendo utilizado para indicar a unidade de investigação da pesquisa "Unidade de Consumo".
} 
O capital social facilita a cooperação espontânea. Um bom exemplo desse princípio é a instituição de poupança informal, largamente difundida nos quatro continentes, chamada associação de crédito rotativo. Tal associação consiste num grupo "que aceita contribuir regularmente para um fundo que é destinado, integral ou parcialmente, a cada contribuinte alternadamente (PUTNAM, 2006, p. 177)

Barqueiro (2001, p.13) comenta que nos dias atuais de globalização “(...) as cidades e as regiões voltaram a colocar-se a questão do desenvolvimento - ou seja, a dos fatores que determinam os processos de acumulação de capital -, na busca de uma alternativa capaz de atender as necessidades e demanda dos cidadãos". O desenvolvimento do setor vestuário sobreviverá endogenamente nos tempos atuais, se houver flexibilidade ${ }^{32}$ nas doutrinas capitalistas que formavam a base do setor produtivo industrial:

É nesse entorno de transformações econômicas, organizacionais, tecnológicas, políticas e institucionais que surge o conceito de desenvolvimento endógeno. Este encara o desenvolvimento econômico como sendo resultante da aplicação do conhecimento aos processos produtivos e da utilização das economias externas geradas nos sistemas produtivos e nas cidades, o que resulta em rendimentos crescentes e, portanto, em crescimento econômico (BARQUERO, 2001)

A Itália nos anos 70 encontrava-se com diversos problemas sociais criados pela reforma administrativa na qual deixou-a de ser um Estado único para ser administrada por vinte regiões com capacidade de autogoverno, onde Putnam descreveu:

Primeiro, em 1970, criaram-se simultaneamente 15 novos governos regionais com estruturas e mandatos constitucionais basicamente idênticos. (...) todas as Erro! A referência de hiperlink não é válidaregiões passaram a ter autoridade sobre uma ampla gama de assuntos públicos. Em contraste parcial com essas 15 regiões "ordinárias", outras cinco "especiais" tinham sido criados alguns anos antes, com poderes constitucionais um pouco mais amplos. (...) Em certos aspectos, os governos regionais especiais se distinguem pelo fato de serem mais antigos e terem poderes mais amplos. (Putnam, 2006)

Então, para equilibrar as diferenças regionais, o governo central italiano adotou a distribuição de recursos e de aplicação de investimentos diferenciado, reconhecendo que os processos de crescimento e de mudanças estruturais na Itália ocorreriam em consequência da inovação no sistema produtivo. Putnam (2006) relata na realização de sua pesquisa sobre a evolução de cada governo, concluindo posteriormente com o "antes" e "depois" das mudanças, reformas e desempenho institucional. Putnam entende que:

Para ter um bom desempenho, uma instituição democrática tem que ser ao mesmo tempo sensível e eficaz: sensível às demandas de seu eleitorado e eficaz na utilização de recursos limitados para atender a essas demandas. (...) por outro lado, o fato de o modelo institucional ser uma constante na experiência regional italiana significa que podemos identificar mais seguramente a influência de outros fatores no êxito institucional (PUTNAM, 2006)

Para aprovação econômica, a avaliação do desempenho evidencia o relacionamento do setor produtivo com forte estrutura institucional que atenda nas áreas de saúde, estradas, educação e tenha foco também na inovação. As afirmações relatadas no trabalho de Putnam (2006) também se assemelham à de Barqueiro (2001):

- A aprendizagem e inovação "integra e domina algum conhecimento, algumas regras, algumas normas e valores e um sistema de relações", onde (...) as organizações e instituições fazem parte de

\footnotetext{
32"Cada sociedade encoraja o surgimento de formas específicas de organização e de instituições que lhe são próprias e que haverão de favorecer ou dificultar a atividade econômica, pelo fato de os agentes econômicos tomarem suas decisões nesse entorno organizacional e institucional e por, evidentemente, nem sempre seguirem as prescrições teóricas dos modelos econômicos". BARQUERO (2001, p.24): Flexibilidade e Complexidade Institucional.
} 
entornos locais com capacidade com capacidade de assimilar conhecimentos, de aprender agir, convertendo-os em uma espécie de cérebro da dinâmica de uma economia local (p. 45);

- A cultura e sociedade condicionam o sistema produtivo nos processos de desenvolvimento local, pelos valores da sociedade (p. 48).

- A política tem seu objetivo voltado para o desenvolvimento sustentável e duradouro, motivo pelo qual tratam de dar ênfase às dimensões econômica, social e de meio ambiente envolvidas.

A avaliação de desempenho institucional Putnam (2006), mostrou que os governos que obtiveram melhores êxitos pertenciam à região norte italiana, concentrando assim duas possibilidades tais como a modernidade socioeconômica (provinda da revolução industrial), a comunidade cívica (participação cívica e solidariedade social). A inovação é um dos fatores que explicam o desempenho alcançado positivamente.

A Teoria da Dependência, numa síntese apertada, afirma que a unidade nacional ou regional somente pode ser entendida em conexão com sua inserção no sistema político-econômico mundial. Em outras palavras, a economia dos países periféricos está condicionada pelo desenvolvimento e expansão das economias dos países centrais.

No caso específico do setor produtivo do vestuário, a teoria afirma que o desenvolvimento e o subdesenvolvimento não são entendidos como estados isolados um do outro, sem relação alguma. Contrariamente, sua ligação é muito estreita desde que fazem parte de um único processo que os abarca: a expansão internacional do capital.

\section{MATERIAIS E MÉTODOS}

O estudo se iniciará com a apreciação de dados e informações socioeconômicas do setor produtivo do vestuário. Uma visão transversal das potencialidades de mercado sustentará a nossa primeira hipótese, qual seja, a de que o setor produtivo do vestuário é preponderante para o crescimento econômico de Mato Grosso.

Na seção seguinte a cadeia do setor produtivo se insere na economia estadual e as contribuições da indústria neste processo serão mais bem delineadas. As informações e os fatos acerca da produção, consumo e fortalecimento institucional do setor, serão conectados ao objeto da pesquisa.

Segundo Pindyck (2004, p. 185-186), a produção tem forte correlação com a utilização de novas tecnologias, a educação intrínseca da mão de obra e ao uso de bens de capital. Ato contínuo, dados como a oferta industrial, a quantidade de produtos exportados e a evolução da produtividade na agregação de valor, servirão de reflexo para se concluir se houve uma melhora em indicadores exógenos e que, sabidamente, alteram a produtividade, como educação e infraestrutura.

Para elaboração aos resultados da pesquisa e posterior análise conclusiva, será elaborado estudo de caso que avalie o setor produtivo do vestuário no Estado de Mato Grosso a partir de informações primárias conseguidas em consultas a fontes públicas, dentre elas o Instituto Mato-grossense de Economia Agrícola (IMEA), o Instituto de Pesquisa Econômica Aplicada (IPEA), o Instituto Brasileiro de Geografia e Estatística (IBGE) e Secretaria de Estado de Desenvolvimento Econômico (SEDEC-MT); e indústrias (empresas privadas) filiadas à Federação das Indústrias no Estado de Mato Grosso (FIEMT).

Da técnica de coleta de dados primários será elaborada a estatística descritiva do setor produtivo do vestuário, para elaboração de planilhas de resultados, utilizados para verificar a hipótese do trabalho e avaliar a sustentabilidade de mercado. Os dados foram tratados nos softwares Gretl®, considerando a variáveis X (exportação), M (importação) e S (saldo)= X-M

\section{RESULTADOS E DISCUSSÕES}

Dos dados, aufere-se que a quantidade anual comercializada pelo setor produtivo do vestuário de MT, onde os agentes que mais consumiram vestuário são pertencentes à faixa etária de 10 a 19 anos com média de $6,0 \%$ a $7,2 \%$ das rendas das famílias brasileiras.

Dentre as quantidades, a produção exportada operou com média anual de 4.352.604/kg e desvio-padrão entre os anos 2010 a 2015 de $334.019 / \mathrm{kg}$, sendo importação com média entre os anos de 167.868.745/kg e desvio-padrão entre 26.981.786/k. Para a balança comercial, a média entre os anos de 2010 a 2015 de () $163.516 .142 / \mathrm{kg}$ e desvio-padrão em $27.279 .893 / \mathrm{Kg}$. 
A série com as oscilações nos preços da balança comercial registrou - PM-US\$-Ton(S) US\$24.556 /ton (médio) e desvio-padrão foi de US\$2.998,55/ton.

Este trabalho tem como intuito maior ser útil à sociedade mato-grossense, auxiliando até mesmo futuras tomadas de decisão dos investidores, assim vale contextualizar estes resultados na realidade do sistema produtivo, que permitirá orçar suas causas e implicações, sendo dividido em três ações estratégicas, sendo 1) pontos de estrangulamentos, 2) redução dos custos de transação e 3) efetividade de mercado.

\section{1) Pontos de estrangulamentos identificados:}

a) Produção nacional em redução nos últimos anos frente à produção mundial de fibras e filamentos verticalizados;

b) Não há quem delibere um consenso entre os atores do montante e a jusante da cadeia produtiva do algodão em MT;

c) Ausência de um sistema de informação/interação permanente entre os atores da cadeia produtiva do algodão.

d) As Tabelas 4 e 5 demonstraram que está havendo uma mudança na estrutura de produção favorecendo fibras químicas;

e) Ainda de acordo com o Gráfico 1, EUA e Europa estão reduzindo a concentração de produção frente à Ásia. Isto pode indicar a hipótese de fusões e incorporações (EUA e Europa), quanto os investimentos estão se concentrando nos países asiáticos. Vale lembrar que MT têm mais importado maior quantidade de produtos dos EUA e Europa, indicando "import duty" (redução da importação) por força do próprio setor privado;

f) Falta de representação política no Congresso Nacional para políticas voltadas à cadeia produtiva do algodão de Mato Grosso. 0 último representante do setor foi o Deputado Federal Homero Pereira (in memorian);

g) Acesso restrito a dados sobre o mercado, design de moda e tecnologia.

\section{2) Redução dos custos de transação:}

a) Fortalecer a revisão fiscal de classificação dos produtos industrializados do setor junto ao Estado pelo setor produtivo;

b) Propor a fusão dos estudos do vestuário MT junto a AMPA, para suporte de gestão as relações entre os agentes e suas redes de transações, estratégias e competitividade contratuais, desenvolvimento tecnológico e recursos humanos.

\section{3) Consolidação institucional do setor junto à cadeia produtiva do algodão:}

a) Promover a revisão fiscal dentro do Estado para produtos industrializados como agasalhos e uniformes à órgãos do Poder Público, associações, clubes, creches, escolas, empresas isentas de inscrição estadual que promoverão a uniformização de seus colaboradores;

b) Fortalecer o levantamento de dados para base de cálculo da tributação e políticas de crédito presumido aos estabelecimentos industriais, para acesso ao Fundo de Desenvolvimento Industrial e Comercial - FUNDEIC $\stackrel{33}{ }$, (Lei no 7.183/1999);

c) Reavaliar tributação para insumos originados de fibras manufaturadas ou químicas (artificiais e sintéticas), tais como lingerie, roupas esportivas e moda praia, incentivando o fomento do elo da jusante à montante do algodão mato-grossense;

Apesar de Mato Grosso possuir uma atividade econômica predominantemente agropecuária, a indústria tem apresentado um crescimento significativo no estado, apresentou a implantação de novas indústrias graças aos incentivos fiscais oferecidos pelo Programa de Desenvolvimento Industrial e Comercial

${ }^{33}$ Lei no 8.420 , de 28 de dezembro de 2005. 
(PRODEIC), chegando a 65 empresas em 2019, contando com os empreendimentos em fase de viabilização, de acordo com dados divulgados pela Procuradoria Geral do Estado de Mato Grosso.

Como esperado, os resultados corroboraram o que as informações descritas quando da exposição da estatística descritiva haviam sugerido: 1) a identificação da liderança e governança do setor produtivo do vestuário em MT; 2) ampliar a área plantada de algodão e suas tecnologias; 3) maior articulação de políticas públicas, controle e fiscalização das importações e; 4) ampliar a participação em congressos e feiras.

Dentre os segmentos que se encontram em pleno crescimento encontra-se a Indústria Têxtil, apesar da constante ameaça dos produtos chineses no Brasil, os quais tendem a aumentar devido ao fim do Acordo de Têxteis e Vestuário (ATV), o qual deve tornar a concorrência das importações mais acirrada no mercado nacional.

Além de ser um pólo importante para a produção do algodão como matéria - prima, Mato Grosso ainda oferece incentivos fiscais às Indústrias Têxteis que queriam se instalar no Estado, o que reduz significativamente o seu custo, pois além da redução dos impostos, o custo para aquisição do algodão torna-se menor, tendo em vista que não haverá mais gastos com o transporte, tornando seus produtos mais competitivos no mercado interno e externo.

\section{REFERÊNCIAS}

[1] ALCÂNTARA, Liliane Cristine Schlemer. Gestão do Desenvolvimento Sustentável na Amazônia Legal. Cuiabá: EdUFMT, 2011.

[2] ANDRADE, Carlos Henrique Coêlho de. Manual de Introdução ao Pacote Econométrico Gretl. Disponível em: <http://www.ufrgs.br/ppge/pcientifica/2013_12.pdf> Acesso em: julho 2015.

[3] ARAUJO, Massilon J. Fundamentos do Agronegócios. - 4ed. São Paulo: Atlas, 2013.

[4] BATALHA, M. O. Sistemas agroindustriais: definições e correntes metodológicas. In: BATALHA, M. O. et al. Gestão Agroindustrial. São Carlos: Ed. Atlas, 1997. p. 24-48.

[5] BATALHA, M. O.; BUAINAIN, A. M.; SOUZA FILHO, H. M. Tecnologia de gestão e

[6] BATALHA, Mário Otávio. Gestão Agroindustrial: GEPAI: Grupo de estudos e pesquisas agroindustriais. - 3ed. - São Paulo: Atlas, 2001, 2008.

[7] BATALHA, Mário Otávio. Gestão Agroindustrial: GEPAI: Grupo de estudos e pesquisas agroindustriais. - 3ed. - São Paulo: Atlas, 2001, 2008.

[8] BATALHA, Mário Otávio. Gestão do agronegócio: textos selecionados. - São Carlos: EdUFSCar, 2005

[9] BRASIL, Casa Civil. Programa Especial de Financiamento a Produtores Rurais. Medida Provisória no 2.078-35, de 27 de dezembro de 2000.

[10] BRASIL, Ministério da Ciência e Tecnologia. Parcerias estratégicas: Centro de Gestão e Estudos Estratégicos. Vol 1, n. 22 (jun 2006) - Brasília : 2006.

[11] BRASIL. IBGE - Instituto Brasileiro de Geografia e Estatística. Censo Agropecuário 2006: Brasil, Grandes Regiões e Unidades da Federação. - Rio de Janeiro: 2006.

[12] BRASIL. IBGE - Instituto Brasileiro de Geografia e Estatística. Manuais técnicos em geociências: Manual Técnico de Pedologia - Rio de Janeiro; 2007. v. 2, n. 4.

[13] BRASIL. IBGE - Instituto Brasileiro de Geografia e Estatística. Manuais técnicos em geociências: Manual Técnico de Pedologia - Rio de Janeiro; 2007. v. 2, n. 4.

[14] BRASIL. IBGE. Pesquisa de Orçamentos Familiares 2002-2003. Análise da disponibilidade domiciliar de alimentos e doestado nutricional no Brasil. Rio de Janeiro: IBGE, 2004. Disponível em: <http://www.ibge.gov.br>. Acesso em: 02 jul. 2015.

[15] BRASIL. IBGE. Indicadores Conjunturais da Indústria: Emprego e Salário. Brasília: IBGE, 2014.

[16] BRASIL. IBGE. Pesquisa nacional por amostra de domicílios PNAD 2005: Pobreza e Desigualdade. Brasília: IBGE, 2007.

[17] COSTA, Eduardo José Monteiro da. Arranjos Produtivos Locais, Políticas Públicas e Desenvolvimento Regional. Brasília, DF: Mais Gráfica Editora, 2010.

[18] GIL, Antônio Carlos. Métodos e técnicas de pesquisa social. - 6. Ed. - São Paulo: Atlas, 2008. 
[19] GOTEXSHOW. FEIRA INTERNACIONAL DE PRODUTOS TÊXTEIS. Disponível em: < http://gotexshow.com.br/mercado/>. Acesso em 29. Setembro. 2019.

[20] HOFFMANN, R. et al. Administração da empresa agrícola. 5 ed. São Paulo: Pioneira, 1987.

[21] IMEA - Instituto Mato-grossense de Economia Agropecuária. Boletim mensal do algodão. março 2020. Disponível em: <http://www.imea.com.br/\#>. Acessado em 15 de março.

[22] JOSEPH, L. C. R.; PEREIRA, B. D.; JOSEPH, T. W. R. Identificando, Mapeando e Analisando Sistemas Produtivos Inovativos e/ou Arranjos Produtivos Locais em Mato Grosso. - Cuiabá, MT: EdUFMT, 2011.

[23] LIMA, L. S.; TOLEDO, J. C. Diagnóstico da gestão da qualidade na produção familiar de hortaliças no município de São Carlos-SP. Revista Produção Online. Florianópolis-SC, v.3, n.4, 2003.

[24] MARQUES, Wagner Luiz. Administração geral e profissional. - Cianorte-PR : Fundação Biblioteca Nacional, 2013.

[25] MATO GROSSO - Secretaria de Meio Ambiente. Mapa de Zoneamento Socioeconômico Ecológico. - Cuiabá: Iomat, 2008.

[26] OMC. Statistics. Databases. Disponível em: <http://www.wto.org/english/res_e/statis_e/statis_bis_e.htm?solution=WTO\&path=/Dashboards/MAPS\&file=Map.w cdf\&bookmarkState $=\{\% 22$ impl\%22:\%22client $\% 22, \% 22$ params $\% 22:\{\% 22$ langParam $\% 22: \% 22 \mathrm{en} \% 22\}\}>$. Acesso em: 19 fev. 2020.

[27] SECEX - Secretaria de Comércio Exterior. 2020. Disponível em: <http://www.mdic.gov.br/index.php/comercio-exterior>. Acesso em 07 jan. 2020.

[28] SLACK, Nigel. Administração de produção. - São Paulo : Atlas, 2007.

[29] Theotônio dos Santos, La Crisis Norte americana y América Latina, Santiago: Editorial Prensa Latino Americana,1971. 


\section{Capítulo 11}

\section{Competitividade e orientação para o mercado em uma empresa do Setor Moveleiro de Coronel Freitas - SC}

\section{Karen Ângela Flores \\ César Augustus Winck}

Resumo: 0 estudo aborda os fatores que afetam a competitividade da empresa cuja principal atividade é a cadeia produtiva moveleira. 0 estudo foi realizado no município de Coronel Freitas, localizado na região Oeste de Santa Catarina, e possui no setor moveleiro o principal gerador de empregos industriais. 0 setor moveleiro responde por $40 \%$ do PIB municipal, contudo, têm-se identificado dificuldades para as empresas deste setor se manterem competitivas, assim como pode ser identificado em outros municípios do Oeste de Santa Catarina. Essas dificuldades, aparentemente, estão relacionadas com a oferta de produtos de origem externa, que competem em qualidade e com preços menores do que os produtos similares produzidos na região, além das questões políticas, econômicas e estruturais que o país vem enfrentando, dificultando às empresas regionais e nacionais de manterem-se competitivas nos mercados interno e externo. A metodologia utilizada foi predominantemente qualitativa, enquadrando-se como descritiva, realizada por meio de pesquisa documental, bibliográfica e bibliométrica. A pesquisa de campo foi desenvolvida utilizando a entrevista como forma de coleta de dados: entrevista semiestruturada com um dos gestores da empresa do setor moveleiro do município. A análise dos dados foi realizada por meio de análise entre as diferentes fontes, utilizando- se a técnica de Análise de Conteúdo. Os resultados apontam que a empresa estudada não está plenamente orientada para o mercado nacional e internacional, embora já esteja consolidada no mercado e tenha tradição de sua marca baseada no aspecto confiança de seus clientes, possuindo um hall de fornecedores estabelecidos que atendem satisfatoriamente às necessidades para a produção. Conclui-se que a empresa tem condições de melhorar a qualidade de seus produtos e ampliar sua participação no mercado de móveis nacionais, bem como incrementar a oferta de produtos para o mercado internacional, mas, para isso, precisa adaptar-se às condições e exigências da atualidade.

Palavras-chave: Competitividade. Orientação para o mercado. Setor moveleiro. 


\section{INTRODUÇÃO}

A complexa competitividade no setor moveleiro é uma das principais razões para que as empresas procurem formas estratégicas baseadas na organização da produção para sobreviver no mercado atual, o qual se encontra altamente competitivo (ZOCCHE, 2011).

A conquista desta posição atraiu a atenção de seus consumidores e sua manutenção implica desafios que perpassam as perspectivas relacionadas ao consumo, à competitividade, à capacidade de orientação dos sistemas produtivos em adequar-se às condições exigidas pelos consumidores nacionais e internacionais (GIANEZINI et al., 2014; RUVIARO, 2010; ANTONI et al., 2013).

O setor moveleiro possui como característica a junção de diversos processos de produção (seriados, modulados, planejados e sob medida), os quais são compostos por diferentes matérias- primas, dentre elas a madeira, resultando em uma diversidade de produtos finais. No Brasil, o setor moveleiro está entre os mais importantes da indústria de transformação nacional, especialmente, em virtude de seu potencial na geração de empregos e fluxo monetário (SEBRAE, 2016).

Segundo estudo realizado pelo Sebrae (2016), o Estado de Santa Catarina, no setor moveleiro se destaca em seus polos produtivos, exemplo, a região de São Bento do Sul, cuja produção é praticamente toda exportada, demonstra assim sua importância como indústria na economia catarinense e internacional. Recentemente, outras regiões do Estado figuram como polos produtores de móveis, há pelo menos seis que se destacam, cada qual com características próprias e diferenciais competitivos característicos: Polo Setorial de Móveis e Aberturas do Extremo Oeste; Polo Setorial das Indústrias de Móveis da região do Meio Oeste; Polo Setorial de Móveis do Norte; Polo Setorial de Móveis do Oeste; Polo Setorial de Móveis e Madeira do Planalto Serrano; e, por fim, o Polo Setorial de Móveis e Madeira da região Sul de Santa Catarina (SEBRAE, 2016).

Assim como no setor moveleiro do Oeste catarinense, o setor moveleiro nacional tem enfrentado dificuldades no que diz respeito à implantação de tecnologias para o desenvolvimento de novos produtos e a competitividade com móveis oriundos do mercado externo, principalmente, da China (HÖFLER et al., 2014). A necessidade de utilizar tecnologias de produção mais adaptadas às exigências do mercado promove a procura por mecanismos que aumentem a competitividade das empresas, que é cada vez mais intensa (HÖFLER et al., 2014). Diante desse cenário de alta competitividade entre as empresas do setor moveleiro no Brasil e exterior, torna-se fundamental para essas organizações adotarem políticas de orientação para o mercado, como forma de superarem em desempenho de qualidade e preço seus concorrentes (FERREIRA, 2006). Essas mudanças acabaram por desencadear maior ênfase aos estudos de Orientação para o Mercado (OPM), crescentes no campo das melhores práticas de gestão (CURI, 2007), cuja teoria passou a ser de interesse de acadêmicos de marketing e administração por considerar as mudanças sociais que alteram o relacionamento das organizações com seus consumidores e públicos de interesse (PEREIRA, 2005; ABBANE et al., 2012).

Nesta primeira década do século XXI, as organizações se depararam com uma nova realidade, principalmente, pela globalização econômica, em que a possibilidade de crescimento em quantidade e qualidade tornou-se mais tangível às empresas, surgindo necessidades de fortalecimento da capacidade produtiva, em razão da forte concorrência de produtos estrangeiros. Isto impôs às empresas, a necessidade de reestruturação e preparação para novas demandas, visando não apenas à melhoria da qualidade de seus produtos, mas, também, sua sobrevivência no mercado (SILVA; BELTRAME; SCHMIDT, 2014).

Para Gaber e Tomaselli (2014), a estratégia das empresas moveleiras nacionais foi direcionada para atender o mercado interno, em detrimento do mercado de exportação, sobretudo, pelo crescimento econômico nacional e o consequente aumento na demanda pelos produtos moveleiros, gerado pela melhoria de renda das classes com menor poder aquisitivo.

Partiu-se da premissa que a Orientação Para o Mercado é fonte de informações necessárias ao processo decisório das organizações, quaisquer que sejam suas características e o segmento de mercado da Cadeia de Valor (a montante e a jusante) (GRUNERT et al., 2002).

A percepção dos princípios do comportamento do consumidor possui maior viabilidade e confiabilidade quando vinculada, entre outros fatores, ao conceito de Orientação Para o Mercado, por ser definido, como base para a tomada de decisão sobre o que e como produzir, como vender e satisfazer ao mesmo tempo o consumidor final (JAWORSKI; KOHLI, 1993). 
O presente estudo foi realizado no município de Coronel Freitas, localizado na região Oeste de Santa Catarina, e que possui no setor moveleiro o principal gerador de empregos industriais e de contribuição ao PIB municipal. 0 setor moveleiro tem considerável importância na região Oeste catarinense, e o município de Coronel Freitas está entre os principais produtores de móveis da região (IBGE, 2014). Isto justifica a escolha do município, para a aplicação da presente pesquisa, além da facilidade de acesso aos empresários, pela pesquisadora proponente do estudo.

Na região Oeste catarinense, existem atualmente 313 empresas do setor madeireiro e/ou moveleiro associadas ao Sindicato dos Trabalhadores nas Indústrias da Construção e do Mobiliário de Chapecó (Siticom), que geram aproximadamente 1778 empregos, e o município de Coronel Freitas possui 28 empresas associadas a este sindicato, produzindo móveis e similares. Neste estudo, considerou-se que estas empresas representam o contexto empresarial da cadeia produtiva de móveis do Oeste de Santa Catarina.

Segundo Grunert et al. (2002), empresas orientadas para o mercado devem ser capazes de atender às demandas atuais e futuras do mercado interno e externo, além de colocar seu negócio à frente dos seus concorrentes. Portanto, os limites para o desenvolvimento da cadeia de valor são relacionados ao acesso ao mercado (local, regional, internacional) (GRUNERT et al., 2005).

Ferreira (2006) analisa que o forte impacto da tecnologia, somado ao processo gradual de mudança, orientado para a globalização das relações econômicas, é uma realidade que deve ser enfrentada regionalmente. As empresas devem somar conhecimento, melhorar sua cultura competitiva para conseguir atender o que o mercado exige, orientar-se para a necessidade do cliente e analisar em termos de negócios, como estratégia básica de dominar o presente, já pensando no futuro da sua empresa.

Esta pesquisa, portanto, está ancorada na teoria de orientação para o mercado considerando uma cadeia de valor, na qual a orientação para o mercado é analisada como um recurso de negócios (capacidade ou competência) que gera subsídios à empresa para ocupar posição de vantagem competitiva e alcançar desempenho superior em relação aos seus concorrentes (MORGAN; HUNT 1994; NARVER; SLATER, 1990). Day (2001) destaca a força de uma empresa orientada para o mercado, que ao adotar essa estratégia consegue superar em desempenho seus concorrentes.

Assim, o problema de pesquisa a ser estudado e respondido neste estudo é: Quais fatores afetam a competitividade de uma empresa da cadeia produtiva moveleira do município de Coronel Freitas, suas consequências e possíveis alternativas para a melhoria destes?

Considerando o contexto regional, a justificativa para pesquisa e o problema identificado no setor moveleiro do Oeste catarinense, o presente estudo tem como principal objetivo analisar os fatores que afetam a competitividade e a orientação para o mercado de uma empresa moveleira do município de Coronel Freitas, que atende os mercados interno e externo, permitindo antecipar oportunidades e definir potencialidades, para maior assertividade no desenvolvimento de ações que busquem o fortalecimento e crescimento da empresa estudada.

\section{REVISÃO BIBLIOGRÁFICA}

\subsection{ORIENTAÇÃO PARA O MERCADO}

A definição da orientação para o mercado tem sido desenvolvida com base na evolução conceitual do arcabouço de marketing (JAWORSKI; KOHLI, 1993). A abordagem de orientação para o mercado vai além do tradicional conceito de orientação para o marketing com foco somente no cliente, equivale a um conjunto de comportamentos alinhados ao conceito em si (URDAN, 2004).

A caracterização de uma estratégia de orientação para o mercado direciona a uma visão em longo prazo, integrando a cultura e a estrutura organizacional, coordenando esforços na criação de valor para o cliente, em todos os setores da empresa, não sendo responsabilidade apenas do marketing (NAVER; SLATER, 1990). A abordagem sistêmica da teoria aponta que empresas orientadas para o mercado contribuem sobremaneira para processos inovadores (CURI, 2007).

Atualmente se observam as necessidades e as expectativas que os clientes têm sobre um produto que está sempre evoluindo; é preciso fornecer sequencialmente novos produtos e serviços, os quais sejam de alta qualidade e que exigem constante acompanhamento e adaptação às necessidades do mercado, sendo definido como orientação para o mercado (JAWORSKI; KOHLI, 2006). Em decorrência dessas constantes melhorias, o termo orientação para o mercado procura estabelecer um parâmetro, no qual a geração de 
uma empresa equivale como um todo, observando assim a inteligência de mercado na empresa mediante necessidades atuais e futuras, a disseminação da inteligência entre os departamentos e a reação de toda a organização a essa inteligência.

Para Grunert et al. (2005), a orientação para o mercado foi vista, principalmente, a partir de uma perspectiva didática, isto é, como uma característica de uma empresa que trabalha com um conjunto de clientes atuais e potenciais. Em sua origem, portanto, procura estabelecer um parâmetro entre as informações sobre o mercado, sua disseminação interna à organização e a capacidade de resposta com base nos dados gerados a respeito do ambiente de negócios (GAVA; SILVEIRA, 2007).

A orientação para o mercado envolve ações concretas em resposta à inteligência do mercado. Essas ações relacionam os segmentos de mercado escolhidos e a concepção de novos produtos e programas, ou, ainda, a modificação dos produtos que já existem, para que se possam atender às necessidades dos clientes. Dessa forma, é importante enfatizar que uma orientação para o mercado não é exclusiva da responsabilidade de um único departamento na empresa e sim de um modo de operação em toda a empresa (JAWORSKI; KOHLI, 1990).

Levitt, em 1960, no seu livro Miopia em marketing, descreve que as empresas costumam fracassar por não ter a abrangência das expectativas dos clientes, na forma de como diferentes produtos vão se destacando e suprindo algumas das necessidades das quais eles estão buscando (URDAN; ROCHA, 2006). A ideia é que as empresas permaneçam no mercado, por meio de orientação, isto é, permitindo que se mantenham competitivas.

A partir do final da década de 1980, a orientação para o mercado foi sendo tomada como elemento de estratégia empresarial. Day (2001) apresentou a relevância de a empresa ser orientada de fora para dentro, isto é, a partir do mercado, no intuito de construir vantagem competitiva. Para ele, embora outras fontes dessa vantagem estivessem presentes nas firmas em posição superior, elas "superariam suas rivais em muitos ou quase todos os elementos de uma orientação para o mercado." (URDAN; ROCHA, 2006). Tal situação acirra ainda mais a concorrência entre as empresas, incentivando-as a ofertar produtos de valor superior a seus clientes, a fim de garantir vantagem competitiva nos mercados em que atuam.

0 conceito de orientação para o mercado tem se tornado cada vez mais importante no estudo e nas práticas de gestão (GEBHARDT et al., 2006), e, atualmente, possui abrangência que envolve, inclusive, aspectos relacionados à cadeia produtiva (LAMBIN; CACERES, 2006).

Os resultados podem ser sentidos: (i) na satisfação dos clientes por um período maior de tempo, caracterizando um processo de fidelização; (ii) na rapidez de respostas fornecidas às exigências e necessidades do mercado; (iii) na criação de sistemas de monitoramento dos concorrentes, e na identificação de seus pontos fortes e fracos; (iv) no estabelecimento de parcerias com os canais de distribuição; (v) no desenvolvimento de novos produtos que entreguem valores superiores a seus clientes; e, finalmente, (vi) no estabelecimento de relações de proximidades com os prescripteurs (solicitantes), que permitem o desenvolvimento de produtos inovadores e mais adaptados às necessidades dos compradores (LAMBIN; CACERES, 2006; DAY, 2001).

A inovação e a orientação para o mercado elevam significativamente o desempenho das organizações, fator que pode influenciar as relações entre os construtos, além dos recursos humanos adequados, isto é, as pessoas certas, com características pertinentes à ocorrência de inovação. Contudo, a burocracia, o excesso de formalidades, limita a capacidade de inovação e atrapalha o processo de desenvolvimento de novos produtos.

Day (2001) defende que em empresas orientadas para o mercado, é possível perceber um maior grau de satisfação dos funcionários, que reflete favoravelmente em sua postura em relação ao mercado. A Teoria da Orientação para o Mercado foi utilizada como âncora teórica do estudo, sendo utilizado o modelo de Grunert (2005) adaptado por Winck e Machado (2011), conforme ilustra a Figura 1. 
Figura 1 - Características determinantes da orientação para o mercado em uma Cadeia Produtiva

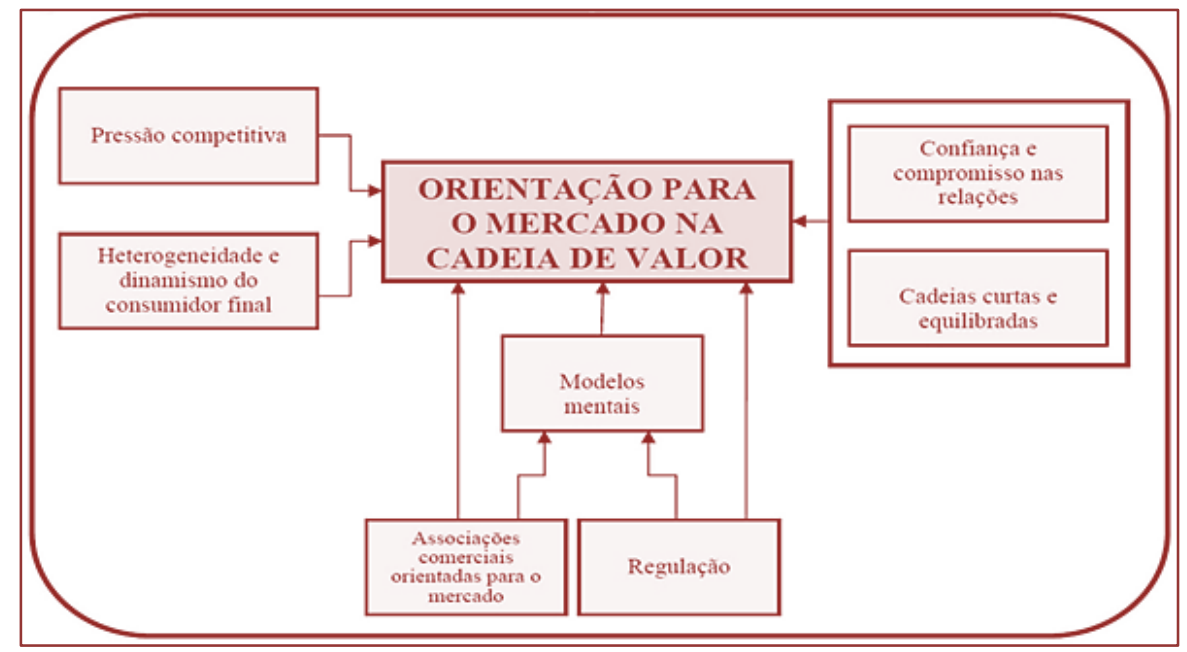

Fonte: Grunert et al. (2005) adaptado por Winck e Machado (2011).

O modelo conceitual de investigação proposto por Grunert et al. (2005) sugere diversas inter-relações e enriquece a literatura existente entre a orientação para o mercado e o contexto agropecuário brasileiro, uma vez que integra as variáveis da teoria em um modelo único por meio de proposições empiricamente fundamentadas sobre os determinantes (características) dos diferentes níveis de orientação para o mercado das cadeias de valor.

As características determinantes propostas no Modelo de Grunert et al. (2005), a serem utilizadas neste estudo, apresentam as seguintes definições conceituais (Quadro 1).

Quadro 1 - Características determinantes no Modelo de Grunert utilizadas para a análise da Cadeia produtiva moveleira do Oeste catarinense

\section{Características determinantes \\ Definição}

Pressão competitiva

A diferença entre os níveis de orientação para o mercado das empresas, muitas vezes se relaciona com as diferenças nas pressões competitivas vivenciadas por estas quando inseridas no mercado.

Heterogeneidade e dinamismo do consumidor final Quanto maior a capacidade de oferta de produtos na cadeia de valor, mais se ampliam os benefícios para todos os elos, visto que o mercado se torna dinâmico, possibilitando que novas tecnologias sejam desenvolvidas, 0 volume de produção seja expandido e o preço torne-se competitivo devido à concorrência. As associações interfirmas (comerciais ou não) podem ter um papel importante na geração

Associações interfirmas orientadas para o mercado de inteligência do mercado, influenciando também a formação de modelos mentais para toda uma indústria. Conforme as associações comerciais desenvolvem suas atividades de forma orientada para o mercado, influencia o grau de orientação para o mercado de toda a cadeia de valor envolvida.

A regulação dos mercados facilita o entendimento das regras para a oferta e demanda de produtos. Operações realizadas em cadeias internacionais frequentemente são reguladas por quotas, acordos de preços mínimos, contratos, possibilitando negociações uni, bi ou multilaterais.

\begin{tabular}{l|l} 
Modelos mentais & Os participantes da cadeia de valor negociam e decidem baseados no conhecimento prévio,
\end{tabular} confiança no parceiro comercial, performance e

competitividade, percepção da qualidade do produto frente à concorrência e na importância do produto para si próprio.

Cadeias curtas e equilibradas Quando a cadeia de valor é controlada por um dos setores envolvidos permite- se um melhor desenvolvimento da orientação para o mercado e o equilíbrio entre os participantes, facilitando as negociações atuais e futuras.

Confiança e compromisso nas relações
Quando há confiança e compromisso entre os setores envolvidos na cadeia de valor, aumentase sensivelmente o intercâmbio de informações e reduzem-se possíveis problemas que impedem os membros participantes da cadeia a desenvolverem atividades para melhoria dos processos a montante e a jusante. 
A opção de tornar a empresa internacionalizada e as decisões de como promover a entrada em mercados externos, implicam numerosos riscos e acabam envolvendo recursos elevados, muitas vezes, acima da capacidade financeira das empresas (KUAZAQUI, 2006).

A internacionalização é uma decisão estratégica e necessita da imediata identificação dos produtos a serem ofertados e dos mercados que se pretende atingir. Além disso, as formas mais adequadas de acesso e de manutenção neste mercado devem ser planejadas com antecedência (KUAZAQUI, 2006).

A presença da empresa no exterior pode ocorrer de forma gradativa, normalmente, iniciando pelo processo de exportação indireta e seguindo sucessivamente para a exportação direta, licenciamento, Joint Venture e no estágio mais avançado com o investimento direto estrangeiro (OSLAND; TAYLOR; ZOU, 2001).

O Quadro 2 apresenta os autores e suas contribuições à Teoria da Orientação para o Mercado Internacional.

Quadro 2 - Contribuição dos autores, conforme o ano, para a Teoria da Orientação para o Mercado, considerando a internacionalização e o desempenho exportador

\begin{tabular}{|c|c|c|}
\hline Autor (es) & Ano & Contribuição teórica à conceituação \\
\hline $\begin{array}{l}\text { Cadogan e } \\
\text { Diamantopoulos }\end{array}$ & 1995 & $\begin{array}{l}\text { Modelo de orientação para o Mercado Internacional: coordenação interfuncional, } \\
\text { geração de inteligência exportadora, disseminação de inteligência exportadora e } \\
\text { ação de resposta. }\end{array}$ \\
\hline $\begin{array}{l}\text { Zou, Taylor e } \\
\text { Osland }\end{array}$ & 1998 & $\begin{array}{l}\text { Performance (desempenho) exportadora é diferencial competitivo no mercado, e } \\
\text { baseia-se em: performance financeira das exportações; performance estratégica das } \\
\text { exportações e percepção do sucesso nas exportações. }\end{array}$ \\
\hline $\begin{array}{l}\text { Cadogan, } \\
\text { Diamantopoulos } \\
\text { e Mortanges }\end{array}$ & 1999 & $\begin{array}{l}\text { Elaboração de uma escala para mensurar o grau de orientação para o mercado } \\
\text { externo em empresas exportadoras. }\end{array}$ \\
\hline $\begin{array}{l}\text { Matsuno, Mentzer } \\
\text { e Rentz }\end{array}$ & 2000 & $\begin{array}{l}\text { Implantação de uma estratégia em particular é um processo de adaptação } \\
\text { organizacional ao mercado, e a orientação para o mercado é fundamental. }\end{array}$ \\
\hline Garrido & 2007 & $\begin{array}{l}\text { Elaboração de uma escala híbrida de modelo válido para mensurar o grau de } \\
\text { orientação para o mercado externo das organizações exportadoras brasileiras. }\end{array}$ \\
\hline Dalmoro & 2007 & $\begin{array}{l}\text { Proposição de um modelo teórico acerca dos valores internos e das } \\
\text { estratégias de internacionalização influenciadores da orientação para mercado } \\
\text { externo e do desempenho exportador. }\end{array}$ \\
\hline
\end{tabular}
Fonte: Winck e Machado (2011).

Os motivos que levam uma empresa a atuar no mercado externo podem ser agrupados em dois fatores: internos, de origem na empresa (características, recursos, objetivos e estratégias da empresa) e externos, de origem externa (pedidos vindos do exterior, apoio governamental do país de origem ou dos hospedeiros, etc.) (KUAZAQUI, 2006).

No Brasil, a internacionalização das empresas ainda é muito recente (final da década de 1960), e foi motivada por incentivos fiscais e de crédito concedidos pelo governo federal e estavam à disposição de todas as empresas de todas as áreas (MACERA; URDAN, 2004).

\subsection{VANTAGEM COMPETITIVA}

Em razão da globalização e da alta competitividade dos mercados, as empresas buscam a inovação para se diferenciar dos concorrentes e melhorar seu desempenho e, consequentemente, sua vantagem competitiva (CARVALHO et al., 2015). A vantagem competitiva é a ocorrência de níveis de desempenho econômico acima da média do mercado em benefício das estratégias adotadas pelas empresas. 0 investimento em inovação pode favorecer o alcance de vantagem competitiva à medida que propicia as condições para um desempenho financeiro superior.

Barney (1996) coloca o constante desafio enfrentado pelas empresas, o qual designou ser o "paradoxo da imitabilidade". Sendo assim, quanto menos custoso for para uma firma desenvolver ou adquirir os recursos que lhe dariam vantagem competitiva, tanto mais fácil será, possivelmente, para seus concorrentes os desenvolverem ou adquirirem por custo semelhante, gerando apenas analogia competitiva na indústria. A solução para esse paradoxo talvez esteja no constante incentivo à inovação. 
Nesse sentido, Madrid-Guijarro, García-Pérez-de-Lema e Van Auken (2013) e Sbragia et al. (2002) analisaram a relação entre inovação e desempenho. Sbragia et al. (2002) buscaram compreender as relações entre o esforço de inovação e um conjunto de indicadores de lucratividade, participação do mercado e faturamento (gerado por produtos novos ou melhorados), e os resultados mostraram que os investimentos em P\&D estão fortemente associados com a futura participação de novos produtos na receita total das empresas.

0 pioneiro na discussão acerca dos diferenciais que promovem um aumento de fatias de mercado que algumas empresas conseguem alcançar ou lutam para isso, foi Michael Porter (1989), quando mencionou pela primeira vez o termo "vantagem competitiva" em seu livro Competitive Advantage. Segundo o autor, a vantagem competitiva deve nascer de um conhecimento detalhado da estrutura da indústria a qual a empresa pertence.

Stalk Júnior (1998) define a vantagem competitiva como sendo um alvo em constante transformação. Para ele, independentemente do ramo que a empresa atua, a chave está em não se ater em uma ideia fixa e única do que seja sua fonte de vantagem.

Os concorrentes mais bem-sucedidos são aqueles que estão sempre em movimento. 0 tempo, na visão de Stalk Júnior (1998), é um padrão de medida de competição mais crítico do que as medições financeiras tradicionais. As empresas de nova geração competem com a fabricação flexível e com sistemas de respostas rápidos, expandindo a variedade e aumentando a inovação.

De tal maneira, tanto a eficácia operacional quanto a estratégia são essenciais para que se possa ter um comportamento superior, afinal, esses são objetivos primordiais de todas as empresas (PORTER, 1999). Para melhor entendimento a eficácia operacional significa ter melhor desempenho de atividades dentro da empresa do que os seus rivais. Já o posicionamento estratégico nada mais é que desempenhar atividades diferentes das exercidas pelos seus rivais, isto é, desenvolver as mesmas atividades, mas de forma diferente.

Para Porter (1990), os diferentes setores de uma empresa em busca de eficiência e de vantagem competitiva não podem ser compreendidos observando a empresa como um todo, uma vez que essa tem sua origem nas inúmeras atividades diferentes que uma empresa executa, seja no projeto, na produção, no marketing, na entrega, no suporte de seu produto, e cada uma destas atividades pode contribuir para a posição dos custos relativos de uma empresa, além de criar uma base para a diferenciação.

As empresas chegam à vantagem competitiva por meio das ações de inovação. É por intermédio de novas tecnologias e novas maneiras de fazer as coisas, de se adaptar ao novo que elas conseguem abordar a inovação em seu sentido mais amplo. Para Porter (1999), a inovação se manifesta no novo desenho do produto, no novo processo de produção, na nova abordagem de marketing ou nos novos métodos de treinamento.

Por conta das inovações que se gera a vantagem competitiva, seguindo uma linha de percepção seja ela de uma oportunidade vista no mercado inteiramente nova ou mediante o atendimento a um segmento de mercado, que foi passado despercebido por outra empresa.

As empresas são inseridas em um contexto em que a concorrência da economia é dinâmica, as organizações têm sua vantagem competitiva baseada principalmente em eficiência a respeito do uso dos principais insumos de produção, o que, consequentemente, requer processos de inovação contínua (PORTER, 1989).

Na visão ampliada sobre inovação, destaca-se a oportunidade em criar vantagem competitiva por meio do trabalho contínuo e coletivo. No entanto, é necessário que exista o gerenciamento dos processos, apreciando não apenas o produto final, mas também sua execução, sua relação no contexto de mercado e a qualidade das equipes internas da organização (BORJA DE MOZOTA; KLÖPSCH; COSTA, 2011).

A estratégia competitiva consiste em estabelecer uma posição lucrativa e sustentável contra as forças que determinam a competição industrial. 0 desafio enfrentado pelos gestores consiste em escolher ou criar um contexto ambiental em que as competências e recursos da empresa possam produzir vantagens competitivas (PORTER, 1986). Segundo Henderson (1998), a competição existiu muito antes do surgimento da estratégia. Com o surgimento da vida, iniciou-se a competição, e quanto mais rico o ambiente, maior o número de variáveis significativas, podendo assim proporcionar a cada espécie uma vantagem única.

Entretanto, quanto mais rico o ambiente, maior o número de competidores, e, consequentemente, mais acirrada a competição. Para Henderson (1998), o número crescente de empresas competidoras numa 
dimensão infinita em um planeta finito faz com que os competidores sejam eliminados um a um, os que forem inferiores no momento de apresentar seus produtos. Os mais aptos sobrevivem e prosperam até que tenham expulsado seus competidores ou crescendo além do que seus recursos permitam. É necessário que cada um seja suficientemente diferente, para que possa conseguir uma vantagem competitiva (HENDERSON, 1998).

A pressão coletiva das cinco forças motiva a habilidade das indústrias de ganhar, em média, aumento de taxas de retorno sobre o investimento em excesso ao custo de capital. A pressão das cinco forças varia de indústria para indústria e pode se modificar quando a indústria evolui (VITORINO FILHO; PERESIN; SACOMANO NETO, 2011).

\subsection{CADEIA MOVELEIRA}

Na cadeia de valor de uma empresa, há diversas atividades, dentre as quais aquelas que abrangem a logística. Essas atividades geram custos, que precisam ser gerenciados para obter sucesso nas empresas (ENGBLOM et al., 2012). A análise da cadeia de valor interna inclui analisar os elos que envolvem a compra, produção, venda e distribuição do produto. A análise da cadeia de valor é um método utilizado pelas empresas, a fim de compreender melhor o comportamento dos custos e das receitas. Ao gerenciar a cadeia de valor e diagnosticar os determinantes do custo para cada atividade, a empresa consegue obter uma vantagem competitiva em relação às empresas concorrentes (DIACONU, 2009).

Falando sobre cadeia de valor, Porter e Millar (1999) destacam que a cadeia de valor de uma empresa é um conjunto de atividades interdependentes as quais são conectadas por elos, que surgem quando a maneira como determinada atividade é desempenhada afetando o custo ou a eficácia de outras.

A cadeia de valor da indústria começa na matéria-prima que vem para a produção, com a chegada de vários itens e de diversos fornecedores e por meio da chegada, a empresa realiza o processo produtivo para a fabricação de um bem. Este bem somente é produzido quando há pedidos, significando que não há produção para estocagem, pois a empresa não possui espaço físico suficiente para isso. Em algumas empresas de móveis, para a facilitação e baixo custo, há a compra da madeira bruta e a realização do processo de secagem. Com essa matéria-prima, fabricam-se os móveis que depois de finalizados seguem para um setor de embalagem no qual são armazenados em local específico até que todos os outros produtos do pedido estejam prontos para serem carregados e entregues ao consumidor final (SOUZA; WEBER; CAMPOS, 2015).

De acordo com Quadros (2002), o setor moveleiro mundial era constituído de indústrias tradicionais, predominantemente micro e pequenas empresas, até que nos anos 1950 visavam atender quase que exclusivamente ao mercado interno de seus países.

A partir dos anos 1950, a indústria dinamarquesa de móveis passou a se voltar para o mercado externo, sendo a pioneira neste comércio. Entretanto, o comércio internacional de móveis somente se ampliou de forma significativa a partir dos anos 1970, sob a liderança da Itália.

A indústria brasileira de móveis está entre os mais importantes segmentos da indústria de transformação no país, não apenas pela importância do valor da sua produção, mas também pela sua geração de empregos na indústria nacional. Em valores monetários, o setor produziu, em 2009, R\$ 19 bilhões, o que é equivalente a 1,3\% do valor de faturamento da indústria de transformação, não mencionando as indústrias extrativas minerais e a construção civil (ABIMOVEL, 2008-2009).

No Brasil, a cadeia produtiva do setor moveleiro é formada por oito indústrias de painéis de madeira e mais de 22,5 mil indústrias de móveis, responsáveis pela geração de aproximadamente 256 mil empregos, sendo a nona força de trabalho no país, segundo o Departamento de Estágios e Cursos de Qualificação Profissional (Depec) (2017). As regiões Sul e Sudeste concentram 77,2\% do número de estabelecimentos, $82,1 \%$ dos empregados e $73 \%$ do faturamento na indústria de móveis.

O Oeste do Estado de Santa Catarina é composto por 54 municípios e possui uma extensão territorial de $11,4 \mathrm{mil} \mathrm{km}{ }^{2}$, o equivalente a 11,9\% do território catarinense. Segundo o IBGE, em 2013, sua população era de 629.853 habitantes. Chapecó é a cidade mais populosa da região (198.188 habitantes), como destacam as Figuras 2 e 3, indicando a localização da região em Santa Catarina (GOOGLE MAPS, 2017). 
Figura 2 - Mapa do Brasil

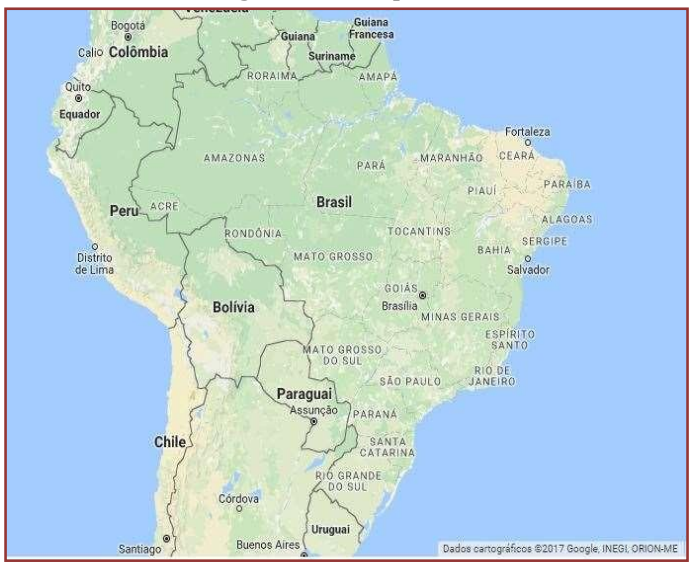

Fonte: Google Maps (2017).
Figura 3 - Mapa do Estado de Santa Catarina

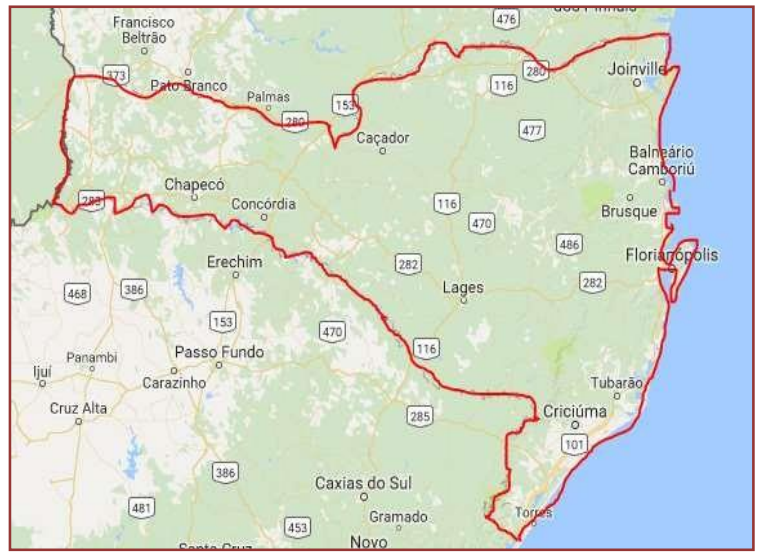

Fonte: Google Maps (2017).

A região teve o seu povoamento, em grande parte, atribuído a grupos de descendentes de imigrantes alemães e italianos, oriundos principalmente do Rio Grande do Sul. O desenvolvimento das agroindústrias influenciou positivamente o desenvolvimento de outros segmentos produtivos, como os segmentos metalomecânico e plásticos (embalagens). Também nessa região há expressividade nos segmentos da cadeia da madeira e da produção de móveis. Para Pires (2013), o setor moveleiro de Santa Catarina possui uma participação de $6,7 \%$ na transformação industrial nacional no mesmo setor, e no Estado sua participação é de $1,75 \%$.

Estudos de Pasqualoto e Ugalde (2010) e Silva, Beltrame e Schmidt (2014) sinalizam a necessidade de adaptação dos produtos quanto a aspectos relativos à marca e à embalagem na cadeia produtiva moveleira. É por meio disso que são encontradas as principais dificuldades para a introdução do design dentro da empresa, o custo para contratação e/ou manutenção de profissionais da área e, também, a ausência de profissionais com capacitação específica para trabalhar no setor moveleiro.

Segundo Silveira et al. (2013), o fato de o setor moveleiro estar em expansão, com suas empresas apresentando crescimento acelerado nos últimos anos, mostra um ambiente propício para que as empresas ineficientes aumentem os índices de aproveitamento dos recursos já disponíveis, por meio da melhor utilização de sua capacidade instalada. É diante de cenários como este que a adoção de estratégias sustentáveis está parcialmente relacionada com o desempenho exportador, embora, a sustentabilidade não esteja totalmente integrada à estratégia da empresa, a partir da sua atuação no exterior, a empresa tem buscado melhorias em produtos e processos, além de parcerias com fornecedores, a fim de reduzir os impactos socioambientais, questão esta significativa e que várias empresas estão adotando como fator preponderante nas negociações internacionais, trabalhando no sentido de permitir que as transações ocorram de maneira adequada e buscando superar conflitos em ambientes globais (ROCHA et al., 2013; BERTOLINI; CISLAGHI; FERNANDES, 2016).

\section{PROCEDIMENTOS METODOLÓGICOS}

0 método utilizado como abordagem de pesquisa foi qualitativo e o tipo de pesquisa descritivo, onde as informações iniciais para a construção do projeto foram coletadas entre junho e julho de 2017. Pesquisa qualitativa se explica porque se trabalhou, sobretudo, com as percepções dos sujeitos, o que confere certo grau de subjetividade, sendo esta uma característica marcante deste tipo de abordagem. A escolha pelo método qualitativo vem crescendo em pesquisas no campo da administração (PAIVA JÚNIOR; LEÃO; MELLO, 2011), porém recebe críticas pelo seu grau de subjetividade.

0 método de pesquisa foi de campo, com entrevista semiestruturada com o gestor da empresa Alfa (nome fictício) que atende o mercado externo e interno, localizada no município de Coronel Freitas, visto que o gestor da empresa permitiu acesso total aos documentos e relatórios da mesma, e concordou em ser entrevistado pelo pesquisador.

O estudo de caso é um método que abrange todas as etapas da pesquisa desde o planejamento, técnica de coleta de dados, abordagem, até a análise dos resultados compondo, portanto, em uma estratégia de pesquisa completa e não apenas em uma parte do processo (YIN, 2010). 
A pesquisa contou com construtos bibliográficos, os quais originaram uma pesquisa sistemática, seguida de pesquisa documental (relatórios e documentos da empresa pesquisada), sendo que a análise dos resultados ocorrerá por meio da Teoria da Orientação para Mercado.

A pesquisa inicialmente foi baseada em construtos bibliográficos para garantir sua integridade. Durante a pesquisa bibliográfica procurou-se desenvolver o levantamento a partir de estudos publicados por vários meios, com o objetivo de verificar contribuições científicas para auxiliar e dar suporte na definição de cada fase da pesquisa.

A análise documental, neste estudo, ocorreu por intermédio de documentos internos (história da empresa, gráficos, tabelas administrativas, comparativos financeiros de 2013 a 2017) repassados pela Empresa, os quais tiveram seus dados consolidados para que fossem apresentados o mais próximo à realidade possível. Para contatar a empresa foi realizada uma troca de informações com o Presidente do Sindicato da Indústria Madeireira e Moveleira do Vale do Uruguai (Simovale) e com a secretária do Sindicato dos Trabalhadores nas Indústrias da Construção e do Mobiliário de Chapecó (Siticom), para melhor entendimento de como são realizadas as intervenções enquanto sindicato e empresa e colaboradores.

O objetivo da pesquisa documental foi contextualizar a importância do setor moveleiro orientado para o mercado, acentuando seus ganhos dentro da empresa e também para a economia do município, bem como a capacidade da produção de móveis em madeira em adaptar-se com as tendências de consumo para manter-se competitivo no mercado. Ou seja, analisar a orientação para o mercado nas cadeias de valor.

Em seguida, foi realizada a pesquisa de campo, que é entendida como a investigação empírica realizada no local que se desenvolveu tal fenômeno e que dispõe de elementos para explicar o objeto a ser estudado (VERGARA, 2013). Assim, foram utilizados instrumentos de coleta de dados, compostos por roteiro de entrevista, entrevista semiestruturada e gravação da entrevista realizada com o gestor da empresa (para fins de preservação do nome da organização e do gestor se utilizou as iniciais do seu nome: L. C, seguido do ano).

Para a entrevista neste estudo, realizou-se um roteiro previamente estabelecido, por meio de um roteiro semiestruturado em virtude de sua flexibilidade de adequação. A elaboração das questões do contexto investigativo esteve apoiada em teorias relacionadas ao tema e pesquisa, o que favorece a descrição dos fenômenos, sua explicação e compreensão (TRIVIÑOS, 1987). De acordo com Bell (2008), a entrevista, quando aplicada de maneira apropriada, torna-se um instrumento adequado para que o pesquisador possa aprofundar respostas e investigar o fenômeno a ser examinado.

A entrevista realizada com o gestor da Alfa foi realizada de modo pessoal, com uma breve visita no interior da empresa para conhecer melhor o processo relatado durante a entrevista. Após, a entrevista foi transcrita para se utilizar dos dados na fase de apresentação e discussão dos resultados. A contemplação dos dados do estudo, no qual foi realizado uma única entrevista semiestruturada individual com um dos gestores da empresa.

Nesse contexto, buscou-se compreender que a análise dos dados incididos das entrevistas em pesquisa qualitativa deve ser realizada de acordo com as categorias (PAIVA JÚNIOR; LEÃO; MELLO, 2011). Acompanhando os autores a necessidade de se "[...] realizar uma reconstrução dos relatos de acordo com os seus significados para o sujeito entrevistado, a fim de se compreender em profundidade a fatualidade dos fatos."

Cabe ressaltar que a presente pesquisa não objetivou quantificar o resultado da entrevista em si, mas buscou captar a percepção do entrevistado em relação ao objetivo do estudo.

A análise dos dados tomou uma abordagem qualitativa do fenômeno por meio da análise de conteúdo. A análise deste trabalho toma como padrão a obra de Bardin (2006), considerada referência em análise de conteúdo na literatura. A análise de conteúdo vem se destacando nos últimos anos como técnica de análise de dados entre os métodos qualitativos de pesquisa no campo da produção científica de Administração, em virtude de preocupações com o rigor científico e a profundidade das pesquisas de estudos organizacionais (MOZZATO; GRZYBOVSKI, 2011).

A análise dos dados foi realizada utilizando a Teoria da Orientação para o Mercado como teoria base, ancorando a análise segundo seus preceitos. 0 Quadro 3 apresenta a relação entre os aspectos da pesquisa e as metodologias utilizadas. A teoria possui elementos subsequentes ao tema, problema e objetivos da pesquisa, sendo assim, respondendo a problemática da investigação, para que sejam compreendidos os elos da esfera produtiva da empresa ao longo dos anos. 
Quadro 3 - Metodologias e aspectos da pesquisa a serem atendidos

\begin{tabular}{|c|c|}
\hline Aspectos a serem pesquisados & Metodologias a serem utilizadas \\
\hline $\begin{array}{l}\text { Problema: } \\
\text { - Quais fatores afetam a competitividade de uma empresa da cadeia } \\
\text { produtiva moveleira do município de Coronel Freitas, suas } \\
\text { consequências e possíveis alternativas para a melhoria destes? }\end{array}$ & $\begin{array}{l}\text { Pesquisa sistemática; pesquisa } \\
\text { bibliográfica; entrevista } \\
\text { semiestruturada e análise } \\
\text { documental }\end{array}$ \\
\hline $\begin{array}{l}\text { Objetivo geral: } \\
\text { Analisar os fatores que afetam a competitividade e a orientação } \\
\text { para o mercado de uma empresa moveleira que atende mercados } \\
\text { internos e externos do município de Coronel Freitas. }\end{array}$ & $\begin{array}{l}\text { Pesquisa bibliográfica; entrevista } \\
\text { semiestruturada e análise } \\
\text { documental. }\end{array}$ \\
\hline $\begin{array}{l}\text { Objetivos específicos: } \\
\text { Caracterizar a orientação para o mercado da empresa, } \\
\text { considerando as ações e atividades que esta desenvolve para } \\
\text { melhorar seu desempenho; }\end{array}$ & $\begin{array}{l}\text { Entrevista documental. } \\
\text { Semiestruturada e análise }\end{array}$ \\
\hline $\begin{array}{l}\text { Determinar os fatores que interferem positiva e/ou negativamente } \\
\text { na competitividade da empresa moveleira pesquisada; }\end{array}$ & $\begin{array}{l}\text { Entrevista documental; } \\
\text { semiestruturada e análise }\end{array}$ \\
\hline $\begin{array}{l}\text { - Identificar as consequências e as possíveis ações para a melhoria } \\
\text { da competitividade da empresa moveleira, considerando os } \\
\text { mercados que ela está inserida. }\end{array}$ & $\begin{array}{l}\text { Entrevista documental. } \\
\text { Semiestruturada e análise }\end{array}$ \\
\hline
\end{tabular}

Fonte: os autores.

Os dados foram triangulados e analisados para se obter as possíveis soluções às questões de competitividade do setor moveleiro do Oeste de Santa Catarina, e que atendam aos objetivos propostos, bem como a resposta ao problema considerado como foco deste estudo.

\section{APRESENTAÇÃO E ANÁLISE DOS RESULTADOS}

As informações e os dados referentes à Empresa em estudo foram retirados de consulta a acervos internos da Empresa e também da observação da pesquisadora no local da pesquisa, organizados assim em relatório de campo.

A Alfa teve início dos seus trabalhos em meados de 1968, na garagem de sua própria casa, no município de Coronel Freitas - SC. Nesta época um dos únicos meios de transporte era a carroça, então o Sr. Antônio (nome fictício usado para descrever o fundador da empresa) viu a necessidade de fabricar e comercializar rodas, inicialmente o trabalho era manual e tinha ajuda dos seus filhos mais velhos. Com o passar dos anos, os carros foram dominando o mercado rapidamente e então o proprietário se viu obrigado a mudar seu ramo de atuação. Partiu assim para a produção moveleira de forma artesanal, com produtos de madeira. A empresa foi crescendo e então a demanda cada vez maior fez com que fosse necessária a produção em linha de móveis, mais especificamente dormitórios em madeira. Este tipo de produto vendia muito bem, até o surgimento de novos materiais e com preços mais acessíveis, como, por exemplo, o MDF (História baseada na entrevista com gestor e documentos internos da empresa).

Na percepção do empresário, a partir de 2002, com a desvalorização do dólar, a empresa teve que voltar suas atenções novamente para o mercado interno, indo em busca de novos clientes. Os produtos tinham pouco valor agregado e precisavam de um volume de vendas muito grande para que pudessem dar um retorno satisfatório. Foi então que a Alfa se "reinventou" e abandonou a produção com MDF, voltando suas atenções para os produtos de madeira, mais especificamente o Pinus. A mudança realizada dentro da empresa ocorreu pelo fato de que se fez um levantamento verificando quais seriam os nichos que queriam ser atendidos dentro de um mercado com crescimento da classe baixa para uma classe média, e também pelo fato de já possuir experiência na produção de móveis com este tipo de matéria-prima.

Este período, segundo o empresário, foi de dificuldades para a indústria moveleira, quando empresas faliram ou venderam seus parques fabris para poderem pagar suas dívidas. Possivelmente, um dos fatores determinantes para a Alfa ter se mantido no mercado foram as anteriormente mencionadas "reinvenções", visto que a empresa buscou sempre nichos de mercado que estavam em ascensão, atingindo um públicoalvo de igual crescimento.

Atualmente, a Alfa conta com um quadro de 75 colaboradores, contendo uma estrutura própria e com intenção de ampliações futuras. Findada a caracterização do local da pesquisa de campo, parte-se para análise e discussão dos resultados por meio das categorias de análise. Com base nos documentos internos da Empresa em estudo, foi analisado o resultado do demonstrativo do ano de 2013 a 2017, sempre obtendo como índice a média de cada demonstrativo. 
As análises dos financiamentos da empresa apontam a origem dos recursos, podendo esses serem derivados dos lucros gerados pela sua atividade, dos seus sócios, no caso das empresas de capital aberto através da emissão de ações no mercado primário ou secundário, e, por último, das dívidas assumidas com terceiros, financiamentos (L. C. 2017, informação verbal).

Por intermédio das análises das médias dos índices de faturamento da empresa, nota-se o crescimento do faturamento da empresa ao longo dos cinco anos em análise. 0 crescimento da empresa em se falando de faturamento do ano de 2013 para 2014 foi de aproximadamente 33,66\%, isso em média de faturamento bruto. Já o crescimento do ano de 2014 para o ano de 2015 foi de, aproximadamente, 15,35\%. Pode-se notar que neste ano houve uma queda de aproximadamente - 18,31\% no faturamento da empresa (foi contatado com a empresa e ela não mencionou o fato desta queda).

Já o crescimento de faturamento da empresa de 2016 em relação ao ano de 2015 foi de aproximadamente 7,58\%. E sobre os dados apresentados no Quadro 6, o crescimento da empresa de 2016 até os cinco primeiros meses do ano de 2017, no qual foram obtidos os dados, o crescimento da empresa foi de aproximadamente 3,46\%. Mediante essa análise é possível perceber que com o passar dos anos a empresa sempre obteve crescimentos e por meio desses crescimentos se pode notar a melhoria do desempenho ao longo dos anos, mesmo o mercado nacional passando por diversos momentos de crise, a empresa tende a se manter de portas abertas no mercado.

Os efeitos de um ano com desaceleração nos negócios e decréscimo produtivo impactaram todos os setores produtivos e, em especial, os elos da cadeia moveleira. Ainda para Daniel Lutz (2017), o setor moveleiro passou por um processo de reposicionamento em que as indústrias procuraram um equilíbrio diante de um mercado interno de retração, forçando as empresas a buscarem alternativas na redução de custos com maior eficiência, tanto na gestão quanto em processos. Tudo isso sem abrir mão de fabricar produtos com qualidade e valor agregado.

Em determinado momento da entrevista, o gestor da empresa em estudo fala que o:

Principal destaque para esse ganho da empresa, tem a ver com as melhorias implementadas no setor produtivo da empresa, onde se obteve um grande ganho não somente em reais, mas também ganho em produtividade e experiências no tempo (L.C., 2017, informação verbal).

Quadro 6 - Média do faturamento bruto total dos anos de 2013 até 2017
\begin{tabular}{|l|l|}
\hline Ano & Reais \\
\hline 2013 & $\mathrm{R} \$ 938.888,61$ \\
\hline 2014 & $\mathrm{R} \$ 1.254 .942,80$ \\
\hline 2015 & $\mathrm{R} \$ 1.447 .586,62$ \\
\hline 2016 & $\mathrm{R} \$ 1.557 .299,78$ \\
\hline $2017 *$ & $\mathrm{R} \$ 1.611 .129,29$ \\
\hline
\end{tabular}
Fonte: os autores.
*dados referentes aos cinco primeiros meses do ano de 2017.

Observando o Quadro 6, é evidente o crescimento ano após ano, sendo neste ponto de vista que a Empresa em estudo teve um crescimento de cerca de $72 \%$ em cinco anos do faturamento médio bruto da empresa de 2013 até os primeiros cinco meses do ano de 2017.

Lutz (2017) destacou que em 2016/2015 houve um decréscimo da produção em -7,7\%, mas para o período 2017/2016 a previsão é de 2,2\% de crescimento no país. Em relação às análises realizadas com a obtenção dos dados da empresa o decréscimo foi no ano de 2014 a 2015, já no ano de 2016/2015 a queda foi de aproximadamente $-7,77 \%$. A partir de agora se espera um crescimento, sabe-se que a retomada dos valores é gradual na economia e o crescimento é efetivo, porém moderado.

É por meio dos índices de liquidez que é avaliada a capacidade de pagamento da empresa frente a suas obrigações. Assim, é fundamental para a administração da empresa as variações destes índices. As informações para o cálculo destes índices são retiradas do Balanço patrimonial, demonstração contábil, que evidencia a posição patrimonial da empresa, devendo ser atualizada constantemente para uma correta análise (ZANLUCA, 2008). 
No Quadro 7, observa-se que no período de estudo, os valores do índice de liquidez foram diminuindo gradativamente. Em 2013 a 2014 a queda foi de 0,98\%, já de 2014 a 2015 a queda foi de 0,08\%, de 2015 a 2016 a queda foi de 0,52\% aproximadamente, e de 2016 até os cinco primeiros meses do ano de 2017 foi de $0,44 \%$. Em relação aos dados, o gestor fala que:

Os valores apresentados condizem com valores em reais sobre a liquidez e a porcentagem de endividamento da empresa, e se percebe que a liquidez diminuiu, pois, a empresa realizou investimentos de melhoria interna na produtividade, no qual foi realizado basicamente com capital de terceiros, o que aumentou o endividamento, diminuindo a liquidez (L.C. 2017, informação verbal).

Quadro 7 - Índice de liquidez, reais x relação da dívida

\begin{tabular}{|l|l|}
\hline Ano & Reais \\
\hline 2013 & $\mathrm{R} \$ 4,06$ \\
\hline 2014 & $\mathrm{R} \$ 3,08$ \\
\hline 2015 & $\mathrm{R} \$ 3,00$ \\
\hline 2016 & $\mathrm{R} \$ 2,43$ \\
\hline 2017 & $\mathrm{R} \$ 2,87$ \\
\hline
\end{tabular}

Fonte: os autores.

*dados referentes aos cinco primeiros meses do ano de 2017.

Para fins de informação os dados que a empresa considera para a obtenção do índice de liquidez são avaliados 6 meses do ano, e de 2013 a 2016 os meses de coleta dessas informações foram, janeiro, março, maio, julho, setembro e novembro, e no ano de 2017, os dados repassados foram dos cinco primeiros meses do ano.

Empresas financiam o seu crescimento com os ganhos de sua capitalização (venda de suas ações no mercado), com parte de seus lucros e com empréstimos. 0 retorno aos acionistas ocorre por meio dos proventos recebidos e pela valorização das ações da empresa. 0 retorno do capital de terceiros ocorre mediante o pagamento das dívidas, dos encargos, dos juros e dos financiamentos contraídos, como mostra o Quadro 8.

Quadro 8 - Porcentagem de endividamento da empresa

\begin{tabular}{|l|c|}
\hline Ano & Porcentagem \\
\hline 2013 & 9 \\
\hline 2014 & 9 \\
\hline 2015 & 13 \\
\hline 2016 & 13 \\
\hline 2017 & 10 \\
\hline
\end{tabular}

Fonte: os autores.

*dados referentes aos cinco primeiros meses do ano de 2017.

Ainda a respeito da porcentagem do endividamento, como mostra o Quadro 8, em meados do ano de 2013 e 2014 a porcentagem se manteve com uma média de $9 \%$, já nos dois anos seguintes o endividamento da empresa subiu para 13\%. Como no ano de 2017 há somente os dados referentes aos cinco primeiros meses do ano, não se pode afirmar qual será a porcentagem, se ela vai se manter ou então aumentar ou diminuir, mas até o presente momento a porcentagem é $10 \%$ de endividamento da empresa.

Para Fonseca (2003), a ordem atual de mercado exige do gestor decisões frequentes sobre novos investimentos. Existem empresas que determinam, conforme sua demanda de mercado, as constantes e contínuas alterações, seja no processo produtivo, seja na necessidade de renovação tecnológica para atingir uma melhor competitividade, e inserção ou manutenção em um mercado globalizado e cada vez mais competitivo. Processos de mudanças podem ser associados diretamente a investimentos. Mudar o perfil de uma empresa, criar um novo produto, implantar uma nova tecnologia, são ações que em geral envolvem altos investimentos (KOCH, 2002 apud COSTA et al., 2004). As organizações atuais buscam na tecnologia um diferencial de competitividade. Espera-se que com a informação, aliada a recursos tecnológicos, seja possível acondicionar as mudanças organizacionais e garantir ganhos operacionais e estratégicos (KOCH, 2002 apud COSTA et al., 2004). É grande a percepção que quando a produtividade da 
empresa aumenta, consequentemente, as margens também melhoram com o passar dos anos. No Quadro 9 se nota a melhoria das taxas de retorno dos investimentos nos quais a empresa realizou nos últimos anos.

Do ano de 2013 a 2014 o retorno foi de 0,07\% em relação aos investimentos realizados na empresa, de 2015 a 2014 o retorno foi de 0,24\%, período este em que a empresa se equilibrou e aumentou sua rentabilidade. Já de 2016 para 2015 houve uma queda de 0,18\% em comparação ao ano anterior. Nos primeiros cinco meses de 2017, em relação ao ano de 2016, teve uma taxa de retorno de 0,07\%, notandose que até chegar ao final do ano de 2017 acredita-se que o retorno será maior.

Quadro 9- Taxa de retorno sem investimento
\begin{tabular}{|l|c|}
\hline Ano & Porcentagem \\
\hline 2013 & 0,49 \\
\hline 2014 & 0,56 \\
\hline 2015 & 0,80 \\
\hline 2016 & 0,62 \\
\hline 2017 & 0,69 \\
\hline
\end{tabular}
*dados referentes aos cinco primeiros meses do ano de 2017.

Qualquer investimento realizado por uma empresa deve e será sempre visto como um desembolso, feito com a finalidade de gerar um fluxo de benefícios futuros, comumente trabalhando com expectativa de retorno em período superior a um ano. 0 investimento é necessário, principalmente, em razão da acirrada concorrência existente no mercado financeiro, aliado à carência de recursos disponíveis para a realização de investimentos (TOSHIKAZU, 2002 apud COSTA et al., 2004).

\subsection{ANÁLISE E DISCUSSÃO DOS RESULTADOS POR MEIO DAS CATEGORIAS DE ANÁLISE}

Neste item estão apresentadas as análises e discussões dos resultados da pesquisa. Os dados são expostos conforme os respectivos objetivos específicos do trabalho. As informações obtidas das diferentes fontes (bibliográficas, entrevista semiestruturada, observação e análise documental) são confrontantes e promove-se a sua relação com a teoria.

As características determinantes do modelo de Grunert, expostas no Quadro 1, são: pressão competitiva, heterogeneidade e dinamismo do consumidor, associações interfirmas orientadas para o mercado, regulação, modelos mentais, cadeias curtas e equilibradas, confiança e compromisso nas relações. Cada uma destas características foi identificada durante o estudo, sendo apresentados os resultados a seguir.

\section{a) Pressão competitiva identificada no estudo}

O empresário considera que não possui um número considerável de concorrentes considerando a linha de móveis que sua empresa atua, visto que o móvel vendido no mercado nacional possui preço abaixo da média dos concorrentes ( $R$ \$ 1.300,00 para o consumidor final, versus $R \$ 3.000,00$ do concorrente), com a qualidade dentro ou acima do padrão mercadológico. Segundo ele:

A vantagem é que não temos tanta concorrência, temos concorrentes diretos, produtos semelhantes, produtos melhores, tem produtos piores, o nosso móvel não é um móvel caro, como um móvel de madeira maciça, que um móvel de madeira maciça sai da fábrica em torno de uns $R \$ 1.300,00$ reais, vai chegar para o consumidor final quase uns $\mathrm{R} \$ 3.000,00$ mil reais, já o nosso não, ele vai chegar lá no final para o consumidor em torno de uns $\mathrm{R} \$ 1.200,00$ a $\mathrm{R} \$ 1.300,00$ reais. (L. C, 2017, informação verbal).

Ao considerar as possíveis desvantagens competitivas que a empresa possui, ele considera que o valor do frete prejudica sua empresa, pois os concorrentes possuem caminhões próprios, e isto melhora o preço de empresas que embora a qualidade seja inferior aos seus produtos, ganham o mercado pelo preço reduzido.

A empresa produz baseada na sua capacidade produtiva, ou seja, produz na sua condição de produção atual, e assim atende o mercado segundo o que consegue produzir. 0 empresário afirma que atende o 
mercado conforme a produção acontece e sua capacidade de estoque permita, embora tenha a preocupação de monitorar o que seus concorrentes estão produzindo e o que o mercado vem exigindo. Segundo ele:

A gente tenta produzir não muito mais do que a nossa capacidade, pois não temos o local adequado para armazenamento e sabemos que se ficar lá atrás (fundos da fábrica), irá ficar por muito tempo. (L. C, 2017, informação verbal).

A empresa monitora seus concorrentes acompanhando os produtos ofertados por estes nas lojas, ou seja, o vendedor da empresa pesquisada, ao visitar os clientes, analisa os produtos ofertados e acompanha os preços dos produtos dos concorrentes. Com isto, e por meio do relatório entregue pelo vendedor, a empresa consegue mapear e alterar preços e produtos vendidos ao mercado. A cada ano são ofertados produtos novos ou modificados, para permitir a competição da empresa no mercado em que ela está inserida.

As empresas ganham vantagem competitiva ao planejarem ofertas que satisfaçam mais as necessidades do consumidor-alvo do que as ofertas dos concorrentes (KOTLER, 1998).

Considerando a postura da administração da empresa, a vantagem competitiva, deve ser levado em consideração: aceitando os riscos com os concorrentes, ter sentido de oportunidade em relação ao mercado, analisar com sabedoria o que realmente deseja para a empresa, formular e operacionalizar estratégias, estabelecer políticas cultural e econômica, ter a visão plenamente voltada para o mercado, ter como ponto principal a liderança sobre toda e qualquer situação da empresa. Isso motiva os colaboradores para que se sintam diferenciados dentro da empresa, estejam sempre abertos à inovação e criatividade, administrem adequadamente os projetos e os recursos disseminados pelos demais gestores da empresa, quando precisar controlar e avaliar de forma rígida as situações corriqueiras, sejam compreensíveis, imparciais, simples e constantes (KOTLER, 1998).

A vantagem competitiva é obtida considerando-se a situação geral da empresa, nos seguintes casos: alta tecnologia que possibilite redução de custos, simplicidade do processo produtivo e preços competitivos dos produtos ou serviços; alta liquidez financeira; baixo grau de endividamento; alto nível do quadro profissional; adequado sistema de informações gerenciais; boa imagem dos produtos e serviços; boa relação com o mercado; adequada situação de capacidade instalada; alto poder de penetração nos segmentos de mercado; e agilidade e flexibilidade interna. 0 importante é estar ciente de que a vantagem competitiva é sempre identificada pela empresa em comparação aos seus concorrentes.

A empresa também demonstrou preocupação com a capacitação dos funcionários, considerando o aspecto desempenho produtivo e atendimento às exigências mercadológicas, visto que o empresário afirma: “[...] buscamos fazer treinamentos para nos aperfeiçoar e para ver como é que vai fazer isso aí, sem ter erros [...]" (L. C, 2017, informação verbal).

Assim, percebe-se que a empresa, embora de porte pequeno, oferece capacitações que permitem reduzir os erros de produção e de gestão, melhorando a oferta de produtos orientados para o mercado. No decorrer do tempo a sociedade tem tomado rumos diferentes, dos quais são chamados de "pós-industrial" ou era dos serviços, no qual procuram mudanças rápidas e constantes, obrigando as empresas a se adaptarem a tal situação para não perderem vantagens.

A qualidade dos produtos também preocupa o empresário e identificou-se que não há diferenciação dos produtos ofertados no mercado interno ou externo. Ou seja, a produção é realizada de forma única e o produto final deve atender ambos os mercados.

No processo de exportação, percebe-se que o aspecto confiança está presente nas negociações e as principais preocupações da empresa referem-se à qualidade do produto e à entrega dentro dos prazos estabelecidos, visto que o transporte se enquadra como FOB (free on board), então não é aconselhável perder os prazos de entrega.

Os nossos fornecedores que ajudam na exportação, nos avisam que eles vêm até a empresa para fazer o carregamento do produto em um determinado dia, neste dia, conforme o combinado, eles estarão aqui, com seu caminhão, com o pessoal qualificado para a coleta dos produtos, e carregam. Nós sempre priorizamos para que o produto esteja pronto, embalado conforme as regras por nos estabelecidas, para até mesmo eles não percam o prazo de escoar esse produto no Porto, pois eles também devem satisfação e qualidade na entrega para os clientes deles fora do Brasil. (L. C, 2017, informação verbal). 
A empresa tem direcionado suas ações para o aumento das exportações, embora o mercado ainda não esteja respondendo para que este incremento aconteça de forma efetiva. $\mathrm{Na}$ atualidade, as exportações têm se mantido dentro dos padrões históricos.

\section{b) Heterogeneidade e dinamismo do consumidor final}

Identificou-se na empresa aspectos de heterogeneidade, visto que embora haja concorrência, a empresa consegue se manter competitiva no mercado pela qualidade do produto entregue e os preços de comercialização de seus produtos.

A empresa produz conforme sua capacidade produtiva e adapta-se às exigências do mercado de acordo com a capacidade de produção da fábrica, e, como um limitante apontado pelo empresário, pode-se considerar a capacidade de estoque de produtos acabados.

Considerando o padrão de qualidade exigido pelos consumidores dos mercados nacional e internacional, a empresa não diferencia sua produção conforme a venda futura, ou seja, os produtos produzidos para a exportação são os mesmos revendidos no mercado nacional. Na entrevista com o empresário, este afirma que: "Acredito que sim, que essas exigências são diferentes, porém acredito que o mercado internacional tem uma exigência um pouco maior." (L. C, 2017, informação verbal).

A empresa, embora saiba que o consumidor externo tenha uma exigência maior, não altera sua forma de produção e controle de qualidade, visto que, segundo o empresário, a qualidade de seus produtos está adequada ao padrão internacional.

A empresa monitora seus concorrentes, ou seja, a qualidade e os preços ofertados por outras empresas que produzem produtos similares é realizada por meio das observações e dos feedbacks trazidos pelos vendedores até a empresa, sendo uma conversa paralela, ou visitando seus clientes de forma rotineira.

Para que seja realizado um comparativo de preços dos seus concorrentes, alguns vendedores analisam os preços dos produtos nas lojas de varejo, onde são vendidos geralmente mais do que um móvel do mesmo segmento, juntamente com os móveis da empresa em estudo. Após essas análises, eles levam sugestões de modificações e melhorias dos móveis, discorrendo com o responsável pelo design da empresa as possíveis alterações para a produção de móveis para o próximo ano.

Tudo isso depois de reuniões e estudos dentro da empresa, juntamente com gestores e responsáveis pelo design, é realizado um estudo, para ver se realmente torna-se compensador as mudanças e se elas não irão agregar um valor mais alto para o consumidor final.

\section{c) Associações interfirmas orientadas para o mercado}

A Alfa participa da Associação Comercial e Industrial de Coronel Freitas, do Sindicato da Indústria Madeireira e Moveleira do Vale do Uruguai (Simovale) e do Sindicato dos Trabalhadores nas Indústrias da Construção e do Mobiliário de Chapecó (Siticom).

Esta participação em órgãos que congregam empresas do mesmo setor permite às empresas a possibilidade de capacitar seus funcionários e gestores, ter acesso à pesquisa de mercado e de preço realizadas durante o ano por essas instituições, permitindo o acesso a novidades tecnológicas mercadológicas e produtivas voltadas principalmente ao setor moveleiro.

A empresa não possui relação comercial e/ou produtiva com seus concorrentes, mas o empresário considera que isso seria importante para o desenvolvimento do setor moveleiro na região. Ele relata dificuldades em trocar experiências produtivas e/ou comerciais com seus concorrentes da região e acredita que isto ocorra pela dificuldade de estabelecer relações de confiança entre os pares. 0 empresário afirma: "[...] a troca de informações, experiências e conhecimentos poderia melhorar muito mais o desenvolvimento do geral, não somente a parte fabril, mas principalmente o setor administrativo e dos negócios [...]" (L. C, 2017, informação verbal). 


\section{d) Regulação}

Para a empresa, os produtos que são comercializados para o mercado externo são os mesmos comercializados no mercado interno, não enfrentam dificuldades com as ações reguladoras para o mercado internacional, visto que a comercialização de seus produtos, que são destinados para fora do país, e o acesso ao mercado externo, na maioria das empresas, é feito por meio dos agentes de exportação. Ainda são raras as iniciativas de inserção no mercado internacional de forma direta.

Para Hill (2011), o comércio internacional apresenta padrões de diversas qualidades, pois possui capacidade ou características que potencializam a produção de determinados produtos ou a prestação de serviços. Essa capacidade dos países leva à criação de padrões, que podem ser derivados de aspetos, como o clima e a abundância de determinados recursos naturais ou ainda de diferenças de produtividade no trabalho.

O Brasil é exportador tradicional de móveis para o exterior, mas esses produtos não entram nos acordos uni ou bilaterais, o que não causa dificuldades para a exportação, e pode-se considerar que o que regula a quantidade exportada pela empresa é, basicamente, a capacidade produtiva e o preço de venda de seus produtos.

\section{e) Modelos mentais}

Identificou-se que o empresário negocia com seus fornecedores e clientes com embasamento no aspecto confiança que este estabeleceu com os atores da cadeia produtiva. 0 empresário afirma que "[...] nós buscamos manter nossos fornecedores por muitos anos, e buscamos também que nossos clientes nos mantenham como fornecedores por muitos anos também." (L. C, 2017, informação verbal).

A empresa mantém relação com seus fornecedores há muitos anos e isto permite que o aspecto qualidade seja mantido ao longo do tempo, além da negociação de prazos com maior facilidade, tornando este aspecto uma vantagem competitiva para a produção de móveis.

Da mesma forma, a relação com os clientes é estabelecida pelo aspecto confiança, pois a empresa possui vários clientes que mantêm relação comercial há pelo menos 10 anos.

Frequentemente, sugere-se que uma orientação para o mercado melhore o desempenho empresarial. 0 argumento é que as organizações voltadas ao mercado, ou seja, aquelas que acompanham as necessidades e preferências dos clientes e reagem a elas, podem melhor satisfazer seus clientes e, portanto, apresentam melhor desempenho (KOHLI; JAWORSKI, 2006).

Os clientes interferem nos modelos de produtos, pois a empresa busca analisar os principais interesses e solicitações dos clientes, mantendo a linha de produtos adequada às exigências do mercado consumidor e, assim, mantendo-se ativa e atuante no setor. A empresa condiz um plano de marketing virtual, por meio da utilização de redes sociais, e tem investido no planejamento estratégico da marca para que os clientes e potenciais clientes possam perceber a empresa como produtora de móveis de qualidade. 0 empresário cita: “[...] o retorno através do marketing virtual, pois ele sempre se paga [...]" (L. C, 2017, informação verbal).

Para Rocha e Veloso (1999), o marketing tem assumido um novo e importante papel, deixando de ser apenas uma ferramenta de convencimento do consumidor, sendo também um meio muito importante de transmissão de mensagens e, principalmente, de conceitos, tornando-se assim um real integrador focado nos interesses dos clientes.

Portanto, a partir do pressuposto, já difundido, de que a conquista da venda não acontece somente em razão do marketing em si, mas do real desenvolvimento do trabalho dos profissionais dessa área, constróise assim um relacionamento entre a empresa e o cliente, agregando valor ao serviço que a empresa presta, melhorando a produção dos móveis, além da confiança e credibilidade do cliente (ROCHA; VELOSO, 1999). 


\section{f) Cadeias curtas e equilibradas}

A empresa está inserida em uma cadeia produtiva que apresenta indícios de ser curta e equilibrada, pois esta não controla de maneira efetiva seus fornecedores e tem uma relação apenas comercial com seus clientes.

Como aspecto positivo da cadeia em que a empresa está inserida, pode-se considerar a previsão de ampliação futura do parque fabril e a busca pela produção de novos modelos de móveis, atendendo, assim, uma demanda reprimida e identificada pela empresa na atualidade.

Considerando a orientação para o mercado, a empresa precisa amadurecer as relações comerciais com seus clientes e fornecedores, ultrapassando o aspecto confiança, que embora esteja presente não garante os contratos futuros.

Para Ferreira (2006), qualidade e preço compatíveis, na era da globalização, são diferenciais competitivos, mas que se tornam obrigatórios e até mesmo comuns diante de várias opções existentes no mercado. 0 grande diferencial é que os consumidores estão cada vez mais exigindo, além de qualidade e preço, a forma como são atendidos.

A comunicação e o ótimo relacionamento interativo desenvolvido com o cliente, a partir de um primeiro contato com a empresa, definirá a satisfação ao longo dos próximos contatos (FERREIRA, 2006)

Kohli e Jaworski (1990) recomendam que uma orientação para o mercado propicia diversos benefícios psicológicos e sociais aos colaboradores. Mais especificamente, afirma-se que uma orientação para o mercado leva a um sentimento de orgulho de pertencer a uma organização em que todos os departamentos e as pessoas trabalham para atingir a meta comum de satisfazer à clientela. Presume-se que a realização desse objetivo resulte no compartilhamento, pelos colaboradores, de um sentido de atribuição e de comprometimento com a organização.

\section{g) Confiança e compromisso nas relações}

Identificou-se na cadeia produtiva da empresa, tanto a montante quanto a jusante as relações de confianças estabelecidas entre os atores, mas pode-se perceber que não há forma efetiva de troca de informações entre a empresa, seus clientes e fornecedores, o que pode gerar problemas futuros à produção e comercialização dos móveis.

Como o intercâmbio de informações não está plenamente estabelecido, as possíveis atividades de melhoria dos processos a montante e a jusante ficam prejudicadas. As possíveis alterações de qualidade dos produtos entregues pelos fornecedores da empresa acabam sendo descobertas após estes insumos entrarem no processo produtivo, o que geram dificuldades na manutenção da linha produtiva funcional e na garantia da qualidade final dos produtos aos clientes. Identificou-se que a empresa está parcialmente orientada para o mercado, mas possui condições de melhorar sua competitividade e ampliar a participação com seus produtos, principalmente, para o mercado interno e, com algumas alterações de processo, para o mercado internacional.

\subsection{A ORIENTAÇÃO PARA O MERCADO NA EMPRESA ALFA}

Por intermédio das características determinantes propostas no Modelo de Grunert et al. (2005) expostas no Quadro 1, o qual foi utilizado para analisar as respostas da entrevista com o gestor da empresa Alfa, foi desenvolvido um Quadro Resumo (Quadro 10) que apresenta a definição de cada característica para analisar se a empresa em estudo é ou não voltada ao mercado.

A Orientação para o Mercado no setor moveleiro permite que as empresas tracem suas estratégias e viabilizem a manutenção de suas estruturas produtivas, possibilitando que em uma análise mais apurada procure ampliar a gama de produtos oferecidos e a conquista de novos mercados. 
Quadro 10 - Características determinantes baseadas no modelo Grunert, que foram analisadas e resumidas por meio das respostas do gestor da Alfa

\begin{tabular}{|c|c|}
\hline Características determinantes & Definição \\
\hline Pressão competitiva & $\begin{array}{l}\text { A situação da empresa segue os casos de vantagem competitiva, tendo } \\
\text { como base a alta tecnologia, simplicidade do processo produtivo, preços } \\
\text { competitivos, alta liquidez financeira, baixo grau de endividamento, alto } \\
\text { nível de quadro de profissionais. }\end{array}$ \\
\hline $\begin{array}{l}\text { Heterogeneidade e dinamismo do } \\
\text { consumidor final }\end{array}$ & $\begin{array}{l}\text { Identificou que existem aspectos de heterogeneidade, mesmo tendo em } \\
\text { vista seus concorrentes diretos e indiretos, consegue manter seus preços e } \\
\text { qualidade do produto. A empresa produz conforme sua capacidade e como } \\
\text { um limitante considera-se que tem capacidade de estoque de produtos } \\
\text { acabados. Não existe diferenciação entre os produtos vendidos no mercado } \\
\text { interno e externo, sempre optando para fazer com que seus } \\
\text { produtos sejam adequados. }\end{array}$ \\
\hline $\begin{array}{l}\text { Associações interfirmas orientadas para } \\
\text { o mercado }\end{array}$ & $\begin{array}{l}\text { A participação em associações e sindicatos congrega as empresas de um } \\
\text { mesmo setor, troca de informações em relação a preços, pesquisa } \\
\text { mercadológica, capacitações, entre outras ferramentas relevantes para } \\
\text { que as empresas se tornem cada vez mais produtivas. }\end{array}$ \\
\hline Regulação & $\begin{array}{l}\text { As ações reguladoras não apresentam dificuldades na hora da negociação } \\
\text { com o mercado externo. Sendo assim, a empresa regula a quantidade } \\
\text { exportada e é basicamente a produtividade e o preço de venda de seus } \\
\text { produtos do mercado interno. }\end{array}$ \\
\hline Modelos mentais & $\begin{array}{l}\text { É mantida uma relação com seus fornecedores e clientes através de muitos } \\
\text { anos, o que permite que o aspecto qualidade seja mantido ao longo do } \\
\text { tempo. Empresas que são voltadas para o mercado são aquelas que } \\
\text { acompanham a necessidade e preferência de seus clientes e reagem } \\
\text { a elas, podendo melhorar a satisfação e preferências deles. }\end{array}$ \\
\hline Cadeias curtas e equilibradas & $\begin{array}{l}\text { Inserção em uma cadeia produtiva que apresenta índices de ser curta e } \\
\text { equilibrada, mas não controla de maneira efetiva seus fornecedores, e tem } \\
\text { uma relação apenas comercial com seus clientes. Logo, é preciso } \\
\text { amadurecer as relações entre clientes x empresa; empresa x fornecedores } \\
\text { que ultrapasse o aspecto confiança. }\end{array}$ \\
\hline Confiança e compromisso nas relações & $\begin{array}{l}\text { Existe relação de confiança entre seus fornecedores e clientes, porém não se } \\
\text { percebe a troca de informações efetivas entre eles. A empresa em pesquisa } \\
\text { está parcialmente orientada para o mercado. }\end{array}$ \\
\hline
\end{tabular}

Fonte: adaptado pelos autores de Grunert et al. (2005).

A viabilidade que a empresa tem em se adequar ao que o mercado está exigindo é levado de maneira séria e eficaz, o que mostra que a Alfa atende às exigências do mercado final. A relação entre confiança juntamente com seus fornecedores e clientes deve ser analisada de maneira que todos saiam ganhando. 0 objetivo deste estudo foi analisar os fatores que afetam a competitividade e a orientação para o mercado da empresa e por meio disso verificar se a empresa tem condições de melhorar a qualidade de seus produtos e ampliar a participação no mercado nacional de móveis, ampliando, assim, a oferta de produtos para o mercado internacional, mas, para isso, é necessário adaptar-se às condições e exigências mercadológicas da atualidade.

\section{CONSIDERAÇÕES FINAIS}

O trabalho de pesquisa analisou uma empresa do setor moveleiro do município de Coronel Freitas (SC), localizado no Oeste de Santa Catarina, buscando entender a sua orientação para o mercado e sua competitividade, tanto nacional quanto internacionalmente.

Os pontos positivos que a empresa executa em seu dia a dia estão voltados à formação por meio de cursos específicos do setor para seus colaboradores e funcionários, tomando decisões significativas para 0 crescimento cultural e comercial da sua empresa, o detalhado e elaborado plano de marketing, voltado, principalmente, às redes sociais da empresa, e a análise dos concorrentes e fornecedores.

Na visão da empresa estudada, percebe-se que os fatores determinantes e que interferem positiva e/ou negativamente à competitividade da empresa podem ser considerados: os cursos de formação continuada, treinamentos por meio de novas tecnologias para colaboradores e gestores, a utilização de ferramentas para a terceirização da venda, bem como a divulgação de seus produtos para o exterior. 
Sobre as respostas da entrevista semiestruturada, a questão era a identificação das consequências e as possíveis ações para melhorar a competitividade da empresa. Portanto, considerando os mercados que ela está inserida, a empresa precisa dar ênfase e se preocupar com o atendimento primordial a seus clientes, destacando a qualidade de seus produtos e criando um procedimento padrão para atender às exigências dos clientes, tanto no aspecto qualidade quanto nas possíveis alterações de layout dos produtos.

Consolidando as relações de seus fornecedores e clientes, é fundamental firmar laços de confiança e transparência, para que se possa garantir o comprometimento com a qualidade, preço e a logística desses produtos (matéria-prima, insumos e produtos finais), o que permitirá a integração da cadeia moveleira, facilitando processos de negociação, visando melhorar o desempenho. Além disso, mediante uma visão mais ampla, considerando as relações comerciais, bem como no sentido de ampliar as exportações, buscando garantir um mercado cativo para a produção da empresa e estabelecer como fundamental a capacitação dos funcionários e gestores por meio de cursos, estimulando-os à formação continuada.

0 impacto voltado às mudanças, buscando soluções para a redução de preços de produtos finais sem alterar a qualidade do produto oferecido, nesta perspectiva, a empresa se torna mais competitiva no contexto atual nas políticas econômicas nacionais

Aumentar o portfólio de produtos ofertados, garantindo assim fatia maior do mercado onde a empresa está inserida, estimulando a aproximação com seus concorrentes, permitindo a troca de ideias e possíveis soluções, sem interferir na produção, reduzindo a pressão competitiva sobre a empresa.

Desse modo, os resultados obtidos nesta pesquisa levam a crer que a Orientação para o Mercado é um construto estratégico responsável pela geração e disseminação da inteligência de mercado.

Os resultados apontam que a empresa estudada não está plenamente orientada para o mercado nacional e internacional, embora esteja consolidada no mercado e tenha tradição de sua marca baseada no aspecto confiança de seus clientes, possuindo um hall de fornecedores estabelecidos e que atendem satisfatoriamente às necessidades para a produção.

Conclui-se que a empresa tem condições de melhorar a qualidade de seus produtos com a ampliação da oferta destes para o mercado internacional, mas, para isso, é necessário adaptar-se às condições e exigências mercadológicas da atualidade.

Salienta-se que a pesquisa apresenta limitações, como o fato de se tratar de um estudo de caso, com a pesquisa sendo realizada em apenas uma empresa. Os resultados obtidos para a orientação para o mercado não podem ser extrapolados para outras empresas moveleiras da região, embora se saiba que existam semelhanças entre estas. Outra limitação diz respeito ao fato de ter- se trabalhado principalmente com as percepções dos sujeitos de pesquisa, o que confere certo grau de subjetividade à pesquisa, de forma que a abordagem a outros sujeitos poderia culminar em resultados diferentes dos encontrados neste estudo.

Para futuros estudos, sugere-se uma abordagem e sondagem às empresas que pertencem ao setor moveleiro da região Oeste catarinense, a fim de replicar o estudo aqui realizado e identificar as dificuldades e vantagens que elas enfrentam em toda a cadeia produtiva, de montante a jusante.

Atualmente, existem cerca de trezentas empresas associadas ao Siticom do setor moveleiro, assim, é possível realizar o estudo com empresas de diversos portes, analisando quais as reais necessidades e os principais aportes para que elas se tornem cada vez mais competitivas, e, principalmente, quais são as estratégias para a competitividade e orientação para o mercado destas. 


\section{REFERÊNCIAS}

[1] ABBADE, E. B.; ZANINI, R. R.; SOUZA, A. M. Orientação para Aprendizagem, Orientação para Mercado e Desempenho Organizacional: Evidências Empíricas. RAC, Rio de Janeiro, v. 16, n. 1, p. 118-136, jan./fev. 2012.

[2] ASSOCIAÇÃO BRASILEIRA DAS INDÚSTRIAS DO MOBILIÁRIO. Panorama do setor moveleiro no Brasil. Abimóvel, informações gerais. 2008-2009. Disponível em: <http://www.abimovel.br/>. Acesso em: 28 out. 2016.

[3] ANTONI, V. N. et al. Orientação para o mercado: influência sobre os processos de comunicação na Embrapa Trigo. Revista Gestão \& Tecnologia, Pedro Leopoldo, v. 13, n. 1, p. 78-102, jan./abr. 2013.

[4] BARDIN, L. Análise de conteúdo. Lisboa: Edições 70, 2006.

[5] BARNEY, J. B. Gaining and Sustaining Competitive Advantage, Reading - MA: Addison- Wesley Publishing Company, 1996.

[6] BELL, J. Projeto de pesquisa: guia para pesquisadores iniciantes em educação, saúde e ciências sociais. 4. ed. Porto Alegre: Artmed, 2008.

[7] BERTOLINI, A. V. A. G.; CISLAGHI, T. P.; FERNANDES, E. B. Negociações internacionais e a ética empresarial: percepções do setor exportador moveleiro da serra gaúcha. Revista Gestão e Planejamento, Salvador, v. 17, n. 2, p. 162-178, maio/ago. 2016.

[8] BORJA DE MOZOTA, B.; KLÖPSCH, C.; COSTA, F. C. X. da. Gestão de design: usando o design para construir valor de marca e inovação corporativa. Porto Alegre: Bookman, 2011.

[9] CARVALHO, D. M.; BARCELLOS, J. O. J. Orientação para o mercado no elo da produção de leite: como lidar com a assimetria de informação. Organizações Rurais \& Agroindustriais, v. 15, n. 2, p. 153-166, 2013.

[10] CARVALHO, G. D. G. et al. Radar da inovação como ferramenta para o alcance de vantagem competitiva para micro e pequenas empresas. Revista de Administração e Inovação, São Paulo, v. 12, n. 4, p. 162-186, out./dez. 2015.

[11] CURI, D. P. Orientação para o mercado: e relação entre a orientação para a tecnologia e o marketing relacional. 2007. 228 f. Tese (Doutorado em Engenharia) -Universidade de São Paulo, São Paulo, 2007.

[12] DAY, G. S. A Empresa orientada para o mercado: compreender, atrair e manter clientes valiosos. Porto Alegre: Bookman, 2001.

[13] DEPARTAMENTO DE PESQUISA E ESTUDOS ECONÔMICOS. Indústria de Móveis.Bradesco. 2017. Disponível em:<https://www.economiaemdia.com.br/EconomiaEmDia/pdf/infset_industria_de_moveis.pdf $>$. Acesso em: 01 maio 2017.

[14] DIACONU, L. Strategic options of the low-cost companies. The annals of the "Ştefan cel Mare". University Suceava. Fascicle of the Faculty of Economics and Public Administration, v. 9, n. 1, p. 81-87, 2009.

[15] ENGBLOM, J. et al. Multiple-method analysis of logistics costs. International Journal Production Economics, v. 137, p. 29-35, mai. 2012

[16] FERREIRA, R. Estratégias de orientação para o mercado em organização de serviço como forma de ganhar vantagem competitiva. 2006. 259 p. Tese (Doutorado em Engenharia de Produção) -Universidade Federal de Santa Catarina, Florianópolis, 2006.

[17] FONSECA, Y. D. Técnicas de Avaliação de Investimentos: Uma breve Revisão da Literatura, Caderno de Análise Regional - Desenbahia/UNIFACS Artigo 5, 2003.

[18] GARBE, E. A.; TOMASELLI, I. Fatores afetando a competitividade da indústria moveleira brasileira no mercado internacional e propostas para melhorias. In: ObservaSC. 2014.Disponível em: <http://observasc.net.br/home/index.php>. Acesso em: 08 fev. 2017.

[19] GAVA, R.; SILVEIRA, T. A Orientação para o Mercado sob a Ótica da Empresa e dos Clientes na Indústria Hoteleira Gaúcha. RAC - Revista de Administração Contemporânea, Rio de Janeiro, v. 11, n. 2, p. 49-69, abr./jun. 2007.

[20] GEBHARDT, G. E. et al. Creating a Market Orientation: A longitudinal multiform, grounded analysis of cultural transformation. Journal of Marketing, Chicago, v. 70, p. 37-55, oct. 2006.

[21] GIANEZINI, M. et al. Sustainability and Market Orientation in the Brazilian Beef Chain.Journal of Agricultural Science and Technology (USA. Print), v. 4, p. 249-260, 2014.

[22] GOOGLE MAPS. Dados cartográficos_2017. Disponível em: <http://www.brasil- turismo.com/santacatarina/mapas/sc-interativo.htm>. Acesso em: 11 jun. 2017.

[23] GONÇALVES FILHO, C.; VEIT, M. R.; MONTEIRO, P. R. R. Inovação, estratégia, orientação para o mercado e empreendedorismo: identificação de clusters de empresas e teste de modelo de predição do desempenho nos negócios. Revista de Administração e Inovação, São Paulo, v.10, n. 2, p. 81-101, abr./jun. 2013. 
[24] GRUNERT, K. G. et al. Market orientation at industry and value chain levels: concepts, determinants and consequences. Journal of Customer Behavior, v. 1, n. 2, p. 167-194, 2002.

[25] GRUNERT, K. G. et al. Market orientation of value chains: a conceptual framework based on four cases studies from the food industry. European Journal of Marketing, v. 39, n. 5/6, p. 428-455, 2005.

[26] HENDERSON, B. H. As origens da estratégia. In: MONTGOMERY, C. A.; PEPPERS, D.; ROGERS, M. Marketing Um a Um: Marketing Individualizado na Era do Cliente. Rio de Janeiro. Campus, 1998.

[27] HILL, C. W. L. International Business: Competing in the Global Marketplace. 2011.

[28] HÖFLER, C. E. et al. Mudança e Aprendizagem no Setor Moveleiro visando à preparação das Indústrias para exportação. 2014.

[29] IBGE. Perfil dos municípios brasileiros: histórico de Coronel Freitas. Rio de Janeiro: IBGE, 2014. Disponível em: <http://www.cidades.ibge.gov.br/painel/historico.php?codmun=420440>. Acesso em: 25 fev. 2017.

[30] JAWORSKI, B. J.; KOHLI, A. K. Market Orientation: the construct, research propositions, and managerial implications. Journal of Marketing, Chicago, v. 45, p. 1-18, apr. 1990.

[31] JAWORSKI, B. J.; KOHLI, A. K. Market orientation: antecedents and consequences. Journal of Marketing, v. 57, p. 53-70, July 1993.

[32] JAWORSKI, B. J. KOHLI, A. K. Orientação para o mercado: antecedentes e consequências.RAE, v. 46, abr./jun. 2006.

[33] KOTLER, P. Administração de Marketing: Análise, Planejamento, Implementação e Controle.5. ed. São Paulo: Atlas, 1998.

[34] KOHLI, A. K.; JAWORSKI, B. Market orientation: the construct, research propositions, and managerial implications. Journal of Marketing, v. 54, p. 1-18, 1990.

[35] KUAZAQUI, E. Marketing internacional. São Paulo: M. Books, 2006.

[36] LAMBIN, J. J.; CACERES, R. C. L'Orientation-marché est-elle une stratégie rentable pour l'entreprise? Recherché et Applications on Marketing, v. 21, n. 2, 2006.

[37] LUTZ, Daniel. Setor moveleiro deve acompanhar retomada gradual da economia em 2017, diz Abimóvel. Estadão, São Paulo: economia.estadao.com.br, $14 \quad$ mar. $2017 . \quad$ Disponível em:<http://economia.estadao.com.br/noticias/releases-ae,setor-moveleiro-deve-acompanhar- retomada-gradual-daeconomia-em-2017-diz-abimovel,70001698675>. Acesso em: 18 ago. 2017.

[38] MACERA, A. P.; URDAN, A. T. Orientação para o mercado externo: teste de um modelo no Brasil e sua aplicação a uma amostra de empresas exportadoras brasileiras. Revista de Administração Contemporânea, v. 8, n. 2, p. 95-115, 2004.

[39] MADRID-GUIJARRO, A.; GARCÍA-PÉREZ-DE-LEMA, D.; VAN AUKEN, H. AnInvestigation of Spanish SME Innovation during Different Economic Conditions. Journal of Small Business Management, v. 51, n. 4, p. 578-601, 2013.

[40] MORAES, G. de V.; ABBADE, E. B.; ANTONI, V. L. Orientações estratégicas e desempenho: evidências do setor varejista de ópticas. Revista de Administração e Inovação, São Paulo, v. 10, n. 3, p. 65-88, jul./set. 2013.

[41] MORGAN, R. A.; HUNT, S. D. The commitment trust theory of relationship marketing.Journal of Marketing, v. 58, n. 3, p. 20-38, 1994

[42] MOZZATO, A. R.; GRZYBOVSKI, D. Análise de Conteúdo como técnica de análise de dados qualitativos no Campo da Administração: Potencial e Desafios. RAC, Curitiba, v. 15, n. 4, p.731-747, jul./ago. 2011.

[43] NARVER, J.; SLATER, S. F. The effect of a marketing orientation on business profitability.

[44] Journal of Marketing, v. 54, n. 3, p. 20-35, 1990.

[45] OSLAND, G. E.; TAYLOR, C. R. E.; ZOU, S. Selecting international modes of entry and expansion. Marketing Intelligence e Planning, v. 19, n. 3, p. 153-161, 2001.

[46] PAIVA JÚNIOR, F. G.; LEÃO A. L. M. S.; MELLO, S. C. B. Validade e Confiabilidade na Pesquisa Qualitativa em Administração. Revista Ciência da Administração, v. 13, n. 31, p. 109-129, 2011.

[47] PASQUALOTO, C.; UGALDE, M. M. Adaptações de produto no processo de internacionalização de empresas gaúchas do setor moveleiro. Internext - Revista Eletrônica de Negócios Internacionais da ESPM, v. 5, n. 2, p. 46-65, jul./dez. 2010.

[48] PEREIRA, B. C. S. Implementação e mensuração da estratégia de orientação para o mercado. In: SEMEAD, 8., 2005, São Paulo. Anais do SemeAd, 2005.

[49] PIRES, T. 0 pinus e o setor florestal em Santa Catarina. 2013. 
[50] PORTER, M. E. A vantagem competitiva das nações. 15. ed. Rio de Janeiro: Elsevier, 1989.

[51] PORTER, M. E. Competição On Competition: Estratégias Competitivas Essenciais. 4. ed. Rio de Janeiro: Campus, 1999.

[52] PORTER, M. E.; MILLAR, Victor E. Como a informação proporciona Vantagem Competitiva. In: PORTER, M. E. Competição On Competition: Estratégias Competitivas Essenciais. Rio de Janeiro: Campus, 1999. cap. 3, p. 83-106.

[53] QUADROS, A. C. O design dos móveis de escritório na s médias e pequenas empresas do setor moveleiro da serra gaúcha - um estudo exploratório. 2002. 101 f. Dissertação (Mestrado em Administração) -Universidade Federal do Rio Grande do Sul, Porto Alegre, 2002.

[54] RAMPANAZZO, S. E.; CORREA, F. Z. M. Desmitificando a metodologia científica: guia prático de produção de trabalhos acadêmicos. Erechim, RS: Habilis, 2008.

[55] ROCHA, A. C. et al. Estratégias sustentáveis e desempenho exportador no setor moveleiro paranaense. R. Adm. FACES Journal, Belo Horizonte, v. 12, n. 3, p. 09-27, jul./set. 2013.

[56] ROCHA, T.; VELOSO, A. A hora da recompensa: Como obter sucesso através dos programas de fidelização. São Paulo: Marcos Cobra, 1999.

[57] RUVIARO, C. F. A rastreabilidade bovina: uma resposta à orientação para o mercado na Amazônia Legal. In: EVENTO CEPAN/UFRGS, 8., 2010, Porto Alegre. Anais..., 2010.

[58] SEBRAE. Fique por dentro dos estudos setoriais da indústria catarinense. Estudo Setorial da Indústria Catarinense: Móveis. 2016. Disponível em:<https://www.sebrae.com.br/sites/PortalSebrae/ufs/sc/noticias/fiquepor-dentro-dos-estudosAcesso em: 09 ago. 2017.

[59] SILVA, J. P. M.; BELTRAME, T. F.; SCHMIDT, A. S. A gestão do design como diferencial de qualidade nas indústrias moveleiras do Alto Uruguai Gaúcho. Rev. Adm. UFSM, Santa Maria, v. 7, n. 2, p. 296-314, jun. 2014.

[60] SILVEIRA, R. I. M. et al. Antecedentes da eficiência produtiva na manufatura: experiências do setor moveleiro brasileiro. Revista de Ciências da Administração, v. 15, n. 37, p. 154-169, dez. 2013.

[61] SOARES, M. do C.; PERIN, M. G.; SAMPAIO, C. H. Os motivos das relações entre orientação para mercado, orientação para aprendizagem e sucesso de novos produtos. RAIMED - Revista de Administração IMED, v. 6, n. 1, p. 3044, jan./abr. 2016.

[62] SOUZA, M. A.; WEBER E. L.; CAMPOS, R. H. Práticas de gestão de custos logísticos internos: estudo de caso em empresa moveleira do sul do Brasil - UFSC, Florianópolis, v. 12, n. 25, p. 27-46, jan./abr. 2015.

[63] SBRAGIA, R. et al. Inovação: como vencer este desafio empresarial. São Paulo: Clio, 2002.

[64] STALK JÚNIOR, G. Tempo: a próxima vantagem competitiva. In: MONTGOMERY, C. A.; PORTER, C. E. (Org.). Estratégia: a busca da vantagem competitiva. Rio de Janeiro: Campus, 1998. p. 43-65.

[65] TRIVIÑOS, A. N. S. Introdução à pesquisa em ciências sociais. São Paulo: Atlas, 1987. URDAN, A. T.; ROCHA, A. D. Orientação para o mercado: Origens, avanços e perspectivas.RAE, v. 46, n. 2, p. 55-60, abr./jun. 2006.

[66] URDAN, F. T. Medindo a orientação para o mercado: Empresas brasileiras versus empresas estrangeiras. FACEF Pesquisa, v. 7, n. 1, 2004.

[67] VERGARA, S. C. Projetos e relatórios de pesquisa em administração. 14. ed. São Paulo: Atlas, 2013.

[68] VIEIRA, V. Antecedents and consequences of market orientation: a Brazilian meta-analysis and an international mega-analysis. Brazilian Administration Review, Curitiba, v. 7, n. 1, p. 40-58, 2010.

[69] VITORINO FILHO, V. A.; PERESIN, G. L.; SACOMANO NETO, M. Vantagem competitiva:uma releitura teórica de Porter. In: CONVIBRA ADMINISTRAÇÃO - CONGRESSO VIRTUAL BRASILEIRO DE ADMINISTRAÇÃO, 9., 2011. Disponível em:<http://www.convibra.com.br/upload/paper/adm/adm_2472.pdf>. Acesso em: 29 mar. 2017.

[70] ZOCCHE, L. Fluxo de informações em uma Indústria Moveleira: um estudo de caso. 2011. Trabalho de Conclusão de Curso (Graduação em Engenharia da Produção) -Universidade Tecnológica Federal do Paraná, Medianeira, 2011.

[71] WINCK, C. A.; MACHADO, J. A. D. Avicultura brasileira: perspectivas para o mercado consumidor chinês. RACE: Revista de Administração, Contabilidade e Economia, Joaçaba: Ed. Unoesc, v. 10, n. 2, p. 241-268, 2011.

[72] YIN, R. K. Estudo de caso: planejamento e métodos. 4. ed. Porto Alegre: Bookman, 2010. 


\title{
Capítulo 12
}

\section{Gestão do saneamento rural no Povoado Mirolândia,} Picos-PI

\author{
Wesley Fernandes Araújo \\ Jaíra Maria Alcobaça Gomes \\ José Natanael Fontenele de Carvalho
}

Resumo: 0 acesso universal ao saneamento básico em áreas rurais do Brasil ainda é um grande desafio a ser alcançado, muitas vezes devido à inviabilidade econômica para concessionárias estaduais ou municipais. Em alguns casos, políticas e programas atuam na implantação de sistemas que garantam às comunidades pelo menos o abastecimento com água tratada, coleta de esgoto e/ou de dejetos humanos. Entretanto, em longo prazo, é comum a existência de dificuldades entre gestores comunitários, no sentido de manterem os sistemas implantados em funcionamento, tendo em vista a falta de experiência e conhecimento gerencial. Por essa razão, modelos de gestão multicomunitários estão em desenvolvimento no País desde os anos 1990, e surgem como uma solução viável econômica e socialmente para que se garanta a continuidade na prestação dos serviços básicos nesses locais. No Piauí, esse paradigma é gerenciado pelo Sistema Integrado de Saneamento Rural do Piauí (SISAR-PI), operando desde 2005 em suas primeiras comunidades. Nessa perspectiva, esta investigação pretende verificar a existência de sustentabilidade econômica do SISAR-PI, bem como de condições de adimplência dos usuários e de manutenção referente às instalações de saneamento no Povoado Mirolândia, em Picos. Os dados mais atualizados de forma agregada desse sistema estão disponíveis em sítio eletrônico após serem apresentados em 2018 pelo Gerente Executivo do SISAR-PI, durante um evento da área. Desse modo, o período de análise vai de 2005 a 2017. Já os indicadores da comunidade analisada foram solicitados e obtidos na sede administrativa deste SISAR, e referem-se ao período de 2016 a 2019. Os resultados indicam uma situação de estabilidade financeira considerada sustentável para a garantia de sua manutenção em longo prazo, com a inadimplência ficando em vários anos inferior a 5\% (considerado ideal). Em Mirolândia, além de bons índices na arrecadação, os dados mostram que a população local também vem contribuindo efetivamente para a manutenção das instalações.

Palavras-chave: Gestão multicomunitária. Alternativa sustentável. Viabilidade econômica. Serviços de saneamento. Desenvolvimento rural. 


\section{INTRODUÇÃO}

O acesso ao saneamento básico é um direito garantido a todos os cidadãos brasileiros, previsto na Constituição Federal e em leis e decretos, a exemplo da Lei no $11.445 / 2007$, que estabelece as diretrizes nacionais para o saneamento básico (BRASIL, 2007), e da Lei no 12.305/2010, que institui a Política Nacional de Resíduos Sólidos (PNRS) no Brasil (BRASIL, 2010), constituindo instrumentos inescusáveis para o alcance de acesso universal ao saneamento básico.

Entretanto, Cunha e Borja (2018) destacam que no Brasil, a universalização do acesso ao saneamento ainda está longe de ser alcançada, mesmo que esse serviço seja reconhecido como um direito humano essencial. Ao lançar-se o olhar para o meio rural no Brasil, observa-se uma realidade que está aquém do desejado, em relação à garantia de acesso aos habitantes dessas áreas a serviços de saneamento, justificada por aspectos como: desinteresse político; vazios demográficos; inviabilidade de investimentos por parte de empresas especializadas; e até mesmo a incapacidade de gerir sistemas instalados.

Define-se saneamento como o conjunto de medidas que buscam preservar ou modificar as condições do meio ambiente, com o intuito de prevenção de doenças e promoção da saúde; melhoria da qualidade de vida da população; produtividade do indivíduo; além de promoção da atividade econômica (INSTITUTO TRATA BRASIL - ITB, 2020).

Não obstante, concebe-se ainda uma grande disparidade entre as áreas urbanas e rurais, como se constata a partir de dados do Instituto Brasileiro de Geografia e Estatística (IBGE), por meio do Sistema IBGE de Recuperação Automática (SIDRA), onde se observa uma comparação entre essas áreas, no tocante aos tipos de esgotamento sanitário e de abastecimento de água.

No Brasil, os dados mais recentes sobre a área rural são de 2015, e mostram que apenas $35 \%$ dos domicílios recebiam água por meio da rede geral de distribuição, enquanto 53,9\% era proveniente de poços ou nascentes. Referente ao tipo de esgotamento sanitário, a fossa rudimentar contava com a maior representatividade, $43,5 \%$; a fossa séptica estava em $32,6 \%$ das residências; a vala era usada em $4 \%$ dos casos; a rede coletora, em 5,3\%; e os lançamentos nos corpos de água representou 3,1\%. Os domicílios sem qualquer meio de coleta de esgoto chegaram a $11 \%$. Todavia, é preciso recordar que o Brasil tem dimensões territoriais de grandes proporções e quando se vislumbram essas variáveis por região, notamse algumas diferenças, mesmo se comparadas apenas a áreas rurais (IBGE, 2017b).

Os números apontam que a população atendida pelo serviço de abastecimento de água da rede geral na Região Nordeste era de 42,8\%, em 2015, enquanto nas demais regiões estava distribuído da seguinte maneira: Sul - 36,7\%; Norte - 23,7\%; Sudeste - 27,4\%; e Centro-Oeste - 13,7\%. No que alude aos tipos de esgotamento sanitário, analisando a situação da falta de qualquer meio de coleta e tratamento dado ao esgoto, o Norte e o Nordeste, principalmente, apresentavam os piores índices $(11,8 \%$ e 17,8\%, respectivamente). Nas demais regiões, os indicadores eram bem menores, sendo 1,5\% no Centro-Oeste; $2,4 \%$ no Sudeste; e 1,1\% no Sul (IBGE, 2017b).

Entretanto, para chegar a soluções que melhorem a realidade desses espaços territoriais, diversas dificuldades são verificadas, a começar pelo entendimento do que possa ou não ser considerado rural, já que buscar uma definição para o que seja zona urbana ou rural no Brasil é algo que muitas vezes se torna cheio de controvérsias, dificultando a formulação de políticas públicas, o que pode gerar limitações, inadequações e fracassos nas ações tomadas. Logo, considerar o tamanho de determinada população para distinguir tais áreas não é algo tão simples (RESENDE; FERREIRA; FERNANDES, 2018).

Grande parte dos órgãos estatísticos nacionais costumam adotar basicamente dois critérios como suporte para as classificações de áreas urbanas e rurais. Um deles é o da divisão baseada em critérios legais ou político-administrativos, como no caso brasileiro, em que os perímetros urbanos (e os rurais, por exclusão) são delimitados por decisão legislativa dos municípios (IBGE, 2017a), já que a demarcação do perímetro urbano fica a cargo da administração municipal. Mas apesar disso, não existe um critério unificado, proposto pela União, para determinar o limite existente entre duas áreas. Geralmente, empregam-se critérios voltados para a cobrança de impostos, como o Imposto Predial e Territorial Urbano (IPTU), que por questões de conveniência, passam a ser o parâmetro delimitador, enquanto o Imposto Territorial Rural (ITR) está definido para imóveis fora das zonas urbanas, o que torna a compreensão acerca do que seja rural como aquela área que não é definida por lei municipal como urbana (RESENDE; FERREIRA; FERNANDES, 2018). 
Diante desse ponto de vista, torna-se imperioso o desenvolvimento e a execução de modelos sustentáveis, capazes de proporcionar aos espaços rurais esses tipos de serviços, por meio de soluções alternativas que incitem a diminuição dos custos existentes, ao lado de ações com viabilidade econômica e técnica, além de envolvimento comunitário, mediante controle social.

Por essas e outras razões, o acesso aos serviços de saneamento em áreas rurais ainda está longe de uma garantia de forma universalizada, nomeadamente quando se trata das Regiões Norte e Nordeste. Nesta, mais especificamente no estado do Piauí, em 2001, lançou-se o Programa de Saúde e Saneamento Básico na Área Rural do Piauí (PROSAR-PI), responsável por garantir o acesso a serviços básicos de saneamento em áreas rurais do estado. 0 programa, resultante de uma cooperação financeira oficial entre Brasil e Alemanha, consolidada entre o Ministério da Saúde, a Secretaria de Estado da Saúde do Piauí (SESAPI) e o banco alemão Kreditanstalt für Wiederaufbau (KfW) - responsável por financiar a execução da implantação, ampliação ou melhoria de Sistemas de Abastecimento de Água (SAA), Sistemas de Esgotamento Sanitário (SES) e/ou Módulos Sanitários Domiciliares (MSD) nas comunidades beneficiadas (BRASIL, 2011).

O susodito programa surgiu com o objetivo de contribuir para a melhoria das condições de saúde e saneamento na área rural do Piauí, com enfoque na região do semiárido e, especificamente, no atendimento à população, com água potável e esgotamento sanitário; na garantia do funcionamento dos sistemas dentro de um modelo sustentável; e na melhoria dos hábitos de higiene e de saúde preventiva da população (BRASIL, 2011).

Para que seus objetivos fossem alcançados, o PROSAR-PI adotou uma estratégia de desenvolvimento comunitário que incentivava a participação ativa dos grupos beneficiados, das Prefeituras Municipais e do associativismo local, almejando garantir a sustentabilidade e a autogestão dos sistemas de abastecimento de água e esgotamento sanitário. Durante a fase de implementação dos projetos, realizavam-se ações de Educação Sanitária e Ambiental (ESA) junto às populações beneficiadas, e para assegurar a operação e manutenção da infraestrutura dentro do modelo sustentável, criou-se um sistema de administração autônomo e participativo, denominado Sistema Integrado de Saneamento Rural do Piauí (SISAR-PI) (BRASIL, 2011).

Dentre as ações sociais, salienta-se que a população beneficiada recebia capacitações sobre higiene pessoal, e os moradores eram orientados a seguir normas de conservação dos sistemas de água e esgoto implantados, o que se tornava mais um fator para assegurar a continuidade das ações nas comunidades. Na prática, isso significava que a comunidade beneficiada passava a gerir todo o sistema instalado, sem qualquer interferência das dinâmicas políticas locais (BRASIL, 2011).

Encerrado no ano de 2016, o PROSAR-PI apresentou duas fases que ficaram conhecidas como PROSARPI/PIAUÍ-I e PIAUÍ-II. A diferença entre elas consistia na forma como se realizavam os financiamentos, já que na primeira fase, os investimentos empreendidos pelo banco alemão ocorreram por meio de um empréstimo com condições especiais, cujo fluxo de recurso era realizado via governo federal, recorrendo ao Ministério da Saúde; a segunda fase referia-se a uma doação ao Programa Fome Zero, transferida diretamente para o Estado do Piauí, mais precisamente para ser investida nos territórios do Vale do Rio Sambito, Guaribas e Canindé, tendo como exigência contratual a realização de auditorias anuais nas contas do Programa, realizadas diretamente pela Controladoria Geral do Estado do Piauí (CGE-PI) (MACS; FICHTNER, 2016).

Dentre os municípios com comunidades beneficiadas pelo PROSAR-PI, destaca-se Picos, onde se localiza a comunidade conhecida como Povoado Mirolândia, uma das beneficiadas pelo PROSAR-PI em sua segunda fase, sendo uma das pioneiras a entrar em operação pelo SISAR-PI. Além disso, é a localidade que apresenta a maior quantidade de residências e, por conseguinte, a que teve um maior número de pessoas atendidas pelo programa nesse município (BEZERRA, 2018).

Sobreleva-se o fato de que a cidade picoense em epígrafe conta com a maior densidade populacional dentre todas beneficiadas pelo PROSAR-PI, com 137,30 hab./ $\mathrm{km}^{2}$, e nela está localizada a sede administrativa do SISAR-PI (IBGE, 2020). 
Considerando que o PROSAR-PI está concluído, valida-se a necessidade de envidar uma investigação para examinar se após a entrega das obras e realização das ações sociais, existem garantias de continuidade na prestação de serviços de saneamento de áreas rurais do Piauí, beneficiadas pelo referido programa.

Deveras, pretende-se analisar, por meio de indicadores financeiros, se a gestão do SISAR-PI apresenta condições de perpetuar-se no tempo e, com isso, salvaguardar a população beneficiada, no sentido de não perder os direitos que foram garantidos. Ao mesmo tempo, reputa-se o mérito de uma avaliação acerca da situação comportamental e de inadimplência das comunidades administradas pelo SISAR, a fim de desvelar se há a conservação por parte da população quanto aos sistemas implantados

Diante dessas considerações, este trabalho tem como escopo verificar a existência de sustentabilidade econômica do SISAR no Piauí entre os anos de 2005 e 2017, bem como de condições de adimplência dos usuários e manutenção referente às instalações de saneamento no Povoado Mirolândia, em Picos. Especificamente, tenciona-se: analisar os indicadores financeiros do SISAR-PI de faturamento e arrecadação; averiguar a presença de garantias econômicas e de conservação que assegurem a durabilidade dos sistemas implantados na supracitada comunidade.

\section{REFERENCIAL TEÓRICO}

\subsection{MODELOS DE GESTÃO EM SANEAMENTO RURAL NO BRASIL}

A realização de investimentos em saneamento rural passa por fatores de grande complexidade. Enquanto nas zonas urbanas, é mais comum que as companhias públicas e privadas ou o próprio governo municipal se tornem responsáveis pelo abastecimento de água e pelas redes de esgoto, as zonas rurais, na maioria dos casos, são deixadas de lado, ficando a população sem acesso a esses serviços básicos. Quando há programas de desenvolvimento rural que realizam investimentos em sistemas de saneamento, ocasionalmente fica a cargo da própria comunidade gerir o que foi implementado. Sem embargo, em longo prazo, torna-se comum a dificuldade na gestão e manutenção o sistema em funcionamento, o que se pode explicar pela ausência de um profissional técnico com experiência na área, carência de recursos técnicos e financeiros, ou até mesmo falta de cuidado por parte da população local (GARRIDO et al., 2016; MARINHO; SANTOS, 2011).

Há, porém, exemplos que podem denotar alternativas institucionais, sociais, técnicas e financeiras sustentáveis, capazes de dar continuidade aos serviços prestados em áreas rurais (MELEG, 2012; SALLES; LIMA, 2016; SILVA; TALEIRES; SILVA, 2019). De acordo com Draibe (2001), quando determinado programa estimula ou cria meios para que seja dada continuidade, ampliação ou multiplicação da experiência, tem-se aí um indicador de efeitos dentro do conceito de efetividade - no que se refere à sustentabilidade do que foi executado em suas ações.

A Bahia e o Ceará são reputados como pioneiros no modelo de gestão de sistemas de saneamento rural, por meio da Central de Associação Comunitária de Manutenção dos Sistemas de Água (CENTRAL-Bahia) e do Sistema Integrado de Saneamento Rural do Ceará (SISAR-CE), instalados em 1995 e 1996, respectivamente. No Piauí, há também um SISAR-PI sediado na cidade de Picos, desde 2004. No ano de 2007, houve a criação dos Serviços de Saneamento Integrado no Norte e Nordeste de Minas Gerais (COPANOR), sendo esta uma subsidiária da Companhia de Saneamento de Minas Gerais (COPASA-MG). Em 2016, inaugurou-se o Sistema Integrado de Saneamento Rural de Alagoas (SISAL) (GARRIDO et al., 2016).

Algumas características em comum podem são observadas entre os modelos de Alagoas, da Bahia, do Ceará e do Piauí. Primeiramente, para que alguma comunidade seja inserida, é preciso atender a algumas pré-condições, a saber: disponibilidade de água subterrânea em quantidade e qualidade; disponibilidade de energia elétrica; características geográficas, políticas e sociais locais; número mínimo de residências; premissa de cobrança de tarifas mensais de seus usuários, que devem estar predispostos a tal conduta; adequação das práticas e do sistema local ao padrão técnico do sistema; existência de um sistema de instalações elétricas adequadas; existência de uma associação comunitária de usuários funcionando adequadamente; e pagamento da taxa de filiação (MELEG, 2012). 
No geral, atendendo a essas particularidades, a localidade fica apta a receber as canalizações para abastecimento de água, um hidrômetro e redes de esgoto e/ou banheiros com fossas. Após receberem os investimentos em saneamento, por intermédio de programas e projetos com recursos para essa finalidade, financiados por órgãos como o governo federal, o Banco Mundial, o banco alemão KfW ou a Fundação Nacional de Saúde (FUNASA), por exemplo, as comunidades, por meio das suas associações, passam a ser filiadas aos seus respectivos sistemas integrados (BROWN; PENA, 2016; GARRIDO et al., 2016; MELEG, 2012; ROCHA, 2013).

Além da organização comunitária, é imprescindível para o pleno funcionamento dos sistemas a seleção de operadores locais, escolhidos pela própria comunidade (MACHADO et al., 2019b), os quais recebem treinamentos para a realização de pequenos reparos, leituras de hidrômetros, entrega das faturas e relato de problemas maiores, que por sua vez, são solucionados por técnicos especializados dos sistemas integrados/central (BROWN; PENA, 2016; GARRIDO et al., 2016). Esses operadores trabalham apenas por um período específico, e geralmente complementam a renda com outras atividades produtivas (ROCHA; SALVETTI, 2017).

No entendimento de Sachs (2007), há cinco dimensões para o conceito de desenvolvimento sustentável, quais sejam: ecológica, social, econômica, espacial e cultural. Especificamente sobre a dimensão espacial, o autor aduz que se dirige para a busca de um equilíbrio na configuração urbano-rural, além de se propor a distribuir da melhor maneira os assentamentos humanos e as atividades econômicas, para que seja possível explorar o potencial existente em áreas rurais e criar oportunidades de emprego não-agrícola nesses locais. Então, além de contribuir para o acesso ao saneamento básico em áreas rurais, esse modelo de gestão mostra-se importante na criação de emprego e renda para moradores que vivem nesses territórios.

Atinente às responsabilidades, devem as Associações Comunitárias gerir e operar os sistemas de água e esgoto instalados; realizar o tratamento da água; além de pequenos consertos, bem como fortalecer o associativismo. Já à Central e aos SISAR's cabe a gestão compartilhada com a associação local; manutenção e controle da qualidade da água; capacitação de operadores e dirigentes. Já os usuários devem pagar regularmente a tarifa cobrada; conservar os sistemas implantados; inibir ligações clandestinas; e fortalecer das associações locais (GARRIDO et al., 2016; MACHADO et al., 2019b; SILVA; TALEIRES; SILVA, 2019).

Institucionalmente, os SISAR's do Piauí e Ceará têm organização semelhantes, ambas constituindo federações que agrupam um conjunto de associações comunitárias filiadas que assumem o papel de cuidar dos serviços de saneamento. Juridicamente, são associações civis de direito privado, não governamental, cuja estrutura se assenta na Assembleia Geral, com seu cotidiano dirigido pelo Conselho de Administração e fiscalizado pelo Conselho Fiscal (BROWN, 2015; ITB, 2018; ROCHA, 2013; SILVA; TALEIRES; SILVA, 2019).

Para a manutenção e durabilidade dos sistemas implantados, além da conservação por parte da população local, cobra-se uma tarifa mensal dos usuários (BROWN, 2015). No Ceará (onde existem oito SISAR's), a taxa é formada por um custo local (operador local; energia; e taxa da associação) e um do SISAR-CE (pessoal; materiais e produtos químicos; instalações da sede; contabilidade; publicações; viagens; e reuniões). A definição anual das tarifas ocorre em assembleia. Os valores pagos ao operador, assim como a taxa de administração, são fixos e acordados com a comunidade, enquanto a energia é rateada conforme o consumo. Já o valor pago ao SISAR-CE é tabelado de acordo com o consumo, não havendo valor mínimo. Da composição da conta a ser paga, apenas o valor referente ao consumo de água fica retido com o SISAR$\mathrm{CE}$, sendo o restante repassado para a associação, que paga ao operador e à concessionária de energia (ITB, 2018; ROCHA, 2013).

No Piauí, constitui-se a tarifa pelos custos com operador, energia, consumo de água, esgoto (fossas), taxa de administração e taxa de permanência. O valor referente ao custo da água é do SISAR-PI, que cobre custos semelhantes aos do SISAR-CE. Para as associações, repassam-se os valores da taxa de administração, do operador e da energia, cujo pagamento é de responsabilidade da própria associação. Cabe ao SISAR-PI a definição quanto às tarifas de água e esgoto, a partir de estudos técnicos, realizados em cooperação com as associações comunitárias que dele participam, devendo obter aprovação do Conselho Administrativo ou mesmo em Assembleia Geral do próprio SISAR (ITB, 2018). 
As contribuições do operador e a taxa administrativa da associação comunitária são definidas pela própria associação, em Assembleia Geral, cujos resultados deverão ser comunicados por ata ao SISAR-PI. A taxa de permanência corresponde à consumação mínima de água, que até 2019 representava $2 \mathrm{~m}^{3}$, e a partir de 2020, passou a ser de $5 \mathrm{~m}^{3}$. Acima desse consumo, o valor cobrado pela água atende a uma tabela progressiva, por meio da qual se cobra o consumo dentro de cada intervalo (ITB, 2018; ROCHA, 2013).

Os trabalhos encontrados na literatura, quando não focam nos modelos de gestão em saneamento rural, de modo geral (GARRIDO et al., 2016; MELEG, 2012), buscam reportar e discutir os resultados dos SISAR's localizados no Ceará, o que demonstra ser o caso mais pesquisado entre os estudiosos (ALVES; ARAÚJO, 2015; ROCHA; SALVETTI, 2017; SALLES; LIMA, 2016; SILVA; TALEIRES; SILVA, 2019).

O Banco Mundial, por exemplo, realizou um estudo com informações referentes aos anos de 2010, 2013 e 2014, alusivo aos modelos de gestão multicomunitários (quando várias associações se unem para manter o sistema operante) e unicomunitários (com apenas uma associação). Os casos de gestão multicomunitários estudados foram: CENTRAL-BA, SISAR-CE, COPANOR-MG, SISAR-PI e CONISA-RN. 0 indicador de controle da inadimplência dá-se pelos seguintes critérios: eficiente $(<5,0 \%)$; mediano $(<15,0 \%)$; e precário (>15,0\%). Em relação à suficiência de caixa, ou seja, à relação receita/custo, adotaram-se os seguintes parâmetros: elevada $(>1,5)$; suficiente $(>1,1)$; e não há suficiência $(<1,0)$ (GARRIDO et al., 2016).

Os dados de 2014 indicaram que a inadimplência esteve dentro de um grau de eficiência $(<5 \%)$ em três casos, com exceção do CONISA-RN (10,1\%) e COPANOR-MG (6,7\%). 0 valor acima de 10\% já foi considerado como uma situação preocupante de descontrole, principalmente tendo em vista que se espera que esse modelo seja capaz de se autossustentar a partir do que se arrecadar em suas comunidades associadas. Por sua vez, a relação receita/custo nesse ano foi superior a 1 nos SISAR-CE e PI, COPANORMG e CONISA-RN, e de 0,94 no caso da CENTRAL-BA (GARRIDO et al., 2016).

O SISAR-CE apresentou o menor índice de inadimplência em 2014 (GARRIDO et al., 2016). Trata-se de um claro exemplo de garantia sustentável de continuidade e ampliação do modelo implantado, contando atualmente com oito unidades SISAR's em funcionamento. Talvez esse aspecto e o fato de beneficiar 35\% da população rural daquele estado (CEARÁ, 2020) explique a ocorrência de muito mais pesquisas que avaliam os casos de gestão em saneamento rural no Ceará.

De acordo com Rocha e Salvetti (2017), em estudo de caso dos Sistemas Integrados cearenses, há sustentabilidade operacional após 15 anos de funcionamento no SISAR-CE/BAC (Sobral-CE). Antes disso, entretanto, o referido SISAR recebia, além de subsídios para investimentos, recursos da Companhia de Água e Esgoto do Ceará (CAGECE) para cobrir custos operacionais. Utilizaram-se tais fundos para pagar parte da equipe técnica e veículos. Os subsídios operacionais existentes foram gradualmente eliminados ao longo desses 15 anos, e em 2016, observou-se um superávit operacional de 9,6\%.

Para a criação dos SISAR's nesse estado, o supracitado autor apontou como essencial a organização da comunidade local por meio de suas associações, sendo necessário um intenso processo participativo, já que todas as famílias devem concordar antes de se filiarem ao SISAR-CE.

O fato de o SISAR Sobral ser o único a não necessitar de auxílio financeiro externo foi igualmente referenciado por Salles e Lima (2016). No entanto, esse SISAR foi o primeiro a ser constituído, e os sete demais, somente a partir de 2001. Outros dados descritos por esses autores indicaram uma elevação significativa do número de localidades, de pessoas beneficiadas e ligações instaladas de água entre 2001 e 2014. De modo geral, apontam como positivo o acesso à rede de abastecimento de água nas regiões rurais do Ceará. No estudo, notou-se que os índices gerais de acesso à água por rede geral com canalização interna na zona rural, no Ceará, foram ampliados a partir dos anos 2000, fato que coincide com a ampliação dos SISAR's naquele estado. Por oportuno, valida-se, de acordo com informações atuais do site institucional do SISAR-CE, que três de suas unidades já são completamente autossustentáveis (SISAR-CE, 2020).

Silva, Taleires e Silva (2019) identificaram no Ceará, mais especificamente no Distrito de Peixe (RussasCE), mudanças positivas quanto ao acesso à água tratada, repercutindo melhorias nas condições de vida da população local. Os benefícios observados, por eixo, foram: educação (educação sanitária junto à população do meio rural; educação em saúde ambiental); saúde (estímulo a hábitos de higiene; cuidados no armazenamento da água; diminuição dos possíveis riscos de ocorrência de enfermidades de veiculação hídrica; diminuição da incidência de doenças e internações hospitalares); econômico (geração de emprego e renda, por meio da prestação de serviços para a execução de obras; redução de custo com internações; valorização imobiliária); socioambiental (bem-estar da população; permanência das famílias no meio 
rural; preservação e sustentabilidade do meio ambiente). Nos últimos eixos, por exemplo, encontram-se evidências sobre como alcançar a sustentabilidade espacial proposta por Sachs (2007), porquanto houve criação de emprego e renda da população local e, consequentemente, impediu-se o êxodo rural, podendo contribuir para a redução da concentração em excesso em áreas metropolitanas.

Alves e Araújo (2015) notaram em seu estudo, realizado no Distrito rural de Cristais (Cascavel-CE), que o SISAR foi uma solução viável, com a participação comunitária em etapas como planejamento, implantação e gestão, e com o aumento na área coberta pelos sistemas de abastecimento de água, além de melhoria da qualidade desta. Contudo, perceberam que fatores culturais por parte da população podem constituir impedimentos, tanto ao pleno sucesso (continuidade sustentável) daquilo que foi implementado, quanto à garantia de melhorias na saúde dessas pessoas, que continuam utilizando tecnologias obsoletas de acesso à água, mantendo-se em condições de vulnerabilidade hídrica.

Aleixo et al. (2019) realizaram uma pesquisa onde avaliaram as condições de acesso à água e as desigualdades relacionadas antes e depois da construção de um SAA em uma comunidade rural, também do Ceará. Para tanto, promoveram um estudo quase-experimental para avaliar as condições de acesso à água para os grupos de estudo (Comunidade Cristais) e controle (Complexo Itapeim). Além do abastecimento com água, parte da população foi beneficiada com MSD. Os resultados indicaram uma melhoria para os beneficiários, já que foi garantida água de boa qualidade e em abundância. O SAA possibilitou aumentar o volume per capita de água consumida pelas famílias e reduzir as desigualdades associadas a esse aspecto. No entanto, assim como em Alves e Araújo (2015), captou-se a persistência de práticas de coleta de água em locais onde ela é contaminada, o que exige o fortalecimento das ações sociais de educação sanitária e ambiental.

O que se infere é que após a instalação dos sistemas de abastecimento de água e esgoto (ou banheiros) nas comunidades, elas passam a fazer parte de um modelo de gestão responsável por garantir a continuidade do que foi implementado, então a população rural desses locais já não sofre mais com problemas de sucateamento das instalações, além de elas mesmas contribuírem, por meio da garantia da operação local e participação nas tomadas de decisões. Quanto mais os usuários são adimplentes com o pagamento das tarifas, maiores são as chances de garantir essa continuidade de forma autossustentável, sem que tenha que depender de contribuições externas. Outrossim, os benefícios obtidos estão em vários eixos, sobretudo na saúde, educação, economia e renda, social e ambiental.

\section{PROCEDIMENTOS METODOLÓGICOS}

\subsection{DELIMITAÇÃO DA ÁREA DE ESTUDO}

Neste trabalho, analisam-se dados financeiros do SISAR-PI desde o ano 2005 (quando houve os primeiros faturamentos com as primeiras comunidades beneficiadas) até 2017. De forma local, sublinha-se o caso do Povoado Mirolândia, em Picos, cuja avaliação revela, além de informações econômicas de 20016 a 2019, dados relativos ao comportamento de sua população com os sistemas instalados.

\subsection{1. ÁREA DE ATUAÇÃO DO SISAR-PI}

O SISAR-PI gerencia 51 comunidades em 27 municípios (BEZERRA, 2018), como se observa no Mapa 1. Ademais, estão localizados a um raio de distância de até $200 \mathrm{~km}$ de sua sede administrativa, em Picos. 
Mapa 1 - Municípios com comunidades administradas pelo SISAR-PI

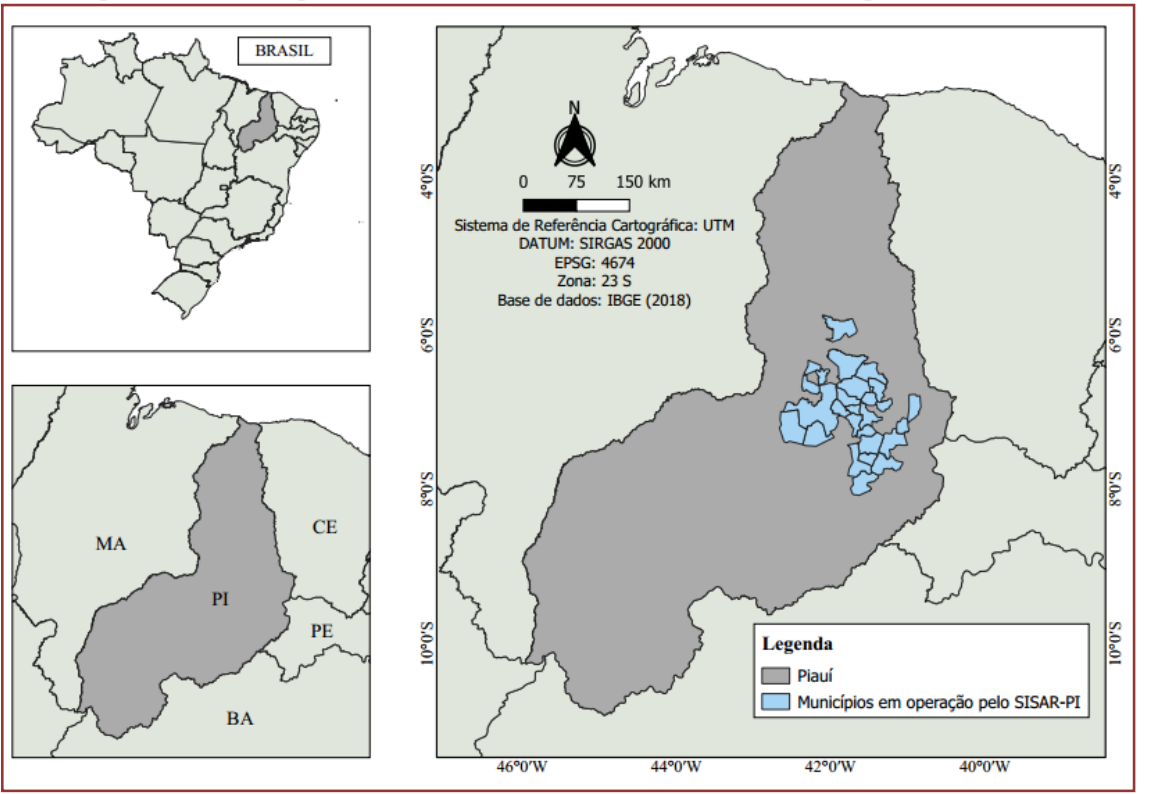

Fontes: elaborado pelos autores (2020), com base em Bezerra (2018); Malha Municipal - IBGE (2018).

A relação de municípios e respectivas comunidades ou sedes municipais que integram o SISAR-PI está disposta no Quadro 1. Destaca-se que a maioria desses locais teve beneficiamento em função de ações do PROSAR-PI (PIAUÍ I e II). No entanto, em alguns casos, houve parceria entre comunidade, prefeitura local (por meio de lei que autoriza a prestação de serviços e cobranças de tarifas) e o próprio SISAR-PI, por meio de convênios, a maioria firmados com recursos do Banco KfW, sendo eles: Km 80 em Campo Grande do Piauí; Chapada do Fio e Loteamento Deputado Sá Urtiga, em Picos; Salinas, em São Francisco do Piauí; Barras e Serra do Maracujá, em São João da Canabrava. Além desses, em Inhuma, as comunidades Baixa dos Potes, Baixa dos Porfírios e Curral Velho tiveram sua inserção efetivada a partir de um projeto realizado em parceria com uma empresa do ramo de bebidas.

Quadro 1 - Municípios e respectivas comunidades administradas pelo SISAR-PI

\begin{tabular}{|c|c|}
\hline Município & 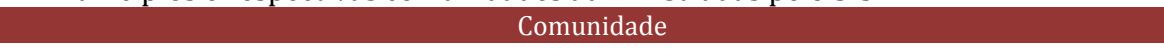 \\
\hline Alagoinha do Piauí & Serra Velha I \\
\hline Barra D'Alcantara & Sede Municipal \\
\hline Campo Grande do Piauí & Km 80; Novo Horizonte \\
\hline Colônia do Piauí & Marrecas; Mourões \\
\hline Conceição do Canindé & Santo Antônio \\
\hline Francinópolis & Malhada Vermelha \\
\hline Inhuma & Baixa dos Potes; Baixa dos Porfírios; Curral Velho; Jabuti; Roque \\
\hline Ipiranga & São José dos Cocos \\
\hline Isaías Coelho & São Domingos \\
\hline Isaías Coelho & Vila Barbosa/Trapiá \\
\hline Patos do Piauí & Cajueiro \\
\hline Picos & Chapada do Fio; Coroatá; Curralinho; Loteamento Dep. Sá Urtiga; Mirolândia; Torrões; Três Potes \\
\hline São Francisco do Piauí & Salinas \\
\hline São João da Canabrava & Barras; Conceição; Estevão; Serra do Maracujá \\
\hline São João da Varjota & São Miguel \\
\hline São José do Piauí & Baixio; Caldeirão do Luis \\
\hline Santa Cruz dos Milagres & Sede Municipal \\
\hline Tanque do Piauí & Bom Princípio \\
\hline Valença do Piauí & Aparecida; Barrinha; Morada Nova; Nova Esperança; Taboquinha \\
\hline Vera Mendes & Sede Municipal \\
\hline
\end{tabular}




\subsubsection{POVOADO MIROLÂNDIA}

Na zona rural de Picos localiza-se o Povoado Mirolândia (Mapa 2), a 7 km da zona urbana do município. Pelo PROSAR-PI/PIAUÍ-II, beneficiaram-se 431 residências, tornando-a a comunidade picoense com maior número de domicílios atendidos. Outrossim, representa cerca de $5 \%$ do que é faturado e arrecadado pelo SISAR-PI, considerando todas as associações comunitárias agregadas que o integram.

Em 2009, a localidade manteve-se entre as primeiras comunidades selecionadas no lote inicial do PROSAR-PI/PIAUÍ-II para receber as obras de saneamento. Em 2010, executou-se o processo licitatório, por meio da modalidade Carta-convite, visando à elaboração do projeto executivo, cumprido pela empresa vencedora no mês de setembro desse mesmo ano, mas somente concluído em julho de 2011, e adotado como termo de referência de nova licitação para a realização das obras. Finalmente, em 2012, o processo ocorreu, na modalidade Tomada de preços, e em novembro, assinou-se o contrato com a empresa vencedora.

Vale salientar que em 2011, a comunidade já estava preparada para receber as obras, quando se concluíram os trabalhos de sensibilização, mobilização e organização social, a fim de que a população estivesse apta a utilizar as instalações de forma adequada e, ao mesmo tempo, assumisse a gestão dos sistemas implantados (SAA's e MSD's), juntamente com o SISAR-PI, que começou a operar na comunidade em dezembro de 2015, com a cobrança da tarifa a partir de fevereiro de 2016.

A pesquisa no local justifica-se, além de sua representatividade junto ao SISAR-PI, pelo tempo decorrido em operação, e ainda do período decorrido até que a população estivesse preparada para receber os sistemas implantados e conservá-los.

Mapa 2 - Localização do Povoado Mirolândia e da sede administrativa do SISAR-PI

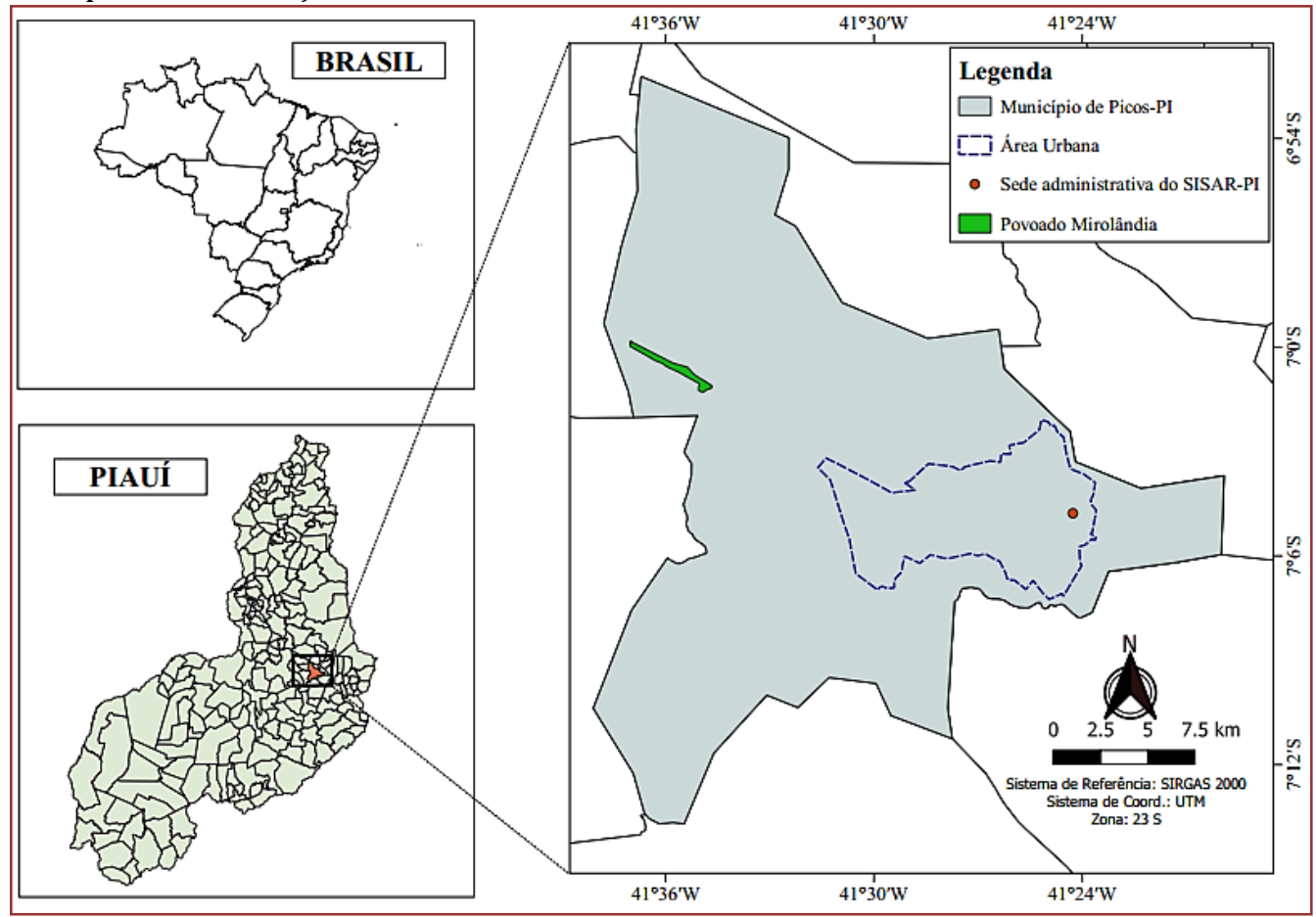

Fonte: elaborado pelos autores (2020), com base em Malha Municipal - IBGE (2019).

\subsection{FONTE DE INFORMAÇÕES E TÉCNICAS DE ANÁLISE}

Obtiveram-se os dados do SISAR-PI, considerando todas as comunidades administradas por ele, a partir de uma apresentação realizada pelo seu atual Gerente Executivo, durante o IX Seminário de Gestão dos SISAR's e Centrais, em maio de 2018, na cidade de Quixadá, no Ceará, e as informações cobrem os anos de 2005 a 2017 (BEZERRA, 2018).

Nesse evento anual, os indicadores financeiros e sociais dos modelos de gestão multicomunitários costumam ser apresentados por um de seus representantes, tornando as informaç̧ões públicas. São considerados para o SISAR-PI os dados agregados de faturamento (isto é, referentes à soma de todas as 
tarifas mensais emitidas para os consumidores, alusivas aos serviços prestados em determinado período) e arrecadação (no sentido de recebimentos, ou seja, no que diz respeito à receita no mesmo período), e com base neles, calcula-se o índice de inadimplência anual, a partir da seguinte equação:

$$
100-\left[\left(\frac{\text { Arrecadação Total }}{\text { Faturamento Total }}\right) \times 100\right]
$$

Já os indicadores do Povoado Mirolândia, coletados por meio de visita de campo à sede administrativa do SISAR-PI, no mês de fevereiro de 2020, referem-se aos anos de 2016 a 2019, correspondente ao período em que a comunidade se encontrava em operação. Além disso, o Gerente Executivo, ao ser entrevistado, forneceu outras informações relevantes. Dos resultados, além do cálculo do índice acima, são analisados indicadores de abastecimento de água, bem como informações desagregadas dos serviços prestados na comunidade e que indicam as condições de uso das instalações por parte da população, e ainda, referentes ao consumo de energia necessária para acesso à água.

\section{RESULTADOS E DISCUSSÃO}

Esta seção compõe-se por duas partes: a primeira refere-se à análise dos indicadores econômicos do SISAR-PI, de forma agregada; a segunda diz respeito ao Povoado Mirolândia, em Picos.

\subsection{DADOS ECONÔMICOS DO SISAR-PI}

O Gráfico 1 ilustra a evolução do faturamento e da arrecadação do SISAR-PI entre os anos de 2005 e 2017. Em 2005, somente quatro comunidades rurais eram administradas pelo referido órgão, e o faturamento total foi de $\mathrm{R} \$ 1.146,90$ enquanto se arrecadou apenas $\mathrm{R} \$ 227,00$ nesses locais, o que significou um índice de adimplência de 19,79\% (calculado a partir da razão arrecadação/faturamento).

Gráfico 1 - Faturamento e arrecadação do SISAR-PI entre 2005 e 2017

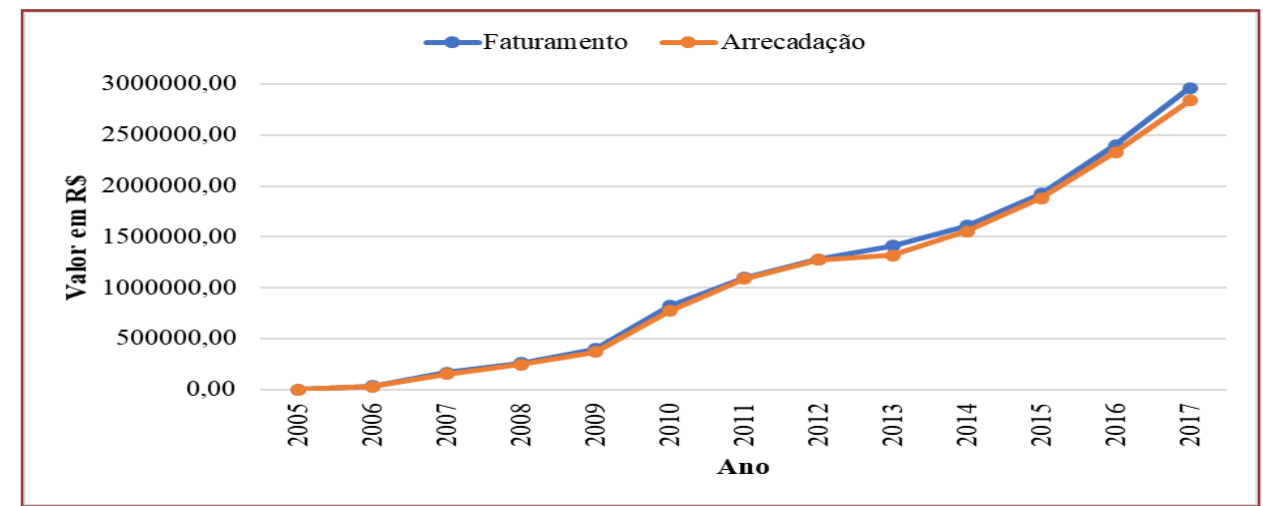

Fonte: Bezerra (2018).

Em 2006, operando em dez comunidades, assistiu-se a uma evolução. Com faturamento de R\$33.801,71 e arrecadação de R\$28.178,71, chegou-se a um índice de adimplência de 83,36\%. Em 2008, esse índice chegou pela primeira vez acima dos 90\%, com faturamento de $R$ \$ 261.289,70 e arrecadação de $R \$$ 247.521,00 em 19 localidades rurais, levando a adimplência ao patamar de 94,73\%. A partir de então, os índices referentes à adimplência permaneceram com variação entre 92\% e 99,6\%, sendo 2011 e 2012 os melhores anos, como se verifica no Gráfico 2, quando a inadimplência atingiu os menores patamares $(0,95 \%$ e $0,42 \%$, respectivamente). Em 2017, quando o SISAR-PI já se fazia presente em 50 comunidades, o faturamento foi de $\mathrm{R} \$ 2.963 .701,3$, e o total arrecadado, $\mathrm{R} \$ 2.838 .797,57$, fazendo com que o índice de adimplência chegasse a 95,79\%.

De acordo com Garrido et al. (2016), um índice de inadimplência superior a 10\% em um modelo de gestão multicomunitário de saneamento em áreas rurais já representa um risco de descontrole e, portanto, deve ser reduzido. 0 ideal, segundo os susoditos autores, é que esse índice seja inferior a 5\% para que haja a 
garantia de continuidade dos sistemas implantados apenas com a participação do que for faturado e arrecadado em todas as comunidades, e assim, cubram-se os custos existentes, conforme descrito pelo ITB (2018).

Para uma visualização mais acurada, o Gráfico 2 mostra a evolução do índice de inadimplência no SISAR-PI para os anos ora indagados.

Gráfico 2 - Índice de inadimplência do SISAR-PI entre 2005 e 2017

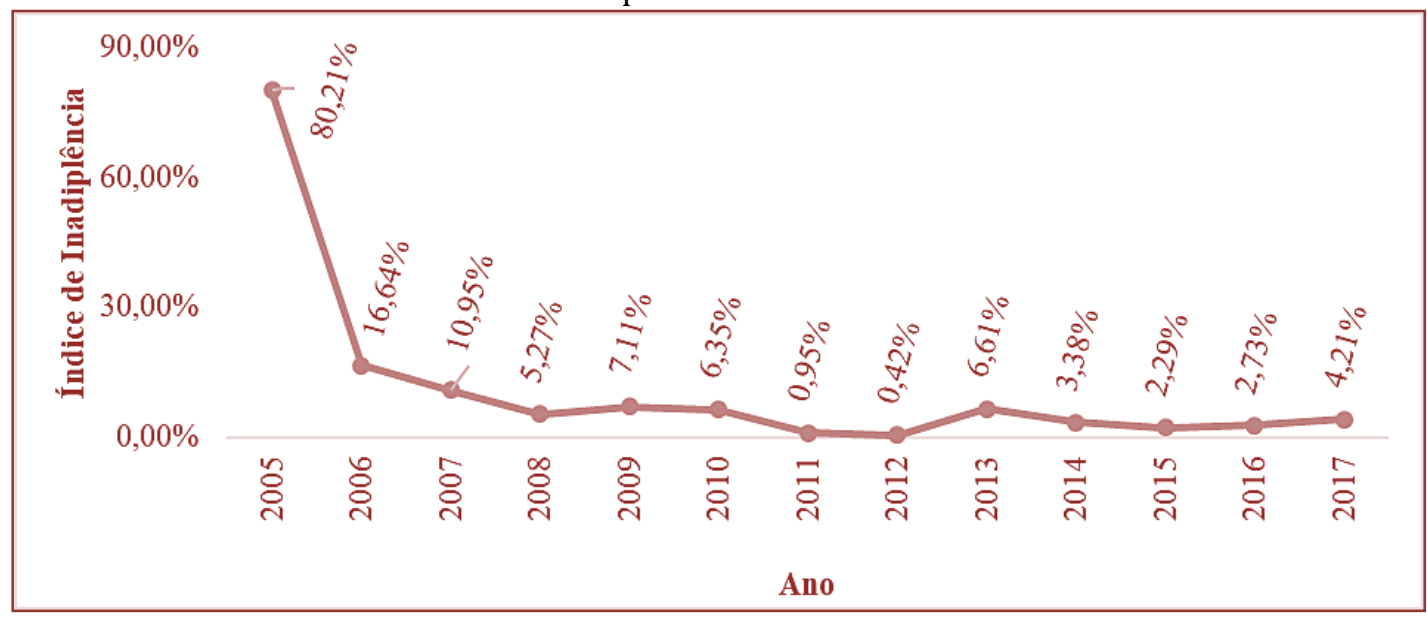

Fonte: Bezerra (2018).

Pela visualização do Gráfico 2, nota-se que a partir de 2008, a inadimplência já se encontrava próximo do ideal proposto por Garrido et al. (2016). Após leves aumentos em 2009 e 2010, o índice teve redução para menos de 1\% em 2011 e 2012, voltando a elevar-se em 2013. A partir de 2014, assimila-se que ele fica variando abaixo dos $5 \%$.

É possível inferir, então, que o SISAR-PI já não necessita mais de outras fontes de receita para cobrir os custos existentes. Por cúmulo, apenas com as comunidades, encontra-se em uma situação de garantia de continuidade, de forma sustentável e com ampliação do sistema, conforme assinala Draibe (2001).

Dessa forma, economicamente falando, o modelo de gestão em saneamento em áreas rurais, como o SISAR-PI, mostra-se capaz de manter os serviços prestados às populações, não os deixando desamparados.

\subsection{INDICADORES DO POVOADO MIROLÂNDIA}

A partir desse momento, enfatiza-se a situação específica do Povoado Mirolândia. A Tabela 1 revela a evolução do faturamento e da arrecadação pelo SISAR-PI nessa comunidade, de 2016 a 2019, por serem períodos com dados consolidados. Nos anos 2016 e 2017, o faturamento da comunidade representou, respectivamente, $5,57 \%$ e $5,35 \%$ do faturamento total do SISAR-PI, enquanto a arrecadação local respondeu por 5,12\% e 5,33\% do total arrecadado no interstício. Nos demais anos, não foi possível obter tais dados, já que não se alcançaram os dados gerais do SISAR-PI para 2018 e 2019 (BEZERRA, 2018).

Tabela 1 - Faturamento e arrecadação do SISAR-PI no Povoado Mirolândia, entre 2016 e 2019

\begin{tabular}{|c|c|c|c|}
\hline Ano & Faturamento $(\mathrm{R} \$)$ & Arrecadação (R\$) & Percentual de arrecadação \\
\hline 2016 & $133.741,29$ & $119.486,17$ & $89,34 \%$ \\
\hline 2017 & $158.444,20$ & $151.256,75$ & $95,46 \%$ \\
\hline 2018 & $190.959,52$ & $188.240,34$ & $98,58 \%$ \\
\hline 2019 & $195.749,46$ & $187.056,67$ & $95,56 \%$ \\
\hline \multicolumn{3}{c|}{ Fonte: SISAR-PI (2020). }
\end{tabular}

O Gráfico 3, por sua vez, demonstra a evolução do índice inadimplência de Mirolândia para os anos em análise, com base nos dados da Tabela 3. Percebe-se que apenas em 2016, esse índice ficou acima de 10\%, e nos demais anos, manteve-se em situação ideal - menos de 5\% -, conforme definição de Garrido et al. (2016). 
Gráfico 3 - Taxa de inadimplência nas tarifas do Povoado Mirolândia, pagas ao SISAR-PI, entre 2016 e 2019

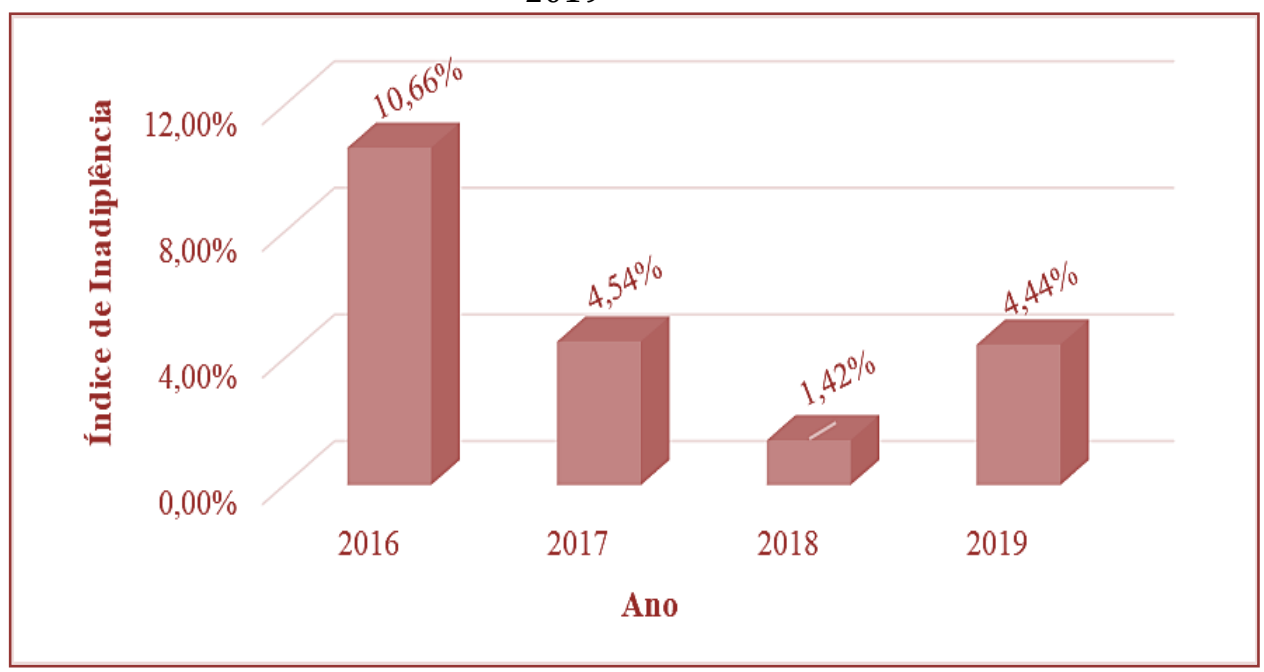

Fonte: SISAR-PI (2020).

Outro indicador relevante diz respeito ao abastecimento de água para que a população seja atendida com esse serviço, mantendo frequência regular e, com isso, cumpra-se um dos objetivos do PROSAR-PI. Com base nisso, a Tabela 2 identifica os casos de interrupção no abastecimento no local, ocasionados por defeitos na bomba responsável por retirar a água do poço.

Apenas uma vez, em 2016, e outra em 2018, por causa de panes elétricas, os moradores ficaram sem acesso a esse serviço, representando o maior período no primeiro ano, quando tiveram de permanecer 21 dias desabastecidos.

Tabela 2 - Interrupções no abastecimento de água no Povoado Mirolândia, entre 2016 e 2019

\begin{tabular}{|c|c|c|c|}
\multirow{2}{*}{ Ano } & \multicolumn{3}{c}{ Causa } \\
\cline { 2 - 4 } 2016 & 1 & 0 & $\begin{array}{c}21 \\
\text { dias }\end{array}$ \\
\hline 2017 & 0 & 0 & - \\
\hline 2018 & 1 & 0 & 5 dias \\
\hline 2019 & 0 & 0 & - \\
\hline \multicolumn{4}{|c}{ Fonte: SISAR-PI $(2020)}$. \\
\hline
\end{tabular}

De acordo com o atual Gerente Executivo do SISAR-PI, uma possível razão para a ocorrência de panes elétricas deve-se ao fato de a bomba esquentar muito, tendo em vista a profundidade elevada do poço (640 metros, com a bomba ficando a 378 metros), que se encontra nessa comunidade, já que lá só foi possível obter água subterrânea nessas condições.

Além disso, assimila-se um impacto direto no consumo de energia, necessário para a retirada da água subterrânea para o reservatório que abastece a comunidade. Como se pode deduzir pela Tabela 3, o valor da energia para cada $\mathrm{m}^{3}$ de água consumido tem-se elevado a cada ano.

Tabela 3 - Reflexo do valor da energia para cada $\mathrm{m}^{3}$ de água no Povoado Mirolândia (2016 a 2019)

\begin{tabular}{|l|c|c|c|c|}
\hline \multicolumn{1}{|c}{ Relação do consumo de água e energia } & 2016 & 2017 & 2018 & 2019 \\
\hline Consumo total de energia (R\$) & 59218,23 & 75336,32 & 109742.96 & 102793,03 \\
\hline Consumo total de água (m ${ }^{3}$ ) & 48300 & 51707 & 50800 & 49807 \\
\hline Reflexo do valor consumido em energia $/ \mathrm{m}^{3}$ & 1,23 & 1,46 & 2,16 & 2,06 \\
\hline
\end{tabular}

Fonte: SISAR-PI (2020) 
Do mesmo modo, na Tabela 4, capta-se que o valor da energia representa a maior parte do que é cobrado nas tarifas dos habitantes de Mirolândia. Entre 2016 e 2019, houve elevação de 18,59\% na representatividade da energia no total faturado, saltando de 44,28\% para 52,21\% no último ano. Mas conforme informações obtidas com o Gerente Executivo desse SISAR, um projeto de instalação de placas solares para reduzir os custos com energia para distribuição da água está em andamento, e deverá contribuir para um desempenho local melhor, reduzindo os custos com energia elétrica. Percebe-se observando que em 2019 (Tabela 3), já houve uma leve redução valor da energia para cada $\mathrm{m}^{3}$ consumido, o que começou a ocorrer a partir de setembro do referido ano, quando o reflexo da energia na tarifa reduziu de valores superiores a $\mathrm{R} \$ 2,00 / \mathrm{m}^{3}$ para menos de $\mathrm{R} \$ 1,90 / \mathrm{m}^{3}$ (SISAR-PI, 2020).

Apesar da importância da sustentabilidade dos indicadores econômicos e técnicos, como o de abastecimento de água, para que haja garantia para uma comunidade se manter em operação pelo SISARPI, a população local também precisa fazer a sua parte. Como destacado anteriormente, antes de receber as instalações, desenvolvem-se trabalhos sociais com os habitantes para que eles possam, além de manter hábitos adequados de higiene, cuidar das instalações de forma apropriada, e evitar que elas sejam danificadas, como mencionado por Brown (2015); Garrido et al. (2016); ITB (2018); Silva, Taleires e Silva (2019).

Por meio das tarifas cobradas aos moradores de cada comunidade beneficiada, é possível ter uma noção se a população local está realmente cumprindo a condição do parágrafo anterior, ou seja, de conservação das instalações.

Como ressaído pelo ITB (2018), ao receber a cobrança em sua residência, garante-se que o morador pagará pelos seguintes serviços: água; esgoto/fossa (que serve como uma "pequena poupança" e que serve para a realização de limpeza nas fossas no período estabelecido); taxa de permanência; energia; operador (definido em assembleia comunitária); e taxa administrativa. Os demais serviços, designados na Tabela 4, só comporão a taxa que deverá ser paga ao SISAR-PI se houver alguma razão para isso, como multa por atraso ou danificações nas instalações.

A partir da Tabela 4, assimila-se que apenas em 2016 e 2019, foi necessária a cobrança em virtude de existência de danificações no hidrômetro, manutenção do kit cavalete, quebra ou retirada de hidrômetro e violação do lacre. Destes, apenas a violação do lacre foi igualmente faturada em 2019, enquanto os demais serviços representaram $0 \%$ do que foi cobrado dos moradores locais neste e nos demais anos.

Tabela 4 - Representatividade das tarifas desagregadas do Povoado Mirolândia, faturadas pelo SISAR-PI de 2016 a 2019 (em \%)

\begin{tabular}{|l|c|c|c|c|}
\hline \multicolumn{1}{|c|}{ Tarifas de serviços } & 2016 & 2017 & 2018 & 2019 \\
\hline Água & 26,76 & 26,36 & 20,17 & 21,38 \\
\hline Danificação do hidrômetro & 0,22 & 0,00 & 0,00 & 0,00 \\
\hline Esgoto / fossa & 2,58 & 2,29 & 1,89 & 2,03 \\
\hline Ligação clandestina ou derivação de canalização & 0,00 & 0,00 & 0,00 & 0,00 \\
\hline Manutenção do kit cavalete & 0,15 & 0,00 & 0,00 & 0,00 \\
\hline Quebra ou retirada de hidrômetro & 0,22 & 0,00 & 0,00 & 0,00 \\
\hline Taxa de atraso & 0,65 & 1,15 & 1,30 & 1,26 \\
\hline Taxa de corte & 0,17 & 0,24 & 0,38 & 0,19 \\
\hline Taxa de permanência & 5,19 & 4,71 & 3,96 & 7,46 \\
\hline Violação do lacre & 0,67 & 0,00 & 0,00 & 0,31 \\
\hline Energia & 44,28 & 47,55 & 57,47 & 52,51 \\
\hline Operador & 8,65 & 7,84 & 6,48 & 6,45 \\
\hline Taxa administrativa & 8,65 & 7,84 & 6,48 & 6,34 \\
\hline
\end{tabular}

Nesse sentido, percebe-se que a população local tem cuidado bem das instalações, o que contribui para a redução de custos que poderiam surgir se fossem necessárias manutenções com grande frequência. Isso mostra, mais uma vez, que se criaram meios para garantir a manutenção e, por conseguinte, a continuidade de forma sustentável, de acordo com o conceito de efetividade de Draibe (2001). 


\section{CONSIDERAÇÕES FINAIS}

Tendo em vista os desafios existentes para a realização de investimentos em saneamento básico em áreas rurais e/ou isoladas no Brasil, ou para gerir os sistemas implementados nesses territórios, o modelo de gestão multicomunitário de saneamento rural emerge como uma alternativa viável e sustentável para garantir a continuidade na prestação de serviços ao longo do tempo, principalmente de abastecimento de água, coleta esgoto e/ou destinação de dejetos humanos.

Alguns casos no País já estão consolidados, a exemplo dos modelos em funcionamento na Bahia, no Ceará, no Piauí, no Rio Grande do Norte e em Minas Gerais. Na maioria deles, vislumbram-se indicadores que revelam a sustentabilidade de sua gestão, sendo criadas as condições para garantir a continuidade e ampliação da experiência, seja por adicionarem novas comunidades, seja pela replicação de novas unidades de modelos multicomunitários nos demais territórios dos estados, como no caso do Ceará, que já possui oito SISAR's distribuídos em suas diversas regiões.

No Piauí, especificamente, o SISAR-PI está operando em comunidades rurais do estado desde 2005, e a análise dos indicadores financeiros de faturamento e arrecadação demonstrou que a partir de seu quarto ano administrando as localidades junto com as associações, já foi possível depreender uma situação de estabilidade financeira considerada sustentável para a garantia de continuidade em longo prazo. No entanto, mesmo com toda a relevância que se deve dar aos aspectos econômicos, é essencial que a população beneficiada com os serviços de saneamento esteja apta a manter de forma adequada as instalações dos sistemas.

Dentre as comunidades administradas pelo SISAR-PI, analisou-se o caso específico do Povoado Mirolândia, localizado em Picos, e que está em operação desde dezembro de 2015, com faturamento e arrecadação desde fevereiro de 2016. Nele, nota-se que a partir do segundo ano, indicadores financeiros denotam um controle da inadimplência local, ou seja, garantias econômicas para manter a comunidade em operação. Além da questão econômica, são raros os momentos em que ocorrem interrupções no abastecimento de água, além de que os moradores apresentam boa conduta no que se refere à conservação dos sistemas instalados, o que significa a eliminação de custos desnecessários para manutenções se situação contrária ocorresse com frequência.

Com base nos dados obtidos, o único ponto crítico, até então, alude ao elevado consumo de energia elétrica necessário para bombear água para o reservatório que abastece as residências. A implantação de painéis de energia fotovoltaica é uma possível solução para esse cenário, reduzindo o valor pago na tarifa pelos moradores da comunidade.

\section{AGRADECIMENTOS}

Os autores agradecem à Coordenação de Aperfeiçoamento de Pessoal de Nível Superior (Capes) pelo apoio financeiro e à gerência executiva do SISAR-PI pelos dados fornecidos.

\section{REFERÊNCIAS}

[1] ALEIXO, B. et al. Infrastructure is a necessary but insufficient condition to eliminate inequalities in access to water: research of a rural community intervention in Northeast Brazil. Science of The Total Environment, v. 652, p. 1445-1455, 2019. ISSN: 0048-9697. DOI: https://doi.org/10.1016/j.scitotenv.2018.10.202. Disponível em: https://www.sciencedirect.com/science/article/pii/S0048969718340932. Acesso em: 17 mar. 2020.

[2] ALVES, F. G. C.; ARAÚJO, F. T. V. Sistemas de abastecimento em comunidades rurais do semiárido: a implantação do SISAR em Cristais, Cascavel, CE. Revista Tecnologia, v. 37, n. 1/2, p. 78-86, 2016. DOI: http://dx.doi.org/10.5020/23180730.2016.V37.1/2.78-86.

https://periodicos.unifor.br/tec/article/view/5695. Acesso em: 17 mar. 2020.

Disponível

em:

[3] BEZERRA, J. M. SISAR-PI: avanços e conquistas. In: IX SEMINÁRIO NACIONAL; IV ENCONTRO LATINOAMERICANO DE SANEAMENTO RURAL; IX SEMINÁRIO DE GESTÃO DOS SISAR’S E CENTRAIS. Quixadá, CE, 23-25 mai. 2018.

[4] BRASIL. Casa Civil. Lei no 11.445, de 5 de janeiro de 2007. Estabelece as diretrizes nacionais para o saneamento básico, cria o Comitê Interministerial de Saneamento Básico. Disponível em: http://www.planalto.gov.br/ccivil_03/_ato2007-2010/2007/lei/l11445.htm. Acesso em: 4 mar. 2020.

[5] BRASIL. Lei no 12.305/2010. Institui a Política Nacional de Resíduos Sólidos; altera a Lei no 9.605, de 12 de fevereiro de 1998; e dá outras providências. 2010. Disponível em: http://www.planalto.gov.br/ccivil_03/_ato20072010/2010/lei/l12305.htm. Acesso em: 15 fev. 2020. 
[6] BRASIL. [Constituição (1988)]. Constituição da República Federativa do Brasil de 1988. Brasília, DF: Presidência da República. Disponível em: http://www.planalto.gov.br/ccivil_03/constituicao/constituicaocompilado.htm. Acesso em: 15 fev. 2020.

[7] BRASIL. Ministério das Cidades. Secretaria Nacional de Saneamento Ambiental. Panorama do Saneamento Básico no Brasil. Avaliação político-institucional do setor de saneamento básico, v. 4. Brasília-DF, 537p. 2011. Disponível https://bibliotecadigital.seplan.planejamento.gov.br/bitstream/handle/iditem/271/PANORAMA_Vol_4.pdf?sequence =4. Acesso em: 30 nov. 2020 .

[8] BROWN, C. Um Sistema Comunitário da Gestão da Água: Abordagem Sociotécnica da Inovação. Cadernos de Trabalho da Rede Waterlat-Gobacit. Série Projetos de Pesquisa - Democratization of Water and Sanitation Governance by Means of Socio-Technical Innovation. The Integrated Rural Sanitation System (SISAR) in Brazil (In Portuguese) v. 2, n. 6, p. 79-162. 2015. Disponível em: https://zenodo.org/record/56087\#.XnEp-6hKj_A. Acesso em: 17 mar. 2020.

[9] BROWN, C. A.; PENA, J. L. Water meters and monthly bills meet rural Brazilian communities: sociological perspectives on technical objects for water management. World Development, v. 84, p. 149-161, 2016. DOI: https://doi.org/10.1016/j.worlddev.2016.03.014. Disponível

em: https://www.sciencedirect.com/science/article/abs/pii/S0305750X15300127. Acesso em: 17 mar. 2020.

[10] CEARÁ. Portal do Governo. Sistema Integrado de Saneamento Rural beneficia 35\% da população rural do Ceará. 2020. Disponível em: https://www.ceara.gov.br/2020/01/29/sistema-integrado-de-saneamento-ruraltransforma-realidade-do-sertao/. Acesso em: 25 mar. 2020.

[11] CUNHA, M. A.; BORJA, P. C. O programa de aceleração do crescimento no estado da Bahia e os desafios da universalização do saneamento básico. Revista Brasileira de Gestão Urbana, Curitiba, PR, v. 10, 2018. Supl.1. ISSN 2175-3369. DOI: https://doi.org/10.1590/2175-3369.010.supl1.ao09. Disponível em: http://www.scielo.br/scielo.php?pid=S2175-33692018000400173\&script=sci_arttext\&tlng=pt. Acesso em: 17 mar. 2020.

[12] DRAIBE, S. M. Avaliação de implementação: esboço de uma metodologia de trabalho em políticas públicas. In: BARREIRA, M. C. R. N.; CARVALHO, M. C. B. (org.). Tendências e Perspectivas na avaliação de políticas e programas sociais. São Paulo: IEE/PUC-SP, 2001.

[13] GARRIDO, J. M. et. al. Estudo de modelos de gestão de serviços de abastecimento de água no meio rural no Brasil, v. 1. (Portuguese) Washington, D.C.: World Bank Group, 2016. Disponível em: https://www.worldbank.org/pt/country/brazil/brief/brazil-publications-agua-brasil-series-water. Acesso em: 17 mar. 2020 .

[14] IBGE. Instituto Brasileiro de Geografia e Estatística. Indicadores de Desenvolvimento Sustentável. Brasil. 2015. Disponível em: http://www.ibge.gov.br/home/geociencias/recursosnaturais/ids/default_2015.shtm. Acesso em: 10 jan. 2019

[15] IBGE. Instituto Brasileiro de Geografia e Estatística. Classificação e caracterização dos espaços rurais e urbanos do Brasil: uma primeira aproximação. Rio de Janeiro: IBGE, 2017a. 84p. Disponível em: https://www.ibge.gov.br/apps/rural_urbano/. Acesso em: 17 mar. 2020.

[16] IBGE. Instituto Brasileiro de Geografia e Estatística. Sistema IBGE de recuperação automática. Indicadores de desenvolvimento sustentável. 2017b. Disponível em: https://sidra.ibge.gov.br/pesquisa/ids/tabelas. Acesso em: 17 jan. 2020.

[17] IBGE. Instituto Brasileiro de Geografia e Estatística. Pesquisa Nacional por Amostra de Domicílios Contínua. 2018. Disponível em: https://loja.ibge.gov.br/pnad-continua-caracteristicas-gerais-dos-domicilios-e-dos-moradores2018.html. Acesso em: 9 jan. 2020.

[18] IBGE. Instituto Brasileiro de Geografia e Estatística. Cidades. Panorama de Picos-PI. 2020. Disponível em: https://cidades.ibge.gov.br/brasil/pi/picos/panorama. Acesso em: 28 fev. 2020.

[19] ITB. Instituto Trata Brasil. Acesso à água nas regiões Norte e Nordeste do Brasil: desafios e perspectivas. São Paulo, SP, 2018. Disponível em: http://tratabrasil.org.br/estudos/estudos-itb/itb/acesso-a-agua-nas-regioes-norte-enordeste-do-brasil-desafios-e-perspectivas. Acesso em: 10 fev. 2020.

[20] ITB. Instituto Trata Brasil. 0 que é saneamento? 2020. Disponível em: http://www.tratabrasil.org.br/saneamento/o-que-e-saneamento. Acesso em: 18 fev. 2020.

[21] MACS, E. \& W.; FICHTNER, W. \& T. Serviços de consultoria para a execução dos Programas de Saúde e Saneamento Básico Piauí I e II. Relatório Final. dez. 2016.

[22] MARINHO, L. S; SANTOS, C. A. G. Diagnóstico do setor de abastecimento de água em áreas rurais no Estado da Paraíba. Revista Econômica do Nordeste, v. 42, n. 4, p. 861-872, 2011. Disponível em: https://ren.emnuvens.com.br/ren/article/view/169. Acesso em: 25 ago. 2020. 
[23] MELEG, A. SISAR: a sustainable management model for small rural decentralized water and wastewater systems in developing countries. Journal of water, sanitation and hygiene for development, v. 2, n. 4, p. 291-300, 2012. ISSN 2043-9083. Disponível em: https://iwaponline.com/washdev/article-abstract/2/4/291/29811. Acesso em: 17 mar. 2020.

[24] RESENDE, R. G.; FERREIRA, S.; FERNANDES, L. F. R. O saneamento rural no contexto brasileiro. Revista Agrogeoambiental, Pouso Alegre, v. 10, n. 1, p. 129-150, 2018. ISSN 2316-1817. Disponível em: https://agrogeoambiental.ifsuldeminas.edu.br/index.php/Agrogeoambiental/article/view/1027. Acesso em: 17 mar. 2020.

[25] ROCHA, W. S. Estudo de caso do modelo de gestão de água potável e saneamento rural denominado "Sistema Integrado de Saneamento Rural" (SISAR) no Brasil. Banco Interamericano de Desenvolvimento, 2013.

[26] ROCHA, W. S.; SALVETTI, M. Case Study SISAR Ceara, Brazil. World Bank Group. 2017. Disponível em: http://publications.iadb.org/ publications/portuguese/document/Estudo-de-caso-do-sistema-integrado-desaneamento-rural-(SISAR)-no-Brasil.pdf. Acesso em: 17 mar. 2020.

[27] SACHS, I. Rumo a ecossocioeconomia: teoria e prática do desenvolvimento. São Paulo, SP: Cortez, 2007.

[28] SALLES, P. V.; LIMA, S. C. R. B. Caracterização do atendimento por redes de abastecimento de água em áreas rurais do Ceará: evidências do impacto da implantação do Sistema Integrado de Saneamento Rural (SISAR). Revista DAE, v. 65, n. 208, p. 102-121, 2016. Disponível em: http://revistadae.com.br/site/artigo/1686-Caracterizacao-doatendimento-por-redes-de-abastecimento-de-agua-em-areas-rurais-do-Ceara-evidencias-do-impacto-da-implantacaodo-Sistema-Integrado-de-Saneamento-Rural-SISAR. Acesso em: 17 mar. 2020.

[29] SILVA, G, M.; TALEIRES, F. C. S; S.; SILVA, I. B. Sistema Integrado de Saneamento Rural no contexto do semiárido, estudo de caso: Distrito de Peixe / Russas-CE. Cadernos de Ciências \& Tecnologia-UECE, v. 1, p. 131-143, jan./jul. 2019. Número especial. Disponível em: https://revistas.uece.br/index.php/CCiT/article/view/794. Acesso em: 17 mar. 2020.

[30] SISAR-CE. Sistema Integrado de Saneamento Rural do Ceará. Institucional. Disponível em: http://www.sisar.org.br/institucional/. Acesso em: 25 fev. 2020.

[31] SISAR-PI. Sistema Integrado de Saneamento Rural do Piauí. Faturamento e arrecadação do Povoado Mirolândia (2016 a 2019). Planilha impressa. 2020. 4f. 


\section{Capítulo 13}

Análise do Programa Cisternas através do Modelo Sistêmico: 0 caso do Distrito de Livramento do Tiúma, Timbaúba-PE

\section{Vitória Roberta Martins de Melo Galindo de Lima}

Mateus Gonçalves Lira

Tales Wanderley Vital

Resumo: Em Timbaúba, 20\% da população não é abastecida com água potável e enfrenta dificuldade de acesso ao recurso, realidade que começou a mudar na zona rural com o Programa Cisternas. Este artigo objetiva analisar a referida política pública em comunidades rurais do distrito Livramento do Tiúma em Timbaúba através do Modelo Sistêmico. Trata-se de um estudo de caso no qual adotou-se um roteiro de entrevista semiestruturada aplicada aos proprietários de cisterna e à presidente da associação de moradores. Com a análise de conteúdo, constatou-se que através da demanda e do apoio materializados pela associação de moradores, pressionou-se o sistema político que decidiu implantar o programa na localidade. Essa decisão gerou benefícios às famílias contempladas, que deixavam de participar das reuniões, enfraquecendo o grupo. Assim, surgiu uma demanda sobre a incorporação do associativismo no distrito.

Palavras-chave: Programa Cisternas. Modelo Sistêmico. Comunidades Rurais. 


\section{INTRODUÇÃO}

A distribuição de água adequada para o consumo humano e para o uso na agropecuária é desigual. De toda a água disponível no planeta, 97,5\% está nos mares e oceanos, consistindo, portanto, em água salgada; e apenas 2,5\% corresponde à parte de água doce, distribuída naturalmente em geleiras (69\%), no subsolo (30\%) e em rios (1\%). Nessa distribuição, o Brasil é privilegiado por concentrar 12\% da água doce disponível no mundo (ANA, 2019).

Contudo, a maior parte da água no país - a saber, 80\% - está concentrada na região Norte, onde vive apenas $5 \%$ da população. As regiões Centro-Oeste, Sudeste e Sul, com aproximadamente 65\% da população, possuem $15 \%$ da água doce; enquanto o Nordeste brasileiro, que concentra cerca de $30 \%$ da população, possui apenas 5\% da água doce do país (ANA, 2019; AUGUSTO et. al. 2012).

Esta última região, juntamente com o estado de Minas Gerais, tem ainda cerca de 27 milhões de habitantes vivendo no Semiárido (ANA, 2018), região com hidrografia pobre e condições hídricas insuficientes para sustentar de forma contínua o volume de água dos rios (IBGE, 2017). Essa escassez de água inviabiliza a sobrevivência em condições dignas, gerando situações de fome e miséria (SOARES, 2013), além de secas, quando intensificada.

A fim de mitigar o problema da escassez de água nestas regiões (Semiárido e Nordeste como um todo), algumas ações foram criadas com o financiamento governamental, dos quais destaca-se o Programa Cisternas. Este programa procura instalar tecnologias sociais de acesso à água para consumo direto em escolas ou residências ou para o uso na produção agropecuária em propriedades localizadas na zona rural, especialmente o Semiárido brasileiro, e com dificuldade de acesso à água (MINISTÉRIO DA CIDADANIA, 2019).

Dados os critérios gerais de recebimento dos programas supracitados, a constatação da presença de cisternas instaladas pelo Programa Cisternas no município de Timbaúba, localizado no estado de Pernambuco, na região Nordeste do Brasil, causou estranheza. Isto porque o município não integra a região do Semiárido e está situado na mesorregião da Zona da Mata pernambucana, caracterizada pela ocorrência de chuvas durante cerca de 8 a 11 meses (SILVA, 2016).

No entanto, por meio de pesquisas preliminares, constatou-se que Timbaúba integra a bacia hidrográfica do Rio Goiana e possui rios perenes, porém, de pequena vazão e de baixo potencial subterrâneo. Além disso, a barreira artificial do curso do rio Tiúma, Barragem do Tiúma, presente no município, abastece apenas $80 \%$ da população (SEMAS, 2011). Portanto, $20 \%$ da população residente no município deve recorrer a outras fontes para obter o recurso. Nesse sentido, começam a aparecer os primeiros indicativos da dificuldade de acesso à água no Município.

Além do exposto no parágrafo anterior, conforme dados da Agência Pernambucana de Águas e Clima, a média anual da precipitação do Município de 2010 até 2019 foi $1000 \mathrm{~mm}$. Já seu índice de aridez é considerado alto $(0,299)$ (VILAR; MEDEIROS, 2019); e, de acordo com dados da Agência Nacional de Águas o balanço hidrográfico da região está em situação muito crítica, semelhante ao que ocorre no Semiárido ${ }^{34}$ brasileiro.

Por conseguinte, diante da importância da questão da escassez de água no Brasil e no mundo, da relevância do Programa Cisternas tanto em termos da promoção do acesso à água, quanto dos recursos públicos nele despendidos, neste artigo pretende-se analisar o processo de implementação da política pública no Município à luz da abordagem sistêmica proposta por Easton (1957).

Para tanto utilizou-se dados coletados junto a agentes institucionais envolvidos e junto aos beneficiários das cisternas conforme detalhado adiante nos procedimentos metodológicos.

Assim sendo, compõem este artigo, além desta introdução, outras quatro seções. Na seção 2, trata-se mais detalhadamente do Programa Cisternas e como este está situado no Município de Timbaúba. Na seção 3, explana-se os aspectos teóricos e metodológicos utilizados para a realização da pesquisa. Na seção 4 , apresenta-se os resultados obtidos. Por fim, na seção 5, expõe-se as considerações finais.

\footnotetext{
${ }^{34}$ A região do Semiárido brasileiro tem por critérios de delimitação a precipitação pluviométrica média anual igual ou inferior a $800 \mathrm{~mm}$; índice de aridez de Thornthwaite igual ou inferior a 0,50; e percentual diário de déficit hídrico igual ou superior a $60 \%$, considerando todos os dias do ano (SUDENE, 2017).
} 


\section{O PROGRAMA CISTERNAS}

\subsection{VISÃO GERAL}

O Programa Nacional de Apoio à Captação de Água de Chuva e outras Tecnologias Sociais (Programa Cisternas) tem sido implementado em regiões afetadas pela seca ou falta regular de água desde 2003.0 público do programa são famílias rurais de baixa renda, especialmente as que estão situadas no semiárido brasileiro.

A utilização de uma tecnologia social para facilitar a convivência da população com a escassez de chuva permite que beneficiários e outros integrantes da comunidade local possam ser incluídos na construção da solução, dando legitimidade ao processo. No caso do Programa Cisternas, mais especificamente, utiliza-se principalmente cisternas de placas, além de 26 outras tecnologias sociais com o objetivo de armazenar água de chuva para utilização no período de estiagem.

As cisternas podem ser utilizadas para consumo direto pelas famílias, por escolas, ou ainda para a produção, sendo aquela primeira finalidade o objeto central deste artigo.

Com um período de instalação rápido, de até dois dias, combinado ao baixo custo - aproximadamente R 3 500 em 2018 (MINAS GERAIS, 2018) -, as cisternas para uso humano são feitas de placas de alvenaria e compõem um sistema de captação e armazenamento de água da chuva, integrado ainda por calhas e canos dispostos nos telhados das residências. Por ser um reservatório coberto, impede a evaporação e a contaminação por diversos fatores. Assim, a cisterna permite, através de sua capacidade de armazenamento de 16 mil litros, a utilização de água para beber e cozinhar de uma família de cinco pessoas durante oito meses de estiagem (MINISTÉRIO DA CIDADANIA, 2019).

Até 2016 foram construídas 958615 tecnologias sociais para captação de água da chuva, distribuídas em 1 446 dos 5570 municípios brasileiros, representando uma proporção de aproximadamente 26\% de abrangência. Desse total, 789.635 cisternas (80\%) em 1358 municípios foram destinadas ao uso humano. Nesta categoria, 18 estados foram contemplados, entre os quais Bahia, Pernambuco e Ceará destacam-se por terem recebido em torno de 2/3 do total de cisternas para o consumo direto (EMBRAPA, 2017).

\subsection{O PROGRAMA CISTERNAS EM TIMBAÚBA E EM LIVRAMENTO DO TIÚMA}

No município de Timbaúba, até dezembro de 2019, foram instaladas 425 cisternas, das quais 400 (94\%, aproximadamente) são destinadas ao consumo humano, de acordo com dados do SIG Cisternas fornecidos pelo Ministério da Cidadania por meio da Secretaria Especial do Desenvolvimento Social. As primeiras cisternas do município chegaram em 2016, evoluindo conforme ilustrado no Gráfico 1.

No distrito de Livramento do Tiúma havia 163 cisternas construídas em dezembro de 2019, de acordo com dados georreferenciados fornecidos pelo Ministério da Cidadania por meio da Secretaria Especial do Desenvolvimento Social.

Neste distrito, mais especificamente nas comunidades integrantes da União de Moradores de Livramento do Tiúma - a saber, Jurema Velha, Lagoa de Pedra, Livramento do Tiúma, Tapadão e Guabiraba -, a demanda com relação à implementação do Programa Cisternas começou em 2012. A Presidente da União de Moradores, uma associação privada, que também atua na vice-presidência do Conselho de Desenvolvimento Rural Sustentável do Município de Timbaúba, apresentava durante as reuniões do Conselho os principais problemas enfrentados pelos residentes das comunidades: dificuldade de acesso à água e vias de acesso de má qualidade. Após cinco anos do início das demandas, as primeiras cisternas do Município chegaram em 2016, evoluindo conforme ilustrado no Gráfico 2. 
Gráfico 5 - Número de cisternas instaladas em Timbaúba por ano.

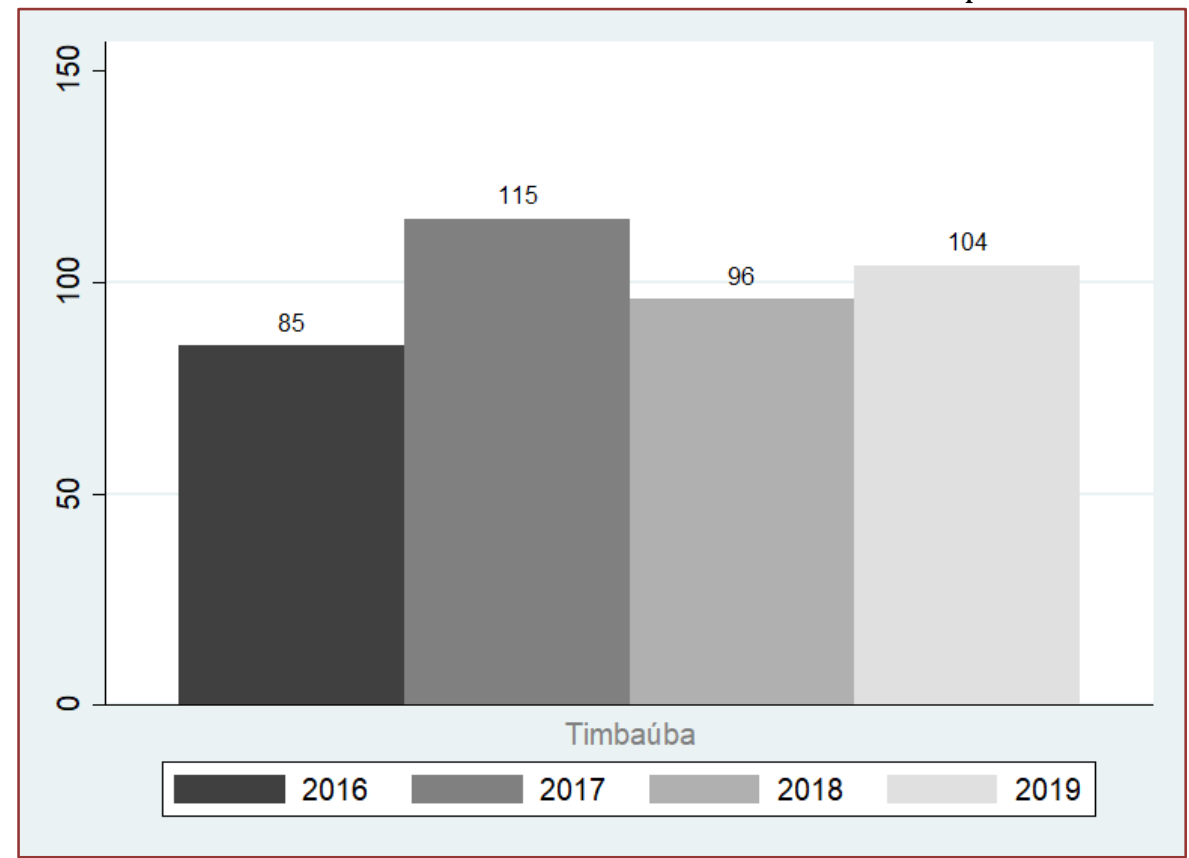

Fonte: elaborado pelos autores com base em dados do Ministério da Cidadania, 2019.

Gráfico 6 - Número de cisternas instaladas em Livramento do Tiúma por ano.

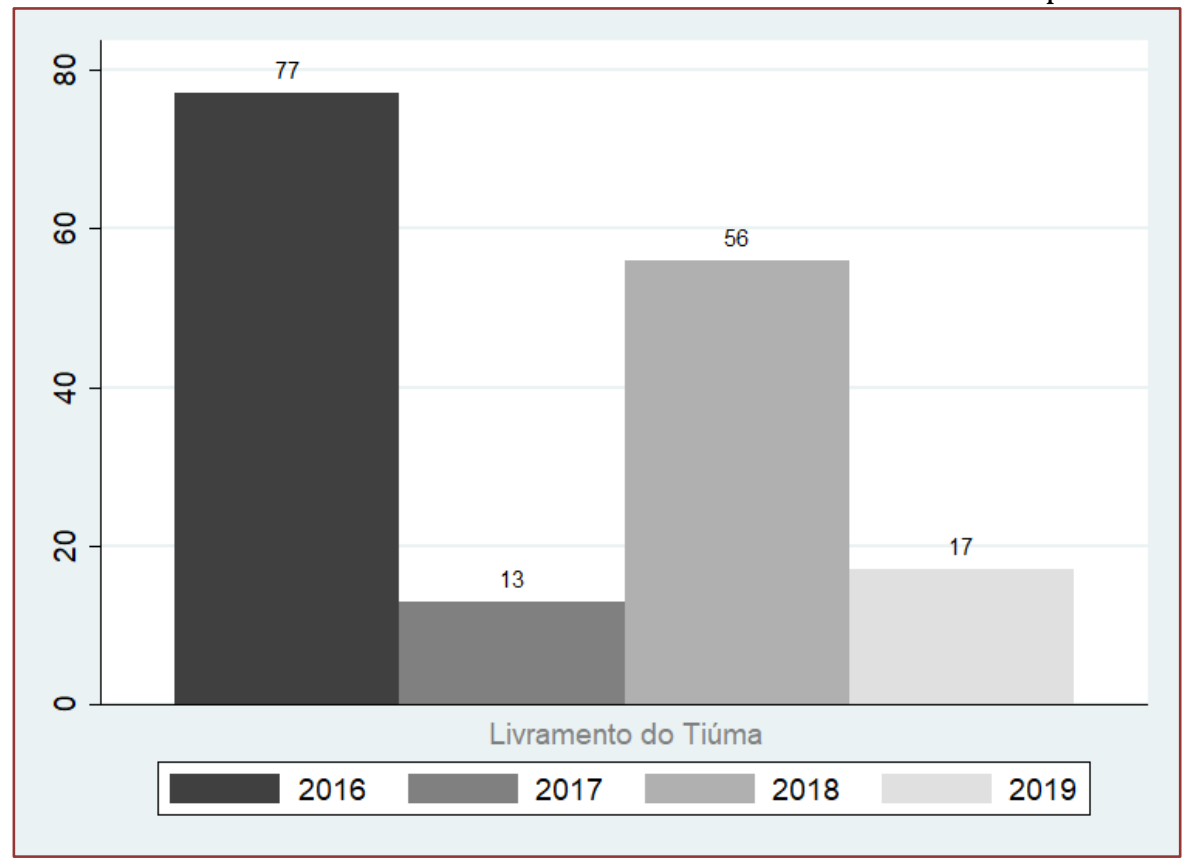

Fonte: elaborado pelos autores com base em dados do Ministério da Cidadania, 2019.

A abordagem sistêmica permite analisar esse processo social de construção das cisternas nesta localidade.

\section{ASPECTOS TEÓRICOS E METODOLÓGICOS}

\subsection{O MODELO SISTÊMICO PARA A ANÁLISE DE POLÍTICAS PÚBLICAS}

São diversas as abordagens existentes para analisar as políticas públicas, uma delas é o modelo sistêmico.

Boulding (1956) classifica os sistemas conforme o seu nível de complexidade. O sistema social é considerado um dos mais complexos. Este sistema caracteriza-se por ser aberto e, portanto, sofrer influências do ambiente no qual está inserido; adaptativo em consequência da capacidade de acumulação 
de conhecimento e da diversidade de indivíduos que o compõem; e dotado de entropia negativa, isto é, não tender ao caos, mas conseguir organizar-se para preservar-se ao longo do tempo.

Easton (1957) acrescenta à literatura a abordagem do sistema político: conjunto de instituições identificáveis que interagem entre si e sofrem influências de inputs (demandas e/ou suportes vindas do ambiente externo) a fim de alocar valores para a sociedade, os outputs. Por suas vezes, os outputs, como voltam para o ambiente externo e podem transformá-lo, geram feedbacks, funcionando como retroalimentação do sistema, podendo gerar novas demandas. Portanto, essa engrenagem gera um ciclo composto por input, processamento, output e retroalimentação. A Figura 1 ilustra essas relações.

Figura 4 - Modelo Sistêmico.

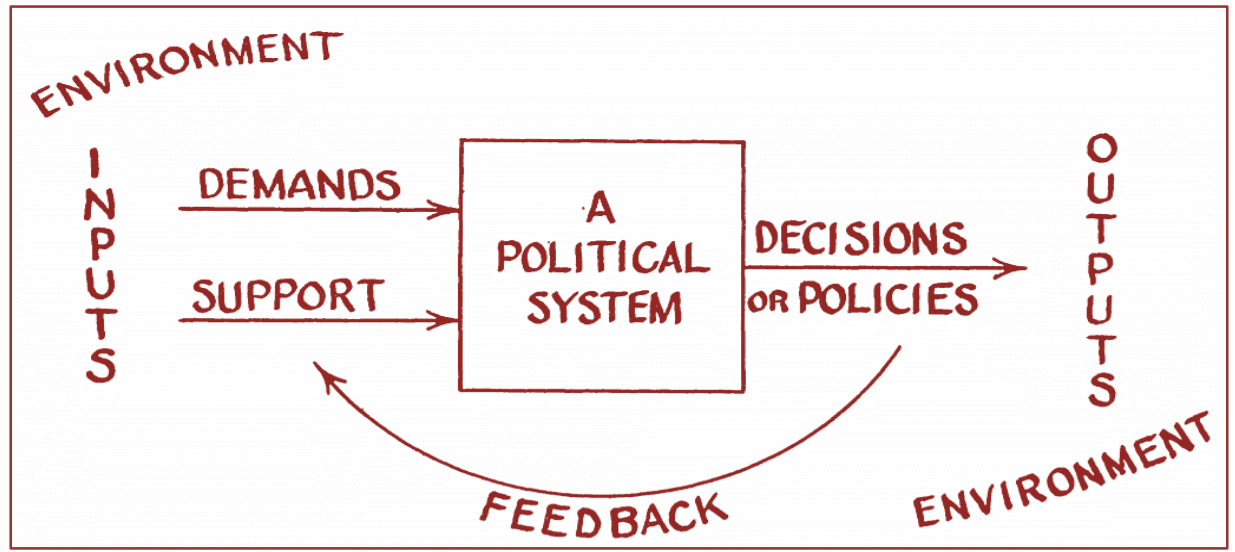

Fonte: EASTON (1957).

\subsection{MODELO ANALÍTICO}

O Modelo Sistêmico, adotado neste artigo, tem origem no século XX com a Teoria Geral dos Sistemas de Ludwig von Bertalanffy (1975).

Bertalanffy (1975) afirma que diversos fenômenos das mais diversas áreas do conhecimento seguem os princípios da definição de um sistema: entidade composta por partes em constante interação entre si e com o ambiente externo, capaz de manter um certo nível de organização e que funciona sob determinadas leis a fim de atingir uma finalidade específica. Em termos de funcionalidade, um sistema deve, portanto, por meio de um processamento, transformar matérias primas vindas do ambiente em produtos que serão devolvidos a este ambiente.

De acordo com Almeida; Rebelato (2006) apud Almond; Powell Jr. (1972), os inputs e os outputs podem ainda ser classificados conforme disposto no Quadro 1. Para este artigo, destacam-se no input a demanda por distribuição de benefícios e serviços e o suporte participatório; e no output, também a distribuição de benefícios e serviços.

Quadro 1 - Tipos de inputs e outputs de um sistema político.

\begin{tabular}{|l|l|l|}
\hline \multicolumn{2}{|c|}{ INPUT } & \multicolumn{2}{c|}{ OUTPUT } \\
\hline Distribuição de benefícios e serviços; & De materiais; & $\begin{array}{l}\text { Extrações (impostos, contribuições, } \\
\text { serviços pessoais); }\end{array}$ \\
\hline Regulamentação de comportamento; & Obediência à lei e aos regulamentos; & $\begin{array}{l}\text { Regulamentações de } \\
\text { comportamento; }\end{array}$ \\
\hline Participação no sistema político; & $\begin{array}{l}\text { Participatório (voto, discussão } \\
\text { política e outras formas de atividade } \\
\text { política); }\end{array}$ & Distribuição de benefícios e serviços; \\
\hline Comunicação e informação. & $\begin{array}{l}\text { Atenção prestada às comunicações } \\
\text { governamentais e evidências de } \\
\text { respeito pela autoridade pública. }\end{array}$ & $\begin{array}{l}\text { Emissões simbólicas, inclusive de } \\
\text { afirmação de valores, apresentação } \\
\text { de símbolos políticos, declaração de } \\
\text { diretrizes e metas. }\end{array}$ \\
\hline
\end{tabular}

Fonte: Elaborado pelos autores com base em ALMEIDA; REBELATO (2006) apud ALMOND; POWELL JR. (1972). 
Apesar de Ham; Hill (1993) criticarem o modelo no que toca à sua simplificação da realidade, a escolha pela abordagem sistêmica dá-se justamente por esse motivo. A possibilidade de uma sistematização mais simplificada da complexidade do sistema social no seu âmbito político mostra-se útil para uma primeira análise do processo de tomada de decisão ou implementação de políticas públicas: o que se propõe neste artigo.

\subsection{BASE DE DADOS: ENTREVISTAS SEMIESTRUTURADAS E ANÁLISE DE CONTEÚDO}

Até a data de realização da pesquisa, a saber, início de dezembro do ano de 2019, existia 425 cisternas no município de Timbaúba, das quais 163 no distrito de Livramento do Tiúma, de acordo com dados georreferenciados fornecidos pelo Ministério da Cidadania por meio da Secretaria Especial do Desenvolvimento Social. Vale ressaltar que algumas dessas cisternas não haviam entrado em funcionamento ainda, fazendo com que o universo de cisternas ativas ${ }^{35}$ fosse reduzida a 149 em Livramento do Tiúma.

No total, foram realizadas 16 entrevistas com os beneficiados no referido distrito. Utilizou-se dois diferentes roteiros de perguntas para guiar a aplicação de entrevistas semiestruturadas aos beneficiados pelo Programa e à Presidente da União de Moradores do Livramento do Tiúma que também é VicePresidente do Conselho de Desenvolvimento Rural Sustentável do Município de Timbaúba. Posteriormente, avaliou-se estas entrevistas por meio da análise de conteúdo.

A amostra foi definida por conveniência, ou seja, foram entrevistadas as famílias que estavam imediatamente disponíveis. 0 critério de seleção da amostra justifica-se pela dificuldade de acesso às residências, devido aos terrenos acidentados e à baixa qualidade das estradas de acesso, além de que os moradores estavam assustados devido à ocorrência recente de um assalto à casa de uma das famílias da comunidade - ao chegar em algumas residências ouvia-se barulho, mas as pessoas não atendiam ao chamado.

Como o processo de amostragem foi não aleatório, não há garantias de representatividade da população quanto aos benefícios do programa. Todavia, o método utilizado encaixou-se perfeitamente nos objetivos e nas limitações às quais se sujeitaram a realização deste trabalho.

No roteiro de perguntas direcionados aos beneficiados pelo Programa Cisternas, abordou-se as temáticas de acesso à água, trabalho, produção agropecuária e renda e saúde e qualidade de vida, numa tentativa de realizar uma pesquisa exploratória, conversando com os entrevistados até que as novas informações fossem esgotadas em suas falas.

A partir das entrevistas com os beneficiados pelo programa, foi possível chegar à Presidente da União dos Moradores de Livramento do Tiúma. Um segundo roteiro de perguntas foi, portanto, elaborado a fim de obter informações a respeito da atuação desta associação no processo de implementação do Programa Cisternas para o distrito.

Posteriormente, analisou-se o conteúdo das respostas, utilizando como materiais de apoio anotações em caderno utilizado ao longo das entrevistas, além da escuta das entrevistas gravadas por meio de dispositivo eletrônico, conforme consentimento do entrevistado. Estes procedimentos possibilitaram a identificação de inputs; do processamento ocorrido dentro do sistema político; dos outputs; e dos feedbacks. Portanto, a aplicação do Modelo Sistêmico na análise do Programa Cisternas foi realizada com êxito.

\section{RESULTADOS E DISCUSSÃO}

Esta seção trata de análise dos resultados do modelo sistêmico aplicado (modelo analítico) aos dados coletados. No Quadro 2, expõe-se os inputs, o processamento que ocorreu dentro do sistema político, os outputs e o feedback do Modelo Sistêmico aplicado à análise da decisão de implementar o Programa

\footnotetext{
35 Para definir o critério de cisternas ativas em Timbaúba, tomou-se como parâmetro o índice pluviométrico mínimo para encher uma cisterna de $16 \mathrm{~m}^{3}$ sendo de $400 \mathrm{~mm}$ (DE ARAÚJO FILHO, 2009). Como em Timbaúba o índice pluviométrico referente aos meses de setembro e outubro foi de $39 \mathrm{~mm}$ e $35 \mathrm{~mm}$, respectivamente, de acordo com o Instituto Agronômico de Pernambuco (IPA), considerou-se que as cisternas construídas nesses meses não poderiam ser preenchidas através da captação da água da chuva, e, portanto, foram consideradas inativas.
} 
Cisternas no distrito de Livramento do Tiúma. Em seguida, descreve-se todo o processo desde à demanda e o apoio até a distribuição do benefício e os retornos para o ambiente identificados.

Quadro 2 - Entrada, processamento e saída do Modelo Sistêmico.

\begin{tabular}{|c|c|c|}
\hline INPUT & SISTEMA POLITICO & OUTPUT \\
\hline $\begin{array}{l}\text { Demanda por distribuição de } \\
\text { benefícios e serviços (água) e } \\
\text { apoio participatório (discussões } \\
\text { políticas a partir da União dos } \\
\text { Moradores do Livramento do } \\
\text { Tiúma). }\end{array}$ & $\begin{array}{l}\text { No Conselho de Desenvolvimento } \\
\text { Rural Sustentável de Timbaúba, } \\
\text { interação entre representantes de } \\
\text { associações privadas, do Sindicato } \\
\text { dos Trabalhadores Rurais do } \\
\text { município, da Prefeitura, do } \\
\text { Instituto Agronômico de } \\
\text { Pernambuco (IPA) e a outros } \\
\text { órgãos do estado de Pernambuco. }\end{array}$ & $\begin{array}{l}\text { Demanda por distribuição de } \\
\text { benefícios e serviços (decisão de } \\
\text { implementar o Programa Cisternas } \\
\text { no distrito de Livramento do } \\
\text { Tiúma). }\end{array}$ \\
\hline \multicolumn{3}{|c|}{$\begin{array}{l}\text { Feedback: as famílias não entendem com clareza a necessidade da frequência nas reuniões da União dos } \\
\text { Moradores, ao mesmo tempo que algumas delas ainda têm demanda por outra cisterna para aumentar a } \\
\text { segurança hídrica. Por isso, existe uma demanda sobre a Universidade no que toca a divulgação da importância e } \\
\text { da funcionalidade do associativismo. }\end{array}$} \\
\hline
\end{tabular}

Fonte: Elaborado pelos autores com base em EASTON (1957).

\subsection{INPUT}

Desde 2012, as reuniões da União de Moradores de Livramento do Tiúma, associação privada dedicada à defesa de direitos sociais, mobilizava esforços na tentativa de trazer para as famílias residentes das comunidades que a integra o Programa Cisternas.

\subsection{SISTEMA POLÍTICO}

Finalmente em 2016, depois de articular-se ao Sindicato dos Trabalhadores Rurais de Timbaúba, ao Conselho de Desenvolvimento Rural Sustentável do município, à prefeitura, ao Instituto Agronômico de Pernambuco (IPA) e a outros órgãos do estado de Pernambuco, as comunidades de Jurema Velha, Lagoa de Pedra, Livramento do Tiúma, Tapadão e Guabiraba começaram a receber as primeiras cisternas do programa.

Um dos critérios para receber a cisterna foi a participação de um representante da família beneficiária em uma capacitação com duração de três dias promovida no centro de Timbaúba pelo SERTA (Serviço de Tecnologia Alternativa), uma Organização de Sociedade Civil de Interesse Público (Oscip), responsável pela instalação das cisternas no Município. Durante esta capacitação, os representantes eram instruídos quanto ao uso e manutenção da cisterna.

Em seguida, uma equipe do SERTA direcionava-se à residência dos moradores propondo o local de instalação da cisterna. A União dos Moradores de Livramento do Tiúma também atuou nessa etapa fazendo visitas às famílias que receberiam as cisternas e mobilizando pessoal para participar da construção das cisternas.

Houve relatos de moradores que resistiram à instalação da cisterna por causa do local proposto inicialmente pela equipe do SERTA. Alguns negociaram outro local mais conveniente para o morador e outros desistiram do recurso.

Definido o local de instalação, uma máquina cavava o buraco onde a cisterna seria construída e as demais etapas da construção eram desempenhadas numa colaboração da equipe do SERTA com integrantes da comunidade. Depois de construída, a cisterna recebia 4 mil litros de água de um caminhão pipa e, por fim, restava esperar a chuva para completar o volume do reservatório.

Por fim, concomitantemente à execução das obras, uma comissão para fiscalização da construção das cisternas, criada a partir do Conselho de Desenvolvimento Rural Sustentável do Município, atuava no sentido de certificar que o número estipulado cisternas estavam sendo construídas nas propriedades das famílias beneficiadas. 


\subsection{OUTPUT}

O output do modelo consiste na decisão de implementar o Programa Cisternas no distrito de Livramento do Tiúma, o que resultou no acesso à água para beber e cozinhar por parte das famílias de baixa renda que antes encontravam-se em situação de vulnerabilidade hídrica.

No Quadro 3, os principais benefícios do programa estão sistematizados. Trata-se das fontes de água disponíveis e utilizadas pelas famílias na primeira coluna, codificadas de 1 a 6 . Já nas segunda e terceira colunas, estão divididas em duas outras colunas cada uma, nas quais são discriminadas as destinações da água, de acordo com a fonte de onde ela era retirada em dois pontos no tempo; com $\mathrm{t}_{0}$ indicando o tempo antes da instalação da cisterna e $t_{1}$ fazendo referência ao tempo depois da cisterna. A última coluna, também dividida em duas, indica os principais benefícios do Programa Cisternas identificados por meio das entrevistas.

Percebe-se que antes de obter a cisterna do programa, as famílias utilizavam água do barreiro (açude), cacimba (poço), tonel de plástico, caixa d'água de plástico, tanque de cimento, pequena cisterna ou de caminhão que passava vendendo tonéis de água para beber e/ou cozinhar. Já com o benefício do reservatório, a água para beber e/ou cozinhar passou a ser exclusivamente retirada da cisterna. Já para os usos "gastar" (referente à limpeza doméstica e higiene pessoal) e atividade agropecuária, as fontes anteriores foram mantidas e o uso da cisterna foi apenas acrescentado.

Quadro 3 - Efeitos do Programa Cisternas na qualidade de vida de famílias em Livramento do Tiúma -

\begin{tabular}{|c|c|c|c|c|c|c|}
\hline $\begin{array}{c}\text { Fontes da } \\
\text { água }\end{array}$ & \multicolumn{2}{|c|}{$\begin{array}{l}\text { Uso da água e fonte } \\
\text { correspondente, } t_{0}\end{array}$} & \multicolumn{2}{|c|}{$\begin{array}{l}\text { Uso da água e fonte } \\
\text { correspondente, } t_{1}\end{array}$} & \multicolumn{2}{|c|}{ Efeitos do Programa Cisternas } \\
\hline 1 - Rio & \multirow[b]{2}{*}{$\begin{array}{l}\text { Beber e/ou } \\
\text { cozinhar }\end{array}$} & \multirow[b]{2}{*}{$2,3,4$ e 5} & \multirow[b]{2}{*}{$\begin{array}{l}\text { Beber e/ou } \\
\text { cozinhar }\end{array}$} & \multirow[b]{2}{*}{6} & \multirow{2}{*}{$\begin{array}{l}\text { Aumento da renda } \\
\text { disponível entre } \\
\mathrm{R} \$ 56 \text { e } \mathrm{R} \$ 100, \\
\text { dependendo do } \\
\text { tamanho da família. }\end{array}$} & \multirow[b]{2}{*}{ Renda } \\
\hline $\begin{array}{l}2 \text { - Barreiro } \\
\text { (açude) }\end{array}$ & & & & & & \\
\hline $\begin{array}{l}3 \text { - Cacimba } \\
\text { (poço) }\end{array}$ & \multirow{3}{*}{$\begin{array}{l}\text { "Gastar" } \\
\text { (limpeza } \\
\text { doméstica e } \\
\text { higiene } \\
\text { pessoal) }\end{array}$} & \multirow{3}{*}{$1,2,3$ e 4} & \multirow{3}{*}{$\begin{array}{l}\text { "Gastar" } \\
\text { (limpeza } \\
\text { doméstica e } \\
\text { higiene } \\
\text { pessoal) }\end{array}$} & \multirow{3}{*}{$1,2,3,4$ e 6} & \multirow{2}{*}{$\begin{array}{l}\text { Sobra mais tempo } \\
\text { para dedicar-se às } \\
\text { tarefas domésticas } \\
\text { e/ou às atividades } \\
\text { agropecuárias. }\end{array}$} & \multirow[b]{2}{*}{ Tempo } \\
\hline $\begin{array}{l}4 \text { - Tonel, } \\
\text { caixa d'água, } \\
\text { tanque de }\end{array}$ & & & & & & \\
\hline $\begin{array}{l}\text { cimento ou } \\
\text { pequena } \\
\text { cisterna }\end{array}$ & & & & & $\begin{array}{l}\text { Diminuição de dor no } \\
\text { "espinhaço" (coluna) } \\
\text { e casos de verminose. }\end{array}$ & Saúde \\
\hline $\begin{array}{l}5 \text { - Caminhão } \\
\text { d'água (R\$ } 14 \\
\text { o tonel) }\end{array}$ & \multirow[t]{2}{*}{ Agropecuária } & \multirow[t]{2}{*}{2,3 e 4} & \multirow[t]{2}{*}{ Agropecuária } & \multirow[t]{2}{*}{$2,3,4$ e 6} & \multirow{2}{*}{$\begin{array}{l}\text { Obtinha água em } \\
\text { fonte de propriedade } \\
\text { vizinhas e passa a } \\
\text { obter água em fonte } \\
\text { própria. }\end{array}$} & \multirow[t]{2}{*}{ Capability } \\
\hline 6 - Cisterna & & & & & & \\
\hline
\end{tabular}

Fonte: Elaborado pelos autores com base em dados de pesquisa de campo, 2019.

A partir dessa mudança, de acordo com a avaliação do conteúdo das entrevistas e da percepção da pesquisadora, foi possível categorizar os benefícios em quatro principais: renda, tempo, saúde e capability.

0 impacto na renda dá-se principalmente pelo aumento da renda disponível, com a diminuição de $\mathrm{R} \$ 56$ a $\mathrm{R} \$ 100$ nos gastos, aproximadamente, dependendo do tamanho da família. Este aumento da renda disponível beneficia, notadamente, as famílias que deixam de adquirir água por meio da compra de vendedores que chegam nas comunidades com caminhões ou das que não precisam mais pagar a vizinhos ou familiares para buscarem água utilizando seus animais.

Da mesma forma, há um impacto positivo na alocação do tempo das famílias. Alguns entrevistados relataram que levavam de 30 minutos a duas horas no trajeto para conseguir obter água. Este tempo que se deixa de gastar com a busca da água é normalmente revertido para as tarefas domésticas e/ou às atividades agropecuárias.

A instalação da cisterna também refletiu na saúde dos beneficiados. Estes relataram que passaram a sentir menos dores no "espinhaço" (coluna) e que identificaram a diminuição das ocorrências de verminoses. 
Por fim, destaca-se o efeito do aumento da "capability", conceito formulado por Amartya Sen que, em tradução livre, significa "as liberdades que as pessoas têm, dadas suas características individuais e seu domínio sobre bens" (TODARO; SMITH, 2015). Isto se aplica para as famílias que antes de possuírem a cisterna, obtinham água em barreiro, cacimba ou cisterna de propriedades vizinhas. De certa forma, essas famílias tornam-se dependentes dos proprietários das fontes, resultando na diminuição das suas liberdades, visto que trata- se de um bem salutar para o desenvolvimento da vida. A partir do momento que as famílias têm suas próprias fontes de água, suas liberdades aumentam, dado o seu domínio sobre o bem.

\subsection{FEEDBACK}

Para mobilizar os moradores a participarem das reuniões com a proposta de estudarem os problemas existentes na comunidade e juntos procurarem soluções, os líderes convocavam reuniões mensais, além de cadastrar os moradores, os quais contribuíam com um valor simbólico. Contudo, uma dificuldade encontrada pela Associação consiste na evasão dos associados depois que conquistavam as cisternas. No momento de realização da pesquisa, havia aproximadamente 30 associados. Contudo, a população do distrito em 2010 era de 4368 habitantes, sendo 3132 considerados residentes em domicílios localizados na zona rural.

Percebeu-se que, apesar da satisfação dos moradores com o recebimento do programa, existe ainda uma demanda por mais cisternas, ao mesmo tempo que esse feedback sofre interferência pelo não entendimento por parte das famílias da necessidade da frequência nas reuniões da União dos Moradores. Nesse sentido, surge uma demanda para a Universidade: disseminar a importância e a funcionalidade do associativismo em locais onde um potencial grupo de pressão apresenta fragilidades.

\section{CONSIDERAÇÕES FINAIS}

Mesmo não sendo caracterizado como um município do Semiárido, Timbaúba apresenta características que resultam em dificuldade de acesso à água, especialmente para a população que vive na zona rural do Município.

A percepção da realidade indica que as famílias entrevistadas não teriam condições de, sozinhas, instalar uma cisterna com a capacidade de 16 mil litros em suas propriedades, pois o custo unitário, apesar de relativamente baixo para os cofres públicos, é expressivo para famílias cuja atividade principal é a agropecuária de subsistência. Isso revela a importância da política para cada um dos beneficiários.

Portanto, evidencia-se a importância da mobilização de um ator social através do qual foi possível expressar a demanda pela água e o apoio à implementação da política pública por meio de discussões. Essa demanda por benefício e o apoio do tipo participatório funcionaram como uma força do ambiente externo sobre o sistema político que encontrou uma solução razoável para o problema: a instalação de um sistema de captação e armazenamento da água da chuva no distrito de Livramento do Tiúma através do Programa Cisternas.

A tecnologia possibilitou ganhos para aquela população mais pobre, principalmente em termos de tempo, saúde, renda e capability, ou seja, liberdades ligadas às características pessoais e à posse de bens.

Apesar da satisfação dos moradores em ter uma cisterna, ainda existe uma deficiência hídrica, visto que o volume armazenado é suficiente apenas para os fins de beber e cozinhar. Contudo, geralmente as famílias beneficiadas não continuam frequentando a as reuniões da associação, onde poderiam continuar expressando os problemas comuns e buscando soluções para tais dificuldades. Nesse sentido, a Universidade pode atuar a fim de disseminar a importância e a funcionalidade do associativismo. 


\section{REFERÊNCIAS}

[1] AGENCIA NACIONAL DE ÁGUAS. Observatório da Escassez Hídrica no Semiárido aponta melhora relativa nas condições da região. [S. l.: s. n.], 2018. Disponível em: <https://bit.ly/2ELZEKY>. Acesso em: 25 out. 2018.

[2] AGENCIA NACIONAL DE ÁGUAS. Panorama das águas. [S. l.: s. n.], 2019. Disponível em: <https://bit.ly/353nvOo>. Acesso em: 30 dez. 2019.

[3] ALMEIDA, Mariana R.; REBELATTO, Daisy AN. O inventário dos modelos de avaliação para políticas públicas. In: Anais do 1ํㅡㄹ Congresso Internacional de Dinâmica de Negócios. 2006.

[4] AUGUSTO, Lia Giraldo da Silva et al. O contexto global e nacional frente aos desafios do acesso adequado à água para consumo humano. Ciência \& saúde coletiva, v. 17, p. 1511-1522, 2012.

[5] BERTALANFFY, Ludwig Von. Teoria geral dos sistemas. Petrópolis: Vozes, 1975.

[6] BOULDING, Kenneth E. General systems theory-the skeleton of science. Management science, v. 2, n. 3, p. 197 $208,1956$.

[7] DE ARAÚJO FILHO, Paulo Frasinete. Dimensionamento sustentável da captação de água de chuva. 2009.

[8] EASTON, David. An approach to the analysis of political systems. World politics, v. 9, n. 3, p. 383-400, 1957.

[9] EMBRAPA. Inclusão produtiva no seu município. [S. l.: s. n.], 2017. Disponível em: <https://bit.ly/36iID4N>. Acesso em: 31 out. 2019.

[10] HAM, Christopher; HILL, Michael. O processo de elaboração de políticas no estado capitalista moderno. Campinas, tradução: Renato Amorim e Renato Dagnino, adaptação e revisão: Renato Dagnino, 1993.

[11] INSTITUTO BRASILEIRO DE GEOGRAFIA E ESTATISTICA. Semiárido Brasileiro. [S. l.: s. n.], 2017. Disponível em: <https://bit.ly/2yCXckH>. Acesso em: 25 out. 2018.

[12] MINISTÉRIO DA CIDADANIA. Programa Cisternas. [S. l.: $\quad$ s. $\quad$ n.], $2019 . \quad$ Disponível em: <https://bit.ly/2PBHiQW>. Acesso em: 31 out. 2019.

[13] SILVA, Cleo Clayton Santos. Análise de complexidade da precipitação mensal no estado de Pernambuco utilizando o sample entropy. 2016.

[14] SOARES, Edmilson. Seca no Nordeste e a transposição do rio São Francisco. Revista Geografias, v. 9, n. 2, p. 75-86, 2013.

[15] SUPERINTNDÊNCIA DO DESENVOLVIMENTO DO NORDESTE. Delimitação do semiárido. [S. l.: s. n.], 2017. Disponível em: <https://bit.ly/2KlgMJY>. Acesso em: 25 out. 2018.

[16] TODARO; Michael P.; SMITH, Stephen. C. Economic Development, 12th Edn; Harlow. 2015.

[17] VILAR, Helano Nobre; DE MEDEIROS, Raimundo Mainar. Índice de aridez na Zona da Mata no Estado de Pernambuco-Brasil. Journal of Environmental Analysis and Progress, v. 4, n. 1, p. 014-020, 2019. 


\section{Capítulo 14}

Análise sobre doenças no aparelho respiratório nos municípios de Mato Grosso devido as queimadas no ano de 2015

Nathalia de Pinho Markus

Kimberly Jéssica Montagner Prote

Arturo Alejandro Zavala Zavala

Resumo: Com clima, relevo e solo favoráveis, Mato Grosso se consolidou como o maior produtor de grãos do país, além de ter considerável representação nacional em outras produções agrossilvipastoril. Com parte da economia pautada nas atividades relacionadas ao campo, e apesar dos avanços tecnológicos que elevaram a produtividade do setor, ainda se utiliza no estado a técnica de queima para abrir grandes extensões de área para produção. As queimadas, naturais ou intencionais, desencadeiam uma série de externalidades negativas ao meio ambiente e problemas socioeconômicos, como a emissão de gases nocivos na atmosfera que afetam a saúde humana. As doenças respiratórias representam o terceiro maior motivo de internação em 2015 de acordo com o Sistema Único de Saúde (SUS). Este trabalho buscou verificar a relação de focos de queimadas com as doenças respiratórias nos 141 municípios de Mato Grosso, bem como se existe similaridades entre os municípios quanto as doenças para o ano de 2015, sendo este o último ano com dados consolidados do Instituto Nacional de Pesquisa Espacial para variáveis do modelo. Para entender o problema foi realizado a regressão de Poisson e agrupamento dos municípios por ordem de similaridade. Todas as variáveis analisadas no modelo de regressão apresentaram relação positiva com o número de pessoas com doenças no aparelho respiratório, principalmente a emissão de monóxido de carbono. Quanto aos agrupamentos, os municípios com centros urbanos mais desenvolvidos apresentaram maiores médias de registro de doenças respiratórias.

Palavras-chave: Doenças Respiratórias; Queimadas; Regressão de Poisson; Método de Agrupamento de dados. 


\section{INTRODUÇÃO}

Situado na região Centro-Oeste do país, Mato Grosso é composto por 3 biomas, sendo eles a Amazônia que ocupa a maior parte da extensão territorial, o Cerrado e o Pantanal (IBGE, 2019). Devido sua grande

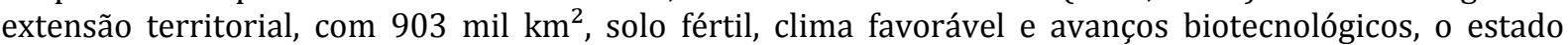
iniciou a ascensão no início dos anos 2000 na produção agropecuária. Na safra 2018/19, Mato grosso se destaca como o maior produtor de grãos do Brasil tendo como principais culturas produtivas de grãos a soja, o milho e o algodão, além de também possuir destaque na produção de bovinos (IMEA, 2019).

O crescimento do estado na produção agrossilvipastoril e a demanda mundial da China por commodities inseriu o país no mercado internacional como um importante player nas exportações de grãos e carnes (DALL'AGNOL et al, 2007). De acordo com os dados do Instituto Mato-grossense de Economia Agropecuária (IMEA, 2019) cerca de 59\% da demanda de soja na safra 2018/19 do estado é destinada a exportações, são 19,34 milhões de toneladas de grãos apenas nessa safra.

De tal forma que a produção em Mato Groso é em sua grande maioria intimamente relacionado ao campo, e apesar dos ganhos tecnológicos da última década, ainda se utiliza no estado a técnica de queima para abrir grandes extensões de área para produção. A queima intencional é regulamentada por lei e deve ser solicitado a licença prévia junto a Secretaria de Meio Ambiente (Sema) do estado para que possa ser realizada a prática de forma segura (MATO GROSSO, 2011), contudo, muitas vezes é realizada sem a autorização da Sema.

0 processo de queimada consiste em elevada exposição da biomassa ao calor que pode ocorrer através da combustão natural, muito comum nos períodos de seca, em função do tipo de vegetação, umidade relativa, precipitação de chuvas (SANTOS et al., 2018), bem como de ações humanas de forma intencional, como na abertura de áreas ou acidentais devido ao descarte incorreto de resíduos inflamáveis.

A queima de biomassa tanto nos processos naturais, como intencionais libera gases na atmosfera como o CO (monóxido de carbono), NOx (óxidos de nitrogênio), HC (hidrocarbonetos) e material particulado (fuligem), que além de serem negativos ao meio ambiente, causando toxicidade aos sistemas ambientais, são prejudiciais à saúde humana elevando a incidência de doenças respiratórias, internações hospitalares, podendo até mesmo levar ao óbito (ARBEX, 2012; PEREIRA et al., 2011; SILVA et. al., 2013; GOMES; SPYRIDES; LUCIO, 2016; NASCIMENTO et al., 2016).

As doenças respiratórias representam o terceiro maior motivo de internação em Mato Grosso, em média $10 \%$ dos casos foram provenientes dessas doenças, no período de 2015 a 2018, ficando atrás apenas de enfermidades compreendidas no capítulo XV e XIX36 do Plano Estadual de Saúde (PES, 2017), que corresponde em média a $23 \%$ e 14\%, respectivamente (DATASUS, 2019). No ano de 2015 o Governo estadual mato-grossense aplicou 13,12\% dos recursos próprios em ações e serviços públicos em saúde, sendo que $90 \%$ dos recursos são destinados a serviços em administração geral e assistência hospitalar e ambulatorial (PES, 2017).

As internações compreendem-se pacientes que ocupam um leito hospitalar em período igual ou superior a 24hrs (BRASIL, 2002). Logo, casos comuns associados as doenças respiratórias que são apenas tratados em atendimentos ambulatoriais não são contabilizados nas estatísticas governamentais, o que leva a crer que as estatísticas estão subestimadas. Quando as doenças respiratórias estão localizadas nas vias aéreas superiores são em gerais autolimitadas e de curso benigno, com reduzido número de internações, como é o caso de resfriados comuns, faringite, amigdalite, dentre outros, ao passo que atingem as vias inferiores estendem-se por maior período de tempo e possuem maiores riscos de mortalidade (BENíCIO et al., 2000). E assim, os dados registrados no Sistema Único de Saúde (SUS) apresentam apenas uma dimensão da morbidade relacionada as doenças respiratórias, uma vez que apenas as internações são contabilizadas.

O Instituto Nacional de Pesquisas Espaciais (INPE) através do método de georreferenciamento e controle de imagens espaciais dos satélites possui indicadores de focos de queimadas, importantes para auxiliar no controle e prevenção desse processo com intuito de diminuir as externalidades negativas. No entanto, não é separado o que é queima natural e/ou intencional ou incêndio florestal, pois o instituto levanta e divulga os dados por meio da análise das imagens de diferentes satélites (NOAA, GOES, AQUA, TERRA e METEOSAT) que identificam focos de calor, não possibilitando essa separação (INPE, 2018).

\footnotetext{
${ }^{36}$ De acordo com a Classificação Internacional de Doenças (CID 10) o capítulo XV corresponde a gravidez, parto e puerpério (000-099) e o capítulo XIX compreende lesões, envenenamento e algumas outras consequências de causa externa (S00-T98).
} 
Esse trabalho tem como objetivos verificar a relação de focos de queimadas, emissão de monóxido de carbono e material particulado com as doenças respiratórias nos 141 municípios de Mato Grosso, bem como se existe similaridades entre os municípios quanto as doenças através do modelo de Regressão de Poisson e a aplicação de agrupamento de dados, respectivamente. Devido à falta de dados recentes quanto a emissões de material particulado e CO para realizar o estudo dentro de uma série histórica extensa, o foco se manteve no ano de 2015, último com dados disponibilizados pelo INPE.

Esse trabalho está divido em mais três seções além dessa introdução, sendo estas queimadas e suas externalidades; relação das queimadas com as doenças respiratórias e a similaridade dos municípios mato-grossenses; resultados e discussões e por fim as considerações finais.

\section{QUEIMADAS E SUAS EXTERNALIDADES}

A influência das ações de um determinado agente em terceiros é denominada externalidade, não sendo necessária a ligação direta entre eles, podem ser influências positivas que acarretam em ganho de bemestar ou negativas que afetam desfavoravelmente os demais (GUJARATI; PORTER, 2011). 0 processo de queimada, prática comum para produção do agronegócio em Mato Grosso, seja para conversão da floresta em pasto, colheita de cana-de-açúcar, retirada de madeira, dentre outros, incorre em diversas externalidades.

Dentre as externalidades negativas ocasionadas, Radojevic \& Hassan (1999) citam que as queimadas podem desencadear diversos problemas na região afetada, como o fechamento de escolas e de aeroportos ocasionados pela fumaça, aumento de acidentes de trânsito terrestre pela perda de visibilidade. A fumaça também tem o potencial de inibir a chuva (ROSENFELD, 1999) e de ocasionar interrupção nas redes de energia, o qual puderam ser observadas na Amazônia (DIAZ, 2002). Além de a dispersão dos poluentes relacionado às queimadas pode ser prejudicial à saúde humana sendo este o foco do estudo.

\subsection{O PROCESSO DAS QUEIMADAS}

As queimadas são processos de combustão da biomassa ocasionados por meios naturais ou de forma induzida. Dentre os poluentes clássicos emitidos pela queimada estão o CO (monóxido de carbono), NOx (óxidos de nitrogênio) e HC (hidrocarbonetos) e material particulado (RIBEIRO; ASSUNÇÃO, 2002). Esta que pode ocorrer por motivos diferentes, como salienta Santos et.al. (2018) A queima natural ocorre em função de períodos secos, baixa umidade e altas temperaturas que contribuem para a combustão natural do solo, enquanto que a induzida também chamada de incêndios, é amplamente utilizada na agropecuária como ferramenta de abertura de área, bem como podem ser iniciadas de forma não intencional através do descarte de materiais de alta combustão.

A queima está condicionada ao tipo de biomassa em combustão, a umidade relativa tanto da biomassa, quanto da atmosfera que, por sua vez está atrelada a temperatura e precipitação e a velocidade dos ventos. O tipo e vegetação local e a época do ano também tem participação na determinação da intensidade das queimadas, devido a vulnerabilidade da vegetação rasteira ao calor em períodos secos (GONÇALVES; CASTRO; HACON, 2012).

A prática da queimada intencional no Brasil é proibida com exceção ao uso para queima de cana-deaçúcar, pesquisas científicas e/ou tecnológicas e controle fitossanitário, justificadas pelo clima e vegetação em que se encontra e sujeito a avaliação e liberação do órgão regulador responsável, a Secretaria do Meio Ambiente (SEMA) em Mato Grosso. MATO GROSSO, 2011).

0 estado de Mato Grosso se encontra na região Centro-Oeste do país e três biomas compõe as características vegetativa: Cerrado, Pantanal e Floresta Amazônica, com clima caracterizado em média por verões chuvosos e invernos secos (PEREIRA et al., 2011; SANTOS et al., 2018). Com umidade relativa do ar em $80 \%$ em média durante o ano (INPE, 2018), propício a produção agrossilvipastoril, que por sua vez utiliza-se da queima como ferramenta na abertura de área produtiva (SANTOS et al., 2018).

\subsection{QUEIMADAS E OS DANOS À SAÚDE DO SER HUMANO}

As queimadas, sejam elas intencionais ou naturais, produzem externalidades ambientais locais. A fumaça liberada por esse processo aumenta a suscetibilidade das pessoas à microrganismos patogênicos devido a partículas muito pequenas contidas na fumaça, além de que a poluição atmosférica relacionada a liberação dos gases, favorece o surgimento de doenças respiratórias e doenças infecciosas pulmonares (ARBEX, 2012). 
A inalação dessa fumaça incorre fortemente na incidência de doenças do aparelho respiratório como asma, bronquite, além de tosse, falta de ar, alergia de pele e, até mesmo desordem cardiovascular, que dependendo da intensidade que ataca tem o potencial de levar à óbito (NASCIMENTO et al., 2016).

A exposição contínua aos poluentes é tão nociva a saúde que elevam a quantidade de pessoas afetadas com entrada hospitalar e podem causar sobrecarga ambulatorial sendo necessário maiores recursos para tratamento. Diversos estudos têm buscado entender a relação de doenças infecciosas respiratórias, Antunes et al. (2013); Gomes, Spydires e Lucio (2016); Passos et. al. (2016); Carvalho, Nakazato e Nascimento (2018), no entanto, sua concentração geralmente fica a encargo de um munícipio ou análises macros de estados.

Em Mato Grosso a relação das queimadas com essa enfermidade em crianças e idosos foi estudada para o município de Cuiabá (SILVA et. al., 2013), e também em Alta Floresta, relacionando ainda com a sazonalidade climática (PEREIRA, et. al., 2011). Entretanto, nenhum trabalho foi identificado que buscasse compreender essa relação dos focos para todo o estado e sua possível relação com as regiões mais voltadas para o agronegócio. Sendo importante analisar o comportamento desse estado que possui elevada quantidade de focos de calor e muitas delas decorrentes de queimadas intencionais. (SEMA, 2015).

0 método mais eficaz de combate à essa prática é a prevenção. Além da necessidade do licenciamento prévio para a prática produtiva de queima ter que ser solicitado junto à Sema em Mato Grosso, o combate às queimas naturais e induzidas ilegalmente ganhou novo aliado através do monitoramento por georreferenciamento por satélites que monitoram os focos de calor do Instituto Nacional de Pesquisas Espaciais (INPE), que se usado preventivamente pode se tornar uma ferramenta eficaz na diminuição dessas externalidades (GONÇALVES; CASTRO; HACON, 2012).

A saúde da população, tanto a rural quanto a urbana é posta em risco, com isso os gastos do governo são pressionados para atender o aumento das ocorrências, o que pode ser constatado em alguns estudos sobre essa relação específica entre esse tipo de doença e o processo de queima no Brasil (ZAVALA; GIGANTE, 2007; ARBEX, 2012), ou até mesmo mais específicos sobre doenças respiratórias em crianças no município de Cuiabá (MACHIN; NASCIMENTO, 2018), mas os estudos ainda são escassos. Uma tentativa de identificar se os casos estão associados com a grande utilização do fogo para o agronegócio será feita a seguir buscando a similaridade nos municípios de Mato Grosso.

\section{RELAÇÃO DAS QUEIMADAS COM AS DOENÇAS RESPIRATÓRIAS E A SIMILARIDADE DOS MUNICÍPIOS MATO-GROSSENSES}

\subsection{MODELO LINEAR GENERALIZADO: REGRESSÃO DE POISSON}

Modelos lineares generalizados (MLGs) são amplamente utilizados como recursos estatístico uma vez que encontrar variáveis que respeitem os pressupostos clássicos para a aplicação de uma regressão linear é dificultoso. O MLG flexibiliza o pressuposto de que os dados não possam apresentar correlação e tendência, garantindo assim que as estimativas dos coeficientes atinjam máxima verossimilhança (PAULA, 2004; DE SOUZA TADANO; UGAYA; FRANCO, 2009).

A regressão de Poisson faz parte da família MLG e é amplamente utilizada nos estudos epidemiológicos, principalmente para verificar a relação entre a poluição do ar com a provocação de doenças respiratórias (DE SOUZA TADANO; UGAYA; FRANCO, 2009; NASCIMENTO et al., 2016). A ligação canônica é responsável por garantir uma boa estimativa dos parâmetros do modelo (PAULA, 2004), a distribuição de Poisson possui a seguinte forma funcional:

$$
\log \mu=\eta \quad \text { (Equação 1) }
$$

Onde:

$\mu$ é uma função monótona e diferenciável e representa a esperança da variável aleatória independente, ou seja, $\mathrm{E}(\mathrm{Y}) ; \eta$ é o preditor linear de $\beta^{2}$.

Logo, como o objetivo é analisar a relação de focos de queimadas com as doenças respiratórias, a regressão de Poisson será utilizada, a partir de dados para os 141 municípios de Mato Grosso. Os registros de focos de queimada foram retirados do Instituto Nacional de Pesquisa Espacial (INPE), que são utilizadas como proxy para queimadas, sejam acidentais ou controladas. 
Os dados sobre doenças respiratórias foram retirados do Departamento de Informática do Sistema Único de Saúde (DATASUS, 2019), órgão da Secretaria Executiva do Ministério da Saúde, no qual são considerados os casos de internação, que incluem os pacientes que ocupam um leito hospitalar por pelo menos $24 \mathrm{hrs}$, já em casos de óbitos são registrados para qualquer período de tempo como internação.

Dentre os poluentes da queima foram considerados o material particulado fino (PM 2.5) e monoxódo de carbono, ambos dados disponíveis na pelo Sistema de informações ambientais integrados a saúde - SISAM (INPE). Também foi levado em consideração o número total da população de cada município como variável socioeconômica (IBGE, 2018).

O modelo de regressão de Poisson foi construído da seguinte maneira:

$$
\log D \cdot \operatorname{Resp}_{i}=\alpha_{i}+\beta_{1} P_{i}+\beta_{2} F I_{i}+\beta_{3} M P_{i}+\beta_{4} C O_{i} \varepsilon_{i}
$$

Onde, $\log$ D. Resp $\mathrm{i}_{\mathrm{i}}$ é número de doenças respiratórias registradas por município em 2015 (SES, 2018); $\alpha_{\mathrm{i}}$ é a constante; $P_{i}$ refere-se a população de cada município (IBGE, 2018); $\mathrm{FI}_{\mathrm{i}}$, são os focos de incêndio por município (INPE, 2018); $\mathrm{CO}_{\mathrm{i}}$ é a emissão do monóxido de carbono por município (INPE, 2018) e, por fim, $\varepsilon_{\mathrm{i}}$ corresponde ao erro aleatório do modelo.

O Coeficiente de Correlação ou Correlação de Pearson indicou uma relação linear entre as variáveis, bem como as estatísticas individuais (p-valor) indicaram que todos os parâmetros estimados são significantes para explicar as doenças, o que aponta um bom ajustamento estatístico, com o seguinte modelo estimado:

$$
\begin{array}{rr}
\log D \cdot \operatorname{Resp}_{i}=0,442+0,000005 P_{i}+0,000028 F I_{i}+0,000005 M P_{i} \\
+0,018087 C O_{i} & \text { (Equação 3) }
\end{array}
$$

Todas as variáveis analisadas apresentaram relação positiva com doenças do aparelho respiratório, tendo o monóxido de carbono o parâmetro com maior representatividade, assim como ressaltado nos estudos epidemiológicos de Diaz (2002) e Nascimento et al. (2016).

Ademais, outros fatores passíveis de afetar a saúde populacional quanto a doenças do aparelho respiratório que fogem do escopo desse trabalho podem ser incluídas no modelo. Gonçalves, Castro e Hacon (2012) indicaram em seu estudo que o nível de pavimentação dos municípios também possui relação com doenças respiratórias, ficando como sugestão para um futuro trabalho abordar essa variável e verificar sua interferência na saúde.

\subsection{SIMILARIDADE DOS MUNICÍPIOS}

Com o objetivo de analisar se há um padrão de comportamento quanto a doenças respiratórias dentre os municípios mato-grossenses será observada a similitudes a partir de uma técnica de agrupamento de dados.

Para identificar as similaridades entre os municípios deve-se agrupa-los de tal forma que cada grupo possua os municípios mais homogêneos entre si e, ao mesmo tempo, que sejam heterogêneos em relação aos outros grupos. Isto é exatamente o que ocorre em uma análise conglomerada, divide-se um grande grupo de observações em grupos menores, sendo a agregação dos grupos menores feitas com base em suas características, de modo que os objetos inclusos no mesmo grupo sejam muito semelhantes, possuindo grande homogeneidade interna, por outro lado diferentes grupos devem ser dissimilares. (HAIR, et. al., 2005; LATTIN; CAROLL; GREEN, 2011)

Existem diversos métodos para análise de clusters, dentre eles o procedimento hierárquico que pode ser feito pelo método aglomerativo ou divisivo, Hair et.al (2005) apontam que este procedimento para formação dos agrupamentos funciona, pelo primeiro método, pela junção em um mesmo grupo das duas observações mais semelhantes, fazendo isso repetidamente até que todas as observações estejam em um só agrupamento. 0 método divisivo, por sua vez, atua de maneira inversa, começando com apenas um grupo e finalizando o número de grupos igual ao número de objetos, tal como se inicia o primeiro método. (HAIR, et.al, 2005)

Para que esta junção entre os objetos possa ser feita existe ainda diferentes métodos de ligação disponíveis, a ligação simples que une a partir da menor distância entre os objetos, a ligação completa tem 
como critério de agrupamento a distância máxima, a ligação média pelo valor médio, o método centroide considera a distância euclidiana simples ou quadrada entre seus centroides37, por fim o método de Ward que ao invés de buscar a distância ele procura dois objetos que se unam obtendo a menor variância dentro do grupo (LATTIN; CARROLL; GREEN, 2011).

Este processo de agrupamento pode ser descrito em etapas para melhor compreensão, este trabalho foi feito por Lattin, Carroll e Green (2011) esclarecendo essas 6 etapas de forma genérica. Sendo a Etapa 0 na qual todos os objetos em agrupamentos separados, com os agrupamentos sendo definidos por C1, C2, C3., $\mathrm{Cn}$, sendo a distância entre dois agrupamentos a distância entre os objetos nele contidos, a etapa 1 consiste em encontrar a distância mínima (ou máxima, média, ou euclidiana, dependendo do método, para facilitar utilizaremos mínima), representando-os por $\mathrm{Ci}$ e $\mathrm{Cj}$, a etapa 3 consiste em combinar estes agrupamentos de menor distância para formar um novo agrupamento denominado Cij.

A próxima etapa é semelhante a anterior, mas ao comparar as distâncias considera-se a distância do novo grupo $\mathrm{Cij}$ e todos os outros agrupamentos $\mathrm{Ck}$, ao encontrar novo grupo com menor distância com Cij adicione-o ao agrupamento, formando um novo grupo, por fim a etapa final é retornar à etapa 1 sucessivas vezes, até que reste apenas 1 agrupamento (LATTIN; CARROLL; GREEN, 2011).

Os resultados finais de agrupamentos hierárquico geralmente são visualizados por meio de gráficos de dendrograma, um exemplo dado oito objetos ( 1 a 8 ) quaisquer pode ser observado na figura 1 , a seguir:

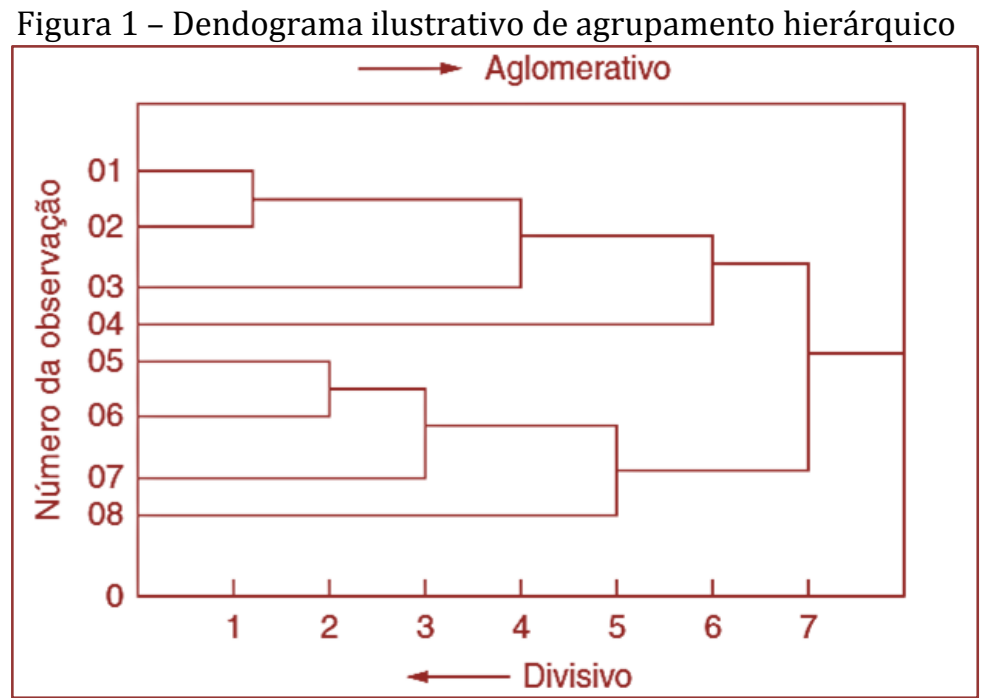

Fonte: HAIR, et. al. (2005, pg. 449)

Na figura 1 também é visualmente perceptível que o método aglomerativo e divisivo seguem direções opostas, mas as mesmas formações de cluster podem ser obtidas. Em geral os softwares utilizam-se do método aglomerativo, este que pode ser visto como um divisivo ao contrário (HAIR, et.al, 2005).

Para identificar quais dos municípios de Mato Grosso apresentam maiores casos de doenças respiratórias em seu conjunto utilizamos o método Multivariado Hierárquico. Para a geração do agrupamento foi utilizado o software SPSS v.22, para Windows, os municípios foram agrupados de acordo com o número de doenças respiratórias no ano de 2015, foram estabelecidos 4 grandes grupos de acordo com os 141 municípios (anexo A). 0 método de aglomeração utilizado é o de Ward, considerando-se as distâncias euclidianas, sendo possível fazer estes grupos após a geração do dendrograma.

A seguir, análise e discussão dos resultados da regressão e do agrupamento serão apresentados.

\section{RESULTADOS E DISCUSSÕES}

A análise de regressão de Poisson realizada indicou elevada correlação com todos os fatores estudados, e como verificado em estudos anteriores, os sinais do modelo apresentaram relação positiva, indicando que o aumento das variáveis do modelo induz o aumento de casos de doenças respiratórias nos municípios do estado.

\footnotetext{
${ }^{37}$ É a média ou valor médio dos objetos contidos no agrupamento sobre cada variável (HAIR et.al, 2005, p.382)
} 
A relação positiva das variáveis explicativas com o aumento das doenças respiratórias por municípios evidencia a necessidade de trabalhar de forma preventiva quanto às queimas, uma vez que as internações pela enfermidade no aparelho respiratório no estado têm sido expressivas nos últimos anos, além do crescente gasto do governamental para atender essa crescente demanda hospitalar (PES, 2017).

0 monóxido de carbono, que possui o parâmetro maior representatividade, indica que com o aumento em $1 \%$ na emissão em sua emissão, as respiratórias se elevam em $0,018 \%$, enquanto os focos de calor implicam em aumento de $0,000028 \%$ nas doenças respiratórias. Apesar de ser uma porcentagem baixa, considerando que outros fatores não foram incluídos no modelo, dificuldade de se obter dados precisos e que a relação que se apresenta é positiva e significativa, isto representa uma pequena parte da dimensão da relação que buscou-se analisar neste artigo.

E ainda, através da análise de agrupamentos chegou-se a 4 grupos divididos por suas similaridades, que estão no ANEXO A, e a partir do dendograma obteve-se a hierarquização dos dados referentes as doenças respiratórias - tabela 2 - tem-se os grupos similares segundo a ordem de grandeza. 0 grupo que apresentou maior média de casos registrados foi o Grupo 4, que inclui os municípios de Comodoro, Cuiabá, Rondonópolis e Várzea Grande, que com exceção do primeiro município os demais são os de maior contingente populacional e mais urbanizados, o que pode também influenciar o grande número de casos, uma vez que a população é o fator determinístico mais forte da regressão.

Tabela 2- Classificação dos grupos por ordem de grandeza da média em doenças respiratórias

\begin{tabular}{|c|c|c|}
\hline \multicolumn{1}{|c|}{ Grupo } & № munic. & Média de Doenças Respiratórias \\
\hline Grupo 1 & 72 & 17,792 \\
\hline Grupo 2 & 41 & 105,000 \\
\hline Grupo 3 & 24 & 351,667 \\
\hline Grupo 4 & 4 & 1438,000 \\
\hline
\end{tabular}

Fonte: Datasus (2019). Elaborado pelos autores.

Alguns trabalhos retratam o grande efeito das queimadas na saúde respiratória (DIAZ, et. al., 2002; GONÇALVES; CASTRO; HACON, 2012; PEREIRA, et. al., 2011), mas em contraposição o grupo que apresentou a menor média de casos neste trabalho são os com municípios que em sua maioria se concentram no bioma Amazônico. Esse resultado pode decorrer do fato da dificuldade de isolar os fatores da queimada nas doenças, com a população recebendo maior importância como fator influenciador da variável dependente, doenças respiratórias, e também de não se tratarem de trabalho que analisem os dados para todo estado e de forma agregada

Dentre os grupos, os munícipios que possuem maiores áreas de floresta apresentaram maiores evidências da influência de queimadas sobre as doenças, no entanto, a média se apresentou baixa em relação aos demais. 0 que é um indicativo de que as doenças também não estão sendo registradas, subestimando alguns resultados.

Além disso, os gases CO e o material particulado resultante da queima de biomassa podem ser transportando para milhares de quilômetros da área na qual ocorreu a queimada, a depender de como funciona a circulação atmosférica na região, bem como os movimentos convectivos e o deslocamento de massas de ar (FREITAS, 2005). Logo, isso também pode explicar porque alguns municípios que apresentam maiores focos de incêndio, não necessariamente apresentaram a maioria dos casos de internação por doenças respiratórias.

\section{CONSIDERAÇÕES FINAIS}

Ao longo deste trabalho procurou-se analisar a relação das práticas de queimadas com sua implicação na saúde humana, com recorte geográfico em Mato Grosso. A escolha do Estado se deu, pois, ele apresenta grandes índices de focos de queimada, figurando sempre entre os três maiores estados, desde 2005 até 2018, sendo o terceiro colocado no ano de análise, o que pode ser relacionado com a atividade agrossivilpastoril em MT.

A análise deu ênfase nas doenças do aparelho respiratório, estas que representaram 10,61\% dos casos de internação da população mato-grossense, também o terceiro maior causa de internação dentre as enfermidades. Isso representa gastos de quase 20 bilhões ao ano dos cofres públicos, além de implicar na saúde da população (DATASUS, 2019). 
Grande parte dos focos de calor são localizados nas regiões norte, noroeste e nordeste do estado, que é justamente onde as novas fronteiras da agricultura e pecuária estão se instaurando. E, apesar da grande utilidade das queimadas, que apresentam baixo custo no processo produtivo agropecuário, gera externalidades negativas para toda sociedade pelas enfermidades decorrentes, bem como os danos ao meio ambiente.

As condições climáticas do estado, clima predominantemente seco, altas temperaturas, baixa umidade do ar são propícias para o aumento do foco de calor, associadas as queimadas elevam ainda mais os números. E, dado que há relação das queimadas com as doenças respiratórias, prevenir as queimadas é fundamental para reduzir as externalidades associadas a ela.

Contudo, algumas ressalvas devem ser consideradas na interpretação dos dados, pois ainda não é possível obter dados que segreguem queimadas intencionais, acidentais e incêndios florestais, o que dificulta relacionar as queimadas intencionais oriundas do agronegócio com as doenças respiratórias. Outro fator é que são consideradas apenas internações decorrentes de enfermidades do aparelho respiratório, não incluindo os casos de doenças respiratórias que não resultam em internação.

E ainda, outras condições como a urbanização dos municípios, nível de industrialização, quantidade de veículos, não foram considerados no trabalho, fatores que também estão atrelados a doenças respiratórias. Esses fatores não considerados podem explicar o porquê qual os maiores centros urbanos do estado apresentaram a maior média de doenças respiratórias ficando no mesmo grupo.

Por fim, ressalta-se que existem intuições responsáveis pela fiscalização das queimadas, tais como Secretaria de Estado do Meio Ambiente (SEMA) e a Polícia Militar Ambiental (PMA), o que contribui para diminuição dos focos de calor no estado. Entretanto, é preciso repensar as políticas públicas, com intensificação das ações de regulação e controle das instituições especializadas.

Pois, mesmo que a prática do uso do fogo seja regulamentada em Mato Grosso pela Lei no 9.584/2011, que minimizam as consequências e impactos ocasionados pelas queimadas, muitos casos de queimada de origem antrópica não estão dentro dessa regulamentação. Mas, não somente órgãos públicos, os setores privados são fundamentais nesse sentido.

Considerando o trabalho do INPE de monitoramento de focos de incêndio e que a queimada é um problema recorrente, além da necessidade ações preventivas e fiscalização mais incisiva, exige cada vez mais sensibilização da população. Uma vez que os gastos com saúde são elevados e a tecnologia está cada vez mais avançada, utilizar outros métodos para abrir para abrir pastagem, preparo do plantio, colheita da cana-de-açúcar, dentre outras utilizações para o fogo, devem ser ponderadas, buscando a redução da emissão dos gases tóxicos e priorizando os benefícios a saúde, meio-ambiente e bem-estar da população.

\section{REFERÊNCIAS}

[1] ANTUNES, Fernanda Pedro et al. Desigualdades sociais na distribuição espacial das hospitalizações por doenças respiratórias. Cadernos de Saúde Pública, v. 29, p. 1346-1356, 2013. Disponível em: <https://www.scielosp.org/scielo.php?pid=S0102-311X2013001100009\&script=sci_arttext>. Acesso: out.2018.

[2] ARBEX, Marcos Abdo et al. A poluição do ar e o sistema respiratório. Jornal Brasileiro de Pneumologia, v. 38, n. 5, p. 643-655, 2012.

[3] BENÍCIO, Maria Helena D.'Aquino et al. Tendência secular da doença respiratória na infância na cidade de São Paulo (1984-1996). Revista de Saúde Pública, v. 34, p. 91-101, 2000.

[4] BRASIL. MINISTERIO DA SAUDE. SECRETARIA DE ASSISTENCIA A SAUDE. DEPARTAMENTO DE SISTEMAS E REDES ASSISTENCIAIS. Padronização da nomenclatura do censo hospitalar. Brasil. Ministério da Saúde, 2002.

[5] CARVALHO, Priscila Camargo; NAKAZATO, Lígia Furitani; NASCIMENTO, Luiz Fernando Costa. Exposure to NO2 and children hospitalization due to respiratory diseases in Ribeirão Preto, SP, Brazil. Ciencia \& saude coletiva, v. 23, p. 2515-2522, 2018. Disponível em: <https://www.scielosp.org/article/csc/2018.v23n8/2515-2522/>. Acesso: out.2018.

[6] DALL'AGNOL, A. et al. O complexo agroindustrial da soja brasileira. Embrapa Soja-Circular Técnica (INFOTECA-E), 2007. Disponível em: <infoteca.cnptia.embrapa.br>. Acesso mar.2019.

[7] DATASUS - Departamento de Informática do SUS / Ministério da Saúde, 2016. SIHSUS - Sistema de Informações Hospitalares do SUS. Disponível em: Acesso em: 05 fev. 2018.

[8] DE SOUZA TADANO, Y.; UGAYA, C. M. L.; FRANCO, A. T. Método de regressão de Poisson: metodologia para avaliação do impacto da poluição atmosférica na saúde populacional. Ambiente \& Sociedade, v. 12, n. 2, p. 241-255, 2009. 
[9] DIAZ, Maria del Carmen Vera et al. O preço oculto do fogo na Amazônia: Os custos econômicos associados as queimadas e incêndios florestais. Belém: Instituto de Pesquisa Ambiental da Amazônia, 2002.

[10] FREITAS, Saulo R. et al. Monitoring the transport of biomass burning emissions in South America. Environmental Fluid Mechanics, v. 5, n. 1-2, p. 135-167, 2005.

[11] GOMES, Ana Carla dos Santos; SPYRIDES, Maria Helena Constantino Spyrides; LUCIO, Paulo Sérgio Lucio. Dynamic Regression Model for Evaluating the Association Between Atmospheric Conditions and Deaths due to Respiratory Diseases in São Paulo, Brazil. Revista Brasileira de Meteorologia, v. 33, n. 1, p. 1-10, 2018. Disponível em: <http://www.scielo.br/scielo.php?pid=S0102-77862018000100001\&script=sci_arttext>. Acesso: out.2018.

[12] GONÇALVES, Karen dos Santos; CASTRO, Hermano Albuquerque de; HACON, Sandra de Souza. As queimadas na região amazônica e o adoecimento respiratório. Ciência \& Saúde Coletiva, 17(6):1523-1532, 2012.

[13] GUJARATI, Damodar N.; PORTER, Dawn C. Econometria Básica-5. Amgh Editora, 2011.

[14] HAIR, Joseph F. et al. Análise multivariada de dados. 5. Ed. -Porto Alegre: Bookman, 2005.

[15] IBGE - Instituto Brasileiro de Geografia e Estatística. Cidades. Brasília; 2007. Disponível em:< http://www.ibge.gov.br/cidadesat/ topwindow.htm?1>. Acesso em: mar. 2019.

[16] IMEA - Instituto Mato-grossense de Economia Agropecuária. Indicadores. Disponível em: <http://www.imea.com.br/imea-site/indicadores>. Acesso: mar.2019.

[17] INPE - Instituto Nacional de Pesquisas Espaciais - Pagina internet do monitoramento de queimadas. Disponível em: <http://www.inpe.br/queimadas /bdqueimadas>. Acesso em: ago.2018.

[18] LATTIN, James; CARROLL, J. Douglas; GREEN, Paul E. Analise de dados multivariados. São Paulo: Cengage Learning, 2011.

[19] MACHIN, Adrian Blanco; NASCIMENTO, Luiz Fernando Costa. Efeitos da exposição a poluentes do ar na saúde das crianças de Cuiabá, Mato Grosso, Brasil. Cadernos de Saúde Pública, v. 34, p. e00006617, 2018.

[20] MATO GROSSO. Lei n.9.584, de 4 de julho de 2011 - D.0. 05.07.2011. Define procedimentos, proibições, estabelece regras de execução e medidas de precaução a serem obedecidas quando do emprego do fogo em práticas agrícolas, pastoris e florestais, e dá outras providências. Disponível em: Acesso em: 06 jan. 2019

[21] NASCIMENTO, Luiz Fernando Costa et al. Air pollution and respiratory diseases: ecological time series. Sao Paulo Medical Journal, v. 134, n. 4, p. 315-321, 2016. Disponível em: <http://www.scielo.br/scielo.php?pid=S1516$31802016000400315 \&$ script=sci_arttext>. Acesso: out.2018.

[22] PASSOS, Saulo Duarte et al. ACUTE RESPIRATORY DISEASES IN BRAZILIAN CHILDREN: ARE CAREGIVERS ABLE TO DETECT EARLY WARNING SIGNS?. Revista Paulista de Pediatria, v. 36, n. 1, p. 3-9, 2018. Disponível em: <http://www.scielo.br/scielo.php?pid=S010305822018000100003\&script=sci_arttext\&tlng=pt>. Acesso: out.2018.

[23] PAULA, Gilberto Alvarenga. Modelos de regressão: com apoio computacional. São Paulo: IME-USP, 2004.

[24] PLANO ESTADUAL DE SAÚDE - PES, de Saúde - PES. MT 2016-2019. Relatório. Mato Grosso SES-MT: Cuiabá. 2017. Disponível em: <http://www.saude.mt.gov.br/publicacoes>. Acesso: out.2018.

[25] PEREIRA, Viviane Solange et al. Análise dos atendimentos ambulatoriais por doenças respiratórias no Município de Alta Floresta-Mato Grosso-Amazônia brasileira. Epidemiologia e Serviços de Saúde, v. 20, n. 3, p. 393400, 2011.

[26] RADOJEVIC, Miroslav; HASSAN, Hasnah. Air quality in Brunei Darussalam during the 1998 haze episode. Atmospheric Environment, v. 33, n. 22, p. 3651-3658, 1999.

[27] RIBEIRO, Helena; ASSUNÇÃO, João Vicente de. Efeitos das queimadas na saúde humana. Estudos avançados, v. 16 , n. 44 , p. $125-148,2002$.

[28] ROGRIGUES, Poliany Cristiny de Oliveira; IGNOTTI, Eliane; HACON, Sandra de Souza. Distribuição espaçotemporal das queimadas e internações por doenças respiratórias em menores de cinco anos de idade em Rondônia, 2001 a 2010. Epidemiol. Serv. Saúde, Brasília, 22(3):455-464, jul-set 2013.

[29] ROSA, Ana Maria. Análise da magnitude das doenças respiratórias em menores de 15 anos, Tangará da Serra/Mato Grosso. Dissertação (Mestre Saúde Coletiva). Universidade Federal de Mato Grosso, Cuiabá, 2008. 144 pp.

[30] ROSENFELD, Daniel. TRMM observed first direct evidence of smoke from forest fires inhibiting rainfall. Geophysical research letters, v. 26, n. 20, p. 3105-3108, 1999.

[31] SANTOS, Paula Resende, et.al. Análise de Queimadas no Cerrado e sua relação com NDVI para os anos de 2000 a 2014. Revista de Geografia (Recife) V. 35, No. 2, 2018.

[32] SEMA - Secretaria de Estado de Meio Ambiente. Relatório de Monitoramento de Focos de Calor 2015. Cuiabá, 2015. $19 \quad$ p. $\quad$ Disponível em: < $\quad$ http://www.sema.mt.gov.br /attachments/article/75/Relatorio\%20Focos\%20de\%20calor\%202015.pdf> Acesso: jan. 2019. 
[33] SILVA, Ageo Mario Candido da et al. Material particulado originário de queimadas e doenças respiratórias. Revista de Saúde Pública, v. 47, p. 345-352, 2013.

[34] ZAVALA, Arturo Alejandro Zavala; GIGANTE, Ludmila Alves. Um estudo da similaridade das queimadas entre municípios no estado de Mato Grosso. SINERGIA, Rio Grande, 11(2): 29-40, 2007. 
ANEXO A - MUNÍCIPIOS DE MATO GROSSO AGRUPADOS

TABELA 1- Grupos por municípios de acordo com suas similitudes

\begin{tabular}{|c|c|c|c|}
\hline \multicolumn{4}{|c|}{ Grupo 1} \\
\hline Acorizal & \multicolumn{2}{|l|}{ Itanhangá } & Porto dos gaúchos \\
\hline Alto boa vista & \multicolumn{2}{|l|}{ Itaúba } & Porto esperidião \\
\hline Alto garças & \multicolumn{2}{|l|}{ Jangada } & Porto estrela \\
\hline Alto paraguai & \multicolumn{2}{|l|}{ Jauru } & Reserva do cabaçal \\
\hline Alto taquari & \multicolumn{2}{|l|}{ Lambari d'oeste } & Ribeirãozinho \\
\hline Araguaiana & \multicolumn{2}{|l|}{ Luciara } & Rondolândia \\
\hline Araguainha & \multicolumn{2}{|c|}{ Nova bandeirantes } & Rosário oeste \\
\hline Araputanga & \multicolumn{2}{|c|}{ Nova brasilândia } & Salto do céu \\
\hline Arenápolis & \multicolumn{2}{|c|}{ Nova canaã do norte } & Santa carmem \\
\hline Barão de melgaço & \multicolumn{2}{|c|}{ Nova guarita } & Santa cruz do xingu \\
\hline Bom jesus do araguaia & \multicolumn{2}{|l|}{ Nova lacerda } & Santa rita do trivelato \\
\hline Campos de júlio & \multicolumn{2}{|l|}{ Nova marilândia } & Santa terezinha \\
\hline Canabrava do norte & \multicolumn{2}{|l|}{ Nova maringá } & Santo afonso \\
\hline Castanheira & \multicolumn{2}{|l|}{ Nova monte verde } & Santo antônio do leste \\
\hline Chapada dos guimarães & \multicolumn{2}{|l|}{ Nova santa helena } & São josé do povo \\
\hline Cláudia & \multicolumn{2}{|c|}{ Nova ubiratã } & São josé do xingu \\
\hline Conquista d'oeste & \multicolumn{2}{|c|}{ Novo horizonte do norte } & São josé dos quatro marcos \\
\hline Curvelândia & \multicolumn{2}{|c|}{ Novo mundo } & São pedro da cipa \\
\hline Feliz natal & \multicolumn{2}{|c|}{ Novo santo antônio } & Serra nova dourada \\
\hline Figueirópolis d'oeste & \multicolumn{2}{|c|}{ Novo são joaquim } & Tesouro \\
\hline Gaúcha do norte & \multicolumn{2}{|l|}{ Planalto da serra } & União do sul \\
\hline Glória d'oeste & \multicolumn{2}{|l|}{ Pontal do araguaia } & Vale de são domingos \\
\hline Indiavaí & Ponte branca & & Vera \\
\hline Ipiranga do norte & Porto alegre do $\mathrm{n}$ & & Vila bela da santíssima trindade \\
\hline & & Grupo 2 & \\
\hline Água boa & Dom aquino & & Pedra preta \\
\hline Alto araguaia & General carneiro & & Querência \\
\hline Apiacás & Guarantã do nort & & Ribeirão cascalheira \\
\hline Aripuanã & Guiratinga & & Rio branco \\
\hline Campinápolis & Itiquira & & Santo antônio do leverger \\
\hline Campo novo do parecis & Juara & & São félix do araguaia \\
\hline Canarana & Juruena & & São josé do rio claro \\
\hline Carlinda & Juscimeira & & Sapezal \\
\hline Cocalinho & Marcelândia & & Tabaporã \\
\hline Colniza & Matupá & & Tapurah \\
\hline Confresa & Nortelândia & & Terra nova do norte \\
\hline Cotriguaçu & Nossa senhora do & amento & Torixoréu \\
\hline Denise & Nova nazaré & & Vila rica \\
\hline Diamantino & Nova xavantina & & \\
\hline & Grupo 3 & & Grupo 4 \\
\hline Barra do bugres & Lucas do rio verde & Poconé & Comodoro \\
\hline Barra do garças & Mirassol d'oeste & Pontes e lacerda & Cuiabá \\
\hline Brasnorte & Nobres & Poxoréu & Rondonópolis \\
\hline Cáceres & Nova mutum & Primavera do leste & Várzea grande \\
\hline Campo verde & Nova olímpia & Sinop & \\
\hline Colíder & Paranaíta & Sorriso & \\
\hline Jaciara & Paranatinga & Tangará da serra & \\
\hline Juína & Peixoto de azevedo & & \\
\hline
\end{tabular}




\section{Capítulo 15}

\section{Sucessão geracional: Fatores decisórios na perspectiva}

de jovens sucessores rurais

\section{Gabrieli dos Santos Amorim \\ Adriano Lago \\ Mariele Boscardin \\ Camila Weber}

Resumo: A migração dos jovens do campo para a cidade ocasiona diversas consequências, dentre elas a falta de sucessão geracional em propriedades rurais. Neste cenário, compreender os fatores decisórios que influenciam a permanência do jovem no campo torna-se essencial para que se garanta o processo de reprodução social e a sucessão geracional. Nesta perspectiva, sustenta-se o objetivo geral do estudo em analisar os fatores decisórios que influenciam no processo de sucessão geracional, na perspectiva de jovens rurais que pertencem a famílias associadas a uma cooperativa agropecuária do segmento de carne na região centro oriental do estado do Rio Grande do Sul. O método de elaboração deste estudo consiste em uma pesquisa mista, com aplicação de um questionário como instrumento de coleta de dados, embasado na metodologia de Slack, Chambers e Johnston (2007), ao utilizar-se de uma escala métrica de nove pontos para obter-se o nível de importância e desempenho de seis fatores decisórios que influenciam na permanência do jovem no campo. Os questionários foram aplicados a uma amostra de 60 jovens sucessores ou com perspectiva de sucessão. Os resultados apontam que o desempenho dos seis fatores decisórios: escolaridade, valorização social do produtor, autonomia, incentivo e reconhecimento, diálogo familiar e matrimônio é menor do que a importância, ou seja, os jovens sucessores não suprem suas expectativas, diante dos fatores. Conclui-se que se necessita aperfeiçoar o desempenho dos fatores decisórios em estudo para complementar a satisfação dos jovens sucessores, através de ações que contribuam para a sua permanência no meio rural e para que se garanta o processo de sucessão geracional.

Palavras-chave: êxodo rural; sucessão geracional; jovens sucessores; permanência no campo. 


\section{INTRODUÇÃO}

A modernização da agricultura que iniciou na década de 50, com o aperfeiçoamento das técnicas de produção agrícolas, contribuiu para o aumento da participação dos mais favorecidos na apropriação de terras e de renda total no meio rural (GRAZIANO DA SILVA, 1993). Como resultado do processo de modernização da agricultura, ocorreu o aumento generalizado da pobreza no campo, e consequentemente ao aceleramento do êxodo rural no país (GRAZIANO DA SILVA, 1993). 0 êxodo rural é declarado como a migração de indivíduos do meio rural para os centros urbanos.

Na perspectiva de Schneider (1994), o deslocamento relevante do número de indivíduos para o meio urbano ocorrido no Brasil, é esclarecido pelo reflexo das transformações que ocorreram na esfera da organização da produção e da realocação de recursos econômicos. Desde 1950, a cada 10 anos, um em cada três indivíduos brasileiros que vivem no campo migram para a cidade (CAMARANO; ABRAMOVAY, 1998).

Nessa concepção, percebe-se que no Brasil nos últimos anos, segundo o Censo Demográfico do Instituto Brasileiro de Geografia e Estatística $(2000,2010)$ a população em situação de domicilio rural decresceu 9,43\%. Ainda, no estado do Rio Grande do Sul a população em situação de domicílio rural representava, em $2000,18,35 \%$ da população total e alterou-se para 14,90\% no ano de 2010 e a população jovem rural no estado decresceu 22,46\% (IBGE, 2000, 2010). Os dados exemplificados comprovam o cenário da saída das novas gerações do meio rural.

0 êxodo rural brasileiro sofreu intensificação e tornou-se seletivo, que acabou por provocar consequências ao ambiente rural, essas consequências, são destacadas por diversos autores como Silvestro et al. (2001); Faccin e Schmidt (2013); Spanevello et al. (2014); Matte, Spanevello e Andreatta (2015).

Nesse sentido, ao comprometer-se a dinâmica da população rural, a falta de sucessão geracional, principalmente em propriedades familiares, é considerada como uma das consequências da saída das novas gerações do campo. Além da masculinização e envelhecimento da população, enfatizada pela saída dos jovens mais escolarizados e do sexo feminino do meio rural e a falta de mão de obra qualificada, de maneira que os jovens são atraídos para a cidade em busca de melhores ofertas de trabalho e estudo. Camarano e Abramovay (1998), enfatizam que até 1980 o êxodo rural era mais homogêneo quanto ao sexo e idade, porém após essa década é principalmente a população jovem e feminina que está deixando o meio rural.

Deste modo, diante de inúmeras consequências provocadas pelo êxodo rural, é relevante refletir sobre a principal, a falta de sucessão geracional. Nesse sentido, surge a preocupação com a reprodução social que, para Spanevello (2008), envolve as dimensões da produção de bens materiais e a organização social dessa produção do trabalho, preocupada com a continuidade das organizações e grupos sociais e que está interligada ao processo sucessão geracional que segundo Gasson e Errington (1993), é o processo de transferência do controle ou do gerenciamento sobre o uso do patrimônio familiar aos filhos sucessores ou a próxima geração.

À vista disso, ocasiona-se o encadeamento da preocupação da garantia da reprodução social da população rural que leva a ocorrência da sucessão geracional, ou seja, sem reprodução social inibe-se o processo de sucessão geracional. Stropasolas (2011), salienta que a não ocorrência da sucessão geracional é uma problemática social que envolve questões culturais e históricas reproduzidas por diversos segmentos na agricultura, não resultando apenas de fatores internos às famílias rurais, mas são também motivados pelas consequências de problemas ainda não resolvidos no mundo rural.

Neste contexto, enfatiza-se estudos como o de Carneiro (2001), Silvestro et al (2001), Stropasolas (2004), Spanevello (2008), Weishemer (2009), Kischener, Kiyota e Perondi (2015), Matte, Spanevello e Andreatta (2015), entre outros na literatura abordam os fatores decisórios que levam os jovens rurais permanecer ou sair do campo. Atualmente, manter os fatores decisórios que influenciam a permanência dos jovens nas propriedades rurais é um obstáculo, pois muitas vezes estes fatores não são supridos devido às condições que se estabelecem no ambiente rural.

Nessa perspectiva, surge a preocupação do estudo em entender os fatores decisórios que influenciam a permanência do jovem rural no campo, com o intuito de contribuir e incentivar para que o jovem permaneça no campo e de continuidade no processo de sucessão geracional. De maneira que, se possa auxiliar ao conhecer as necessidades e desejos dos jovens diante de suas expectativas. 
Com base nessas questões, o objetivo deste estudo consiste em analisar os fatores decisórios que influenciam no processo de sucessão geracional na perspectiva de jovens rurais que pertencem a famílias associadas a uma cooperativa agropecuária dos segmentos de carnes na região centro oriental do estado do Rio Grande do Sul. A região que abarca o estudo, apresenta de fato a redução da população rural em 5,33\% na região centro oriental do estado e 9,33\% na microrregião de Lajeado-Estrela onde localiza-se a cooperativa agropecuária (IBGE, 2000, 2010).

O estudo está estruturado em três seções principais, além desta introdução. A primeira seção abrange uma revisão que compreende o eixo principal da interação entre a sucessão geracional e os fatores decisórios. A segunda seção evidencia os procedimentos metodológicos utilizados para a coleta de dados. A terceira seção apresenta a análise e interpretação dos dados da pesquisa, referente a perspectiva dos jovens sobre os fatores decisórios no processo de sucessão geracional. Por fim, salienta-se as considerações finais do estudo baseadas nos resultados.

\section{OS FATORES DECISÓRIOS NO PROCESSO DE SUCESSÃO GERACIONAL}

A sucessão geracional se equivale da troca de titularidade de determinado direito, relacionado à passagem desse direito para as próximas gerações familiares, onde o jovem rural tem o compromisso com a família, para o funcionamento e a reprodução da unidade produtiva rural familiar e que depende fundamentalmente da sua participação no sistema das atividades familiares (WANDERLEY, 2007; CHEMIN; AHLERT, 2010).

Ainda, é possível ressaltar que segundo Abramovay et al (1998), os aspectos essenciais à sucessão vão além da questão estrutural como a terra, existem dimensões subjetivas e valores próprios para dar continuidade aos processos de sucessão no meio rural, existe um certa fusão entre os objetivos dos pais da continuidade do estabelecimento e dos filhos em serem agricultores.

Neste sentido, diferentemente das gerações passadas, as novas gerações estão interligadas a numerosas relações sociais e culturais que fazem os jovens rurais repensar sobre seus objetivos e interesses pessoais, torna-se um processo de individualização associado a fatores que interferem na permanência dos jovens nas propriedades rurais (fatores internos familiares ou econômicos) (BRUMER et al, 2000; SPANEVELLO, 2008). Corrobora, Schwarz (2004), ao enfatizar que para cada indivíduo os fatores vinculados a propriedade rural, são representados e assumidos de distintas maneiras, devido que são diferentes pessoas, coisas e momentos.

Os fatores como a viabilidade econômica da propriedade rural (renda), a valorização da profissão de agricultor, relações de gênero, a relação entre pais e filhos, a pluriatividade das atividades agrícolas e a qualificação do possível sucessor, são expressos por Brumer et al (2000), como fatores que interferem na permanência do jovem no rural.

Silvestro et al (2001) em estudo desenvolvido no oeste de Santa Catarina, aponta fatores decisórios como a oportunidade dos jovens ao ampliar sua participação na tomada de decisão da propriedade, porém essa oportunidade não é acompanhada de novas possibilidades de realização profissional, o nível de escolaridade dificulta o desempenho da atividade agrícola e principalmente a organização e o desenvolvimento das novas atividades que se colocam para o meio rural.

Carneiro (2001) buscou entender as formas de transmitir a herança e sua relação com a reprodução social de agricultores familiares em duas regiões distintas: no município de Nova Pádua, na região de influência de Caxias do Sul, no estado do Rio Grande do Sul, e na região serrana do estado do Rio de Janeiro, município de Nova Friburgo.

0 autor identifica como fatores, que as propriedades não comportam todos os filhos, ausência do mercado de terras, desvalorização do trabalho agrícola com a oferta de emprego urbano, valorização do estudo como meio de ascensão, as mulheres deixam de ver o casamento como única forma de inserção social, atividades não agrícolas são mais atrativas e a desvalorização da identidade de agricultor (CARNEIRO, 2001).

Stropasolas (2004) em estudo com jovens das comunidades rurais da cidade de Ouro, situada na região Oeste de Santa Catarina, identificou os fatores referentes ao controle sobre a sexualidade feminina, noção de vida urbana com mais liberdade, que a escolaridade apresenta novas oportunidades, a fraca participação dos jovens no processo decisório da agricultura familiar, a imagem inferior de moças do meio rural em comparação a moças da cidade e o incentivo dos pais para as moças saírem do campo. 
Spanevello (2008) teve como objetivo em seu estudo analisar o processo social da sucessão entre os agricultores familiares nos municípios de Pinhal Grande e Dona Francisca no Rio Grande do Sul. Os fatores internos que influenciam o processo social da sucessão no estudo são: a penosidade do trabalho, a baixa renda das atividades produtivas, quanto menos diversificada a propriedade maior a probabilidade de um dos filhos se ausentarem, os pais não incentivam a permanência dos filhos, os próprios agricultores não veem na agricultura uma boa alternativa, a desvalorização da ocupação agrícola, as dificuldades econômicas e produtivas de competir com propriedades capitalizadas e os fatores externos: altos custos dos insumos, baixo preço pago pelo produto, a condição estrutural do estabelecimento e que a sucessão é um processo masculino excludente para as mulheres (SPANEVELLO, 2008).

Weishemer (2009) identificou os diferentes traços juvenis na agricultura familiar para explicar a construção de seus projetos profissionais nas mesorregiões do estado do Rio Grande do Sul, os principais fatores evidenciados são a busca de inserção profissional em outras atividades, que o meio urbano oferece maiores oportunidades, a importância da continuidade da escolarização e a busca de emprego com renda mensal.

Em estudo realizado no Rio Grande do Sul Spanevello et al (2014), relata que propriedades com boas condições financeiras (aspectos materiais como terra, equipamentos modernos que garantam a renda) e que valorizam seus sucessores (como a autonomia) os filhos são mais propensos a permanecer na propriedade rural. Kischener, Kiyota e Perondi (2015), em estudo no Sudoeste do Paraná classificam os principais fatores que condicionam a sucessão geracional: a história, gênero, renda, escolaridade, o projeto de vida dos jovens, a sociabilidade urbana, a comunidade e o trabalho.

Por fim, Matte, Spanevello e Andreatta (2015), procuravam analisar a perspectiva de sucessão na concepção de filhos de pecuaristas no município de Dom Pedrito no Rio Grande do Sul, na visão dos filhos existem fatores internos e externos à propriedade que afetam a decisão de permanecer ou não no meio rural como pecuaristas. Entre eles destacam-se: o matrimônio, a educação formal, a ausência de escolas técnicas, a redução da população rural e a autonomia no interior da propriedade.

\section{METODOLOGIA}

0 método de elaboração do presente estudo consiste em uma pesquisa mista com enfoque em abordagens qualitativas e quantitativas de forma complementar. Os procedimentos de coleta de dados de pesquisas mistas podem ser sequenciais, concomitantes ou transformadores, pois a coleta de dados envolve informações numéricas e de textos, obtendo-se um banco de dados qualitativo e quantitativo (CRESWELL, 2007).

Para cumprir o objetivo deste trabalho buscou-se realizar uma coleta de dados primários, ao aplicar um questionário em uma pesquisa de campo no mês de setembro de 2019, a uma amostra representativa de 60 jovens, filhos de associados de uma cooperativa agropecuária do segmento de carnes localizada na região Centro Oriental do estado do Rio Grande do Sul.

Os jovens que foram selecionados deviam respeitar os critérios, de apresentar perspectiva de sucessão geracional, viver no meio rural e ter idades entre 18 e 30 anos, o recorte de faixa etária indica que nesta idade o projeto de vida do jovem já foi definido. A partir da definição destes critérios, obteve-se uma população de 90 jovens identificados através do cadastro de associados da cooperativa, da população total apenas 60 jovens estiveram dispostos a participar. Além disso, cabe destacar que a aplicação do questionário foi realizada sem a presença de integrantes da cooperativa, para que os jovens pudessem se sentir à vontade, durante a realização da entrevista.

Com a finalidade de compor o instrumento de coleta de dados, foram elencados por meio da literatura disponível os fatores decisórios que influenciam na permanência do jovem no campo, para a realização deste estudo foram selecionados seis fatores decisórios. Com a intenção da apuração dos fatores decisórios, o questionário compreende uma escala métrica quantitativa e de rótulo numérico, adaptada a uma escala de nove pontos de escolha forçada, ou seja, não há categoria que possa ser considerada neutra ou sem opinião.

A escala métrica utilizada é para a obtenção de respostas do nível de importância e de desempenho dos fatores decisórios, baseada na metodologia de Slack, Chambers e Johnston (2007), que envolve um aperfeiçoado conhecimento da análise dos níveis de importância (o quanto o fator é importante para a sua vida) e de desempenho (como o fator se comporta na realidade) de fatores e que de acordo com seus escores ou classificações nesses critérios que resulta em sua prioridade de melhoramento. 
Por fim, realizou-se a organização e análise dos dados, em planilhas eletrônicas no software Microsoft Excel@, apurou-se as médias de importância e desempenho dos fatores decisórios apresentadas em gráfico e analisou-se de forma descritiva a opinião dos respondentes, em busca de descrever as interpretações pertinentes e conciliá-las ao objetivo do trabalho.

\section{A PERSPECTIVA DOS JOVENS SUCESSORES RURAIS SOBRE OS FATORES DECISÓRIOS NO PROCESSO DE SUCESSÃO GERACIONAL}

0 roteiro do questionário abarcou questões que envolvem, uma breve caracterização da amostra em estudo. Nesse sentido, os jovens na sua maioria são representados pelo sexo masculino 76,67\% dos respondentes e do sexo feminino 23,33\%, o que demonstra uma significativa presença de jovens do sexo masculino na condição de sucessores das propriedades rurais.

Ainda, no que tange ao estado civil dos jovens a maior parte dos respondentes são solteiros 63,33\% e $36,67 \%$ são casados ou possuem união estável. A faixa etária dos jovens sucessores é composta por $58,34 \%$ entre 25 a 30 anos de idade, sendo que de 29 a 30 anos é representada por $26,67 \%$ dos jovens. Em relação a escolaridade, $51,67 \%$ dos jovens possui o ensino médio completo, seguido de $25 \%$ que possui o ensino profissionalizante técnico, voltado 86,96\% para as ciências agrárias.

Deste modo, percebe-se a predominância masculina entre os jovens sucessores, solteiros e com a maior idade do estudo em ênfase. 0 resultado vai de encontro aos dados do Censo Demográfico do Instituto Brasileiro de Geografia e Estatística (2010), que demonstra que no estado do Rio Grande do Sul o sexo masculino é representado por $52 \%$ dos indivíduos e $48 \%$ do sexo feminino, do total de 1.593 .638 indivíduos que vivem no meio rural. Ainda, a faixa etária de 18 a 30 anos é representada por 53\% de jovens do sexo masculino no estado.

Nesta perspectiva, o estudo de Froehlich et al (2011), aponta em resultados de sua pesquisa na região Central do estado do Rio Grande do Sul, a consolidação do processo de masculinização no ambiente rural sendo a população adulta a mais atingida. No entanto, essa caracterização pode comprometer a sucessão nas propriedades rurais ao indicar um êxodo rural seletivo (FROEHLICH et al, 2011).

Inicialmente, estão dispostos no Gráfico 1, representados pelas suas médias, os seis fatores decisórios que influenciam no processo de sucessão geracional.

Gráfico 1 - Média da importância e desempenho dos fatores decisórios

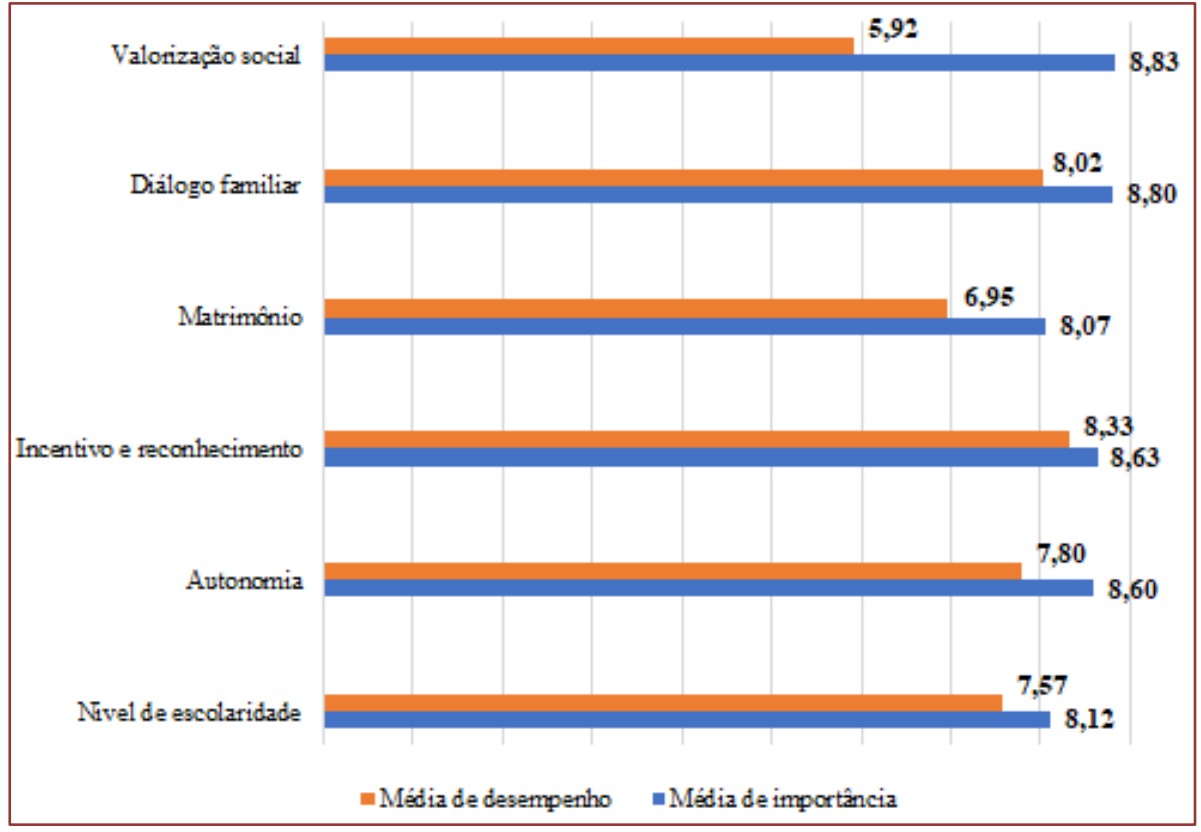

Fonte: Dados da pesquisa (2019). 
Primeiramente, percebe-se no Gráfico 1 que as médias de importância dos seis fatores decisórios encontram-se entre os valores de 8,07 e 8,83, esse resultado demonstra que a importância dos fatores decisórios, segundo a escala métrica proposta por Slack, Chambers e Johnston (2007), possui classificação considerada de maior importância e de intensidade média, na perspectiva dos jovens sucessores.

Rresultado de importância demonstra que, para os jovens a totalidade dos fatores decisórios: a escolaridade $(8,12)$, autonomia $(8,60)$, incentivo e reconhecimento $(8,63)$, matrimônio $(8,07)$, diálogo familiar $(8,80)$ e a valorização social do produtor $(8,83)$, são importantes e influenciam a sua permanência na propriedade rural como sucessores.

Ainda, observa-se as médias de desempenho dos seis fatores decisórios, apresentam-se os valores das médias entre 5,92 e 8,33, o resultado expressa que existe opiniões diferentes entre o desempenho dos fatores decisórios e que divergem da importância. Em um primeiro momento, considera-se os fatores de valorização social e matrimonial, os dois fatores representam uma classificação de regular desempenho de intensidade média $(5,92)$ e intensidade forte $(6,95)$, respectivamente. Os fatores decisórios de escolaridade, autonomia, incentivo e reconhecimento e diálogo familiar, possuem classificação de melhor desempenho de intensidade fraca $(7,57)$ e $(7,80)$ e de intensidade média $(8,33)$ e $(8,02)$, respectivamente.

Desta maneira, os resultados de desempenho também influenciam a permanência na propriedade e constata-se que precisam ser melhorados, para suprir as expectativas relatadas na importância. Diante dos resultados expostos, pode-se dizer que de maneira em geral que todos os fatores decisórios possuem maior importância que desempenho para a vida dos jovens sucessores, ou seja, tem-se uma expectativa maior do que realmente se vivencia no dia a dia dos jovens.

Pode-se observar e realizar uma análise dos fatores decisórios em três grupos, baseado no resultado da média de desempenho que possui uma variação em suas classificações, devido que a importância segue a mesma intensidade na sua classificação. 0 primeiro grupo refere-se aos fatores decisórios com menor desempenho o matrimonial e a valorização social.

Os jovens sucessores foram indagados de forma descritiva e explicativa se pelo fator matrimonial deixariam as atividades no meio rural para estabelecer uma relação afetiva com alguém na cidade. No Quadro 1, a seguir encontram-se as opiniões relatadas pelos jovens sucessores.

Quadro 1 - Fator decisório matrimonial Matrimônio

Se o jovem sairia do rural na busca de estabelecer uma relação afetiva

\begin{tabular}{|l|c|}
\hline Sim & respondentes \\
\hline Não & $7 \%$ \\
\hline Não sabe se sim ou não & $87 \%$ \\
\hline & $6 \%$ \\
\hline Pelo motivo de gostar da atividade rural, não largaria a atividade & $\begin{array}{c}\text { Percentual de } \\
\text { respondentes }\end{array}$ \\
\hline A companheira (o) reside no rural & $17 \%$ \\
\hline Companheira (o) pode vir residir no rural & $12 \%$ \\
\hline Poderia residir na cidade, mas continuaria a trabalhar na propriedade rural & $7 \%$ \\
\hline Não sairia do rural pela renda, tranquilidade e qualidade de vida & $7 \%$ \\
\hline Não sai do rural, a vida na cidade é diferente, não iria se adaptar & $5 \%$ \\
\hline Permanece no rural pela estrutura e investimentos da propriedade & $5 \%$ \\
\hline A companheira (o) mora na propriedade, mas tem origem do rural & $5 \%$ \\
\hline A companheira (o) reside na propriedade, mas tem origem da cidade & $3 \%$ \\
\hline Não se vê em outro lugar, reflete sobre o tipo de emprego que teria & $3 \%$ \\
\hline Permanece no rural para cuidar dos pais & $3 \%$ \\
\hline Companheira (o) incentivou a permanecer no rural & $2 \%$ \\
\hline $\begin{array}{l}\text { Prefere permanecer no rural, o companheiro (a) tem que entender as suas } \\
\text { condições }\end{array}$ & $2 \%$ \\
\hline Permanece no rural, pela pouca escolaridade & $2 \%$ \\
\hline
\end{tabular}

Fonte: Dados da pesquisa (2019). 
No Quadro 1, verifica-se que em sua maioria 87\% dos jovens sucessores não tem a pretensão de sair do meio rural para estabelecer uma relação afetiva com alguém. O resultado contrapõe a média de desempenho do fator decisório matrimonial que é baixa e demonstra insatisfação diante da importância. Neste sentido, interpreta-se que mesmo que o jovem não sai pelos motivos elencados no Quadro 1, ele ainda não está satisfeito com as condições que se estabelecem para manter a relação com um companheiro (a), ou seja, ainda necessitam ser melhoradas.

As principais opiniões dos jovens sucessores que se destacam pela opção de não sair do rural são: gosto pela atividade rural, o companheiro (a) residir ou que possa a vir residir no rural, renda e estrutura da propriedade. Além disso, destaca-se a opinião do jovem ir morar na cidade, mas continuar com as atividades de trabalho rural, pelo motivo de gostar do tipo de trabalho que realiza. 0 estudo de Matte, Spanevello e Andreatta (2015), afirma que o matrimônio representa uma situação de incerteza da permanência do jovem no meio rural, devido a possível influência do futuro companheiro (a) na decisão de onde fixar residência.

Pode-se dizer, que mesmo que a maioria dos jovens não tenha pretensão de sair do rural, aqueles que afirmam que o companheiro (a) reside ou possa vir a residir, podem sofrer influência de onde fixar residência, como aqueles que também supõe sair do rural para morar na cidade e continuar com as atividades de trabalho no campo. Matte, Spanevello e Andreatta (2015), ainda se referem nos seus resultados aqueles que estão casados e residem no campo com indícios de incerteza de continuidade no rural.

Em sequência sobre o segundo fator de desempenho do primeiro grupo de menor desempenho, os jovens sucessores responderam suas considerações, sentem-se valorizados socialmente como produtores rurais. A seguir, no Quadro 2 encontram-se as principais opiniões dos jovens sobre a valorização social do produtor rural.

Quadro 2 - Fator decisório valorização social

\begin{tabular}{|l|c|}
\multicolumn{1}{|c|}{ Se o jovem se sente valorizado como produtor rural } & $\begin{array}{c}\text { Percentual de } \\
\text { respondentes }\end{array}$ \\
\hline \multicolumn{1}{|c|}{ Opim } & $70 \%$ \\
\hline Não & $\begin{array}{c}\text { Percentual de } \\
\text { respondentes }\end{array}$ \\
\hline $\begin{array}{l}\text { É valorizado pois é produtor rural que alimenta o mundo pela produção de } \\
\text { alimentos }\end{array}$ & $15 \%$ \\
\hline $\begin{array}{l}\text { É valorizado pela opinião válida, pelo reconhecimento em não ser esquecido, pelos } \\
\text { benefícios e recompensas }\end{array}$ & $12 \%$ \\
\hline $\begin{array}{l}\text { Não é valorizado pelo preconceito ao produtor rural, mas está melhorando a cada } \\
\text { dia }\end{array}$ & $7 \%$ \\
\hline Desvalorizado por falarem mal do produtor rural & $7 \%$ \\
\hline É valorizado por ser bem recebido pelas pessoas e comunidade & $5 \%$ \\
\hline Desvalorizado pelo preço baixo do produto & $5 \%$ \\
\hline Não é valorizado por trabalhar aos finais de semana & $3 \%$ \\
\hline $\begin{array}{l}\text { Depende de quem está avaliando o produtor rural, por lado é valorizado por outro } \\
\text { não (veganos, poluição, venenos) }\end{array}$ & $3 \%$ \\
\hline Não é valorizado pelas leis trabalhistas e aposentadoria & $3 \%$ \\
\hline Desvalorizado pela legislação ambiental & $3 \%$ \\
\hline Desvalorizado pelo alto custo & $2 \%$ \\
\hline Desvalorizado pelo preconceito de pouca escolaridade & $2 \%$ \\
\hline Desvalorizado pela falta de financiamento & $2 \%$ \\
\hline Sente-se valorizado financeiramente, mas no social não & $2 \%$ \\
\hline
\end{tabular}

Fonte: Dados da pesquisa (2019). 
No Quadro 2, identifica-se que a maioria dos jovens sucessores $70 \%$ se sentem valorizados socialmente como produtores rurais. Este resultado, também contrapõe a média de desempenho do fator de valorização social do produtor, que apresenta a média mais baixa diante dos outros fatores em estudo e insatisfação perante a importância. Neste contexto, interpreta-se que por mais que a maioria dos jovens sinta-se valorizados considera-se que ainda existe a necessidade de melhorar essa valorização social, considerada baixa pela maioria dos respondentes e também pela parcela que não se sente valorizada como produtor rural.

As opiniões dos jovens que se destacam ao afirmarem que são valorizados são: por produzir alimentos para alimentar o mundo e pelo reconhecimento e benefícios que possui como produtor rural, em contrapartida os $30 \%$ que destacam não serem valorizados socialmente referem-se principalmente a desvalorização do produtor rural pelo preconceito, pelas pessoas julgar maldosamente o produtor e pelo preço baixo oferecido aos produtos agrícolas.

A valorização social do produtor é exposta em diversos contextos, como diz Camarano e Abramovay (1998) inclusive pela falta de valorização das atividades das mulheres na propriedade rural. Para Brumer et al (2000), a valorização da profissão de agricultor estão entre as condições internas familiares tanto sociais quanto econômicas que interferem na perspectiva de permanência dos filhos nas propriedade rurais. Nesse sentido, Carneiro (2001) salienta que a valorização de oportunidades no urbano como o emprego formal têm efeitos sobre a desvalorização do trabalho agrícola e da identidade do produtor rural.

O segundo grupo refere-se aos fatores decisórios com médio desempenho o de escolaridade e o de autonomia. Como resultado, a escolaridade dos jovens sucessores não supre as suas expectativas, pois mais de 50\% dos jovens apresentam ensino médio completo. Diante disso, 3\% dos respondentes afirmam que uma das dificuldades em suceder a propriedade é o pouco estudo. Ainda, salientam 33,33\% dos jovens que cursos e capacitações (técnicos e de gestão da propriedade) poderiam ser ações desenvolvidas pela cooperativa agropecuária que a família pertence, para estimular a sua permanência.

Matte, Spanevello e Andreatta (2015), enfatizam que à educação formal é considerada um fator que motiva a saída dos jovens para os centros urbanos, pois verifica-se um desejo dos jovens em continuar os estudos que permitam melhorar suas atividades na propriedade. Porém, o que limita esse anseio é a falta de oportunidades de estudo próximas onde vivem (MATTE; SPANEVELLO; ANDREATTA, 2015).

A perspectiva das autoras anteriormente vai ao encontro do que os jovens sucessores em estudo salientam ao solicitar ações de cursos e capacitações a partir da cooperativa agropecuária, como um agente facilitador. Além disso, reforçam Faccin e Schmidt (2013) que nos casos de migrações dos jovens para as cidades, as propriedades rurais perdem a mão de obra qualificada, pois são eles que apresentam maior nível de escolaridade e conhecimento tecnológico para dar continuidade nas atividades rurais.

Em continuidade, trata-se do segundo fator de desempenho do segundo grupo de médio desempenho, a autonomia. $\mathrm{O}$ fator decisório de autonomia apresenta como resultado insuficiência, diante da importância dada pelos jovens sucessores ao fator. Nesse intuito, pode-se mencionar que na gestão da propriedade rural 58\% dos jovens respondentes divide as decisões sobre os negócios com os seus pais, comprova-se que esses jovens não tem autonomia para tomar alguma decisão sobre as atividades da propriedade rural.

De acordo com Brumer et al (2000), os condicionantes para a sucessão e a permanência dos jovens no meio rural ocorre quando os pais ou a família consideram que os filhos necessitam ter autonomia para conduzir algum tipo de atividade na propriedade rural ao ampliar seus espaços sociais de atuação. Portanto, relata-se a importância de os jovens sucessores em estudo, ampliarem a sua autonomia dentro da propriedade rural.

O terceiro grupo é composto pelos fatores decisórios com melhor desempenho, o incentivo e reconhecimento familiar e o diálogo familiar. 0 fator decisório de incentivo e reconhecimento familiar é o fator que se apresenta mais próximo a importância e o desempenho, esse resultado demonstra que os jovens sucessores estão próximos a satisfação do incentivo e reconhecimento que recebem dos seus pais para permanecerem na propriedade rural.

Para afirmar esse resultado o estudo constata que $87 \%$ dos jovens concordam que recebem incentivos dos pais para permanecer na propriedade rural. Deste modo, destaca-se que os incentivos para a permanência são através de bens simbólicos onde $92 \%$ dos jovens afirmam receber esse tipo de incentivo e $42 \%$ declara receber incentivos de bens materiais como carro, moto, casa, terreno ou parte de área de terra. 
Nesta questão, Spanevello (2008) ressalta que os incentivos são estímulos dados por possibilidades materiais e simbólicas, que colaboram na permanência do jovem sucessor no campo. A autora complementa que é importante o maior envolvimento dos jovens nas responsabilidades das tarefas agrícolas, onde é preciso dar um voto de confiança aos jovens sucessores ao assumirem o comando de algumas atividades individualmente na propriedade.

Em seguida, sobre o segundo fator de desempenho do terceiro grupo de melhor desempenho, os jovens sucessores destacaram suas opiniões sobre se consideram o diálogo com seus pais positivo ou negativo. No Quadro 3, a seguir apresenta-se as principais opiniões dos jovens sobre o diálogo familiar.

\begin{tabular}{|c|c|}
\hline $\begin{array}{c}\text { Diálogo familiar } \\
\text { Se o jovem considera o diálogo com os pais positivo ou negativo }\end{array}$ & $\begin{array}{l}\text { Percentual de } \\
\text { respondentes }\end{array}$ \\
\hline Positivo & $100 \%$ \\
\hline Opiniões dos respondentes & $\begin{array}{l}\text { Percentual de } \\
\text { respondentes }\end{array}$ \\
\hline É discutido trocado ideias, entram em acordo e conseguem se entender & $23 \%$ \\
\hline $\begin{array}{l}\text { Costumam ter horários para conversas entre a família, de forma unida para combinar as } \\
\text { atividades a realizar na propriedade }\end{array}$ & $22 \%$ \\
\hline O diálogo é positivo para tomar decisões & $10 \%$ \\
\hline Pais cabeça aberta, aceitam as ideias diferentes & $7 \%$ \\
\hline $\begin{array}{l}\text { Mesmo discutindo entram em consenso, conseguem se entender, mas não é } 100 \% \text {, não se fala } \\
\text { tudo que é preciso devido as diferentes ideias }\end{array}$ & $7 \%$ \\
\hline Pais não aceitam novos desafios, pensamentos ou opiniões diferentes & $5 \%$ \\
\hline O diálogo é um aprendizado, os pais gostam de ensinar e tirar dúvidas & $5 \%$ \\
\hline A família tem objetivos positivos que gera um bom relacionamento & $3 \%$ \\
\hline $\begin{array}{l}\text { Diálogo familiar a base de incentivos para permanência na propriedade e para realização de } \\
\text { investimentos }\end{array}$ & $2 \%$ \\
\hline Diálogo positivo pela idade, convivência e experiência dos pais & $2 \%$ \\
\hline
\end{tabular}

Fonte: Dados da pesquisa (2019).

No Quadro 3, percebe-se que a totalidade de jovens sucessores, $100 \%$ dos respondentes, considera o diálogo familiar positivo. Desta maneira, os jovens destacam algumas opiniões acerca do assunto, a mais relevante considerada por $23 \%$ dos respondentes, é que através do diálogo habitualmente entra-se em acordo, seguido por $22 \%$ dos que consideram a união e horários para conversar em família e $10 \%$ aqueles que consideram o diálogo positivo para se tomar decisões.

Além disso, cabe destacar que por mais que todos os respondentes considerem o diálogo familiar positivo, existe uma parcela de $5 \%$ que ressalta que por mais que seja positivo, os pais não aceitam novos desafios e opiniões, de maneira que os jovens já estão acostumados a aceitar esse modo de dialogar com os pais. A partir desse resultado, revela-se a baixa da média do nível de desempenho do fator decisório em relação a importância.

Conforme Costa (2006), evidencia-se em seu estudo que as relações familiares rurais sofrem transformações e estão cada vez mais complexas e a falta de comunicação pode resultar em problemas quando diz respeito ao planejamento da unidade familiar, porém nos dias atuais aponta-se a possibilidade de maior diálogo entre as gerações.

Vale ressaltar, sobre a preparação para assumir a propriedade como sucessores, que $82 \%$ dos jovens relatam estar preparados. As formas de preparação elencadas pelos jovens são: participação nas atividades da propriedade, apontada por $86 \%$ dos jovens, e com $37 \%$ o fator decisório do diálogo com os pais, como uma importante forma de preparação para a continuidade das atividades na propriedade.

Portanto, como visto anteriormente em relação aos fatores decisórios de matrimônio, diálogo familiar e valorização social do produtor rural, alguns respondentes do estudo direcionaram de forma descritiva e explicativa diversas considerações e opiniões acerca do assunto, em relação a justificativa de suas respostas do nível de importância e desempenho dos fatores decisórios. Vale considerar que, nem todos os respondentes declararam a justificativa de suas respostas da importância e desempenho, pois a resposta era voluntária. 


\section{CONSIDERAÇÕES FINAIS}

Em síntese, este estudo teve por objetivo analisar, na perspectiva de jovens sucessores rurais, os fatores decisórios que influenciam no processo de sucessão geracional, ou seja, na permanência dos jovens na propriedade rural e nas atividades de trabalho no campo. 0 interesse em analisar os fatores que interferem na decisão jovem é proveniente do cenário, em que o êxodo rural da população jovem é significativo nos últimos tempos, principalmente no estado do Rio Grande do Sul.

Em virtude do cenário da migração dos jovens do campo para cidade, surgem diversas consequências, como a falta de sucessão geracional, a masculinização dos indivíduos que permanecem no campo e na falta de mão de obra para as atividades produtivas. Na concepção dessas complicações, remete-se a necessidade da permanência das novas gerações no campo.

Deste modo, com a utilização da metodologia de Slack, Chambers e Johnston (2007), que permitiu analisar a importância e o desempenho dos fatores decisórios no processo de sucessão geracional, obteve-se resultados que, de maneira geral que indicam a fragilidade no desempenho de todos os seis fatores decisórios para os jovens sucessores, pois as suas expectativas perante os mesmos não estão sendo supridas, o que indica obstáculos para a permanência do jovem no meio rural.

Apesar de algumas das opiniões descritivas dos respondentes, contrapor os resultados das médias de desempenho dos fatores decisórios, como por exemplo o de valorização social do produtor e matrimonial que apresentam menor desempenho, compreendeu-se que por mais positivas sejam as opiniões descritivas dos jovens, ainda necessita-se alavancar o desempenho dos fatores decisórios para se complementar aumentar a satisfação dos jovens e garantir a sua permanência na propriedade rural.

Por fim, vale ressaltar, que os fatores decisórios assumem níveis de importância e desempenho diferente entre os respondentes da pesquisa, devido que cada um dos jovens sucessores apresenta distintas características familiares, na área produtiva e de infraestrutura da propriedade rural.

O estudo teve como intuito contribuir para formulação de ferramentas direcionadas a manutenção dos jovens no campo, ou seja, organizar ações para as mais diversas necessidades dos jovens rurais. Sugere-se que a cooperativa agropecuária que compreende a amostra em estudo, possa ser uma organização apoie melhorias no desempenho dos fatores decisórios estudados.

Embora, as cooperativas agropecuárias possam ter uma contribuição relevante em diferentes frentes, nos fatores decisórios relacionados as características pessoais e familiares dos jovens há um enorme desafio na forma de abordar tais aspectos junto as famílias associadas. Nesse sentido, destaca-se que os pais dos jovens sucessores têm um papel fundamental e a responsabilidade de manter o desempenho dos fatores decisórios, pois é a perspectiva de trabalhar e viver com os pais que influencia a permanência dos jovens na propriedade.

\section{AGRADECIMENTOS}

“O presente trabalho foi realizado com o apoio da Coordenação de Aperfeiçoamento de Pessoal de Nível Superior - Brasil (CAPES) - Código de Financiamento 001 e financiado pelo Conselho Nacional de Desenvolvimento Científico e Tecnológico (CNPq)".

\section{REFERÊNCIAS}

[1] ABRAMOVAY, R. et al. Juventude e agricultura familiar: desafios dos novos padrões sucessórios. Brasília: Unesco, 1998. 104p.

[2] BRUMER, A. et al. Juventude rural e divisão do trabalho na unidade de produção familiar. In: Congresso Internacional Rural Sociology Association (IRSA), 10. 2000. Rio de Janeiro.

[3] Anais. Rio de Janeiro: IRSA, 2000.

[4] CAMARANO, A. A.; ABRAMOVAY, R. Êxodo rural, envelhecimento e masculinização no Brasil: panorama dos últimos cinquenta anos. Revista Brasileira de Estudos de População, Brasília, v. 15, n.2, p.45-65, 1998. Disponível em: < www.rebep.org.br/index.php/revista/article/download/404/pdf_380 >. Acesso em: 20 fev. 2020.

[5] CARNEIRO, M. J. Herança e gênero entre agricultores familiares. Revista Estudos Feministas, Florianópolis, v. 9, n. 2, p. 22-55, jun./dez. 2001. Disponível: <http://www.scielo.br/pdf/ref/v9n1/8602.pdf >. Acesso em: 18 mar. 2020. 
[6] CHEMIN B. F.; AHLERT L. A Sucessão patrimonial na Agricultura Familiar. Estudo e Debate, Lajeado, v. 17, n. 1, p. 50-52, jan. 2010.

[7] COSTA, M. R. C. Agricultura familiar e sucessão hereditária: estudo de caso no município de Morro Redondo, RS. 2006. 107f. Dissertação (Mestrado em Agronomia). Programa de Pós-Graduação em Agronomia, Universidade Federal de Pelotas, Pelotas, $2006 . \quad$ Disponível <http://www2.ufpel.edu.br/tede/tde_busca/arquivo.php?codArquivo=346>. Acesso em: 15 fev. 2020.

[8] CRESWELL, J. W. Projeto de pesquisa: métodos qualitativo, quantitativo e misto. 2 ed. Porto Alegre: Artemed, 2007.

[9] FACCIN, O. P.; SCHMIDT, C. E. Sucessão nas Propriedades Rurais Familiares Integrantes de uma Cooperativa Agropecuária. In COTRIM, Décio. S (Org). Gestão de cooperativas: produção acadêmica da Ascar - (Coleção Desenvolvimento Rural, v. 2, 694 p). Porto Alegre, RS: Emater/RS-Ascar, p. 371-396, 2013.

[10] FROEHLICH, J.M et al. Êxodo seletivo, masculinização e envelhecimento da população rural na região central do RS. Ciência Rural, v.41, n.9, p.1674-1680, set. 2011. Disponível em: < http://www.scielo.br/pdf/cr/v41n9/a10411cr3002.pdf>. Acesso em: 18 mar. 2020.

[11] GASSON, R. ERRINGTON, A. The Farm Family Business. Wallingford: Cab International, 1993.

[12] GRAZIANO DA SILVA, J. Uma agricultura alternativa ou um capitalismo verde. Revista Ciência e Ambiente, v.4, n.6, p. 7-20, jan/jun.1993.

[13] IBGE. Instituto Brasileiro de Geografia e Estatística. Censo Demográfico 1991/2000/2010. Disponível em: < https://sidra.ibge.gov.br/pesquisa/censo-demografico/seriestemporais/ series-temporais/>. Acesso em: $15 \mathrm{de}$ fev. 2020.

[14] KISCHENER, M.; KIYOTA, N.; PERONDI, M. Sucessão geracional na agricultura familiar: lições apreendidas em duas comunidades rurais. Mundo Agrário, v.16, n.33, dezembro de 2015. Disponível em: < https://www.mundoagrario.unlp.edu.ar/article/view/MAv16n33a07 >. Acesso em: 20 fev. 2020.

[15] MATTE, A; SPANEVEllo, R. M.; ANDREATTA, T. Perspectivas de Sucessão em Propriedades de Pecuária Familiar no Município de Dom Pedrito-RS. Holos, v. 1, p. 144-159, fev. 2015. Disponível em: <http://www2.ifrn.edu.br/ojs/index.php/HOLOS/article/view/1964>. Acesso em: 02 abr. 2020.

[16] SCHNEIDER, I. Êxodo, envelhecimento populacional e estratégias de sucessão na exploração agrícola. Porto Alegre: FEE, 1994. (Resultado de uma pesquisa intitulada Perfil etário da População Economicamente Ativa na agricultura gaúcha, 1980-1991).

[17] SCHWARZ, U. To Farm or Not to Farm: Gendered Paths to Succession and Inheritance.

[18] Munster: Lit Verlag. 2004.

[19] SILVESTRO, M et al. Os impasses sociais da sucessão hereditária na agricultura familiar. Brasília: EPAGRINEAD, 2001.

[20] SLACK, N.; CHAMBERS, S.; JOHNSTON, R. Administração da Produção. 1 ed. São Paulo: Atlas, 2007. 526p.

[21] SPANEVELLO, R. M. A dinâmica sucessória na agricultura familiar. 2008. 236f. (Tese doutorado em Desenvolvimento Rural) - Universidade Federal do Rio Grande do Sul, Porto

[22] Alegre, RS, 2008. Disponível em: < https://lume.ufrgs.br/handle/10183/16024 >. Acesso em: 18 mar. 2020.

[23] SPANEVELLO, R. M. et al. As estratégias para manter a sucessão em estabelecimentos familiares. In: RENK, A; DORIGON, C. (Orgs.). Juventude rural, cultura e mudança social. Chapecó: Argos, p. 163-188. 2014.

[24] STROPASOLAS, V. L. O valor (do) casamento na agricultura familiar. Estudos Feministas, Florianópolis, v.12, n.1, p. 253-267, jan./abr. 2004. Disponível em: <https://periodicos.ufsc.br/index.php/ref/article/view/S0104026X2004000100013/8697>. Acesso em: 15 de fev. 2020.

[25] STROPASOLAS, V. L. Os desafios da sucessão geracional na agricultura familiar. Agriculturas, v. 8, n. 1, p. 26 29, março de 2011. Disponível em: <http://aspta.org.br/wp-content/uploads/2011/08/artigo-5.pdf>. Acesso em: 03 mar. 2020

[26] WANDERLEY, M. de N. B. Jovens rurais de pequenos municípios de Pernambuco: que sonhos para o futuro. In: CARNEIRO, Maria José. CASTRO, Elisa Guaraná. Juventude Rural em Perspectiva. Rio de Janeiro: Mauad X, p. 21 33. 2007.

[27] WEISHEIMER, N. A situação juvenil na agricultura familiar. 2009. 330f. Tese (Doutorado em Desenvolvimento Rural). Programa de Pós-Graduação em Desenvolvimento Rural, Universidade Federal do Rio Grande do Sul, Porto Alegre, 2009. Disponível em: <http://pct.capes.gov.br/teses/2009/42001013012P7/TES.PDF>. Acesso em: 20 fev. 2020. 


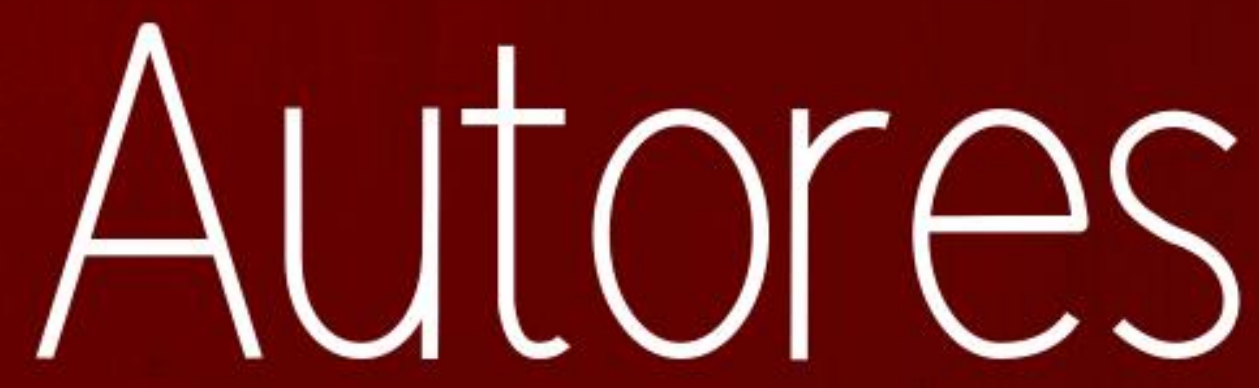




\section{EZEQUIEL REDIN (ORGANIZADOR)}

Professor Adjunto do Instituto de Ciências Agrárias da Universidade Federal dos Vales do Jequitinhonha e Mucuri (UFVJM) e Vice-Coordenador do Programa de Pós-Graduação Interdisciplinar em Estudos Rurais). Membro da Academia Centro Serra de Letras, ocupando a cadeira n. 21. Membro dos Comitês de avaliação da FAPERGS/RS, FAPESC/SC e FAPITEC/SE. Editor do Periódico Extensão Rural (Santa Maria). Tesoureiro da Associação Riograndense dos Tecnólogos (ARTECNOL). Formado na licenciatura do Programa Especial de Graduação de Formação Pedagógica de Professores (PEG/UFSM - 2012-2013). Formado no curso de Filosofia Licenciatura (UFSM - 2016-2019). Formado no Mestrado em Extensão Rural (2009-2011). Formado na Pós-graduação em Gestão Pública Municipal (2010-2011). Formado na Pós-graduação em Tecnologias de Informação e Comunicação aplicadas à Educação (UFSM - 2013-2014). Formado na Pós-graduação em Ensino de Sociologia no Ensino Médio (2014-2015). Formado na Pós-graduação em Ensino de Filosofia no Ensino Médio (2017-2018). Doutorado em Extensão Rural pelo Programa de Pós-graduação em Extensão Rural (2011-2015). Foi o criador da Pósgraduação Lato Sensu e Coordenador do Curso de Pós-graduação em Agronegócios da Faculdade Metodista de Santa Maria (2017-2018). Foi Coordenador do Curso de Administração (2018-2018). Foi Coordenador do Curso de Ciências Contábeis (2018-2018). Foi Assessor da Pós-graduação da Faculdade Metodista de Santa Maria (2017-2018).

\section{ADRIANO LAGO}

Graduado em Agronomia pela Universidade Federal de Santa Maria (2002), Mestre em Extensão Rural pela Universidade Federal de Santa Maria (2004). Doutor em Agronegócios pela Universidade Federal do Rio Grande do Sul. Tem experiência na área de Agronomia, com ênfase em agronegócios, atuando principalmente nos seguintes temas: Agronegócios, gestão estratégica do agronegócio, agricultura familiar, sucessão rural, cooperativismo, desenvolvimento rural. Atualmente professor Associado II do Departamento de Administração e Vice-Diretor do Campus de Palmeira das Missões da Universidade Federal de Santa Maria. Também atua como professor do Programa de Pós-Graduação em Agronegócios da UFSM - Campus Palmeira das Missões.

\section{ÁLVARO ALVES DE MOURA JR.}

Economista pela Universidade Presbiteriana Mackenzie, Mestre em Economia e Doutor em Ciências Sociais (Área de Concentração: Política) pela PUC-SP. Professor dos cursos de graduação em Ciências Econômicas e pós-graduação stricto sensu em Economia e Mercados da Universidade Presbiteriana Mackenzie. Também é sócio da Urbana Consultoria em Desenvolvimento Econômico e Social, onde atua como especialista nas áreas de diagnóstico e avaliação de impactos socioeconômicos e análises setoriais.

\section{AMILCAR BAIARDI}

Professor titular aposentado da Universidade Federal da Bahia (UFBA) e da Universidade Federal do Recôncavo da Bahia (UFRB), Prêmio Jaboti (1997) e membro fundador da Academia de Ciências da Bahia. Doutor em Economia pela UNICAMP (1986), Mestre em Desenvolvimento Rural pela UFRRJ (1979) e engenheiro agrônomo pela UFBA (1964). Atua há mais de 40 anos na área de desenvolvimento rural.

\section{ANDERSON NUNES VIEIRA DE CARVALHO}

Mestre em Agronegócios e Desenvolvimento Regional (UFMT)

\section{ANDERSON PEREIRA ROCHA}

Graduando em Ciências Econômicas pela Fundação Universidade Federal de Rondônia (UNIR). Atualmente é pesquisador do Grupo de Pesquisa em Economia Aplicada da Amazônia GPEAM/UNIR. Tem experiência na área de Economia, com ênfase em Métodos e Modelos 
Matemáticos, Econométricos e Estatísticos Econômicos, atuando principalmente nos seguintes temas: Agronegócio, Desenvolvimento Econômico Sustentável e Econometria.

\section{ANGÉLICA MASSUQUETTI}

Possui doutorado em Desenvolvimento, Agricultura e Sociedade pela Universidade Federal Rural do Rio de Janeiro (UFRRJ) (2008) e fez Doutorado Sanduíche na Ecole des Hautes Etudes en Sciences Sociales - Paris/França (2003/2004). Possui mestrado em Economia Rural (1998) e graduação em Ciências Econômicas (1994) pela Universidade Federal do Rio Grande do Sul (UFRGS). Vinculou-se à UNISINOS em 2000, dedicando-se a projetos de pesquisa e ao ensino em nível de Graduação e de Pós-Graduação, na área de Economia, em cursos da Escola de Gestão e Negócios da UNISINOS. É professora permanente no Programa de Pós-Graduação em Economia (PPGE), Editora Assistente da Revista Perspectiva Econômica e Colíder do Grupo de Pesquisa: Integração Internacional - Estudos Empíricos de Comércio Internacionais (UNISINOS - CNPq).

\section{ARTURO ALEJANDRO ZAVALA ZAVALA}

Possui graduação em Estadística e Informática - Universidad Nacional Agraria La Molina (1988), mestrado em Estatística pela Universidade de São Paulo (2001), doutorado em Estatística pela Universidade de São Paulo (2004) e Pós Doutorado em Economia Aplicada no PIMES-UFPE (2011). Atualmente é professor Associado II da Universidade Federal de Mato Grosso. Tem experiência na área de Probabilidade e Estatística, Análise de Regressão, Econometria e Análise Multivariada, atuando principalmente nos seguintes temas: Desenvolvimento Regional, Agronegócio e Sustentabilidade.

\section{CAMILA WEBER}

Graduada em Direito pela Universidade Regional do Noroeste do Estado do Rio Grande do Sul, Pós Graduação em Produção e Desenvolvimento Rural pela Faculdade Futura - Instituto de Ciência, Educação e Tecnologia de Votuporanga. Pós Graduanda em Gestão do Agronegócio no Instituto Federal Farroupilha - Campus Santo Augusto. Mestranda do Programa de Pós Graduação Mestrado em Agronegócios, UFSM - Palmeira da Missões. Integrante do Núcleo de Pesquisa e Extensão em Agronegócios (NPEAGRO).

\section{CELSO EDUARDO PEREIRA RAMOS}

Possui Graduação em Agronomia pela UFPEL (Universidade Federal de Pelotas), especialização em Plantas Medicinais pela UFLA (Universidade Federal de Lavras), mestrado em Educação Brasileira pela UNESP (Universidade Estadual de São Paulo - Câmpus Marilia), Doutorado em Produção Vegetal pela UFPR (Universidade Federal do Paraná). Atualmente trabalha como professor na UTFPR (Universidade Tecnológica Federal do Paraná - Câmpus Dois Vizinhos - PR)

\section{CÉSAR AUGUSTUS WINCK}

É Doutor em Agronegócios (2012) pela Universidade Federal do Rio Grande do Sul (UFRGS), Mestre em Ciências Veterinárias (2007) e Médico Veterinário (1998) pela Universidade do Estado de Santa Catarina (UDESC). Bacharel em Administração (2016) e Especialista em Tecnologia e Educação a Distância (2013) pela Universidade do Contestado (UnC), também é Especialista em Gestão Agroindustrial (2002) e em Produção de Ruminantes (2006) pela Universidade Federal de Lavras - MG (UFLA). Professor e pesquisador da Universidade Alto Vale do Rio do Peixe (UNIARP), onde atua como professor e vice-coordenador do Mestrado Acadêmico em Desenvolvimento e Sociedade.

\section{CRISTINA VENÂNCIO PEREIRA}

Técnica em agropecuária pelo Centro de Educação Profissional CEDUP- Campo Erê (2014-2017) Graduanda de agronomia pela Universidade Tecnológica Federal do Paraná- Campus Dois Vizinhos 
(2017 até o momento) Bolsista do projeto alternativas a diversificação da agricultura da UTFPRCampus Dois Vizinhos (2019 até o momento)

\section{EDIVANE DE SOUSA LIMA}

Professora do Departamento de Economia da Universidade Federal do Piauí e Pesquisadora do Núcleo de Economia Regional do Piauí (NERPI)

\section{ESDRAS WARLEY NUNES DE JESUS}

Mestre em Agronegócios e Desenvolvimento Regional (UFMT)

\section{GABRIELE FERREIRA DA SILVA MONTE}

Graduanda em Economia na Universidade Federal do Piauí e bolsista do Programa Voluntário de Iniciação Científica (ICV)

\section{GABRIELI DOS SANTOS AMORIM}

Graduada em Administração pela Universidade Federal de Santa Maria (UFSM) - Campus Palmeira das Missões/RS (2017). Mestranda do Programa de Pós-Graduação em Agronegócios (PPGAGR/UFSM). Integrante do Núcleo de Pesquisa e Extensão em Agronegócios (NPEAGRO), atua em projeto de pesquisa voltado para a área de Desenvolvimento Rural com ênfase para os estudos em sucessão familiar e cooperativismo agropecuário.

\section{GILTON ALVES ARAGÃO}

DSc em Desenvolvimento Regional e Urbano (UNIFACS), doutorado Sandwich na HEC Montreal (Canada), Professor do Curso de Economia da Universidade Estadual de Feira de Santana.

\section{GLAUCO RODRIGUES CARVALHO}

Pesquisador da Embrapa Gado de Leite. Bacharel em Ciências Econômicas pela Universidade Federal de Minas Gerais. Mestre em Economia Aplicada pela ESALQ/USP. Especialista em Métodos Estatísticos Computacionais pela Universidade Federal de Juiz de Fora. Ph.D. em Agricultural Economics pela Texas A\&M University.

\section{GUILHERME FONSECA TRAVASSOS}

Bacharel em Ciências Econômicas pela Universidade Federal de Juiz de Fora. Mestre em Economia Aplicada pela Universidade Federal de Viçosa. Especialista em Métodos Estatísticos Computacionais pela Universidade Federal de Juiz de Fora. Doutor em Economia Aplicada pela Universidade Federal de Viçosa, com período de sanduíche na University of Illinois at UrbanaChampaign. Atualmente é pós-doutorando no Departamento de Economia Rural da Universidade Federal de Viçosa.

\section{GUILHERME FONTANA RAMOS}

Engenheiro Agrônomo pela Universidade Federal de Santa Maria(2016) com experiência em agricultura familiar e agroecologia. Mestrando do Programa de Pós-graduação em Agroecologia e Desenvolvimento Rural Sustentável, da Universidade Federal da Fronteira Sul.

\section{IRINEU BRINKER}

Possui graduação em Gestão Financeira pela Universidade do Vale do Rio dos Sinos, especialista em Gestão em Finanças Empresariais pela Faculdade Educacional da Lapa e graduado em Ciências 
Contábeis pela Universidade do Vale do Rio dos Sinos 2017. Mestre em economia pelo Programa de Pós Graduação da Universidade do Vale do Rio dos Sinos (2019). Funcionário do Banco do Brasil, tem experiência na área bancária e crédito agrícola.

\section{JAÍRA MARIA ALCOBAÇA GOMES}

Possui Graduação em Ciências Econômicas pela Universidade Federal do Piauí (UFPI), Mestrado em Economia Rural pela Universidade Federal de Campina Grande (UFCG) e Doutorado em Economia Aplicada pela Escola Superior de Agricultura Luiz de Queiroz. Professora do Departamento de Ciências Econômicas da UFPI e do Mestrado e Doutorado em Desenvolvimento e Meio Ambiente (PRODEMA/UFPI).

\section{JOÃO PAULO DE ALMEIDA FERREIRA SILVA}

Tecnólogo em Gestão da Produção Industrial (FATEC SENAI-MT)

\section{JOSÉ NATANAEL FONTENELE DE CARVALHO}

Graduado em Ciências Econômicas pela Universidade Federal do Piauí (UFPI). Mestre e Doutor em Desenvolvimento e Meio Ambiente (PRODEMA/UFPI). Professor Adjunto do Departamento de Ciências Econômicas e Quantitativas da Universidade Federal do Delta do Parnaíba (UFDPar)

\section{JOSUÉ DE SOUZA OLIVEIRA}

Possui graduação e Mestrado em ENGENHARIA DE ALIMENTOS, e Especialização em Meio Ambiente e Desenvolvimento pela UNIVERSIDADE ESTADUAL DO SUDOESTE DA BAHIA ITAPETINGA. Doutor em Biotecnologia com área de concentração em Biotecnologia Industrial pela UFRPE - RENORBIO. É Professor de Ensino Básico, Técnico e Tecnológico do Instituto Federal de Educação, Ciência e Tecnologia Baiano - Campus Uruçuca. Tem experiência na área de Ciência e Tecnologia de Alimentos, com ênfase em Engenharia de Alimentos, atuando principalmente nos seguintes temas: Tecnologia de leite e derivados, Gestão da Qualidade e Qualidade Ambiental

\section{JULIANA MOTA MONTEIRO DA SILVA}

Bacharel em Ciências Econômicas pela UFJF. Mestranda em Economia Aplicada pela ESALQ/USP.

\section{KAREN ÂNGELA FLORES}

Mestre em Administração pela Universidade do Oeste de Santa Catarina (2017), graduação em Engenharia Florestal pela Universidade do Oeste de Santa Catarina (2012) e especialista em Engenharia e Segurança do Trabalho pela UNOCHAPECó.

\section{KIMBERLY JÉSSICA MONTAGNER PROTE}

Economista (UFMT) e Mestre em Economia Aplicada (UFMT). Pesquisadora sobre economia . Atualmente, Consultora e Coordenadora de projetos de desenvolvimento de soluções tecnológicas e inovações, execução de Políticas Públicas de Transferência Tecnológica e desenvolvimento Regional e participação ativa em projetos de educação empreendedora para jovens.

\section{LUCAS CAMPIO PINHA}

Professor Adjunto da UFRRJ - Campus Três Rios. Graduado em Ciências Econômicas pela UFJF, Mestre e Doutor em Economia Aplicada pela UFV. 


\section{LUCIANE ALIPRANDINI}

Engenheira de alimentos da plataforma Circuitos Agroecológicos e membro da Rede Povos da Mata/BA, graduada pela UFSC - Universidade Federal de Santa Catarina, e pós graduada em Tecnologia de Alimentos com ênfase em Cacau e Chocolate pelo IFBaiano - Instituto Federal Baiano. Possui 15 anos de experiência em indústrias de alimentos, em produção, segurança alimentar, garantia da qualidade, regulamentação sanitária e rotulagem. Atuou em diversas consultorias de atividades alimentícias, fazendo elaboração e implementação de sistemas de Boas Práticas de Fabricação (BPF), Manuais de Procedimentos Operacionais (POP, PPHO), Análise de Perigos e Pontos Críticos de Controle (APPCC), projetos e adequações sanitárias, elaboração de rotulagem, treinamentos e capacitações técnicas. Possui diversas vivências em acompanhamentos de auditorias dos órgãos fiscalizadores (MAPA, ANVISA, INMETRO).

\section{LUCIMARI ANDRADE PAGGIOSSI}

Mestre em Economia e Mercados pela Universidade Mackenzie. Executive MBA pela Fundação Getúlio Vargas - FGV. Pós-Graduação em Analise de Sistemas pela Universidade Mackenzie e Matemática pela Faculdade Moema. Implementação de diversos projetos e portfolios para clientes no Brasil, Espanha, Inglaterra, Chile e Porto Rico (Grupo Sant Gobain, Grupo Endessa Espanha, Chile e Brasil, British Gas Inglaterra e Brasil, Roche, Acesita, Braskem, Petrobras, Yamana Gold, Suzano Papel, Votorantim, Pirelli, PDVSA Porto Rico/Venezuela, Provilven Porto Rico/Venezuela, Fertinitro Porto Rico/Venezuela) através de grandes empresas como PwC, IBM do Brasil e Honeywell do Brasil. PMO Manager para Latina América com 14 profissionais na área de BPO (Business Process Outsourcing) pela IBM do Brasil para clientes como Unilever, Avon, Sul America, Bunge e etc. Professora e coordenadora de cursos presencial e online de Gestão Projetos e escritora de artigos e livros sobre Tecnologia e Economia na área de Agronegócio.

\section{MANUEL ANTONIO VALDÉS BORRERO}

Possui graduação em Planejamento da Economia Nacional pela Universidade da Havana (1987), mestrado em Política Científica e Tecnológica pela Universidade Estadual de Campinas (1994) e doutorado em Planejamento de Sistemas Energéticos pela Universidade Estadual de Campinas (1999). Atualmente é professor titular da Universidade Federal de Rondônia e Membro do corpo editorial da International Online Multidisciplinary Journal. Tem experiência na área de Economia, com ênfase em Economia Regional e Urbana. Atuando principalmente nos seguintes temas: Meio Ambiente, Análise de Correspondência, Álcool como combustível.

\section{MARIA CLOTILDE MEIRELS RIBEIRO}

DSc em Administração (UFBA), doutorado Sandwich na University of Toronto (Canadá), Professora Adjunta da Universidade Federal do Vale do São Francisco (Univasf), da Graduação e da Pós Graduação, junto aos Programas de Dinâmicas de Desenvolvimento do Semiárido e de Administração Pública

\section{MARIELE BOSCARDIN}

Zootecnista graduada pela Universidade Federal de Santa Maria (UFSM), Campus de Palmeira das Missões- RS e Mestre em Desenvolvimento Rural pela Universidade Federal do Rio Grande do Sul (UFRGS). Atuou em projetos de pesquisa e extensão voltados para a área de Desenvolvimento Rural com ênfase para os estudos em sucessão familiar, juventude e gênero, ambos relacionados a agricultura familiar. Atuou ainda como Tutora à distância no Curso de Bacharelado em Desenvolvimento Rural da UFRGS e como Técnica de Campo do Programa Nacional de Educação na Reforma Agrária- PRONERA, na Universidade Regional Integrada do Alto Uruguai e das Missões, URI, Campus de Frederico Westphalen. Atualmente participa como Pesquisadora do Núcleo de Pesquisa e Extensão em Agronegócios (NPEAGRO) da Universidade Federal de Santa Maria, sendo bolsista de Fixação de Recursos Humanos do CNPq do projeto: Análise da Sucessão Geracional em Cooperativas Agropecuárias de distintos segmentos no Rio Grande do Sul. 


\section{MATEUS GONÇALVES LIRA}

Economista pela Universidade Federal de Pernambuco (2018).

\section{NATHALIA DE PINHO MARKUS}

Economista (UFMT) e Mestre em Economia (UFMT). Pesquisadora sobre economia criativa, economia da educação e setor industrial. Atualmente, analista do Observatório da Indústria da Federação das Indústrias no Estado de Mato Grosso, atuando em projetos, estruturação e análise de dados, estudos econômicos e elaboração de relatórios de BI para inteligência de mercado.

\section{SIDEMAR PRESOTTO NUNES}

Possui graduação em Agronomia pela Universidade Tecnológica Federal do Paraná (2001), mestrado em Sociologia pela Universidade Federal do Paraná (2007) e doutorado em Meio Ambiente e Desenvolvimento pela Universidade Federal do Paraná (2012). Atualmente é professor de sociologia rural; associativismo e cooperativismo e legislação agrária na UTFPR.

\section{TALES WANDERLEY VITAL}

Engenheiro Agronônomo pela Universidade Federal Rural de Pernambuco (1969), Mestre em Economia Agrícola pela Universidade Federal do Ceará (1977) e Doutor em Economia pela Universidade Federal de Pernambuco (1991). Pós - Doutor em Comércio Internacional Agrícola por Paris1 Pantheon Sorbonne (1997) e Pós - Doutor em Economia Territorial por Grenoble II (2008). Professor Titular da Universidade Federal Rural de Pernambuco. Atua na área de Economia Agrícola, nos temas: política agrícola, cadeia produtiva, agricultura familiar e desenvolvimento rural.

\section{TATIANE BOTELHO DA CRUZ}

Especialização em Agroecologia Aplicada a Agricultura Familiar pela Universidade Estadual de Santa Cruz - UESC (2015) e Ciência e Tecnologia de Alimentos com ênfase em Cacau e Chocolate pelo Instituto Federal de Educação, Ciência e Tecnologia Baiano - IF Baiano (2019), graduação em Gestão Ambiental pela Universidade Norte do Paraná (2010) e Técnica Agrícola de Nível Médio pela Escola Media de Agropecuária Regional da CEPLAC (2004). Atualmente está cursando Licenciatura em Ciências Biológicas na UESC, no $8^{\circ}$ semestre. Dentre as diversas funções desenvolvidas, seu ponto forte é assessoria e extensão rural para agricultores familiares, assentados da reforma agraria e comunidades tradicionais.

\section{TIAGO WICKSTROM ALVES}

Possui graduação em Ciências Econômicas pela Universidade Federal de Santa Maria (1990), mestrado em Economia Rural pela Universidade Federal do Rio Grande do Sul (1995) e doutorado em Economia pela Universidade Federal do Rio Grande do Sul (1999). Atua na Universidade do Vale do Rio dos Sinos, onde foi Coordenador Adjunto da Graduação do curso de Ciências Econômicas, Coordenador do PPG de Economia, Coordenador do PPG de Ciências Contábeis e Diretor do Centro de Ciências Econômicas. Atualmente leciona na graduação do curso de Ciências Econômicas, no PPG de Economia e no PPG de Ciências Contábeis e é líder do Grupo de Pesquisa intitulado: Mercados e Competitividade de instituições de Ensino Superior. Tem experiência na área de Economia Rural, Microeconomia e Métodos Quantitativos, atuando principalmente nos seguintes temas: Custos, Avaliação de Desempenho das Organizações, Análise da Competitividade das Instituições e Mercado de Ensino Superior; fundamentados em Microeconomia Aplicada e Economia Comportamental.

\section{VITÓRIA ROBERTA MARTINS DE MELO GALINDO DE LIMA}

Economista pela Universidade Federal Rural de Pernambuco (2019). 


\section{VIVIANE MARIA BARAZETTI}

Engenheira Florestal pela Universidade do Oeste de Santa Catarina (2010), mestrado (2013), Doutorado (2019) em Produção Vegetal pela Universidade Estadual de Santa Cruz, no Programa de Pós Graduação em Produção Vegetal na área de Solos e Nutrição de Plantas em Ambiente Tropical Úmido e Pós-Doutoranda pela Universidade Federal de Lavras (2020) e Pós-doc em Ciências Florestais pela Universidade Federal de Lavras (2020).Tem experiência em sistema agroflorestal, na implantação e manejo de sistemas agroflorestais, restauração florestal e atua na área de agroecologia.

\section{WALBERTI SAITH}

Possui graduação em Ciências Econômicas pela Universidade Federal de Rondônia (2009), mestrado em Economia pela Universidade Estadual de Maringá (2012) e doutorado em Economia Aplicada pela Universidade Federal de Viçosa (2017). Atualmente é professor da Universidade Federal de Rondônia. Tem experiência na área de Economia, com ênfase em econometria, atuando principalmente nos seguintes temas: volatilidade de preço, agropecuária, política fiscal, desigualdade de renda e crescimento econômico.

\section{WESLEY FERNANDES ARAÚJO}

Mestrando pelo Programa de Pós-Graduação em Desenvolvimento e Meio Ambiente da Universidade Federal do Piauí (PRODEMA/UFPI). Possui graduação em Ciências Econômicas pela UFPI, Campus Ministro Reis Velloso, Parnaíba-PI. 
